THIAGO BORGES ORTEGA

DIMENSIONAMENTO OTIMIZADO DE CANAL TRAPEZOIDAL PELO CRITÉRIO DE CUSTO GLOBAL 


\title{
DIMENSIONAMENTO OTIMIZADO DE CANAL TRAPEZOIDAL PELO CRITÉRIO DE CUSTO GLOBAL
}

\author{
Dissertação apresentada à Escola \\ Politécnica da Universidade de São \\ Paulo para obtenção do título de \\ mestre em Engenharia Civil. \\ Área de Concentração: \\ Engenharia Hidráulica \\ Orientador: Prof. Dr. \\ José Rodolfo Scarati Martins
}


Este exemplar foi revisado e alterado em relação à versão original, sob responsabilidade única do autor e com a anuência de seu orientador.

São Paulo, de agosto de 2012.

Assinatura do autor

Assinatura do orientador

FICHA CATALOGRÁFICA

Ortega, Thiago Borges

Dimensionamento otimizado de canal trapezoidal pelo critério de custo global / T.B. Ortega. -- ed.rev. -- São Paulo, 2012. $222 \mathrm{p}$.

Dissertação (Mestrado) - Escola Politécnica da Universidade de São Paulo. Departamento de Engenharia Hidráulica e Ambiental.

1. Otimização não linear 2. Canais artificiais I. Universidade de São Paulo. Escola Politécnica. Departamento de Engenharia Hidráulica e Ambiental II. t. 


\section{DEDICATÓRIA}

Ao meu pai, Ricardo Chiquito Ortega,

A minha mãe, Joana Angélica Borges Ortega,

E aos meus irmãos, Ricardo Borges Ortega e Leonardo Henrique Borges Ortega. 


\section{AGRADECIMENTOS}

A Deus, por me fartar o espírito de paz em todos os momentos, em especial aqueles de maior angústia e desespero, e me dar em abundancia tudo aquilo que precisei para chegar até aqui.

Ao meu Colega, Professor e Orientador, Dr. José Rodolfo Scarati Martins, por compartilhar seu vasto conhecimento de forma tão didática, e pelo empenho na elaboração deste trabalho.

A Escola Politécnica da Universidade de São Paulo, a quem eu devo grande parte do meu conhecimento e amadurecimento.

A todos que torceram de maneira sincera pelo meu sucesso. 


\section{RESUMO}

Este trabalho apresenta um modelo matemático de suporte à decisão para projeto de canais com seção trapezoidal, cujo regime de escoamento seja do tipo unidimensional, fluvial e permanente, para terrenos naturais. A seção é otimizada pelo critério de custo global, composto pelos custos de implantação (motorização, escavação, aterro, revestimento) e manutenção (conservação e operação, contabilizada através da perda de energia). A determinação da seção ótima foi feita por algoritmo de programação não linear.

As variáveis analisadas foram o revestimento (custo, espessura, coeficiente de Manning), a vazão, a declividade de fundo do canal, a vida útil, taxa de juros, seções topográficas (com horizontes geotécnicos), e o resultado contempla a largura de fundo e consequentemente a altura da seção.

Palavras-Chave: Canal trapezoidal, otimização 


\begin{abstract}
This work presents a decision support mathematical model for design of trapezoidal section's channel, for the case of one-dimensional, subcritical, steady and openchannel flow. The section is optimized by the criterion of total cost, composed by the costs of implementation (engine, excavation, landfill, lining) and maintenance (conservation and operation, accounted for by the loss of energy). The determination of optimum section was performed by nonlinear programming algorithm.

The variables analyzed were the lining (cost, thickness, Manning's coefficient), flow, the channel bottom's slope, the project lifetime, interest rates, topographic sections (including geotechnical data), and the result includes the width and consequently the height of the section.
\end{abstract}

Keywords: Trapezoidal channel, optimization. 


\section{LISTA DE FIGURAS}

Figura 4.1 - Seção Mista Ótima (ABDULRAHMAN, 2007) …................................11

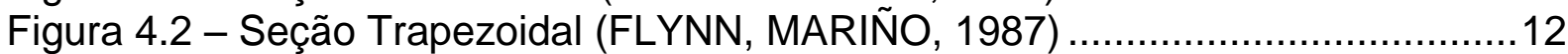

Figura 4.3 - Seção Trapezoidal e Suas Variáveis (DAS, 2008) …………….........15

Figura 4.4 - Seção Trapezoidal e suas variáveis (DAS, 2000) …..........................17

Figura 4.5 - Definição dos Elementos do Canal (LOGANATHAN, 1991) ..................20

Figura 4.6 - Elementos de Cálculo da Seção Ótima (BHATTACHARJYA, 2007).....23

Figura 4.7 - Fluxograma de cálculo de seção ótima, adaptado a partir de

BHATTACHARJYA et al (2007) ..............................................................26

Figura 4.8 - Tipos de Sistemas de Canais (adaptado de CARRIAGA et al., 2000) ..30

Figura 4.9 - Dimensões Empregadas por SOUZA (s.d.) ……............................... 31

Figura 5.1 - Conformação Canal / Terreno .......................................................51

Figura 5.2 - Área Escavada na Seção Transversal ...........................................52

Figura 5.3 - Tensões de Arraste no fundo e taludes de um canal (SIMONS \&

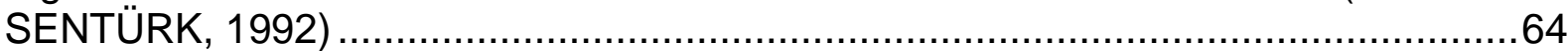

Figura 5.4 - Curva de Shields (SIMONS \& SENTÜRK, 1992) ...............................66

Figura 5.5 - Resultados para $\mathrm{m}=0,5$ e revestimento em gabião tipo caixa...............77

Figura 5.6 - Resultados para $m=0,5$ e revestimento em gabião tipo colchão ..........77

Figura 5.7 - Resultados para $\mathrm{m}=0,5$ e revestimento em concreto projetado ….......78

Figura 5.8 - Resultados para $m=0,5$ e revestimento com geocomposto .................78

Figura 5.9 - Resultados para $\mathrm{m}=0,5 \mathrm{em}$ terreno natural ......................................79

Figura 5.10 - Resultados para $m=1,0$ e revestimento em gabião tipo caixa ............79

Figura 5.11 - Resultados para $m=1,0$ e revestimento em gabião tipo colchão ........80

Figura 5.12 - Resultados para $m=1,0$ e revestimento em concreto projetado .........80

Figura 5.13 - Resultados para $m=1,0$ e revestimento com geocomposto …...........81

Figura 5.14 - Resultados para $m=1,0$ em terreno natural ................................... 81

Figura 5.15 - Resultados para $m=2,0$ e revestimento em gabião tipo caixa.............82

Figura 5.16 - Resultados para $m=2,0$ e revestimento em gabião tipo colchão ........82

Figura 5.17 - Resultados para $m=2,0$ e revestimento em concreto projetado .........83

Figura 5.18 - Resultados para $m=2,0$ e revestimento com geocomposto …...........83

Figura 5.19 - Resultados para $m=2,0$ em terreno natural ..................................... 84

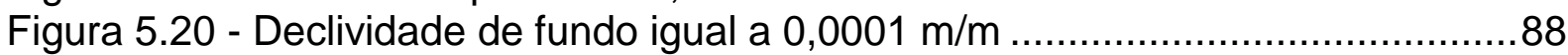

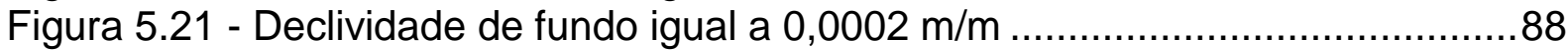

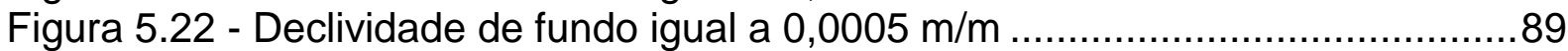

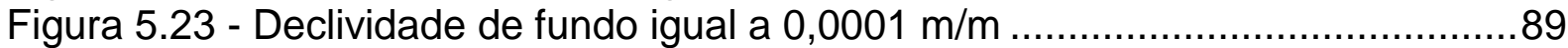

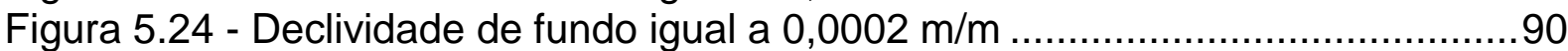

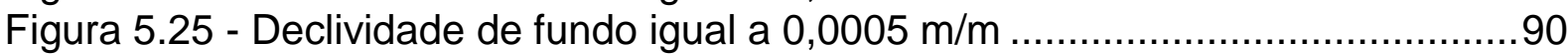

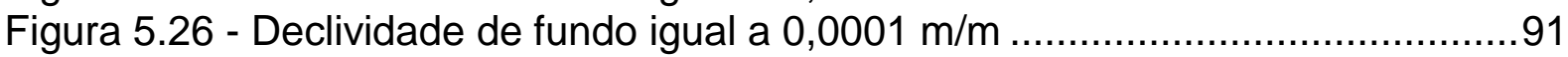

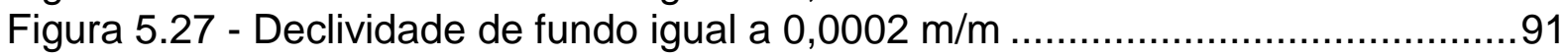

Figura 5.28 - Declividade de fundo igual a $0,0005 \mathrm{~m} / \mathrm{m} \ldots \ldots \ldots \ldots \ldots \ldots \ldots \ldots \ldots \ldots \ldots \ldots . . .92$

Figura 5.29 - Composição dos elementos de custo para $m=0,5$ e i $=0,0001 \ldots \ldots \ldots . .95$

Figura 5.30 - Composição dos elementos de custo para $m=0,5$ e i $=0,0002 \ldots \ldots \ldots . .96$

Figura 5.31 - Composição dos elementos de custo para $m=0,5$ e $i=0,0005 \ldots \ldots \ldots . .96$

Figura 5.32 - Composição dos elementos de custo para $m=1,0$ e $i=0,0001 \ldots \ldots \ldots . .97$

Figura 5.33 - Composição dos elementos de custo para $m=1,0$ e $i=0,0002 \ldots \ldots \ldots . .97$

Figura 5.34 - Composição dos elementos de custo para $m=1,0$ e $i=0,0005 \ldots \ldots \ldots . .98$

Figura 5.35 - Composição dos elementos de custo para $m=2,0$ e $i=0,0001 \ldots \ldots \ldots . .98$

Figura 5.36 - Composição dos elementos de custo para $m=2,0$ e $i=0,0002 \ldots \ldots \ldots . .99$ 
Figura 5.37 - Composição dos elementos de custo para $m=2,0$ e i $=0,0005 \ldots \ldots \ldots . .99$ 


\section{LISTA DE TABELAS}

Principais Tipos de Revestimentos ...........................................................54

Classes e Subclasses dos Grupos A e B - adaptado de (ANEEL, 2005) …..............58

Tarifa Social de Baixa Renda (Fonte: AES Eletropaulo, 2010) ….........................59

Velocidade Máxima Recomendada (adaptado de FORTIER \& SCOBEY, 1926) ......60

Velocidade Máxima Admissível (Adaptado de LENCASTRE, 1972) ........................62

Redução na Tensão Cisalhante Limite (adaptado de LANE, 1955) ..........................65

Preços Unitários (Data De Referência: 30/06/2011 - Fonte: DER) ..........................72

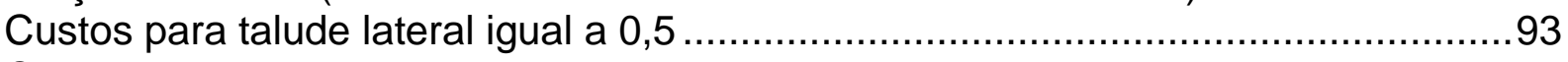

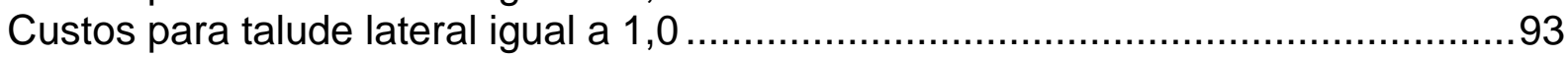

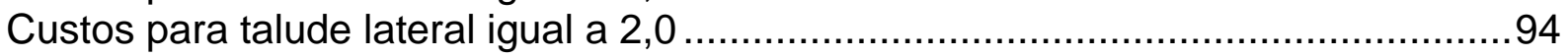




\section{LISTA DE SIGLAS E ABREVIATURAS}
ANA
Agência Nacional de Águas
ANEEL
Agência Nacional de Energia Elétrica
ASCE
American Society of Civil Engineer
DER
Departamento de Estradas de Rodagem
EXCEL
Aplicativo desenvolvido por Microsoft $<\underline{w w w}$.microsoft.com $>$
GAMS/MINOS
Aplicativo desenvolvido por Gams < $\underline{w w w . g a m s . c o m}>$
IARH
Int. Assoc. for Hydro-Environment Engineering and Research
IWPDC
International Water Power and Dam Construction
MATLAB
Aplicativo desenvolvido por MathWorks $<$ www.mathworks.com $>$
USP
Universidade de São Paulo 


\section{SUMÁRIO}

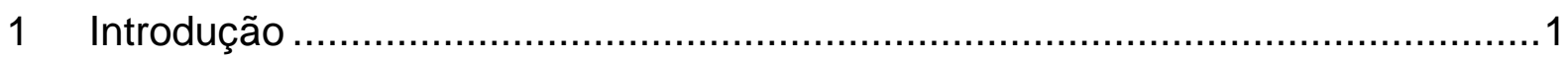

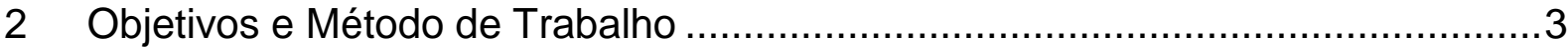

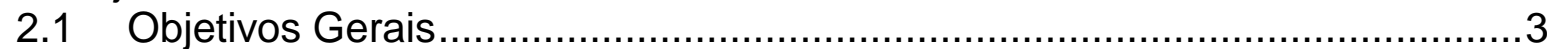

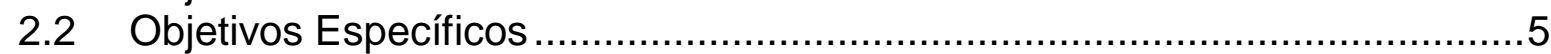

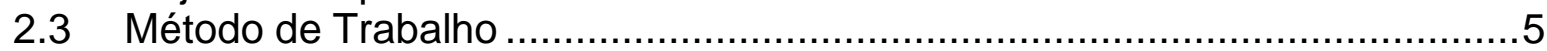

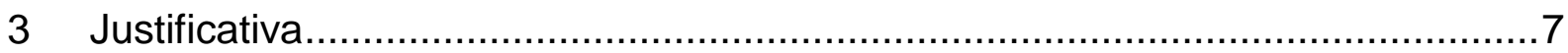

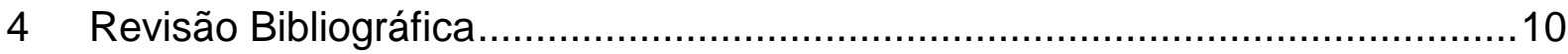

5 Desenvolvimento do modelo e Estudo de Caso..............................................36

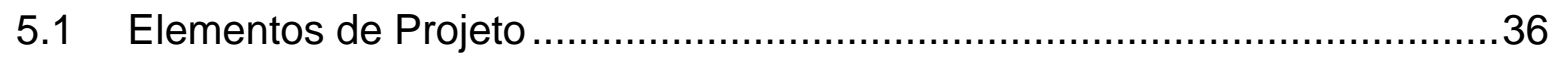

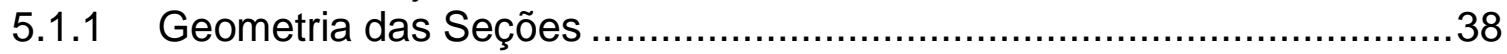

5.1.2 Velocidade Máxima Admissível ........................................................41

5.1.3 Tensão de Arraste Crítica ............................................................. 41

5.1.4 Perda de Carga no Canal .............................................................. 43

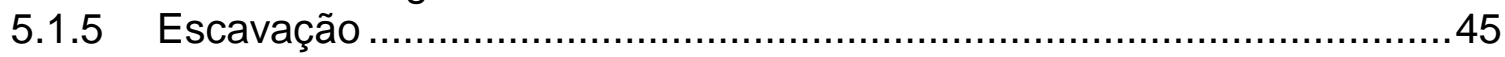

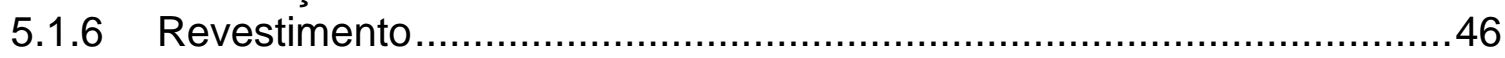

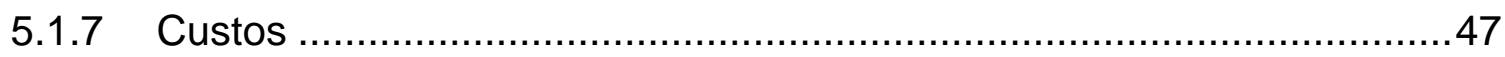

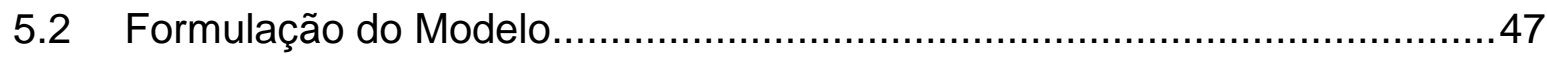

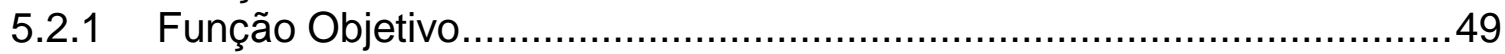

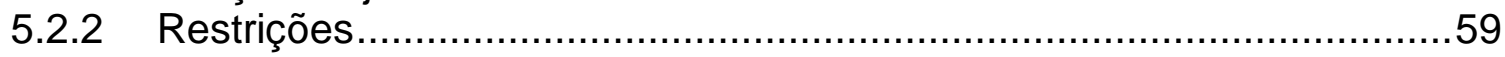

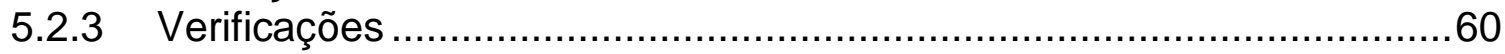

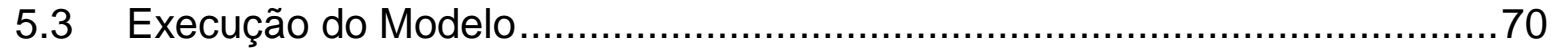

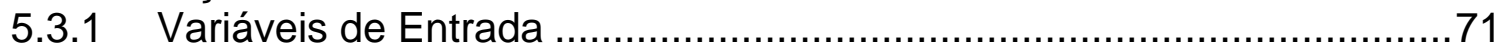

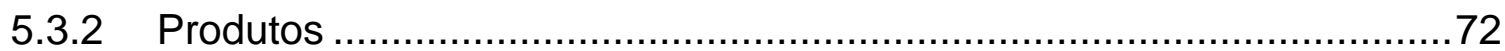

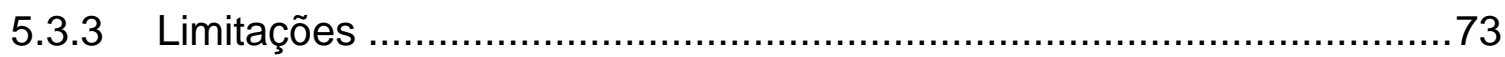

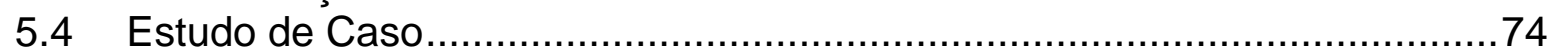

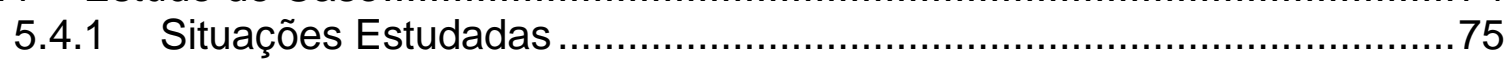

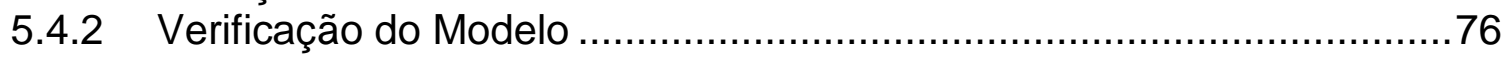

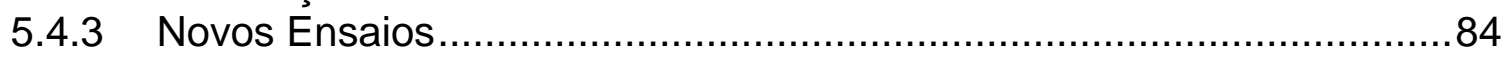

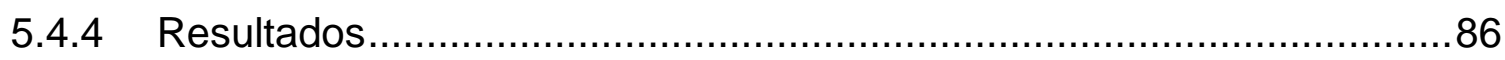

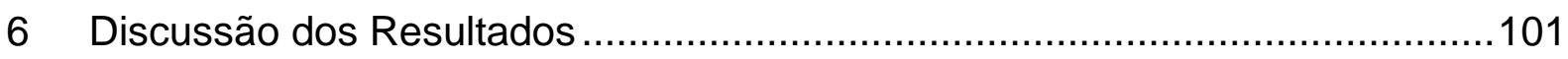

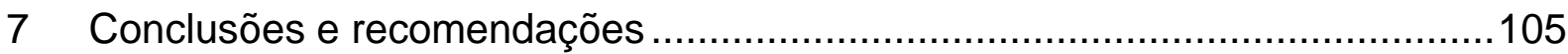

8 Referências Bibliográficas....................................................................107

ANEXO A - Tabela de Tarifas Energéticas (AES Eletropaulo) …….....................109

ANEXO B - Resultados dos Cálculos de Remanso..........................................112

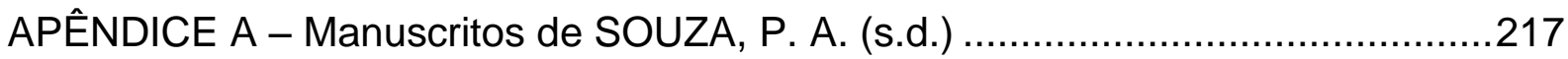




\section{INTRODUÇÃO}

Canalizações estão relacionadas ao desenvolvimento da civilização humana: com o objetivo de melhorar a eficiência agrícola, tribos nômades acabaram fixando-se nas margens de rios como Nilo, Tigre, Eufrates e Jordão e, como consequência, surgiram os primeiros Estados centralizadores, eventualmente militarizados, e já providos de uma classe de trabalhadores; estes povos conceberam também os primeiros canais de que se tem registro, e haviam laboriosos envolvidos tanto nas lavouras quanto nas obras de canalização, dando origem assim às conhecidas "Civilizações Hidráulicas".

No entanto, apesar de canais serem uma estrutura amplamente usada pela humanidade há milhares de anos, o estudo de seção ótima somente pôde se desenvolver a partir da evolução da engenharia hidráulica, através do conhecimento das leis que governam o escoamento.

O estudo de otimização de canais trata da maneira mais eficiente de conduzir a água, que é um recurso natural de crescente importância e escassez e como, de maneira geral, canais apresentam vida útil elevada e operação intensa, seu dimensionamento tem recebido importantes contribuições ao longo dos últimos 50 anos.

O desenvolvimento de novas ferramentas de cálculo também influenciou o estudo de otimização, pois facilitou a exploração de modelos matemáticos, indispensáveis em casos de otimização não linear, dando agilidade à execução dos cálculos.

Dentre os estudos existentes sobre eficiência de seção transversal de canais, um fato notório é que a maioria destes estudos é direcionada a canais cuja função é a de transportar água para fins de irrigação. 
Entretanto, canais podem assumir diversas funções além da irrigação, como por exemplo, a navegação, o abastecimento urbano, rural ou industrial, o desvio de água de reservatórios para turbinas hidrelétricas entre outros; além disso, há que se considerar também o estudo direcionado à recuperação de canais existentes, que tende a se tornar mais frequente. Para estes casos, a literatura é bastante pobre no que tange a metodologia de otimização de seção; entretanto, os avanços feitos para dimensionamento de canais de irrigação podem ser amplamente explorados em outros tipos de canalização, devendo-se ajustar os modelos existentes para as considerações que devem ser feitas nos casos particulares.

Devido ao fato de no escoamento em canais naturais haver forças cisalhantes entre o fluido e o leito do canal, além de turbulência, há transformação de energia cinética e potencial do fluido em formas não aproveitáveis para esta aplicação (principalmente calor), gerando então "perda" de carga.

Como em canalizações normalmente a perda de carga pode atingir valores relevantes, um importante ajuste a ser feito nos modelos de otimização de canal existentes, e que permite dimensionar outros tipos de canal, é a consideração da perda de energia, cujo custo é indiretamente calculado como sendo função da perda de carga. 


\section{OBJETIVOS E MÉTODO DE TRABALHO}

O objetivo principal deste trabalho é o de apresentar uma consolidação dos métodos

e ferramentas disponíveis para o dimensionamento otimizado de canais para condução de água explorando o conceito do mínimo custo global através de um estudo comparativo aplicado aos canais trapezoidais. Além disso, esta dissertação tem como intento servir de sumário sobre o estado da arte das técnicas de otimização de seção para canais, abrangendo a literatura disponível referente a este tema. São aqui pesquisadas as principais contribuições existentes sobre o assunto e dado os devidos créditos aos autores.

São avaliados tais métodos, e é feita uma análise conceitual sobre deles. Por fim, será apresentado um modelo matemático, capaz de dar suporte à decisão no cálculo de seção transversal ótima para canal de seção trapezoidal, considerando-se uma dada condição de geometria, custos e outras restrições.

\subsection{Objetivos Gerais}

O estudo de seção ótima de um canal deve ser capaz de encontrar a melhor configuração do mesmo, o que implica se definir o melhor conjunto de dimensões de base, largura, altura de lâmina d'água, inclinação de talude e declividade de fundo.

Tal estudo deve considerar as limitações hidráulicas representadas pela formulação universal da resistência ao escoamento, além de atender às condições de estabilidade, representadas pela velocidade máxima permissível do revestimento e a tensão de arraste crítica, que objetivam a estabilidade de forma do canal, ou seja, a não ocorrência de erosão e/ou assoreamento no fundo do mesmo. Outras restrições 
podem se fazer presentes para casos particulares, como por exemplo largura máxima do canal, ou altura máxima de lâmina d'água, devido limitações específicas de um determinado projeto.

Além de considerar estas restrições, um sistema de otimização de seções deve apresentar um objetivo bem definido que depende especificamente do que se pretende com o canal: pode desejar-se a mínima área de seção transversal do canal, mitigando assim os impactos da construção, ou então se pode desejar um mínimo custo de operação e manutenção, tendo em vista que o canal pode localizarse em região distante. O objetivo mais comum, entretanto, costuma ser o de minimização dos custos totais envolvidos na construção e operação do canal para um dado horizonte de projeto.

A meta de otimização é representada por uma função matemática, cujo resultado pode ser, por exemplo, a área da seção, ou o custo total do empreendimento, composto pelas parcelas referentes ao custo de implantação (que engloba a escavação, o aterro, o revestimento e a motorização) e ao custo de operação (que prevê os gastos com a conservação do canal e com a perda de energia durante a operação). As variáveis desta função são as grandezas que definem uma canalização, citadas no primeiro parágrafo deste subitem, e a meta é minimizar o resultado desta função.

Para isso, lança-se mão de diversas ferramentas computacionais e matemáticas, como por exemplo, os solvers MATLAB, EXCEL ou GAMS-MINOS, sendo este último para resolução de algoritmos do tipo genético", "grid search", programação quadrática sequencial, $\mathrm{GRG}^{2}$ não linear, de Lagrange, entre outros.

\footnotetext{
${ }^{1}$ Algoritmos que simulam as leis evolucionárias de seres vivos

${ }^{2}$ Gradiente reduzido genérico
} 


\subsection{Objetivos Específicos}

Este trabalho tem como objetivo específico desenvolver um modelo matemático para o projeto otimizado de canais, utilizando ferramentas de solução não linear das variáveis de dimensionamento, para o caso específico do canal de seção trapezoidal, por ser a mais utilizada na prática.

Neste estudo será levada em consideração também a perda de carga na função objetivo "custo", visto que a energia despendida pelo escoamento, ainda que por gravidade, representa um componente econômico importante.

É esperado que o modelo desenvolvido seja capaz de dar suporte à decisão de qual seção deve ser empregada neste tipo de canal, permitindo a comparação entre diferentes tipos de revestimentos, vazões e declividades, e que se possa, com os resultados, determinar qual a melhor opção de canal.

Para uma melhor avaliação da seção econômica, o modelo deverá fornecer ao usuário subsídios para uma análise de sensibilidade das diferentes alterações possíveis nas restrições de projeto.

\subsection{Método de Trabalho}

O método de trabalho aplicado nesta dissertação seguiu, em ordem cronológica, as seguintes etapas:

- Pesquisa: busca bibliográfica em bibliotecas, entidades como ASCE, IARH, IWPDC, e sites como <www.isiknowledge.com > e <www.google.com>, por palavras chave como "canal desing", "optimal sections", "open channel", "optimization", "cross sections", "cost effective", 
- Modelagem: concepção das variáveis de entrada, da sequencia de cálculo e das variáveis de saída, implementação do modelo matemático e verificações de coerência básicas,

- Aplicação: simulação de dois casos, sendo o primeiro destinado à verificação do modelo elaborado (por comparação com outro existente) e o segundo uma aplicação prática,

- Resultados: Agrupamento e apresentação dos valores encontrados, de forma a facilitar a observação de comportamentos e tendências, e a definição de conclusões,

- Dissertação: Redação do texto contendo as pesquisas bibliográficas, considerações do modelo, resultados de ensaios, conclusões e sugestões para futuros trabalhos. 


\section{JUSTIFICATIVA}

O estudo de otimização de canais vem recebendo importantes contribuições ao longo dos últimos anos, em especial na última década, reflexo da popularização do uso de modelos matemáticos. Esses modelos viabilizam a obtenção de soluções para complexos sistemas de otimização, caracterizados por uma função objetivo a ser minimizada (ou maximizada), considerando uma ou várias restrições, frequentemente com muitas variáveis, tanto na função objetivo quanto nas restrições.

Todo este avanço tecnológico contrasta com os conhecimentos no campo da engenharia hidráulica, que tiveram grande desenvolvimento em meados do século $\mathrm{XX}$ e até os dias de hoje continuam atendendo bem às demandas $\mathrm{e}$ às necessidades dos engenheiros de projetos hidráulicos, como é o caso do dimensionamento de canais.

No capítulo 4, Revisão Bibliográfica, é apresentado um apanhado dos estudos publicados sobre seção ótima de canais que se tornaram mais influentes e importantes neste campo.

A otimização visando mínimo custo de construção, manutenção e operação é explorada por diversos autores, sendo o estudo de CARRIAGA et al (1999) o mais abrangente sobre os elementos que incidem no valor total de um canal. DAS (2008) acrescentou na análise de orçamento um estudo de probabilidade de ocorrência que é bastante útil para consideração dos riscos de falha e deve ser usado quando se deseja uma seção econômica.

Outro fator bastante relevante no projeto de seções econômicas é a altura de freeboard ou borda livre, que é a altura adicional acrescentada na seção transversal 
para diversas finalidades, dentre as quais a acomodação de ondas, recalques e até mesmo composição paisagística e segurança hidrológica. Frequentemente adota-se uma altura fixa acima da lâmina d'água, porém quando se deseja uma seção otimizada, deve-se estudar o efeito do freeboard tanto em função da vazão quanto em função da profundidade (LOGANATHAN, 1991).

CARRIAGA (2000) também acrescentou à modelagem de seção otimizada de canal o estudo de canais com múltiplos trechos que, devido a diferenças de vazão e/ou revestimentos, devem apresentar diferenças em suas dimensões básicas, como é o caso da largura, da declividade de fundo, da velocidade de escoamento e da lâmina d'água. Sua importância se faz presente quando se utiliza uma rede de canais ou quando um mesmo para um único canal que, por questões geológicas, por exemplo, apresenta trechos com diferentes revestimentos, caracterizando distintos trechos que devem ser otimizados em separado.

Apesar de os trabalhos acima citados serem individualmente eficientes, ainda não existe um estudo que agrega todas as ideias num mesmo modelo, tornando-o mais versátil e abrangente.

Além disso, outra característica relevante e que não foi encontrada em nenhum estudo anterior, visto que a maioria dos trabalhos apresentados se destina ao dimensionamento de canais de irrigação ou drenagem, é o custo associado à perda de carga ao longo do canal. Esta é imprescindível na otimização de canais como aqueles destinados à adução para usinas hidrelétricas, por exemplo, mas também pode ser importante em irrigações com bombeamento de água, já que a perda de carga deverá ser compensada pelo aumento da potência da bomba e do consumo de energia, que são aspectos importantes no dimensionamento do sistema. 
Também ainda não é corrente o uso de modelagem matemática para escolher o tipo de revestimento a ser empregado dentre uma determinada quantidade de opções, o que implica analisar a seção ótima para cada um dos revestimentos e os custos associados a cada um deles, permitindo a melhor escolha.

Tais carências, portanto, motivam o desenvolvimento do presente estudo. 


\section{REVISÃo BIBLIOGRÁFICA}

Seções ótimas de canais vêm sendo estudadas ao longo dos últimos anos, com diferentes enfoques e contribuições.

ABDULRAHMAN (2007) elaborou um estudo baseado na equação de Manning, equação esta que permite afirmar que a vazão em um canal é máxima se, mantidos a área molhada, declividade de fundo e coeficiente de Manning, o perímetro molhado for mínimo. Outra conclusão a que se pode chegar, a partir da mesma equação, é a de que, para uma vazão constante, a melhor seção hidráulica é a que apresenta área mínima.

O objetivo do trabalho foi encontrar qual das seções mistas entre formas geométricas simples (retângulo, quadrado, trapézio e triângulo) é a mais eficiente. Desta forma, o autor parametriza área e perímetro em função das variáveis: base, inclinação do talude e altura da lâmina d'água e, derivando-os (área e perímetro) em função da altura de lâmina d'água, com o auxílio de algumas simplificações e substituições matemáticas, encontra o valor ótimo.

O resultado encontrado matematicamente foi que a melhor composição é formada por um trapézio seguido de um retângulo, conforme ilustra a Figura 4.1. A seção composta ótima é aquela igual à metade de um octógono, que é a única que consegue circunscrever um semicírculo, assim como ocorre com a seção ótima de canais retangulares (que resulta em um semiquadrado) e canais trapezoidais (que resulta em um semihexágono). Esta forma é a que mais se aproxima de um semicírculo, o que hidraulicamente é mais eficiente. 


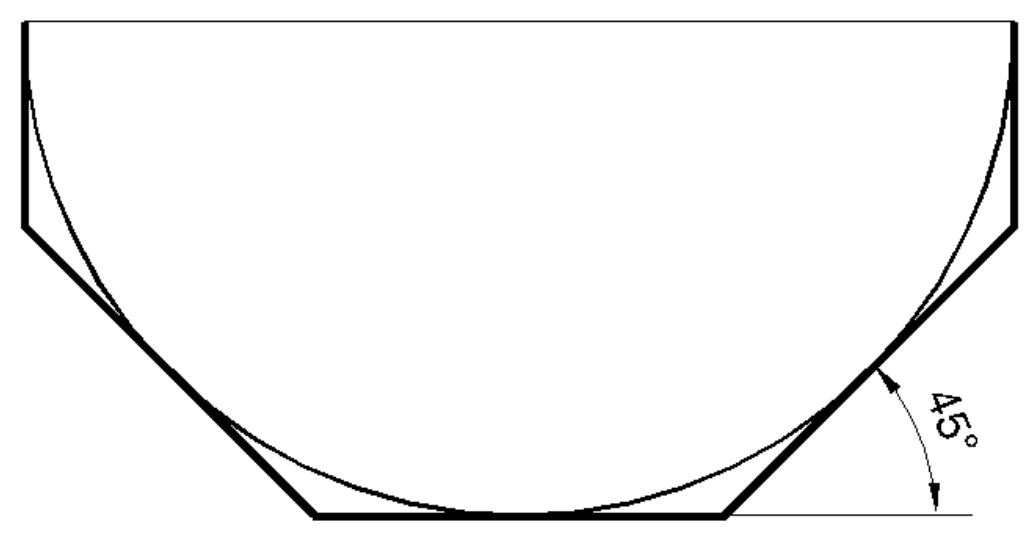

Figura 4.1 - Seção Mista Ótima (ABDULRAHMAN, 2007)

Uma restrição construtiva deste tipo de seção é que a consideração de taludes verticais na parte superior (retangular) do canal pode não ser viável em muitos casos reais, quando é descartado o emprego de revestimento no canal.

Além disso, este enfoque de maximizar a vazão / perímetro para otimizar a seção é bastante simplificado. Apesar de se afirmar no início do artigo que a melhor seção hidráulica é a mais eficiente porque requer o mínimo de escavação e revestimento, não foi feita menção aos custos envolvidos na construção, manutenção e perda de carga do canal.

Outro estudo de seção ótima de canal procura encontrar a seção mais eficiente para canais trapezoidais (incluindo retangulares e triangulares) e também para canais circulares, parabólicos e para a seção otimizada (FLYNN, MARIÑO, 1987).

Este estudo, em seus exemplos, emprega a mesma concepção de maximizar a área para um dado perímetro molhado e uma dada declividade, porém com um enfoque diferente. Nele, emprega-se um parâmetro de forma adimensional (Equação 4.1), que é uma relação entre dimensões básicas da seção, para criar uma função restrição que faz parte de um modelo não linear de otimização, para encontrar a melhor seção. 


$$
I P=\frac{P^{2}}{A}
$$

Equação 4.1

Nesta equação, os termos indicados representam:

IP = Parâmetro adimensional,

$\mathrm{P}=$ Perímetro molhado,

$A=$ Área da seção.

A seção trapezoidal pode ser parametrizada em função do ângulo de inclinação do talude $(\theta)$ e da largura da superfície (L), conforme ilustra a Figura 4.2 exibida a seguir.

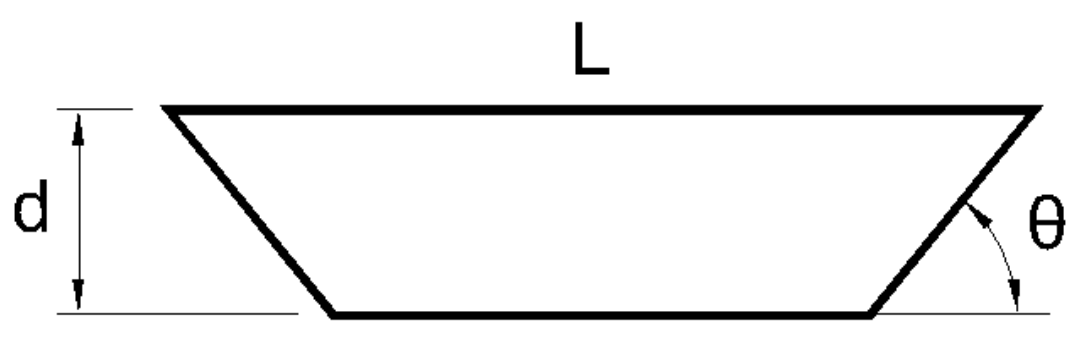

Figura 4.2 - Seção Trapezoidal (FLYNN, MARIÑO, 1987)

Sabendo-se que a melhor seção hidráulica atende à relação:

$$
L=\frac{2 d}{\operatorname{sen} \theta}
$$

Equação 4.2

Pode-se parametrizar $L$ em função de uma variável $K$, conforme Equação 4.3, sendo $K \geq \cos \theta$, de forma que quanto maior for o $K$, maior o valor de $L$ e, para um dado valor de $\theta$, a seção ótima apresenta $K=1$. 


$$
L=\frac{2 K d}{\operatorname{sen} \theta}
$$

Equação 4.3

Assim, obtém-se a área molhada e o perímetro molhado em função de $\mathrm{K}, \mathrm{d}$ e $\theta$. Com isso, é possível definir o adimensional IP em função destas grandezas, resultando na Equação 4.4:

$$
I P(K, \theta)=\frac{4(K+1-\cos \theta)^{2}}{\operatorname{sen} \theta(2 K-\cos \theta)}
$$

Equação 4.4

O adimensional IP assume valor mínimo, igual a $2 \pi$, para uma seção transversal semicircular, o que permite mensurar o quanto uma seção trapezoidal qualquer está destoando da ótima (semicircular).

A partir do valor de IP, que está associado a um determinado ângulo $\theta$, e das constantes $\mathrm{n}$ de Manning, vazão e declividade de fundo, pode-se obter todos os outros parâmetros do canal, ou seja, área, perímetro molhado, velocidade, altura da lâmina d'água, largura da base e largura superficial da seção.

Pode-se afirmar que este é um estudo mais versátil do que o apresentado por ABDULRAHMAN (2007) por permitir o cálculo de seções circulares e parabólicas, e principalmente por permitir a inclusão, na função objetivo do sistema não-linear, dos parâmetros de custo - apesar de não se tê-lo feito na publicação. Isso permite encontrar uma seção ótima não só do ponto de vista hidráulico, como foi feito no artigo, mas também sob o aspecto econômico, levando em conta os diversos parâmetros de uma função objetivo de custo global estendido, podendo então ser empregada na otimização desta função. 
Foi produzida também uma nota técnica sobre otimização de canais trapezoidais em uma abordagem rara sobre o assunto, considerando não apenas os custos dos diversos parâmetros de construção, mas também as suas incertezas e as incertezas nas características físicas do canal - rugosidade, dimensões, declividade de fundo e vazões (DAS, 2008).

Assumiu-se neste trabalho que os parâmetros de custos têm distribuição probabilística e que as variáveis aleatórias dos parâmetros da seção seguem distribuição normal. Foi apresentada então a Equação 4.5,

$$
F_{1}(x)=k_{1} F+k_{2}\left\{\sum \phi_{x}^{2} x^{2}\left(\frac{\partial F}{\partial x}\right)^{2}\right\}^{\frac{1}{2}}
$$

cujas variáveis representam,

$\mathrm{k}_{1}=$ Coeficiente de ponderação,

$\mathrm{k}_{2}=$ Coeficiente de ponderação,

$\mathrm{x}=$ Vetor de todos os parâmetros de projeto,

$\phi_{\mathrm{x}} \mathrm{x}=$ Desvio padrão de $\mathrm{x}$,

$\mathrm{F}=$ Custo total esperado, por unidade de comprimento do canal, expresso como

$$
F=c_{1} A_{f}+c_{2} P_{1 f}+c_{3} P_{2 f}+c_{4} P_{3 f}
$$

Equação 4.6

na qual

$\mathrm{F}=$ Custo total esperado

$\mathrm{Af}=$ Área total esperada da seção transversal

$\mathrm{C}_{1}=$ Custo esperado por unidade de área da seção transversal

$c_{2}=$ Custo esperado por unidade de comprimento da seção para o perímetro $P_{1 f}$

$c_{3}=$ Custo esperado por unidade de comprimento da seção para o perímetro $P_{2 f}$

$\mathrm{C}_{4}=$ Custo esperado por unidade de comprimento da seção para o perímetro $P_{3 f}$

$\mathrm{P}_{1 \mathrm{f}}, \mathrm{P}_{2 \mathrm{f}}, \mathrm{P}_{3 \mathrm{f}}=$ vide Figura 4.3 


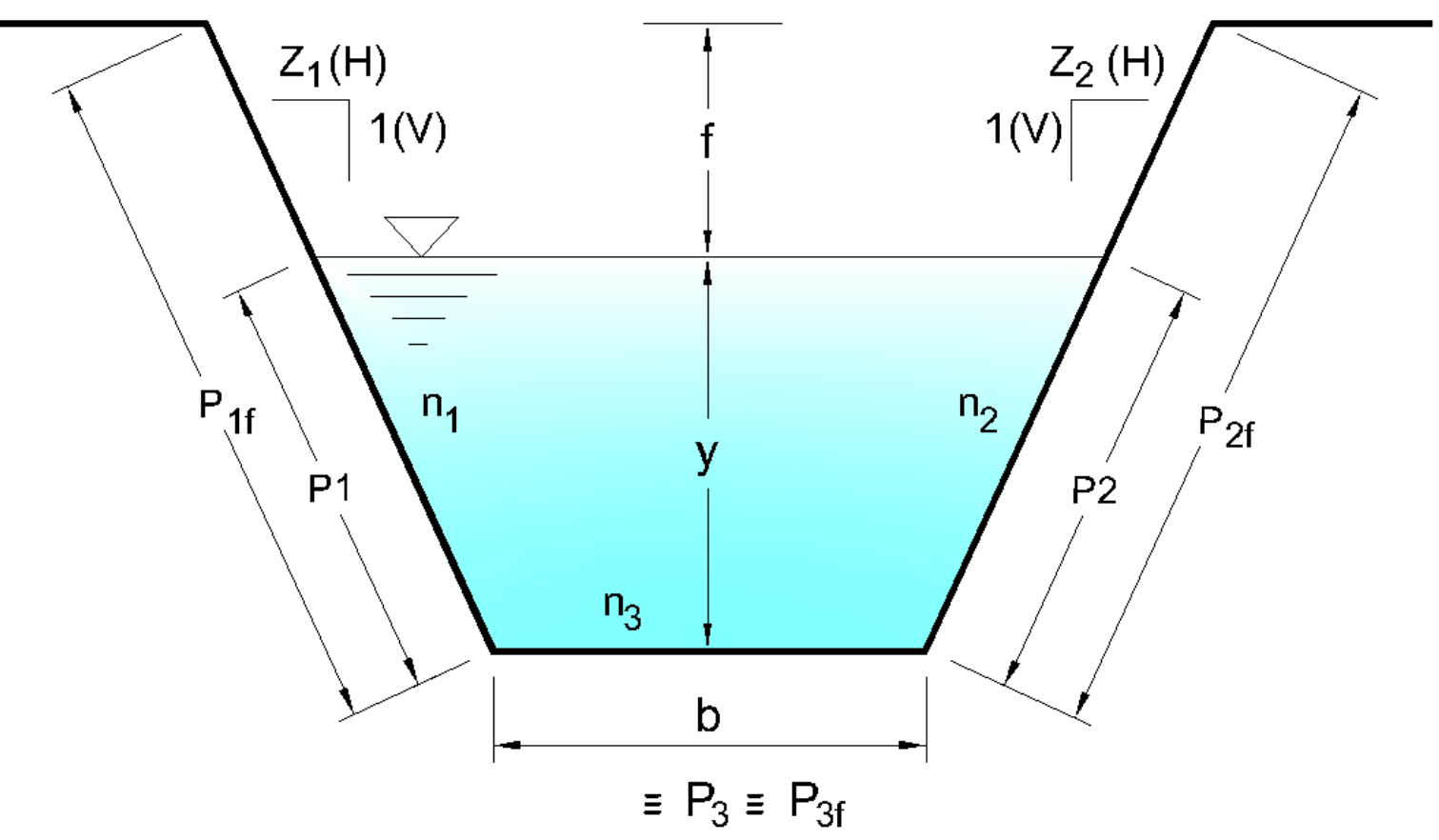

Figura 4.3 - Seção Trapezoidal e Suas Variáveis (DAS, 2008)

Como condição de contorno é admitido que a capacidade de escoamento do canal deva permanecer maior ou igual a vazão de projeto, com uma específica probabilidade de ser excedida, ou seja

$$
P\left(\sqrt{S o} \frac{A^{5 / 3}}{\left(\sum n i^{3 / 2} P i\right)^{2 / 3}}>Q\right) \geq k_{3}
$$

na qual

$\mathrm{k}_{3}=$ Probabilidade excedente

$\mathrm{Q}=$ Vazão esperada de projeto

$\mathrm{S}_{\mathrm{o}}=$ Declividade de fundo esperada

$\mathrm{A}=$ Área de escoamento esperada da seção transversal

$\mathrm{P}_{\mathrm{i}}=$ Perímetro molhado esperado da seção transversal

$\mathrm{n}_{\mathrm{i}}=$ Valor esperado do coeficiente de Manning 
O modelo de otimização da seção é formalmente definido por uma função objetivo (Equação 4.5) que deve ser minimizada, maximizando-se $k_{3}$, e restrito, como condição de contorno, à equação (Equação 4.7).

O artigo não entrou no detalhe de qual software empregou para resolver o sistema, os limites de iteração, tolerâncias etc., mas teria sido interessante tê-lo feito.

Outra simplificação deste modelo é a de que, na forma como foi conduzido, não há previsão para a consideração de diferentes revestimentos entre as paredes do canal, e também entre o revestimento de fundo.

Já o estudo de DAS (2000) trata da otimização econômica, ou seja, de mínimo custo, de seção transversal de canais com rugosidades distintas entre cada uma das margens e o fundo do canal. Esta solução pode se tornar uma alternativa interessante, pois os custos de construção para cada tipo de revestimento variam regionalmente e, além disso, em situações particulares, por exemplo, onde não se podem ter perdas por infiltração, pode ser necessário o emprego de diferentes revestimentos em cada parede do canal.

No método proposto, o valor de n de Manning equivalente da seção é parametrizado em função da inclinação dos taludes laterais, dos valores de rugosidade de cada uma das arestas do canal, da altura de lâmina d'água e da largura da base do canal, de acordo com a fórmula proposta por "Horton" (Equação 4.8),

$$
n e=\left\{\frac{\left[\left(z_{1}^{2}+1\right)^{0,5} * n_{1}^{1.5}+\left(z_{2}^{2}+1\right)^{0,5} * n_{2}^{1,5}\right] * y+b^{*} n_{3}^{1,5}}{\left[\left(z_{1}^{2}+1\right)^{0,5}+\left(z_{2}^{2}+1\right)^{0,5}\right] * y+b}\right\}^{2 / 3}
$$


cujos valores de $n_{1}, n_{2}, n_{3}, z_{1}, z_{2}$, b estão representados na Figura 4.4.

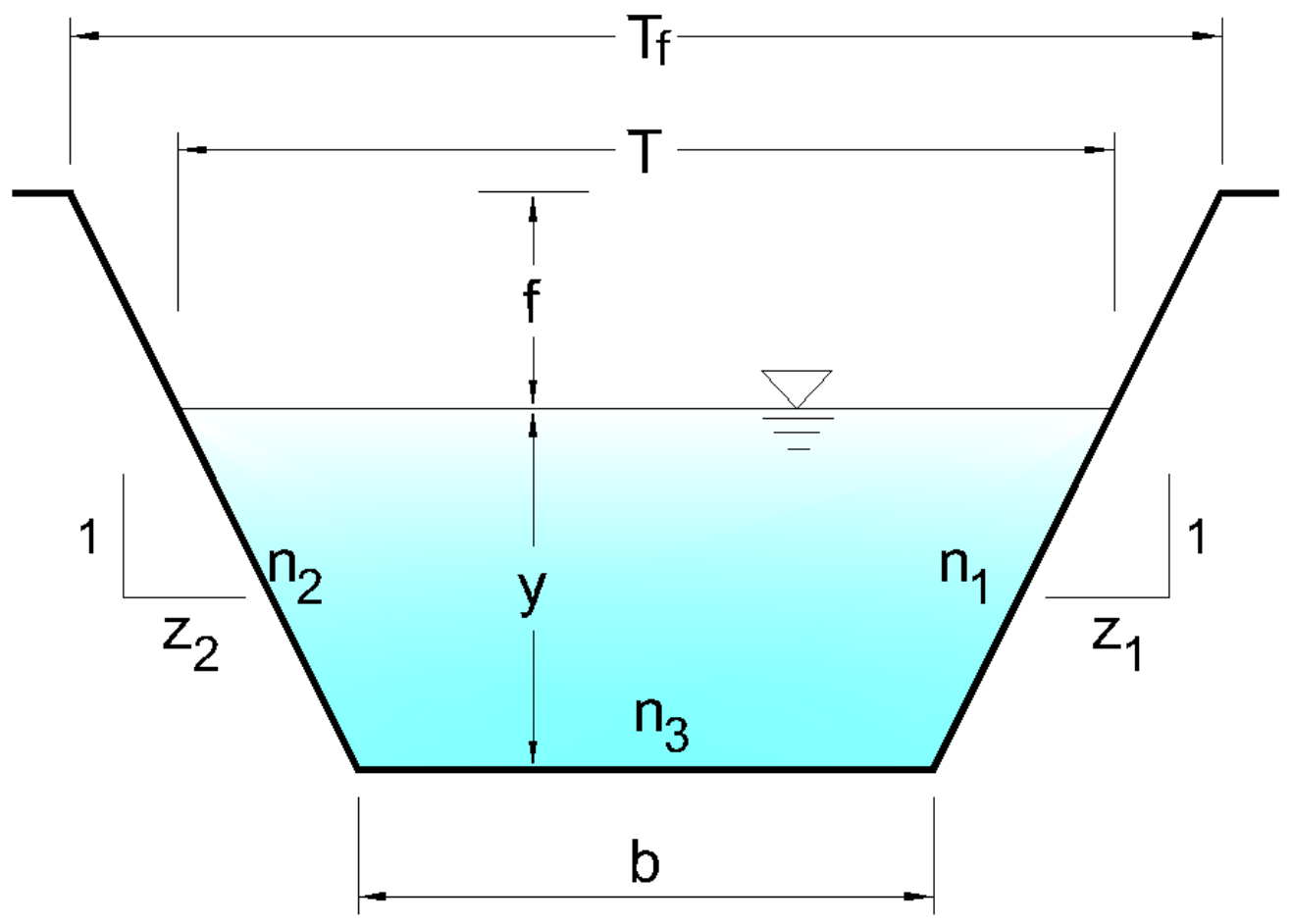

Figura 4.4 - Seção Trapezoidal e suas variáveis (DAS, 2000)

Empregando-se a parametrização para o cálculo de escoamento uniforme, pode-se chegar à Equação 4.9, exibida a seguir, que emprega como $n$ de Manning o valor equivalente, exposto na Equação 4.8, e considera as variáveis "área molhada" e "perímetro molhado" em função de b, y, $z_{1}$ e $z_{2}$.

$$
\frac{q}{\left(s_{o}\right)^{0,5}}=\frac{1}{n e} * \frac{\left\{b^{*} y+\left(z_{1}+z_{2}\right) * y^{2} / 2\right\}^{5 / 3}}{\left.\left\{\left(z_{1}^{2}+1\right)^{0,5}+\left(z_{2}^{2}+1\right)^{0,5}\right] * y+b\right\}^{2 / 3}}
$$

Equação 4.9

Para encontrar-se a seção trapezoidal ótima deve-se resolver um sistema de otimização não linear, cuja função objetivo é a de mitigação do custo por metro linear de canal, obedecendo-se à equação de escoamento uniforme (Equação 4.9), limitando-se as variáveis de projeto a valores positivos, e podendo ser especificada uma declividade dos taludes laterais mínima, maior que zero. 
Além disso, devem ser definidos também, a priori, os valores de rugosidade de Manning, vazão de projeto, declividade longitudinal, e os valores dos elementos de custo.

DAS (2000) complementou sua nota técnica com uma metodologia para solução do modelo, que pode ser classificado como um problema de otimização não linear, cujas variáveis são b, y, $z_{1}$ e $z_{2}$.

Em seu trabalho, a função custo foi definida conforme a Equação 4.10, apresentada a seguir,

$C=c_{1}\left[b(y+f)+\frac{\left(z_{1}+z_{2}\right)(y+f)^{2}}{2}\right]+\left[c_{2}\left(z_{1}^{2}+1\right)^{0,5}+c_{3}\left(z_{2}^{2}+1\right)^{0,5}\right](y+f)+b c_{4}$

Equação 4.10

na qual

$\mathrm{C}=$ Custo total unitário

$\mathrm{c}_{1}=$ Custo por unidade de área da seção transversal

$\mathrm{C}_{2}=$ Custo por unidade de comprimento da seção lateral 1

$\mathrm{C}_{3}=$ Custo por unidade de comprimento da seção lateral 2

$\mathrm{C}_{4}=$ Custo por unidade de comprimento da largura de fundo

DAS (2000) empregou o algoritmo de Lagrange para obter equações necessárias para resolver o modelo de minimização de custos, que calcula o valor de cada uma das variáveis $z_{1}$ e $z_{2}$, sendo que serão encontradas duas raízes para cada uma das variáveis citadas. Cabe ao modelo encontrar a menor delas e, a partir do resultado, encontrar os valores de b e y. Não foi computado o custo decorrente da perda de carga; porém, é possível acrescentá-lo como um novo elemento de custo. 
A seção parabólica ótima de canal foi estudada em (LOGANATHAN, 1991). Neste artigo foi apresentada uma solução do problema em uma abordagem onde houve inovação em dois aspectos principais, que são descritos a seguir.

O primeiro aspecto diferencial deste trabalho foi que a otimização da borda livre (freeboard) foi incluída no esquema de seção ótima. Normalmente esta grandeza sequer é calculada (adota-se apenas uma folga sobre a linha d'água máxima), mas para se obter a seção ótima, deve-se adotar uma borda livre calculada, por exemplo, em função da profundidade normal, ou então da vazão (neste estudo foram analisados os dois casos).

O segundo destaque deste trabalho é que foram consideradas restrições de cálculo quanto às dimensões permitidas no canal de largura, profundidade e velocidade de escoamento, que se podem fazer necessárias por questões topográficas, de custo, etc.

Outro aspecto interessante é que, nos estudos de eficiência econômica, ao invés de se adotar custos absolutos de escavação e revestimento, foi feita uma análise de sensibilidade da relação entre estas duas grandezas, eliminando a tarefa de se adquirir dados de valores absolutos, e facilitando a análise de custos incremental.

O equacionamento proposto baseia-se na Figura 4.5. 


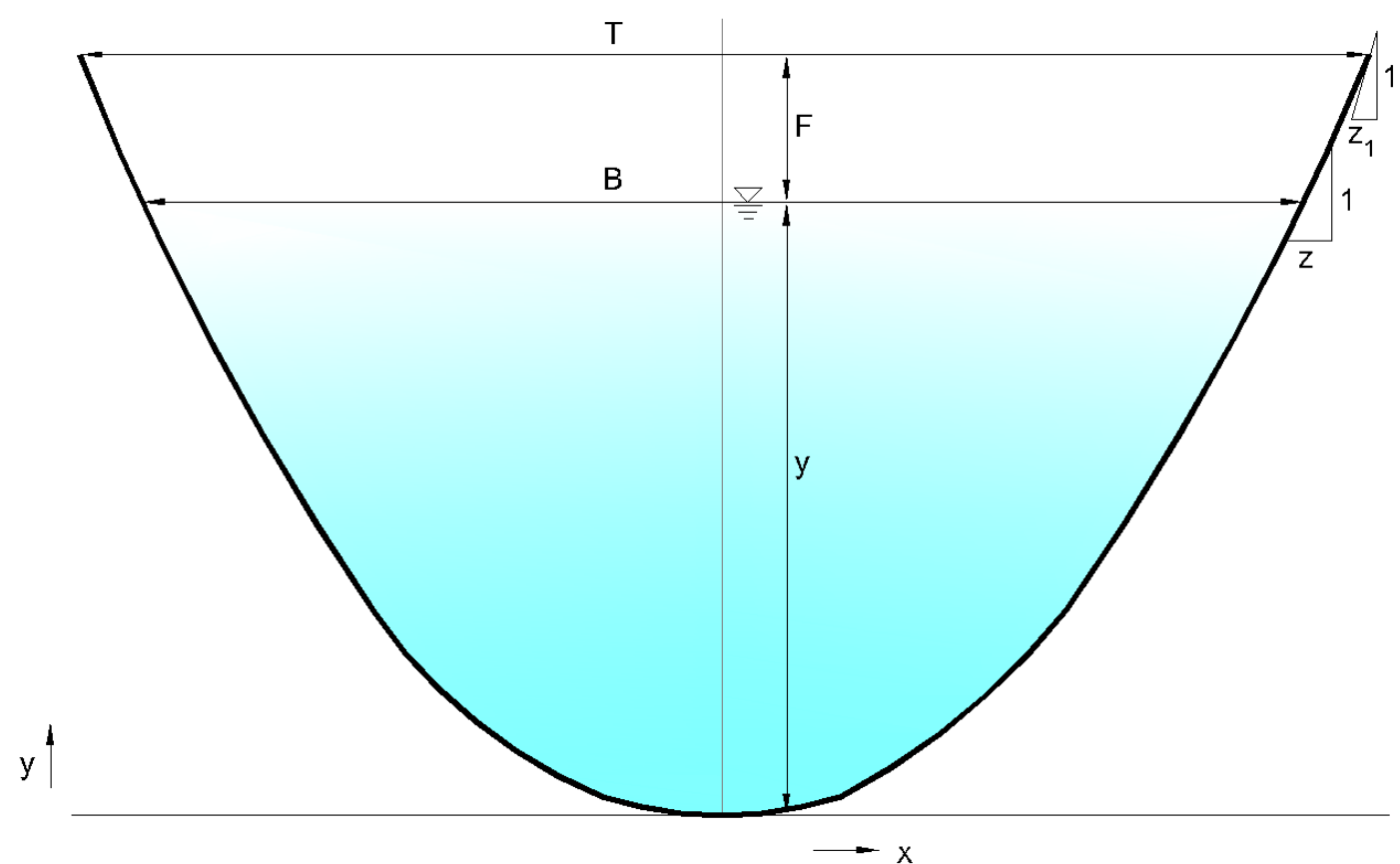

Figura 4.5 - Definição dos Elementos do Canal (LOGANATHAN, 1991)

Em um primeiro momento, considerando-se o freeboard "F" como função da vazão, o autor derivou a função "f" em "z", onde "f" representa o quadrado da função área, chegando à Equação 4.11 .

$$
\frac{d f}{d z}=\left[\frac{64}{9}(y+F)^{2} z\right]\left[2(y+F) y+(y+F) z \frac{d y}{d z}+3 y z \frac{d y}{d z}\right]=0
$$

Equação 4.11

que pode ser simplificada pela Equação 4.12

$$
2(y+F) y+(y+F) z \frac{d y}{d z}+3 y z \frac{d y}{d z}=0
$$

Equação 4.12

na qual

$$
\frac{d y}{d z}=-\frac{5}{8} C J^{1 / 4} z^{-13 / 8}+\frac{1}{4} C J^{-3 / 4} z^{-5 / 8} \frac{d J}{d z}
$$




$$
\begin{gathered}
C=0,5417\left(\frac{n Q}{1,49 \sqrt{S_{o}}}\right)^{3 / 8} \\
J(z)=2 z^{2}\left[\frac{1}{z} \sqrt{1+\frac{1}{z^{2}}}+\ln \left(\frac{1}{z}+\sqrt{1+\frac{1}{z^{2}}}\right)\right] \\
\frac{d J}{d z}=4 z\left[\ln \left(\frac{1}{z}+\sqrt{1+\frac{1}{z^{2}}}\right)\right]
\end{gathered}
$$

Equação 4.16

sendo

$\mathrm{n}=$ Coeficiente de Manning,

$\mathrm{Q}=$ Vazão,

$S_{0}=$ Declividade longitudinal.

Para análise do freeboard em função da vazão, LOGANATHAN empregou a Equação 4.17 proposta por (CHOW, 1959) e (CUENCA, 1989)

$$
F=\in y^{\delta}
$$

cujos coeficientes

$\epsilon=$ Variável de acordo com a vazão,

$\delta=0,5$.

Assim, a formulação fundamental é aquela apresentada na Equação 4.18

$$
\frac{d f}{d z}=\left[\frac{64}{9}(y+F)^{2} z\right]\left[2(y+F) y+(y+F) z \frac{d y}{d z}+3 y z\left(\frac{d y}{d z}+\frac{d F}{d z}\right)\right]=0
$$


Neste artigo são então apresentadas análises de seção ótima considerando as seguintes situações:

- Admitindo-se cálculo de freeboard em função da descarga (para uma descarga dada, o freeboard é um valor fixo conhecido), com a função objetivo de mínima área (minimizar escavação);

- Admitindo-se cálculo de freeboard em função da descarga, considerando-se restrições de altura e largura da superfície da água na solução ótima;

- Admitindo-se cálculo de freeboard em função da lâmina d'água (o que implica em uma equação que correlaciona lâmina d'água com altura de freeboard);

- Admitindo-se cálculo de freeboard em função da lâmina d'água, considerando-se restrições de altura e largura da superfície da água na solução ótima;

- Restrição quanto à velocidade máxima admissível de escoamento;

- Mitigação de custo, englobando os custos de escavação e revestimento.

Seções trapezoidais econômicas também foram estudadas com enfoque na seção estável do ponto de vista geotécnico, englobando o custo de construção - apenas os custos de escavação e revestimento, por metro linear de canal (BHATTACHARJYA et al, 2007). Foi proposta uma nova metodologia, incorporando o critério de estabilidade do talude para obter uma seção de canal ótima.

A estabilidade de um talude qualquer pode ser determinada calculando-se o fator de segurança crítico, que é função das características do solo: coesão, ângulo de atrito, peso específico entre outros. Existem diversas teorias de cálculo que permitem esta estimativa, destacando-se o método de fatias proposto por Fellenius em 1936 e o método modificado, proposto por Bishop em 1955. Em (BHATTACHARJYA et al, 2007), o cálculo do fator de segurança do círculo crítico de ruptura foi calculado usando o método de Fellenius.

No modelo proposto, um algoritmo calcula o fator de segurança do terreno em uma etapa e o resultado é aplicado à outra etapa do algoritmo, de cálculo de seção ótima - as etapas são independentes, porém ligadas externamente. 
Na primeira etapa, o cálculo de estabilidade de talude foi feito por otimização de função objetivo. Nas equações seguintes apresenta-se a forma usual de notação de um problema de otimização, onde se indica a meta da função objetivo e as restrições aplicáveis.

$$
\begin{array}{cc}
\text { Minimizar: } & F(p, q, r) \\
\text { Restrições: } & p_{\text {min }}<p<p_{\text {max }} q_{\text {min }}<q<q_{\text {max }} \\
r_{\min }<r<r_{\text {max }}
\end{array}
$$

Na qual as variáveis p, q e r estão representadas na Figura 4.6.
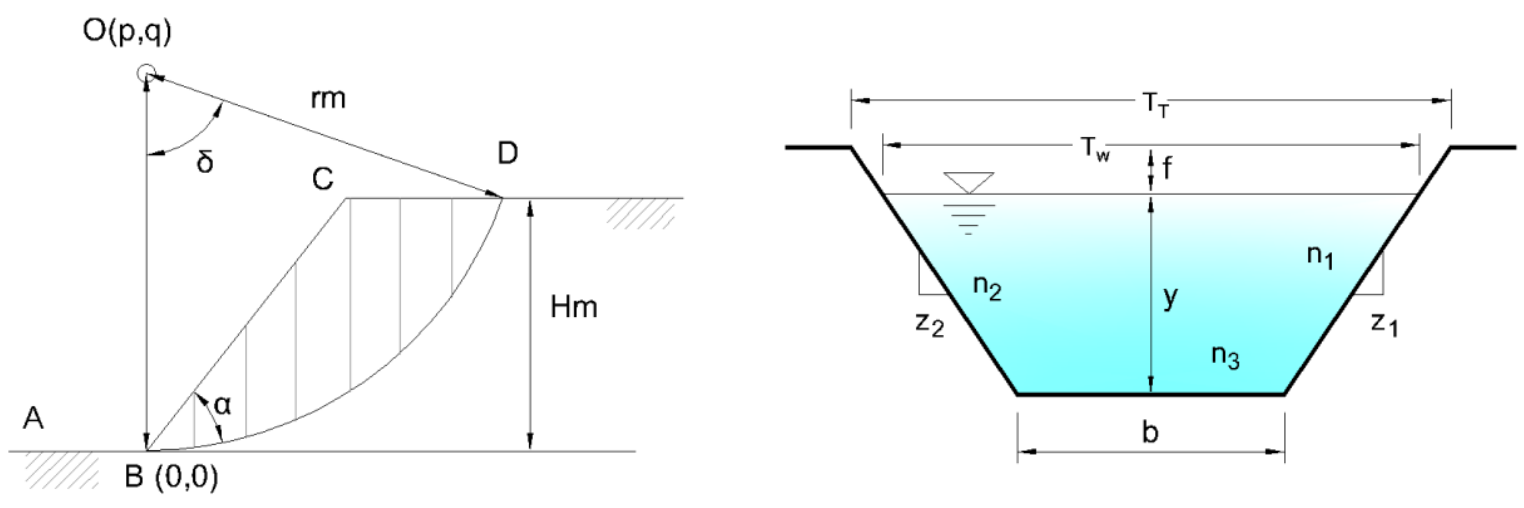

Figura 4.6 - Elementos de Cálculo da Seção Ótima (BHATTACHARJYA, 2007)

Esta otimização foi elaborada em ambiente MATLAB empregando algoritmo genético, de forma a superar os principais obstáculos inerentes das técnicas de otimização clássica: a relevância de dados iniciais necessários para a primeira iteração, que são especificados pelo usuário, e a convergência para mínimos locais, que eventualmente podem não ser mínimos globais do sistema, ou seja, a solução ideal. Uma simplificação de cálculos também encontrada no algoritmo genético é que não é necessário resolver derivadas de funções, permitindo o emprego de funções objetivo complexas, agregando diversas restrições. 
A segunda etapa do algoritmo, responsável pelo cálculo de seção ótima, ocorre tendo como dado de entrada o resultado da primeira etapa. Neste novo sistema, outra otimização não linear foi empregada, também em ambiente MATLAB, mas desta vez o modelo empregado foi o de programação quadrática sequencial. Este modelo contempla uma seção trapezoidal conforme indicado na Figura 4.6.

Foi considerada no modelo de otimização apresentado a possibilidade de emprego de diferentes revestimentos para as paredes e o fundo da seção, com diferentes rugosidades $\left(n_{1}, n_{2}\right.$ e $\left.n_{3}\right)$. A rugosidade equivalente, assim como em DAS (2000), foi calculada através do método de ponderação proposto por Horton (Equação 4.8).

Admitiu-se escoamento uniforme e, portanto, válida a equação de Manning (Equação 4.21). As outras restrições impostas ao modelo são o fator de segurança maior ou igual àquele calculado na $1^{\circ}$ etapa (Equação 4.22), e as variáveis de decisão não negativas.

$$
\begin{aligned}
& \psi_{1}\left(b, y, z_{1}, z_{2}\right)=\frac{Q \cdot n_{e}}{\sqrt{S o}}-\frac{A^{5 / 3}}{P^{2 / 3}}=0 \\
& \psi_{2}\left(y, z_{1}, z_{2}, c, \phi, \gamma, r_{u}\right)=F \geq F p
\end{aligned}
$$

Equação 4.21

Equação 4.22

Na qual

$\psi_{1}=$ Inequação de verificação da restrição de escoamento uniforme,

$\psi_{2}=$ Inequação de verificação da restrição da estabilidade dos taludes laterais,

$\mathrm{C}=$ Coesão do solo,

$\phi=$ Ângulo de atrito do solo,

$\gamma=$ Peso específico do solo,

$r_{u}=$ Razão de pressão dos poros,

$\mathrm{F}=$ Fator de segurança do talude lateral do solo,

$\mathrm{Fp}=$ Fator de segurança permissível do talude lateral do solo. 
A função objetivo é a de minimizar a função custo (Equação 4.23 - \$/m), sendo este considerado apenas o custo de construção (soma dos custos de escavação e revestimento), levando em conta as seguintes variáveis:

$$
\operatorname{Custo}\left(b, y, z_{1}, z_{2}\right)=c_{1} \cdot A_{T}+c_{2} \cdot P_{1}+c_{3} \cdot P_{2}+c_{4} \cdot P_{3}
$$

Equação 4.23

sendo

$\mathrm{c}_{1}=$ Custo de escavação por unidade de volume do canal $\left(\$ / \mathrm{m}^{3}\right)$,

$\mathrm{C}_{2}=$ Custo de revestimento por unidade de área para o segmento $1\left(\$ / \mathrm{m}^{2}\right)$,

$\mathrm{c}_{3}=$ Custo de revestimento por unidade de área para o segmento $2\left(\$ / \mathrm{m}^{2}\right)$,

$\mathrm{C}_{4}=$ Custo de revestimento por unidade de área para o segmento $3\left(\$ / \mathrm{m}^{2}\right)$,

$A_{T}=$ Área total da seção do canal $\left(\mathrm{m}^{3}\right)$,

$\mathrm{P}_{1}=$ Perímetro do segmento $1\left(\mathrm{~m}^{2}\right)$,

$\mathrm{P}_{2}=$ Perímetro do segmento $2\left(\mathrm{~m}^{2}\right)$,

$\mathrm{P}_{3}=$ Perímetro do segmento $3\left(\mathrm{~m}^{2}\right)$.

Devido à grande quantidade de variáveis em $\psi_{2}$ e, consequentemente, do grau de complexidade da Equação 4.23, foi feita uma simplificação no modelo, substituindose tal equação pelo seguinte:

$$
z_{1} \geq z_{1}^{\min } \text { e } z_{2} \geq z_{2}^{\min }
$$

Equação 4.24

O modelo pode finalmente ser representado pelo seguinte fluxograma. 


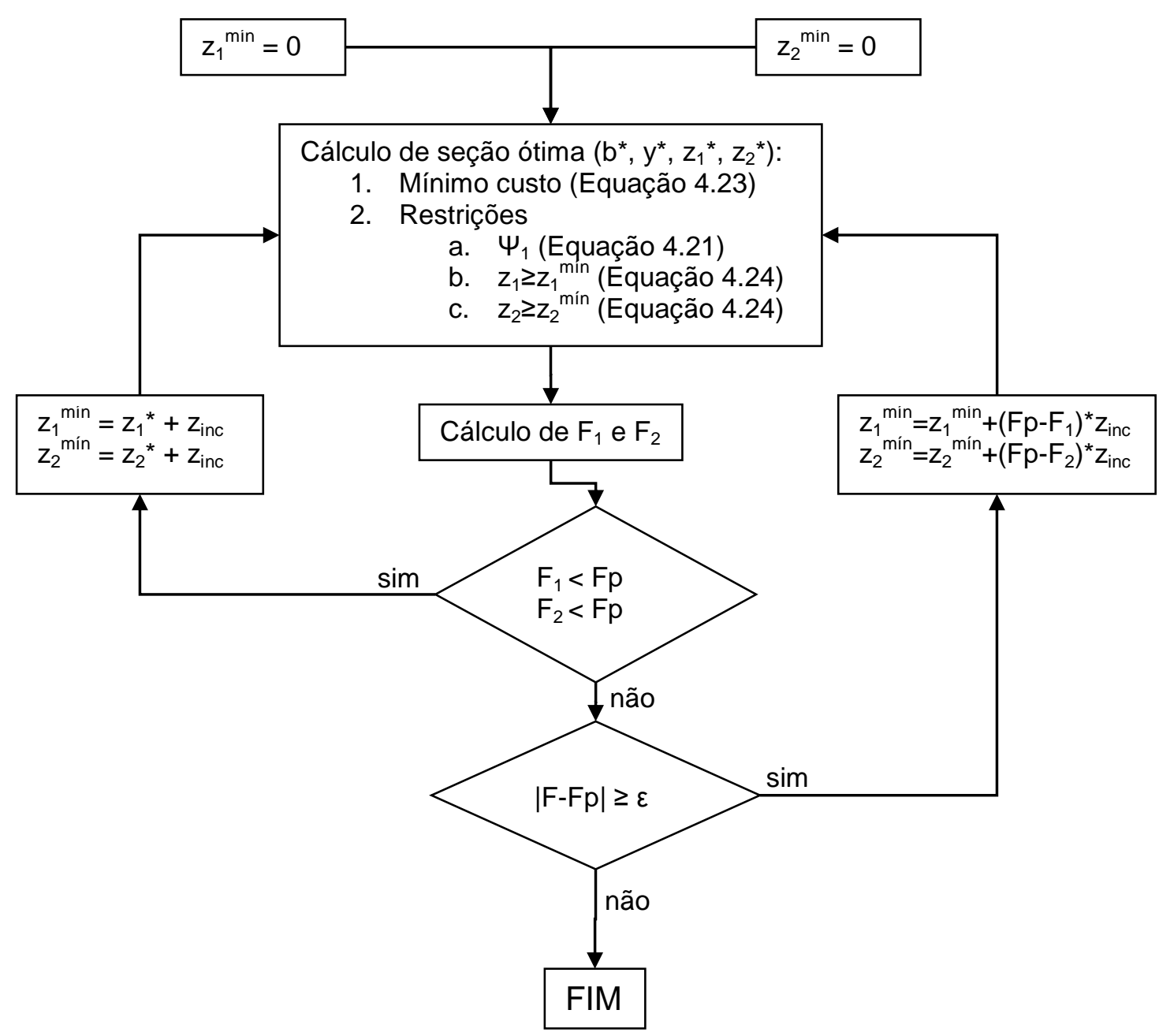

Figura 4.7 - Fluxograma de cálculo de seção ótima, adaptado a partir de BHATTACHARJYA et al (2007)

Este modelo é hibrido, pois apresenta dois tipos de algoritmos de otimização (genético e programação quadrática sequencial), e é interessante por levar em consideração o conceito de estabilidade de talude.

O estudo de CARRIAGA et al (1999) foi desenvolvido para otimização de seção de canais baseando-se no critério comumente adotado na fase de projeto e que leva em conta a estabilidade de fundo através dos conceitos de velocidade admissível e tensão de arraste crítica.

Tradicionalmente verificam-se, por tentativa e erro, as condições de movimento do leito e mobilidade do canal acima citadas, em conjunto com a capacidade de 
escoamento. CARRIAGA (1999) propõe a incorporação a esta metodologia de um modelo de otimização não linear, levando em conta os custos. O modelo proposto é definido pelo sistema composto da função objetivo e restrições impostas, conforme a Equação 4.25 e Equação 4.26, respectivamente.

$$
\begin{gathered}
C=\operatorname{Min}\left(\sum_{i=1}^{N} c_{i}(u, x)\right) \\
p_{\min } \leq p(u, x) \leq p_{\max } \\
p(u, x)=0 \\
u, x \geq 0
\end{gathered}
$$

na qual

$\mathrm{C}_{\mathrm{i}}(\mathrm{u}, \mathrm{x})=$ Componentes de custo inclusos no projeto,

$p=$ Requisitos físicos e hidráulicos do sistema,

u = Variável de decisão,

$\mathrm{X}=$ Variável de entrada.

Dentre os componentes de custo "ci" citou-se, a título de exemplo, a escavação do canal, outras movimentações de terra, estruturas hidráulicas de controle da linha d'água (escadas de drenagem, por exemplo), custos de aquisição de terra para direito de passagem e para servidão de drenagem, revegetação, recuperações diversas, mobilização, engenharia, operação, manutenção e reparo. A lista mostra o quão versátil o modelo pode ser, contemplando diversos elementos de custo.

Os requisitos físicos e hidráulicos "p" do modelo devem englobar a máxima velocidade permissível no canal e a tensão de arraste crítica, responsáveis pelo critério de estabilidade, requisitos de regime do escoamento, requisitos de altura de degraus das escadas de dissipação, e outras eventuais estruturas hidráulicas presentes. 
Para comprovar a sensibilidade do método, fez-se um estudo de caso no qual foi calculada a seção ótima para quatro diferentes situações, cujas restrições impostas foram:

- Velocidade máxima permissível

- Tensão de arraste crítica

- Seção econômica

- Seção ótima

Tais condições foram simuladas empregando-se a ferramenta GAMS-MINOS que, apesar do significativo esforço gasto na sua formulação e codificação, e da incerteza a respeito da solução final - se foi atingida realmente a melhor solução global ou se foi encontrado apenas um mínimo local que não é de fato a melhor solução - os resultados alcançados foram, na opinião do autor, bastante convincentes, pois foi possível distinguir com clareza as sensíveis diferenças entre os resultados para cada uma das situações de função objetivo.

O modelo implementado também presta-se para análises de sensibilidade em estudos comparativos para novas restrições construtivas ou de alteração de materiais de revestimento, comuns em projetos de canais otimizados.

CARRIAGA et al (2000) também prestaram contribuição ao estudo de otimização de canalizações com o trabalho sobre sistemas de canais, abrangendo desde casos simples (de trecho único) até casos complexos (múltiplos trechos organizados de forma paralela, em série ou mesmo dentrítica), sendo exclusivo ao tratar da otimização de múltiplos trechos de canal.

Este trabalho apresenta procedimentos de cálculo de otimização para um ou mais trechos de canal através de programação não linear, cuja função objetivo prioriza o desempenho econômico, e o conjunto de equações que governam o sistema diz 
respeito às leis de escoamento, de mobilidade do canal e estabilidade de fundo (o que engloba os critérios de velocidade máxima permissível e tensão de arraste crítica), assim como no trabalho de 1999 (CARRIAGA et al, 1999).

O grande diferencial deste trabalho, que o torna exclusivo, é a consideração não só de trecho simples de canal, mas também de trechos com mais de um afluente, inclusive prevê a ocorrência de drenagens dentríticas, que são aquelas com diversos afluentes em ramos e, por conseguinte, diversas vazões, cada uma associada a um trecho, conforme ilustra a Figura 4.8

A teoria empregada para determinação da vazão de projeto em cada trecho de um sistema complexo, composto por mais de um trecho de canal, foi o emprego da equação da continuidade: a vazão num determinado trecho com influência de montante é calculada pela soma das vazões afluentes.

As funções objetivo e restrições foram as mesmas empregadas no trabalho de 1999 (CARRIAGA et al., 1999) e a ferramenta de otimização, que executa as iterações e encontra as raízes da otimização, também foi o GAMS-MINOS.

O autor elaborou quatro estudos de caso empregando o modelo, um para cada caso apresentado na Figura 4.8 e obteve grandes variações nas grandezas largura de fundo, declividade de fundo do canal, velocidade máxima e altura de lâmina d'água de cada trecho, reflexo das diferentes vazões em cada caso.

O modelo requer, no entanto, descrição específica para cada caso, discriminando-se a sequência de trechos e as vazões individuais daqueles de montante, além de eventuais contribuições pontuais. 


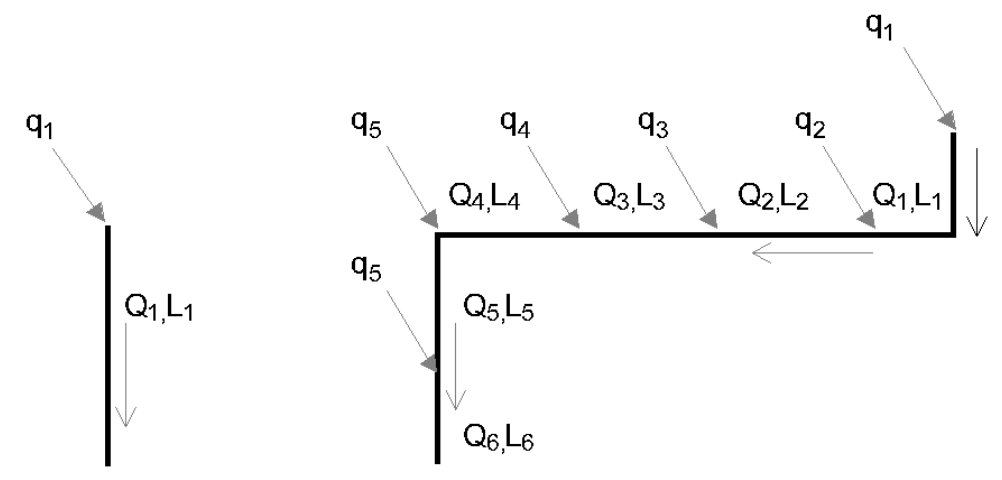

(a)

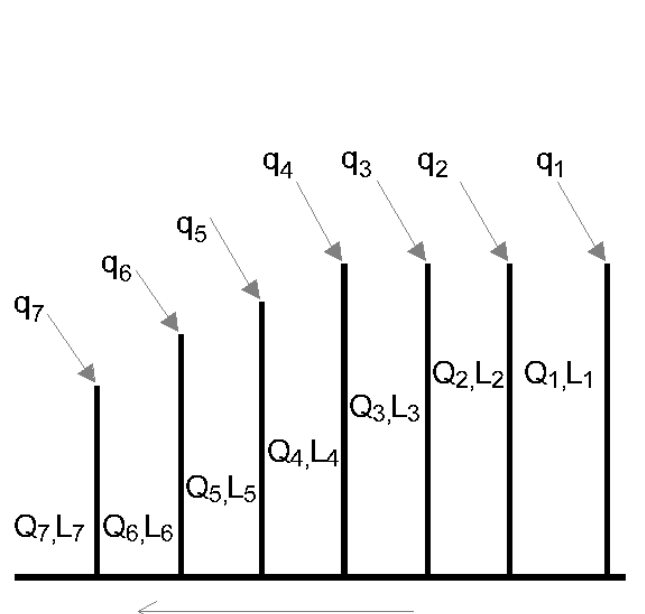

(c)

Sistema de múltiplos trechos em paralelo

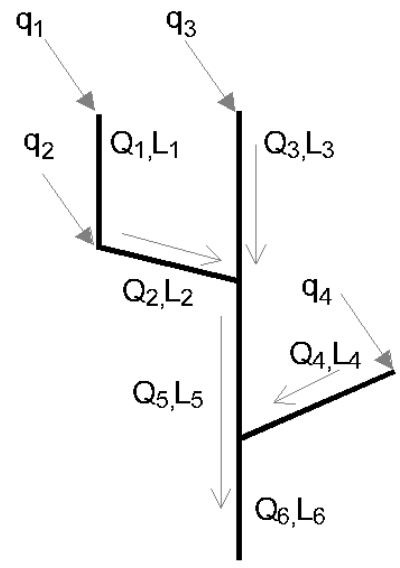

(d)

Sistema de trechos dendrítico

Figura 4.8 - Tipos de Sistemas de Canais (adaptado de CARRIAGA et al., 2000)

Uma solução analítica que leva em conta o critério de minimização de custo foi proposta por Souza, P.A. (s.d.) $)^{3}$, para otimização de canais de seção trapezoidal, pelo critério de custo global. Seu estudo não publicado, e disponibilizado no Apêndice $A$ deste trabalho para fins de documentação acadêmica, dado o brilhantismo da solução, considerou tanto a escavação quanto revestimento na

\footnotetext{
${ }^{3}$ Podalyro Amaral de Souza, graduado em Engenharia Civil pela Universidade de São Paulo (1971), mestre (1978) e doutor (1985) em Engenharia Civil pela Universidade de São Paulo é Engenheiro do Departamento de Águas e Energia Elétrica do Estado de São Paulo, Professor Assistente Doutor da Universidade de São Paulo, Assessor ad-hoc da Fundação de Amparo à Pesquisa do Estado de São Paulo (FAPESP) e autor de diversos livros e artigos relativos ao estudo da hidráulica aplicada.
} 
função custo, e o algoritmo de otimização aplicado foi o de Lagrange, assim como em DAS (2000). A definição do problema e respectiva formulação do algoritmo de solução são apresentadas a seguir.

Inicialmente, a formulação universal da perda de carga no escoamento livre em canais foi escrita em função de b e y, cujo resultado deve ser nulo para atender as premissas do estudo (escoamento uniforme):

$$
\begin{gathered}
A R^{2 / 3}=\frac{\left(b y+m y^{2}\right)^{5 / 3}}{\left(b+2 y \sqrt{1+m^{2}}\right)^{2 / 3}}=\frac{A^{5 / 3}}{P^{2 / 3}}=\frac{Q k^{1 / 6}}{8 \sqrt{g i}} \\
f(b, y)=A R^{2 / 3}-\frac{Q k^{1 / 6}}{8 \sqrt{g i}}=0=\frac{A^{5 / 3}}{P^{2 / 3}}-\frac{Q k^{1 / 6}}{8 \sqrt{g i}} \\
f(b, y)=\frac{\left(b y+m y^{2}\right)^{5 / 3}}{\left(b+2 y \sqrt{1+m^{2}}\right)^{2 / 3}}-\frac{Q k^{1 / 6}}{8 \sqrt{g i}}=0
\end{gathered}
$$

nas quais
$A=$ Área $\left(m^{2}\right)$,
$R=$ Raio Hidráulico $(m)$,
$\mathrm{Q}=\operatorname{Vazão}\left(\mathrm{m}^{3} / \mathrm{s}\right)$,
$\mathrm{m}=$ declividade do talude lateral $(1 \mathrm{~V}: \mathrm{m} \mathrm{H})$,
$\mathrm{g}=$ aceleração da gravidade $\left(\mathrm{m}^{3} / \mathrm{s}\right)$,
$\mathrm{i}=$ declividade de fundo do canal $(\mathrm{m} / \mathrm{m})$,
$\mathrm{k}=$ coeficiente relacionado a perda de carga do canal,
b, y como indicados na Figura 4.9.

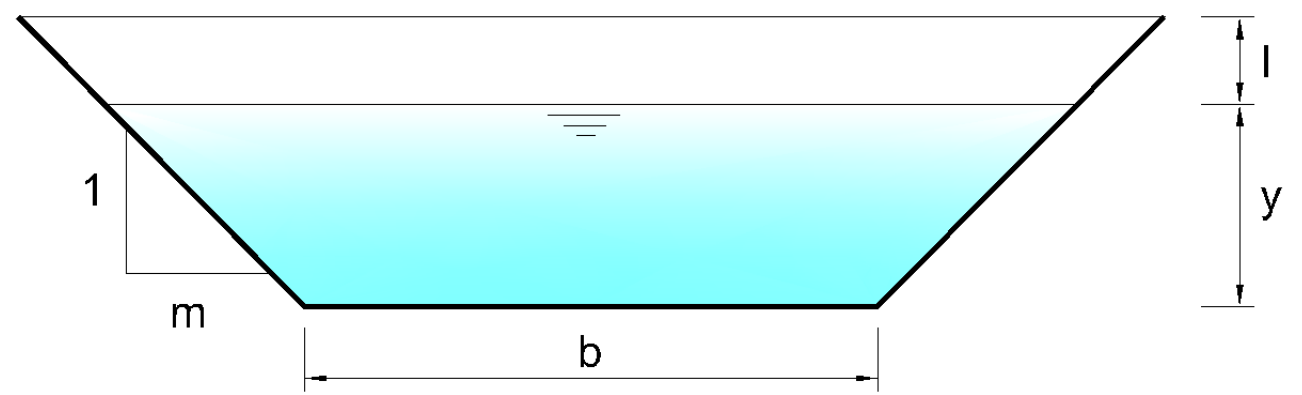

Figura 4.9 - Dimensões Empregadas por SOUZA (s.d.) 
A função objetivo, por sua vez, foi definida como

$$
C=C_{t}+C_{b}+C_{e}
$$

Equação 4.30

sendo

$C=$ Custo total,

$C_{t}=$ Custo do revestimento do talude por unidade de comprimento,

$C_{b}=$ Custo de revestimento da base por unidade de comprimento,

$C_{e}=$ Custo de escavação por unidade de comprimento,

na qual

$$
\begin{gathered}
C_{t}=2 \tau(y+l) \sqrt{1+m^{2}} \\
C_{b}=b \beta+c \\
C_{e}=\left[b(y+l)+m(y+l)^{2}\right] \varepsilon
\end{gathered}
$$

$\tau=$ Preço do revestimento do talude por unidade de área

$\beta=$ Preço do revestimento da base por unidade de área

$\varepsilon=$ Preço de escavação por unidade de volume

$c=$ Preço do material do canto por unidade de comprimento

A função custo é então definida como:

$$
C=2 \tau(y+l) \sqrt{1+m^{2}}+b \beta+c+\left[b(y+l)+m(y+l)^{2}\right] \varepsilon
$$

Pelo teorema de Lagrange, tem-se:

$$
\begin{gathered}
C=C(b, y) \\
\frac{\partial}{\partial b}[C(b, y)+\lambda f(b, y)]=0 \\
\frac{\partial}{\partial y}[C(b, y)+\lambda f(b, y)]=0 \\
\left\{\begin{array}{l}
\frac{\partial}{\partial b}[C+\lambda f]=0 \\
\frac{\partial}{\partial y}[C+\lambda f]=0
\end{array}\right.
\end{gathered}
$$




$$
\begin{gathered}
\left\{\begin{array}{l}
\frac{\partial C}{\partial b}+\lambda \frac{\partial f}{\partial b}=0 \\
\frac{\partial C}{\partial y}+\lambda \frac{\partial f}{\partial y}=0
\end{array}\right. \\
\frac{\partial f / \partial b}{\partial f / \partial y}=\frac{\partial C / \partial b}{\partial C / \partial y}
\end{gathered}
$$

Equação 4.38

Equação 4.39

Sabendo-se que a área pode ser equacionada por

$$
A=b y+m y^{2}
$$

Equação 4.40

tem-se:

$$
\left\{\begin{array}{c}
\frac{\partial A}{\partial b}=y \\
\frac{\partial A}{\partial y}=b+2 m y
\end{array}\right.
$$

O perímetro molhado, por sua vez, pode ser calculado por:

$$
P=b+2 y \sqrt{1+m^{2}}
$$

Logo, obtém-se:

$$
\left\{\begin{array}{c}
\frac{\partial P}{\partial b}=1 \\
\frac{\partial P}{\partial y}=2 \sqrt{1+m^{2}}
\end{array}\right.
$$

A função custo é definida por:

$$
C=2 \tau(y+l) \sqrt{1+m^{2}}+b \beta+c+\left[b(y+l)+m(y+l)^{2}\right] \varepsilon
$$

E suas derivadas parciais são:

$$
\left\{\begin{array}{c}
\frac{\partial C}{\partial b}=\beta+(y+l) \varepsilon \\
\frac{\partial C}{\partial y}=2 \tau \sqrt{1+m^{2}}+b \varepsilon+2 m \varepsilon(y+l)
\end{array}\right.
$$


Desta forma, chega-se à equação a ser satisfeita, em função de "b" e "y", para um determinado $\mathrm{m}$ :

$$
\begin{gathered}
\frac{\left[2\left(b y+m y^{2}\right)-5\left(b+2 y \sqrt{1+m^{2}}\right) y\right]}{\left[2\left(b y+m y^{2}\right) 2 \sqrt{1+m^{2}}-5\left(b+2 y \sqrt{1+m^{2}}\right)(b+2 m y)\right]} \\
=\frac{\beta+(y+l) \varepsilon}{2 \tau \sqrt{1+m^{2}}+b \varepsilon+2 m \varepsilon(y+l)}
\end{gathered}
$$

A Equação 4.46 pode ser resolvida através da ferramenta "Atingir Meta" disponível no aplicativo de planilha eletrônica Excel, definindo-se que o primeiro termo da igualdade subtraído pelo segundo termo da igualdade, deve atingir o valor zero, variando-se o termo "b".

Este modelo simplifica a condição de escoamento ao admitir regime uniforme ao longo do canal, ao invés de regime gradualmente variado, e também desconsidera, no volume de escavação, o volume do próprio revestimento.

Pelo exposto nota-se o quão difundido é o uso de sistemas não-lineares na solução de problemas de otimização de canais. Como exemplo, pode-se citar CARRIAGA et al (1999) como um bom trabalho sobre otimização de canal visando mínimo custo de construção, manutenção e operação, e DAS (2008), que acrescentou à analise de custo um estudo de probabilidade de ocorrência que é bastante interessante na elaboração de projetos econômicos, pois permite ao investidor maximizar seu lucro em função do risco a que se esteja disposto a admitir.

Sistemas não lineares também foram empregados no estudo de freeboard tanto em função da vazão quanto em função da profundidade por LOGANATHAN (1991), expandindo o alcance da otimização de seções, assim como fez CARRIAGA (2000), 
que acrescentou à modelagem de seção otimizada de canal o estudo de canais com múltiplos trechos.

Todos estes estudos reforçam a ideia de emprego de sistemas não lineares na otimização de canais. 


\section{DESENVOLVIMENTO DO MODELO E ESTUDO DE CASO}

A seguir será definido o modelo matemático que tem como objetivo dar suporte a decisão de qual a melhor configuração de seção transversal (seção ótima) de um canal, considerando parâmetros construtivos e operacionais. Isto requer a definição do problema, com todas as suas variáveis, relações e restrições.

Para verificação da validade do modelo, será feito um estudo de caso comparando seus resultados com um modelo existente, apresentado na revisão bibliográfica, para diversos tipos de revestimento, em diferentes vazões, alterando-se a declividade de fundo e também a inclinação de talude.

Em seguida, para verificação da aplicação do modelo, serão feitas novas simulações, considerando o efeito da perda de carga para um período de retorno arbitrário no custo total do empreendimento, e a partir dos resultados serão apresentadas considerações, de forma a se obter subsídios que permitam a escolha da seção ótima de canal.

\subsection{Elementos de Projeto}

É frequente, no projeto de canalizações, principalmente aqueles de grande extensão, atribuir-se mais atenção ao traçado em planta do que à geometria da seção transversal do canal.

Porém, ainda que menor, a importância da forma geométrica, dimensões e revestimento empregado pode assumir influência considerável, em valores absolutos, notadamente em casos que se tenha um canal extenso, ou canal com revestimento e (ou) seção muito ineficiente em termos energéticos. 
É de fundamental importância, portanto, a otimização desta estrutura. Entende-se por seção ótima pelo critério de custo global a seção que não somente minimize gastos com escavações e revestimentos, como também seja estável e proporcione menores perdas de carga (maximize a eficiência hidráulica). A seção ótima, portanto, deve ser aquela que minimiza a função custo global estendido, função esta que engloba os custos de escavação do canal, custos de revestimento, custos de manutenção e os custos referentes à perda de carga, governada pela sua eficiência hidráulica, visto que interferem diretamente na geração de energia ao longo de todo o horizonte de projeto. Tal função, proposta na Equação 4.1, se assemelha à proposta por BHATTACHARJYA (2007).

$$
\mathrm{F}_{\mathrm{CGE}}=\mathrm{F}_{\mathrm{ESC}}+\mathrm{F}_{\mathrm{ATR}}+\mathrm{F}_{\mathrm{REV}}+\mathrm{F}_{\mathrm{MAN}}+\mathrm{F}_{\triangle \mathrm{H}}
$$

\section{Equação 5.1}

Os termos desta equação representam:

$\mathrm{F}_{\mathrm{CGE}}=$ Função custo global estendido

$\mathrm{F}_{\mathrm{ESC}}=$ Função custo de escavação

$\mathrm{F}_{\mathrm{ATR}}=$ Função custo de aterro

$\mathrm{F}_{\mathrm{REV}}=$ Função custo de revestimento

$\mathrm{F}_{\text {MAN }}=$ Função custo de manutenção

$\mathrm{F}_{\Delta H}=$ Função perdas financeiras causadas pela perda de carga

Isto posto, a seção deve ser escolhida dentre uma gama de possibilidades, entendendo-se por possíveis as seções que sejam viáveis técnica e economicamente. Tradicionalmente, emprega-se um número restrito de tipos de geometria, a saber: parabólica, trapezoidal, retangular, mista (trapezoidal + retangular). Seções circulares, por exemplo, são sabidamente eficientes do ponto de vista hidráulico, porém, por serem de difícil execução, têm uso restrito em situações de pequeno porte como, por exemplo, em experimentos de laboratório. 
A determinação da seção ótima será atingida através do cálculo de custos esperados para cada uma das possibilidades de geometria envolvidas. Para isso, deve ser levada em conta a elevação do topo rochoso, a(s) rugosidade(s) da superfície do canal, os custos de escavação, revestimento e manutenção, o horizonte de projeto do empreendimento, e o abatimento de talude máximo aceitável para o solo da região, ou para o revestimento empregado no canal. Todos estes dados devem ser entradas para a análise da eficiência.

A seguir, serão feitas considerações a respeito de cada uma das variáveis que interferem no cálculo de eficiência do modelo.

\subsubsection{Geometria das Seções}

A equação universal revela que a melhor seção hidráulica tem uma área molhada mínima, para uma determinada descarga. Porém, as melhores seções hidráulicas para diferentes geometrias não são igualmente eficientes. A forma hidráulica ideal é a semicircular, mas esta forma não é fácil de ser construída.

Dentre as seções viáveis, pode-se destacar:

\subsubsection{Seção Retangular}

O dimensionamento da seção retangular é o mais simples dentre as diferentes geometrias empregadas usualmente. Suas variáveis geométricas para uma determinada vazão de projeto são apenas a largura do canal e a profundidade da lâmina d'água, sendo que esta é função direta da largura. 
Desta forma, o cálculo resume-se em iterar entre diversas larguras, encontrando-se para cada uma delas a profundidade do canal, a perda de carga e os custos de construção e manutenção associados. Seções mais estreitas implicam em escavações mais profundas e seções mais largas implicam em maiores áreas de ocupação.

Esta solução pode ser empregada em situações que permitam a existência de parede vertical, o que pode ocorrer quando se tem escavação em rocha ou quando as paredes do canal são estruturas de concreto.

\subsubsection{Seção Trapezoidal}

As seções do tipo trapezoidal são largamente empregadas em diversas aplicações de canais porque são de fácil execução, podendo ser adaptadas a uma grande diversidade de solos, desde aqueles com elevada resistência, aplicando-se nas paredes do canal abatimento reduzido, até solos pouco resistentes, usando-se neste caso abatimento elevado das paredes do canal ou revestimentos mais delgados.

Além de solos, quando bem projetada, esta geometria de seção também se adapta perfeitamente a todos os tipos de revestimentos. Assim, é a principal forma geométrica utilizada para seção transversal de canais, seja de adução, de irrigação ou qualquer outra finalidade.

O dimensionamento desta geometria engloba as variáveis: largura de fundo, inclinação das paredes e altura da lâmina d'água. Dadas as restrições iniciais de estabilidade dos taludes, devem-se iterar diferentes larguras de fundo com diferentes 
abatimentos para se obter o par que melhor atenda as demandas de maximização de eficiência com minimização de custo.

Eventualmente, seções profundas podem requerer maior escavação em rocha do que seções largas, e serem preteridas ainda que sua eficiência hidráulica seja reduzida. Para definir a seção final, portanto, é imprescindível a contabilização dos custos associados.

\subsubsection{Seção Mista}

As seções mistas, caracterizadas por uma forma trapezoidal abaixo de uma seção retangular, são bastante empregadas, pois conseguem atingir maior eficiência hidráulica do que apenas um retângulo ou um trapézio isoladamente.

No entanto, elas sofrem a mesma restrição no trecho retangular de uma seção completamente retangular, ou seja, os taludes admissíveis, que são função exclusiva do tipo de revestimento e do solo na região.

Assim, seu emprego depende das condições locais, o que explica porque esta geometria é tão difícil de ser encontrada em aplicações práticas.

\subsubsection{Seção Parabólica}

Esta configuração é sem dúvida a mais complexa de se executar, e a dificuldade construtiva se reflete, assim como nas seções retangulares e mistas, na frequência do seu emprego. 
Hidraulicamente, no entanto, esta configuração sempre se destaca com eficiência elevada em relação às demais apresentadas neste subitem, razão pela qual existem diversos estudos a seu respeito, até mesmo estudos de otimização de seção, como é o caso de LOGANATHAN (1991).

Portanto, apesar da dificuldade construtiva, a eficiência hidráulica ainda torna este tipo de geometria viável, e somente um estudo de otimização amplo e bem elaborado pode descartar o seu emprego.

\subsubsection{Velocidade Máxima Admissível}

A velocidade máxima admissível em um canal é definida como a velocidade média de escoamento limite que precede a ocorrência de erosão no canal. A erosão em um canal tem ocorrência associada tanto ao tipo de material do leito e das margens, como à profundidade do escoamento e ao traçado do leito.

Existem algumas formas de se definir a velocidade máxima admissível em uma dada seção de canal: há equacionamentos embasados em conhecimentos científicos, e também há maneira empírica que permite estimar esta grandeza.

Usualmente, tabelas empíricas são de grande simplicidade e eficiência, razão pela qual são largamente empregadas em situações reais de projeto.

\subsubsection{Tensão de Arraste Crítica}

O estudo de tensão de arraste crítica em canais, apesar de receber consideráveis esforços na tentativa de equacioná-lo, ainda não é completamente dominado no 
meio científico, devido à grande complexidade envolvida no processo de iteração entre o escoamento do fluido e o material de revestimento do canal.

A principal dificuldade está na caracterização da camada que recobre a superfície do canal, que pode apresentar uma enorme diversidade de composições, função da litologia no local no caso de canais naturais, e uma infinidade de possíveis distribuições granulométricas. Tal barreira pode ser evidenciada através da simples observação dos métodos existentes de estimativa de tensão de arraste crítica, que se baseiam ora no diâmetro característico $D_{35}$, ora no $D_{50}$, ou mesmo no $D_{90}$, sendo que em alguns casos chegam até a computar o desvio da amostra, na tentativa de obter uma caracterização mais fiel do solo.

Dentre os diversos modelos existentes sobre tensão de arraste crítica, um que recebe aqui destaque é daquele proposto por Ackers \& White, em 1983, fruto de uma análise dimensional das seguintes grandezas:

- Tamanho da partícula $\left(D_{35}\right)$,

- Peso específico da água,

- Peso específico do sedimento,

- Densidade do sedimento,

- Velocidade média do escoamento,

- Profundidade do escoamento,

- Velocidade de atrito,

- Viscosidade cinemática do fluído,

- Aceleração da gravidade.

A metodologia proposta por eles tem como principal atrativo o fato de ter sido amplamente testada, sendo desenvolvida a partir de diversas calibrações, e ser bem aceita pelo meio técnico. Em contrapartida, sua maior desvantagem é a abrangência restrita a casos cujo numero de Froude não supere o valor de 0,8 e cuja distribuição granulométrica é bastante concentrada (partículas uniformes, com grãos entre $0,04 \mathrm{~mm}$ e 4,0 mm, ou seja, não coesivas). 


\subsubsection{Perda de Carga no Canal}

A análise de perda de carga no canal deve ser feita a partir do estudo do escoamento permanente gradualmente variado, considerando as características físicas que influem no escoamento (seção topobatimétrica do canal, rugosidade do fundo etc.) e a resistência ao escoamento.

O tratamento do escoamento permanente gradualmente variado vem sendo objeto de estudo por parte dos pesquisadores por mais de 100 anos, o que revela sua complexidade e importância. Esta complexidade origina-se do próprio tratamento matemático das equações que regem o movimento e também do grande número de parâmetros hidráulicos sujeitos a sensíveis variações ao longo da corrente (PORTO, 2006).

As equações básicas do escoamento unidimensional nos canais, também conhecidas como equações de SAINT-VENANT, expressam a conservação da massa e da quantidade de movimento, em termos da vazão em escoamento, num trecho discreto, e da cota do nível d'água (Equação 5.2). As perdas de energia por atrito são representadas pelo gradiente energético do trecho, segundo a expressão de Chézy (CHOW, 1959).

$$
\begin{gathered}
\frac{\partial Q}{\partial x}+\frac{\partial A}{\partial t}=q \\
\frac{\partial Q}{\partial t}+\frac{\partial}{\partial x}\left(\frac{\beta Q^{2}}{A}\right)+g A \frac{\partial h}{\partial x}+g A S_{f}=q v \cos \gamma
\end{gathered}
$$


na qual

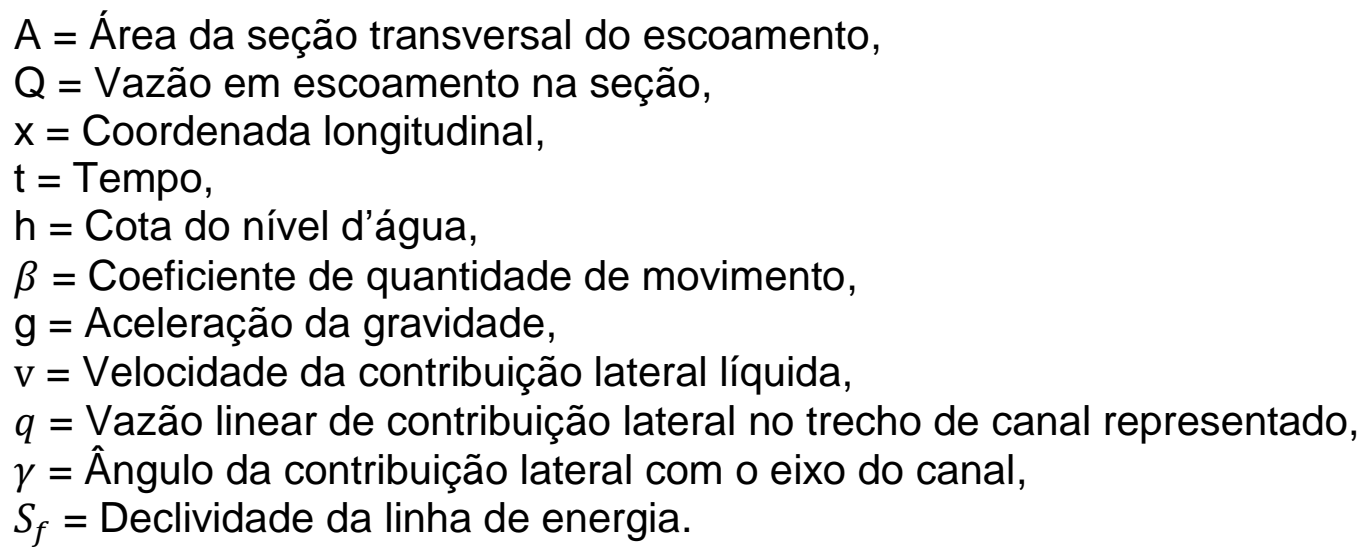

O termo $\mathrm{C}$ pode ser estimado através da expressão de Manning ou ainda através de Darcy-Weissbach, com ajuste proposto por Henderson (1966):

$$
\begin{gathered}
C=\frac{1}{n} R_{h}{ }^{1 / 6} \\
C=\left(\frac{8 g}{-2 \log \frac{k}{12 R_{h}}}\right)^{1 / 2}
\end{gathered}
$$

Equação 5.4

Equação 5.5

na qual

$\mathrm{n}$ = Coeficiente de rugosidade de Manning,

$\mathrm{R}_{\mathrm{h}}=$ Raio hidráulico,

$\mathrm{k}=$ Rugosidade equivalente hidráulica.

Deve-se ter em conta que nos canais naturais os valores de coeficientes de rugosidade diferem daqueles normalmente aceitos para condutos regulares. Isto ocorre porque nos cursos irregulares há a necessidade de se considerar também a rugosidade de forma da seção, que provoca perdas de energia em função da turbulência gerada (SOUZA, P. A.; MARTINS, J. R. S.; FADIGA JUNIOR, F. M., 1991). 
Para o escoamento permanente admite-se, por hipótese, que a Equação 5.2 é automaticamente satisfeita e que na Equação 5.3 possam ser desprezados os termos dependentes do tempo. Desta forma, resulta:

$$
2 \beta \frac{Q}{A} q+g A\left(1-\beta F_{r}^{2}\right) \frac{\partial y}{\partial x}+g A S_{f}=0
$$

Equação 5.6

As equações apresentadas formam um sistema sem solução analítica geral, sendo necessário lançar mão de alguns artifícios para se resolvê-lo. $\mathrm{O}$ método numérico existente mais conhecido atualmente para resolução do sistema é o método das diferenças finitas.

Este método caracteriza-se por simplificar os diferenciais por diferenças finitas, permitindo assim uma resolução numérica por meio de iterações, razão pela qual é adequado em modelagens unidimensionais e bidimensionais, e tem uso bastante difundido.

Existem esquemas explícitos e implícitos para se chegar à solução. Os esquemas explícitos realizam cálculos com variáveis conhecidas no tempo e espaço (por exemplo, os métodos McCormack e Difusivo), enquanto os esquemas implícitos realizam cálculos iterativos sem se ter conhecimento das variáveis no tempo, necessitando, por isso, de maiores recursos de cálculo (por exemplo, o esquema de Preissman).

\subsubsection{Escavação}


Uma boa estimativa da escavação de qualquer canal deve considerar, primeiramente, o material a ser escavado. Materiais mais resistentes requerem maiores esforços para sua retirada, o que se reflete em maiores custos de escavação.

$\mathrm{Na}$ engenharia civil, é comum agrupar os materiais de escavação em três categorias, da seguinte forma:

- 19ategoria: escavado com equipamentos comuns

- 2a Categoria: escavado com auxílio de escarificadores e de dimensões médias

- $\quad 3^{a}$ Categoria: só podem ser escavados com o uso de explosivos

Além disso, devem-se avaliar também as distâncias de transporte, sendo comum a classificação do transporte entre superior ou inferior a uma ou mais distâncias. Tal classificação existe tendo em vista que transportes para curtas distâncias perdem maior porcentagem do tempo útil em mobilizações de carga e descarga, tendo assim menor produtividade, e precisam ser recompensados com um maior valor do $\mathrm{m}^{3}$ transportado.

\subsubsection{Revestimento}

A proteção dos cursos d'água pode ser feita com os mais variados materiais e técnicas de revestimento, que são definidos em função das características do solo, dos materiais disponíveis, da ação das correntes e ondas e dos objetivos a serem atingidos.

Deve-se definir um tipo de proteção que mais se adapte às condições locais, não somente quanto à resistência à ação do escoamento, mas também quanto à resistência às deformações do solo de base, e que atenda às condicionantes 
ambientais, rugosidade resultante, facilidade de execução, além do custo final da obra (MACCAFERRI DO BRASIL, 2009).

Neste estudo existe a possibilidade de emprego de diversos materiais de revestimentos, porém foge ao escopo do trabalho uma análise da resistência, da eficiência, da durabilidade, enfim, da otimização do revestimento. Este trabalho se restringe apenas ao custo do revestimento e a sua resistência ao escoamento.

\subsubsection{Custos}

Como critério de escolha entre as configurações de cada geometria envolvida neste estudo e entre as formas geométricas em análise, um importante fator será associado aos custos envolvidos.

Por tanto, é imprescindível que se tenha custos unitários devidamente estipulados, para que o modelo seja capaz de diferenciar as alternativas de seção atendendo à expectativa do usuário.

Quanto aos custos medidos ao longo da vida útil do empreendimento, como por exemplo, o de manutenção do canal e o de perda de carga, é necessária a atualização destes, corrigindo-os para valor presente.

Tal operação é feita a partir dos dados de número de períodos a serem contabilizados (anos ou meses de horizonte de projeto), e da taxa de juros adotado para cada período.

\subsection{Formulação do Modelo}


Este modelo calcula, numericamente, para uma dada situação, o perfil de linha d'água, e a partir desta define as dimensões do trapézio necessárias para a lâmina d'água dada, admitindo uma folga de freeboard, em cada uma das seções. Em seguida, faz a conformação deste trapézio com o terreno, calculando os custos que incorrem da implantação da estrutura numa dada topografia. Estes cálculos todos são feitos em ambiente Microsoft Office Excel $2010^{\circledR}$.

Devido à presença no modelo de muitas variáveis e da inter-relação entre elas, o problema aqui tratado é caracterizado como uma típica aplicação da técnica de otimização não linear. Sua definição requer uma função objetivo e restrições, que estão descritas ao longo deste capítulo.

A título de esclarecimento, cabe dizer que otimização, na matemática, é a programação de um dado problema em uma função objetivo (cujas variáveis são denominadas "variáveis de decisão") e uma ou mais restrições (relações de igualdade e/ou desigualdade que envolvem as variáveis de decisão). A classificação linear e não linear diz respeito à relação entre as variáveis de decisão na função objetivo e nas restrições da programação, e há ainda classificações acerca dos valores passíveis de serem assumidos pelas variáveis (inteiros, reais, booleanos ou mistos) e quanto a natureza da função objetivo (convexa ou côncava).

As etapas de cálculo do modelo, que define os valores de custo da perda de carga, da escavação, do revestimento e de aterro para uma dada condição inicial fornecida pelo usuário, estão apresentadas a seguir:

1. Leitura dos dados de entrada: seções (X, Y, Progressiva), vazão, declividade do talude $(\mathrm{m})$, condições de contorno (cota de fundo de jusante e nível d'água de jusante), características do revestimento (Manning, espessura), declividade de fundo do canal, freeboard, nível do material de primeira categoria e de segunda categoria em relação à cota de fundo do trapézio - VBA;

2. Cálculo das distâncias relativas entre seções, da distância do talvegue (X médio da seção), da cota de fundo do trapézio de cada seção - VBA; 
3. Interpolação (linear), no terreno, dos pontos da base do trapézio / trapézio revestido - VBA;

4. Cálculo, para cada uma das seções, e para cada valor de $X$, da cota (Y) correspondente tanto do trapézio quanto do trapézio revestido - VBA;

5. Atribuição ao canal / canal revestido dos valores provisórios do trapézio / trapézio revestido - VBA;

6. Inicialização do cálculo de linha d'água (atribuição de valores iniciais para a lamina d'água em cada seção) - VBA;

7. Cálculo de linha d'água - VBA;

8. Interpolação, em cada seção, dos pontos de intersecção da lâmina d'água + freeboard com o trapézio / trapézio revestido - VBA;

9. Definição dos valores finais do canal / canal revestido (encaixe do trapézio / trapézio revestido com o terreno, respectivamente) - VBA;

10. Cálculo dos volumes de escavação, volumes de aterro e áreas de revestimento - VBA;

11. Cálculo dos custos, função das áreas e volumes calculados e dos custos unitários - Planilha Excel.

(Nota: VBA significa que a etapa foi elaborada com o uso de programação no Excel - Macro -, em linguagem VBA)

A otimização neste modelo é feita empregando-se o Solver do próprio Excel 2010, que busca o mínimo custo variando o valor da base da seção, restrita a valores positivos, através da modelagem de GRG (Generalized Reduced Gradient) não linear, utilizada em problemas não lineares uniformes, como este. A função desenvolvida em VBA calcula automaticamente os resultados de volumes e, por conseguinte, o custo total é calculado, para cada iteração do solver de base do trapézio.

\subsubsection{Função Objetivo}

Por se tratar de um modelo de otimização por critério de custo global, a função objetivo, da qual o modelo deverá pesquisar o valor mínimo, não poderia ser outra senão a de custo total do empreendimento. No presente modelo, o custo global do empreendimento é definido por: 


$$
F_{G L}=F_{M O}+F_{A}+F_{E}+F_{R}+F_{M A}
$$

Onde:

$F_{G L}=$ Função custo global

$F_{M O}=$ Função custo de motorização

$F_{A}=$ Função custo de aterro

$F_{E}=$ Função custo de escavação

$F_{R}=$ Função custo de revestimento

$F_{M A}=$ Função custo de manutenção

Os custos de implantação, escavação, revestimento e aterro podem ser agrupados como custo de construção, enquanto o custo de manutenção, neste modelo, é definido pelas perdas que ocorrem durante a vida útil do canal.

- Motorização

A função custo de motorização é relacionada com vazão e com a diferença de nível d'água entre jusante e montante do canal e, portanto, depende também da perda de carga. Aplica-se tanto para canais de adução (custo de unidades geradoras de aproveitamentos hidrelétricos), quanto para canais de irrigação, abastecimento etc (bombas de recalque).

- Aterro

O aterro é o depósito de material no terreno para obter uma regularização do mesmo em relação a um dado projeto, e o seu custo é calculado pelo volume de material depositado, multiplicado pelo respectivo custo unitário, sendo que o volume é calculado pela integração dos aterros que ocorrem entre seções sequentes. Entre duas seções, este volume é o produto da distância entre elas e a área média 
aterrada (dada pela diferença entre o canal e o terreno natural, como indicado na Figura 5.1).

O canal é definido da seguinte forma: na seção trapezoidal, compreendida entre a cota de fundo do trapézio e a elevação correspondente ao nível d’água mais freeboard $(\mathrm{H}+\mathrm{f}$, na Figura 5.1), o canal acompanha o trapézio. Fora deste intervalo, o canal é definido pela elevação mínima entre o terreno e o trapézio (margem direita) desde que a elevação não seja inferior ao nível H+f, caso contrário, o canal segue a elevação de $\mathrm{H}+\mathrm{f}$ (margem esquerda).

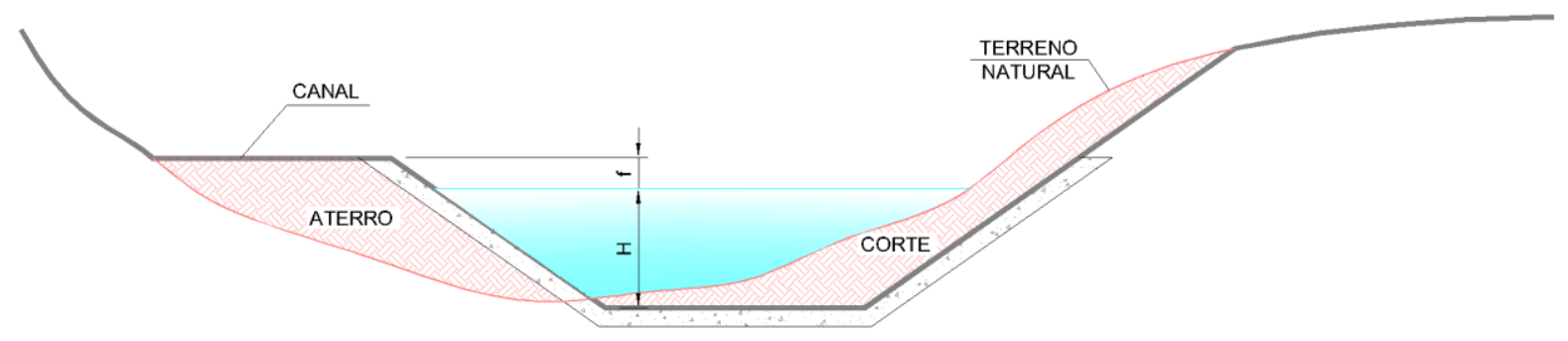

Figura 5.1 - Conformação Canal / Terreno

\section{- Escavação}

A função custo de escavação é o resultado da somatória dos custos de escavação em cada uma das três categorias tratadas no item 5.1.5. Para o cálculo do custo de escavação de cada uma das categorias, multiplica-se o custo unitário de escavação da categoria pelo respectivo volume.

O volume de escavação de uma categoria é calculado pela somatória dos volumes de escavação desta categoria entre seções consecutivas, que é igual ao produto da 
distância entre elas pela área média de escavação, assim como ocorre no calculo do aterro, devendo-se englobar na área escavada a fração pertinente a implantação de revestimento (vide Figura 5.2).

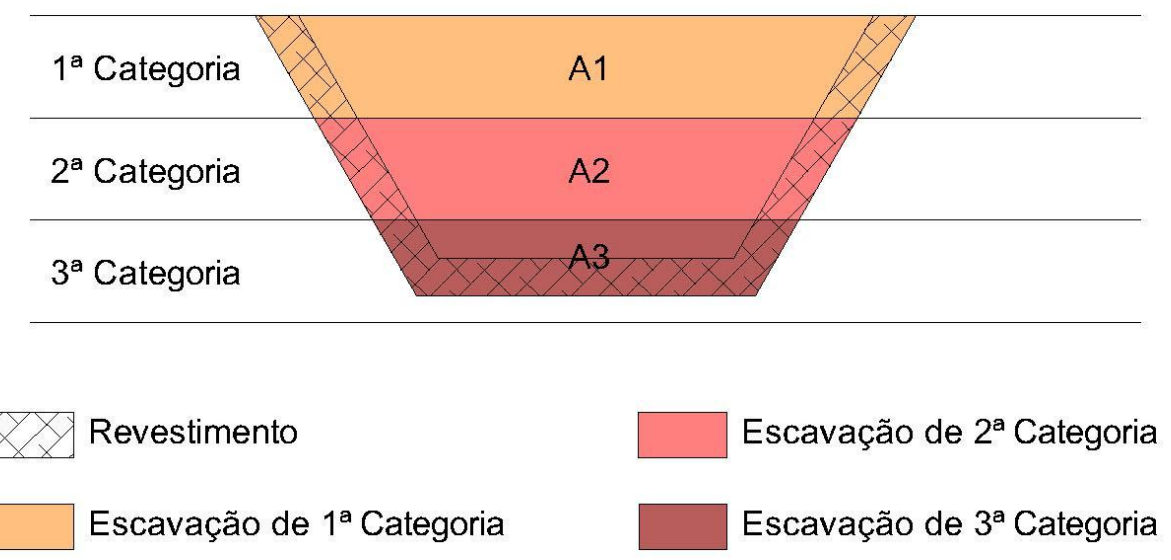

Figura 5.2 - Área Escavada na Seção Transversal

Logo, o computo do custo de escavação total é feito conforme apresentado na Equação 5.8 .

$$
\begin{gathered}
C_{E S C}=C_{1} \sum_{i=1}^{n-1}\left(\frac{A_{1(i)}+A_{1(i+1)}}{2}\right) d_{i}+C_{2} \sum_{i=1}^{n-1}\left(\frac{A_{2(i)}+A_{2(i+1)}}{2}\right) d_{i} \\
+C_{3} \sum_{i=1}^{n-1}\left(\frac{A_{3(i)}+A_{3(i+1)}}{2}\right) d_{i}
\end{gathered}
$$

sendo que os coeficientes equivalem a:

$C_{E S C}=$ Custo total de escavação,

$\mathrm{A}_{1}=$ Área escavada para categoria 1 ,

$\mathrm{A}_{2}=$ Área escavada para categoria 2,

$\mathrm{A}_{3}=$ Área escavada para categoria 3,

$\mathrm{C}_{1}=$ Custo de escavação para categoria 1,

$\mathrm{C}_{2}=$ Custo de escavação para categoria 2,

$\mathrm{C}_{3}=$ Custo de escavação para categoria 3,

$\mathrm{n}=$ Número total de seções no canal,

$d_{(i)}=$ Distância entre a seção (i) e a seção (i+1). 
Outra consideração a ser feita sobre o custo de escavação é quanto à distância de transporte ao bota-fora. Esta parcela de custo é particular de cada empreendimento, e não foi considerada neste trabalho, mas deve ser calculada em casos onde o custo de transporte tenha valores expressivos, principalmente em canais de grande extensão ou nos casos onde o bota-fora esteja distante das obras e não seja possível aplicar o material escavado no empreendimento.

- Revestimento

O custo de revestimento é função direta do tipo de revestimento e da área a ser protegida. Como principais tipos de revestimento, se pode citar aqueles presentes na Tabela 5.1. 
Tabela 5.1 Principais Tipos de Revestimentos ${ }^{4}$

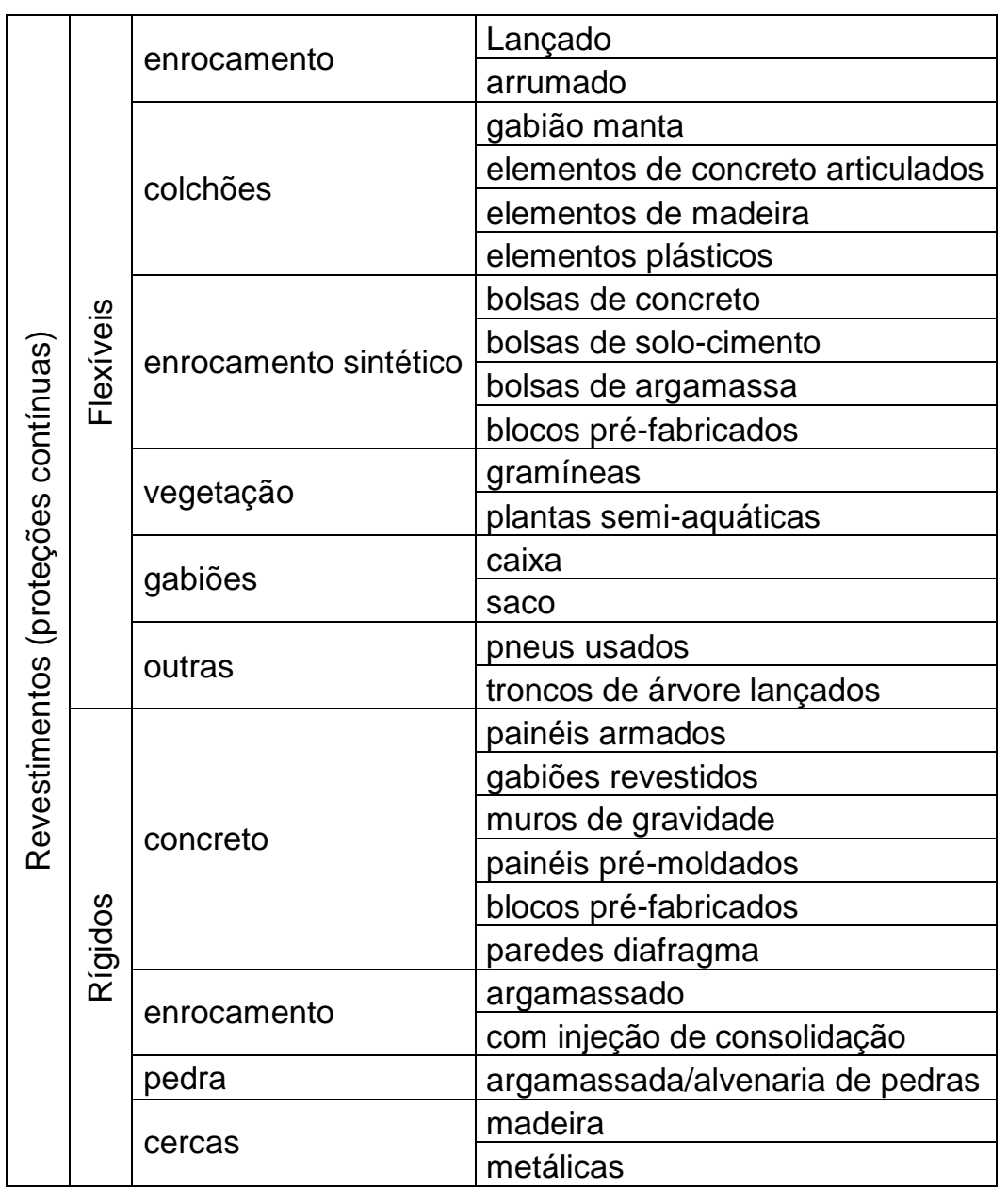

Cada revestimento apresenta diferentes valores de custo unitário, espessura, e coeficiente de atrito. Desta forma, a única forma de se saber as consequências no custo global do emprego de um revestimento é calculando-se a perda de carga causada por ele, e os volumes adicionais de escavação e aterro necessários para implantá-lo. Soma-se a estes custos o valor do próprio revestimento.

Fica claro que a alteração entre diferentes revestimentos implica diretamente na eficiência econômica final atingida pelo empreendimento, e o modelo aqui

\footnotetext{
${ }^{4}$ Extraído de BRIGHETTI, G., MARTINS, J. R. S., (Universidade de São Paulo) Notas de Aula Obras Hidráulicas. Departamento de Engenharia Hidráulica e Sanitária, 2001.
} 
desenvolvido é uma ferramenta de suporte à decisão, dentre outras coisas, de qual revestimento deve ser empregado.

- Manutenção

A função custo de manutenção do canal é aquela que prevê as perdas financeiras que ocorrem durante a vida útil do canal. Dentre estas perdas estão os custos de conservação do revestimento (face ao desgaste natural, depredação etc.), custos de limpeza do canal e o custo associado à perda de carga.

O custo de manutenção será influenciado pelo tipo de revestimento. Um gabião, por exemplo, pode necessitar de ajustes periódicos da tela que faz a contenção dos gabiões, ou um canal com paredes de concreto pode necessitar de reparo em trincas excessivas, que estejam sendo alargadas em ritmo acelerado pela infiltração da água.

Uma consequência da falta de manutenção nas paredes e fundo do canal é o aumento da rugosidade: a perda de carga neste caso aumentaria, interferindo na geração de energia, e este custo deve ser computado.

Além disso, a depender da quantidade de sedimentos que a água transporta, pode ser necessária também uma dragagem periódica do fundo do canal para retirar sedimentos que tenham se depositado.

Deve-se ter o cuidado de trazer estes custos durante a vida do empreendimento a valor presente, permitindo assim a sua comparação com os demais custos de obra. Tal correção se faz através da multiplicação do custo anual pelo fator de correção apresentado na Equação 5.9. 


$$
F_{C}=\frac{(1+i)^{n}-1}{i(1+i)^{n}}
$$

\section{Equação 5.9}

na qual

$F_{C}=$ Fator de correção;

$i=$ Taxa de juros, por período;

$n=$ Número de períodos durante a vida útil.

Por simplificação, pode-se admitir o custo de manutenção como sendo a verba anual fixa de manutenção, incluindo dragagem e inspeção, além de outra verba relativa à perda de carga do canal, corrigida para valor presente, permitindo assim a sua comparação com os demais custos da obra.

$$
\mathrm{F}_{\mathrm{MA}}=\left(\mathrm{F}_{\mathrm{FI}}+\mathrm{F}_{\mathrm{PC}}\right) \mathrm{F}_{\mathrm{C}}
$$

cujos coeficientes representam

$\mathrm{F}_{\mathrm{MA}}=$ Função custo de manutenção,

$\mathrm{F}_{\mathrm{Fl}}=$ Função custo de manutenção fixo,

$\mathrm{F}_{\mathrm{PC}}=$ Função custo de perda de carga,

$\mathrm{F}_{\mathrm{C}}=$ Fator de correção (Equação 5.9).

Quanto à perda de carga, há que se considerar o uso do canal: em canais de adução, a perda de carga deve ser contabilizada pelo custo da geração que deixou de ser feita, e eventualmente pode implicar também em redução na dimensão da(s) unidade(s) geradora(s), e este caso particular deve ser calculado contabilizando-se o custo de comercialização da energia ao longo do horizonte de projeto (e a variação no custo de implantação das máquinas, quando pertinente, conforme mencionado na função custo de motorização). 
Nos demais canais, a forma de se medir o custo da perda de carga é através do cálculo da perda de energia associada, uma vez que a energia possui custo de referência conhecido. A energia consumida em um determinado intervalo de tempo pela perda de carga é calculada da seguinte forma:

$$
\Delta \mathrm{E}=\Delta \mathrm{h} \times \Delta t \times \mathrm{Q} \times \mathrm{g} \times \rho \times \eta
$$

na qual

$\Delta \mathrm{E}=$ Energia média consumida pela perda de carga (MWh),

$\Delta \mathrm{h}=$ Perda de carga média $(\mathrm{m})$,

$\Delta t=$ Intervalo de tempo de estudo $(h)$,

$\mathrm{Q}=$ Vazão média $\left(\mathrm{m}^{3} / \mathrm{s}\right)$,

$\mathrm{g}=$ Aceleração da gravidade $\left(\mathrm{m} / \mathrm{s}^{2}\right)$,

$\rho=$ Massa específica da água $\left(\mathrm{kg} / \mathrm{m}^{3}\right)$,

$\eta=$ Rendimento da bomba, turbina e/ou gerador.

Assim, a função custo da perda de carga pode ser calculada a partir da energia consumida encontrada pela Equação 5.11, da seguinte forma

$$
F_{P C}=\Delta E C_{E}
$$

Equação 5.12

sendo

$F_{P C}=$ Função custo de perda de carga anual,

$\Delta E$ = Energia média anual consumida pela perda de carga (Equação 5.11- MWh), $C_{E}=$ Custo unitário da energia $(\mathrm{R} \$ / \mathrm{MWh})$.

O custo da energia elétrica é definido pela quantidade de energia elétrica consumida num dado período, multiplicada pela tarifa correspondente àquele período, que é variável e estabelecida pela Agência Nacional de Energia Elétrica (ANEEL, 2005). 
Para definir as tarifas de energia elétrica, a ANEEL considera o consumo de energia (valor acumulado pelo uso da potência elétrica disponibilizada ao consumidor durante o período de consumo) e a demanda de potência (maior potência elétrica solicitada pelo consumidor ao longo do período de consumo).

Tais componentes são mensurados diferentemente entre dois grupos de consumidores: Grupo A - atendido pela rede de alta tensão, de 2,3 kV a 230 kV - e grupo B - unidades consumidoras atendidas em tensão inferior a 2,3 kV.

Existe ainda uma subdivisão dos grupos nas seguintes classes/subclasses:

Tabela 5.2 Classes e Subclasses dos Grupos A e B - adaptado de (ANEEL, 2005)

\begin{tabular}{|c|c|}
\hline GRUPO A & GRUPO B \\
\hline $\begin{array}{l}\text { A1: } 230 \mathrm{kV}+ \\
\text { A2: } 88 \mathrm{kV}-138 \mathrm{kV} \\
\text { A3: } 69 \mathrm{kV} \\
\text { A3a: } 30 \mathrm{kV} \text { a } 44 \mathrm{kV} \\
\text { A4: } 2,3 \mathrm{kV} \text { a } 25 \mathrm{kV} \\
\text { AS: Sistema Subterrâneo }\end{array}$ & $\begin{array}{l}\text { B1: Residencial (Baixa Renda*) } \\
\text { B2: Rural (agropecuária*, cooperativa de eletrificação } \\
\text { rural }^{*} \text {, indústria rural }{ }^{*} \text {, serviço público de irrigação rural }{ }^{*} \text { ) } \\
\text { B3: Industrial, comercial, serviços, poder público (serviço } \\
\text { público e consumo próprio) } \\
\text { B4: Iluminação pulica }\end{array}$ \\
\hline
\end{tabular}

${ }^{*}$ Subclasses

A estrutura tarifária é definida então da seguinte forma:

- Grupo A

- Convencional: Tarifas de consumo de energia e de demanda de potência independentes da hora de utilização do dia e dos períodos do ano;

- Horo-Sazonal: Tarifas de consumo de energia variável pela hora do dia entre ponta (18 hs a $21 \mathrm{hs}$ ) e fora de ponta, e pelo período do ano, 
seco e úmido. A demanda de potência pode ser única (horo-sazonal verde) ou variável pelo horário (horo-sazonal azul).

- Grupo B

- Tarifa fixa no tempo para cada classe, que considera somente o consumo de energia elétrica visto que a demanda de potência é incorporada ao fornecimento de energia;

- Tarifa social de baixa renda, destinada à subclasse residencial de baixa renda do grupo $B$, composta por usuários cujo consumo mensal é inferior a 80 kWh/mês, ou entre 80 e 220 kWh/mês, que comprovem inscrição no cadastro único de programas sociais do governo federal. Os descontos para este público são escalonados da seguinte forma:

Tabela 5.3 Tarifa Social de Baixa Renda (Fonte: AES Eletropaulo, 2010)

\begin{tabular}{|l|l|}
\hline \multicolumn{1}{|c|}{ Faixa de Consumo } & $\begin{array}{c}\text { Desconto Tarifário em Relação à } \\
\text { Classe Residencial }\end{array}$ \\
\hline $0 \mathrm{kWh}$ a $30 \mathrm{kWh}$ & $65 \%$ \\
\hline $31 \mathrm{kWh}$ a $100 \mathrm{kWh}$ & $40 \%$ \\
\hline $101 \mathrm{kWh}$ ao Limite Regional & $10 \%$ \\
\hline
\end{tabular}

\subsubsection{Restrições}

A restrição feita ao modelo, que calcula a variável largura da base na otimização, é que esta dimensão seja maior do que zero. Como o solver do EXCEL não usa o sinal de maior para configurar uma restrição, foi empregada então a restrição na base $(B)$ : 


$$
B \geq 0,1
$$

\subsubsection{Verificações}

Os requisitos físicos e hidráulicos do modelo devem englobar a máxima velocidade permissível no canal e a tensão de arraste crítica, responsáveis pelo critério de estabilidade, e obedecer aos requisitos de regime do escoamento (atender aos princípios da continuidade e de quantidade de movimento).

- Velocidade Máxima Admissível

A velocidade máxima admissível é a restrição de proteção do corpo do canal, que quando atendida evita o desgaste exagerado do revestimento e alteração na forma do canal, e, portanto é uma característica relacionada ao tipo de revestimento em uso no canal. Além do revestimento, a velocidade máxima admissível também está relacionada com a característica hidráulica de profundidade do escoamento, e com a forma do canal. CHOW (1959) sugere que esta velocidade também tem relação com a idade do canal, existindo maior estabilidade em canais mais antigos, cujas partículas coloidais apresentam maior sedimentação.

Os valores de velocidade máxima admissível em função do tipo de material que compõe a superfície do canal foram tabelados por diversas instituições, sendo uma das publicações mais populares aquela apresentada pela ASCE em 1926.

Tabela 5.4 Velocidade Máxima Recomendada (adaptado de FORTIER \& SCOBEY, 1926)

\begin{tabular}{|l|l|l|l|l|l|}
\hline \multirow{2}{*}{ Material } & \multirow{2}{*}{$\mathrm{n}$} & \multicolumn{2}{|c|}{ água limpa } & \multicolumn{2}{|c|}{$\begin{array}{c}\text { agua transportando } \\
\text { silte coloidal }\end{array}$} \\
\cline { 3 - 6 } & & $\mathrm{V}(\mathrm{m} / \mathrm{s})$ & $\tau_{\mathrm{s}}\left(\mathrm{N} / \mathrm{m}^{2}\right)$ & $\mathrm{V}(\mathrm{m} / \mathrm{s})$ & $\tau_{\mathrm{s}}\left(\mathrm{N} / \mathrm{m}^{2}\right)$ \\
\hline
\end{tabular}


Tabela 5.4 Velocidade Máxima Recomendada (adaptado de FORTIER \& SCOBEY, 1926)

\begin{tabular}{|l|r|r|r|r|r|}
\hline \multirow{2}{*}{ Material } & \multirow{2}{*}{$\mathrm{n}$} & \multicolumn{2}{c|}{ água limpa } & \multicolumn{2}{c|}{$\begin{array}{c}\text { agua transportando } \\
\text { silte coloidal }\end{array}$} \\
\cline { 5 - 7 } & & $\mathrm{V}(\mathrm{m} / \mathrm{s})$ & $\tau_{\mathrm{s}}\left(\mathrm{N} / \mathrm{m}^{2}\right)$ & $\mathrm{V}(\mathrm{m} / \mathrm{s})$ & $\tau_{\mathrm{s}}\left(\mathrm{N} / \mathrm{m}^{2}\right)$ \\
\hline Areia fina, coloidal & 0,020 & 0,46 & 1,292 & 0,76 & 3,589 \\
\hline Areia com turfa, não coloidal & 0,020 & 0,53 & 1,770 & 0,76 & 3,589 \\
\hline Silte com turfa, não coloidal & 0,020 & 0,61 & 2,297 & 0,91 & 5,263 \\
\hline Silte aluvial, não coloidal & 0,020 & 0,61 & 2,297 & 1,07 & 7,177 \\
\hline Turfa resistente & 0,020 & 0,76 & 3,589 & 1,07 & 7,177 \\
\hline Cinza vulcânica & 0,020 & 0,76 & 3,589 & 1,07 & 7,177 \\
\hline Argila dura, muito coloidal & 0,025 & 1,14 & 12,440 & 1,52 & 22,010 \\
\hline Silte aluvial, coloidal & 0,025 & 1,14 & 12,440 & 1,52 & 22,010 \\
\hline Folhelhos e crosta laterítica & 0,025 & 1,83 & 32,057 & 1,83 & 32,057 \\
\hline Cascalho fino & 0,020 & 0,76 & 3,589 & 1,52 & 15,311 \\
\hline Turfa graduada a pedra de mão, não coloidal & 0,030 & 1,14 & 18,182 & 1,52 & 31,579 \\
\hline Silte gradualdo a pedra de mão, coloidal & 0,030 & 1,22 & 20,574 & 1,68 & 38,278 \\
\hline Cascalho grosseiro, não coloidal & 0,025 & 1,22 & 14,354 & 1,83 & 32,057 \\
\hline Pedra de mão & 0,035 & 1,52 & 43,541 & 1,68 & 52,632 \\
\hline
\end{tabular}

LENCASTRE (1972) também apresenta valores de velocidade média máxima admissível, como apresentado a seguir. 
Tabela 5.5 Velocidade Máxima Admissível (Adaptado de LENCASTRE, 1972)

\begin{tabular}{|c|c|c|c|c|c|c|c|c|c|c|c|}
\hline \multirow{15}{*}{ 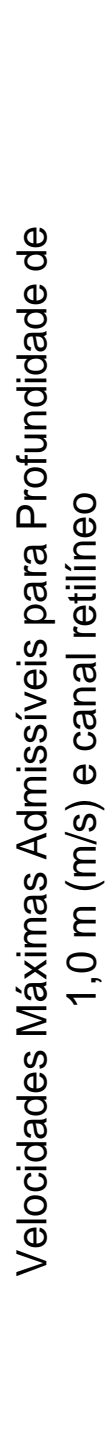 } & \multicolumn{11}{|c|}{ Materiais não coesivos } \\
\hline & Material & \multicolumn{2}{|c|}{$\begin{array}{c}\text { Diametro } \\
\mathrm{mm}\end{array}$} & $\begin{array}{l}\text { Vel. Médi } \\
\mathrm{ms}^{-1}\end{array}$ & \multicolumn{3}{|c|}{ Material } & \multicolumn{2}{|c|}{$\begin{array}{c}\text { Diametro } \\
\mathrm{mm}\end{array}$} & \multicolumn{2}{|c|}{$\begin{array}{l}\text { Vel. Média } \\
\mathrm{ms}^{-1}\end{array}$} \\
\hline & lodo & \multicolumn{2}{|c|}{0,005} & 0,15 & \multicolumn{3}{|c|}{ cascalho fino } & \multicolumn{2}{|c|}{15,00} & \multicolumn{2}{|c|}{1,20} \\
\hline & areia fina & \multicolumn{2}{|c|}{0,05} & 0,20 & \multicolumn{3}{|c|}{ cascalho médio } & \multicolumn{2}{|c|}{25,00} & \multicolumn{2}{|c|}{1,40} \\
\hline & areia média & \multicolumn{2}{|c|}{0,25} & 0,30 & \multicolumn{3}{|c|}{ cascalho grosso } & \multicolumn{2}{|c|}{40,00} & \multicolumn{2}{|c|}{1,80} \\
\hline & areia grossa & \multicolumn{2}{|c|}{1,00} & 0,55 & \multicolumn{3}{|c|}{ cascalho grosso } & \multicolumn{2}{|c|}{75,00} & \multicolumn{2}{|c|}{2,40} \\
\hline & lodo fino & \multicolumn{2}{|c|}{2,50} & 0,65 & \multicolumn{3}{|c|}{ cascalho grosso } & \multicolumn{2}{|c|}{100,00} & \multicolumn{2}{|c|}{2,70} \\
\hline & lodo médio & \multicolumn{2}{|c|}{5,00} & 0,80 & \multicolumn{3}{|c|}{ cascalho grosso } & \multicolumn{2}{|c|}{150,00} & \multicolumn{2}{|c|}{3,50} \\
\hline & lodo grosso & \multicolumn{2}{|c|}{10,00} & 1,00 & \multicolumn{3}{|c|}{ cascalho grosso } & \multicolumn{2}{|c|}{200,00} & 3,9 & \\
\hline & Materiais co & vos & & & & & & & & & \\
\hline & $\begin{array}{l}\text { Material } \\
\text { coesivo do le }\end{array}$ & & $\begin{array}{r}\text { Mi } \\
\text { comp } \\
\text { uma } \\
\text { vazi }\end{array}$ & $\begin{array}{l}\text { to pouco } \\
\text { actado com } \\
\text { relação de } \\
\text { s de } 2,0 \text { a } \\
1,2\end{array}$ & va & $\begin{array}{c}\text { Pouco } \\
\text { compactado } \\
\text { com uma } \\
\text { relação de } \\
\text { azios de } 1,2 \text { a } \\
0,6\end{array}$ & & $\begin{array}{r}\text { Compac } \\
\text { com u } \\
\text { relaçã } \\
\text { /azios d } \\
0,3\end{array}$ & $\begin{array}{l}\text { do } \\
\text { de } \\
6 \mathrm{a}\end{array}$ & $\begin{array}{r}\mathrm{Mu} \\
\text { compa } \\
\text { com } \\
\text { relaçã } \\
\text { vazios c } \\
0,\end{array}$ & $\begin{array}{l}\text { o } \\
\text { tado } \\
\text { ma } \\
\text { de } \\
0,3 \text { a }\end{array}$ \\
\hline & $\begin{array}{l}\text { Argilas areno } \\
\text { (percentagen } \\
\text { areia inferior }\end{array}$ & & & 0,45 & & 0,90 & & 1,3 & & $1, \varepsilon$ & \\
\hline & $\begin{array}{l}\text { Solos com gra } \\
\text { quantidades } \\
\text { argilas }\end{array}$ & & & 0,40 & & 0,85 & & 1,2 & & 1,7 & \\
\hline & Argilas & & & 0,35 & & 0,80 & & 1,2 & & 1,6 & \\
\hline & Argilas muito & & & 0,32 & & 0,70 & & 1,0 & & 1,3 & \\
\hline & Fator corre & pal & altur & as de águ & $\mathrm{ah} ;$ & $\neq 1 \mathrm{~m}$ & & & & & \\
\hline 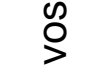 & Altura média & & & 0,3 & 0,5 & 0,75 & 1 & 1,5 & 2 & 2,5 & 3 \\
\hline$\overline{\underline{\alpha}}$ & Fator corretiv & & & 0,8 & 0,9 & 0,95 & 1 & 1,1 & $\sim 1,1$ & 1,2 & $\sim 1,2$ \\
\hline J & Fator corre & par & can & is com cu & rvas & & & & & & \\
\hline $\begin{array}{l}\frac{0}{\pi} \\
\stackrel{\sim}{\leftarrow}\end{array}$ & Grau de sinuc & & & Retilír & neo & Pouco sinuo & & $\begin{array}{r}\text { Moder } \\
\text { sir }\end{array}$ & $\begin{array}{l}\text { lamente } \\
\text { oso }\end{array}$ & Muito & inuoso \\
\hline & Fator corretiv & & & 1,0 & & 0,95 & & & & & 78 \\
\hline
\end{tabular}


Outra maneira de se definir a velocidade máxima admissível é empregando-se a equação apresentada por NEILL (1967), que correlaciona um diâmetro característico que representa o material não coesivo encontrado no revestimento do canal com a velocidade máxima admissível da seguinte forma:

$$
\frac{V^{2}}{\left(\frac{\gamma_{s}}{\gamma}-1\right) g}=2,5\left(\frac{\mathrm{D}_{50}}{\mathrm{y}}\right)^{-0,20}
$$

cujas variáveis representam

$\mathrm{V}=$ Velocidade do escoamento $(\mathrm{m} / \mathrm{s})$

$\gamma_{s}=$ Peso específico do material $\left(\mathrm{kN} / \mathrm{m}^{3}\right)$

$\gamma=$ Peso específico da água $\left(\mathrm{kN} / \mathrm{m}^{3}\right)$

$\mathrm{g}=$ Aceleração da gravidade $\left(\mathrm{m} / \mathrm{s}^{2}\right)$

$D_{50}=$ Diâmetro característico do material $(\mathrm{mm})$

$\mathrm{y}=$ Profundidade do escoamento $(\mathrm{m})$

Neste modelo, o cálculo de velocidade de escoamento é feito de seção em seção, e o valor máximo encontrado é retornado pela função para o usuário, que desta forma é capaz de acompanhar se houve extrapolação do valor máximo admissível pelos métodos acima expostos e, desta forma, rever as restrições de projeto e refazer a otimização.

- Tensão de Arraste Crítica

A tensão de arraste crítica, como se pode intuir, é bastante influenciada pelo tipo de material presente na superfície do canal. Além disso, a forma da seção transversal do canal também interfere na distribuição da velocidade, que tende a ser maior na calha do canal, aumentando a tensão de arraste nesta região, como ilustra a Figura 5.3. 


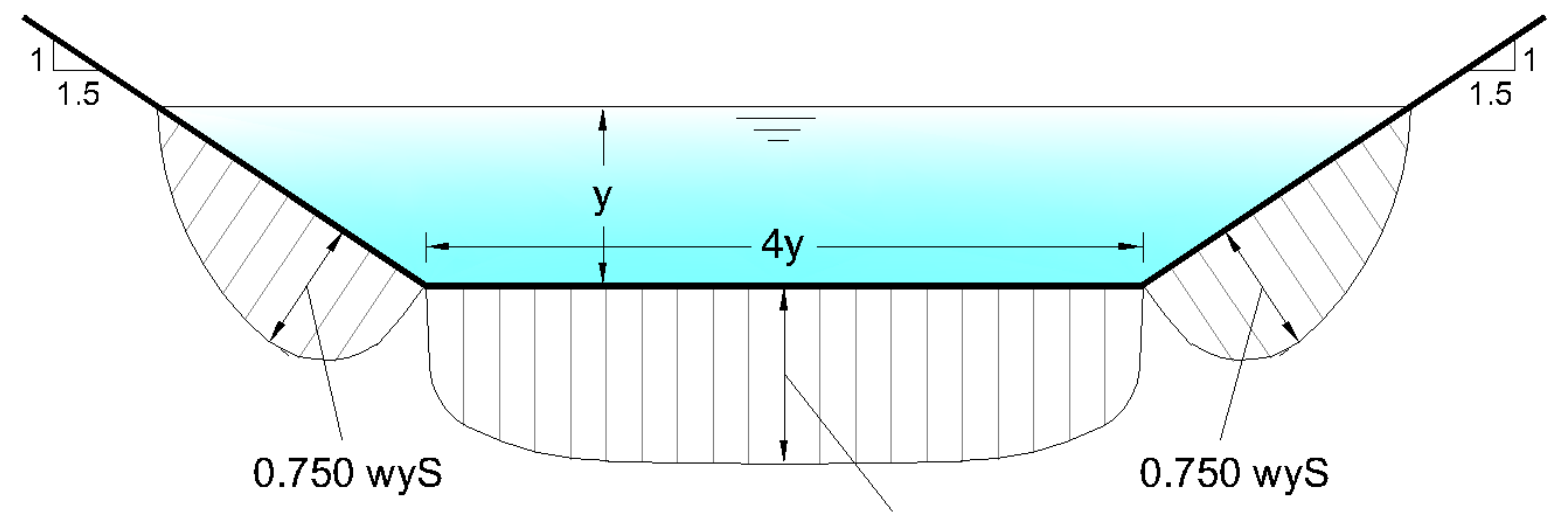

0.970 wys

Figura 5.3 - Tensões de Arraste no fundo e taludes de um canal (SIMONS \& SENTÜRK, 1992)

Assim, o cálculo da tensão de arraste crítica é baseado em diversas relações empíricas, como se pode perceber no dimensionamento do diâmetro característico dos materiais de margem e fundo de canais, feito, inicialmente, a partir da definição da tensão cisalhante unitária nestas regiões (como mostra a Figura 5.3), respectivamente:

$$
\begin{gathered}
\tau_{\text {máxm }}=0,75 \times \gamma \times R \times S_{0} \\
\tau_{\text {máxf }}=0,97 \times \gamma \times R \times S_{0}
\end{gathered}
$$

Equação 5.16

na qual

$$
\begin{aligned}
& \tau_{\text {máxf }}=\text { Tensão cisalhante no fundo }\left(\mathrm{kN} / \mathrm{m}^{2}\right) \\
& \tau_{\text {máxm }}=\text { Tensão cisalhante na margem }\left(\mathrm{kN} / \mathrm{m}^{2}\right) \\
& \gamma=\text { Peso específico do material }(\mathrm{kN}) \\
& \mathrm{R}=\text { Raio hidráulico (aproximado pela altura da lâmina d'água) }(\mathrm{m}) \\
& S_{0}=\text { Declividade de fundo do canal }(\mathrm{m} / \mathrm{m})
\end{aligned}
$$

O passo seguinte é definir a tensão cisalhante limite, no fundo e nas margens, para um determinado diâmetro característico, através das Equações apresentadas a seguir. 


$$
\begin{gathered}
\tau_{l, f}=\frac{W_{s}}{A} \times \tan \alpha \\
\tau_{l, m}=\frac{W_{s}}{A} \times \cos \theta \times \tan \alpha \times \sqrt{1-\frac{\tan ^{2} \theta}{\tan ^{2} \alpha}}
\end{gathered}
$$

sendo

$\tau_{l, f}=$ Tensão cisalhante limite no fundo $\left(\mathrm{kN} / \mathrm{m}^{2}\right)$

$\tau_{l, m}=$ Tensão cisalhante limite na margem $\left(\mathrm{kN} / \mathrm{m}^{2}\right)$

$\alpha=$ Ângulo de repouso (rad)

$\theta=$ Inclinação do talude $(\mathrm{m} / \mathrm{m})$

$\mathrm{W}_{\mathrm{s}}=$ Peso submerso da partícula $(\mathrm{kN})$

$A=$ Área em estudo $\left(\mathrm{m}^{2}\right)$

É necessário corrigir a tensão cisalhante limite devido ao fato de a sinuosidade do canal reduzir a força de cisalhamento.

Tabela 5.6 Redução na Tensão Cisalhante Limite (adaptado de LANE, 1955)

\begin{tabular}{|l|c|}
\hline \multicolumn{1}{|c|}{ Grau de Sinuosidade } & Fator Multiplicativo da Força Cisalhante Unitária \\
\hline Canais Retilíneos & 1.00 \\
\hline Canais pouco sinuosos & 0.90 \\
\hline Canais moderadamente sinuosos & 0.75 \\
\hline Canais muito sinuosos & 0.60 \\
\hline
\end{tabular}

Determina-se então o diâmetro característico dos materiais da margem e de fundo, empregando-se para isso a curva de Shields adimensionalizada, apresentada na Figura 5.4 . 


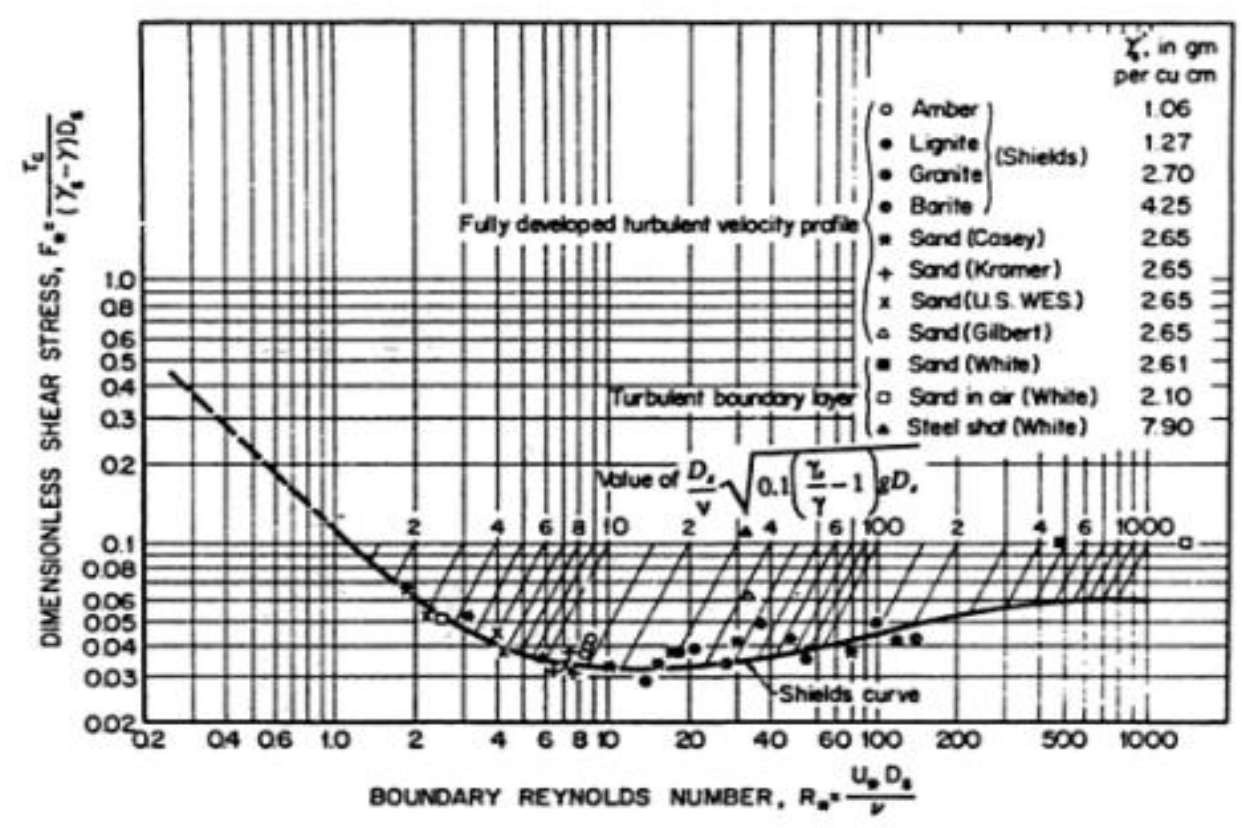

Figura 5.4 - Curva de Shields (SIMONS \& SENTÜRK, 1992)

sendo

$$
\begin{gathered}
\operatorname{Re}^{*}=\frac{V_{*} \times D}{v} \\
\psi=\frac{V_{*}^{2}}{g \times D}=\frac{\tau_{l}}{\left(\gamma_{s}-\gamma\right) \times D_{50}} \\
\sqrt{\frac{\tau_{l, f}}{\rho}}=\sqrt{g \times R \times S_{o}}=V_{*}
\end{gathered}
$$

nas quais

$\mathrm{Re}^{*}=$ Reynolds de atrito

$V_{*}=$ Velocidade de atrito $(\mathrm{m} / \mathrm{s})$,

$S_{o}=$ Declividade de fundo $(\mathrm{m} / \mathrm{m})$,

$\mathrm{R}=$ Raio hidráulico $(\mathrm{m})$,

$v=$ Viscosidade cinemática $\left(\mathrm{m}^{2} / \mathrm{s}\right)$,

$\mathrm{D}$ = Diâmetro característico do grão $(\mathrm{mm})$,

$\tau_{l}=$ Tensão limite (de fundo ou da margem) $\left(\mathrm{kN} / \mathrm{m}^{2}\right)$.

Caso o diâmetro característico encontrado na curva de Shields não seja compatível com aquele empregado na determinação da tensão de cisalhamento limite, deve-se 
arbitrar outro diâmetro característico na determinação da tensão de cisalhamento limite, de forma a atingir o mesmo valor em ambos. Caso contrário, o diâmetro arbitrado é o limite de estabilidade, sendo os diâmetros menores levados pelo arraste da água.

Neste modelo, o cálculo de tensão de arraste é feito de seção em seção, e o valor máximo encontrado é retornado pela função para o usuário, que desta forma é capaz de acompanhar se houve extrapolação do valor máximo admissível pelos métodos acima expostos e, desta forma, rever as restrições de projeto e refazer a otimização

- Condições de Escoamento

O escoamento de água em um canal pode assumir diversas formas, em função da vazão e das dimensões e forma do canal. Este trabalho considera um caso particular de escoamento, com o objetivo de simplificar o trabalho, sem deixar de atender situações reais que ocorrem em canalizações normais. Foi considerado apenas escoamento do tipo permanente, ou seja, sem variação da vazão no canal ao longo do tempo, unidimensional (a direção e a intensidade da velocidade é a mesma para todos os pontos), e escoamento do tipo fluvial.

Para modelagem matemática desta situação particular, foram utilizadas as equações básicas de SAINT-VENANT, de forma a atender aos princípios tanto de conservação da massa quanto de conservação da quantidade de movimento. Estas equações são genéricas e englobam não só as condições de escoamento tratadas neste modelo como também as demais situações possíveis de escoamento unidimensional, como os casos de escoamento não permanentes, quer em regime fluvial ou torrencial, quando todos os parâmetros hidráulicos variam ao longo do tempo. 
O parâmetro $S_{f}$ representa a perda de carga por unidade de comprimento, usualmente calculadas pela equação de Chézy, da forma

$$
S_{f}=Q|Q| K^{-2}
$$

Equação 5.22

na qual

$$
K=C A \sqrt{R_{h}}
$$

Equação 5.23

A Equação 5.3, referente à quantidade de movimento, pode ser reescrita na forma:

$$
\frac{\partial Q}{\partial t}+\frac{Q^{2}}{A} \frac{\partial \beta}{\partial x}+2 \beta \frac{Q}{A} \frac{\partial Q}{\partial x}+g A\left(1-\beta F_{r}^{2}\right) \frac{\partial y}{\partial x}-\beta \frac{Q^{2}}{A^{2}} \frac{\partial A}{\partial x_{(y=c t e)}}+g A S_{f}=q v \cos \gamma
$$

Equação 5.24

Onde o quadrado do número de Froude pode ser definido por:

$$
F_{r}^{2}=\frac{Q^{2} B}{g A^{3}}
$$


Para o caso de escoamento permanente (onde não há variação da vazão no tempo), e desprezando-se a contribuição lateral na vazão, podem-se fazer simplificações na Equação 5.24, resultando:

$$
2 \beta \frac{Q}{A} q+g A\left(1-\beta F_{r}^{2}\right) \frac{\partial y}{\partial x}+g A S_{f}=0
$$

Equação 5.26

Para calcular a linha d'água, representada pelo valor de y em cada seção, faz-se necessário resolver a Equação 5.2 e Equação 5.26 em todas as seções e, para isso, são empregados artifícios matemáticos que permitem a obtenção destes valores.

Este modelo aplica a substituição das grandezas diferenciais da Equação 5.26 por diferenças finitas para resolver as equações. Desta forma, cada variável será substituída por seu valor médio espacial:

$$
\begin{array}{cc}
\bar{\beta}=\frac{\beta_{i+1}+\beta_{i}}{2} & \bar{A}=\frac{A_{i+1}+A_{i}}{2} \\
\overline{F_{r}}=\frac{F_{r i+1}+F_{r i}}{2} & \overline{S_{f}}=\frac{S_{f i+1}+S_{f i}}{2}
\end{array}
$$

Equação 5.27

Substituindo os termos Equação 5.22, Equação 5.23, Equação 5.25 e Equação 5.27 em Equação 5.26, obtemos uma equação da forma:

$$
D_{i} y_{i+1}+B_{i} y_{i}=E_{i}
$$

Equação 5.28

na qual

$$
D_{i}=g \frac{A_{i}}{\Delta x}\left(1-F_{r i}\right) \quad B_{i}=-D_{i}
$$

Equação 5.29 


$$
E_{i}=q_{i} v_{i}-2 \frac{\overline{\beta_{l}} \bar{Q}_{\imath} q_{i}}{\overline{A_{\iota}}}-g \overline{A_{l}} \overline{S_{f}}-\frac{\bar{Q}_{\imath}^{2}}{\overline{A_{l}}}\left(\frac{\overline{\beta_{l+1}}+\bar{\beta}_{l}}{\Delta x}\right)
$$

A Equação 5.29, quando aplicada a um conjunto de $n$ seções dá origem a um sistema de $n-1$ equações a $n$ incógnitas em y. Como aqui é dada inicialmente uma condição de contorno na extremidade de jusante, por se tratar de regime fluvial, é possível obter a solução, na ordem de jusante para montante, para todo o conjunto de seções. O cálculo parcial, entre cada seção é feito aplicando-se a seguinte fórmula de recorrência:

$$
y_{i}=\frac{E_{i}-D_{i} y_{i+1}}{B_{i}}
$$

Equação 5.30

\subsection{Execução do Modelo}

O estudo de seção ótima que é executado no modelo considera apenas a seção transversal de forma geométrica trapezoidal, por ser a mais relevante em canais. É iterativo, ou seja, para cada um dos revestimentos disponíveis são geradas diversas configurações da seção, através da alteração dos parâmetros de declividade de fundo, talude lateral (m) e vazão, e é calculado o valor da função custo de cada uma delas, a fim de permitir a definição de qual configuração é melhor para o revestimento correspondente.

Antes da execução do modelo, devem ser fornecidas as variáveis de entrada do caso em estudo e, após os cálculos, o modelo apresentará uma série de produtos, conforme descrito a seguir. 


\subsubsection{Variáveis de Entrada}

As variáveis de entrada de um sistema são o conjunto mínimo de variáveis que representam uma determinada situação de projeto e cujo conhecimento permite determinar as soluções do sistema. Neste modelo, estas variáveis são listadas a seguir:

1. Seções:

- Topobatimetria,

- Progressiva

- Horizontes geotécnicos (em relação à própria cota de fundo);

2. Condições de contorno:

- Cota de fundo de jusante

- Nível d'água de jusante

3. Canal:

- i $(\mathrm{m} / \mathrm{m})$ - Declividade de fundo do canal

- Freeboard

- $\mathrm{m}$ - Talude do canal $(1 \mathrm{~V} \times \mathrm{m} \mathrm{H})$

4. Revestimento

- Manning

- Espessura

- Custo de base

- Custo de talude

- (m mínimo)

- (V máxima)

- $\left(\tau_{0}\right.$ máximo)

5. Custos unitários

- Escavação de 1ํㅡㄹ categoria

- Escavação de 20 categoria

- Escavação de 3o categoria

- Aterro

6. Energia

- Horizonte de projeto (anos)

- Rendimento de motorização

- Taxa de energia elétrica

7. Vazão

Os custos unitários de cada um dos revestimentos, além dos custos de movimentação de terra, foram obtidos da TPU (tabela de preços unitários) do DER 
mais recente (06/2011), disponível em < http://www.der.sp.gov.br>. Já os valores de Manning foram arbitrados em função de valores conhecidos no meio técnico.

Tabela 5.7 Preços Unitários (Data De Referência: 30/06/2011 - Fonte: DER)

\begin{tabular}{|l|r|r|r|r|}
\hline \multicolumn{1}{|c|}{ Revestimento } & \multicolumn{1}{c|}{$\begin{array}{c}\text { Código } \\
\text { TPU }\end{array}$} & Valor Unitário & Espessura & $\begin{array}{r}\text { Manning } \\
\text { Adotado }\end{array}$ \\
\hline $\begin{array}{l}\text { Gabião tipo caixa largura } 50 \mathrm{~cm} \\
\text { tela galvanizada }\end{array}$ & 24.09 .04 & $341,60 \mathrm{R} \$ / \mathrm{m}^{3}$ & $50 \mathrm{~cm}$ & 0,025 \\
\hline $\begin{array}{l}\text { Gabião tipo colchão espessura } \\
23 \mathrm{~cm} \text { tela galvanizada }\end{array}$ & 24.09 .06 .01 & $111,64 \mathrm{R} \$ / \mathrm{m}^{2}$ & $23 \mathrm{~cm}$ & 0,025 \\
\hline Concreto projetado & 25.09 .10 & $1.118,48 \mathrm{R} \$ / \mathrm{m}^{3}$ & $10 \mathrm{~cm}$ & 0,015 \\
\hline $\begin{array}{l}\text { Geocomposto drenante } \\
\text { (geomanta + geotêxtil) 10 mm }\end{array}$ & 24.23 .05 & $28,58 \mathrm{R} \$ / \mathrm{m}^{2}$ & $10 \mathrm{~mm}$ & 0,013 \\
\hline $\begin{array}{l}\text { Espalhamento, regularização e } \\
\text { compactação de material }\end{array}$ & 22.02 .09 & $2,0 \mathrm{R} \$ / \mathrm{m}^{3}$ & & 0,022 \\
\hline $\begin{array}{l}\text { Escavação e carga de material } \\
\text { de 1/2ª categoria }\end{array}$ & 22.02 .01 & $4,0 \mathrm{R} \$ / \mathrm{m}^{3}$ & & \\
\hline $\begin{array}{l}\text { Escavação e carga de material } \\
\text { de 3 }\end{array}$ & 22.02 .04 & $27,29 \mathrm{R} \$ / \mathrm{m}^{3}$ & & \\
\hline $\begin{array}{l}\text { Aterro sologoria } \\
\text { c/ Pulverização }\end{array}$ & 25.01 .03 & $42,52 \mathrm{R} \$ / \mathrm{m}^{3}$ & & \\
\hline
\end{tabular}

\subsubsection{Produtos}

O principal produto calculado pelo modelo é o valor de base ótimo para a situação ensaiada; a partir dele é possível se ter todas as demais grandezas físicas que definem o canal.

A função desenvolvida neste trabalho calcula também, automaticamente, os valores de perda de carga, escavação de $1^{\circ}, 2^{\circ}$ e $3^{\circ}$ categorias, volumes de revestimento de base e de talude e volume de aterro. 
Além disso, ao final de cada simulação, são apresentados os valores de vazão máxima encontrada para respectiva configuração de canal, a velocidade máxima e o valor de $\tau_{0}$ máximo, encontrados durante a simulação, para verificação do usuário.

Também de forma automática, são calculados os custos de escavação, aterro, revestimento e manutenção, e, por conseguinte o custo total do empreendimento, em valor presente. Por restrição do Excel, a atualização do custo ocorre apenas quando há variação nos valores da vazão, de Manning, da extensão da base, do talude lateral $(\mathrm{m})$ ou da declividade, que foram as variáveis escolhidas como entradas para a função programada em VBA.

Para simulação de diversas situações de projeto, com diferentes vazões, revestimentos, declividades de canal, declividade de talude $(\mathrm{m})$, foi desenvolvido um novo programa, que altera os valores na planilha e armazena os resultados em um arquivo em separado.

Com os resultados deste arquivo podem ser produzidos gráficos comparativos, entre os diferentes revestimentos, que darão subsídios para o empreendedor que pretende construir um canal, escolher, dentre todas as alternativas, aquela mais interessante.

\subsubsection{Limitações}

Conforme citado, este trabalho considera um caso particular de escoamento, o escoamento do tipo permanente, ou seja, sem variação da vazão no canal ao longo do tempo, unidimensional (a direção e a intensidade da velocidade é a mesma para todos os pontos), e do tipo fluvial, onde não foram consideradas declividades altas 
que levassem o escoamento a romper a barreira do número de Froude crítico. Estas condições devem ser verificadas em estudos futuros e desdobramentos deste trabalho. A condição fluvial, entretanto, é largamente justificada, pois trata-se da maioria das aplicações em canais de drenagem e irrigação e se exemplifica através dos grandes projetos de irrigação como Nilo Coelho e Integração do São Francisco.

Deve-se observar também que modelo de otimização, GRG não linear, empregado pelo Excel na otimização, pode retornar soluções mínimas locais que, eventualmente não são as mínimos globais - uma grande quantidade de rodadas ajuda a diminuir o erro.

\subsection{Estudo de Caso}

A análise do modelo através de estudo de caso foi dividida em duas etapas. A primeira delas teve foco na verificação do modelo, através da comparação dos resultados encontrados por ele com aqueles encontrados por outro modelo disponível na bibliografia estudada. Em uma etapa seguinte, com objetivo de testar a aplicação prática, foi criado um caso hipotético para verificar da eficiência do modelo no suporte à decisão.

O modelo adotado para comparação e validação indireta do método foi aquele elaborado por SOUZA (s.d.), onde algumas simplificações foram introduzidas, como por exemplo, a não consideração do efeito de remanso, do custo de aterro e do volume de escavação para acomodação do revestimento no cálculo de custo global. Tais simplificações podem ser pouco significativas e o modelo numérico aqui desenvolvido é capaz de verificar tal suposição. Serão descritas e apresentadas as comparações das situações simuladas. 
$\mathrm{Na}$ aplicação prática, haverá bastante semelhança com a simulação de verificação (os mesmos revestimentos, vazões, declividades e custos serão empregados), com a diferença de manter uma topografia única, de perfis geológicos fixos, de forma a se avaliar os impactos de cada revestimento na otimização global do canal.

\subsubsection{Situações Estudadas}

Em ambas as etapas de estudo de caso, foram escolhidos 5 tipos de revestimento nos quais todas as vazões, taludes e declividades foram simuladas. Foram escolhidos revestimentos de relativa popularidade e de comportamento bastante diferente em relação ao custo de implantação e a eficiência hidráulica, para se ter uma boa sensibilidade da eficiência do modelo, principalmente na comparação que envolve o custo da perda de carga. Os revestimentos estão listados a seguir:

1. Gabião Caixa

2. Gabião Colchão (Reno)

3. Concreto Projetado

4. Combinação Geomanta com Geotextil

5. Solo natural

Após algumas simulações iniciais, o modelo mostrou-se ineficiente no cálculo de declividades de fundo da ordem de $0,001 \mathrm{~m} / \mathrm{m}$ ou superior. Tal instabilidade levou ao desenvolvimento de testes apenas em declividades de fundo entre $0,0001 \mathrm{~m} / \mathrm{m}$, $0,0002 \mathrm{~m} / \mathrm{m}$ e $0,0005 \mathrm{~m} / \mathrm{m}$.

Outra instabilidade encontrada foi em vazões muito altas. Foram ensaiadas vazões que variaram de $50 \mathrm{~m}^{3} / \mathrm{s}$ a $350 \mathrm{~m}^{3} / \mathrm{s}$, com passos de $50 \mathrm{~m}^{3} / \mathrm{s}$, que possuem uma variação grande entre o primeiro e último valores, e cobrem bem o intervalo entre ambos, permitindo acompanhar a variação para valores intermediários. 
Quanto ao talude lateral, para não se trabalhar com valores "quebrados", foram adotados valores de $\mathrm{m}$ (talude) iguais a 0,5, 1,0 e 2,0, com o objetivo de se ter uma amostragem suficientemente boa para comparar os efeitos de cada um dos revestimentos no custo.

Não foi computado o custo de motorização em nenhum dos estudos aqui desenvolvidos, devido a complexidade de pesquisa desta parcela no custo total, e também, como será visto adiante, as variações de nível d'água não sugerem alterações tão expressivas entre as diferentes alternativas estudadas para este equipamento.

\subsubsection{Verificação do Modelo}

Para fazer uma comparação equivalente, foi adotado para cada um dos casos simulados o nível d'água de jusante igual ao resultante do modelo elaborado por SOUZA (s.d.) disponível em Apêndice, e, da mesma forma, foi ajustada para cada simulação a elevação do terreno equivalente, plano e de elevação igual ao nível d'água acrescido de borda livre (escavação apenas no trapézio do canal e sem ocorrência de aterro).

A declividade do canal empregada nesta comparação foi a de $0,0001 \mathrm{~m} / \mathrm{m}$. Os valores de y/B, para cada uma das vazões estudadas, são apresentados a seguir. 


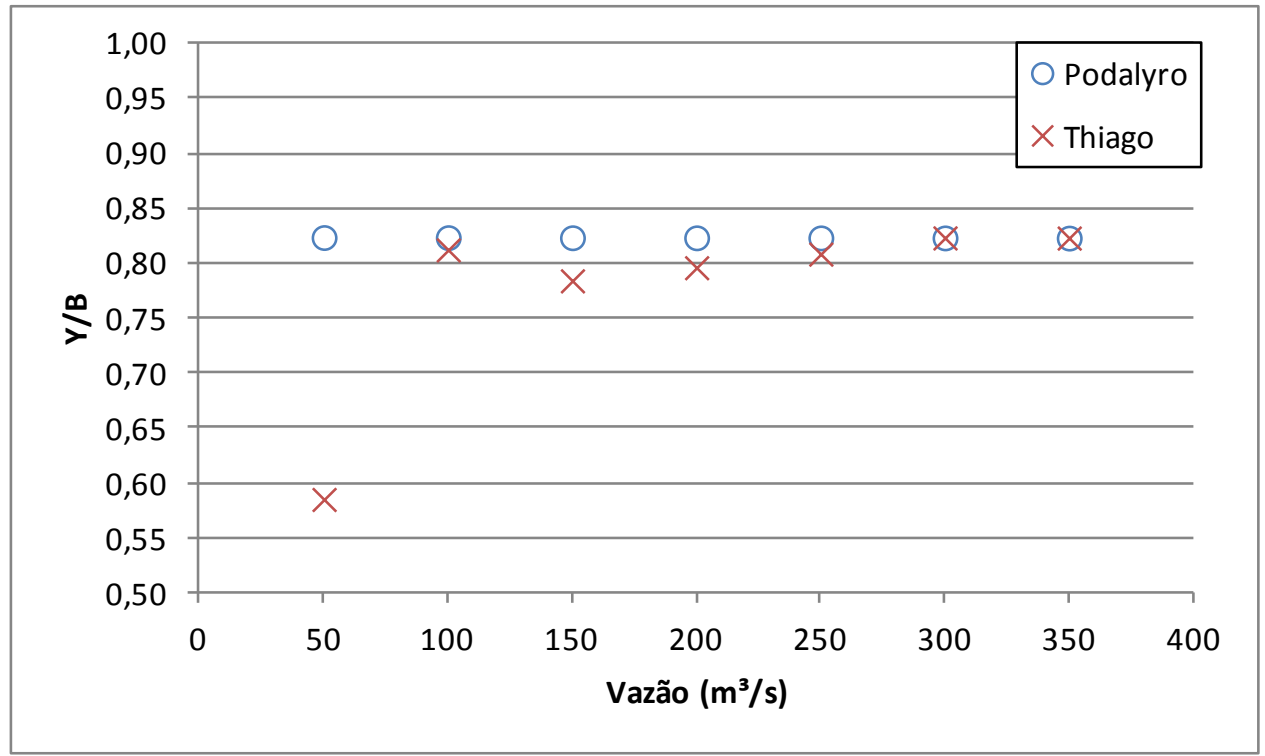

Figura 5.5 - Resultados para $m=0,5$ e revestimento em gabião tipo caixa

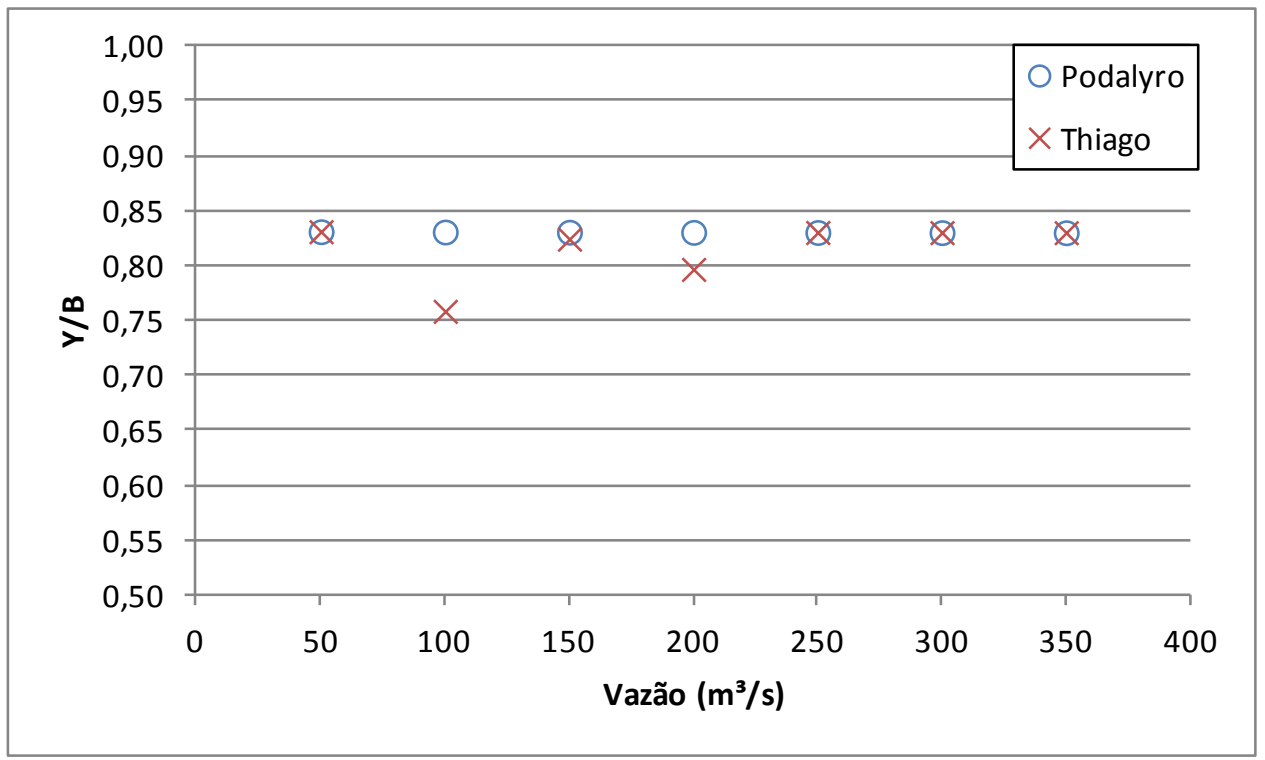

Figura 5.6 - Resultados para $m=0,5$ e revestimento em gabião tipo colchão 


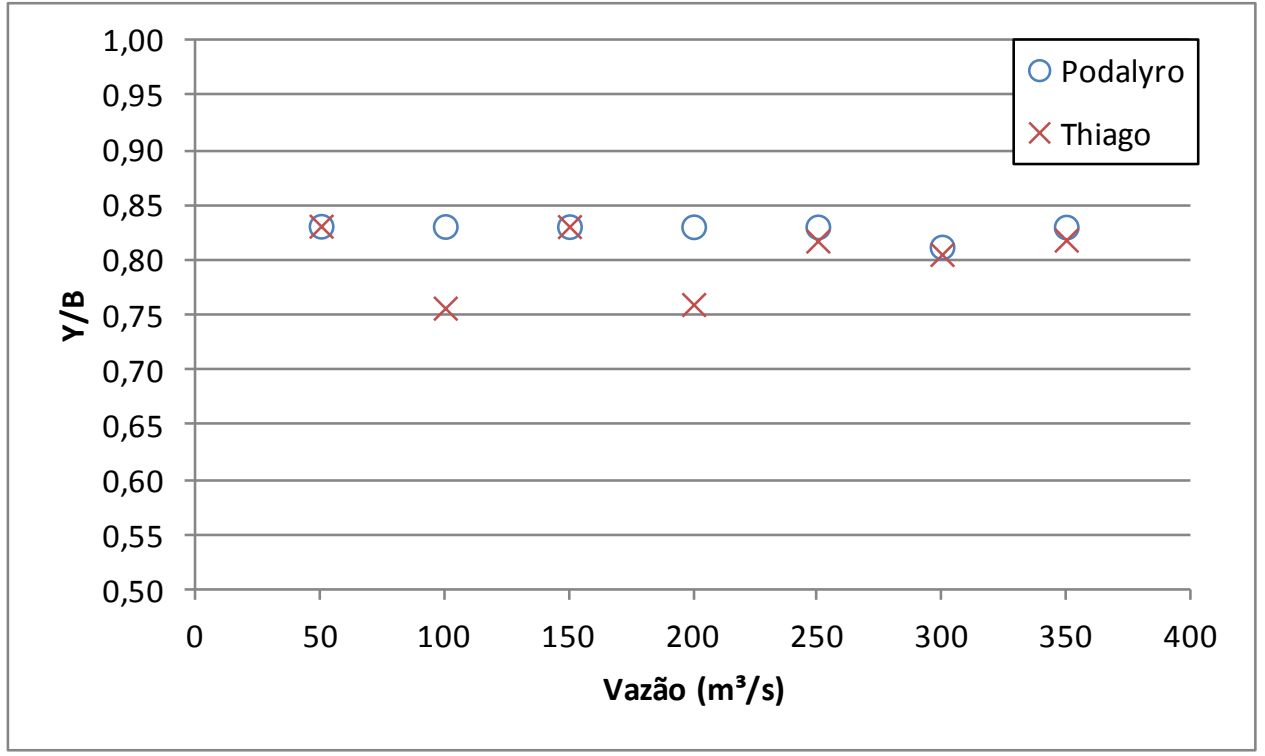

Figura 5.7 - Resultados para $m=0,5$ e revestimento em concreto projetado

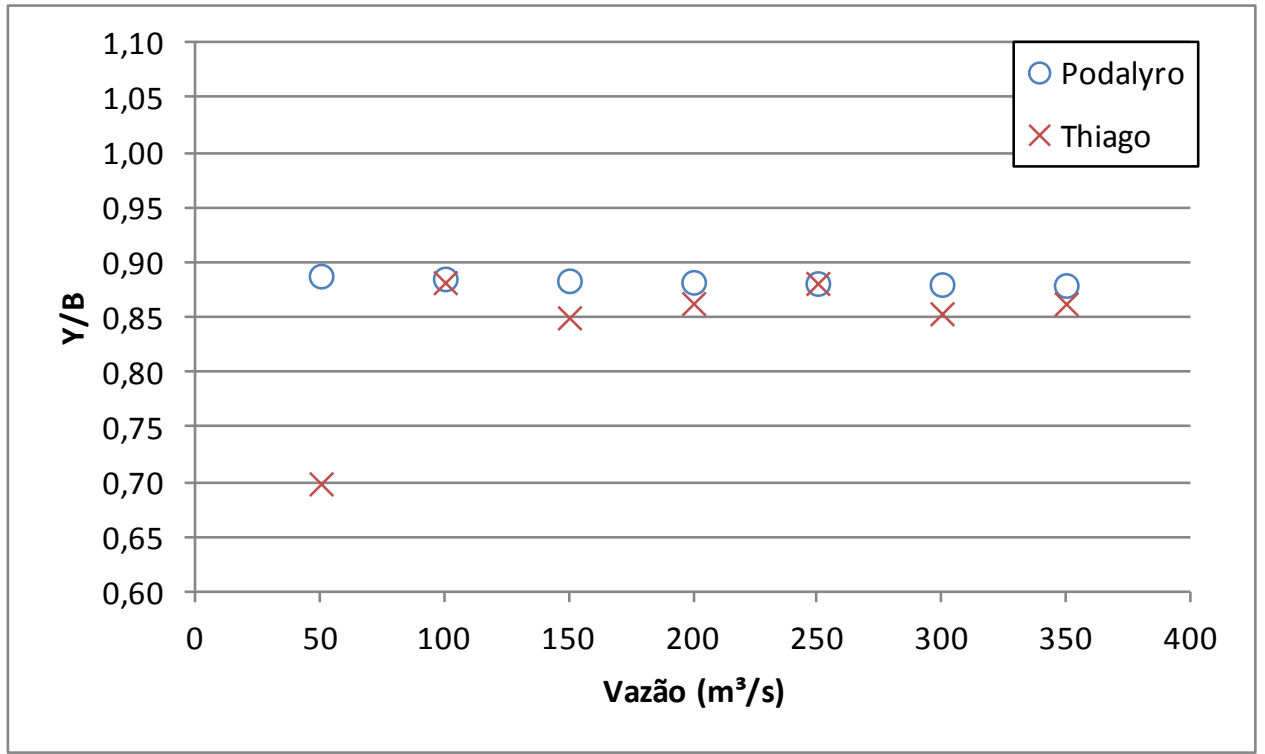

Figura 5.8 - Resultados para $m=0,5$ e revestimento com geocomposto 


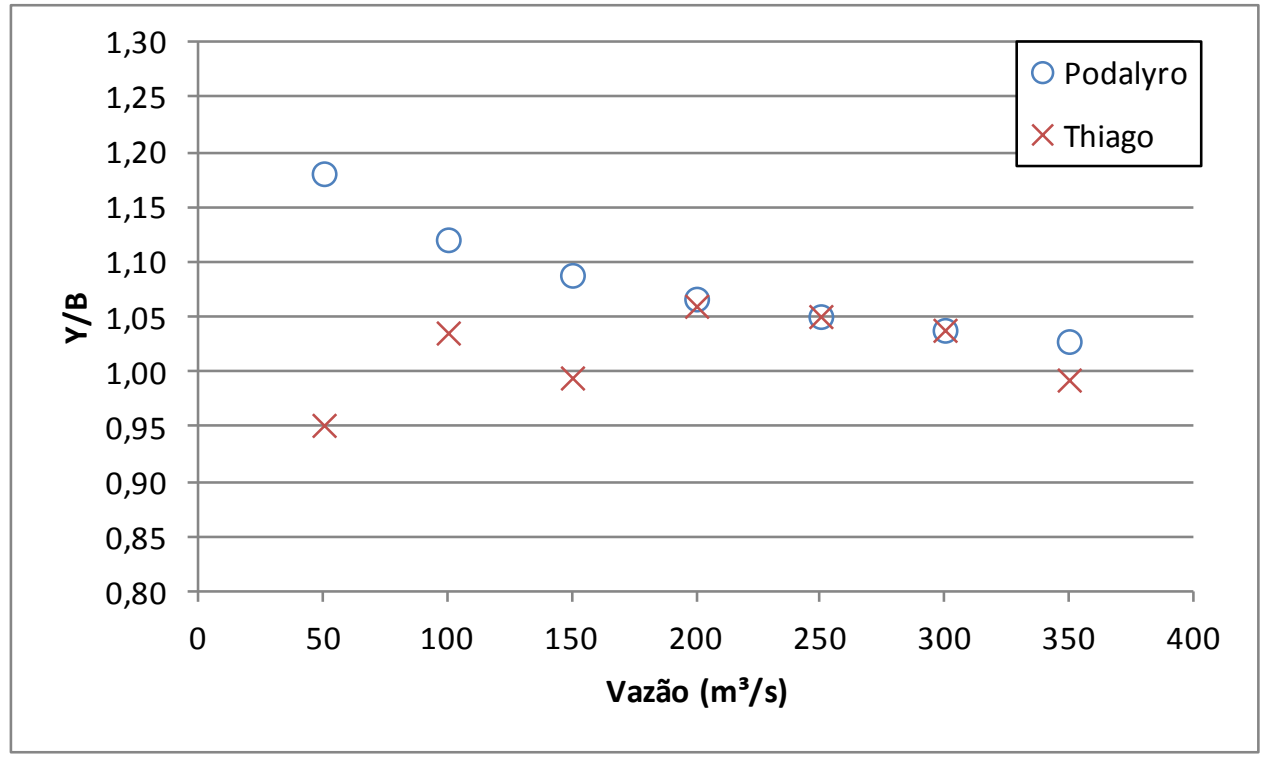

Figura 5.9 - Resultados para $\mathrm{m}=0,5 \mathrm{em}$ terreno natural

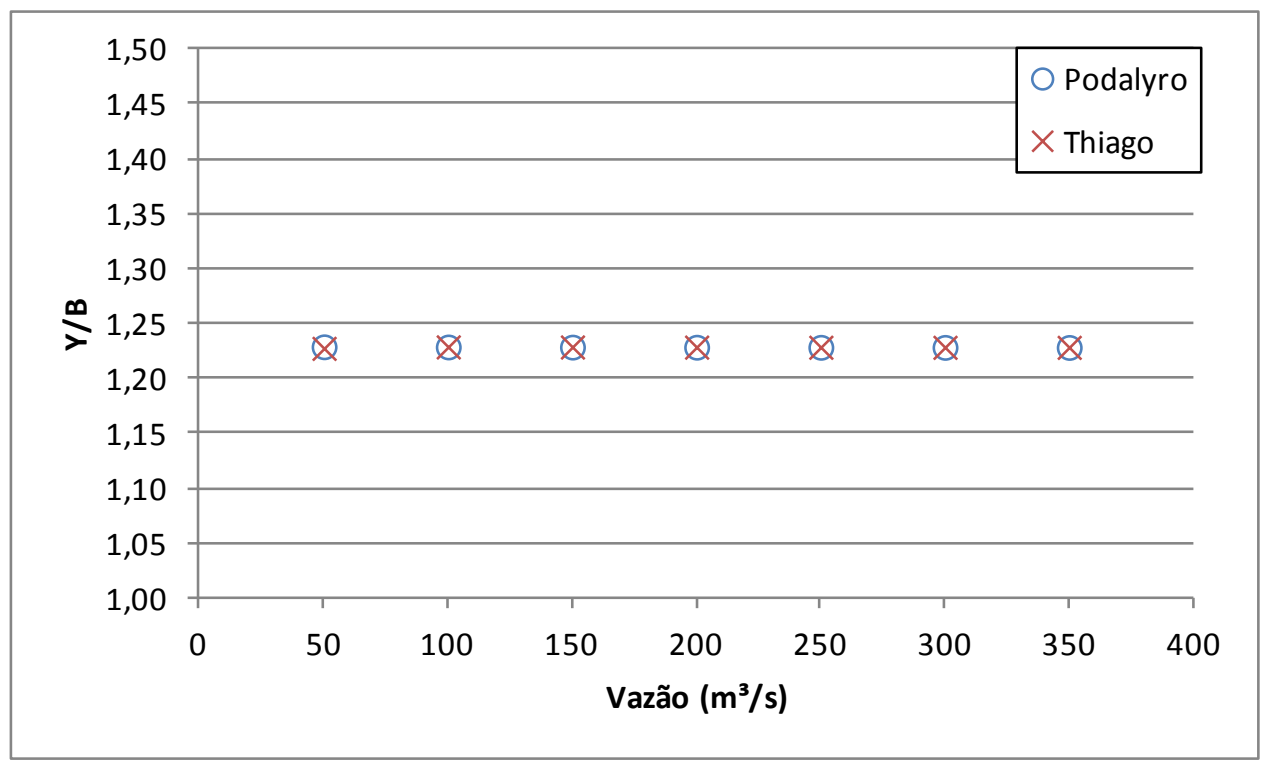

Figura 5.10 - Resultados para $m=1,0$ e revestimento em gabião tipo caixa 


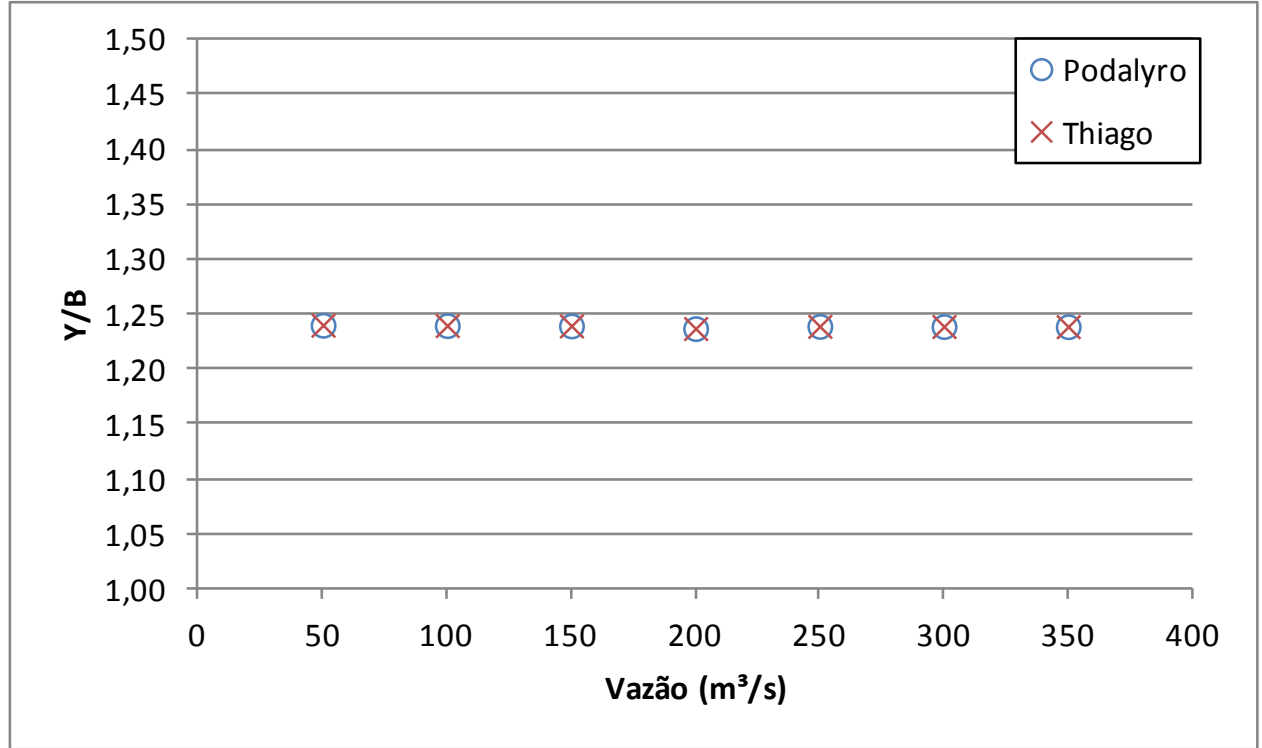

Figura 5.11 - Resultados para $m=1,0$ e revestimento em gabião tipo colchão

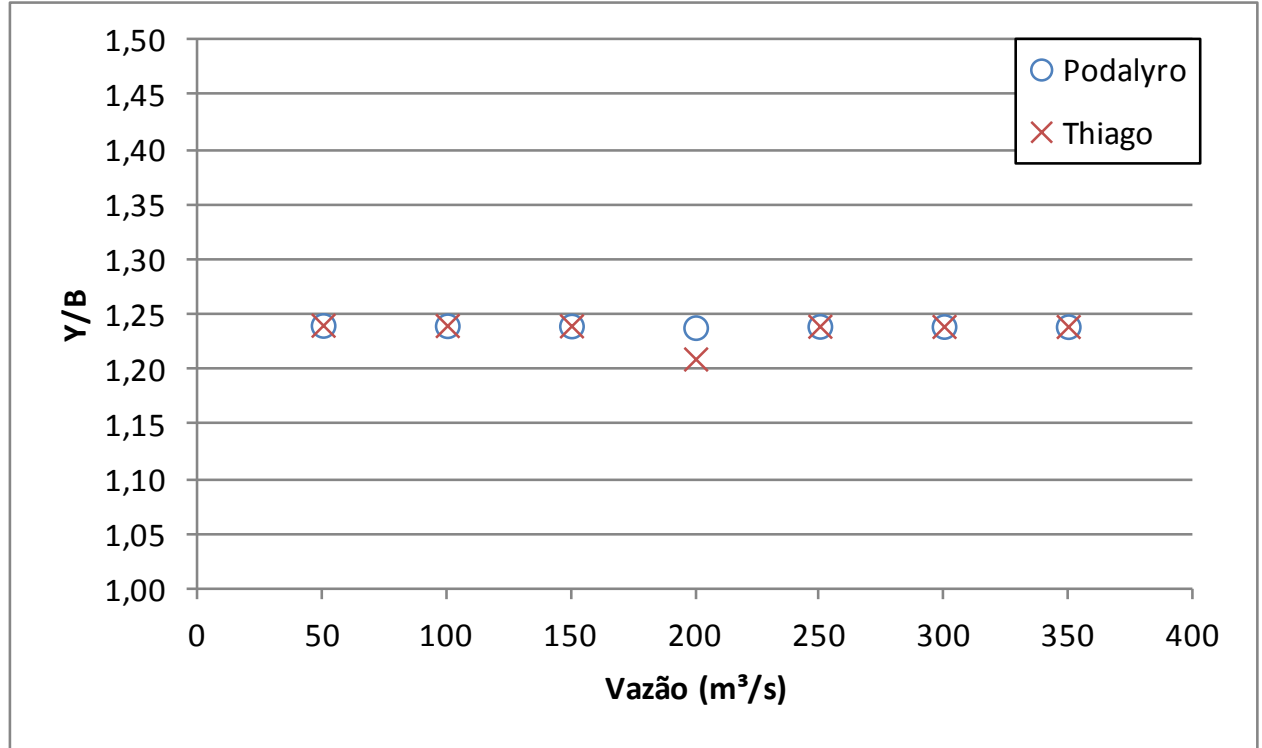

Figura 5.12 - Resultados para $m=1,0$ e revestimento em concreto projetado 


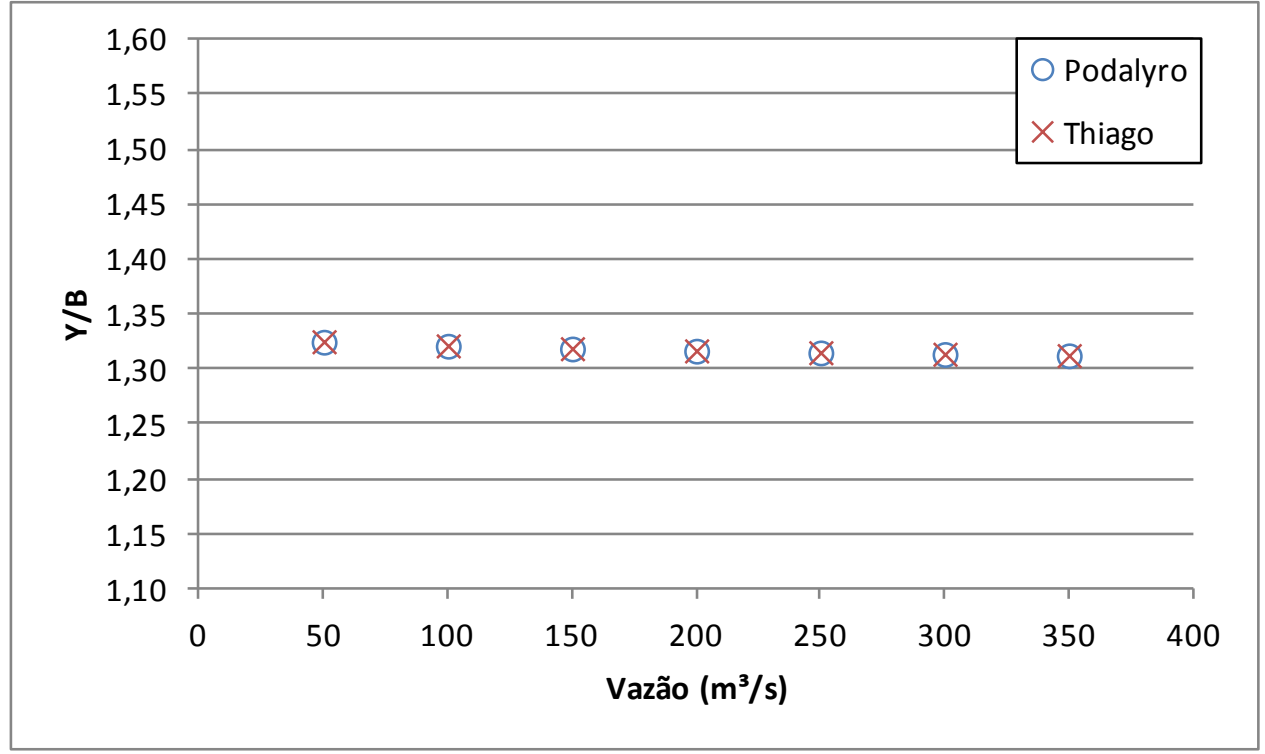

Figura 5.13 - Resultados para $m=1,0$ e revestimento com geocomposto

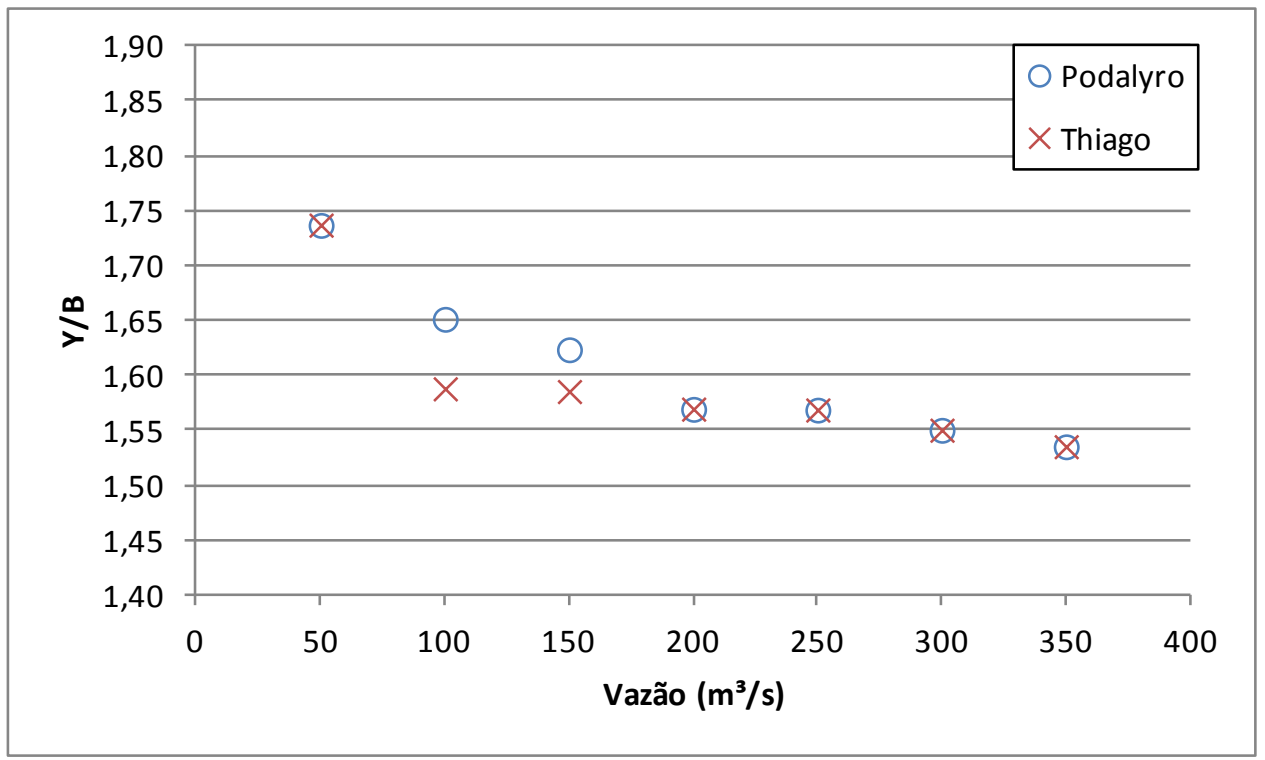

Figura 5.14 - Resultados para $m=1,0$ em terreno natural 


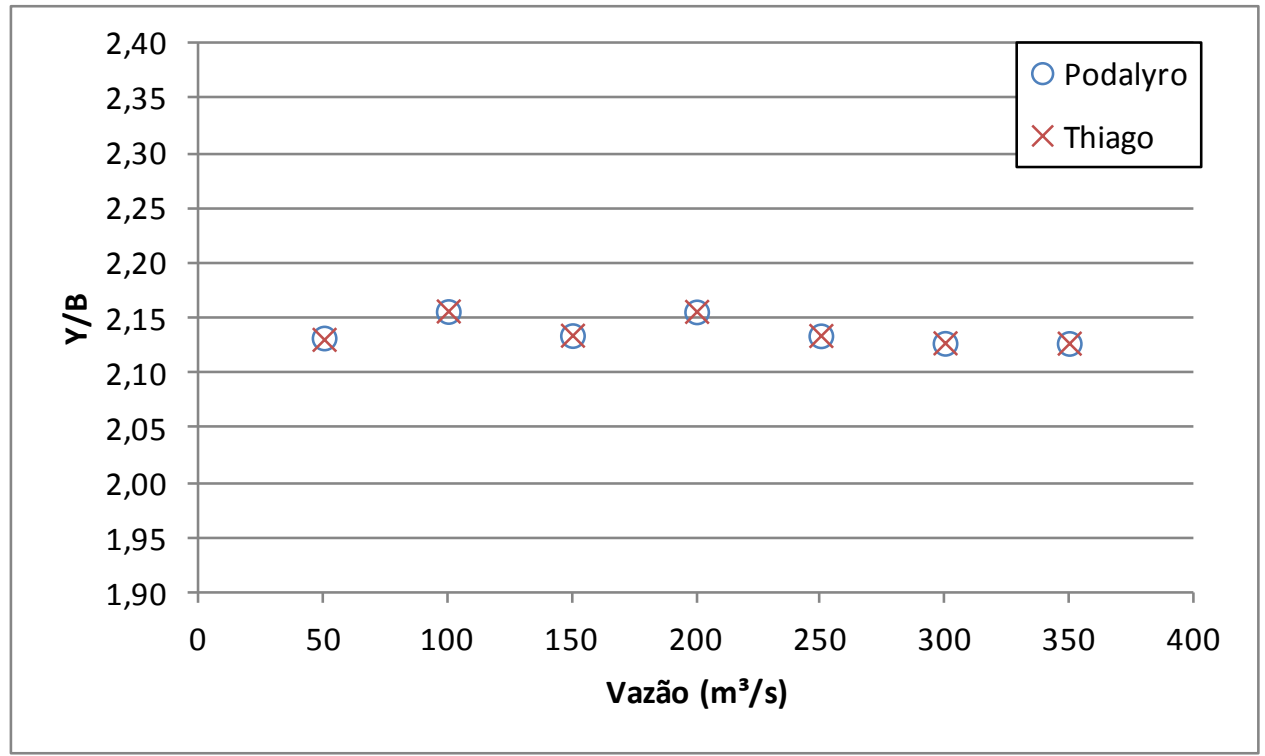

Figura 5.15 - Resultados para $m=2,0$ e revestimento em gabião tipo caixa

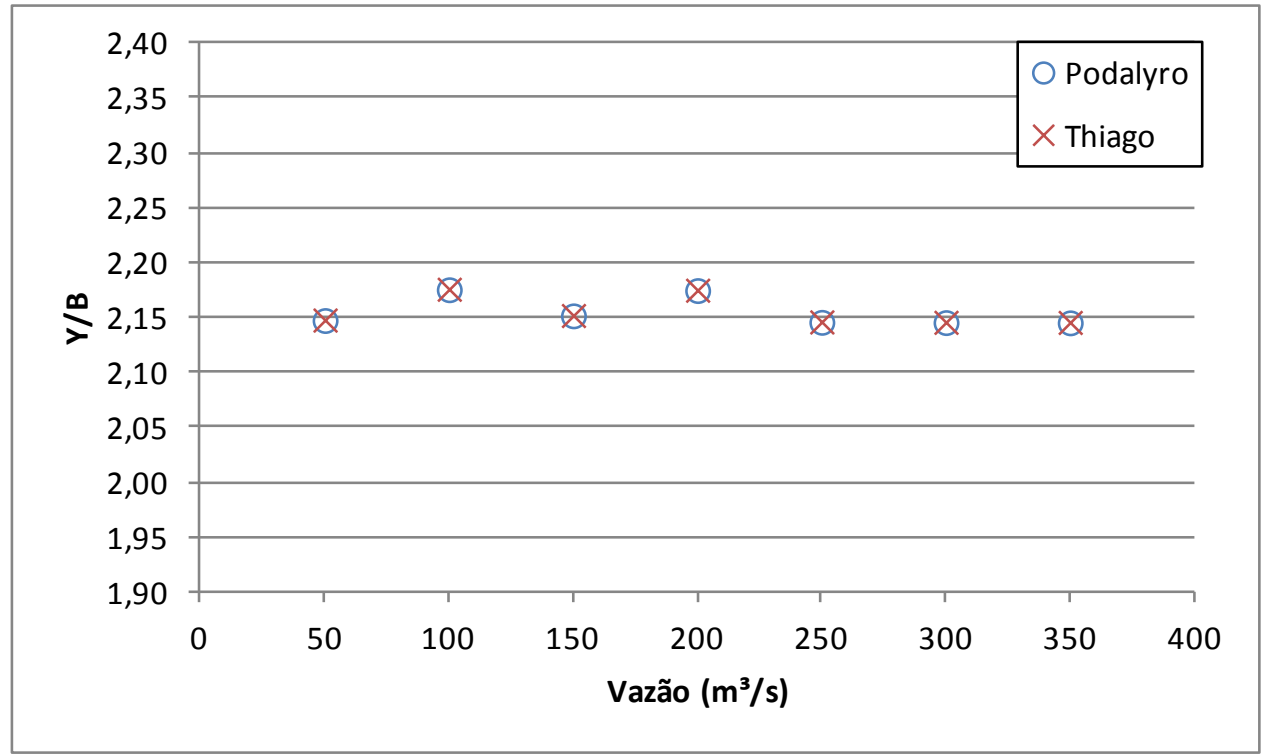

Figura 5.16 - Resultados para $m=2,0$ e revestimento em gabião tipo colchão 


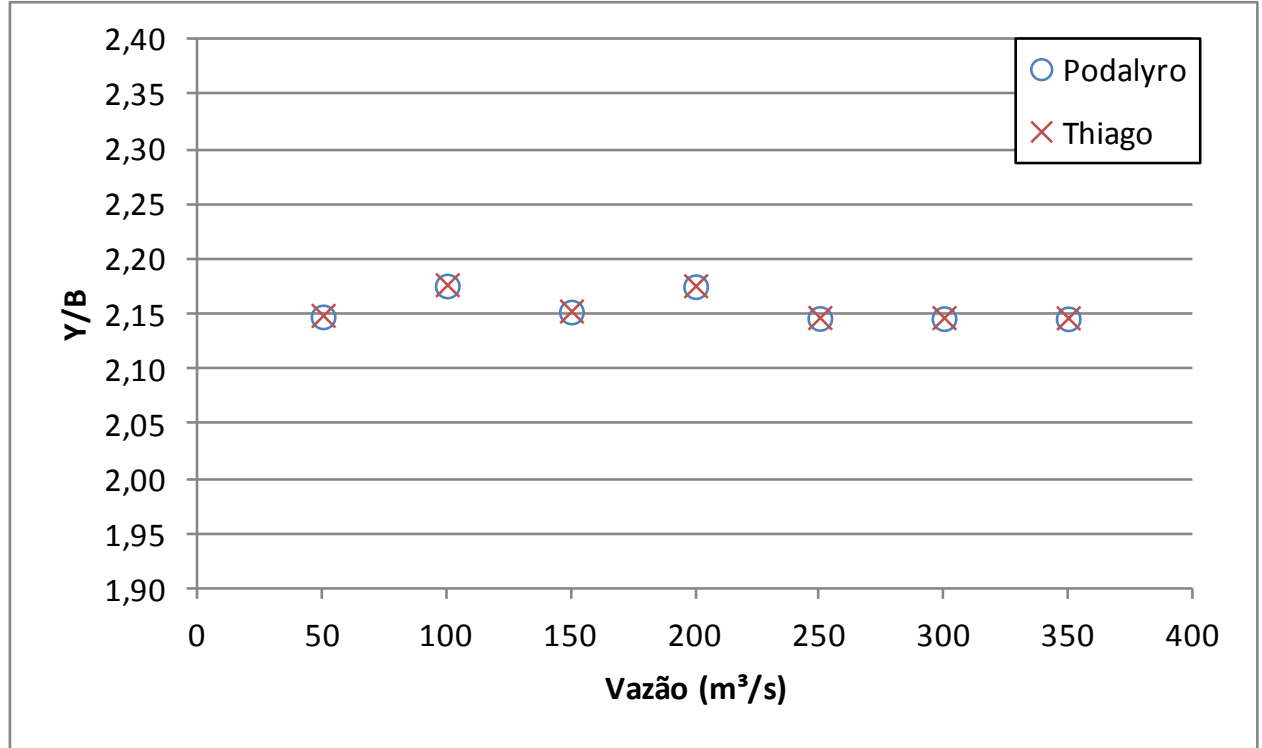

Figura 5.17 - Resultados para $m=2,0$ e revestimento em concreto projetado

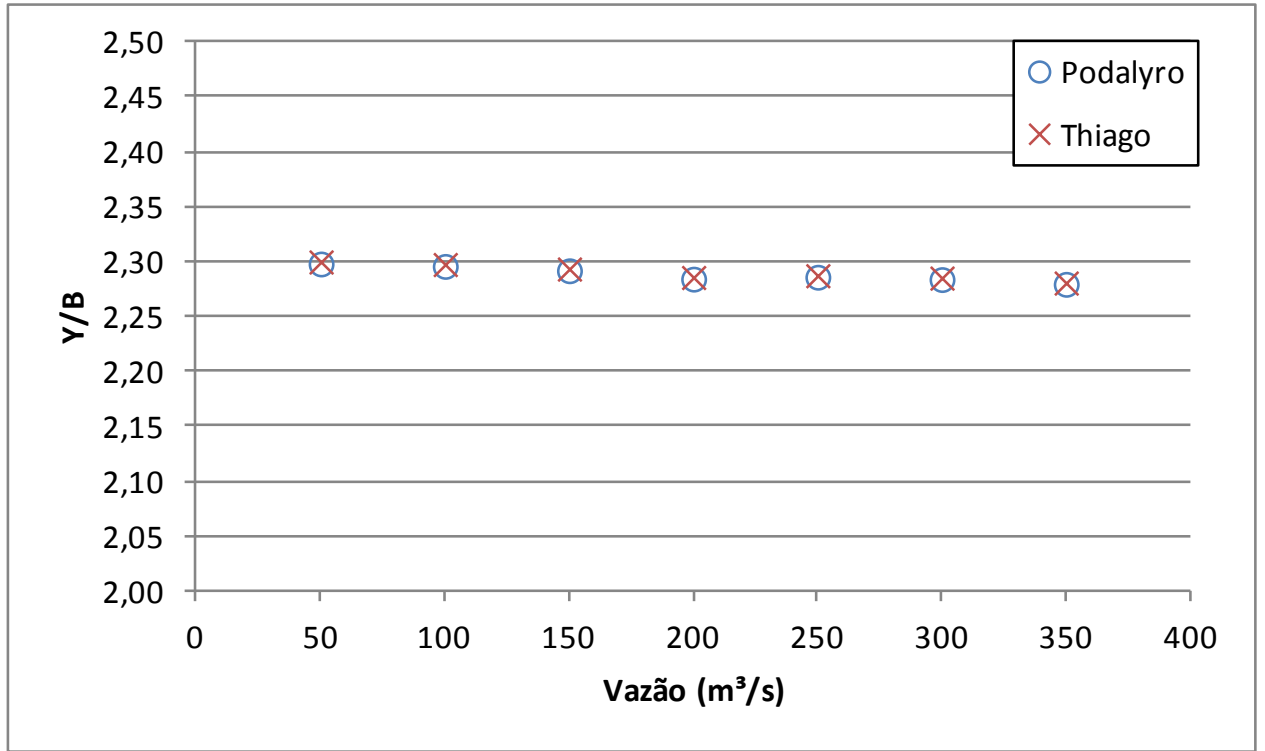

Figura 5.18 - Resultados para $m=2,0$ e revestimento com geocomposto 


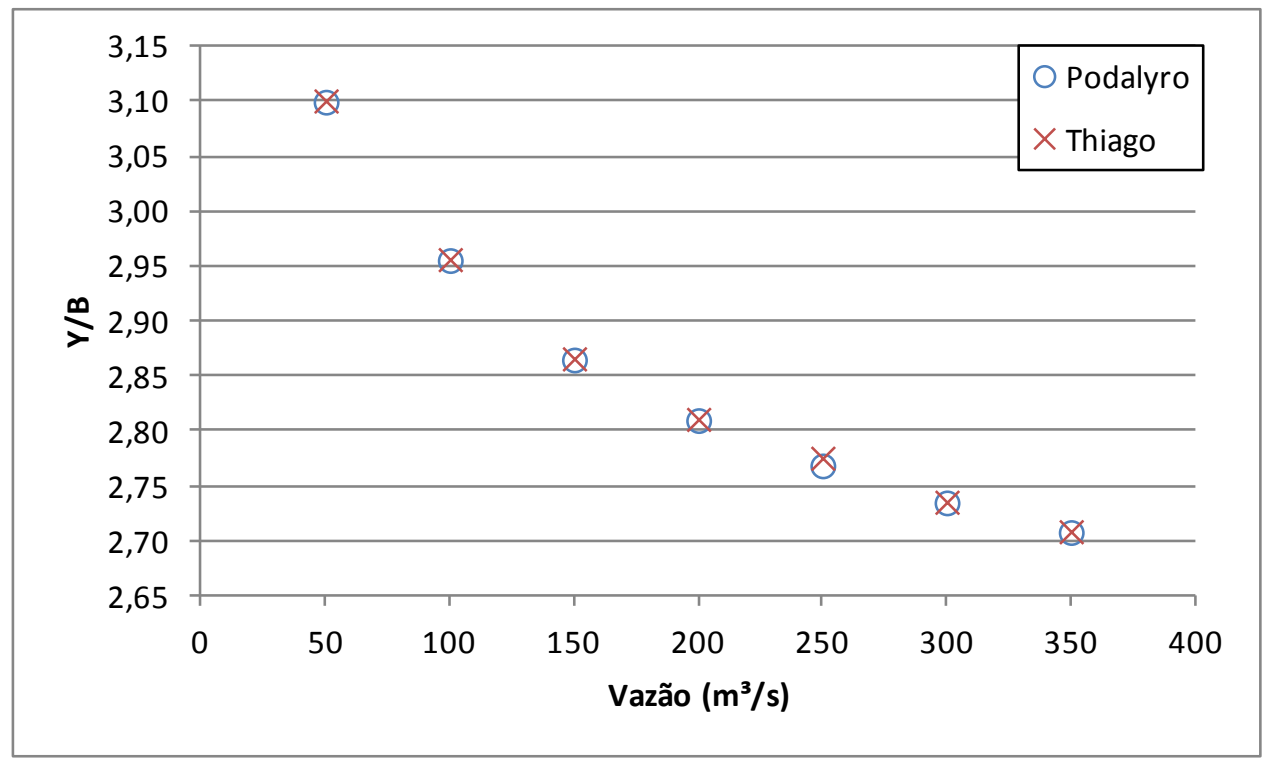

Figura 5.19 - Resultados para $\mathrm{m}=\mathbf{2 , 0} \mathrm{em}$ terreno natural

Os resultados mostram que o modelo teórico analítico, desenvolvido por SOUZA (s.d.), e o modelo numérico proposto apresentam valores muito próximos na relação entre a lâmina d'água e largura de base otimizados.

Tal verificação confirma que as simplificações propostas por SOUZA (s.d.) de regime uniforme ao invés de gradualmente variado, desconsideração de espessura de revestimento no custo da escavação, para os casos ensaiados, são perfeitamente aceitáveis.

\subsubsection{Novos Ensaios}

Concluída a verificação do modelo, uma nova série de ensaios foi elaborada com objetivo de verificar o comportamento do mesmo numa situação prática de suporte a decisão, que é o objetivo deste trabalho. 
Nesta exploração do modelo, foi admitida uma topografia única para todos os ensaios, bem como os horizontes geotécnicos. Na consideração do consumo equivalente de energia, isto é, a energia despendida no processo de escoamento e que se equivale ao correspondente bombeamento, foram admitidos os parâmetros de consumo de um sistema de bombeamento de água.

Tal conceito visa incorporar a ideia de que o escoamento de água por gravidade tem um equivalente econômico que é o custo do bombeamento necessário para que o mesmo ocorra sem a gravidade, atribuindo-se a este componente um peso correspondente ao consumo de energia proporcional à perda de carga (energia por unidade de peso) e tempo de operação, que resultam na potência consumida. Não foi considerado entretanto, o denominado custo de demanda, que é aquele relativo à remuneração da instalação de fornecimento de energia, no caso a elétrica, pois este é um custo que depende da instalação - foi usado apenas o consumo como representativo da perda de carga - de forma semelhante ao procedimento empregado por FURUSAWA (2011). Descreve-se a seguir os componentes deste custo de energia:

- Canalização

Funcionamento Diário: $18 \mathrm{~h} / \mathrm{dia}$;

Funcionamento Anual: 6570 h/ano;

Vida Útil: 20 anos.

- Custo de energia elétrica

Grupo A (Alta e Média Tensão);

Sub-Grupo A4 (2,3 kV a $25 \mathrm{kV})$;

Tarifa: Convencional;

Custo de Energia por Demanda: 31,31 R $\$ / \mathrm{kW}$;

Custo de Energia por Consumo: 0,16132 R $\$ / \mathrm{kWh}$; 
Taxa de Juros: $8,00 \%$ ao ano;

Fator de Atualização: 10,60.

Arbitrou-se como condição de contorno a cota de fundo do canal a jusante igual a 100,0 m, lâmina d'água igual a 12,0 m, cota do terreno a jusante igual a $113,0 \mathrm{~m}$, declividade do terreno igual a $0,0002 \mathrm{~m} / \mathrm{m}$.

Paralelamente à superfície do terreno, os limites que separam a primeira da segunda categoria de escavação e a segunda da terceira categorias são, respectivamente, 4,0 m e 8,0 m abaixo da superfície do terreno.

A numeração de legenda, dos revestimentos, segue a seguinte ordem:

1. Gabião Caixa

2. Gabião Colchão (Reno)

3. Concreto Projetado

4. Combinação Geomanta com Geotextil

5. Solo natural

\subsubsection{Resultados}

As simulações geraram uma grande quantidade de dados, pois quando se calcula todas as possibilidades de declividade de fundo, inclinação de talude, vazão e tipos de revestimento ensaiados contabiliza-se um total de 315 situações otimizadas e, para cada uma delas existem dados de linha d'água, volumes de escavação e aterro, volumes de revestimento, variáveis hidráulicas (número de froude máximo, velocidade máxima, tensão cisalhante máxima e perda de carga), além dos custos de cada componente. Desta forma, será detalhada apenas uma otimização e, em seguida, serão exibidos os custos envolvidos para todos os casos.

Como exemplo de resultados gerados pelo modelo para um único caso, foi adotada aleatoriamente a situação de declividade de fundo igual a $0,0001 \mathrm{~m} / \mathrm{m}$, talude lateral 
de inclinação de $1(\mathrm{~V}): 0,5(\mathrm{H})$, vazão de $350 \mathrm{~m}^{3} / \mathrm{s}$, para o revestimento de gabião do tipo caixa. Neste caso, a lâmina d'água a jusante tem espessura de 12,00 m (premissa adotada) e, a montante, 12,78 m (mais detalhes do cálculo de linha d'água para esta situação podem ser encontrados no ANEXO B - Resultados dos Cálculos de Remanso). A largura de base encontrada foi de 10,89 m e, para a seção de jusante foi obtida a velocidade mais alta do canal, igual a $1,73 \mathrm{~m} / \mathrm{s}$, um pouco acima do valor de referência de 1,52 m/s (considerando água limpa) previsto por FORTIER \& SCOBEY (1926) - há que se ponderar que o estudo de referência é demasiadamente antigo, não considera um importante efeito do fluxo que é a turbulência e, portanto aparece na comparação apenas a título de referência. A tensão cisalhante máxima foi de $5,60 \mathrm{E}-3 \mathrm{kN} / \mathrm{m}^{2}$, bastante abaixo do valor de $4,35 \mathrm{E}$ $2 \mathrm{kN} / \mathrm{m}^{2}$ previsto por FORTIER \& SCOBEY (1926) e o máximo Froude encontrado é igual a 0,0343 , confirmando o regime de escoamento do tipo fluvial.

Além disso, obteve-se também que a perda de carga total foi de $1,75 \mathrm{~m}$, com volumes de escavação por metro de canal, nas categorias 1, 2 e 3, de 115,1 m³, $74,0 \mathrm{~m}^{3}$ e $70,1 \mathrm{~m}^{3}$, respectivamente, sendo que a área de revestimento por metro de canal é igual a $41,0 \mathrm{~m}^{2}$.

Admitindo-se todo o universo de situações ensaiadas, e comparando-se o custo global do empreendimento por metro linear de canal, para cada um dos revestimentos, e para os valores de declividade de talude variando entre 0,5, 1,0 e 2,0 e declividade de fundo do canal projetado variando entre $0,0001,0,0002$ e 0,0005 , o resultado gráfico que se obteve foi o seguinte.

- Para declividade de talude igual a $0,5(1 \mathrm{~V}: 0,5 \mathrm{H})$ : 


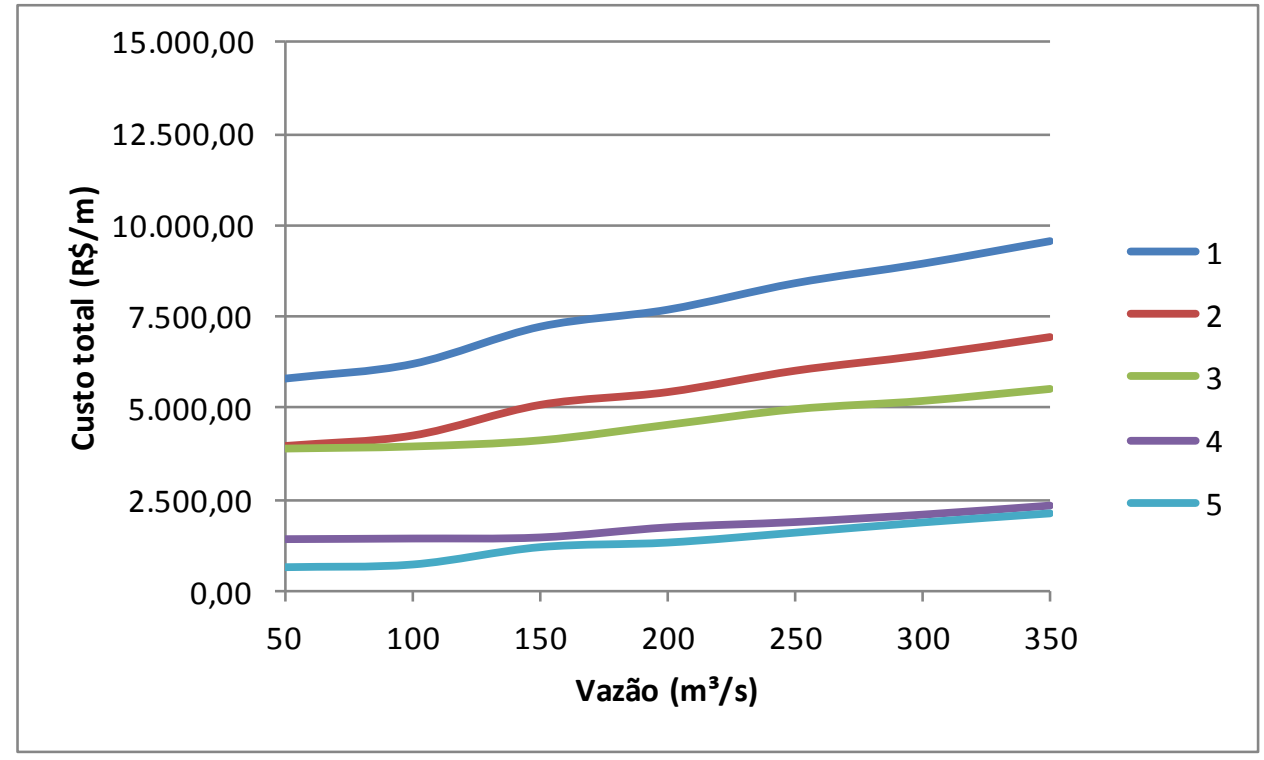

Figura 5.20 - Declividade de fundo igual a $0,0001 \mathrm{~m} / \mathrm{m}$

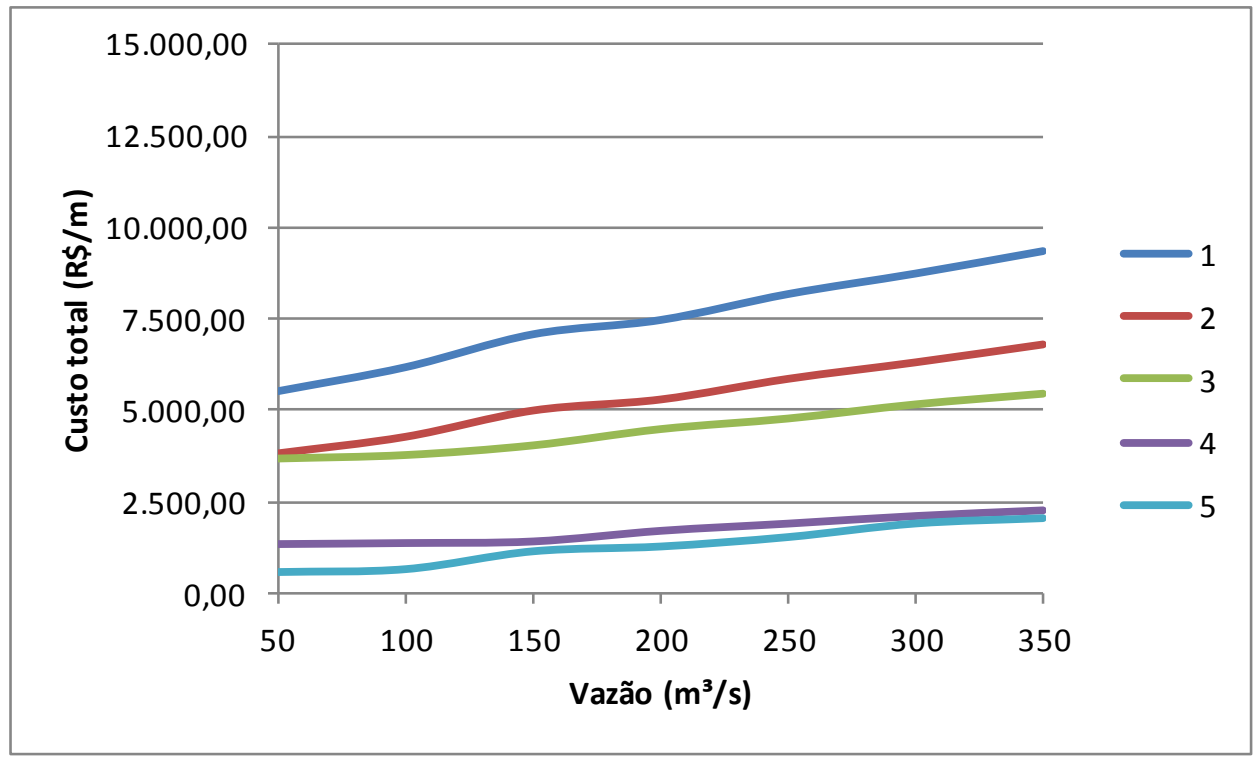

Figura 5.21 - Declividade de fundo igual a $0,0002 \mathrm{~m} / \mathrm{m}$ 


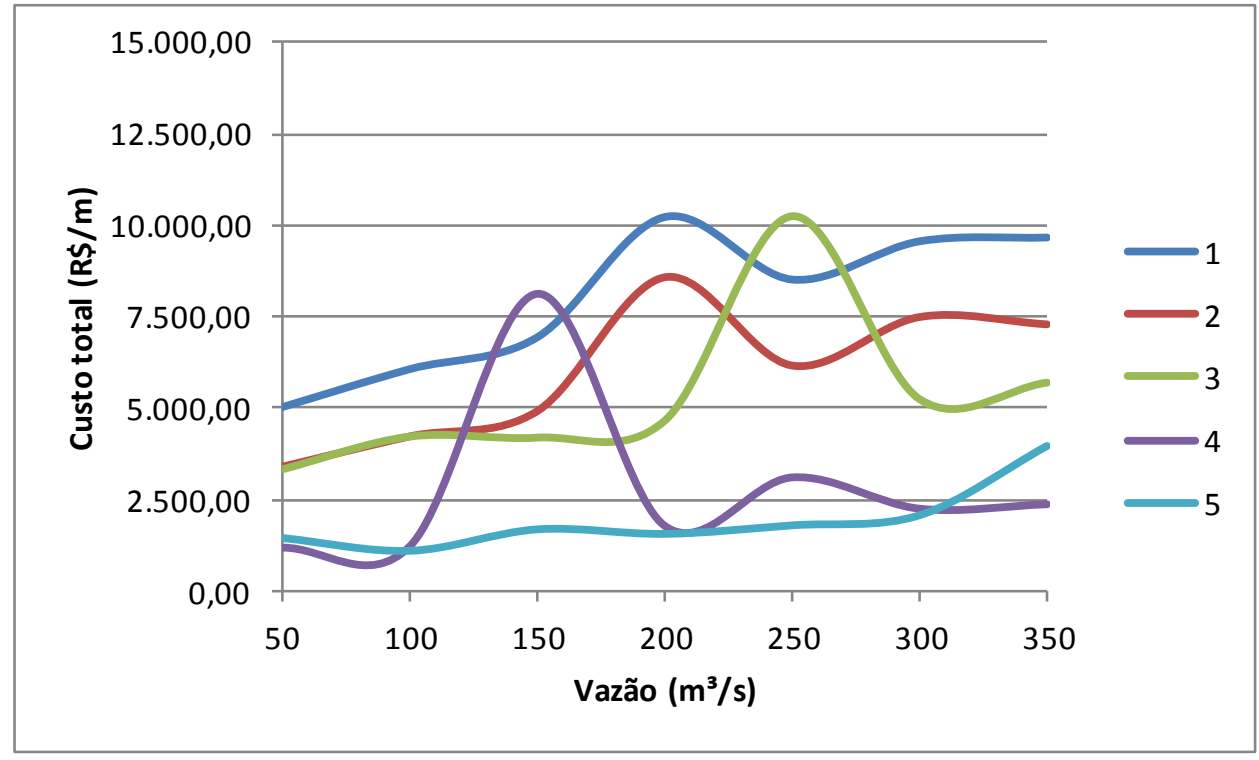

Figura 5.22 - Declividade de fundo igual a $0,0005 \mathrm{~m} / \mathrm{m}$

- Para declividade de talude igual a 1,0 (1 V : $1 \mathrm{H})$ :

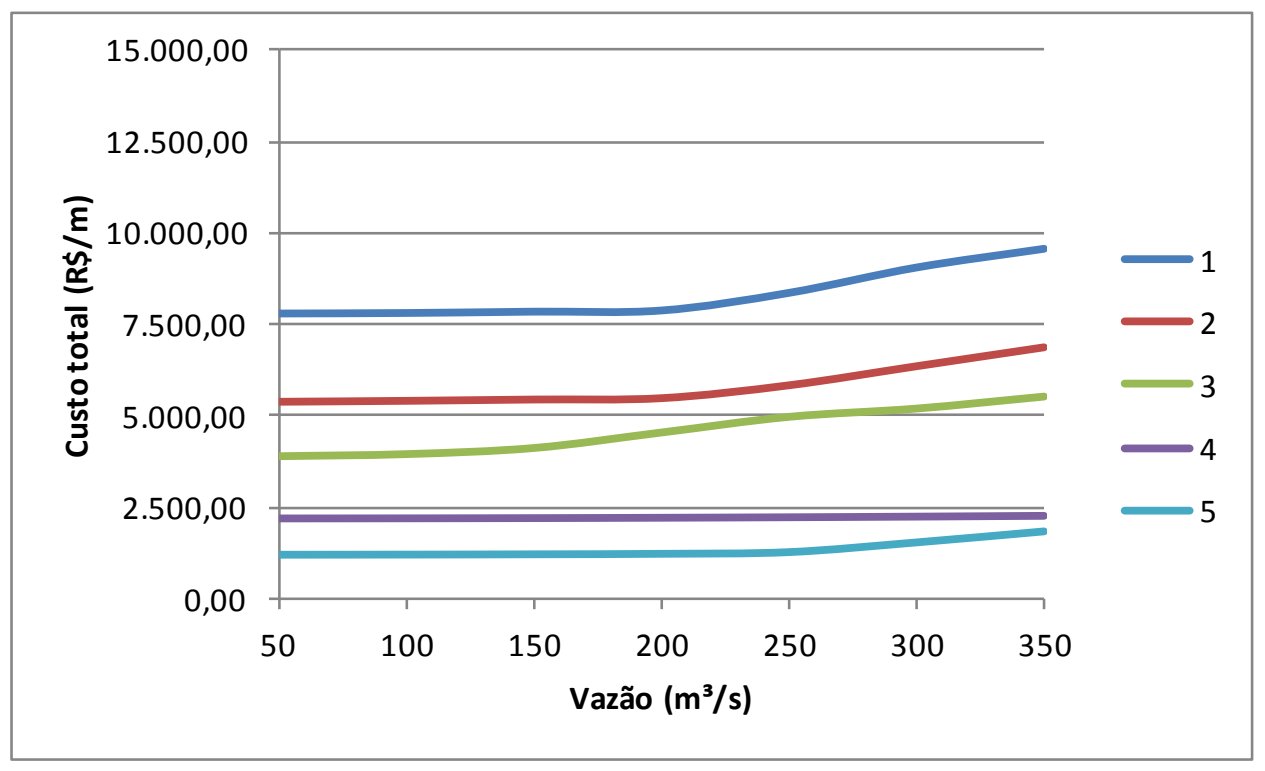

Figura 5.23 - Declividade de fundo igual a $0,0001 \mathrm{~m} / \mathrm{m}$ 


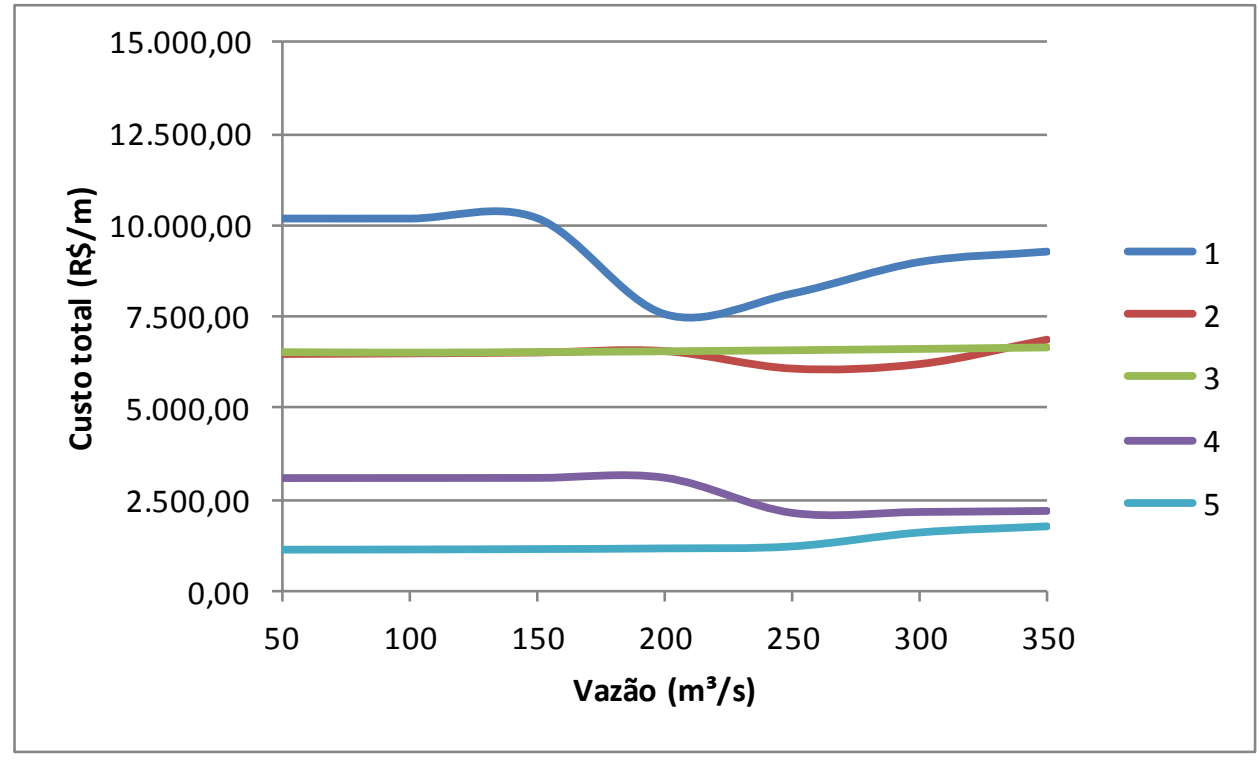

Figura 5.24 - Declividade de fundo igual a $0,0002 \mathrm{~m} / \mathrm{m}$

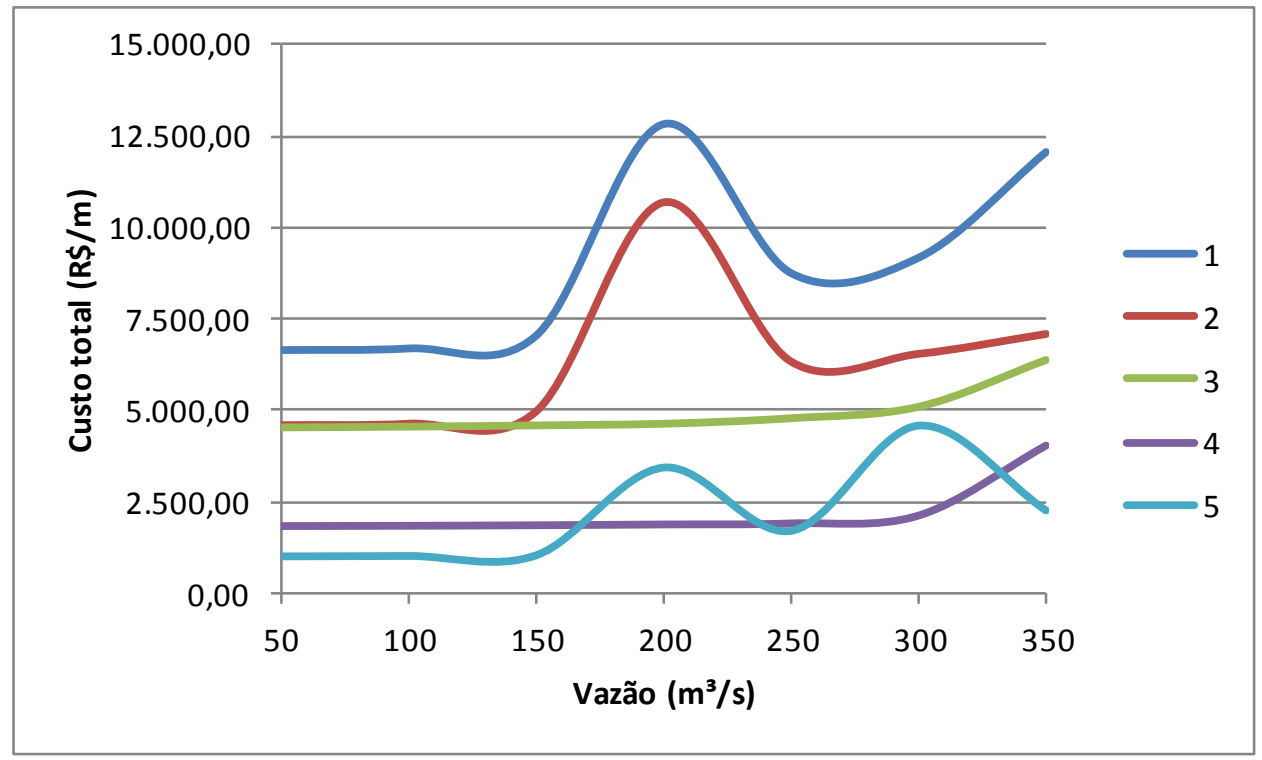

Figura 5.25 - Declividade de fundo igual a $0,0005 \mathrm{~m} / \mathrm{m}$

- Para declividade de talude igual a 2,0 (1 V : $2 \mathrm{H})$ : 


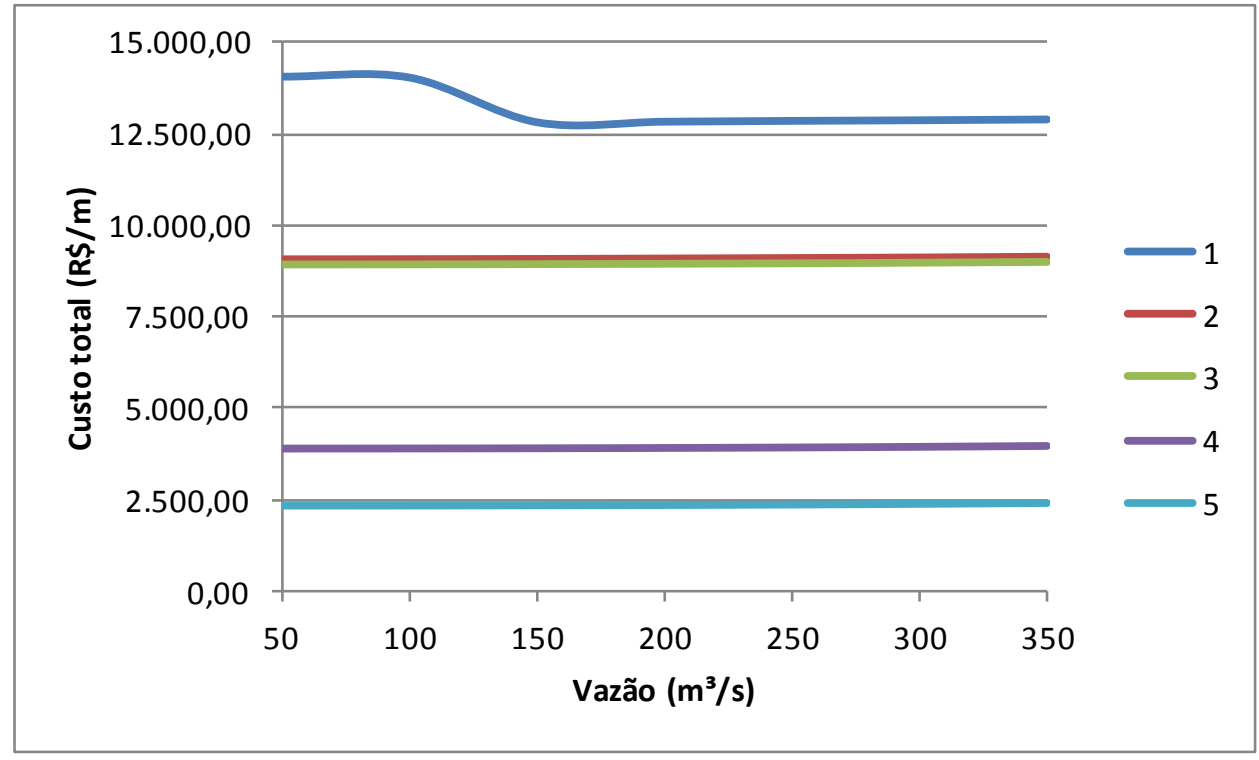

Figura 5.26 - Declividade de fundo igual a $0,0001 \mathrm{~m} / \mathrm{m}$

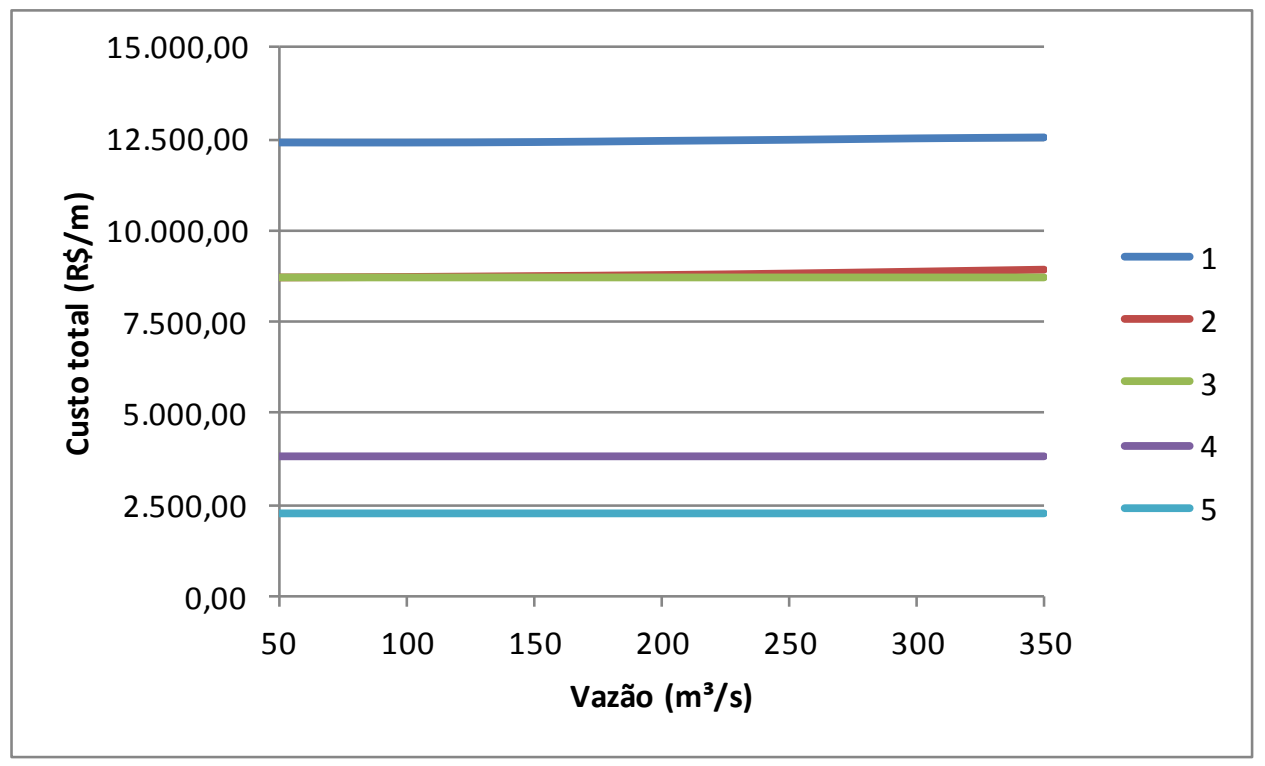

Figura 5.27 - Declividade de fundo igual a $0,0002 \mathrm{~m} / \mathrm{m}$ 


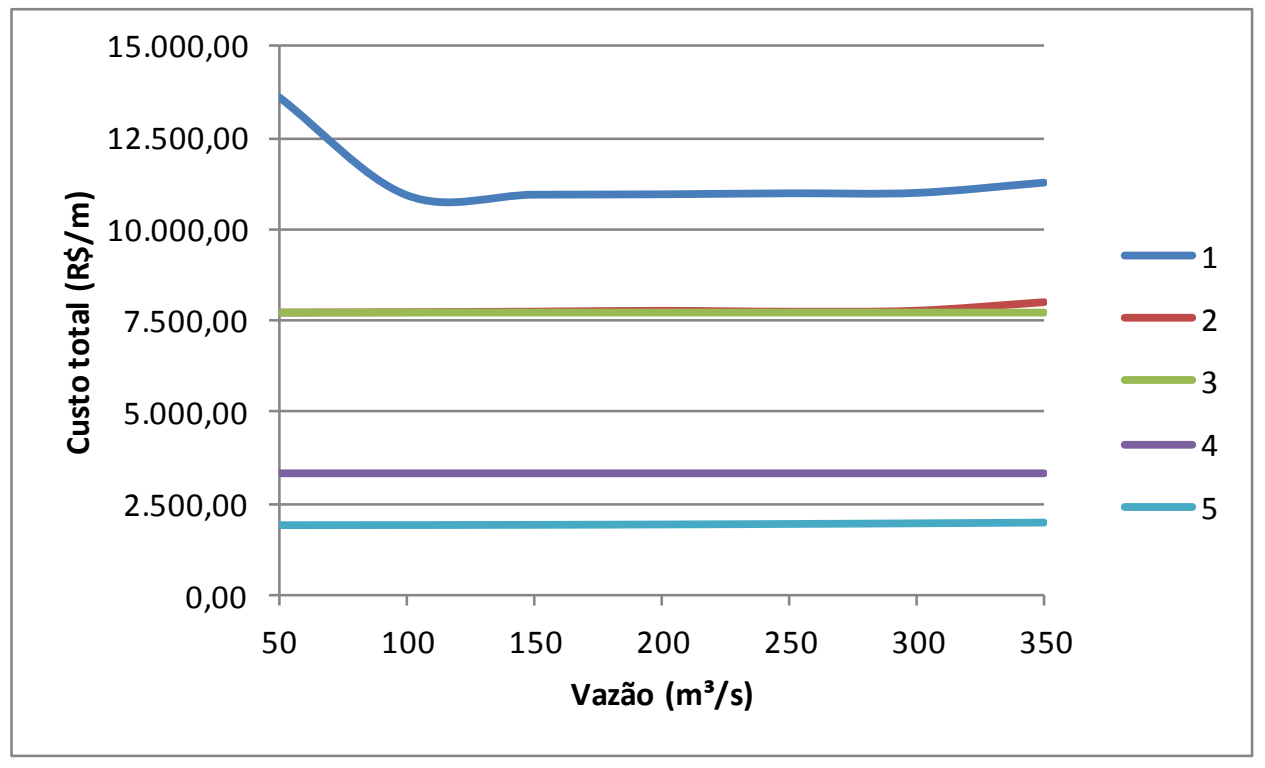

Figura 5.28 - Declividade de fundo igual a $0,0005 \mathrm{~m} / \mathrm{m}$

Estes gráficos mostram que, em praticamente todas as situações, o revestimento 5 (solo natural) apresenta o menor custo global.

Investigando-se melhor esta solução, como era de se esperar, o custo de manutenção, aqui representado pelo custo da perda de carga é o maior dentre todos. Para a situação de maior perda de carga (vazão máxima ensaiada), os custos foram: 
Tabela 5.8 Custos para talude lateral igual a 0,5

\begin{tabular}{|r|r|r|r|r|r|r|r|}
\hline $\begin{array}{r}\text { Talude } \\
\text { lateral }\end{array}$ & Revestim. & $\begin{array}{c}\text { Declividade } \\
\text { de fundo }\end{array}$ & $\begin{array}{c}\text { Custo } \\
\text { Escavação }\end{array}$ & $\begin{array}{c}\text { Custo } \\
\text { Revestim. }\end{array}$ & $\begin{array}{c}\text { Custo } \\
\text { Energia }\end{array}$ & $\begin{array}{c}\text { Custo } \\
\text { Aterro }\end{array}$ & \multicolumn{1}{c|}{$\begin{array}{c}\text { Custo } \\
\text { Total }\end{array}$} \\
\hline 0,5 & 1 & 0,0001 & $2.669,30$ & $7.000,38$ & 62,65 & 0,00 & $9.732,33$ \\
\hline 0,5 & 2 & 0,0001 & $2.492,94$ & $4.578,66$ & 62,22 & 0,00 & $7.133,82$ \\
\hline 0,5 & 3 & 0,0001 & $1.641,17$ & $4.059,60$ & 56,53 & 0,00 & $5.757,30$ \\
\hline 0,5 & 4 & 0,0001 & $1.366,04$ & 996,56 & 59,26 & 0,00 & $2.421,86$ \\
\hline 0,5 & 5 & 0,0001 & $2.071,83$ & 78,74 & 63,64 & 12,88 & $2.227,09$ \\
\hline 0,5 & 1 & 0,0002 & $2.423,26$ & $6.818,68$ & 71,18 & 0,00 & $9.313,12$ \\
\hline 0,5 & 2 & 0,0002 & $2.247,33$ & $4.457,49$ & 71,12 & 0,00 & $6.775,94$ \\
\hline 0,5 & 3 & 0,0002 & $1.450,46$ & $3.912,09$ & 67,11 & 0,00 & $5.429,66$ \\
\hline 0,5 & 4 & 0,0002 & $1.192,15$ & 961,39 & 71,46 & 0,00 & $2.225,00$ \\
\hline 0,5 & 5 & 0,0002 & $1.879,60$ & 76,81 & 71,46 & 0,00 & $2.027,87$ \\
\hline 0,5 & 1 & 0,0005 & $1.883,80$ & $6.475,59$ & 95,43 & $2.500,73$ & $10.955,54$ \\
\hline 0,5 & 2 & 0,0005 & $1.749,43$ & $4.251,52$ & 93,17 & $2.007,20$ & $8.101,32$ \\
\hline 0,5 & 3 & 0,0005 & $1.153,92$ & $3.681,55$ & 88,41 & 315,63 & $5.239,51$ \\
\hline 0,5 & 4 & 0,0005 & 973,49 & 902,65 & 91,83 & 345,42 & $2.313,39$ \\
\hline 0,5 & 5 & 0,0005 & $1.476,01$ & 73,29 & 91,31 & $1.420,63$ & $3.061,24$ \\
\hline
\end{tabular}

Tabela 5.9 Custos para talude lateral igual a 1,0

\begin{tabular}{|r|r|r|r|r|r|r|r|}
\hline $\begin{array}{r}\text { Talude } \\
\text { lateral }\end{array}$ & Revestim. & $\begin{array}{c}\text { Declividade } \\
\text { de fundo }\end{array}$ & $\begin{array}{c}\text { Custo } \\
\text { Escavação }\end{array}$ & $\begin{array}{c}\text { Custo } \\
\text { Revestim. }\end{array}$ & $\begin{array}{c}\text { Custo } \\
\text { Energia }\end{array}$ & \multicolumn{1}{c|}{$\begin{array}{c}\text { Custo } \\
\text { Aterro }\end{array}$} & \multicolumn{1}{c|}{$\begin{array}{c}\text { Custo } \\
\text { Total }\end{array}$} \\
\hline 1 & 1 & 0,0001 & $2.323,44$ & $7.377,56$ & 61,10 & 0,27 & $9.762,36$ \\
\hline 1 & 2 & 0,0001 & $2.186,97$ & $4.840,82$ & 59,73 & 0,00 & $7.087,52$ \\
\hline 1 & 3 & 0,0001 & $1.265,49$ & $4.273,97$ & 57,47 & 0,00 & $5.596,93$ \\
\hline 1 & 4 & 0,0001 & $1.224,31$ & $1.084,91$ & 46,70 & 0,00 & $2.355,91$ \\
\hline 1 & 5 & 0,0001 & $1.844,89$ & 84,13 & 57,54 & 0,00 & $1.986,56$ \\
\hline 1 & 1 & 0,0002 & $2.071,06$ & $7.145,67$ & 71,46 & 0,00 & $9.288,19$ \\
\hline 1 & 2 & 0,0002 & $2.043,64$ & $4.743,48$ & 64,94 & 0,00 & $6.852,05$ \\
\hline 1 & 3 & 0,0002 & $1.945,64$ & $4.643,82$ & 29,69 & 0,00 & $6.619,16$ \\
\hline 1 & 4 & 0,0002 & $1.067,29$ & $1.039,99$ & 56,97 & 0,00 & $2.164,26$ \\
\hline 1 & 5 & 0,0002 & $1.575,07$ & 80,76 & 70,88 & 0,00 & $1.726,71$ \\
\hline 1 & 1 & 0,0005 & $1.621,12$ & $6.736,40$ & 100,89 & $3.125,04$ & $11.583,45$ \\
\hline 1 & 2 & 0,0005 & $1.486,59$ & $4.405,54$ & 100,66 & $3.076,58$ & $9.069,37$ \\
\hline 1 & 3 & 0,0005 & 912,33 & $3.843,95$ & 99,32 & $1.160,18$ & $6.015,78$ \\
\hline 1 & 4 & 0,0005 & 708,54 & 938,10 & 108,97 & $2.028,31$ & $3.783,92$ \\
\hline 1 & 5 & 0,0005 & $1.200,08$ & 75,61 & 103,06 & $3.261,00$ & $4.639,76$ \\
\hline
\end{tabular}


Tabela 5.10 Custos para talude lateral igual a 2,0

\begin{tabular}{|r|r|r|r|r|r|r|r|}
\hline $\begin{array}{r}\text { Talude } \\
\text { lateral }\end{array}$ & Revestim. & $\begin{array}{c}\text { Declividade } \\
\text { de fundo }\end{array}$ & $\begin{array}{c}\text { Custo } \\
\text { Escavação }\end{array}$ & $\begin{array}{c}\text { Custo } \\
\text { Revestim. }\end{array}$ & $\begin{array}{c}\text { Custo } \\
\text { Energia }\end{array}$ & $\begin{array}{c}\text { Custo } \\
\text { Aterro }\end{array}$ & \multicolumn{1}{c|}{$\begin{array}{c}\text { Custo } \\
\text { Total }\end{array}$} \\
\hline 2 & 1 & 0,0001 & $2.794,79$ & $10.279,56$ & 34,90 & 0,00 & $13.109,26$ \\
\hline 2 & 2 & 0,0001 & $2.589,22$ & $6.716,15$ & 34,90 & 0,00 & $9.340,28$ \\
\hline 2 & 3 & 0,0001 & $2.493,66$ & $6.685,37$ & 14,45 & 0,00 & $9.193,49$ \\
\hline 2 & 4 & 0,0001 & $2.428,83$ & $1.699,75$ & 11,11 & 0,00 & $4.139,69$ \\
\hline 2 & 5 & 0,0001 & $2.421,70$ & 119,99 & 28,28 & 0,00 & $2.569,97$ \\
\hline 2 & 1 & 0,0002 & $2.545,49$ & $9.951,89$ & 40,68 & 0,00 & $12.538,06$ \\
\hline 2 & 2 & 0,0002 & $2.352,17$ & $6.495,29$ & 40,68 & 0,00 & $8.888,15$ \\
\hline 2 & 3 & 0,0002 & $2.177,66$ & $6.513,78$ & 18,49 & 0,00 & $8.709,93$ \\
\hline 2 & 4 & 0,0002 & $2.118,32$ & $1.664,44$ & 14,33 & 0,00 & $3.797,09$ \\
\hline 2 & 5 & 0,0002 & $2.111,80$ & 116,48 & 35,13 & 0,00 & $2.263,41$ \\
\hline 2 & 1 & 0,0005 & $1.700,43$ & $8.847,68$ & 81,51 & 124,95 & $10.754,58$ \\
\hline 2 & 2 & 0,0005 & $1.598,51$ & $5.831,28$ & 79,20 & 37,85 & $7.546,85$ \\
\hline 2 & 3 & 0,0005 & $1.532,60$ & $5.802,14$ & 42,32 & 0,00 & $7.377,06$ \\
\hline 2 & 4 & 0,0005 & $1.487,80$ & $1.477,24$ & 34,73 & 0,00 & $2.999,77$ \\
\hline 2 & 5 & 0,0005 & $1.400,69$ & 102,73 & 73,22 & 0,00 & $1.576,64$ \\
\hline
\end{tabular}

Fica claro, pelos resultados expostos, que apesar de a solução em terreno natural apresentar os mais altos custos de energia em relação as demais soluções, e valores de escavação muito próximos daqueles encontrados em outros revestimentos para esta simulação (mesmo não havendo sobre escavação devido a espessura de revestimento nula), o fator decisivo para a opção por este revestimento se deve pelo custo do próprio revestimento, muito mais barato para o caso de terreno natural.

Se o custo de energia fosse maior, ou mesmo o custo de escavação (trecho todo em material de terceira categoria, por exemplo), talvez o custo de revestimento pudesse ter menor expressão, e assim outro revestimento pudesse competir com o terreno natural.

Desconsiderando-se o terreno natural da comparação, o revestimento mais eficiente neste caso simulado seria o composto por Geomanta / Geotêxtil, que também 
apresenta baixíssimo custo de revestimento, que é o principal custo na diferenciação das soluções.

Analisando-se o revestimento de terreno natural em mais detalhe, para todas as vazões ensaiadas, pode se obter de Figura 5.29 a Figura 5.37 a seguir, que mostram o custo relativo de cada parcela em relação ao custo total de cada uma das situações estudadas.

Tais figuras demonstram a importância do custo de escavação em relação aos demais elementos de custo.

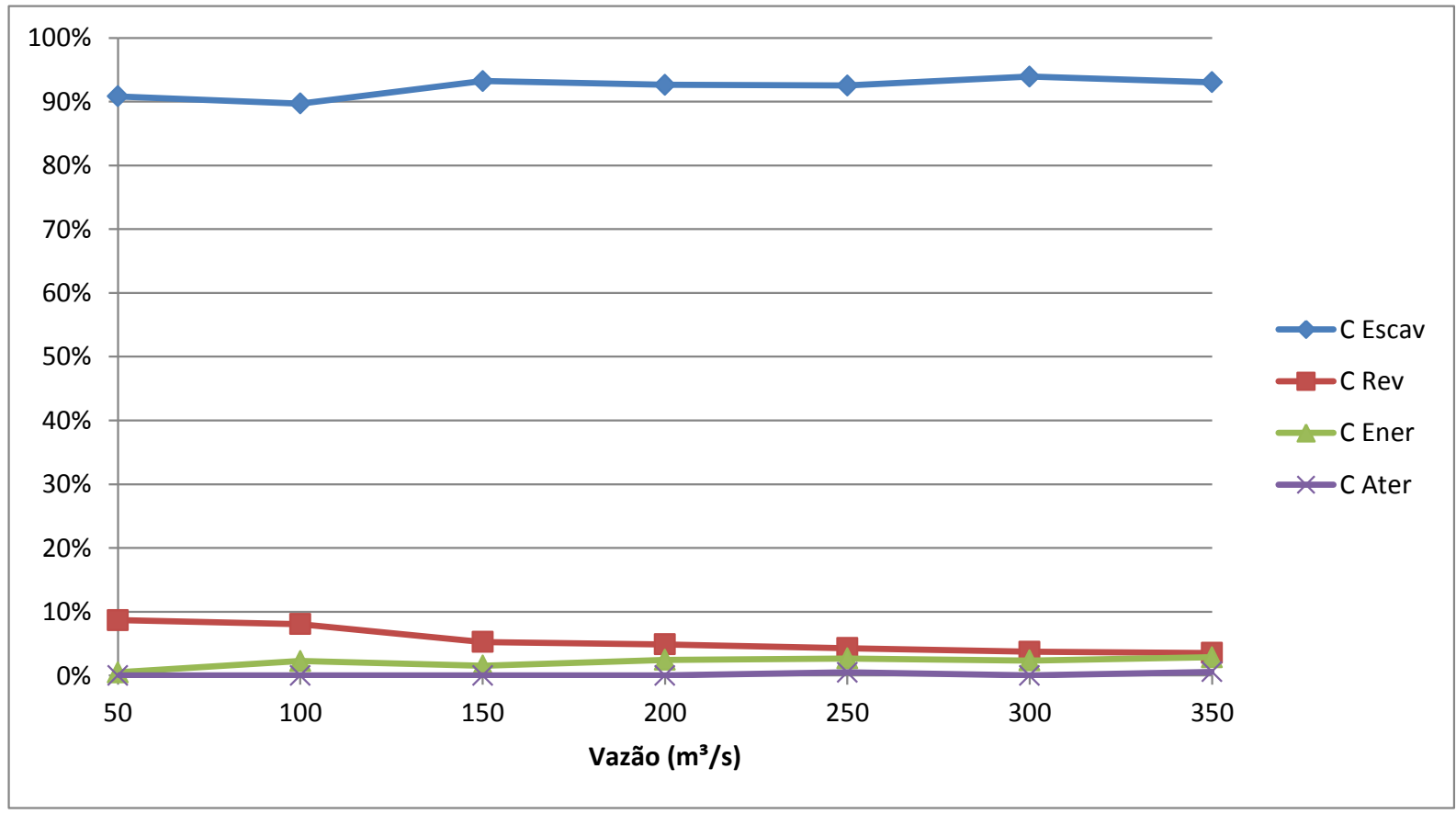

Figura 5.29 - Composição dos elementos de custo para $\mathrm{m}=0,5 \mathrm{e} \mathrm{i}=\mathbf{0 , 0 0 0 1}$ 


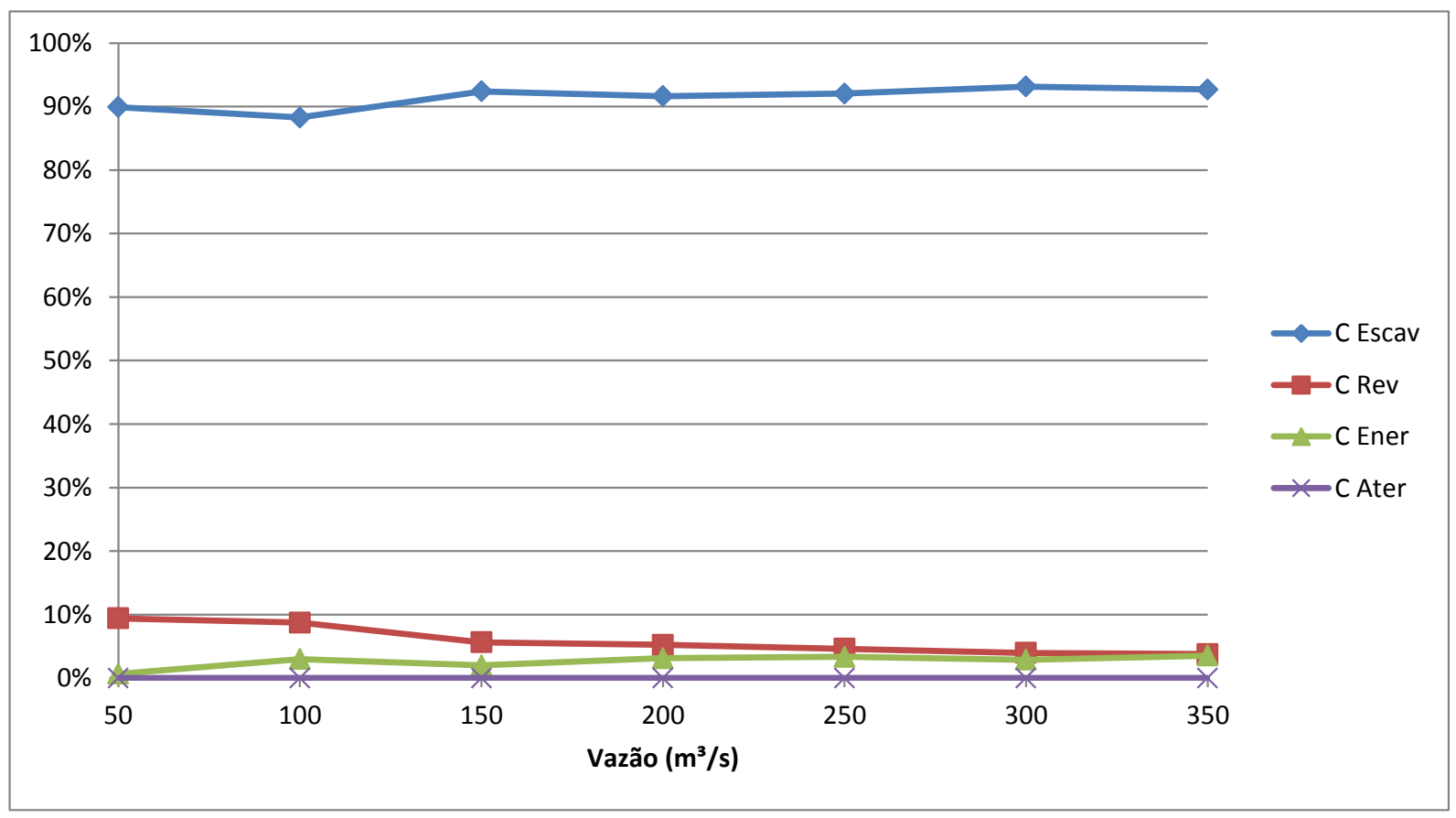

Figura 5.30 - Composição dos elementos de custo para $\mathrm{m}=0,5$ e $\mathrm{i}=0,0002$

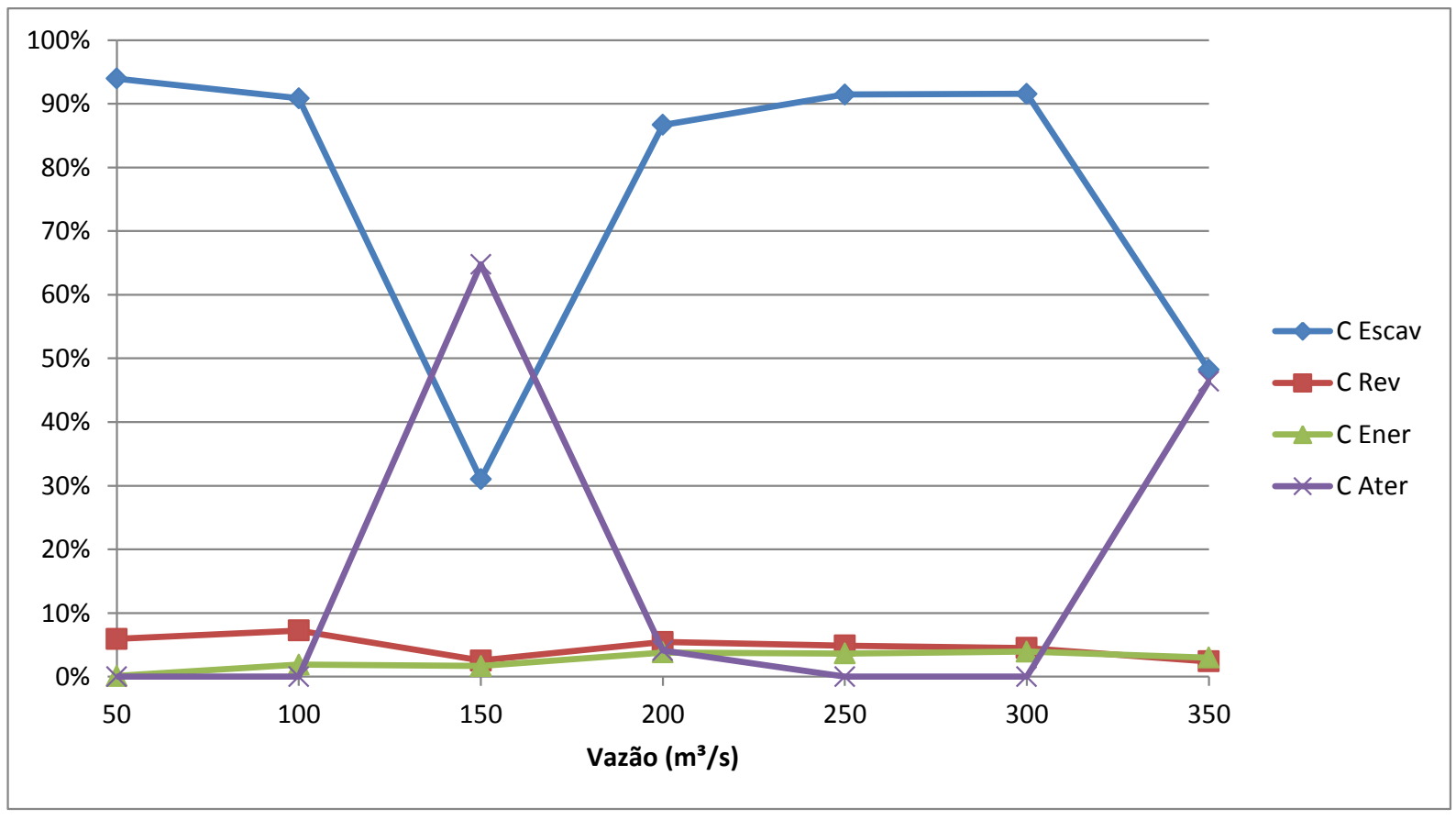

Figura 5.31 - Composição dos elementos de custo para $m=0,5$ e i $=0,0005$ 


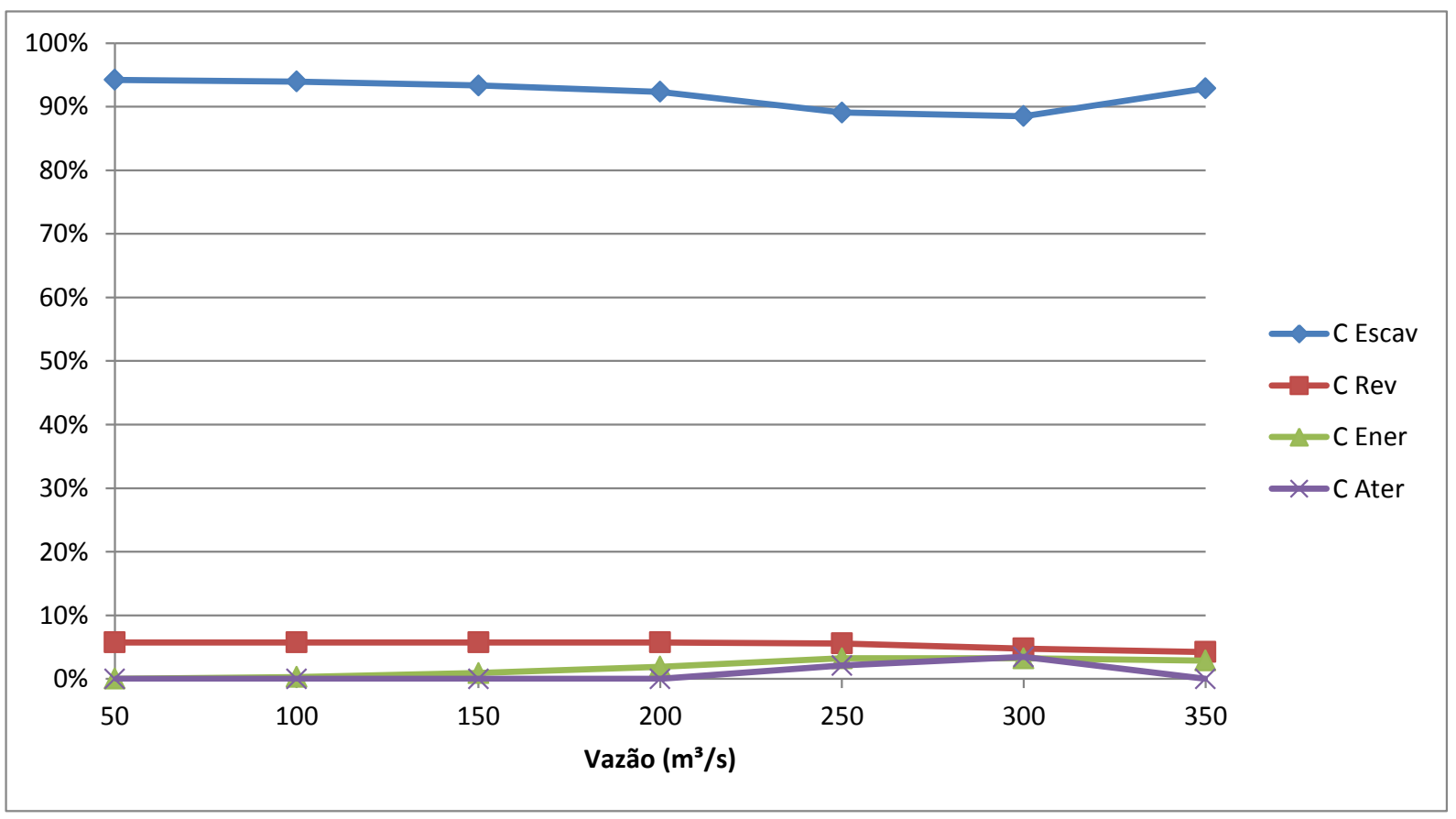

Figura 5.32 - Composição dos elementos de custo para $m=1,0$ e i $=0,0001$

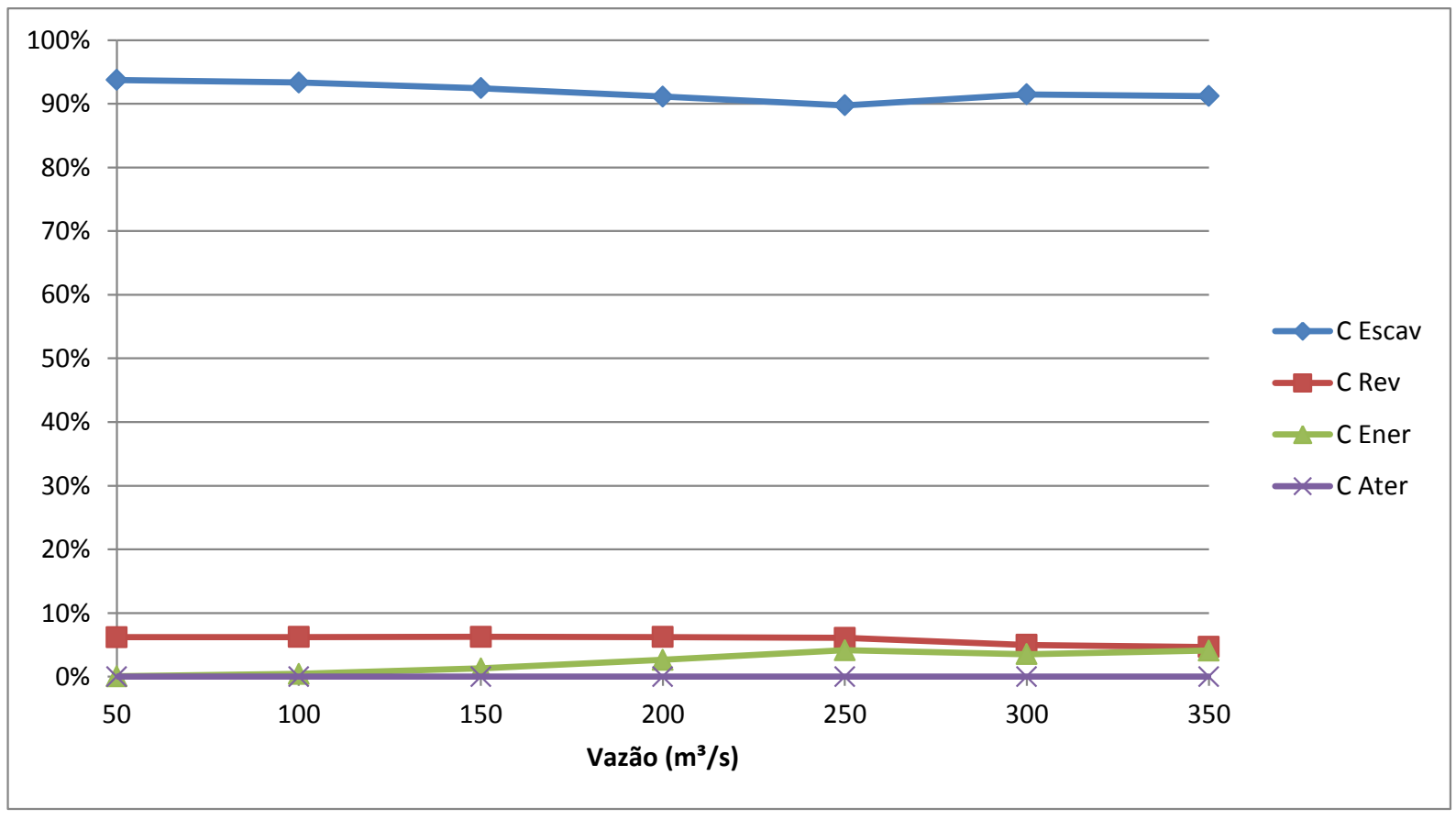

Figura 5.33 - Composição dos elementos de custo para $m=1,0$ e $i=0,0002$ 


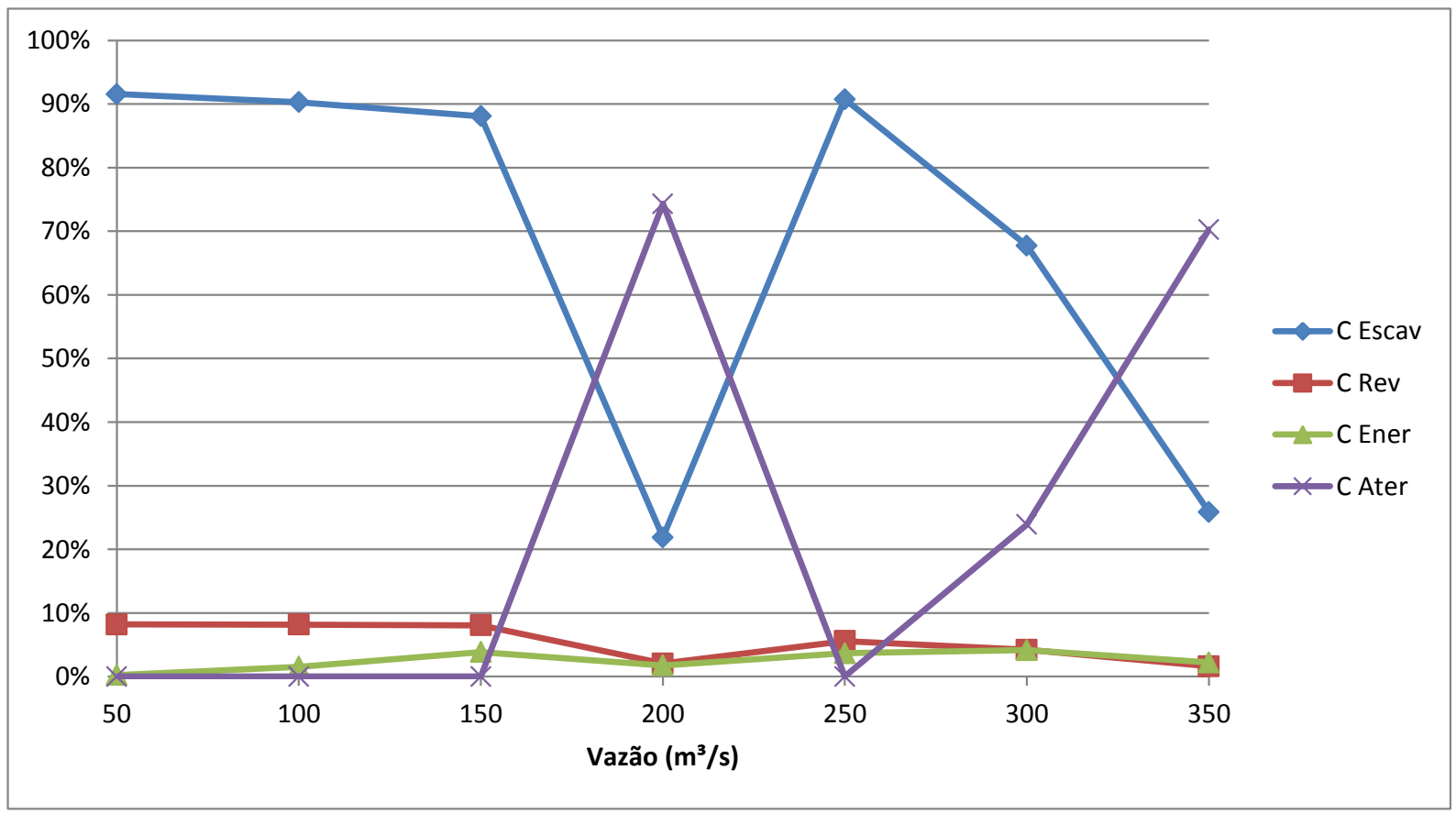

Figura 5.34 - Composição dos elementos de custo para $m=1,0$ e $i=0,0005$

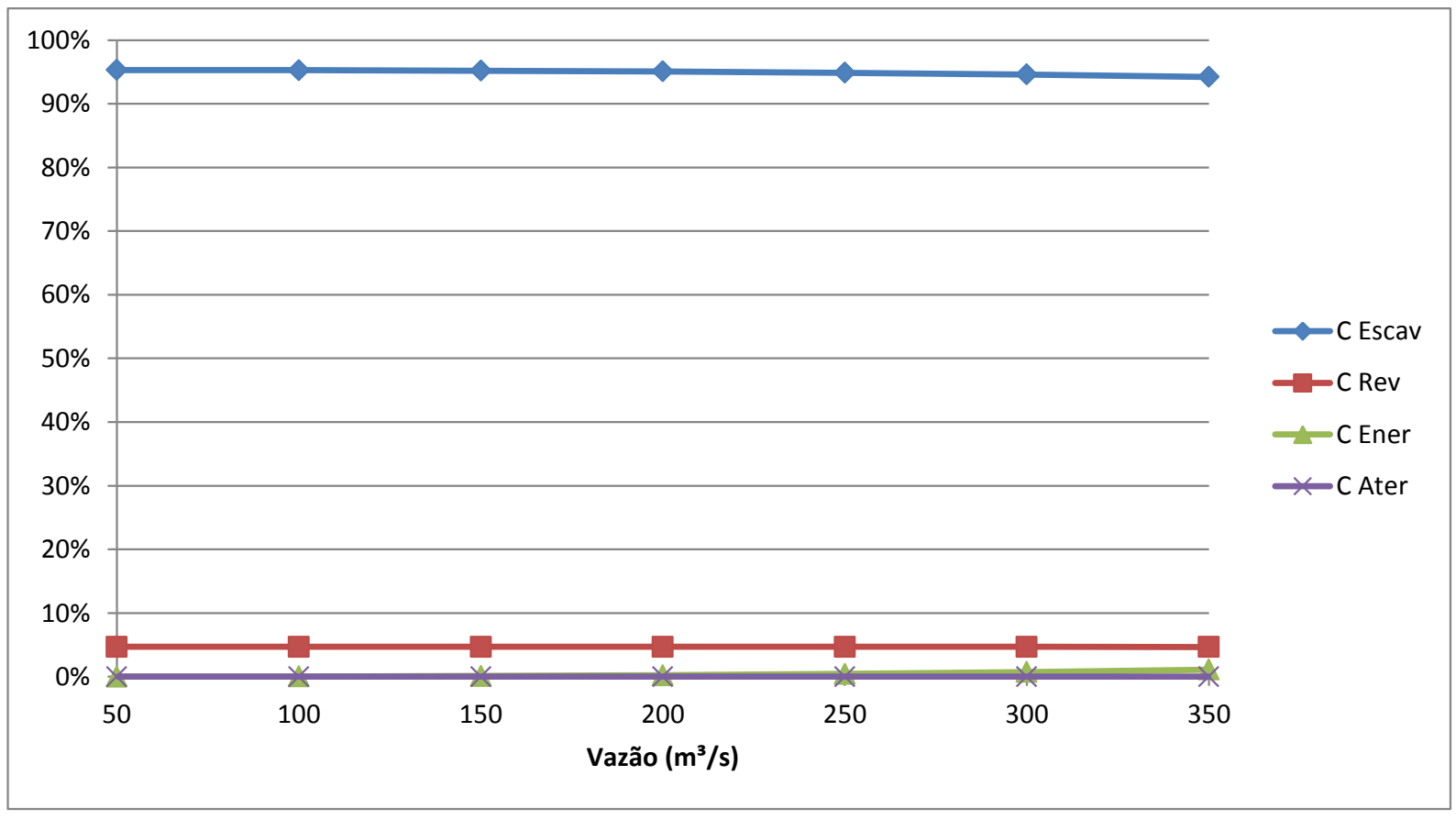

Figura 5.35 - Composição dos elementos de custo para $m=2,0$ e $\mathrm{i}=0,0001$ 


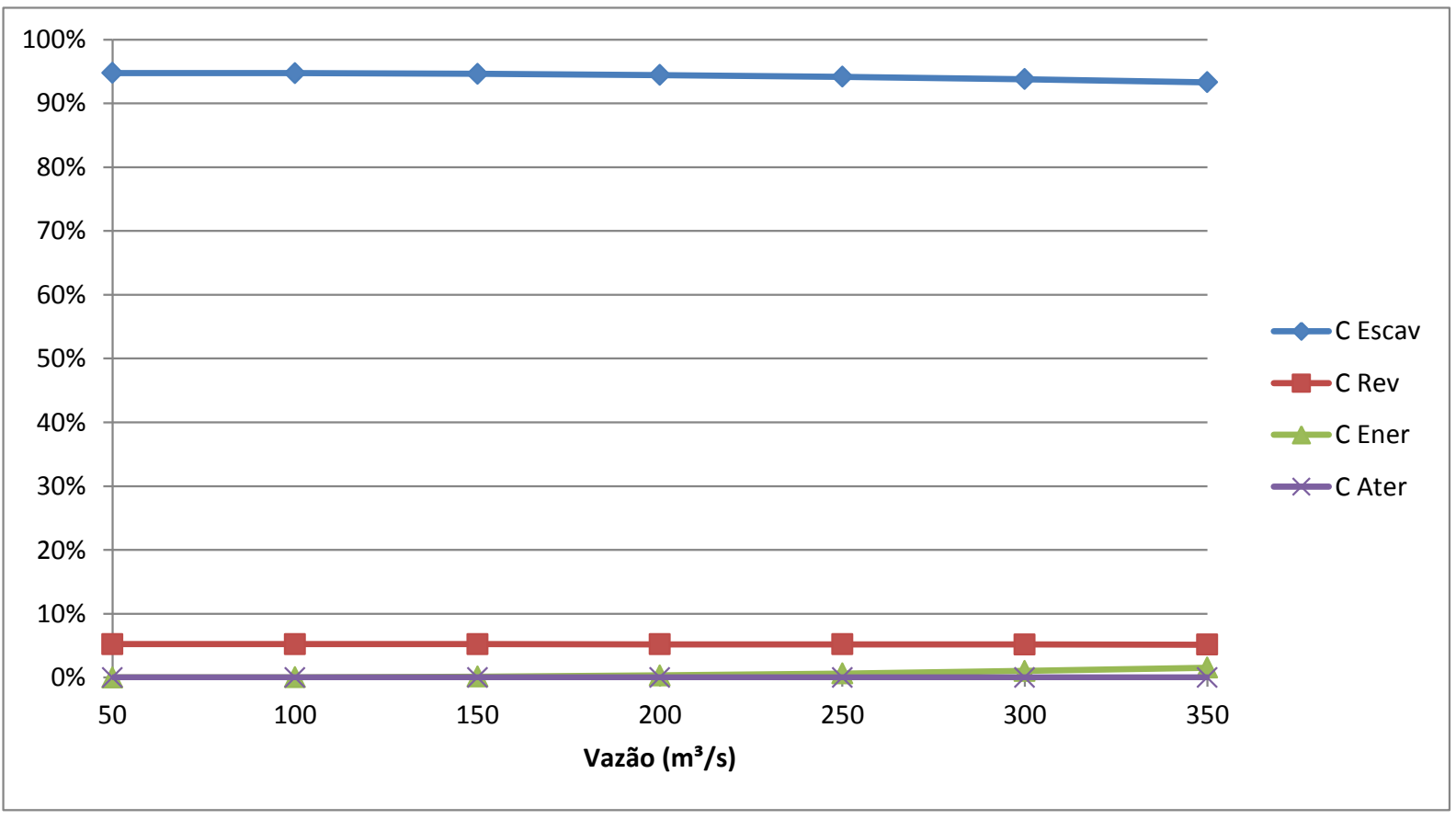

Figura 5.36 - Composição dos elementos de custo para $m=2,0$ e $\mathrm{i}=0,0002$

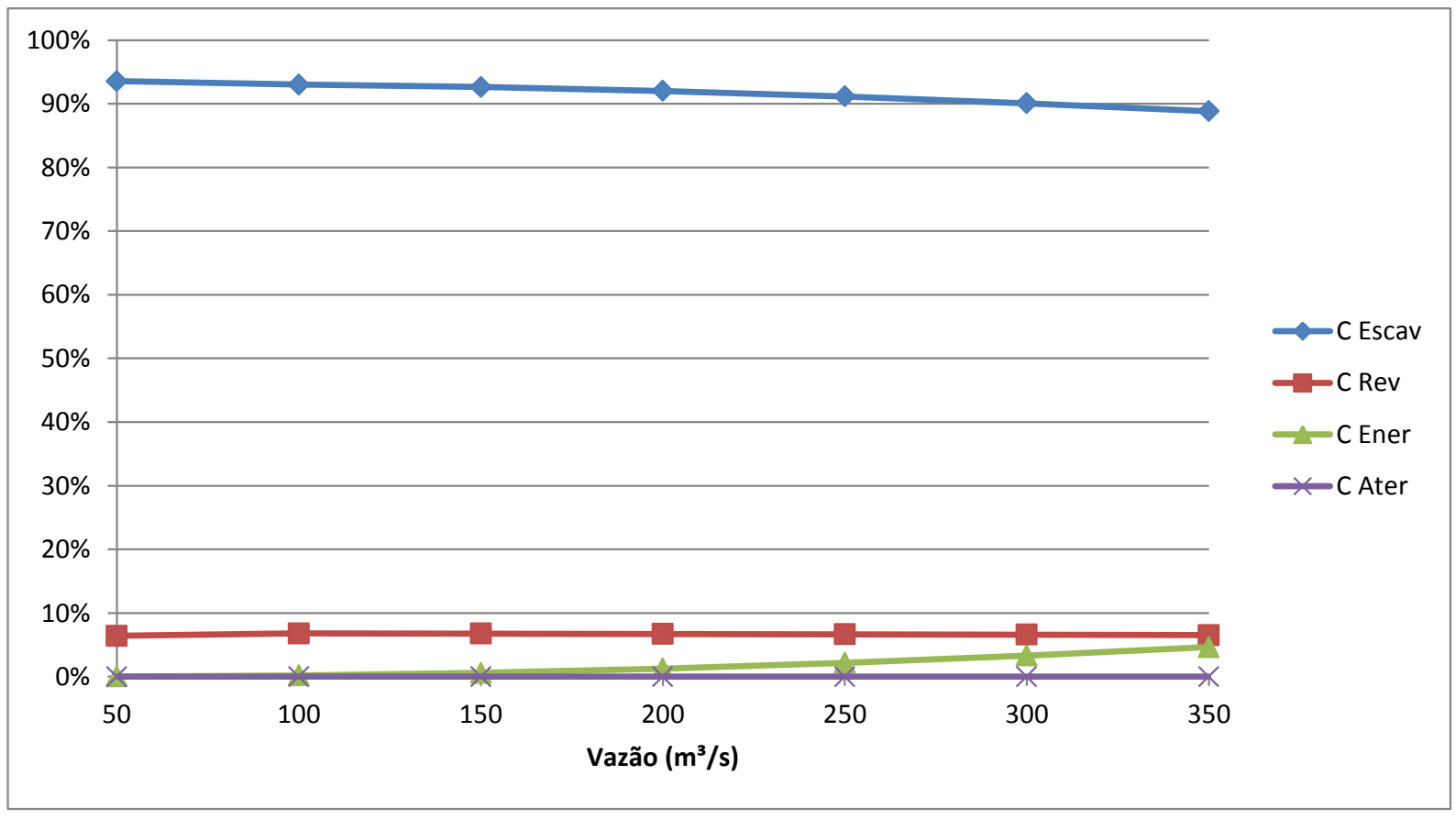

Figura 5.37 - Composição dos elementos de custo para $m=2,0$ e i $=0,0005$

Apesar de o custo de energia apresentar-se sempre crescente com o aumento da vazão, seus valores relativos não são suficientemente grandes face ao custo de 
escavação para causar grande alteração no custo total do empreendimento e, por conseguinte, na escolha da seção ótima. 


\section{DISCUSSÃO DOS RESULTADOS}

Foram realizadas duas rodadas de simulação, ambas em condições hipotéticas, sendo a primeira delas para verificação da adequação dos resultados obtidos (através da comparação dos valores encontrados no modelo com aqueles encontrados por outra metodologia disponível na revisão bibliográfica), e em seguida foi processado um novo ensaio, desta vez com maior nível de detalhes nos dados de entrada, procurando simular um caso prático de aplicação da modelagem, para analise da eficácia do método proposto.

$\mathrm{Na}$ etapa de verificação, a metodologia adotada para comparação foi àquela proposta por SOUZA (s.d.), devido ao fato de ser uma solução conceitualmente diferente do que se propõe neste trabalho, visto que a abordagem analítica de SOUZA simplifica diversos detalhes de implantação e desconsidera os efeitos da operação, ao contrário da solução numérica que procura computar todos os custos envolvidos na construção e manutenção do canal. Além disso, o modelo analítico proposto não envolve a complexidade da otimização não linear, o que torna sua aplicação mais fácil e precisa, tendo em vista as limitações do otimizador GRG não linear disponível no aplicativo EXCEL.

Tais diferenças despertaram o interesse do autor no resultado da comparação, pois independentemente da metodologia, a solução ótima é única, e os resultados corroboraram a expectativa, pois na maioria absoluta das simulações os resultados encontrados no Modelo estavam praticamente idênticos àqueles calculados por SOUZA. Nos poucos casos em que houve divergência, pode-se atribuir aos desvios às seguintes causas: 1) a influência das simplificações adotadas no modelo analítico 
e 2) Obtenção pelo modelo numérico de uma otimização local, ao invés da otimização global.

Uma vez verificada a coerência do Modelo, a etapa de aplicação prática teve como objetivos lidar com os dados gerados (filtrar, classificar, apresentar e avaliar), conhecer a sensibilidade do modelo às diferentes situações de cálculo em uma aplicação prática (variação de talude, declividade de fundo, vazão e revestimento) e descobrir as limitações e dificuldades de aplicação.

A forma de apresentação desenvolvida no Estudo de Caso foi suficiente para visualizar os contrastes entre as diferentes condições de projeto, constatar comportamentos e tendências e até mesmo verificar a coerência das soluções propostas pelo modelo. A apresentação de custos de escavação, aterro, revestimento e energia de forma percentual em relação ao custo total, para cada caso analisado, trouxe a percepção do quão relevante eram cada um destes termos, levando inclusive a uma melhor compreensão das simplificações adotadas por SOUZA (s.d.). Outra facilidade criada pela forma como foi feita a apresentação das informações é o custo total apresentado para cada um dos revestimentos e vazões, por metro linear de canal, viabilizando uma rápida comparação com outros casos de estudo de otimização de canais que já se tenha feito no passado.

A partir da análise destes dados, é possível concluir que:

- Declividades de fundo: pelas curvas de linha d'água apresentadas em Anexo, observa-se que quanto maior a declividade de fundo há uma tendência de convergência na espessura da lâmina d'água, independentemente do tipo de revestimento, da vazão adotada ou do talude empregado; 
- Talude lateral: tem grande influência na espessura de lâmina d'água, para baixas declividades de fundo. Observa-se que para taludes menores $(1,0 \mathrm{~V}: 0,5 \mathrm{H})$ o nível de montante fica acima daquele calculado para o talude de $(1,0 \mathrm{~V}: 2,0 \mathrm{H})$, sendo que $\mathrm{o}$ talude de $(1,0 \mathrm{~V}: 1,0 \mathrm{H})$ oscila entre ambos, ficando mais próximo do talude menor em vazões altas, e mais próximo do talude maior em vazões baixas;

- Elementos de custo: no estudo de caso desenvolvido, a movimentação de terra (escavação / aterro) foi responsável por algo em torno de $90 \%$ do custo total do empreendimento, sendo, portanto decisiva na escolha;

- Revestimentos: foi verificada a coerência entre o custo de perda de carga e o Manning adotado para cada revestimento empregado nos ensaios; no entanto, nem o custo de carga e nem o custo do revestimento foram capazes de interferir de forma relevante no custo total do empreendimento.

Quanto às dificuldades de operação do modelo, nota-se que a metodologia de suporte a decisão, da forma como foi aqui proposta, implica a simulação de todos os casos que se tenha interesse (diferentes valores de vazão, declividade de fundo, revestimento e talude lateral).

Portanto, uma complicação na aplicação do modelo é a necessidade de se desenvolver programas em linguagem VBA ("macros") a fim de se poupar o usuário da árdua tarefa de simular caso a caso isoladamente.

O tempo de processamento consumido no estudo de caso também foi uma restrição na formulação dos casos ensaiados, pois na forma como foram elaborados, considerando 7 diferentes vazões, 3 taludes laterais, 3 declividades de fundo e 5 revestimentos (315 casos), e, considerando ainda 3 rodadas de cada caso a fim de 
verificar a convergência, foram consumidas aproximadamente 3:30 horas apenas no processamento computacional, sem considerar o tratamento posterior da informação gerada. A grande quantidade de dados (arquivo de resultados com aproximadamente $1 \mathrm{Mb}$ e arquivo com linhas d'água com todas as simulações, inclusive as do solver, de $30 \mathrm{Mb}$ ) requer consideráveis esforços de pós processamento até alcançarem a apresentação como se faz no item 5.4.4, Resultados.

Observa-se, portanto, que o Modelo desenvolvido, em comparação com aqueles apresentados na Revisão Bibliográfica, agregou ao cálculo de otimização de seção uma maior precisão no custo global por considerar elementos de custo não vistos em outras publicações, como por exemplo, a perda de carga e a espessura de revestimento no volume de escavação total, além da consideração de implantação do canal em terrenos naturais, admitindo inclusive horizontes geotécnicos para diferenciar os materiais de escavação.

Outra vantagem da metodologia proposta foi a facilidade de cálculo para diversos revestimentos, algo que também não havia sido explorado em outros trabalhos, mas que, em casos práticos de estudo de otimização, é de bastante interesse do empreendedor. 


\section{CONCLUSÕES E RECOMENDAÇÕES}

Este trabalho teve por objetivo a formulação de um modelo matemático capaz de dar suporte à decisão em projetos de canal de seção trapezoidal, por meio de otimização pelo critério de custo global. Foi empregado na modelação o solver do Microsoft Office Excel® 2010, que é amplamente conhecido, de fácil aplicação e bastante flexível, o que é importante devido a possibilidade de se fazerem ajustes na metodologia para diferentes situações e considerações que se possa vir a fazer no futuro.

A metodologia de dimensionamento proposta empregou as equações de SAINTVENANT (conservação de massa e quantidade de movimento) simplificadas para o caso específico de ausência de contribuição lateral e em regime permanente, são perfeitamente cabíveis para as situações de projeto idealizadas para aplicação do modelo, de escoamento unidimensional e leito de fundo fixo.

Os resultados encontrados durante as simulações de testes e dos estudos de caso foram coerentes com o esperado, sendo verificado aumento da perda de carga e do consumo de energia elétrica para maiores vazões, maiores volumes de escavação para revestimentos mais espessos, revestimentos de menor Manning apresentam menor perda de carga, etc.

Os cálculos de estudo de caso revelaram a importância da movimentação de terra na implantação de canais, o que justifica o porquê de os estudos de traçado de canais atraírem maiores recursos na elaboração de projeto em relação ao estudo de seção. Isso não tira a importância do estudo de seção, pelo contrário: um estudo de seção rápido e confiável colabora e muito no estudo de traçados, podendo-se avaliar as diferenças entre diversos traçados com precisão. 
Ficou comprovada também a eficiência do modelo analítico, que durante as fases de estudos preliminares (quando não se dispõe de muitos dados de campo) pode ser uma ferramenta bastante útil, permitindo a obtenção instantânea de custos com grande aproximação dos valores reais.

Sugere-se, para futuros trabalhos, o cálculo mais amplo do escoamento, englobando as condições de regime não permanente, torrencial e também a consideração da contribuição lateral que atualmente ainda não são suportadas, mas caso fossem tornariam o modelo mais versátil. Outra pesquisa interessante seria a otimização de diversos critérios concomitantes, como por exemplo, o conjunto largura de base / talude lateral / declividade de fundo do canal, e a aplicação de solver com algoritmo genético, mais eficiente no calculo de mínimo global.

Recomenda-se também para novas pesquisas a consideração de diferentes conformações de seção transversal, além da trapezoidal, como por exemplo, as seções parabólicas, retangulares, mistas e triangulares, sendo que para alguns casos deve-se adotar revestimento estrutural, como por exemplo concreto, tela de concreto ou elementos articulados. 


\section{REFERÊNCIAS BIBLIOGRÁFICAS}

ABDULRAHMAN, A. (2007). Best Hydraulic Section of a Composite Channel, Journal of Hydraulic Engineering-ASCE, 133(6), 695-697.

AES ELETROPAULO (2010). Tarifas de energia, AES Eletropaulo. Disponível em $<$ http://www.aeseletropaulo.com.br>. Acesso em 15 dez. 2011.

AGÊNCIA NACIONAL DE ENERGIA ELÉTRICA - ANEEL (2005). Tarifas de fornecimento de energia elétrica, Cadernos temáticos ANEEL no 4, Brasilia, 30p. Disponível em <http://www.aneel.gov.br/arquivos/pdf/caderno4capa.pdf $>$. Acesso em 30 nov. 2011.

BHATTACHARJYA, R. B., SATISH M. G. (2007) Optimal Design of a Stable Trapezoidal Channel Section Using Hybrid Optimization Techniques, J. Irrig. and Drain. Eng. - ASCE 133(4), 323-329

CARRIAGA, C. C., MAYS, L. W. (1999) Optimization Approach To Stable Channel Design, Proceedings ASCE 26th Annual Water Resources Planning and Management Conference, Tempe, Arizona, 1999

CARRIAGA, C. C., TUNCOK, I. K., MAYS L. W. (2000) Optimization Modeling Approach in the Design of Stable Channel System, Proceedings of Joint Conference on Water Resource Engineering and Water Resources Planning and Management, Minneapolis, 2000

CHOW, V.T., Open Channel Hydraulics, McGraw-Hill, New York, 1959, 680p.

CUENCA, R.H., Irrigation system design: an engineering approach, Prentice Hall, 1989, 552p.

DAS, A. (2000) Optimal channel cross section with composite roughness, J. Irrig. Drain. Eng. - ASCE 126(1), 68-72

DAS, A. (2008) Chance constrained optimal design of trapezoidal channels, Journal of Water Resources Planning And Management - ASCE, 134(3), 310-313.

DEPARTAMENTO DE ESTRADAS E RODAGEM - DER (2011), Tabela de Preços Unitários (Data de Referência 30/06/2011), Disponível em $<$ http://www.der.sp.gov.br/documentos/tabelas/tabela precos.aspx>. Acesso em 09 ago. 2011.

FLYNN, L. E., MARIÑO, M. A. (1987) Canal design: Optimal cross sections, J. Irrig. Drain. Eng., 113(3), 335-355.

FORTIER, S., SCOBEY, F.C. (1926) Permissible canal velocities, Trans. ASCE, 89 (1), 940-984. 
FURUSAWA, R. T., Contribuição ao dimensionamento de rede de distribuição de água por critério de custo global, Dissertação (Mestre) - Universidade de São Paulo, São Paulo, 2011, 207 p.

HENDERSON, F. M., Open Channel Flow, MacMillan, New York, 1966, 522 p.

LANE, E. W., The importance of fluvial morphology in hydraulic engineering. Proceedings, American Society of Civil Engineers, 1955, no 745, Jul

LENCASTRE, A., Manual de hidráulica geral, São Paulo, Edgard Blücher, 1972, $411 \mathrm{p}$.

LOGANATHAN, G. V. (1991) Optimal design of parabolic canals, J. Irrig. Drain. Eng., 117(5), 716-735.

MACCAFERRI DO BRASIL, Defesas de margens e obras transversais: necessidades e soluções, Jundiaí : Maccaferri do Brasil, 2009, 100 p.

MME, Manual de Inventário Hidroelétrico de Bacia Hidrográfica, 2007

NEILL, C. R., Mean velocity criterion for scour of coarse uniform bed material, Proceedings 12th Congress of the International Association for Hydraulic Research, Fort Collins, Colorado, USA, 1967, Vol.3, 46-54.

PORTO, R. M. HIDRÁULICA BÁSICA 4a edição. 4. ed. São Paulo: Rettec Gráfica E Editora, 2006. v. 2500.529 p.

SIMONS, D. B., SENTÜRK, F., Sediment transport technology: water and sediment dynamics, Water Resources Publications, Colorado, USA, 1992, 919 p.

SOUZA ET AL. Métodos Computacionais para Engenharia Hidráulica, São Paulo, Fundação Centro Tecnológico de Hidráulica, 1991. V. 1, 75 p. 


\section{ANEXO A - TABELA DE TARIFAS ENERGÉTICAS (AES ELETROPAULO)}

\section{Tarifas Grupo A}

\begin{tabular}{|c|c|c|c|c|c|c|c|c|}
\hline \multirow[t]{2}{*}{$\begin{array}{c}\text { GRUPO "A" } \\
\text { ALTA E MÉDIA } \\
\text { TENSÃO (RTE 7,9) }\end{array}$} & \multicolumn{2}{|c|}{$\begin{array}{c}\text { SUBGRUPO AS } \\
\text { PORT. 456/00 - ART.82 }\end{array}$} & \multicolumn{2}{|c|}{$\begin{array}{l}\text { SUBGRUPO A2 } \\
\text { (88 KV à } 138 \mathrm{KV})\end{array}$} & \multicolumn{2}{|c|}{$\begin{array}{l}\text { SUBGRUPO A3a } \\
\text { (30 KV a } 44 \mathrm{KV})\end{array}$} & \multicolumn{2}{|c|}{$\begin{array}{l}\text { SUBGRUPO A4 } \\
(2,3 \mathrm{KV} \text { a } 25 \mathrm{KV})\end{array}$} \\
\hline & DEMANDA & CONSUMO & DEMANDA & CONSUMO & DEMAND/ & CONSUMO & DEMAND/ & CONSUMO \\
\hline CONVENCIONAIS & $\begin{array}{c}\mathrm{R} \$ / \mathrm{KW} \\
46,22\end{array}$ & $\mathrm{R} \$ / \mathrm{MWh}$ & $\mathbf{R} \$ / \mathrm{KW}$ & $\mathrm{R} \$ / \mathrm{MWh}$ & $\mathrm{R} \$$ / KW & $\mathrm{R} \$ / \mathrm{MWh}$ & $\begin{array}{c}R \$ \text { / KW } \\
31.31\end{array}$ & $\begin{array}{c}\mathrm{R} \$ / \mathrm{MWh} \\
161,32\end{array}$ \\
\hline $\begin{array}{l}\text { HORO-SAZONAIS } \\
\text { TARIFA AZUL }\end{array}$ & & Tor, & & & 22,02 & 101,02 & & \\
\hline PONTA SECA & 33,84 & 249,04 & 19,79 & 249,04 & 23,84 & 249,04 & 32,39 & 249,04 \\
\hline PONTA ÚMIDA & 33,84 & 226,21 & 19,79 & 226,21 & 23,84 & 226,21 & 32,39 & 226,21 \\
\hline $\begin{array}{c}\text { FORA DE PONTA } \\
\text { SECA }\end{array}$ & 8,35 & 159,12 & 2,82 & 159,12 & 5,16 & 159,12 & 7,99 & 159,12 \\
\hline $\begin{array}{l}\text { FORA DE PONTA } \\
\text { ÚMIDA }\end{array}$ & 8,35 & 145,87 & 2,82 & 145,87 & 5,16 & 145,87 & 7,99 & 145,87 \\
\hline ULTRAPASSAGEM & & & & & & & & \\
\hline (PS ou PU) & 101,52 & & 59,37 & & 71,52 & & 97,17 & \\
\hline (FPS ou FPU) & 25,05 & & 8,46 & & 15,48 & & 23,97 & \\
\hline TARIFA VERDE & & & & & & & & \\
\hline PONTA SECA & 8,35 & 1034,75 & & & 5,16 & 802,51 & 7,99 & $1.001,06$ \\
\hline PONTA ÚMIDA & 8,35 & 1011,92 & & & 5,16 & 779,68 & 7,99 & 958,23 \\
\hline $\begin{array}{l}\text { FORA DE PONTA } \\
\text { SECA }\end{array}$ & 8,35 & 159,12 & & & 5,16 & 159,12 & 7,99 & 159,12 \\
\hline $\begin{array}{l}\text { FORA DE PONTA } \\
\text { ÚMIDA } \\
\text { ULTRAPASSAGEM }\end{array}$ & 8,35 & 145,87 & & & 5,16 & 145,87 & 7,99 & 145,87 \\
\hline SECO E ÚMIDO & 25,05 & & & & 15,48 & & 23,97 & \\
\hline
\end{tabular}

\section{Tarifas Grupo B}

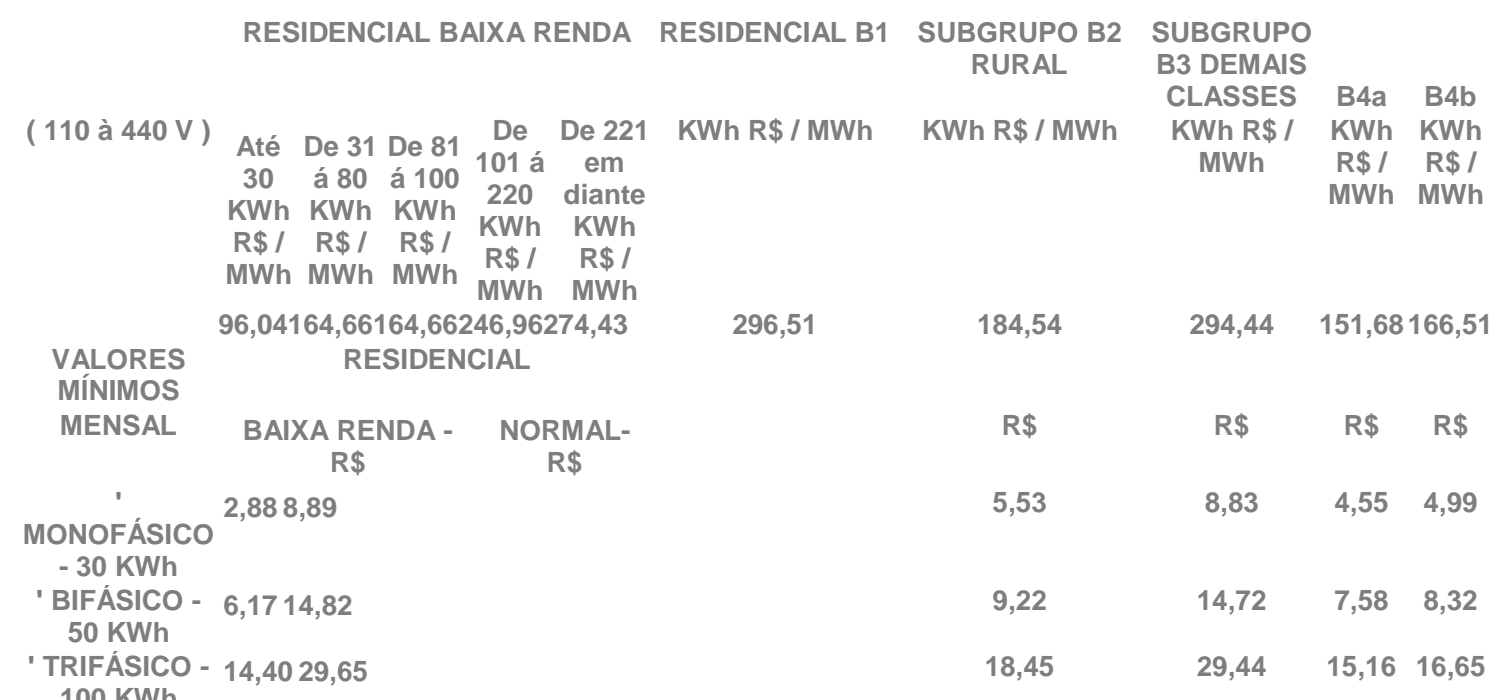

Desconto BT: Água, Esgoto e

Saneamento ( $15 \%$ s/ Tarifa do

B2 Coop. Elet. Rural - R\$ 139,58 / MWh

Subgrupo B3 - $\mathbf{R} \$ 250,27$ 
TUSD CONSUMIDORES LIVRES

\begin{tabular}{ccccc} 
& \multicolumn{2}{c}{ TUSD + TUST } & \multicolumn{2}{c}{ TUSD } \\
SUBGRUPO & \multicolumn{2}{c}{ DEMANDA (RS / KW) } & \multicolumn{2}{c}{ Encargos R\$/MWh } \\
& PONTA & FORA DE PONTA & PONTA & FORA DE PONTA \\
A2 (88 A 138KV) & 19,79 & 2,82 & 34,84 & 34,84 \\
A3a ( 30 a 44 kV) & 23,84 & 5,16 & 34,84 & 34,84 \\
A4 (2,3 a 25 kV) & 32,39 & 7,99 & 34,84 & 34,84 \\
BT ( Menor que & 53,43 & 9,26 & 34,84 & 34,84 \\
2,3kV) & & & &
\end{tabular}

TUSD CONSUMIDORES LIVRES - Em atendimento aos Arts 19 e 20 da Resolução Normativa ANEEL no. 166/2005

\begin{tabular}{|c|c|c|c|c|}
\hline \multirow[t]{2}{*}{ SUBGRUPO } & \multicolumn{2}{|c|}{ TUSD + TUST } & \multicolumn{2}{|c|}{$\begin{array}{c}\text { TUSD } \\
\text { Encargos R\$/MWh }\end{array}$} \\
\hline & PONTA & FORA DE PONTA & PONTA & FORA DE PONTA \\
\hline A2 (88 A 138KV) & 19,79 & 2,82 & 2,24 & 2,24 \\
\hline A3a ( 30 a $44 \mathrm{kV})$ & 23,84 & 5,16 & 2,24 & 2,24 \\
\hline A4 ( 2,3 a $25 \mathrm{kV})$ & 32,39 & 7,99 & 2,24 & 2,24 \\
\hline BT ( Menor que 2,3kV) & 53,43 & 9,26 & 2,24 & 2,24 \\
\hline
\end{tabular}

TUSD CONSUMIDORES LIVRES - Aplicação de desconto previsto nas Resoluções no. 77, de 18 de agosto de 2004, e no. 247, de 21 de dezembro de 2006

SUBGRUPO

Parcela sujeita ao desconto A2 (88 A 138KV)
A3a ( 30 a $44 \mathrm{kV})$
A4 (2,3 a $25 \mathrm{kV})$
T (Menor que $2,3 \mathrm{kV})$
TUSD DEMANDA ( $\mathrm{R}$ / KW) PONTA Parcela não sujeita ao
desconto

18,37

22,13

30,08

49,63
Parcela sujeita ao desconto

1,42

1,71

2,31

3,80
FORA DE PONTA

Parcela não sujeita ao desconto

$\begin{array}{ll}2,62 & 0,20 \\ 4,79 & 0,37 \\ 7,42 & 0,57 \\ 8,60 & 0,66\end{array}$


TUSD GERAÇĀO

TUSD + TUST

SUBGRUPO

DEMANDA (R\$ / KW)

PONTA FORA DE PONTA

A4 ( 2,3 a $25 \mathrm{kV})$

$29,307,22$

TUSD GERAÇÃO

SUBGRUPO

TUSD + TUST

DEMANDA (R\$ / KW)

UTE FERNANDO

GASPARIAN (N.PIRAT)

3,15

UTE PIRATININGA

3,15

PCH RASGAO

1,41

UTE SÃO JOÃO BIOGÁS

0,88

NOVAS CENTRAIS

GERADORES NÃO

CONSIDERADAS NO

ANEXO IV (RES. 845/2009)

1,52

\section{TUSD GERAÇÃO}

SUBGRUPO

$$
\text { TUSD + TUST }
$$

DEMANDA (R\$ / KW)

A4 ( 2,3 a $25 \mathrm{kV})$

2,61 


\section{ANEXO B - RESULTADOS DOS CÁLCULOS DE REMANSO}

\begin{tabular}{|r|r|r|r|}
\hline \multirow{2}{*}{ Progr. } & \multicolumn{3}{|c|}{ Lâmina d'água (m) } \\
\cline { 2 - 4 } & $\mathrm{m}=0,5$ & $\mathrm{~m}=1,0$ & $\mathrm{~m}=2,0$ \\
\hline 0 & 12,00 & 12,00 & 12,00 \\
\hline 500 & 11,99 & 11,95 & 11,95 \\
\hline 1000 & 11,98 & 11,90 & 11,90 \\
\hline 1500 & 11,97 & 11,85 & 11,85 \\
\hline 2000 & 11,95 & 11,80 & 11,80 \\
\hline 2500 & 11,94 & 11,76 & 11,76 \\
\hline 3000 & 11,93 & 11,71 & 11,71 \\
\hline 3500 & 11,92 & 11,66 & 11,66 \\
\hline 4000 & 11,91 & 11,61 & 11,61 \\
\hline 4500 & 11,90 & 11,56 & 11,56 \\
\hline 5000 & 11,89 & 11,51 & 11,51 \\
\hline 5500 & 11,88 & 11,46 & 11,46 \\
\hline 6000 & 11,87 & 11,41 & 11,41 \\
\hline 6500 & 11,86 & 11,37 & 11,36 \\
\hline 7000 & 11,86 & 11,32 & 11,32 \\
\hline 7500 & 11,85 & 11,27 & 11,27 \\
\hline 8000 & 11,84 & 11,22 & 11,22 \\
\hline 8500 & 11,83 & 11,17 & 11,17 \\
\hline 9000 & 11,82 & 11,12 & 11,12 \\
\hline 9500 & 11,81 & 11,07 & 11,07 \\
\hline 10000 & 11,80 & 11,03 & 11,02 \\
\hline & & & \\
\hline
\end{tabular}

\section{Revest. $1, i=0,0001, Q=50 \mathrm{~m}^{3} / \mathrm{s}$}

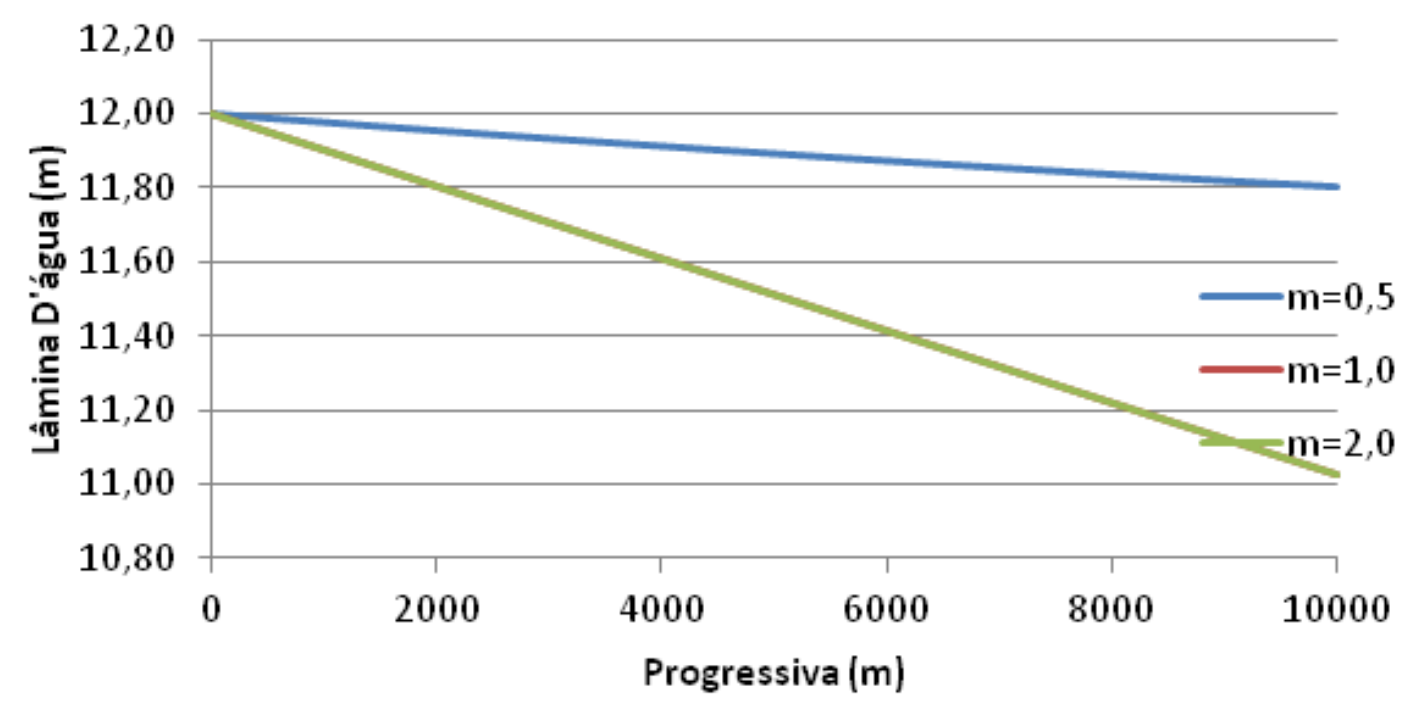




\begin{tabular}{|r|r|r|r|}
\hline \multirow{2}{*}{ Progr. } & \multicolumn{3}{|c|}{ Lâmina d'água $(\mathrm{m})$} \\
\cline { 2 - 4 } & $\mathrm{m}=0,5$ & $\mathrm{~m}=1,0$ & $\mathrm{~m}=2,0$ \\
\hline 0 & 12,00 & 12,00 & 12,00 \\
\hline 500 & 12,05 & 11,97 & 11,95 \\
\hline 1000 & 12,10 & 11,94 & 11,91 \\
\hline 1500 & 12,15 & 11,91 & 11,86 \\
\hline 2000 & 12,20 & 11,89 & 11,82 \\
\hline 2500 & 12,24 & 11,86 & 11,77 \\
\hline 3000 & 12,28 & 11,83 & 11,72 \\
\hline 3500 & 12,33 & 11,80 & 11,68 \\
\hline 4000 & 12,37 & 11,78 & 11,63 \\
\hline 4500 & 12,40 & 11,75 & 11,59 \\
\hline 5000 & 12,44 & 11,73 & 11,54 \\
\hline 5500 & 12,48 & 11,70 & 11,50 \\
\hline 6000 & 12,51 & 11,67 & 11,45 \\
\hline 6500 & 12,55 & 11,65 & 11,41 \\
\hline 7000 & 12,58 & 11,62 & 11,36 \\
\hline 7500 & 12,61 & 11,60 & 11,32 \\
\hline 8000 & 12,64 & 11,57 & 11,27 \\
\hline 8500 & 12,67 & 11,55 & 11,23 \\
\hline 9000 & 12,70 & 11,53 & 11,18 \\
\hline 9500 & 12,72 & 11,50 & 11,14 \\
\hline 10000 & 12,75 & 11,48 & 11,10 \\
\hline & & & \\
\hline
\end{tabular}

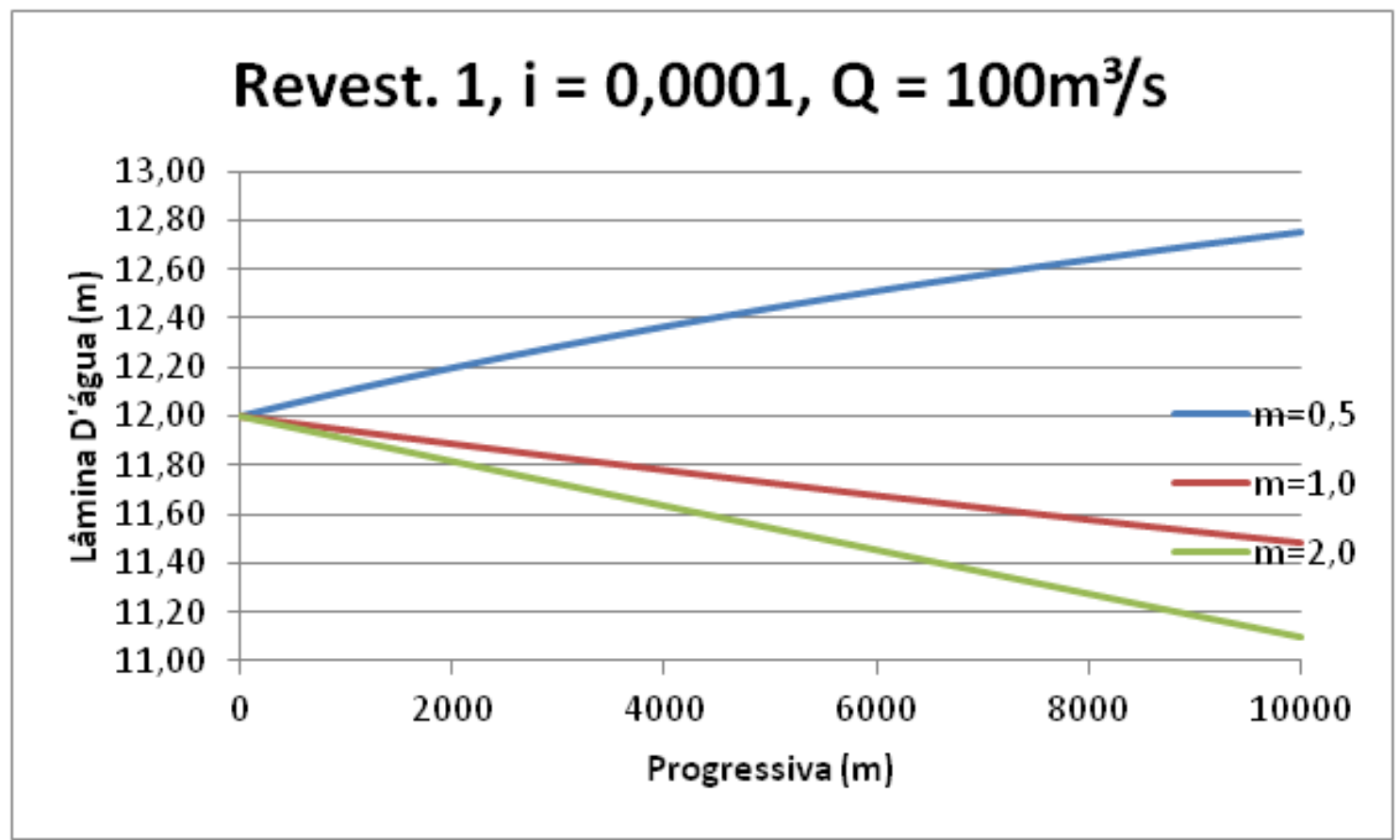




\begin{tabular}{|r|r|r|r|}
\hline \multirow{2}{*}{ Progr. } & \multicolumn{3}{|c|}{ Lâmina d'água $(\mathrm{m})$} \\
\cline { 2 - 4 } & $\mathrm{m}=0,5$ & $\mathrm{~m}=1,0$ & $\mathrm{~m}=2,0$ \\
\hline 0 & 12,00 & 12,00 & 12,00 \\
\hline 500 & 12,03 & 12,00 & 11,96 \\
\hline 1000 & 12,05 & 12,00 & 11,92 \\
\hline 1500 & 12,08 & 11,99 & 11,88 \\
\hline 2000 & 12,10 & 11,99 & 11,84 \\
\hline 2500 & 12,12 & 11,99 & 11,80 \\
\hline 3000 & 12,15 & 11,99 & 11,76 \\
\hline 3500 & 12,17 & 11,99 & 11,72 \\
\hline 4000 & 12,19 & 11,99 & 11,68 \\
\hline 4500 & 12,21 & 11,98 & 11,64 \\
\hline 5000 & 12,23 & 11,98 & 11,60 \\
\hline 5500 & 12,25 & 11,98 & 11,56 \\
\hline 6000 & 12,27 & 11,98 & 11,52 \\
\hline 6500 & 12,29 & 11,98 & 11,48 \\
\hline 7000 & 12,31 & 11,98 & 11,44 \\
\hline 7500 & 12,33 & 11,98 & 11,40 \\
\hline 8000 & 12,34 & 11,97 & 11,36 \\
\hline 8500 & 12,36 & 11,97 & 11,32 \\
\hline 9000 & 12,38 & 11,97 & 11,29 \\
\hline 9500 & 12,40 & 11,97 & 11,25 \\
\hline 10000 & 12,41 & 11,97 & 11,21 \\
\hline & & & \\
\hline
\end{tabular}

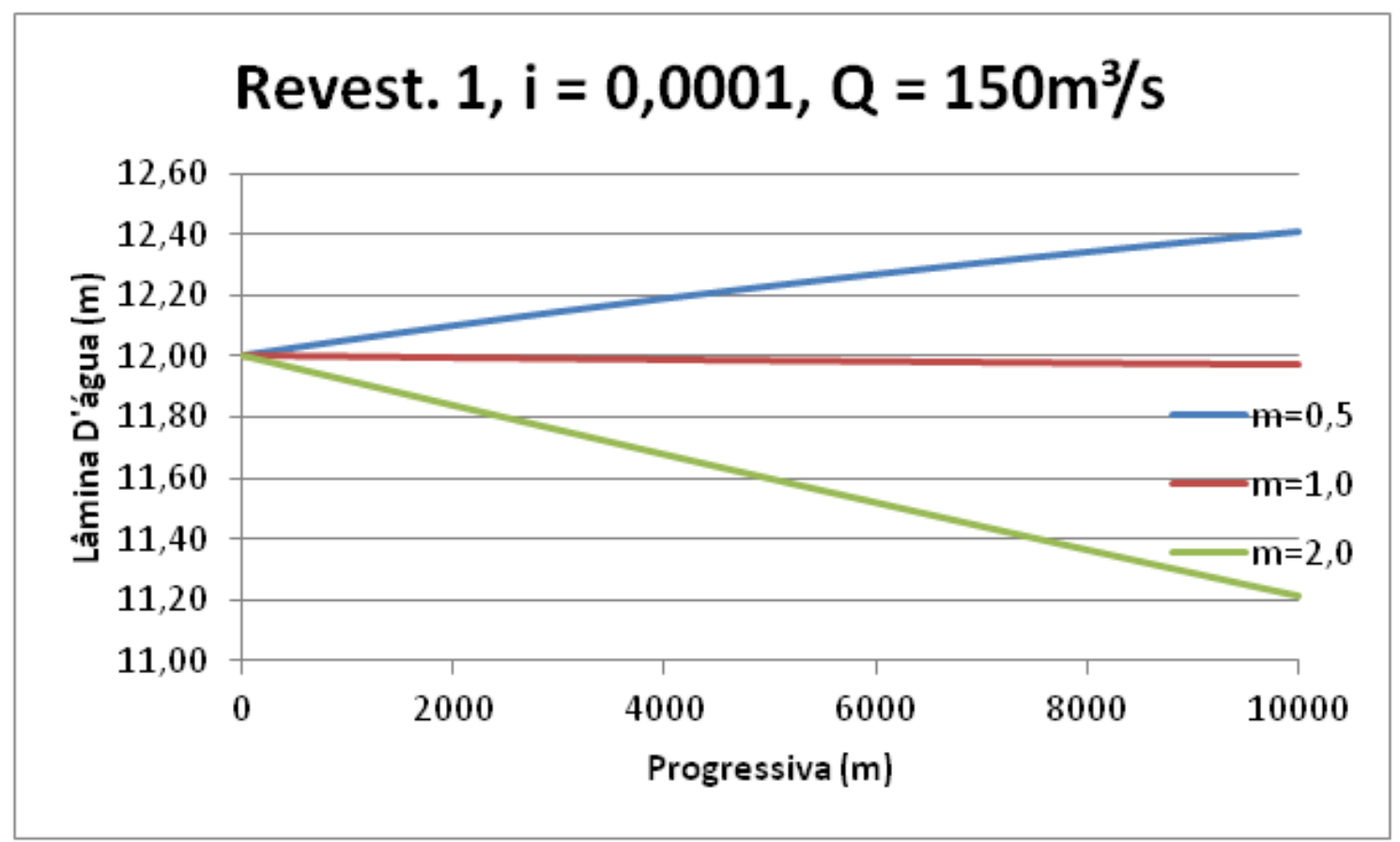




\begin{tabular}{|r|r|r|r|}
\hline \multirow{2}{*}{ Progr. } & \multicolumn{3}{|c|}{ Lâmina d'água $(\mathrm{m})$} \\
\cline { 2 - 4 } & $\mathrm{m}=0,5$ & $\mathrm{~m}=1,0$ & $\mathrm{~m}=2,0$ \\
\hline 0 & 12,00 & 12,00 & 12,00 \\
\hline 500 & 12,05 & 12,04 & 11,97 \\
\hline 1000 & 12,09 & 12,07 & 11,93 \\
\hline 1500 & 12,14 & 12,10 & 11,90 \\
\hline 2000 & 12,18 & 12,14 & 11,86 \\
\hline 2500 & 12,22 & 12,17 & 11,83 \\
\hline 3000 & 12,26 & 12,20 & 11,80 \\
\hline 3500 & 12,30 & 12,23 & 11,77 \\
\hline 4000 & 12,34 & 12,25 & 11,73 \\
\hline 4500 & 12,38 & 12,28 & 11,70 \\
\hline 5000 & 12,42 & 12,31 & 11,67 \\
\hline 5500 & 12,45 & 12,33 & 11,64 \\
\hline 6000 & 12,49 & 12,36 & 11,61 \\
\hline 6500 & 12,52 & 12,38 & 11,57 \\
\hline 7000 & 12,55 & 12,40 & 11,54 \\
\hline 7500 & 12,58 & 12,42 & 11,51 \\
\hline 8000 & 12,61 & 12,45 & 11,48 \\
\hline 8500 & 12,64 & 12,47 & 11,45 \\
\hline 9000 & 12,67 & 12,49 & 11,42 \\
\hline 9500 & 12,70 & 12,51 & 11,39 \\
\hline 10000 & 12,73 & 12,53 & 11,36 \\
\hline & & & \\
\hline
\end{tabular}

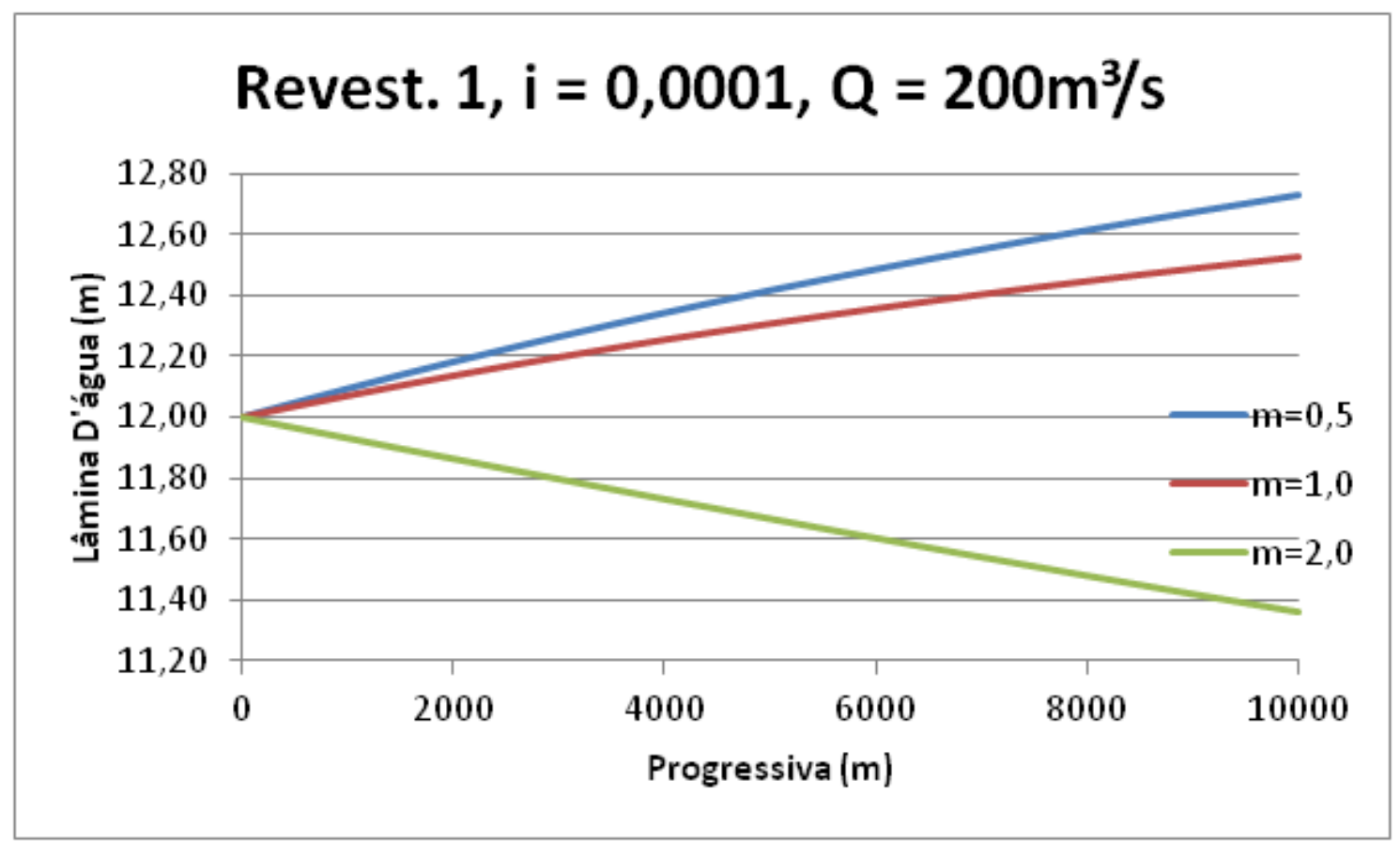




\begin{tabular}{|r|r|r|r|}
\hline \multirow{2}{*}{ Progr. } & \multicolumn{3}{|c|}{ Lâmina d'água $(\mathrm{m})$} \\
\cline { 2 - 4 } & $\mathrm{m}=0,5$ & $\mathrm{~m}=1,0$ & $\mathrm{~m}=2,0$ \\
\hline 0 & 12,00 & 12,00 & 12,00 \\
\hline 500 & 12,04 & 12,05 & 11,97 \\
\hline 1000 & 12,09 & 12,10 & 11,95 \\
\hline 1500 & 12,13 & 12,15 & 11,92 \\
\hline 2000 & 12,17 & 12,19 & 11,90 \\
\hline 2500 & 12,21 & 12,23 & 11,88 \\
\hline 3000 & 12,24 & 12,28 & 11,85 \\
\hline 3500 & 12,28 & 12,32 & 11,83 \\
\hline 4000 & 12,31 & 12,35 & 11,80 \\
\hline 4500 & 12,35 & 12,39 & 11,78 \\
\hline 5000 & 12,38 & 12,43 & 11,76 \\
\hline 5500 & 12,42 & 12,46 & 11,74 \\
\hline 6000 & 12,45 & 12,49 & 11,71 \\
\hline 6500 & 12,48 & 12,53 & 11,69 \\
\hline 7000 & 12,51 & 12,56 & 11,67 \\
\hline 7500 & 12,54 & 12,59 & 11,65 \\
\hline 8000 & 12,57 & 12,62 & 11,63 \\
\hline 8500 & 12,60 & 12,64 & 11,61 \\
\hline 9000 & 12,62 & 12,67 & 11,59 \\
\hline 9500 & 12,65 & 12,70 & 11,57 \\
\hline 10000 & 12,68 & 12,72 & 11,55 \\
\hline & & & \\
\hline
\end{tabular}

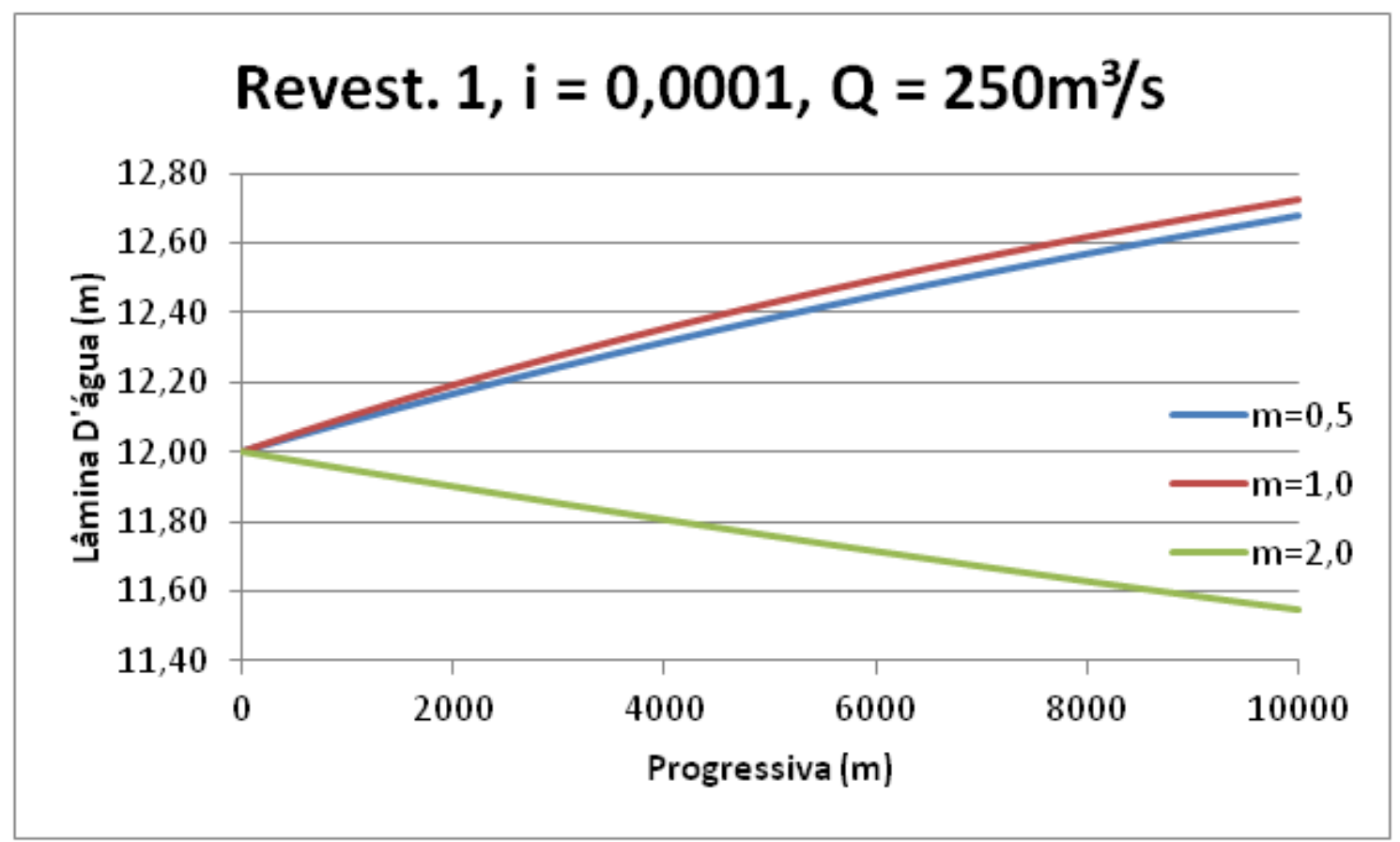




\begin{tabular}{|r|r|r|r|}
\hline \multirow{2}{*}{ Progr. } & \multicolumn{3}{|c|}{ Lâmina d'água $(\mathrm{m})$} \\
\cline { 2 - 4 } & $\mathrm{m}=0,5$ & $\mathrm{~m}=1,0$ & $\mathrm{~m}=2,0$ \\
\hline 0 & 12,00 & 12,00 & 12,00 \\
\hline 500 & 12,05 & 12,04 & 11,99 \\
\hline 1000 & 12,10 & 12,09 & 11,97 \\
\hline 1500 & 12,15 & 12,13 & 11,96 \\
\hline 2000 & 12,19 & 12,17 & 11,94 \\
\hline 2500 & 12,24 & 12,21 & 11,93 \\
\hline 3000 & 12,28 & 12,24 & 11,92 \\
\hline 3500 & 12,32 & 12,28 & 11,90 \\
\hline 4000 & 12,36 & 12,31 & 11,89 \\
\hline 4500 & 12,40 & 12,34 & 11,88 \\
\hline 5000 & 12,44 & 12,38 & 11,87 \\
\hline 5500 & 12,48 & 12,41 & 11,85 \\
\hline 6000 & 12,52 & 12,44 & 11,84 \\
\hline 6500 & 12,55 & 12,47 & 11,83 \\
\hline 7000 & 12,59 & 12,50 & 11,82 \\
\hline 7500 & 12,62 & 12,52 & 11,81 \\
\hline 8000 & 12,65 & 12,55 & 11,80 \\
\hline 8500 & 12,69 & 12,58 & 11,78 \\
\hline 9000 & 12,72 & 12,60 & 11,77 \\
\hline 9500 & 12,75 & 12,63 & 11,76 \\
\hline 10000 & 12,78 & 12,65 & 11,75 \\
\hline & & & \\
\hline
\end{tabular}

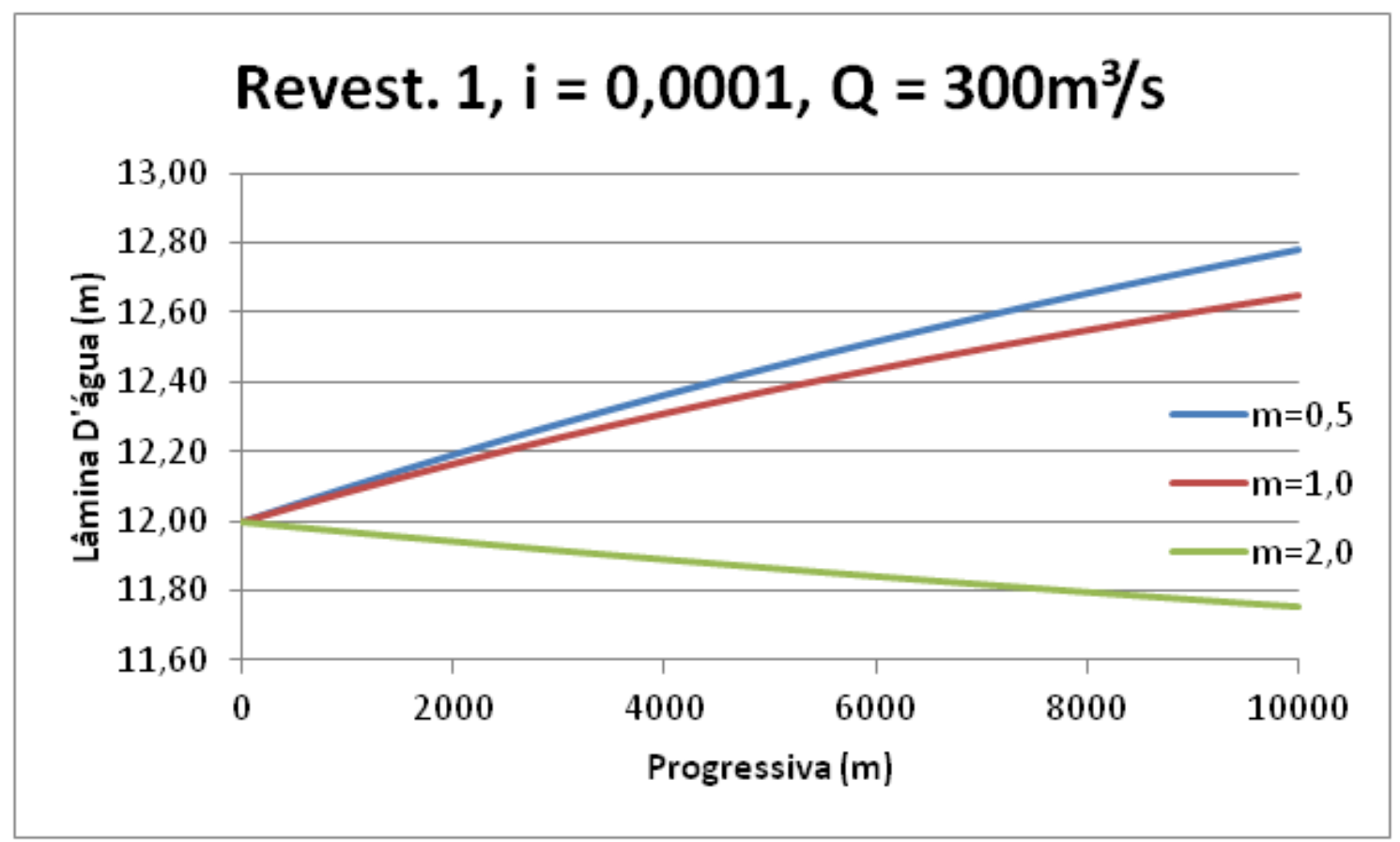




\begin{tabular}{|r|r|r|r|}
\hline \multirow{2}{*}{ Progr. } & \multicolumn{3}{|c|}{ Lâmina d'água $(\mathrm{m})$} \\
\cline { 2 - 4 } & $\mathrm{m}=0,5$ & $\mathrm{~m}=1,0$ & $\mathrm{~m}=2,0$ \\
\hline 0 & 12,00 & 12,00 & 12,00 \\
\hline 500 & 12,05 & 12,05 & 12,00 \\
\hline 1000 & 12,10 & 12,10 & 12,00 \\
\hline 1500 & 12,15 & 12,15 & 12,00 \\
\hline 2000 & 12,19 & 12,19 & 11,99 \\
\hline 2500 & 12,24 & 12,23 & 11,99 \\
\hline 3000 & 12,28 & 12,28 & 11,99 \\
\hline 3500 & 12,32 & 12,32 & 11,99 \\
\hline 4000 & 12,36 & 12,35 & 11,99 \\
\hline 4500 & 12,40 & 12,39 & 11,99 \\
\hline 5000 & 12,44 & 12,43 & 11,99 \\
\hline 5500 & 12,48 & 12,46 & 11,99 \\
\hline 6000 & 12,51 & 12,50 & 11,98 \\
\hline 6500 & 12,55 & 12,53 & 11,98 \\
\hline 7000 & 12,58 & 12,56 & 11,98 \\
\hline 7500 & 12,62 & 12,59 & 11,98 \\
\hline 8000 & 12,65 & 12,62 & 11,98 \\
\hline 8500 & 12,68 & 12,65 & 11,98 \\
\hline 9000 & 12,72 & 12,68 & 11,98 \\
\hline 9500 & 12,75 & 12,71 & 11,98 \\
\hline 10000 & 12,78 & 12,74 & 11,98 \\
\hline & & & \\
\hline
\end{tabular}

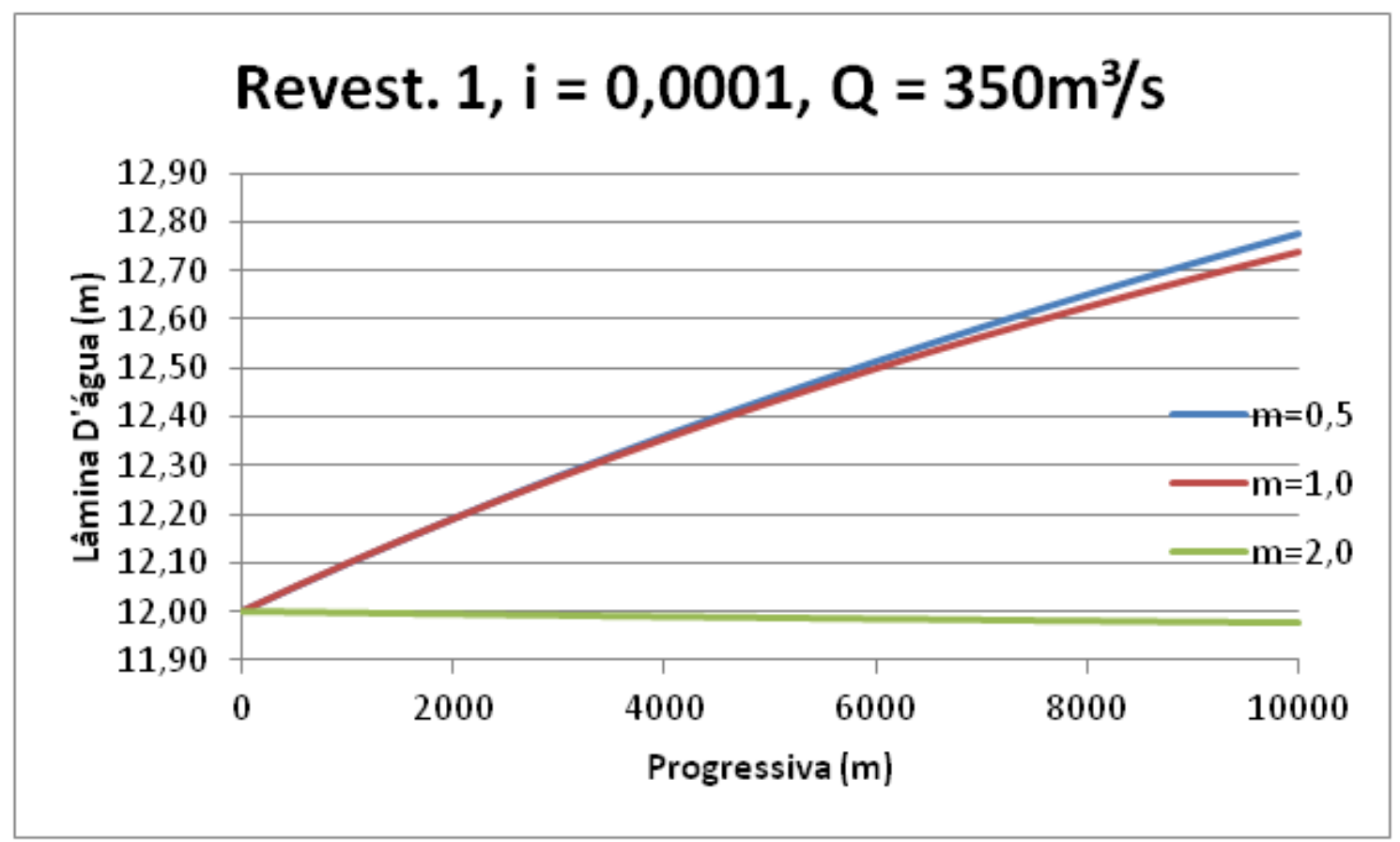




\begin{tabular}{|r|r|r|r|}
\hline \multirow{2}{*}{ Progr. } & \multicolumn{3}{|c|}{ Lâmina d'água $(\mathrm{m})$} \\
\cline { 2 - 4 } & $\mathrm{m}=0,5$ & $\mathrm{~m}=1,0$ & $\mathrm{~m}=2,0$ \\
\hline 0 & 12,00 & 12,00 & 12,00 \\
\hline 500 & 11,94 & 11,90 & 11,90 \\
\hline 1000 & 11,88 & 11,80 & 11,80 \\
\hline 1500 & 11,82 & 11,70 & 11,70 \\
\hline 2000 & 11,76 & 11,61 & 11,60 \\
\hline 2500 & 11,70 & 11,51 & 11,50 \\
\hline 3000 & 11,65 & 11,41 & 11,41 \\
\hline 3500 & 11,59 & 11,31 & 11,31 \\
\hline 4000 & 11,54 & 11,21 & 11,21 \\
\hline 4500 & 11,49 & 11,11 & 11,11 \\
\hline 5000 & 11,43 & 11,01 & 11,01 \\
\hline 5500 & 11,38 & 10,92 & 10,91 \\
\hline 6000 & 11,33 & 10,82 & 10,81 \\
\hline 6500 & 11,29 & 10,72 & 10,72 \\
\hline 7000 & 11,24 & 10,62 & 10,62 \\
\hline 7500 & 11,19 & 10,52 & 10,52 \\
\hline 8000 & 11,15 & 10,43 & 10,42 \\
\hline 8500 & 11,11 & 10,33 & 10,32 \\
\hline 9000 & 11,06 & 10,23 & 10,22 \\
\hline 9500 & 11,02 & 10,13 & 10,13 \\
\hline 10000 & 10,98 & 10,03 & 10,03 \\
\hline & & & \\
\hline
\end{tabular}

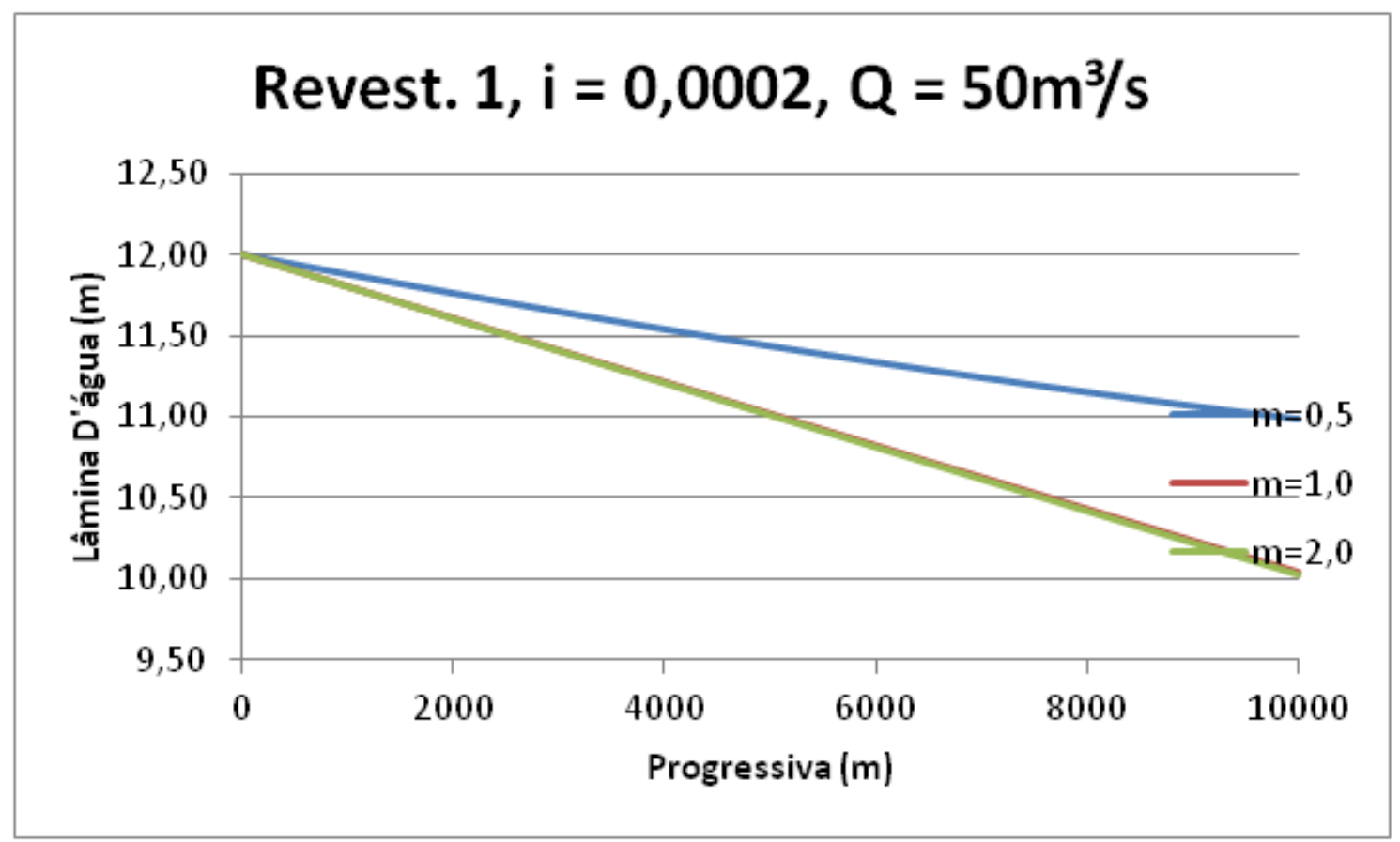




\begin{tabular}{|r|r|r|r|}
\hline \multirow{2}{*}{ Progr. } & \multicolumn{3}{|c|}{ Lâmina d'água $(\mathrm{m})$} \\
\cline { 2 - 4 } & $\mathrm{m}=0,5$ & $\mathrm{~m}=1,0$ & $\mathrm{~m}=2,0$ \\
\hline 0 & 12,00 & 12,00 & 12,00 \\
\hline 500 & 11,98 & 11,90 & 11,90 \\
\hline 1000 & 11,95 & 11,81 & 11,81 \\
\hline 1500 & 11,93 & 11,71 & 11,71 \\
\hline 2000 & 11,91 & 11,62 & 11,62 \\
\hline 2500 & 11,89 & 11,53 & 11,52 \\
\hline 3000 & 11,87 & 11,43 & 11,42 \\
\hline 3500 & 11,85 & 11,34 & 11,33 \\
\hline 4000 & 11,83 & 11,24 & 11,23 \\
\hline 4500 & 11,81 & 11,15 & 11,14 \\
\hline 5000 & 11,79 & 11,06 & 11,04 \\
\hline 5500 & 11,78 & 10,96 & 10,95 \\
\hline 6000 & 11,76 & 10,87 & 10,86 \\
\hline 6500 & 11,74 & 10,78 & 10,76 \\
\hline 7000 & 11,73 & 10,69 & 10,67 \\
\hline 7500 & 11,71 & 10,59 & 10,58 \\
\hline 8000 & 11,70 & 10,50 & 10,48 \\
\hline 8500 & 11,68 & 10,41 & 10,39 \\
\hline 9000 & 11,67 & 10,32 & 10,30 \\
\hline 9500 & 11,66 & 10,23 & 10,21 \\
\hline 10000 & 11,64 & 10,14 & 10,11 \\
\hline & & & \\
\hline
\end{tabular}

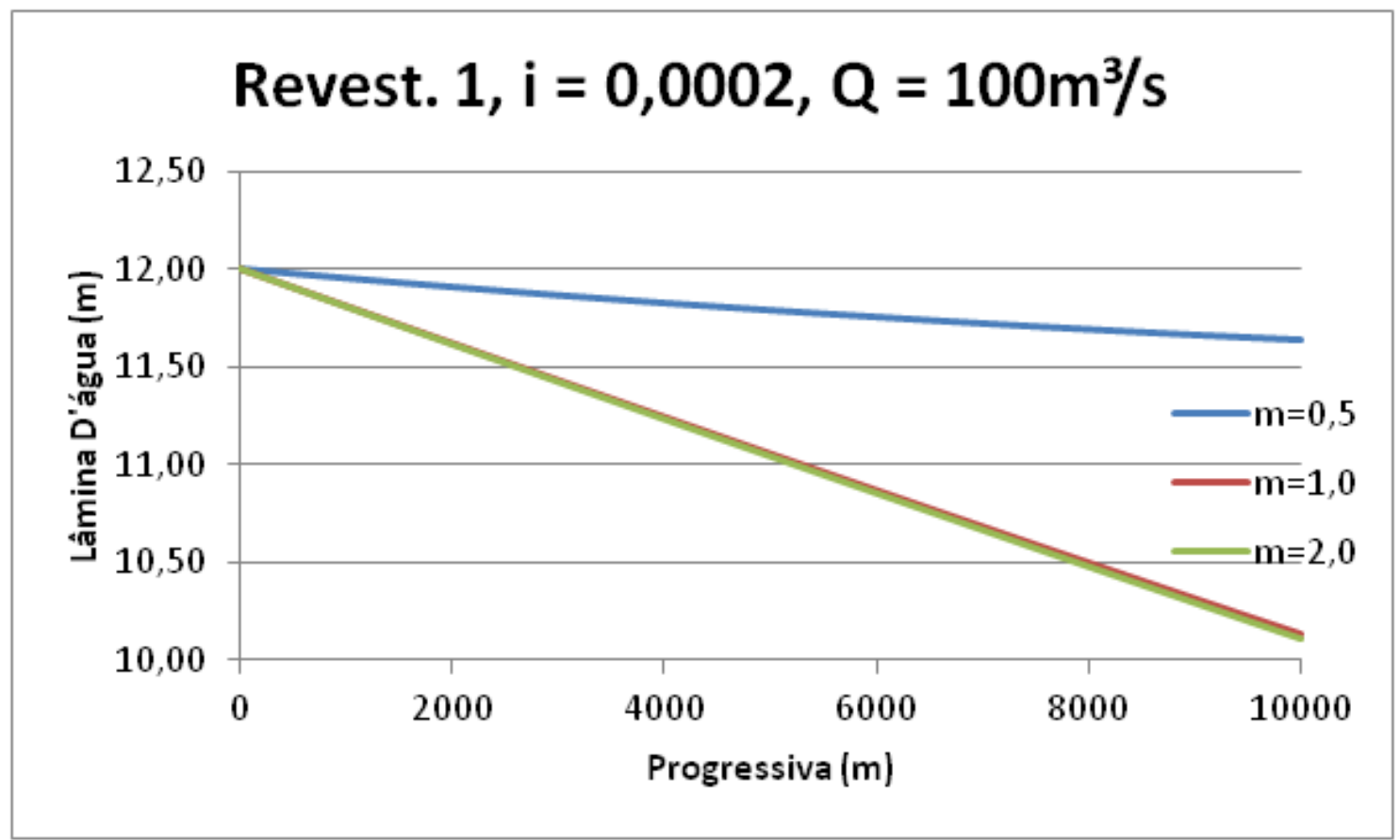




\begin{tabular}{|r|r|r|r|}
\hline \multirow{2}{*}{ Progr. } & \multicolumn{3}{|c|}{ Lâmina d'água $(\mathrm{m})$} \\
\cline { 2 - 4 } & $\mathrm{m}=0,5$ & $\mathrm{~m}=1,0$ & $\mathrm{~m}=2,0$ \\
\hline 0 & 12,00 & 12,00 & 12,00 \\
\hline 500 & 11,97 & 11,91 & 11,91 \\
\hline 1000 & 11,94 & 11,82 & 11,82 \\
\hline 1500 & 11,91 & 11,73 & 11,73 \\
\hline 2000 & 11,89 & 11,65 & 11,63 \\
\hline 2500 & 11,86 & 11,56 & 11,54 \\
\hline 3000 & 11,83 & 11,47 & 11,45 \\
\hline 3500 & 11,81 & 11,38 & 11,36 \\
\hline 4000 & 11,78 & 11,30 & 11,28 \\
\hline 4500 & 11,76 & 11,21 & 11,19 \\
\hline 5000 & 11,74 & 11,13 & 11,10 \\
\hline 5500 & 11,71 & 11,04 & 11,01 \\
\hline 6000 & 11,69 & 10,96 & 10,92 \\
\hline 6500 & 11,67 & 10,87 & 10,84 \\
\hline 7000 & 11,65 & 10,79 & 10,75 \\
\hline 7500 & 11,63 & 10,71 & 10,67 \\
\hline 8000 & 11,61 & 10,62 & 10,58 \\
\hline 8500 & 11,59 & 10,54 & 10,50 \\
\hline 9000 & 11,57 & 10,46 & 10,41 \\
\hline 9500 & 11,55 & 10,38 & 10,33 \\
\hline 10000 & 11,53 & 10,30 & 10,25 \\
\hline & & & \\
\hline
\end{tabular}

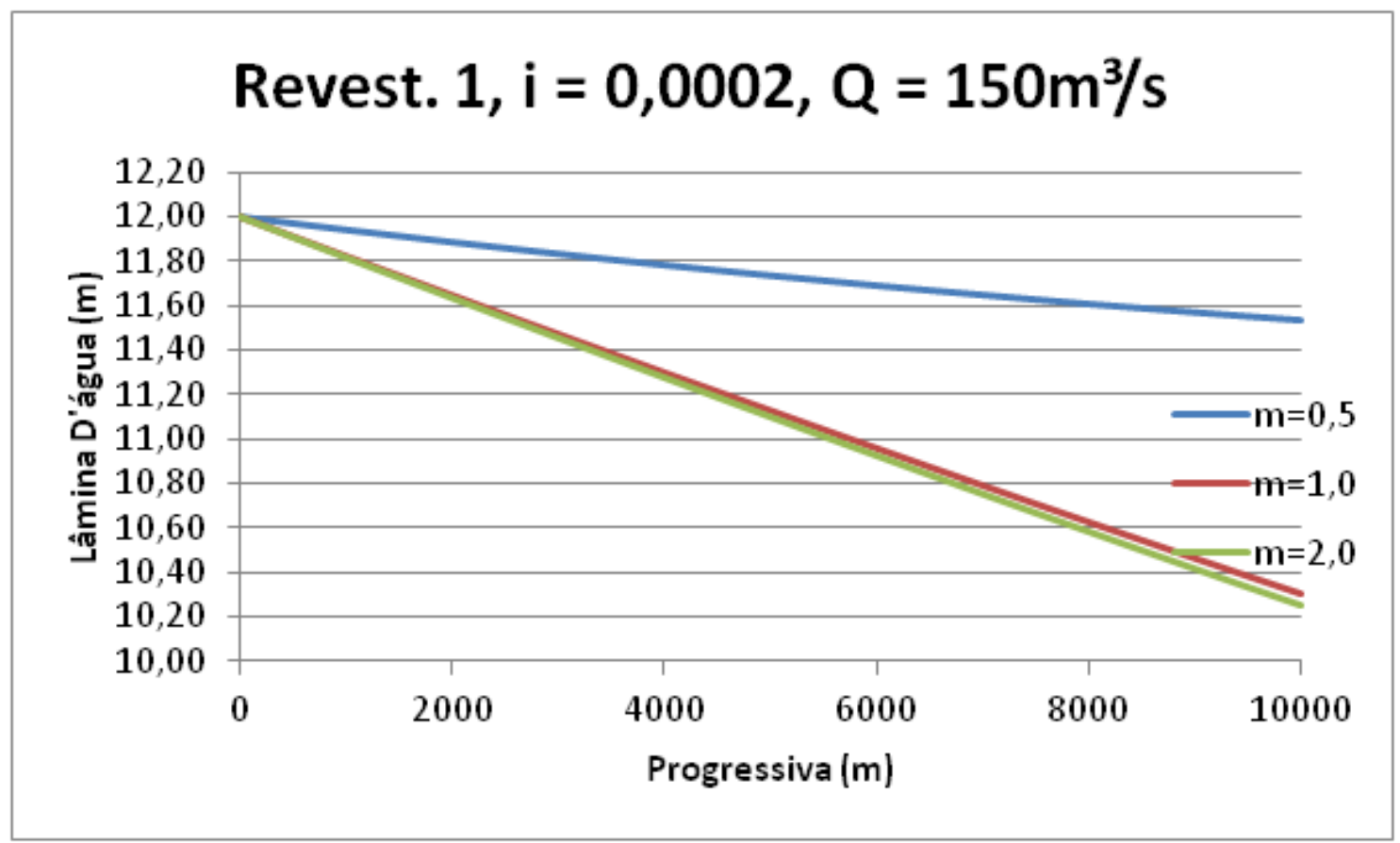




\begin{tabular}{|r|r|r|r|}
\hline \multirow{2}{*}{ Progr. } & \multicolumn{3}{|c|}{ Lâmina d'água $(\mathrm{m})$} \\
\cline { 2 - 4 } & $\mathrm{m}=0,5$ & $\mathrm{~m}=1,0$ & $\mathrm{~m}=2,0$ \\
\hline 0 & 12,00 & 12,00 & 12,00 \\
\hline 500 & 12,00 & 11,99 & 11,91 \\
\hline 1000 & 12,00 & 11,97 & 11,83 \\
\hline 1500 & 12,00 & 11,96 & 11,75 \\
\hline 2000 & 12,00 & 11,95 & 11,66 \\
\hline 2500 & 12,00 & 11,93 & 11,58 \\
\hline 3000 & 12,00 & 11,92 & 11,50 \\
\hline 3500 & 12,00 & 11,91 & 11,41 \\
\hline 4000 & 11,99 & 11,90 & 11,33 \\
\hline 4500 & 11,99 & 11,89 & 11,25 \\
\hline 5000 & 11,99 & 11,88 & 11,17 \\
\hline 5500 & 11,99 & 11,87 & 11,09 \\
\hline 6000 & 11,99 & 11,86 & 11,02 \\
\hline 6500 & 11,99 & 11,85 & 10,94 \\
\hline 7000 & 11,99 & 11,84 & 10,86 \\
\hline 7500 & 11,99 & 11,83 & 10,79 \\
\hline 8000 & 11,99 & 11,83 & 10,71 \\
\hline 8500 & 11,99 & 11,82 & 10,64 \\
\hline 9000 & 11,99 & 11,81 & 10,57 \\
\hline 9500 & 11,99 & 11,80 & 10,50 \\
\hline 10000 & 11,99 & 11,80 & 10,42 \\
\hline & & & \\
\hline
\end{tabular}

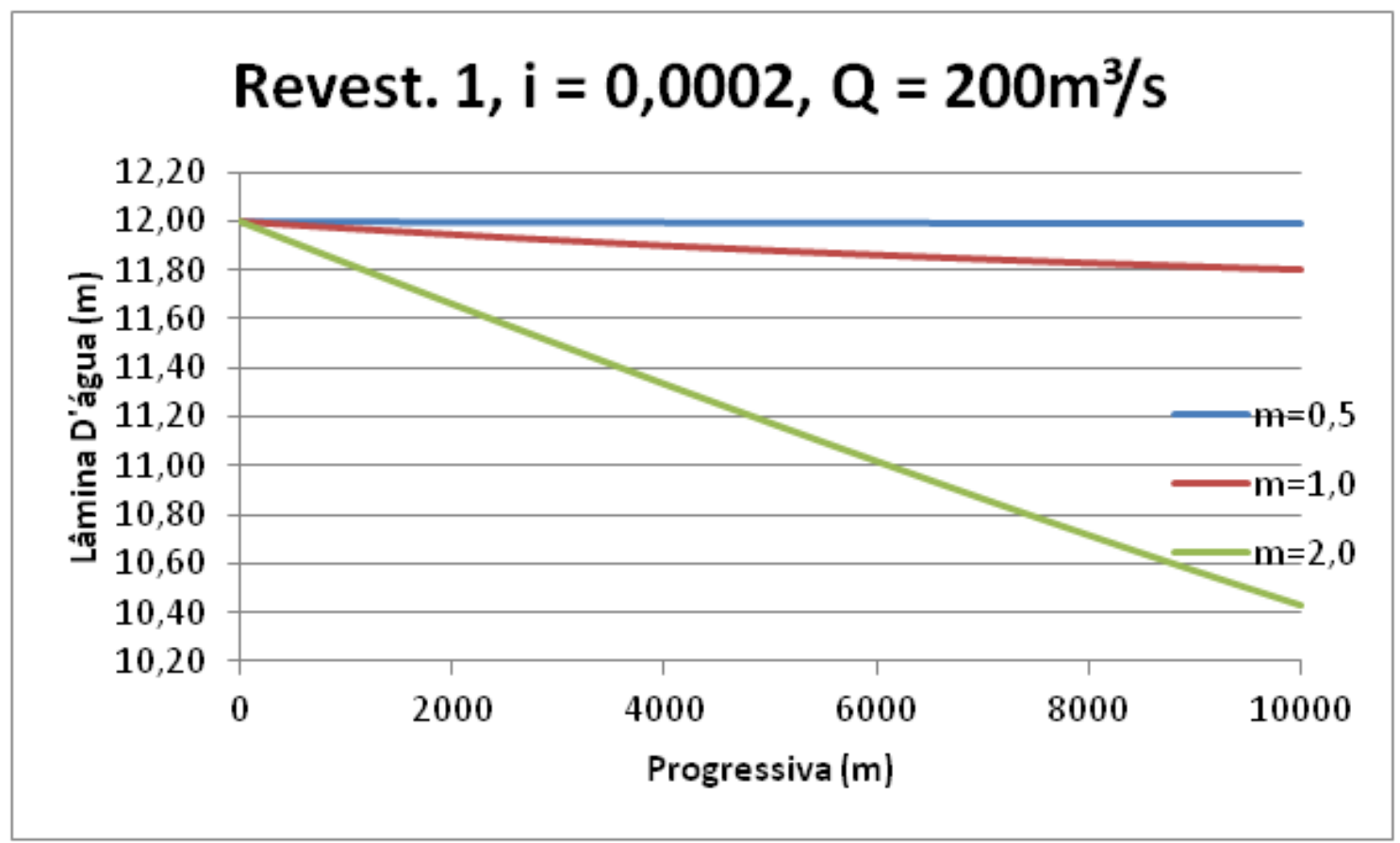




\begin{tabular}{|r|r|r|r|}
\hline \multirow{2}{*}{ Progr. } & \multicolumn{3}{|c|}{ Lâmina d'água $(\mathrm{m})$} \\
\cline { 2 - 4 } & $\mathrm{m}=0,5$ & $\mathrm{~m}=1,0$ & $\mathrm{~m}=2,0$ \\
\hline 0 & 12,00 & 12,00 & 12,00 \\
\hline 500 & 12,00 & 11,99 & 11,92 \\
\hline 1000 & 11,99 & 11,99 & 11,85 \\
\hline 1500 & 11,99 & 11,98 & 11,77 \\
\hline 2000 & 11,98 & 11,98 & 11,70 \\
\hline 2500 & 11,98 & 11,97 & 11,62 \\
\hline 3000 & 11,97 & 11,97 & 11,55 \\
\hline 3500 & 11,97 & 11,96 & 11,48 \\
\hline 4000 & 11,96 & 11,96 & 11,41 \\
\hline 4500 & 11,96 & 11,95 & 11,34 \\
\hline 5000 & 11,96 & 11,95 & 11,27 \\
\hline 5500 & 11,95 & 11,95 & 11,20 \\
\hline 6000 & 11,95 & 11,94 & 11,13 \\
\hline 6500 & 11,95 & 11,94 & 11,06 \\
\hline 7000 & 11,94 & 11,93 & 11,00 \\
\hline 7500 & 11,94 & 11,93 & 10,94 \\
\hline 8000 & 11,94 & 11,93 & 10,87 \\
\hline 8500 & 11,93 & 11,93 & 10,81 \\
\hline 9000 & 11,93 & 11,92 & 10,75 \\
\hline 9500 & 11,93 & 11,92 & 10,69 \\
\hline 10000 & 11,92 & 11,92 & 10,63 \\
\hline & & & \\
\hline
\end{tabular}

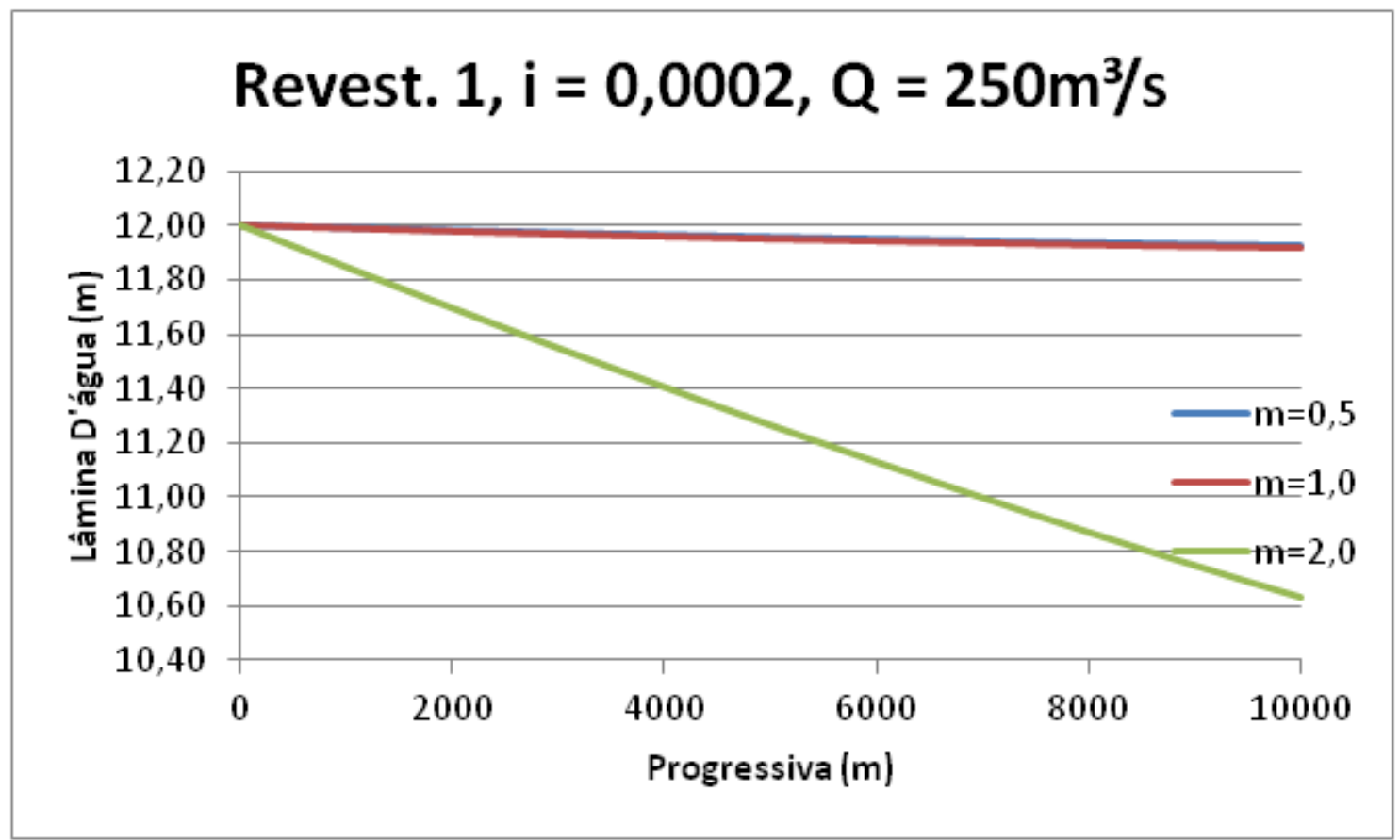




\begin{tabular}{|r|r|r|r|}
\hline \multirow{2}{*}{ Progr. } & \multicolumn{3}{|c|}{ Lâmina d'água $(\mathrm{m})$} \\
\cline { 2 - 4 } & $\mathrm{m}=0,5$ & $\mathrm{~m}=1,0$ & $\mathrm{~m}=2,0$ \\
\hline 0 & 12,00 & 12,00 & 12,00 \\
\hline 500 & 12,00 & 11,98 & 11,93 \\
\hline 1000 & 12,00 & 11,96 & 11,87 \\
\hline 1500 & 12,00 & 11,95 & 11,80 \\
\hline 2000 & 12,00 & 11,93 & 11,74 \\
\hline 2500 & 12,00 & 11,91 & 11,67 \\
\hline 3000 & 12,00 & 11,90 & 11,61 \\
\hline 3500 & 12,00 & 11,88 & 11,55 \\
\hline 4000 & 12,00 & 11,87 & 11,49 \\
\hline 4500 & 12,00 & 11,85 & 11,43 \\
\hline 5000 & 12,00 & 11,84 & 11,38 \\
\hline 5500 & 12,00 & 11,83 & 11,32 \\
\hline 6000 & 12,00 & 11,81 & 11,26 \\
\hline 6500 & 12,00 & 11,80 & 11,21 \\
\hline 7000 & 12,00 & 11,79 & 11,16 \\
\hline 7500 & 12,00 & 11,78 & 11,11 \\
\hline 8000 & 12,00 & 11,77 & 11,05 \\
\hline 8500 & 12,00 & 11,75 & 11,01 \\
\hline 9000 & 12,00 & 11,74 & 10,96 \\
\hline 9500 & 12,00 & 11,73 & 10,91 \\
\hline 10000 & 12,00 & 11,72 & 10,87 \\
\hline & & & \\
\hline
\end{tabular}

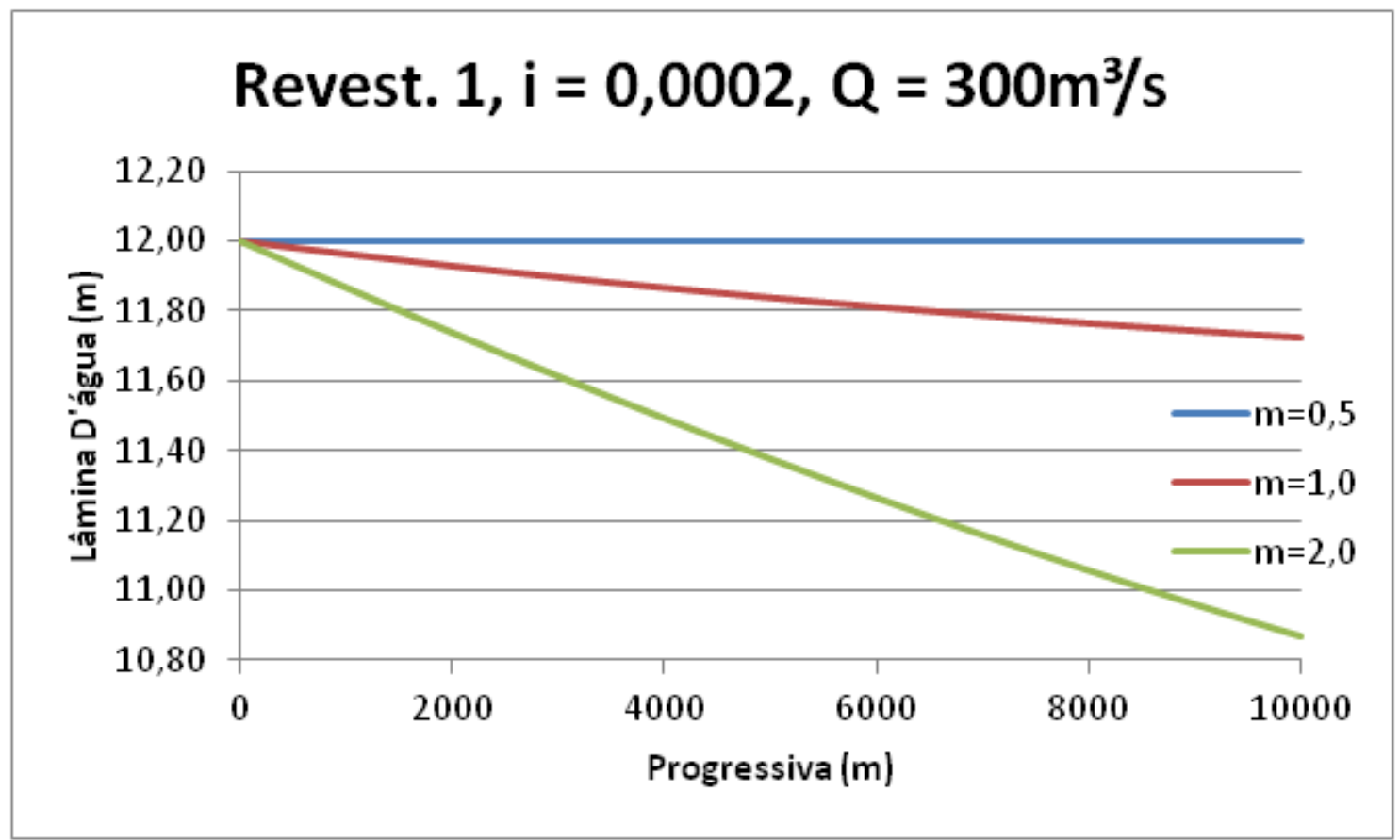




\begin{tabular}{|r|r|r|r|}
\hline \multirow{2}{*}{ Progr. } & \multicolumn{3}{|c|}{ Lâmina d'água $(\mathrm{m})$} \\
\cline { 2 - 4 } & $\mathrm{m}=0,5$ & $\mathrm{~m}=1,0$ & $\mathrm{~m}=2,0$ \\
\hline 0 & 12,00 & 12,00 & 12,00 \\
\hline 500 & 12,00 & 12,00 & 11,94 \\
\hline 1000 & 12,00 & 12,00 & 11,89 \\
\hline 1500 & 12,00 & 12,00 & 11,84 \\
\hline 2000 & 12,00 & 12,00 & 11,79 \\
\hline 2500 & 12,00 & 12,00 & 11,74 \\
\hline 3000 & 12,00 & 12,00 & 11,69 \\
\hline 3500 & 12,00 & 12,00 & 11,64 \\
\hline 4000 & 12,00 & 12,00 & 11,59 \\
\hline 4500 & 12,00 & 12,00 & 11,54 \\
\hline 5000 & 12,00 & 12,00 & 11,50 \\
\hline 5500 & 12,00 & 12,00 & 11,46 \\
\hline 6000 & 11,99 & 12,00 & 11,41 \\
\hline 6500 & 11,99 & 12,00 & 11,37 \\
\hline 7000 & 11,99 & 12,00 & 11,33 \\
\hline 7500 & 11,99 & 12,00 & 11,29 \\
\hline 8000 & 11,99 & 12,00 & 11,25 \\
\hline 8500 & 11,99 & 12,00 & 11,22 \\
\hline 9000 & 11,99 & 12,00 & 11,18 \\
\hline 9500 & 11,99 & 12,00 & 11,15 \\
\hline 10000 & 11,99 & 12,00 & 11,11 \\
\hline & & & \\
\hline
\end{tabular}

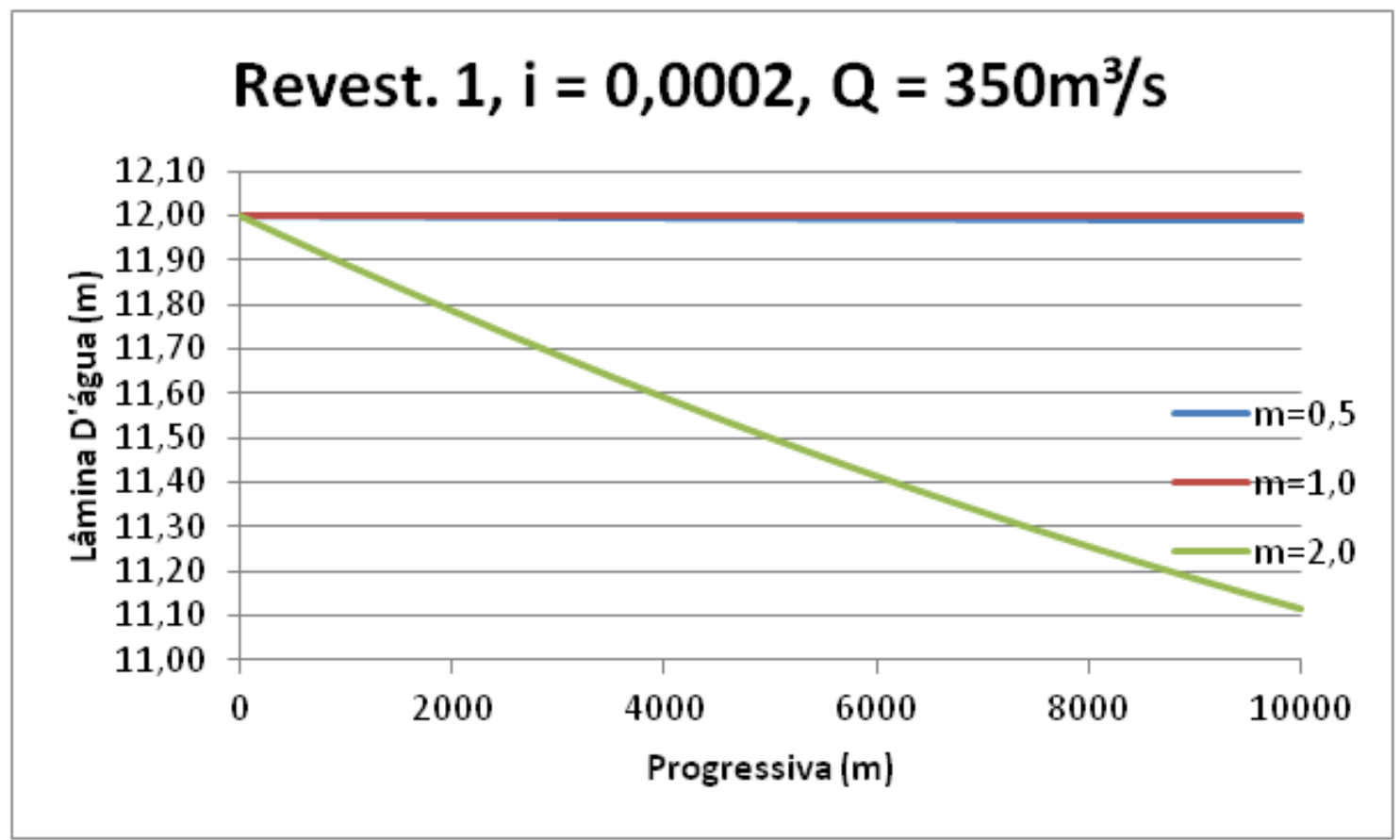




\begin{tabular}{|r|r|r|r|}
\hline \multirow{2}{*}{ Progr. } & \multicolumn{3}{|c|}{ Lâmina d'água $(\mathrm{m})$} \\
\cline { 2 - 4 } & $\mathrm{m}=0,5$ & $\mathrm{~m}=1,0$ & $\mathrm{~m}=2,0$ \\
\hline 0 & 12,00 & 12,00 & 12,00 \\
\hline 500 & 11,79 & 11,76 & 11,75 \\
\hline 1000 & 11,58 & 11,51 & 11,50 \\
\hline 1500 & 11,38 & 11,27 & 11,25 \\
\hline 2000 & 11,18 & 11,02 & 11,00 \\
\hline 2500 & 10,98 & 10,78 & 10,75 \\
\hline 3000 & 10,79 & 10,54 & 10,50 \\
\hline 3500 & 10,61 & 10,30 & 10,26 \\
\hline 4000 & 10,43 & 10,06 & 10,01 \\
\hline 4500 & 10,26 & 9,83 & 9,76 \\
\hline 5000 & 10,10 & 9,59 & 9,51 \\
\hline 5500 & 9,95 & 9,36 & 9,26 \\
\hline 6000 & 9,80 & 9,13 & 9,01 \\
\hline 6500 & 9,66 & 8,90 & 8,77 \\
\hline 7000 & 9,53 & 8,68 & 8,52 \\
\hline 7500 & 9,41 & 8,46 & 8,27 \\
\hline 8000 & 9,30 & 8,24 & 8,02 \\
\hline 8500 & 9,20 & 8,03 & 7,78 \\
\hline 9000 & 9,10 & 7,83 & 7,53 \\
\hline 9500 & 9,02 & 7,63 & 7,29 \\
\hline 10000 & 8,94 & 7,44 & 7,05 \\
\hline & & & \\
\hline
\end{tabular}

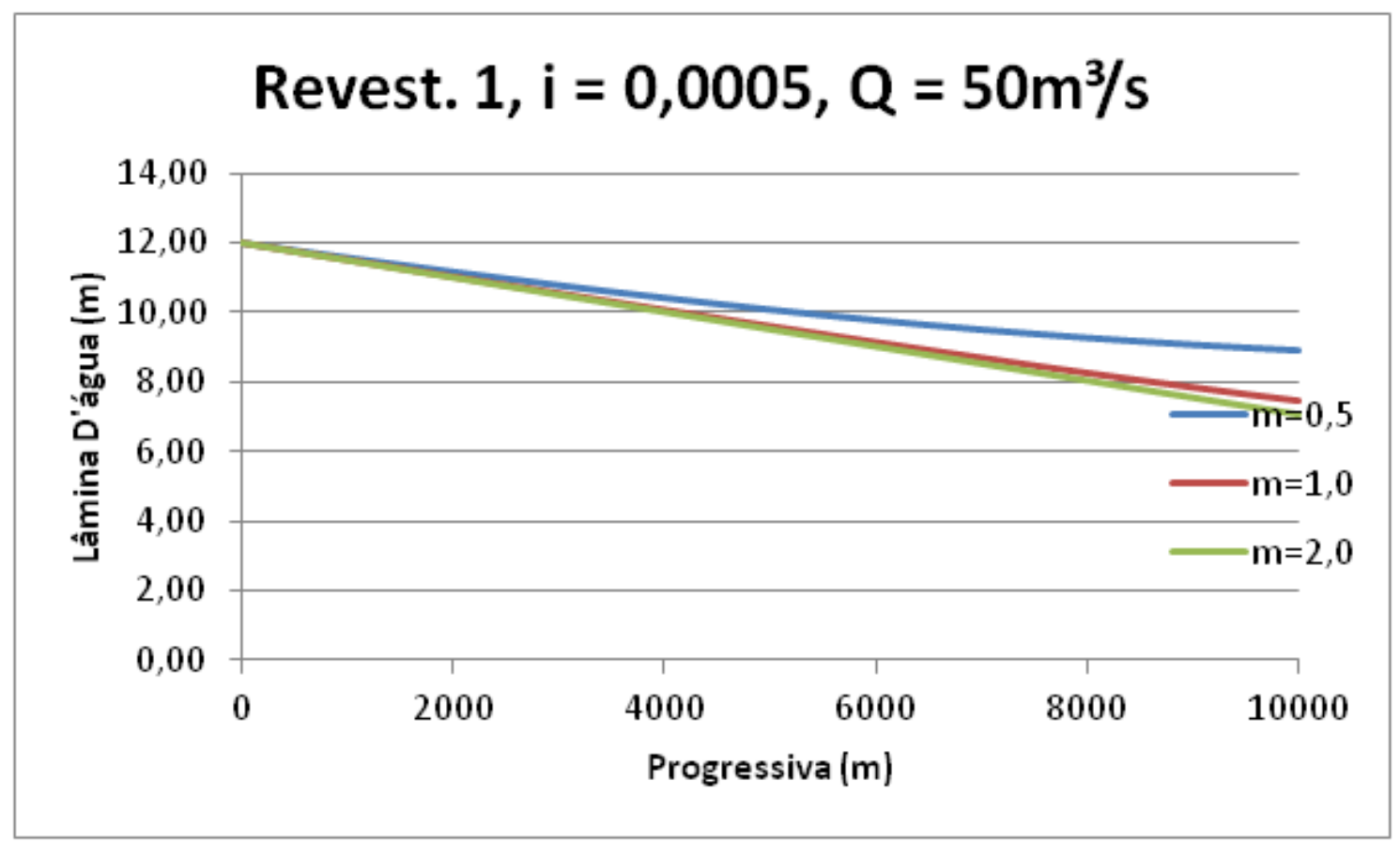




\begin{tabular}{|r|r|r|r|}
\hline \multirow{2}{*}{ Progr. } & \multicolumn{3}{|c|}{ Lâmina d'água $(\mathrm{m})$} \\
\cline { 2 - 4 } & $\mathrm{m}=0,5$ & $\mathrm{~m}=1,0$ & $\mathrm{~m}=2,0$ \\
\hline 0 & 12,00 & 12,00 & 12,00 \\
\hline 500 & 11,79 & 11,77 & 11,75 \\
\hline 1000 & 11,59 & 11,54 & 11,51 \\
\hline 1500 & 11,39 & 11,32 & 11,26 \\
\hline 2000 & 11,19 & 11,10 & 11,02 \\
\hline 2500 & 11,00 & 10,88 & 10,77 \\
\hline 3000 & 10,81 & 10,66 & 10,53 \\
\hline 3500 & 10,63 & 10,45 & 10,29 \\
\hline 4000 & 10,45 & 10,25 & 10,05 \\
\hline 4500 & 10,28 & 10,05 & 9,81 \\
\hline 5000 & 10,11 & 9,85 & 9,57 \\
\hline 5500 & 9,95 & 9,66 & 9,33 \\
\hline 6000 & 9,79 & 9,48 & 9,09 \\
\hline 6500 & 9,64 & 9,30 & 8,86 \\
\hline 7000 & 9,50 & 9,13 & 8,63 \\
\hline 7500 & 9,37 & 8,97 & 8,40 \\
\hline 8000 & 9,24 & 8,82 & 8,18 \\
\hline 8500 & 9,12 & 8,68 & 7,96 \\
\hline 9000 & 9,00 & 8,55 & 7,74 \\
\hline 9500 & 8,90 & 8,43 & 7,53 \\
\hline 10000 & 8,80 & 8,32 & 7,33 \\
\hline & & & \\
\hline
\end{tabular}

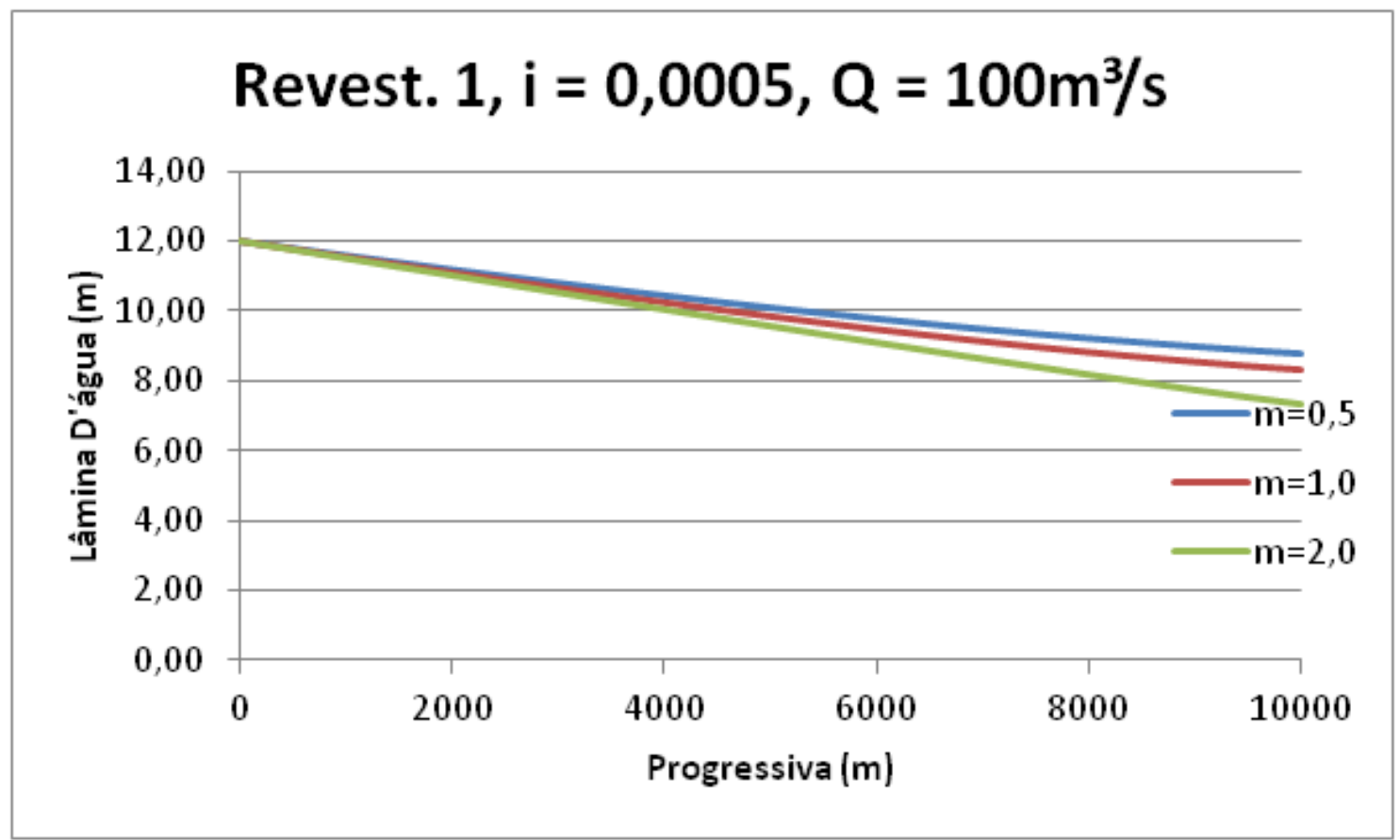




\begin{tabular}{|r|r|r|r|}
\hline \multirow{2}{*}{ Progr. } & \multicolumn{3}{|c|}{ Lâmina d'água $(\mathrm{m})$} \\
\cline { 2 - 4 } & $\mathrm{m}=0,5$ & $\mathrm{~m}=1,0$ & $\mathrm{~m}=2,0$ \\
\hline 0 & 12,00 & 12,00 & 12,00 \\
\hline 500 & 11,85 & 11,80 & 11,76 \\
\hline 1000 & 11,70 & 11,60 & 11,52 \\
\hline 1500 & 11,55 & 11,40 & 11,28 \\
\hline 2000 & 11,42 & 11,22 & 11,04 \\
\hline 2500 & 11,29 & 11,03 & 10,80 \\
\hline 3000 & 11,16 & 10,86 & 10,57 \\
\hline 3500 & 11,04 & 10,69 & 10,33 \\
\hline 4000 & 10,93 & 10,52 & 10,10 \\
\hline 4500 & 10,82 & 10,37 & 9,87 \\
\hline 5000 & 10,72 & 10,22 & 9,65 \\
\hline 5500 & 10,63 & 10,08 & 9,42 \\
\hline 6000 & 10,54 & 9,95 & 9,21 \\
\hline 6500 & 10,46 & 9,83 & 8,99 \\
\hline 7000 & 10,38 & 9,72 & 8,78 \\
\hline 7500 & 10,31 & 9,62 & 8,58 \\
\hline 8000 & 10,25 & 9,52 & 8,38 \\
\hline 8500 & 10,19 & 9,43 & 8,19 \\
\hline 9000 & 10,13 & 9,36 & 8,00 \\
\hline 9500 & 10,08 & 9,29 & 7,83 \\
\hline 10000 & 10,03 & 9,22 & 7,66 \\
\hline & & & \\
\hline
\end{tabular}

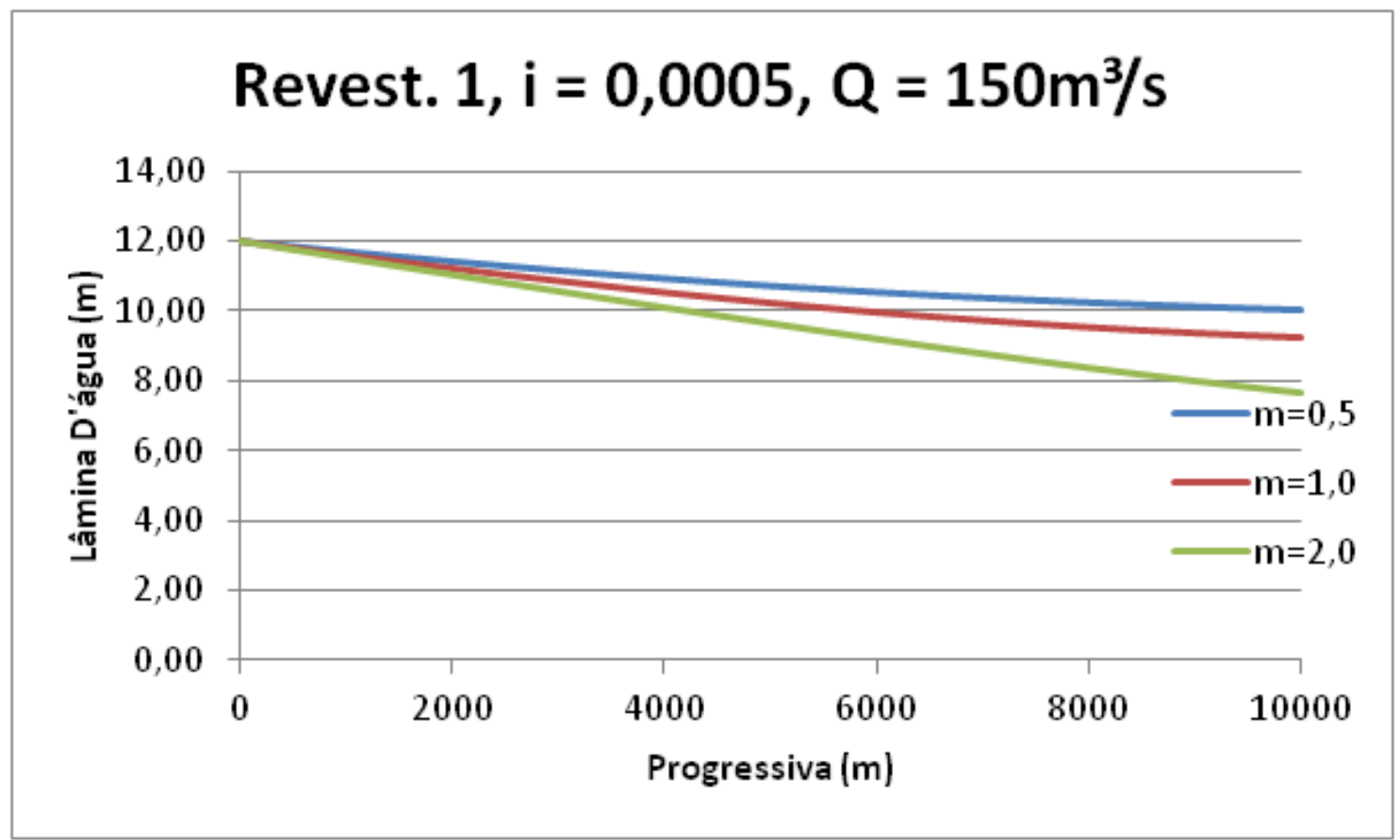




\begin{tabular}{|r|r|r|r|}
\hline \multirow{2}{*}{ Progr. } & \multicolumn{3}{|c|}{ Lâmina d'água $(\mathrm{m})$} \\
\cline { 2 - 4 } & $\mathrm{m}=0,5$ & $\mathrm{~m}=1,0$ & $\mathrm{~m}=2,0$ \\
\hline 0 & 12,00 & 12,00 & 12,00 \\
\hline 500 & 11,80 & 11,83 & 11,76 \\
\hline 1000 & 11,59 & 11,67 & 11,53 \\
\hline 1500 & 11,40 & 11,52 & 11,30 \\
\hline 2000 & 11,20 & 11,37 & 11,07 \\
\hline 2500 & 11,01 & 11,24 & 10,84 \\
\hline 3000 & 10,82 & 11,11 & 10,62 \\
\hline 3500 & 10,64 & 10,98 & 10,40 \\
\hline 4000 & 10,46 & 10,87 & 10,18 \\
\hline 4500 & 10,29 & 10,76 & 9,97 \\
\hline 5000 & 10,12 & 10,66 & 9,76 \\
\hline 5500 & 9,96 & 10,57 & 9,55 \\
\hline 6000 & 9,80 & 10,49 & 9,35 \\
\hline 6500 & 9,65 & 10,41 & 9,16 \\
\hline 7000 & 9,50 & 10,34 & 8,97 \\
\hline 7500 & 9,36 & 10,28 & 8,80 \\
\hline 8000 & 9,22 & 10,22 & 8,63 \\
\hline 8500 & 9,09 & 10,17 & 8,47 \\
\hline 9000 & 8,97 & 10,13 & 8,32 \\
\hline 9500 & 8,85 & 10,09 & 8,18 \\
\hline 10000 & 8,74 & 10,05 & 8,05 \\
\hline & & & \\
\hline
\end{tabular}

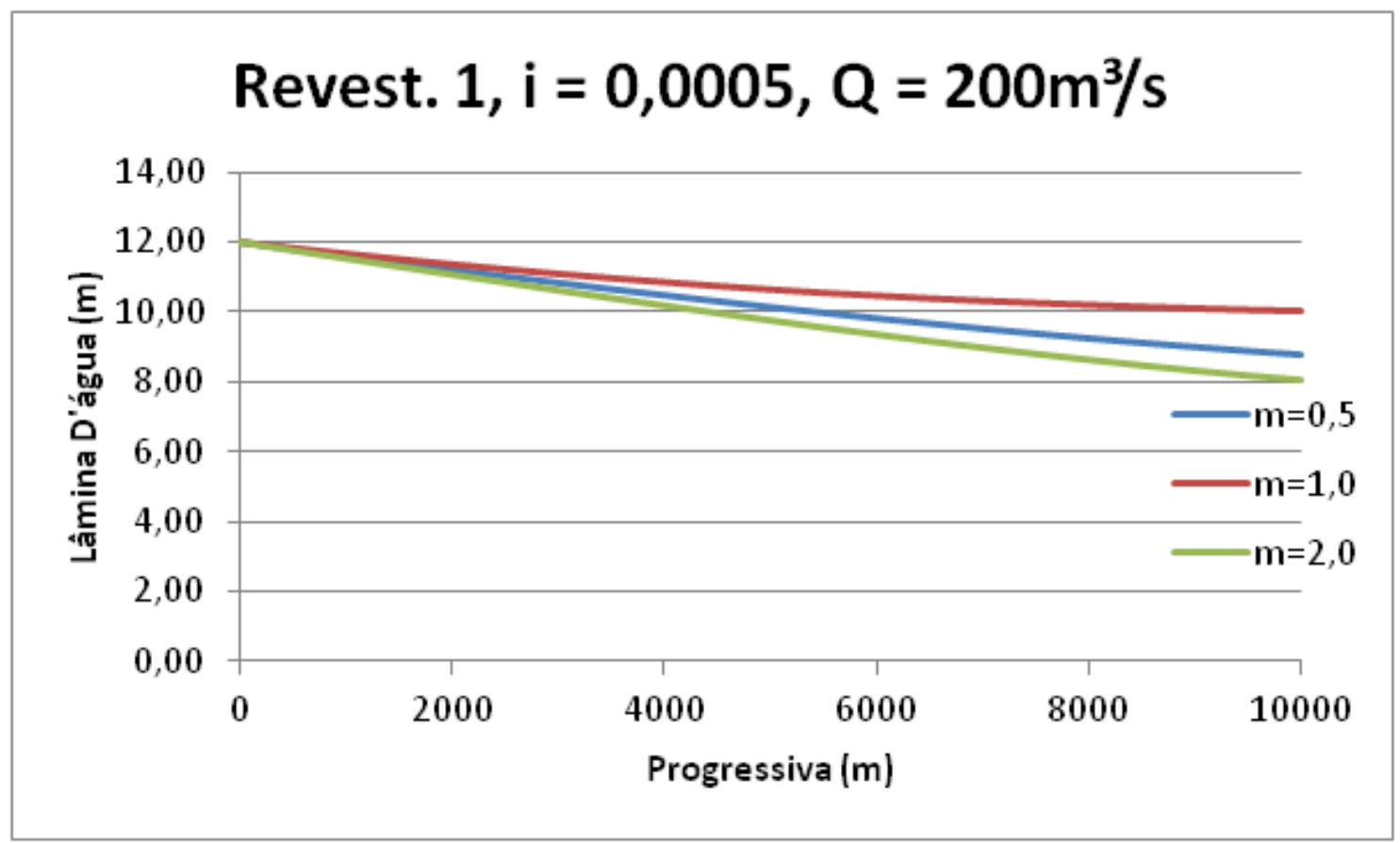




\begin{tabular}{|r|r|r|r|}
\hline \multirow{2}{*}{ Progr. } & \multicolumn{3}{|c|}{ Lâmina d'água $(\mathrm{m})$} \\
\cline { 2 - 4 } & $\mathrm{m}=0,5$ & $\mathrm{~m}=1,0$ & $\mathrm{~m}=2,0$ \\
\hline 0 & 12,00 & 12,00 & 12,00 \\
\hline 500 & 11,81 & 11,79 & 11,77 \\
\hline 1000 & 11,62 & 11,58 & 11,55 \\
\hline 1500 & 11,43 & 11,38 & 11,33 \\
\hline 2000 & 11,25 & 11,18 & 11,11 \\
\hline 2500 & 11,07 & 10,98 & 10,89 \\
\hline 3000 & 10,90 & 10,79 & 10,68 \\
\hline 3500 & 10,73 & 10,60 & 10,48 \\
\hline 4000 & 10,57 & 10,42 & 10,28 \\
\hline 4500 & 10,41 & 10,24 & 10,08 \\
\hline 5000 & 10,25 & 10,07 & 9,89 \\
\hline 5500 & 10,11 & 9,90 & 9,71 \\
\hline 6000 & 9,96 & 9,74 & 9,53 \\
\hline 6500 & 9,83 & 9,59 & 9,36 \\
\hline 7000 & 9,69 & 9,44 & 9,20 \\
\hline 7500 & 9,57 & 9,31 & 9,05 \\
\hline 8000 & 9,45 & 9,17 & 8,91 \\
\hline 8500 & 9,33 & 9,05 & 8,78 \\
\hline 9000 & 9,23 & 8,94 & 8,65 \\
\hline 9500 & 9,13 & 8,83 & 8,54 \\
\hline 10000 & 9,03 & 8,73 & 8,44 \\
\hline & & & \\
\hline
\end{tabular}

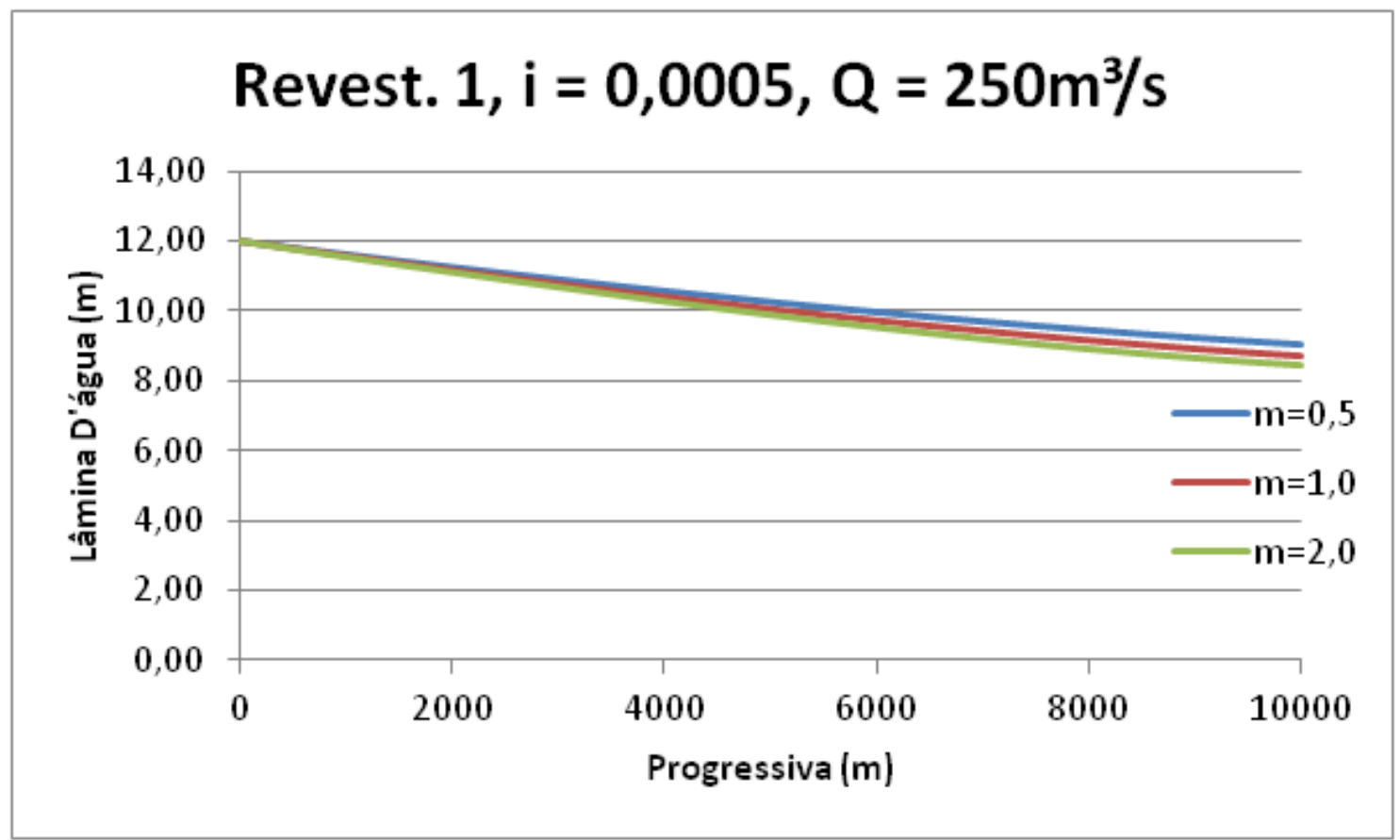




\begin{tabular}{|r|r|r|r|}
\hline \multirow{2}{*}{ Progr. } & \multicolumn{3}{|c|}{ Lâmina d'água $(\mathrm{m})$} \\
\cline { 2 - 4 } & $\mathrm{m}=0,5$ & $\mathrm{~m}=1,0$ & $\mathrm{~m}=2,0$ \\
\hline 0 & 12,00 & 12,00 & 12,00 \\
\hline 500 & 11,81 & 11,81 & 11,78 \\
\hline 1000 & 11,62 & 11,62 & 11,57 \\
\hline 1500 & 11,44 & 11,43 & 11,36 \\
\hline 2000 & 11,26 & 11,25 & 11,16 \\
\hline 2500 & 11,08 & 11,08 & 10,96 \\
\hline 3000 & 10,91 & 10,91 & 10,76 \\
\hline 3500 & 10,74 & 10,74 & 10,57 \\
\hline 4000 & 10,58 & 10,58 & 10,39 \\
\hline 4500 & 10,43 & 10,43 & 10,21 \\
\hline 5000 & 10,27 & 10,29 & 10,04 \\
\hline 5500 & 10,13 & 10,15 & 9,88 \\
\hline 6000 & 9,98 & 10,02 & 9,73 \\
\hline 6500 & 9,85 & 9,89 & 9,58 \\
\hline 7000 & 9,72 & 9,77 & 9,45 \\
\hline 7500 & 9,59 & 9,66 & 9,32 \\
\hline 8000 & 9,48 & 9,56 & 9,21 \\
\hline 8500 & 9,36 & 9,46 & 9,10 \\
\hline 9000 & 9,26 & 9,37 & 9,00 \\
\hline 9500 & 9,16 & 9,29 & 8,91 \\
\hline 10000 & 9,06 & 9,22 & 8,84 \\
\hline & & & \\
\hline
\end{tabular}

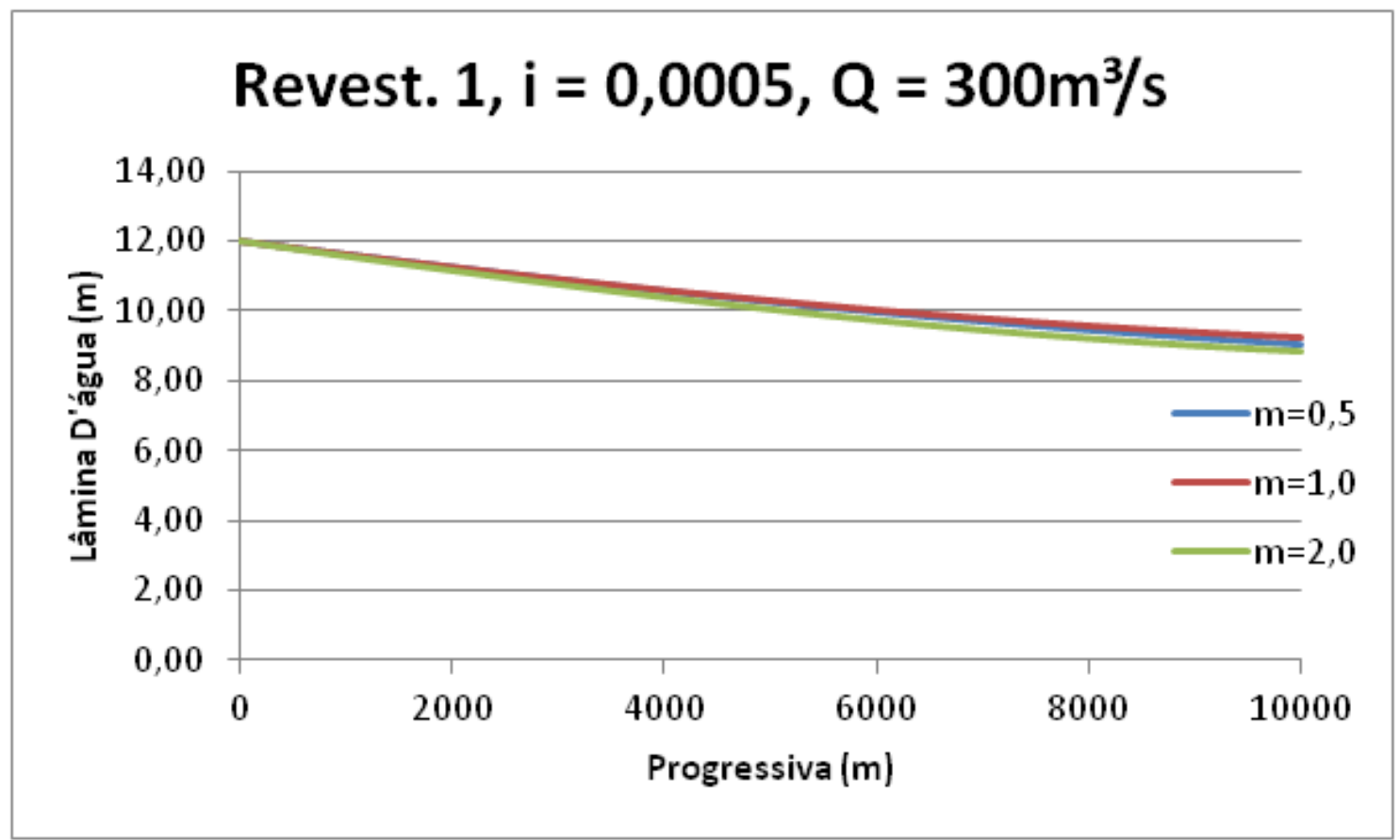




\begin{tabular}{|r|r|r|r|}
\hline \multirow{2}{*}{ Progr. } & \multicolumn{3}{|c|}{ Lâmina d'água $(\mathrm{m})$} \\
\cline { 2 - 4 } & $\mathrm{m}=0,5$ & $\mathrm{~m}=1,0$ & $\mathrm{~m}=2,0$ \\
\hline 0 & 12,00 & 12,00 & 12,00 \\
\hline 500 & 11,83 & 11,83 & 11,79 \\
\hline 1000 & 11,67 & 11,66 & 11,59 \\
\hline 1500 & 11,51 & 11,50 & 11,39 \\
\hline 2000 & 11,35 & 11,34 & 11,20 \\
\hline 2500 & 11,20 & 11,19 & 11,01 \\
\hline 3000 & 11,05 & 11,04 & 10,83 \\
\hline 3500 & 10,91 & 10,90 & 10,66 \\
\hline 4000 & 10,78 & 10,77 & 10,49 \\
\hline 4500 & 10,64 & 10,65 & 10,33 \\
\hline 5000 & 10,52 & 10,53 & 10,18 \\
\hline 5500 & 10,40 & 10,42 & 10,04 \\
\hline 6000 & 10,28 & 10,31 & 9,90 \\
\hline 6500 & 10,18 & 10,21 & 9,78 \\
\hline 7000 & 10,07 & 10,12 & 9,66 \\
\hline 7500 & 9,97 & 10,03 & 9,55 \\
\hline 8000 & 9,88 & 9,96 & 9,45 \\
\hline 8500 & 9,79 & 9,88 & 9,36 \\
\hline 9000 & 9,71 & 9,82 & 9,28 \\
\hline 9500 & 9,63 & 9,75 & 9,21 \\
\hline 10000 & 9,56 & 9,70 & 9,14 \\
\hline & & & \\
\hline
\end{tabular}

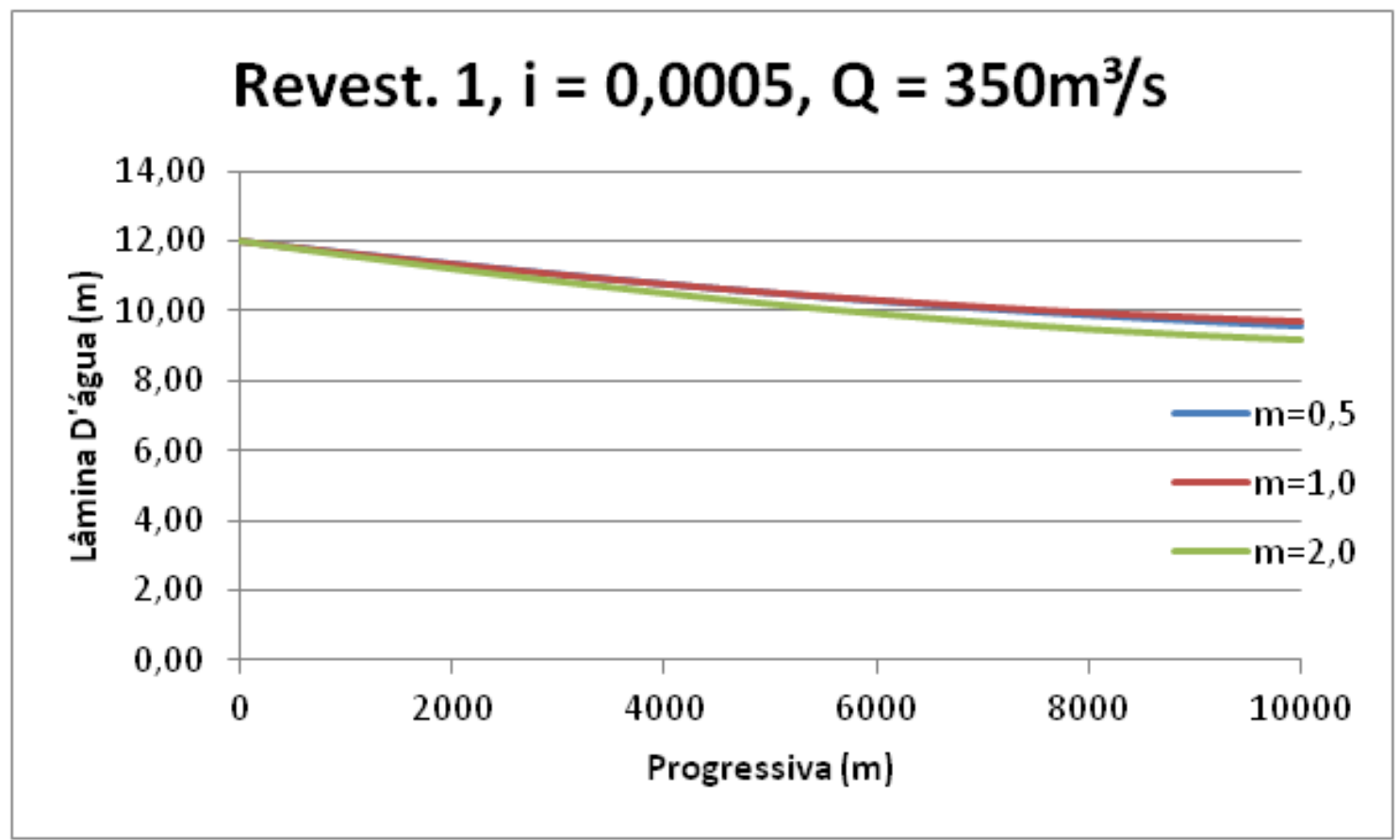




\begin{tabular}{|r|r|r|r|}
\hline \multirow{2}{*}{ Progr. } & \multicolumn{3}{|c|}{ Lâmina d'água $(\mathrm{m})$} \\
\cline { 2 - 4 } & $\mathrm{m}=0,5$ & $\mathrm{~m}=1,0$ & $\mathrm{~m}=2,0$ \\
\hline 0 & 12,00 & 12,00 & 12,00 \\
\hline 500 & 11,99 & 11,96 & 11,95 \\
\hline 1000 & 11,98 & 11,91 & 11,90 \\
\hline 1500 & 11,97 & 11,87 & 11,85 \\
\hline 2000 & 11,95 & 11,82 & 11,80 \\
\hline 2500 & 11,94 & 11,78 & 11,76 \\
\hline 3000 & 11,93 & 11,73 & 11,71 \\
\hline 3500 & 11,92 & 11,69 & 11,66 \\
\hline 4000 & 11,91 & 11,65 & 11,61 \\
\hline 4500 & 11,90 & 11,60 & 11,56 \\
\hline 5000 & 11,89 & 11,56 & 11,51 \\
\hline 5500 & 11,88 & 11,51 & 11,46 \\
\hline 6000 & 11,87 & 11,47 & 11,41 \\
\hline 6500 & 11,86 & 11,43 & 11,36 \\
\hline 7000 & 11,86 & 11,39 & 11,32 \\
\hline 7500 & 11,85 & 11,34 & 11,27 \\
\hline 8000 & 11,84 & 11,30 & 11,22 \\
\hline 8500 & 11,83 & 11,26 & 11,17 \\
\hline 9000 & 11,82 & 11,21 & 11,12 \\
\hline 9500 & 11,81 & 11,17 & 11,07 \\
\hline 10000 & 11,80 & 11,13 & 11,02 \\
\hline & & & \\
\hline
\end{tabular}

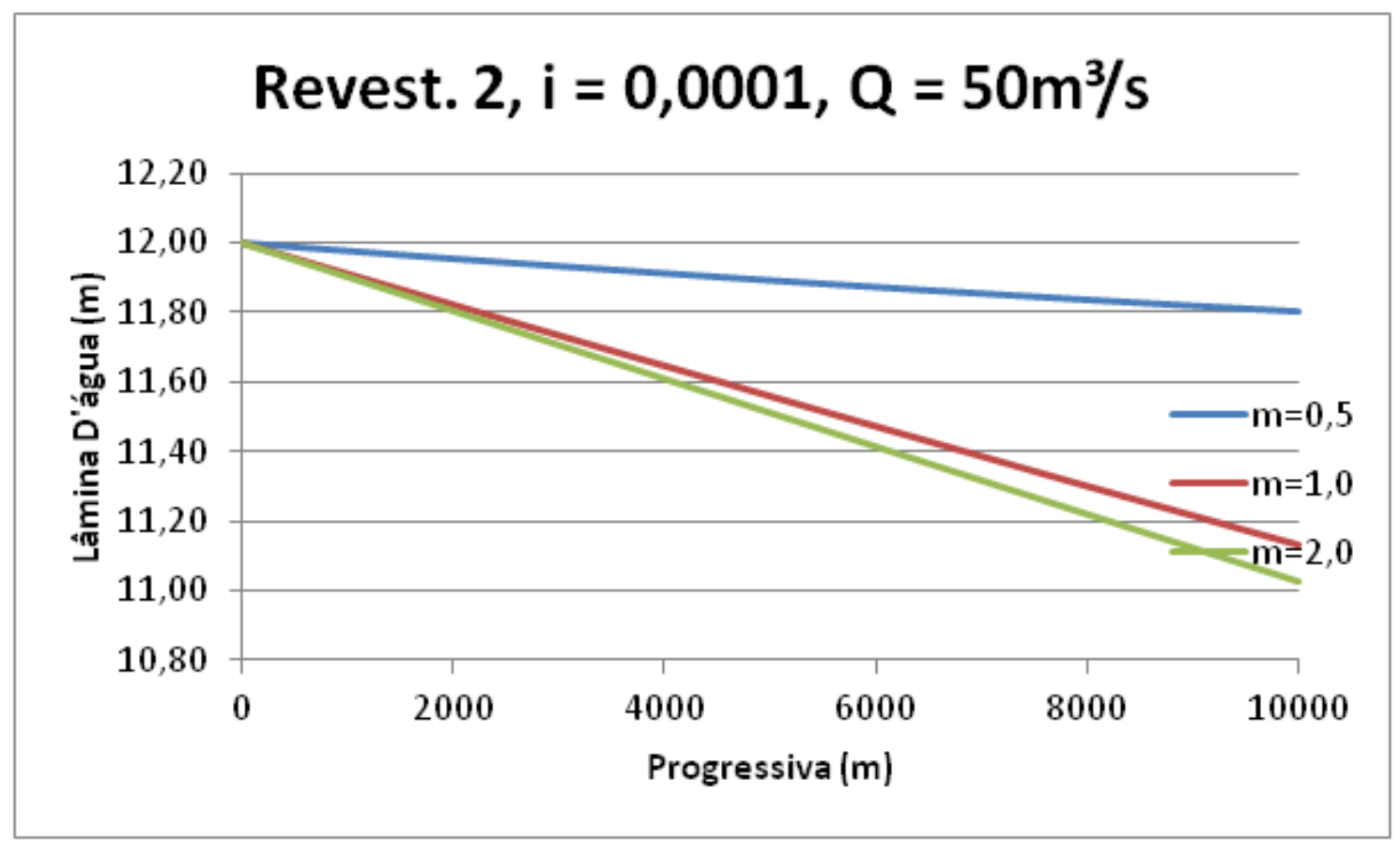




\begin{tabular}{|r|r|r|r|}
\hline \multirow{2}{*}{ Progr. } & \multicolumn{3}{|c|}{ Lâmina d'água $(\mathrm{m})$} \\
\cline { 2 - 4 } & $\mathrm{m}=0,5$ & $\mathrm{~m}=1,0$ & $\mathrm{~m}=2,0$ \\
\hline 0 & 12,00 & 12,00 & 12,00 \\
\hline 500 & 12,05 & 11,97 & 11,95 \\
\hline 1000 & 12,10 & 11,94 & 11,91 \\
\hline 1500 & 12,15 & 11,91 & 11,86 \\
\hline 2000 & 12,19 & 11,89 & 11,82 \\
\hline 2500 & 12,24 & 11,86 & 11,77 \\
\hline 3000 & 12,28 & 11,83 & 11,72 \\
\hline 3500 & 12,32 & 11,81 & 11,68 \\
\hline 4000 & 12,36 & 11,78 & 11,63 \\
\hline 4500 & 12,40 & 11,75 & 11,59 \\
\hline 5000 & 12,44 & 11,73 & 11,54 \\
\hline 5500 & 12,47 & 11,70 & 11,50 \\
\hline 6000 & 12,50 & 11,67 & 11,45 \\
\hline 6500 & 12,54 & 11,65 & 11,41 \\
\hline 7000 & 12,57 & 11,62 & 11,36 \\
\hline 7500 & 12,60 & 11,60 & 11,32 \\
\hline 8000 & 12,63 & 11,57 & 11,27 \\
\hline 8500 & 12,66 & 11,55 & 11,23 \\
\hline 9000 & 12,69 & 11,53 & 11,18 \\
\hline 9500 & 12,71 & 11,50 & 11,14 \\
\hline 10000 & 12,74 & 11,48 & 11,10 \\
\hline & & & \\
\hline
\end{tabular}

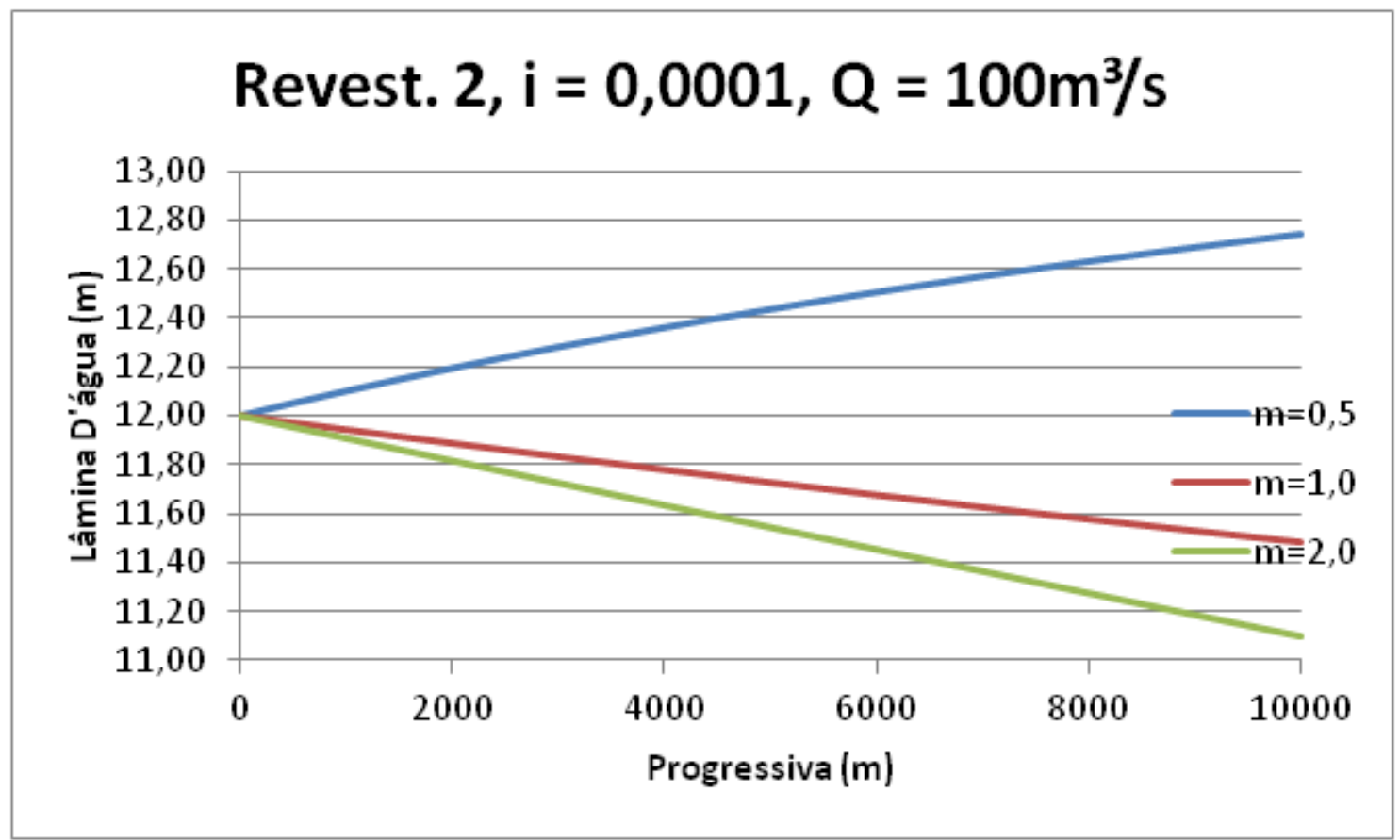




\begin{tabular}{|r|r|r|r|}
\hline \multirow{2}{*}{ Progr. } & \multicolumn{3}{|c|}{ Lâmina d'água $(\mathrm{m})$} \\
\cline { 2 - 4 } & $\mathrm{m}=0,5$ & $\mathrm{~m}=1,0$ & $\mathrm{~m}=2,0$ \\
\hline 0 & 12,00 & 12,00 & 12,00 \\
\hline 500 & 12,03 & 12,00 & 11,96 \\
\hline 1000 & 12,05 & 12,00 & 11,92 \\
\hline 1500 & 12,07 & 11,99 & 11,88 \\
\hline 2000 & 12,10 & 11,99 & 11,84 \\
\hline 2500 & 12,12 & 11,99 & 11,80 \\
\hline 3000 & 12,14 & 11,99 & 11,76 \\
\hline 3500 & 12,17 & 11,99 & 11,72 \\
\hline 4000 & 12,19 & 11,99 & 11,68 \\
\hline 4500 & 12,21 & 11,99 & 11,64 \\
\hline 5000 & 12,23 & 11,98 & 11,60 \\
\hline 5500 & 12,25 & 11,98 & 11,56 \\
\hline 6000 & 12,27 & 11,98 & 11,52 \\
\hline 6500 & 12,29 & 11,98 & 11,48 \\
\hline 7000 & 12,30 & 11,98 & 11,44 \\
\hline 7500 & 12,32 & 11,98 & 11,40 \\
\hline 8000 & 12,34 & 11,98 & 11,36 \\
\hline 8500 & 12,36 & 11,97 & 11,32 \\
\hline 9000 & 12,37 & 11,97 & 11,29 \\
\hline 9500 & 12,39 & 11,97 & 11,25 \\
\hline 10000 & 12,41 & 11,97 & 11,21 \\
\hline & & & \\
\hline
\end{tabular}

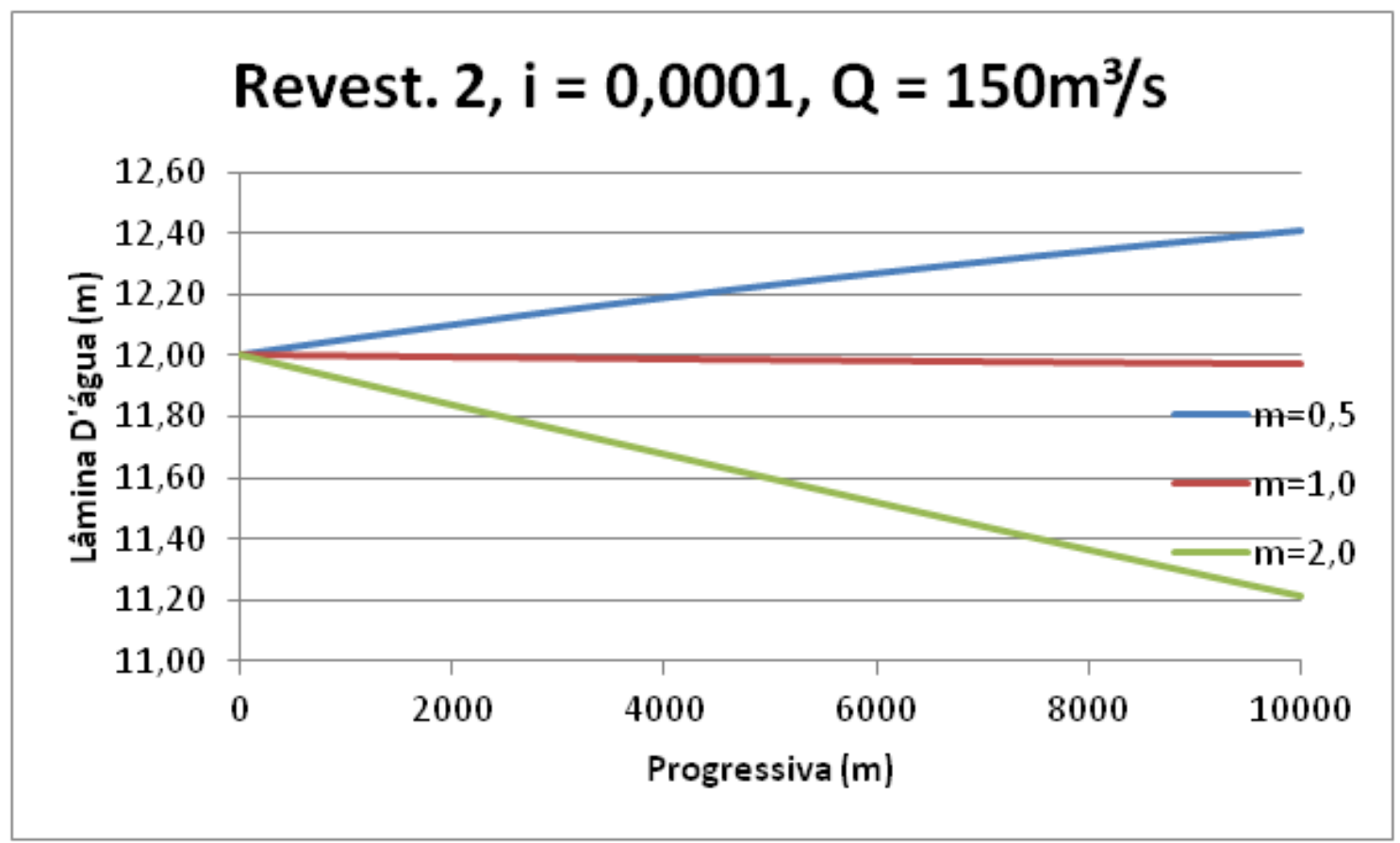




\begin{tabular}{|r|r|r|r|}
\hline \multirow{2}{*}{ Progr. } & \multicolumn{3}{|c|}{ Lâmina d'água $(\mathrm{m})$} \\
\cline { 2 - 4 } & $\mathrm{m}=0,5$ & $\mathrm{~m}=1,0$ & $\mathrm{~m}=2,0$ \\
\hline 0 & 12,00 & 12,00 & 12,00 \\
\hline 500 & 12,05 & 12,04 & 11,97 \\
\hline 1000 & 12,09 & 12,07 & 11,93 \\
\hline 1500 & 12,14 & 12,10 & 11,90 \\
\hline 2000 & 12,18 & 12,14 & 11,86 \\
\hline 2500 & 12,22 & 12,17 & 11,83 \\
\hline 3000 & 12,26 & 12,20 & 11,80 \\
\hline 3500 & 12,30 & 12,23 & 11,77 \\
\hline 4000 & 12,34 & 12,25 & 11,73 \\
\hline 4500 & 12,37 & 12,28 & 11,70 \\
\hline 5000 & 12,41 & 12,31 & 11,67 \\
\hline 5500 & 12,44 & 12,33 & 11,64 \\
\hline 6000 & 12,48 & 12,36 & 11,61 \\
\hline 6500 & 12,51 & 12,38 & 11,57 \\
\hline 7000 & 12,54 & 12,40 & 11,54 \\
\hline 7500 & 12,57 & 12,43 & 11,51 \\
\hline 8000 & 12,61 & 12,45 & 11,48 \\
\hline 8500 & 12,63 & 12,47 & 11,45 \\
\hline 9000 & 12,66 & 12,49 & 11,42 \\
\hline 9500 & 12,69 & 12,51 & 11,39 \\
\hline 10000 & 12,72 & 12,53 & 11,36 \\
\hline & & & \\
\hline
\end{tabular}

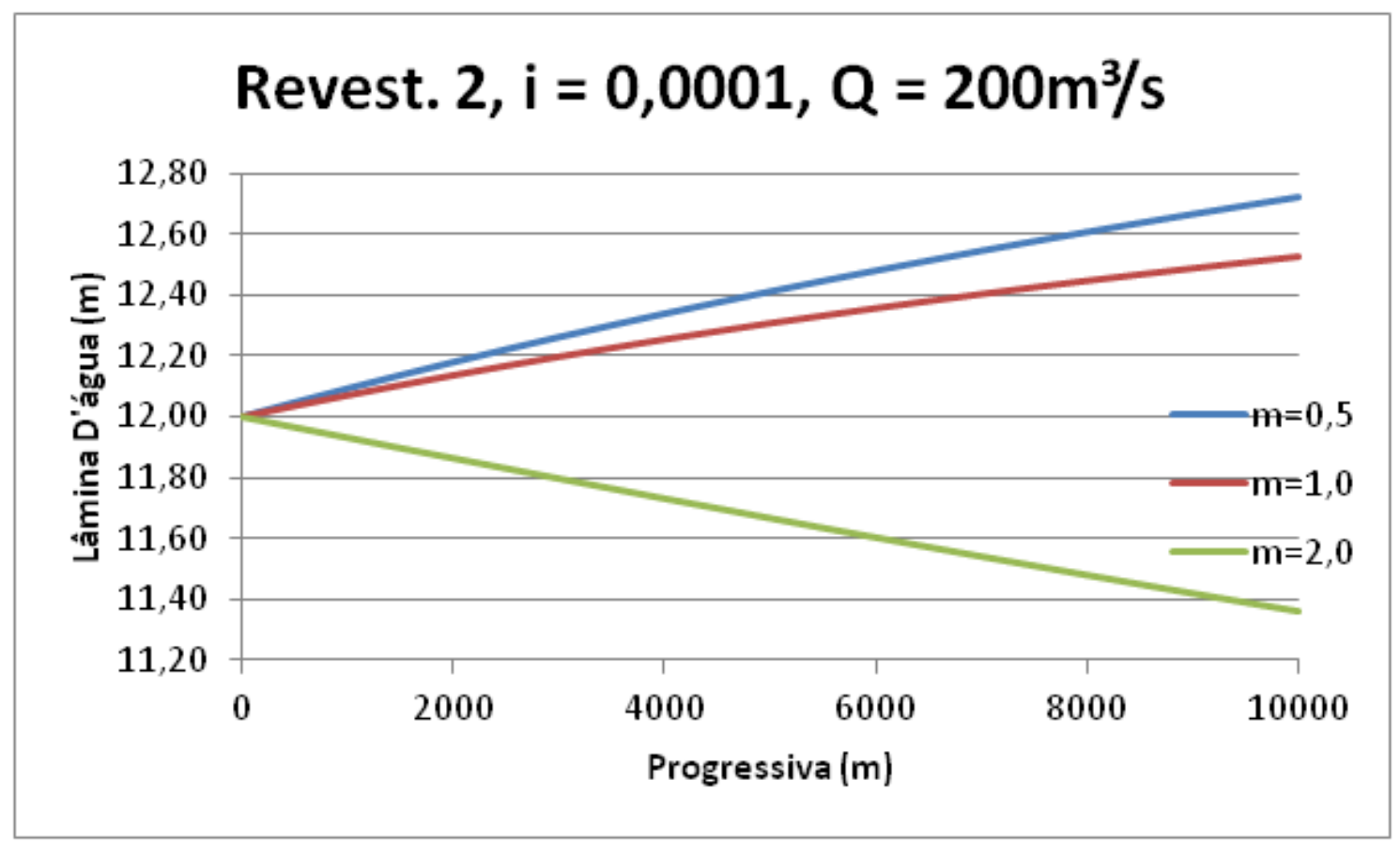




\begin{tabular}{|r|r|r|r|}
\hline \multirow{2}{*}{ Progr. } & \multicolumn{3}{|c|}{ Lâmina d'água $(\mathrm{m})$} \\
\cline { 2 - 4 } & $\mathrm{m}=0,5$ & $\mathrm{~m}=1,0$ & $\mathrm{~m}=2,0$ \\
\hline 0 & 12,00 & 12,00 & 12,00 \\
\hline 500 & 12,04 & 12,05 & 11,97 \\
\hline 1000 & 12,08 & 12,09 & 11,95 \\
\hline 1500 & 12,12 & 12,13 & 11,92 \\
\hline 2000 & 12,16 & 12,17 & 11,90 \\
\hline 2500 & 12,20 & 12,21 & 11,88 \\
\hline 3000 & 12,24 & 12,25 & 11,85 \\
\hline 3500 & 12,27 & 12,29 & 11,83 \\
\hline 4000 & 12,31 & 12,32 & 11,80 \\
\hline 4500 & 12,34 & 12,36 & 11,78 \\
\hline 5000 & 12,38 & 12,39 & 11,76 \\
\hline 5500 & 12,41 & 12,42 & 11,74 \\
\hline 6000 & 12,44 & 12,45 & 11,71 \\
\hline 6500 & 12,47 & 12,48 & 11,69 \\
\hline 7000 & 12,50 & 12,51 & 11,67 \\
\hline 7500 & 12,53 & 12,54 & 11,65 \\
\hline 8000 & 12,56 & 12,56 & 11,63 \\
\hline 8500 & 12,59 & 12,59 & 11,61 \\
\hline 9000 & 12,61 & 12,62 & 11,59 \\
\hline 9500 & 12,64 & 12,64 & 11,57 \\
\hline 10000 & 12,67 & 12,66 & 11,55 \\
\hline & & & \\
\hline
\end{tabular}

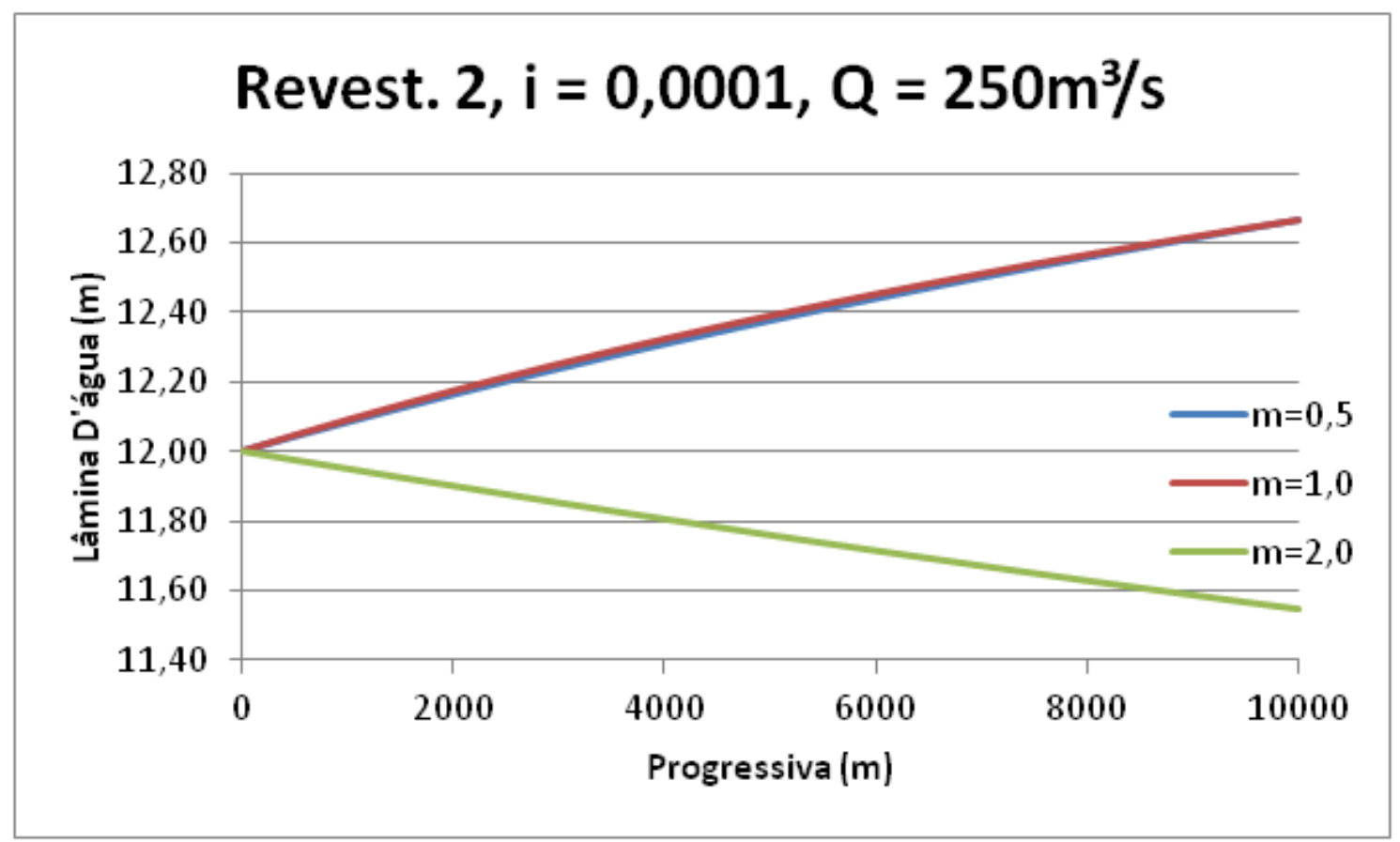




\begin{tabular}{|r|r|r|r|}
\hline \multirow{2}{*}{ Progr. } & \multicolumn{3}{|c|}{ Lâmina d'água $(\mathrm{m})$} \\
\cline { 2 - 4 } & $\mathrm{m}=0,5$ & $\mathrm{~m}=1,0$ & $\mathrm{~m}=2,0$ \\
\hline 0 & 12,00 & 12,00 & 12,00 \\
\hline 500 & 12,05 & 12,06 & 11,99 \\
\hline 1000 & 12,10 & 12,11 & 11,97 \\
\hline 1500 & 12,14 & 12,16 & 11,96 \\
\hline 2000 & 12,19 & 12,21 & 11,94 \\
\hline 2500 & 12,23 & 12,26 & 11,93 \\
\hline 3000 & 12,28 & 12,31 & 11,92 \\
\hline 3500 & 12,32 & 12,35 & 11,90 \\
\hline 4000 & 12,36 & 12,40 & 11,89 \\
\hline 4500 & 12,40 & 12,44 & 11,88 \\
\hline 5000 & 12,43 & 12,48 & 11,87 \\
\hline 5500 & 12,47 & 12,52 & 11,85 \\
\hline 6000 & 12,51 & 12,55 & 11,84 \\
\hline 6500 & 12,54 & 12,59 & 11,83 \\
\hline 7000 & 12,58 & 12,63 & 11,82 \\
\hline 7500 & 12,61 & 12,66 & 11,81 \\
\hline 8000 & 12,64 & 12,69 & 11,80 \\
\hline 8500 & 12,68 & 12,72 & 11,78 \\
\hline 9000 & 12,71 & 12,75 & 11,77 \\
\hline 9500 & 12,74 & 12,78 & 11,76 \\
\hline 10000 & 12,77 & 12,81 & 11,75 \\
\hline & & & \\
\hline
\end{tabular}

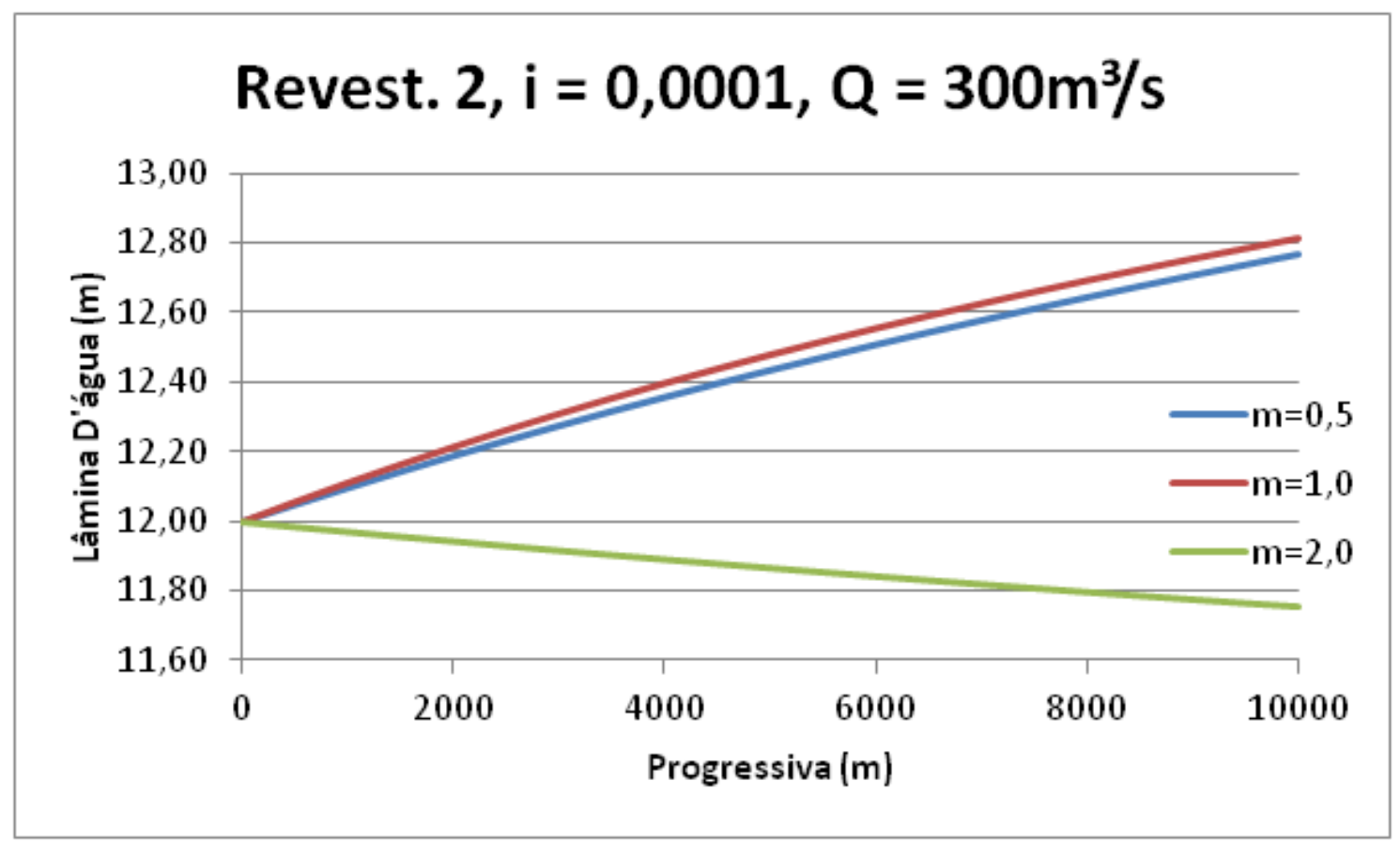




\begin{tabular}{|r|r|r|r|}
\hline \multirow{2}{*}{ Progr. } & \multicolumn{3}{|c|}{ Lâmina d'água $(\mathrm{m})$} \\
\cline { 2 - 4 } & $\mathrm{m}=0,5$ & $\mathrm{~m}=1,0$ & $\mathrm{~m}=2,0$ \\
\hline 0 & 12,00 & 12,00 & 12,00 \\
\hline 500 & 12,05 & 12,05 & 12,00 \\
\hline 1000 & 12,10 & 12,09 & 12,00 \\
\hline 1500 & 12,14 & 12,14 & 12,00 \\
\hline 2000 & 12,19 & 12,18 & 11,99 \\
\hline 2500 & 12,23 & 12,22 & 11,99 \\
\hline 3000 & 12,27 & 12,26 & 11,99 \\
\hline 3500 & 12,32 & 12,30 & 11,99 \\
\hline 4000 & 12,36 & 12,33 & 11,99 \\
\hline 4500 & 12,39 & 12,37 & 11,99 \\
\hline 5000 & 12,43 & 12,40 & 11,99 \\
\hline 5500 & 12,47 & 12,44 & 11,99 \\
\hline 6000 & 12,51 & 12,47 & 11,98 \\
\hline 6500 & 12,54 & 12,50 & 11,98 \\
\hline 7000 & 12,58 & 12,53 & 11,98 \\
\hline 7500 & 12,61 & 12,56 & 11,98 \\
\hline 8000 & 12,64 & 12,59 & 11,98 \\
\hline 8500 & 12,67 & 12,62 & 11,98 \\
\hline 9000 & 12,70 & 12,64 & 11,98 \\
\hline 9500 & 12,74 & 12,67 & 11,98 \\
\hline 10000 & 12,76 & 12,70 & 11,98 \\
\hline & & & \\
\hline
\end{tabular}

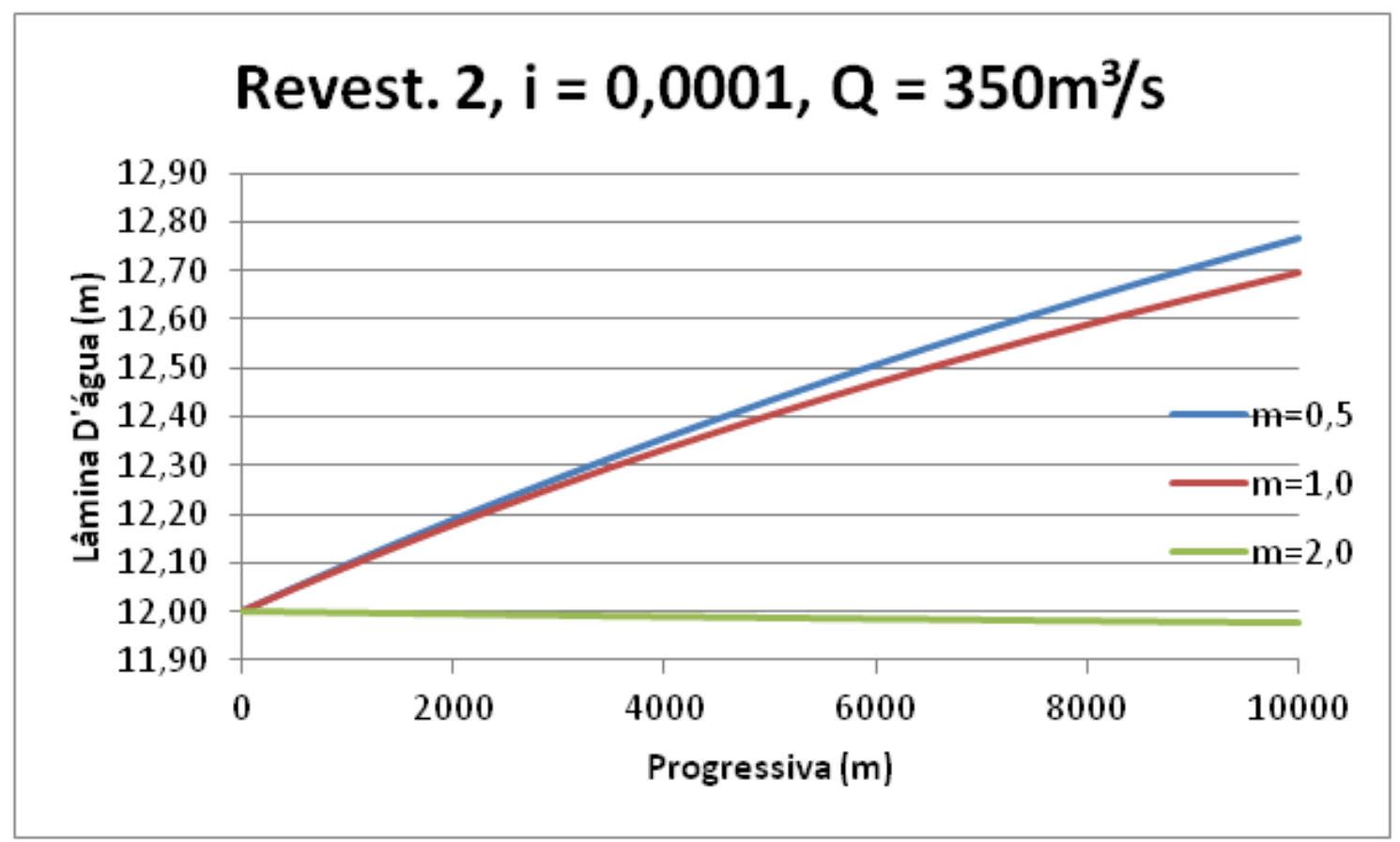




\begin{tabular}{|r|r|r|r|}
\hline \multirow{2}{*}{ Progr. } & \multicolumn{3}{|c|}{ Lâmina d'água $(\mathrm{m})$} \\
\cline { 2 - 4 } & $\mathrm{m}=0,5$ & $\mathrm{~m}=1,0$ & $\mathrm{~m}=2,0$ \\
\hline 0 & 12,00 & 12,00 & 12,00 \\
\hline 500 & 11,94 & 11,90 & 11,90 \\
\hline 1000 & 11,88 & 11,80 & 11,80 \\
\hline 1500 & 11,82 & 11,71 & 11,70 \\
\hline 2000 & 11,76 & 11,61 & 11,60 \\
\hline 2500 & 11,70 & 11,51 & 11,50 \\
\hline 3000 & 11,65 & 11,41 & 11,41 \\
\hline 3500 & 11,59 & 11,32 & 11,31 \\
\hline 4000 & 11,54 & 11,22 & 11,21 \\
\hline 4500 & 11,49 & 11,12 & 11,11 \\
\hline 5000 & 11,43 & 11,02 & 11,01 \\
\hline 5500 & 11,38 & 10,93 & 10,91 \\
\hline 6000 & 11,33 & 10,83 & 10,81 \\
\hline 6500 & 11,29 & 10,73 & 10,72 \\
\hline 7000 & 11,24 & 10,64 & 10,62 \\
\hline 7500 & 11,19 & 10,54 & 10,52 \\
\hline 8000 & 11,15 & 10,44 & 10,42 \\
\hline 8500 & 11,11 & 10,35 & 10,32 \\
\hline 9000 & 11,06 & 10,25 & 10,22 \\
\hline 9500 & 11,02 & 10,15 & 10,13 \\
\hline 10000 & 10,98 & 10,06 & 10,03 \\
\hline & & & \\
\hline
\end{tabular}

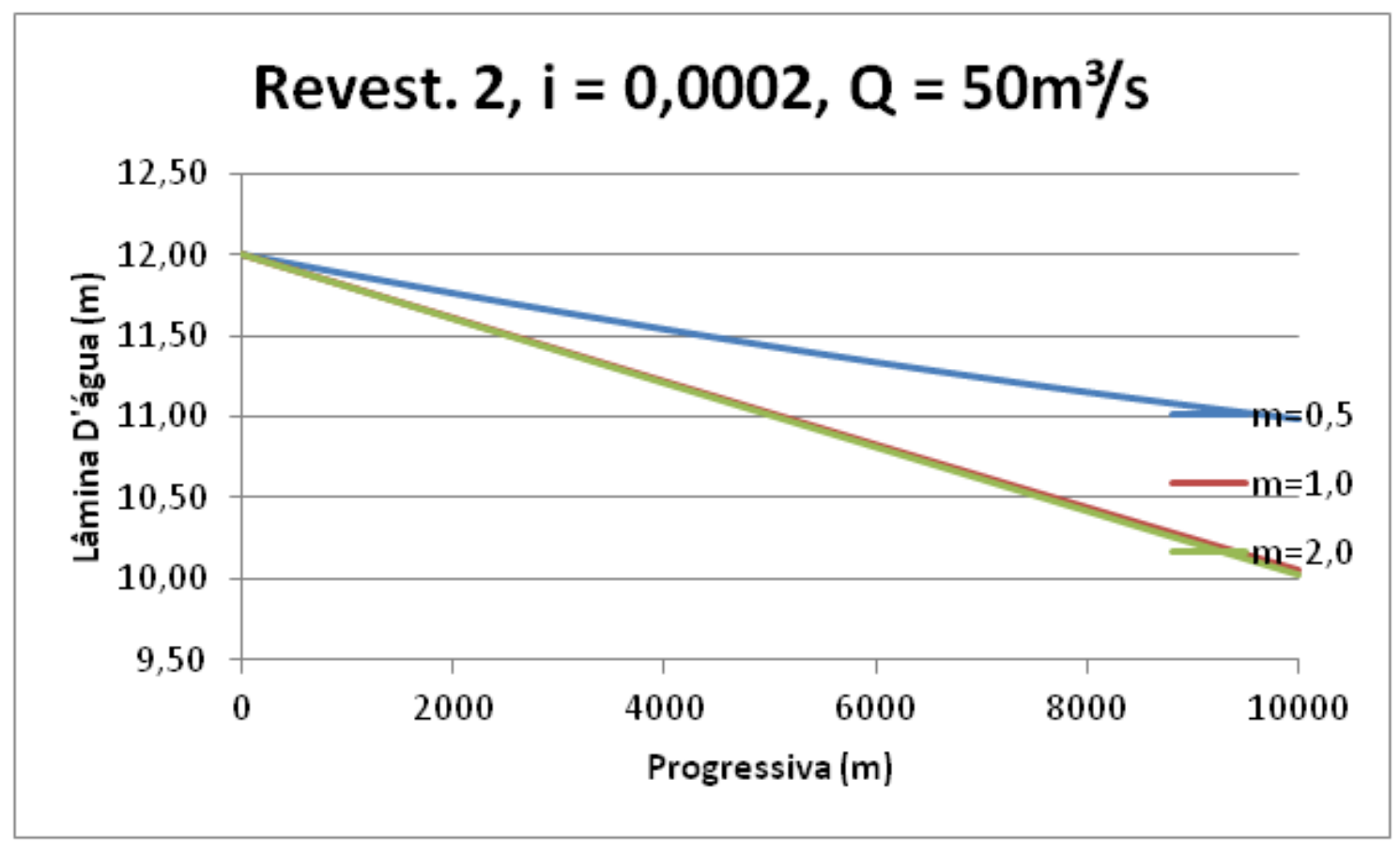




\begin{tabular}{|r|r|r|r|}
\hline \multirow{2}{*}{ Progr. } & \multicolumn{3}{|c|}{ Lâmina d'água $(\mathrm{m})$} \\
\cline { 2 - 4 } & $\mathrm{m}=0,5$ & $\mathrm{~m}=1,0$ & $\mathrm{~m}=2,0$ \\
\hline 0 & 12,00 & 12,00 & 12,00 \\
\hline 500 & 11,98 & 11,91 & 11,90 \\
\hline 1000 & 11,95 & 11,82 & 11,81 \\
\hline 1500 & 11,93 & 11,72 & 11,71 \\
\hline 2000 & 11,91 & 11,63 & 11,62 \\
\hline 2500 & 11,89 & 11,54 & 11,52 \\
\hline 3000 & 11,87 & 11,45 & 11,42 \\
\hline 3500 & 11,85 & 11,36 & 11,33 \\
\hline 4000 & 11,83 & 11,27 & 11,23 \\
\hline 4500 & 11,81 & 11,18 & 11,14 \\
\hline 5000 & 11,79 & 11,09 & 11,04 \\
\hline 5500 & 11,78 & 11,00 & 10,95 \\
\hline 6000 & 11,76 & 10,92 & 10,86 \\
\hline 6500 & 11,74 & 10,83 & 10,76 \\
\hline 7000 & 11,73 & 10,74 & 10,67 \\
\hline 7500 & 11,71 & 10,65 & 10,58 \\
\hline 8000 & 11,70 & 10,57 & 10,48 \\
\hline 8500 & 11,68 & 10,48 & 10,39 \\
\hline 9000 & 11,67 & 10,40 & 10,30 \\
\hline 9500 & 11,66 & 10,31 & 10,21 \\
\hline 10000 & 11,64 & 10,23 & 10,11 \\
\hline & & & \\
\hline
\end{tabular}

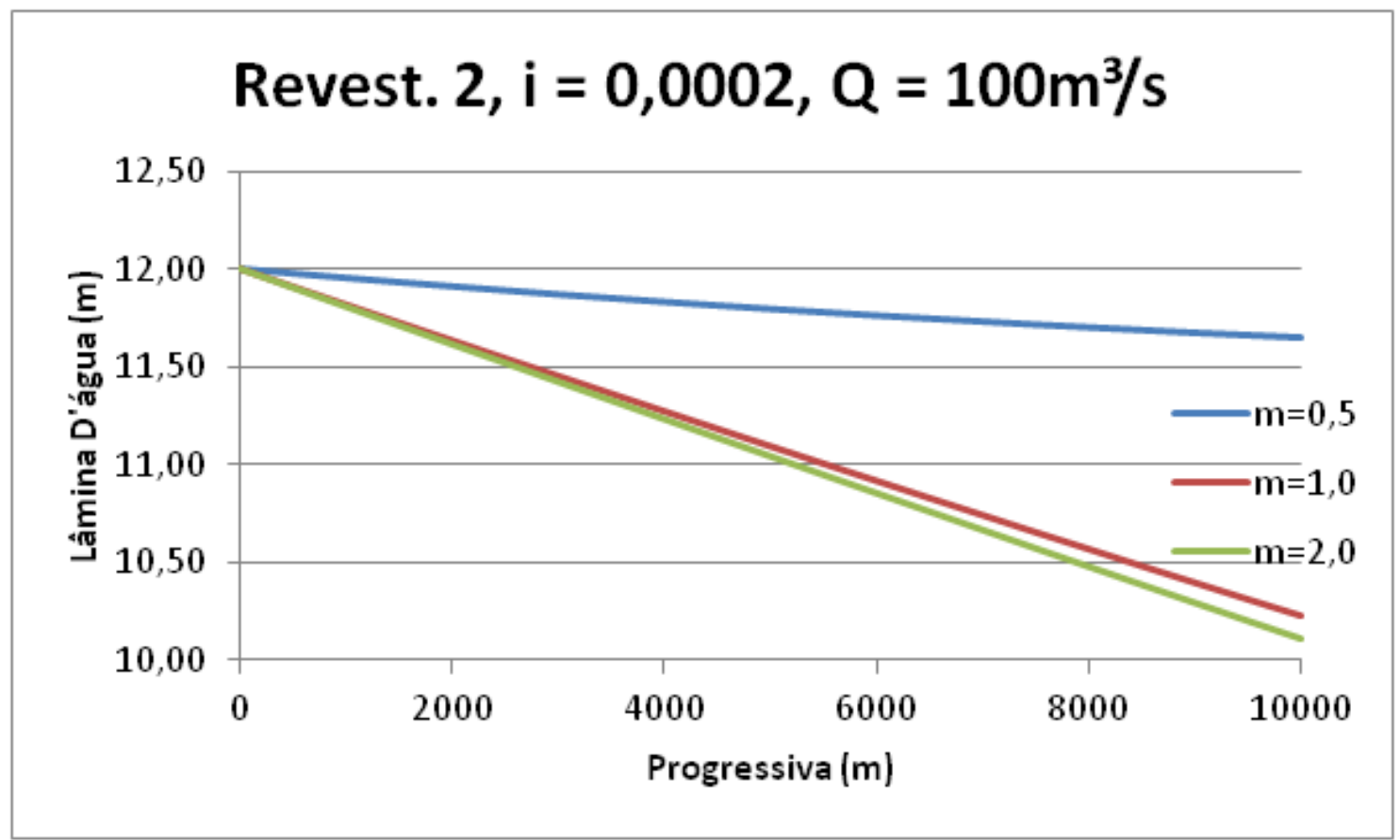




\begin{tabular}{|r|r|r|r|}
\hline \multirow{2}{*}{ Progr. } & \multicolumn{3}{|c|}{ Lâmina d'água $(\mathrm{m})$} \\
\cline { 2 - 4 } & $\mathrm{m}=0,5$ & $\mathrm{~m}=1,0$ & $\mathrm{~m}=2,0$ \\
\hline 0 & 12,00 & 12,00 & 12,00 \\
\hline 500 & 11,97 & 11,92 & 11,91 \\
\hline 1000 & 11,94 & 11,84 & 11,82 \\
\hline 1500 & 11,91 & 11,76 & 11,73 \\
\hline 2000 & 11,89 & 11,68 & 11,63 \\
\hline 2500 & 11,86 & 11,60 & 11,54 \\
\hline 3000 & 11,83 & 11,52 & 11,45 \\
\hline 3500 & 11,81 & 11,44 & 11,36 \\
\hline 4000 & 11,78 & 11,36 & 11,28 \\
\hline 4500 & 11,76 & 11,28 & 11,19 \\
\hline 5000 & 11,74 & 11,21 & 11,10 \\
\hline 5500 & 11,71 & 11,13 & 11,01 \\
\hline 6000 & 11,69 & 11,06 & 10,92 \\
\hline 6500 & 11,67 & 10,98 & 10,84 \\
\hline 7000 & 11,65 & 10,91 & 10,75 \\
\hline 7500 & 11,63 & 10,84 & 10,67 \\
\hline 8000 & 11,61 & 10,77 & 10,58 \\
\hline 8500 & 11,59 & 10,69 & 10,50 \\
\hline 9000 & 11,57 & 10,62 & 10,41 \\
\hline 9500 & 11,55 & 10,56 & 10,33 \\
\hline 10000 & 11,54 & 10,49 & 10,25 \\
\hline & & & \\
\hline
\end{tabular}

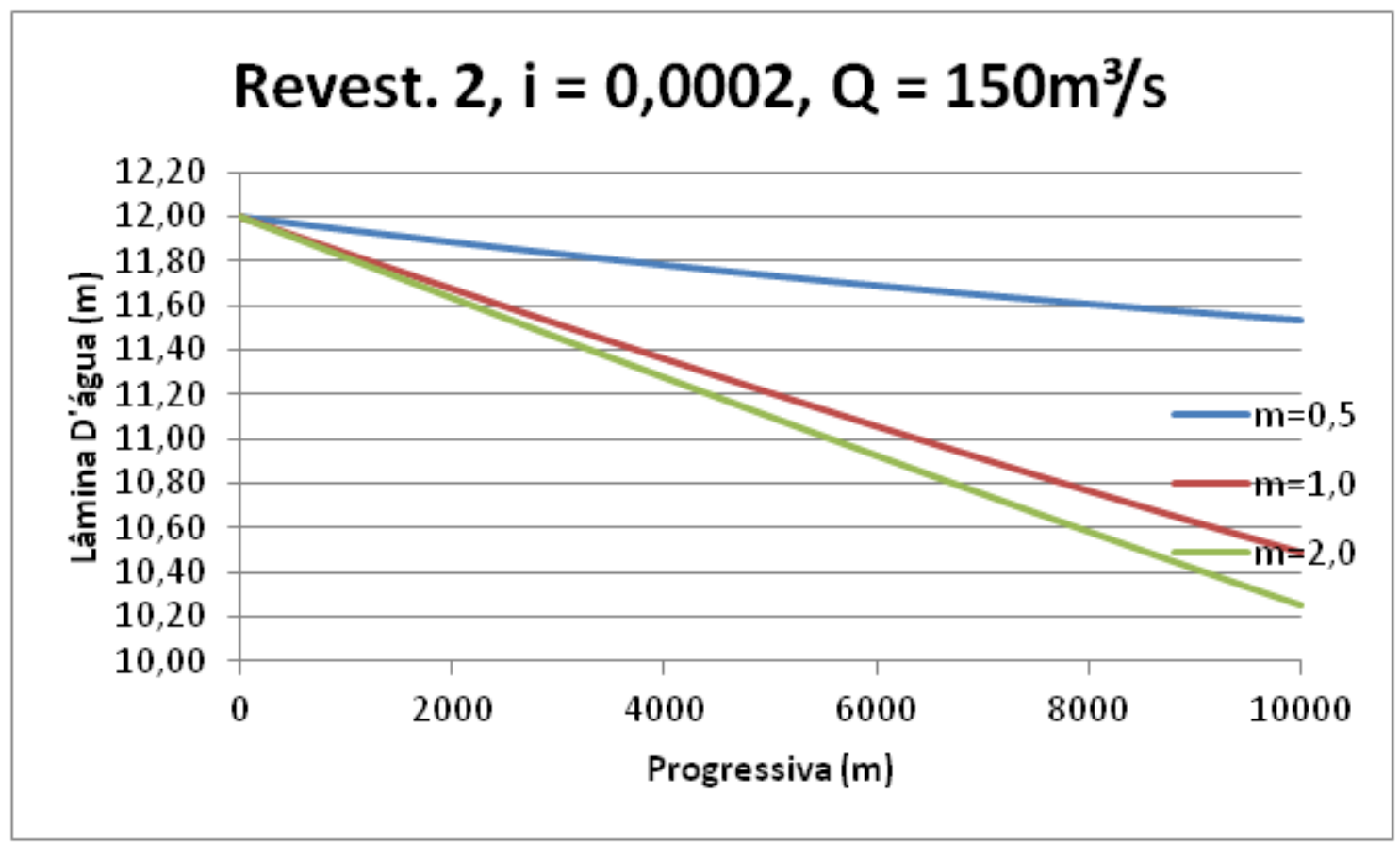




\begin{tabular}{|r|r|r|r|}
\hline \multirow{2}{*}{ Progr. } & \multicolumn{3}{|c|}{ Lâmina d'água $(\mathrm{m})$} \\
\cline { 2 - 4 } & $\mathrm{m}=0,5$ & $\mathrm{~m}=1,0$ & $\mathrm{~m}=2,0$ \\
\hline 0 & 12,00 & 12,00 & 12,00 \\
\hline 500 & 12,00 & 11,93 & 11,91 \\
\hline 1000 & 12,00 & 11,86 & 11,83 \\
\hline 1500 & 12,00 & 11,80 & 11,75 \\
\hline 2000 & 12,00 & 11,73 & 11,66 \\
\hline 2500 & 12,00 & 11,67 & 11,58 \\
\hline 3000 & 12,00 & 11,60 & 11,50 \\
\hline 3500 & 12,00 & 11,54 & 11,41 \\
\hline 4000 & 12,00 & 11,48 & 11,33 \\
\hline 4500 & 12,00 & 11,42 & 11,25 \\
\hline 5000 & 12,00 & 11,36 & 11,17 \\
\hline 5500 & 12,00 & 11,30 & 11,09 \\
\hline 6000 & 11,99 & 11,24 & 11,02 \\
\hline 6500 & 11,99 & 11,19 & 10,94 \\
\hline 7000 & 11,99 & 11,13 & 10,86 \\
\hline 7500 & 11,99 & 11,07 & 10,79 \\
\hline 8000 & 11,99 & 11,02 & 10,71 \\
\hline 8500 & 11,99 & 10,97 & 10,64 \\
\hline 9000 & 11,99 & 10,92 & 10,57 \\
\hline 9500 & 11,99 & 10,86 & 10,50 \\
\hline 10000 & 11,99 & 10,82 & 10,42 \\
\hline & & & \\
\hline
\end{tabular}

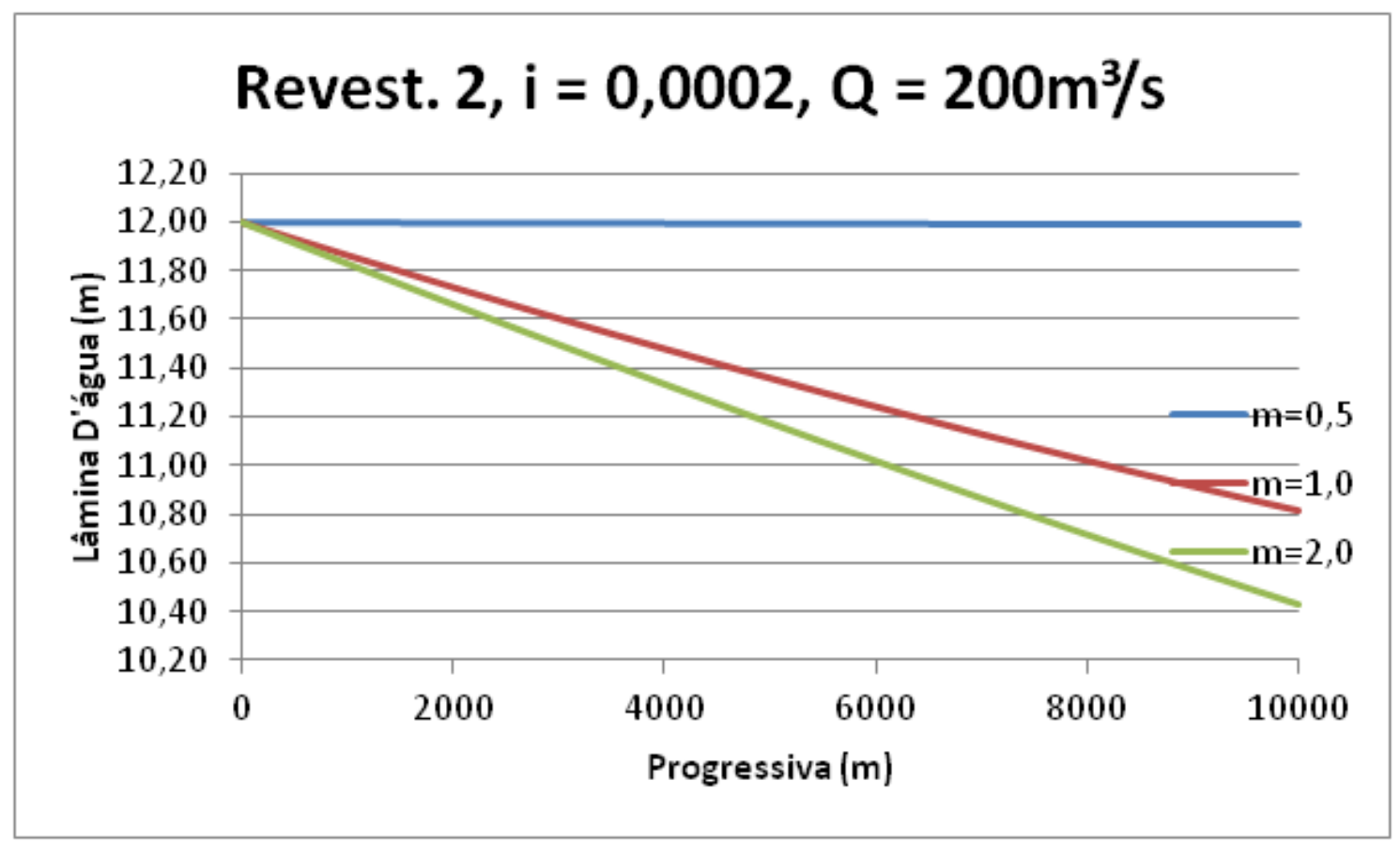




\begin{tabular}{|r|r|r|r|}
\hline \multirow{2}{*}{ Progr. } & \multicolumn{3}{|c|}{ Lâmina d'água $(\mathrm{m})$} \\
\cline { 2 - 4 } & $\mathrm{m}=0,5$ & $\mathrm{~m}=1,0$ & $\mathrm{~m}=2,0$ \\
\hline 0 & 12,00 & 12,00 & 12,00 \\
\hline 500 & 12,00 & 11,97 & 11,92 \\
\hline 1000 & 11,99 & 11,95 & 11,85 \\
\hline 1500 & 11,99 & 11,92 & 11,77 \\
\hline 2000 & 11,98 & 11,90 & 11,70 \\
\hline 2500 & 11,98 & 11,87 & 11,62 \\
\hline 3000 & 11,97 & 11,85 & 11,55 \\
\hline 3500 & 11,97 & 11,82 & 11,48 \\
\hline 4000 & 11,97 & 11,80 & 11,41 \\
\hline 4500 & 11,96 & 11,78 & 11,34 \\
\hline 5000 & 11,96 & 11,76 & 11,27 \\
\hline 5500 & 11,96 & 11,74 & 11,20 \\
\hline 6000 & 11,95 & 11,72 & 11,13 \\
\hline 6500 & 11,95 & 11,70 & 11,06 \\
\hline 7000 & 11,95 & 11,69 & 11,00 \\
\hline 7500 & 11,94 & 11,67 & 10,94 \\
\hline 8000 & 11,94 & 11,65 & 10,87 \\
\hline 8500 & 11,94 & 11,63 & 10,81 \\
\hline 9000 & 11,93 & 11,62 & 10,75 \\
\hline 9500 & 11,93 & 11,60 & 10,69 \\
\hline 10000 & 11,93 & 11,59 & 10,63 \\
\hline & & & \\
\hline
\end{tabular}

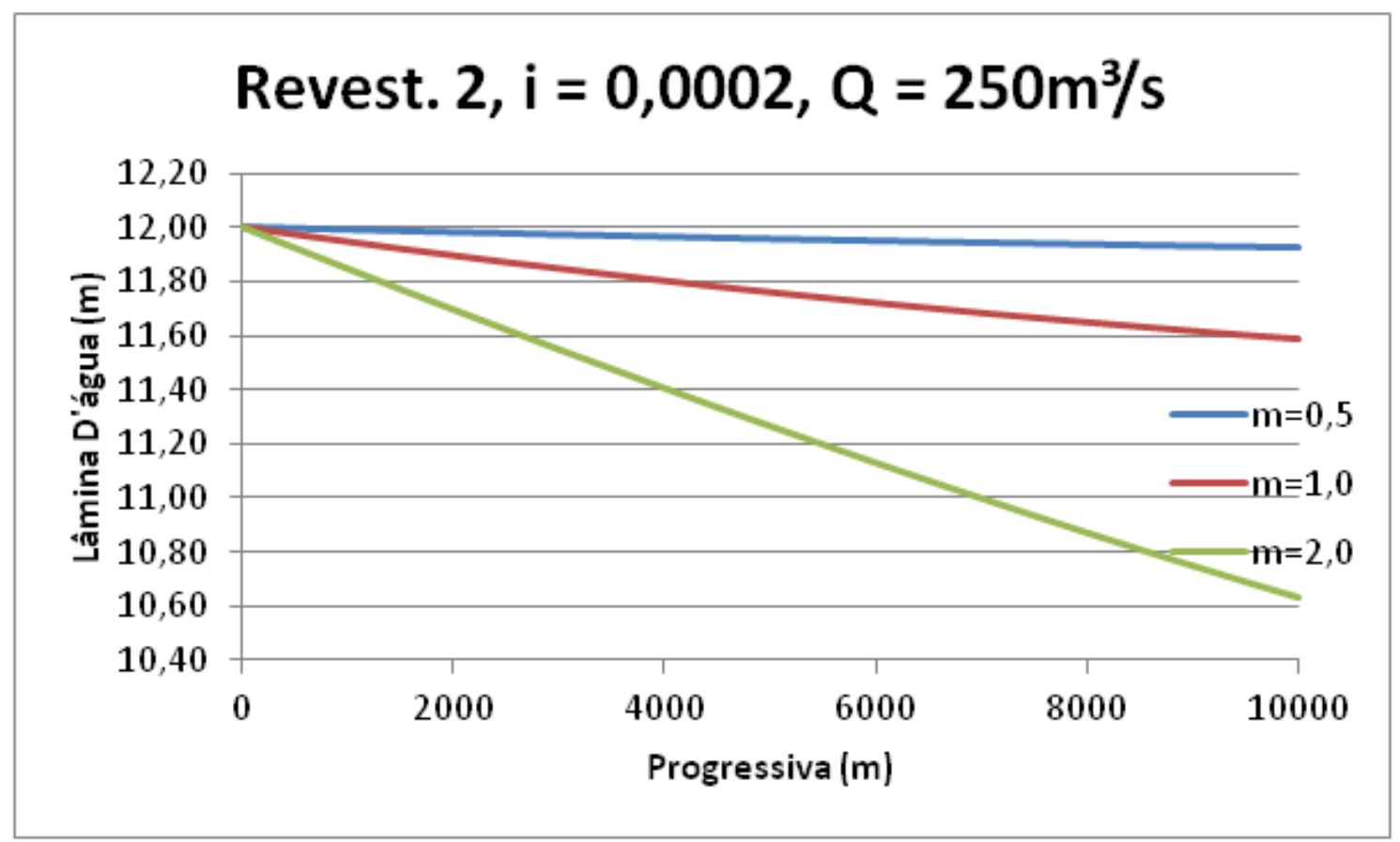




\begin{tabular}{|r|r|r|r|}
\hline \multirow{2}{*}{ Progr. } & \multicolumn{3}{|c|}{ Lâmina d'água $(\mathrm{m})$} \\
\cline { 2 - 4 } & $\mathrm{m}=0,5$ & $\mathrm{~m}=1,0$ & $\mathrm{~m}=2,0$ \\
\hline 0 & 12,00 & 12,00 & 12,00 \\
\hline 500 & 12,00 & 12,00 & 11,93 \\
\hline 1000 & 12,00 & 12,00 & 11,87 \\
\hline 1500 & 12,00 & 12,00 & 11,80 \\
\hline 2000 & 12,00 & 12,00 & 11,74 \\
\hline 2500 & 12,00 & 12,00 & 11,67 \\
\hline 3000 & 12,00 & 12,00 & 11,61 \\
\hline 3500 & 12,00 & 12,00 & 11,55 \\
\hline 4000 & 12,00 & 12,00 & 11,49 \\
\hline 4500 & 12,00 & 12,00 & 11,43 \\
\hline 5000 & 12,00 & 12,00 & 11,38 \\
\hline 5500 & 12,00 & 12,00 & 11,32 \\
\hline 6000 & 12,00 & 12,00 & 11,26 \\
\hline 6500 & 12,00 & 12,00 & 11,21 \\
\hline 7000 & 12,00 & 11,99 & 11,16 \\
\hline 7500 & 12,00 & 11,99 & 11,11 \\
\hline 8000 & 12,00 & 11,99 & 11,05 \\
\hline 8500 & 12,00 & 11,99 & 11,01 \\
\hline 9000 & 12,00 & 11,99 & 10,96 \\
\hline 9500 & 12,00 & 11,99 & 10,91 \\
\hline 10000 & 12,00 & 11,99 & 10,87 \\
\hline & & & \\
\hline
\end{tabular}

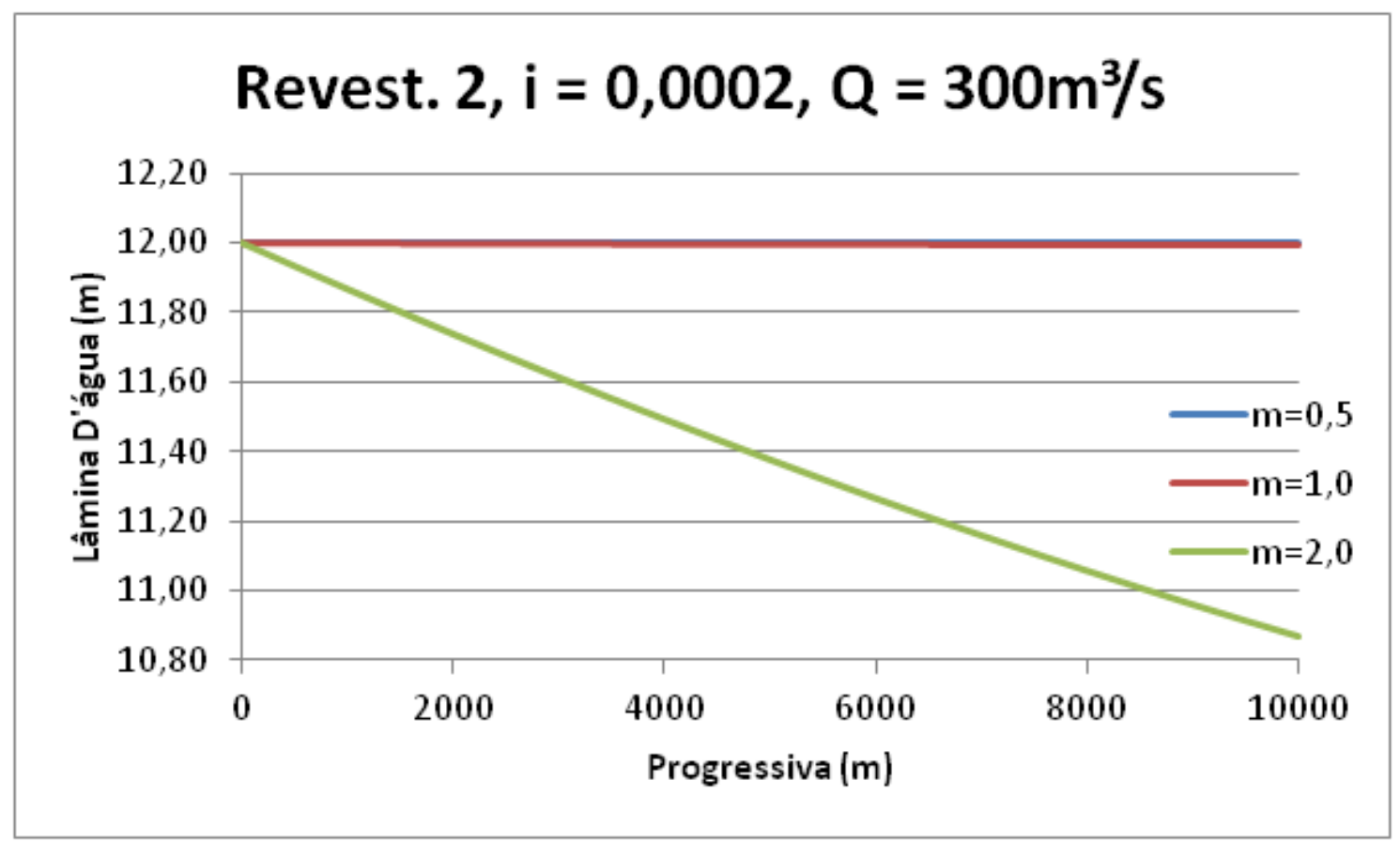




\begin{tabular}{|r|r|r|r|}
\hline \multirow{2}{*}{ Progr. } & \multicolumn{3}{|c|}{ Lâmina d'água $(\mathrm{m})$} \\
\cline { 2 - 4 } & $\mathrm{m}=0,5$ & $\mathrm{~m}=1,0$ & $\mathrm{~m}=2,0$ \\
\hline 0 & 12,00 & 12,00 & 12,00 \\
\hline 500 & 12,00 & 11,99 & 11,94 \\
\hline 1000 & 12,00 & 11,97 & 11,89 \\
\hline 1500 & 12,00 & 11,96 & 11,84 \\
\hline 2000 & 12,00 & 11,95 & 11,79 \\
\hline 2500 & 12,00 & 11,94 & 11,74 \\
\hline 3000 & 12,00 & 11,93 & 11,69 \\
\hline 3500 & 12,00 & 11,92 & 11,64 \\
\hline 4000 & 12,00 & 11,91 & 11,59 \\
\hline 4500 & 11,99 & 11,90 & 11,54 \\
\hline 5000 & 11,99 & 11,89 & 11,50 \\
\hline 5500 & 11,99 & 11,88 & 11,46 \\
\hline 6000 & 11,99 & 11,87 & 11,41 \\
\hline 6500 & 11,99 & 11,86 & 11,37 \\
\hline 7000 & 11,99 & 11,85 & 11,33 \\
\hline 7500 & 11,99 & 11,85 & 11,29 \\
\hline 8000 & 11,99 & 11,84 & 11,25 \\
\hline 8500 & 11,99 & 11,83 & 11,22 \\
\hline 9000 & 11,99 & 11,82 & 11,18 \\
\hline 9500 & 11,99 & 11,82 & 11,15 \\
\hline 10000 & 11,99 & 11,81 & 11,11 \\
\hline & & & \\
\hline
\end{tabular}

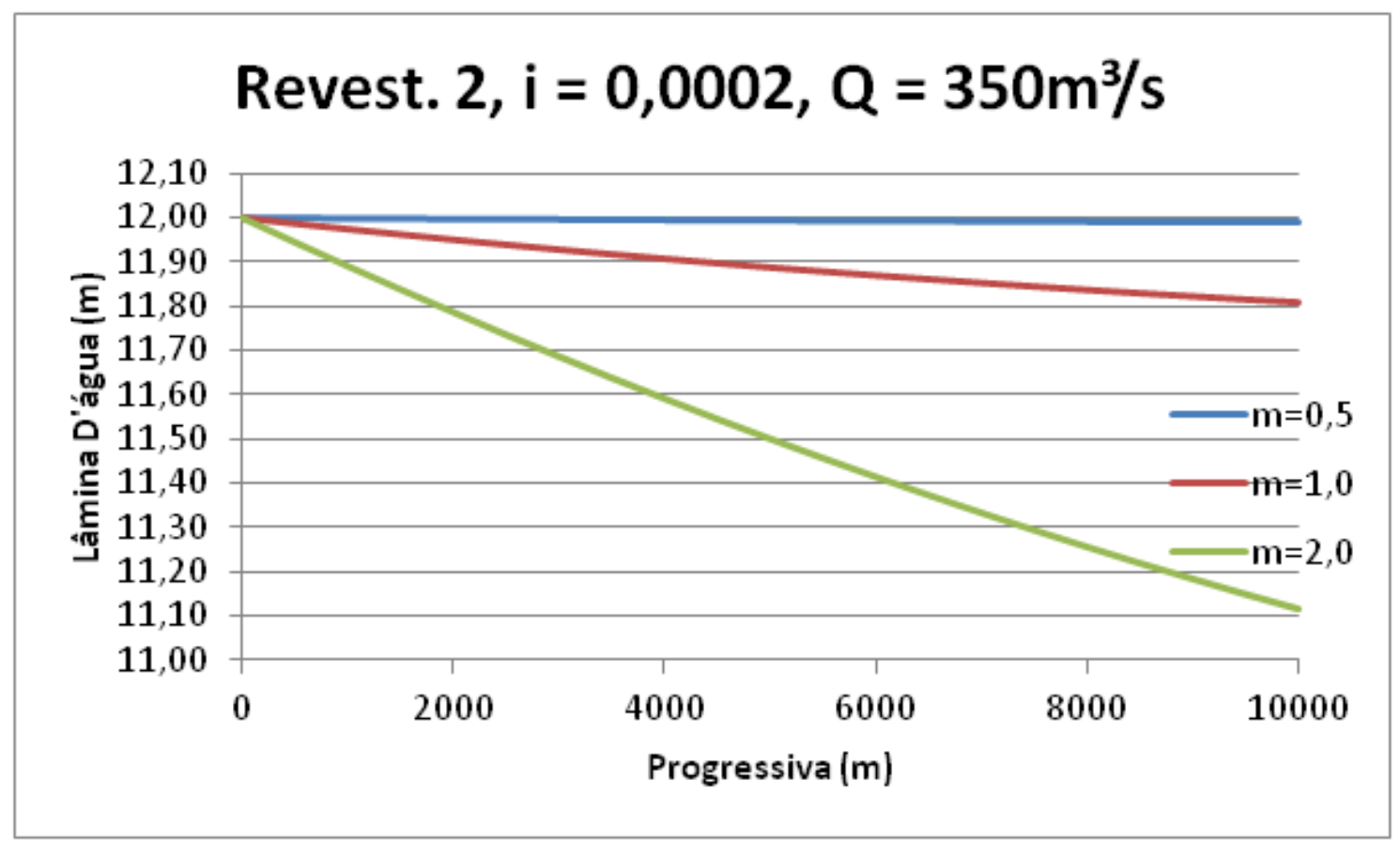




\begin{tabular}{|r|r|r|r|}
\hline \multirow{2}{*}{ Progr. } & \multicolumn{3}{|c|}{ Lâmina d'água $(\mathrm{m})$} \\
\cline { 2 - 4 } & $\mathrm{m}=0,5$ & $\mathrm{~m}=1,0$ & $\mathrm{~m}=2,0$ \\
\hline 0 & 12,00 & 12,00 & 12,00 \\
\hline 500 & 11,79 & 11,76 & 11,75 \\
\hline 1000 & 11,58 & 11,51 & 11,50 \\
\hline 1500 & 11,38 & 11,27 & 11,25 \\
\hline 2000 & 11,18 & 11,02 & 11,00 \\
\hline 2500 & 10,99 & 10,78 & 10,76 \\
\hline 3000 & 10,80 & 10,54 & 10,51 \\
\hline 3500 & 10,61 & 10,30 & 10,26 \\
\hline 4000 & 10,44 & 10,06 & 10,01 \\
\hline 4500 & 10,27 & 9,83 & 9,76 \\
\hline 5000 & 10,11 & 9,59 & 9,52 \\
\hline 5500 & 9,95 & 9,36 & 9,27 \\
\hline 6000 & 9,81 & 9,13 & 9,02 \\
\hline 6500 & 9,67 & 8,90 & 8,78 \\
\hline 7000 & 9,54 & 8,68 & 8,53 \\
\hline 7500 & 9,42 & 8,46 & 8,29 \\
\hline 8000 & 9,31 & 8,24 & 8,04 \\
\hline 8500 & 9,21 & 8,03 & 7,80 \\
\hline 9000 & 9,12 & 7,82 & 7,56 \\
\hline 9500 & 9,03 & 7,63 & 7,32 \\
\hline 10000 & 8,96 & 7,43 & 7,08 \\
\hline & & & \\
\hline
\end{tabular}

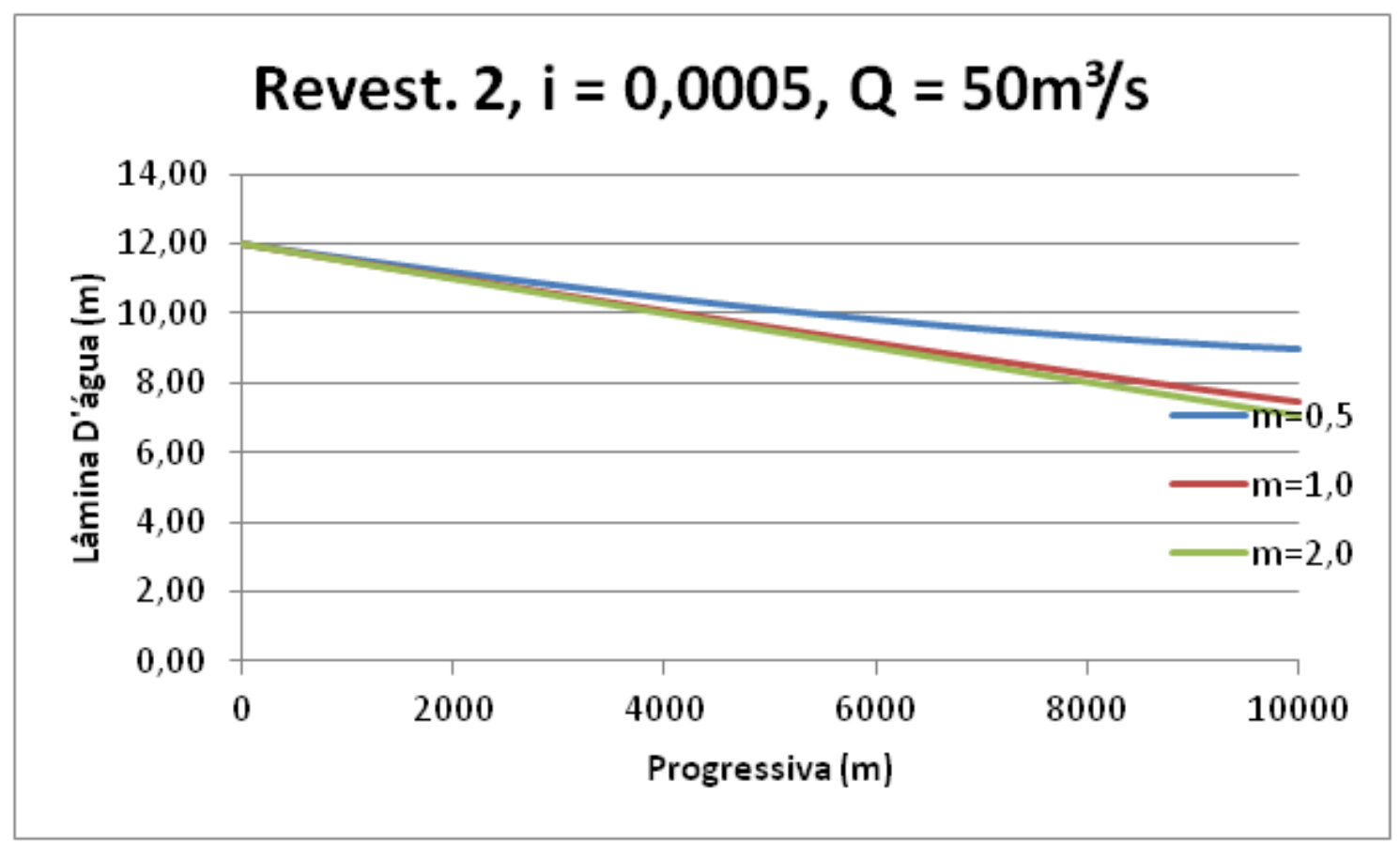




\begin{tabular}{|r|r|r|r|}
\hline \multirow{2}{*}{ Progr. } & \multicolumn{3}{|c|}{ Lâmina d'água $(\mathrm{m})$} \\
\cline { 2 - 4 } & $\mathrm{m}=0,5$ & $\mathrm{~m}=1,0$ & $\mathrm{~m}=2,0$ \\
\hline 0 & 12,00 & 12,00 & 12,00 \\
\hline 500 & 11,79 & 11,77 & 11,75 \\
\hline 1000 & 11,59 & 11,54 & 11,51 \\
\hline 1500 & 11,39 & 11,32 & 11,26 \\
\hline 2000 & 11,19 & 11,10 & 11,02 \\
\hline 2500 & 11,00 & 10,88 & 10,77 \\
\hline 3000 & 10,81 & 10,66 & 10,53 \\
\hline 3500 & 10,63 & 10,45 & 10,29 \\
\hline 4000 & 10,45 & 10,25 & 10,04 \\
\hline 4500 & 10,28 & 10,04 & 9,80 \\
\hline 5000 & 10,12 & 9,85 & 9,56 \\
\hline 5500 & 9,96 & 9,66 & 9,33 \\
\hline 6000 & 9,80 & 9,47 & 9,09 \\
\hline 6500 & 9,65 & 9,30 & 8,86 \\
\hline 7000 & 9,51 & 9,13 & 8,62 \\
\hline 7500 & 9,38 & 8,97 & 8,40 \\
\hline 8000 & 9,25 & 8,82 & 8,17 \\
\hline 8500 & 9,13 & 8,68 & 7,95 \\
\hline 9000 & 9,02 & 8,54 & 7,73 \\
\hline 9500 & 8,92 & 8,42 & 7,52 \\
\hline 10000 & 8,82 & 8,31 & 7,31 \\
\hline & & & \\
\hline
\end{tabular}

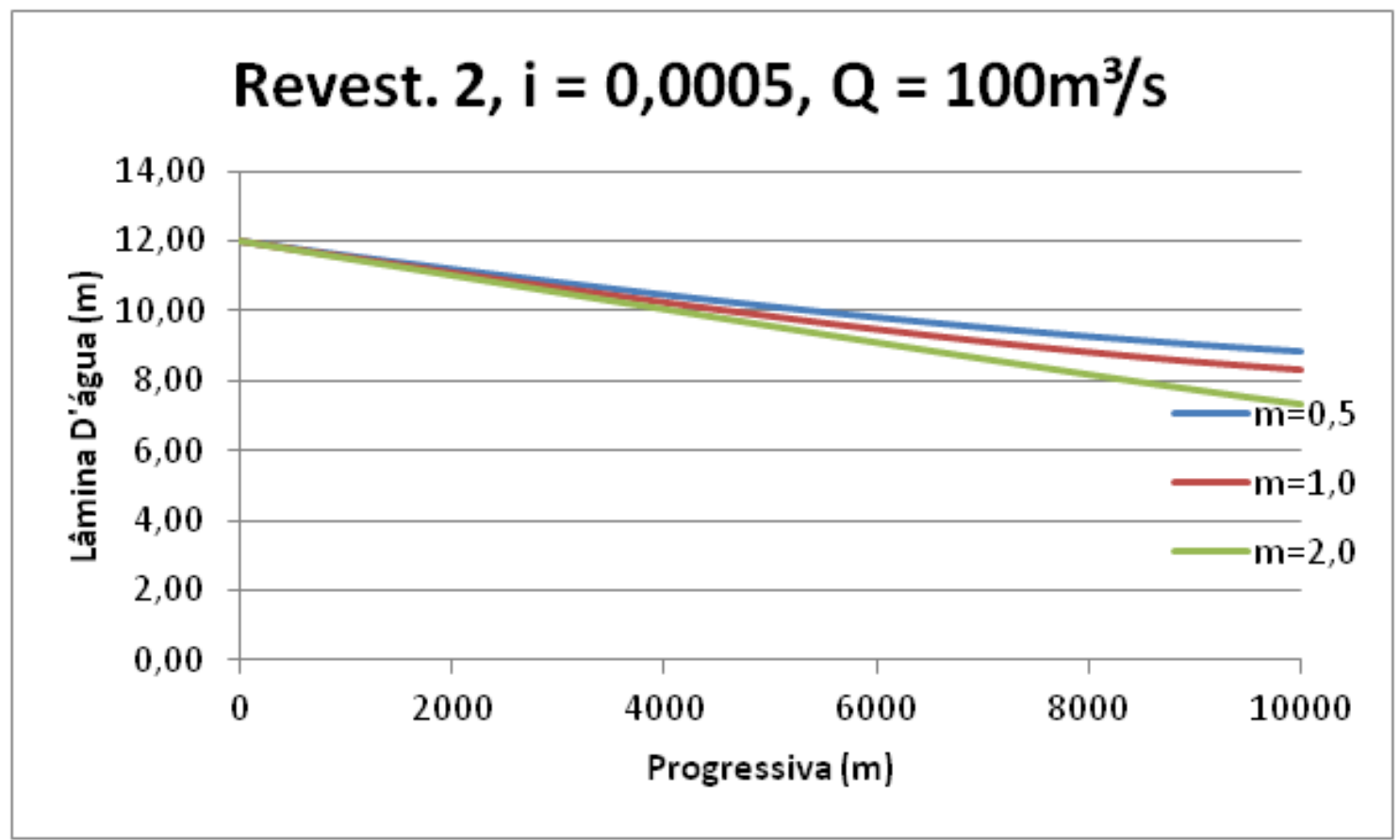




\begin{tabular}{|r|r|r|r|}
\hline \multirow{2}{*}{ Progr. } & \multicolumn{3}{|c|}{ Lâmina d'água $(\mathrm{m})$} \\
\cline { 2 - 4 } & $\mathrm{m}=0,5$ & $\mathrm{~m}=1,0$ & $\mathrm{~m}=2,0$ \\
\hline 0 & 12,00 & 12,00 & 12,00 \\
\hline 500 & 11,80 & 11,80 & 11,76 \\
\hline 1000 & 11,60 & 11,60 & 11,52 \\
\hline 1500 & 11,40 & 11,40 & 11,28 \\
\hline 2000 & 11,21 & 11,21 & 11,04 \\
\hline 2500 & 11,02 & 11,03 & 10,80 \\
\hline 3000 & 10,83 & 10,85 & 10,56 \\
\hline 3500 & 10,65 & 10,68 & 10,33 \\
\hline 4000 & 10,48 & 10,52 & 10,10 \\
\hline 4500 & 10,31 & 10,37 & 9,87 \\
\hline 5000 & 10,14 & 10,22 & 9,64 \\
\hline 5500 & 9,98 & 10,08 & 9,42 \\
\hline 6000 & 9,83 & 9,95 & 9,20 \\
\hline 6500 & 9,68 & 9,83 & 8,98 \\
\hline 7000 & 9,54 & 9,71 & 8,77 \\
\hline 7500 & 9,40 & 9,61 & 8,56 \\
\hline 8000 & 9,27 & 9,51 & 8,36 \\
\hline 8500 & 9,15 & 9,43 & 8,17 \\
\hline 9000 & 9,03 & 9,35 & 7,98 \\
\hline 9500 & 8,93 & 9,28 & 7,80 \\
\hline 10000 & 8,82 & 9,21 & 7,64 \\
\hline & & & \\
\hline
\end{tabular}

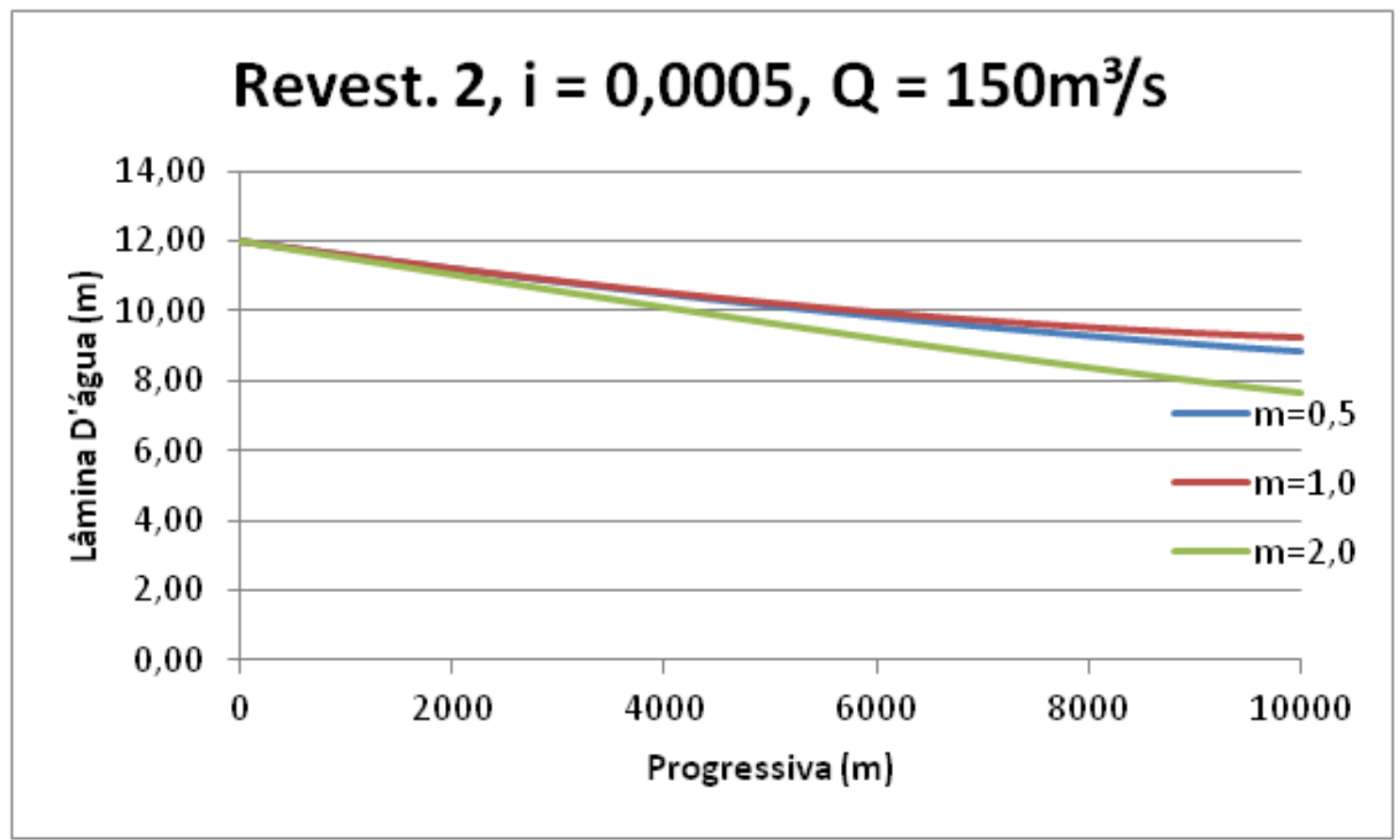




\begin{tabular}{|r|r|r|r|}
\hline \multirow{2}{*}{ Progr. } & \multicolumn{3}{|c|}{ Lâmina d'água $(\mathrm{m})$} \\
\cline { 2 - 4 } & $\mathrm{m}=0,5$ & $\mathrm{~m}=1,0$ & $\mathrm{~m}=2,0$ \\
\hline 0 & 12,00 & 12,00 & 12,00 \\
\hline 500 & 11,83 & 11,83 & 11,76 \\
\hline 1000 & 11,67 & 11,67 & 11,53 \\
\hline 1500 & 11,51 & 11,52 & 11,30 \\
\hline 2000 & 11,36 & 11,37 & 11,07 \\
\hline 2500 & 11,22 & 11,23 & 10,84 \\
\hline 3000 & 11,07 & 11,10 & 10,61 \\
\hline 3500 & 10,94 & 10,98 & 10,39 \\
\hline 4000 & 10,81 & 10,86 & 10,17 \\
\hline 4500 & 10,69 & 10,76 & 9,96 \\
\hline 5000 & 10,57 & 10,66 & 9,75 \\
\hline 5500 & 10,45 & 10,56 & 9,54 \\
\hline 6000 & 10,35 & 10,48 & 9,34 \\
\hline 6500 & 10,25 & 10,40 & 9,14 \\
\hline 7000 & 10,15 & 10,33 & 8,96 \\
\hline 7500 & 10,06 & 10,27 & 8,78 \\
\hline 8000 & 9,98 & 10,21 & 8,60 \\
\hline 8500 & 9,90 & 10,16 & 8,44 \\
\hline 9000 & 9,83 & 10,12 & 8,29 \\
\hline 9500 & 9,76 & 10,08 & 8,14 \\
\hline 10000 & 9,70 & 10,04 & 8,01 \\
\hline & & & \\
\hline
\end{tabular}

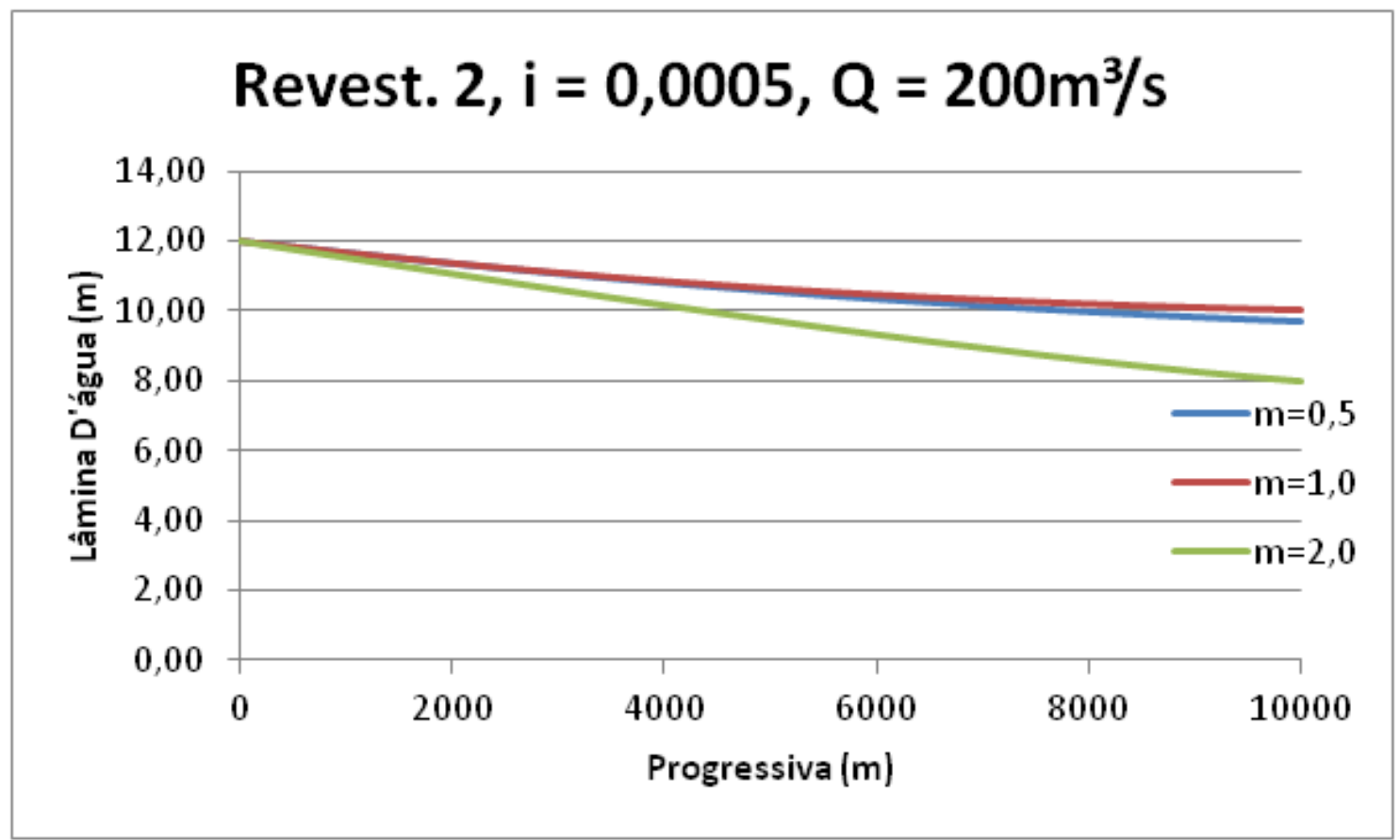




\begin{tabular}{|r|r|r|r|}
\hline \multirow{2}{*}{ Progr. } & \multicolumn{3}{|c|}{ Lâmina d'água $(\mathrm{m})$} \\
\cline { 2 - 4 } & $\mathrm{m}=0,5$ & $\mathrm{~m}=1,0$ & $\mathrm{~m}=2,0$ \\
\hline 0 & 12,00 & 12,00 & 12,00 \\
\hline 500 & 11,80 & 11,79 & 11,77 \\
\hline 1000 & 11,60 & 11,58 & 11,55 \\
\hline 1500 & 11,41 & 11,38 & 11,32 \\
\hline 2000 & 11,22 & 11,17 & 11,10 \\
\hline 2500 & 11,03 & 10,98 & 10,89 \\
\hline 3000 & 10,85 & 10,78 & 10,68 \\
\hline 3500 & 10,67 & 10,60 & 10,47 \\
\hline 4000 & 10,50 & 10,41 & 10,27 \\
\hline 4500 & 10,33 & 10,24 & 10,07 \\
\hline 5000 & 10,17 & 10,06 & 9,88 \\
\hline 5500 & 10,01 & 9,90 & 9,69 \\
\hline 6000 & 9,86 & 9,74 & 9,51 \\
\hline 6500 & 9,71 & 9,59 & 9,34 \\
\hline 7000 & 9,56 & 9,44 & 9,18 \\
\hline 7500 & 9,43 & 9,30 & 9,02 \\
\hline 8000 & 9,30 & 9,17 & 8,88 \\
\hline 8500 & 9,17 & 9,05 & 8,74 \\
\hline 9000 & 9,05 & 8,93 & 8,62 \\
\hline 9500 & 8,94 & 8,82 & 8,50 \\
\hline 10000 & 8,84 & 8,72 & 8,40 \\
\hline & & & \\
\hline
\end{tabular}

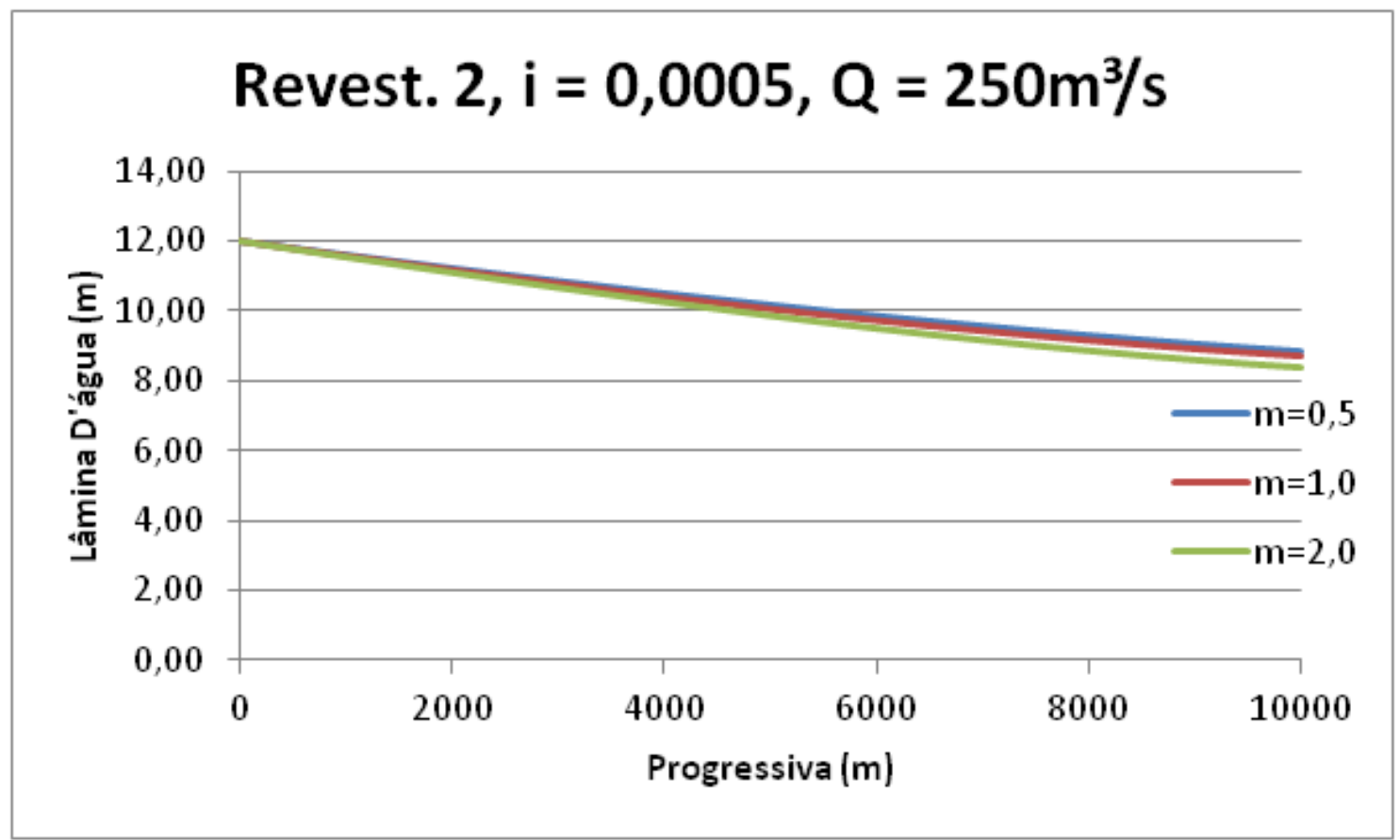




\begin{tabular}{|r|r|r|r|}
\hline \multirow{2}{*}{ Progr. } & \multicolumn{3}{|c|}{ Lâmina d'água $(\mathrm{m})$} \\
\cline { 2 - 4 } & $\mathrm{m}=0,5$ & $\mathrm{~m}=1,0$ & $\mathrm{~m}=2,0$ \\
\hline 0 & 12,00 & 12,00 & 12,00 \\
\hline 500 & 11,81 & 11,81 & 11,78 \\
\hline 1000 & 11,62 & 11,62 & 11,57 \\
\hline 1500 & 11,43 & 11,43 & 11,36 \\
\hline 2000 & 11,25 & 11,25 & 11,16 \\
\hline 2500 & 11,07 & 11,07 & 10,96 \\
\hline 3000 & 10,90 & 10,90 & 10,76 \\
\hline 3500 & 10,73 & 10,74 & 10,57 \\
\hline 4000 & 10,56 & 10,58 & 10,39 \\
\hline 4500 & 10,40 & 10,43 & 10,21 \\
\hline 5000 & 10,25 & 10,28 & 10,04 \\
\hline 5500 & 10,10 & 10,14 & 9,88 \\
\hline 6000 & 9,95 & 10,01 & 9,73 \\
\hline 6500 & 9,81 & 9,89 & 9,58 \\
\hline 7000 & 9,68 & 9,77 & 9,45 \\
\hline 7500 & 9,55 & 9,66 & 9,32 \\
\hline 8000 & 9,43 & 9,56 & 9,21 \\
\hline 8500 & 9,32 & 9,46 & 9,10 \\
\hline 9000 & 9,21 & 9,37 & 9,00 \\
\hline 9500 & 9,10 & 9,29 & 8,91 \\
\hline 10000 & 9,01 & 9,21 & 8,84 \\
\hline & & & \\
\hline
\end{tabular}

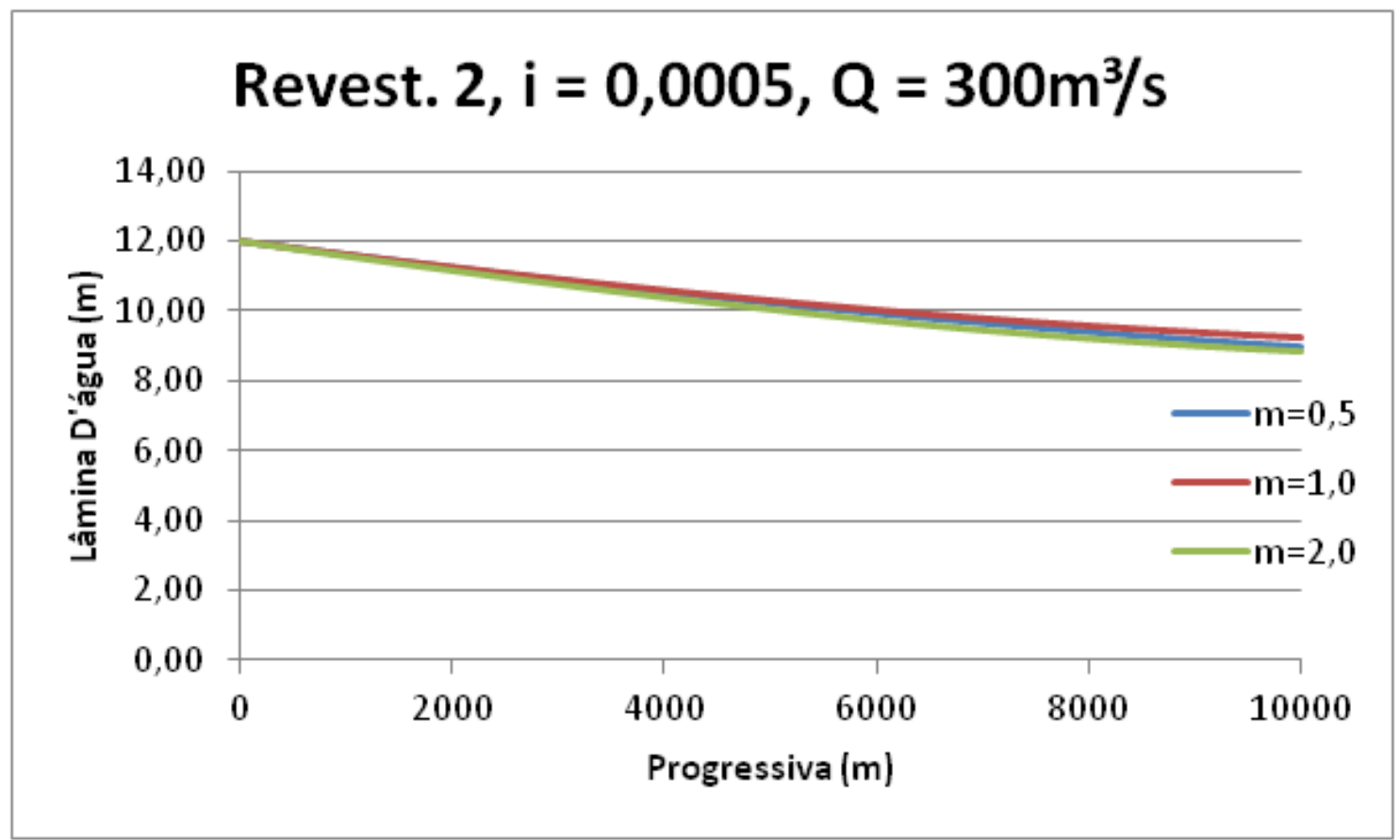




\begin{tabular}{|r|r|r|r|}
\hline \multirow{2}{*}{ Progr. } & \multicolumn{3}{|c|}{ Lâmina d'água $(\mathrm{m})$} \\
\cline { 2 - 4 } & $\mathrm{m}=0,5$ & $\mathrm{~m}=1,0$ & $\mathrm{~m}=2,0$ \\
\hline 0 & 12,00 & 12,00 & 12,00 \\
\hline 500 & 11,83 & 11,83 & 11,79 \\
\hline 1000 & 11,66 & 11,66 & 11,59 \\
\hline 1500 & 11,50 & 11,49 & 11,39 \\
\hline 2000 & 11,34 & 11,34 & 11,19 \\
\hline 2500 & 11,18 & 11,19 & 11,00 \\
\hline 3000 & 11,03 & 11,04 & 10,82 \\
\hline 3500 & 10,89 & 10,90 & 10,64 \\
\hline 4000 & 10,75 & 10,77 & 10,47 \\
\hline 4500 & 10,62 & 10,64 & 10,31 \\
\hline 5000 & 10,49 & 10,52 & 10,15 \\
\hline 5500 & 10,36 & 10,41 & 10,01 \\
\hline 6000 & 10,25 & 10,31 & 9,87 \\
\hline 6500 & 10,13 & 10,21 & 9,74 \\
\hline 7000 & 10,03 & 10,11 & 9,62 \\
\hline 7500 & 9,92 & 10,03 & 9,51 \\
\hline 8000 & 9,83 & 9,95 & 9,40 \\
\hline 8500 & 9,74 & 9,88 & 9,31 \\
\hline 9000 & 9,65 & 9,81 & 9,22 \\
\hline 9500 & 9,57 & 9,75 & 9,15 \\
\hline 10000 & 9,50 & 9,69 & 9,08 \\
\hline & & & \\
\hline
\end{tabular}

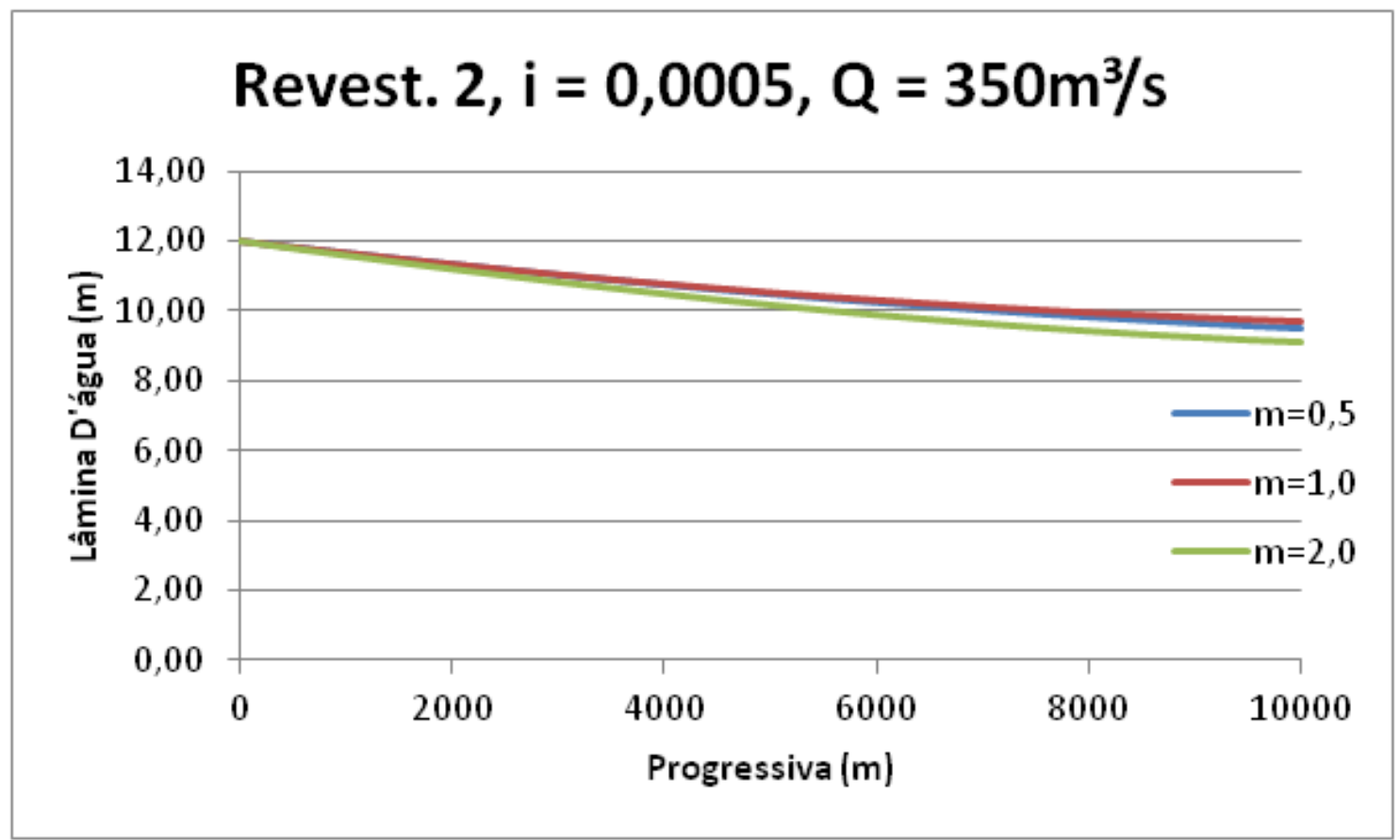




\begin{tabular}{|r|r|r|r|}
\hline \multirow{2}{*}{ Progr. } & \multicolumn{3}{|c|}{ Lâmina d'água $(\mathrm{m})$} \\
\cline { 2 - 4 } & $\mathrm{m}=0,5$ & $\mathrm{~m}=1,0$ & $\mathrm{~m}=2,0$ \\
\hline 0 & 12,00 & 12,00 & 12,00 \\
\hline 500 & 11,96 & 11,95 & 11,95 \\
\hline 1000 & 11,93 & 11,90 & 11,90 \\
\hline 1500 & 11,89 & 11,85 & 11,85 \\
\hline 2000 & 11,86 & 11,80 & 11,80 \\
\hline 2500 & 11,82 & 11,75 & 11,75 \\
\hline 3000 & 11,79 & 11,70 & 11,70 \\
\hline 3500 & 11,75 & 11,65 & 11,65 \\
\hline 4000 & 11,72 & 11,61 & 11,60 \\
\hline 4500 & 11,68 & 11,56 & 11,55 \\
\hline 5000 & 11,65 & 11,51 & 11,50 \\
\hline 5500 & 11,61 & 11,46 & 11,45 \\
\hline 6000 & 11,58 & 11,41 & 11,40 \\
\hline 6500 & 11,55 & 11,36 & 11,36 \\
\hline 7000 & 11,51 & 11,31 & 11,31 \\
\hline 7500 & 11,48 & 11,26 & 11,26 \\
\hline 8000 & 11,45 & 11,21 & 11,21 \\
\hline 8500 & 11,41 & 11,16 & 11,16 \\
\hline 9000 & 11,38 & 11,11 & 11,11 \\
\hline 9500 & 11,35 & 11,07 & 11,06 \\
\hline 10000 & 11,32 & 11,02 & 11,01 \\
\hline & & & \\
\hline
\end{tabular}

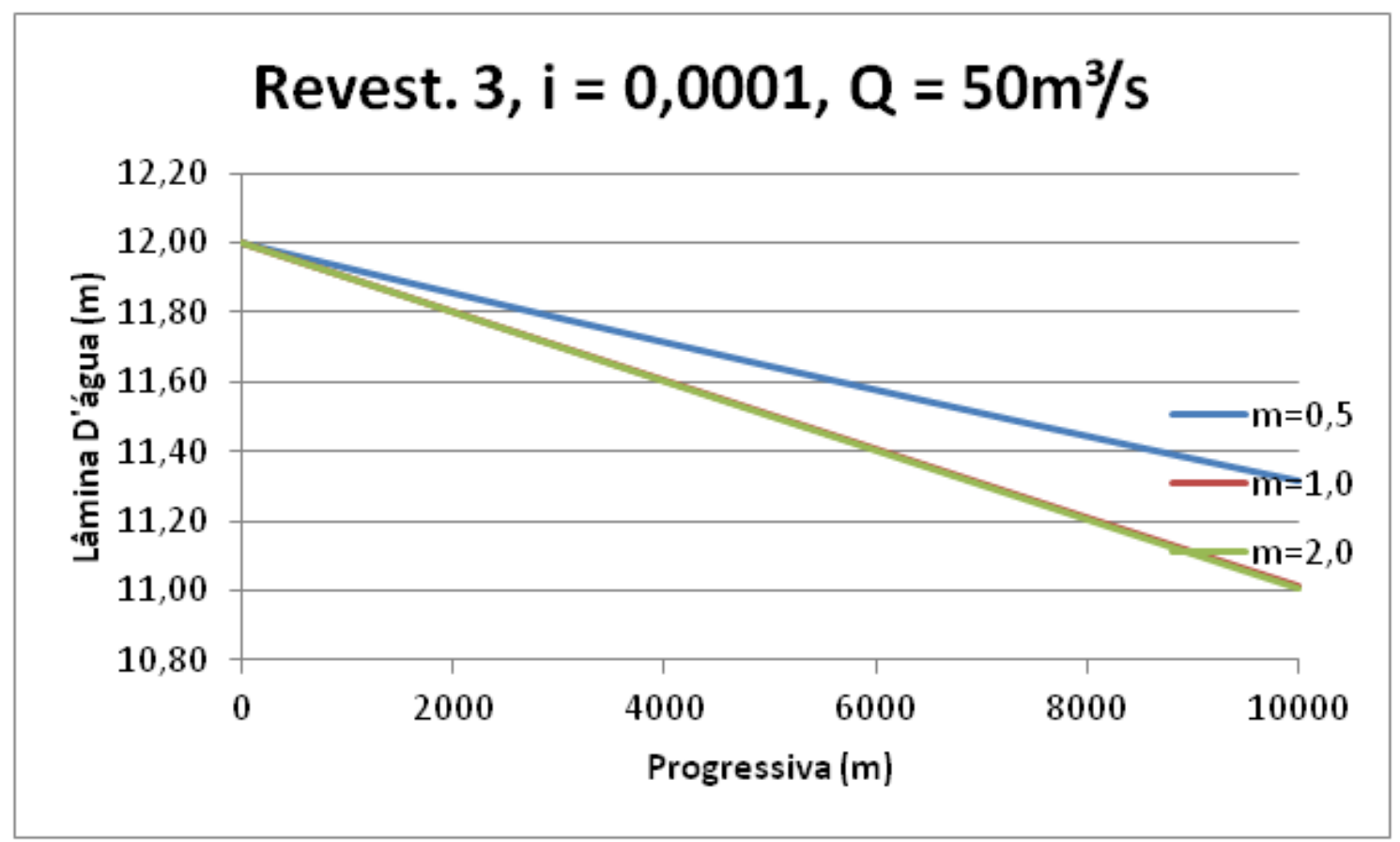




\begin{tabular}{|r|r|r|r|}
\hline \multirow{2}{*}{ Progr. } & \multicolumn{3}{|c|}{ Lâmina d'água $(\mathrm{m})$} \\
\cline { 2 - 4 } & $\mathrm{m}=0,5$ & $\mathrm{~m}=1,0$ & $\mathrm{~m}=2,0$ \\
\hline 0 & 12,00 & 12,00 & 12,00 \\
\hline 500 & 12,01 & 11,95 & 11,95 \\
\hline 1000 & 12,01 & 11,91 & 11,90 \\
\hline 1500 & 12,02 & 11,86 & 11,85 \\
\hline 2000 & 12,02 & 11,81 & 11,81 \\
\hline 2500 & 12,03 & 11,76 & 11,76 \\
\hline 3000 & 12,03 & 11,72 & 11,71 \\
\hline 3500 & 12,04 & 11,67 & 11,66 \\
\hline 4000 & 12,04 & 11,62 & 11,61 \\
\hline 4500 & 12,04 & 11,58 & 11,56 \\
\hline 5000 & 12,05 & 11,53 & 11,51 \\
\hline 5500 & 12,05 & 11,48 & 11,47 \\
\hline 6000 & 12,06 & 11,44 & 11,42 \\
\hline 6500 & 12,06 & 11,39 & 11,37 \\
\hline 7000 & 12,07 & 11,34 & 11,32 \\
\hline 7500 & 12,07 & 11,30 & 11,27 \\
\hline 8000 & 12,07 & 11,25 & 11,23 \\
\hline 8500 & 12,08 & 11,20 & 11,18 \\
\hline 9000 & 12,08 & 11,16 & 11,13 \\
\hline 9500 & 12,08 & 11,11 & 11,08 \\
\hline 10000 & 12,09 & 11,06 & 11,03 \\
\hline & & & \\
\hline
\end{tabular}

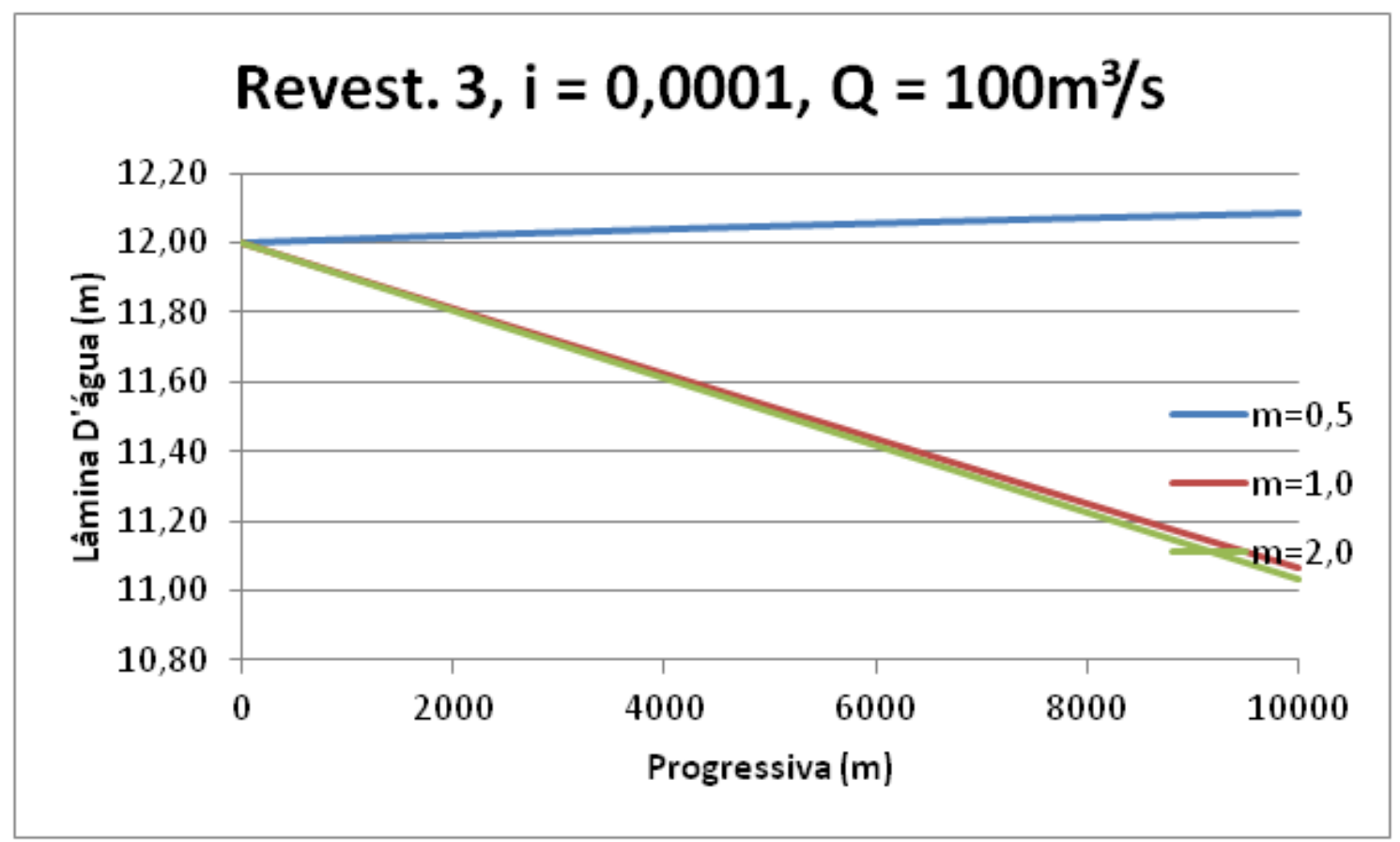




\begin{tabular}{|r|r|r|r|}
\hline \multirow{2}{*}{ Progr. } & \multicolumn{3}{|c|}{ Lâmina d'água $(\mathrm{m})$} \\
\cline { 2 - 4 } & $\mathrm{m}=0,5$ & $\mathrm{~m}=1,0$ & $\mathrm{~m}=2,0$ \\
\hline 0 & 12,00 & 12,00 & 12,00 \\
\hline 500 & 12,05 & 11,97 & 11,95 \\
\hline 1000 & 12,10 & 11,93 & 11,91 \\
\hline 1500 & 12,15 & 11,90 & 11,86 \\
\hline 2000 & 12,20 & 11,87 & 11,81 \\
\hline 2500 & 12,24 & 11,84 & 11,77 \\
\hline 3000 & 12,28 & 11,81 & 11,72 \\
\hline 3500 & 12,32 & 11,77 & 11,67 \\
\hline 4000 & 12,36 & 11,74 & 11,63 \\
\hline 4500 & 12,40 & 11,71 & 11,58 \\
\hline 5000 & 12,44 & 11,68 & 11,53 \\
\hline 5500 & 12,47 & 11,65 & 11,49 \\
\hline 6000 & 12,50 & 11,62 & 11,44 \\
\hline 6500 & 12,54 & 11,59 & 11,39 \\
\hline 7000 & 12,57 & 11,56 & 11,35 \\
\hline 7500 & 12,60 & 11,53 & 11,30 \\
\hline 8000 & 12,63 & 11,50 & 11,26 \\
\hline 8500 & 12,66 & 11,47 & 11,21 \\
\hline 9000 & 12,68 & 11,44 & 11,17 \\
\hline 9500 & 12,71 & 11,42 & 11,12 \\
\hline 10000 & 12,74 & 11,39 & 11,07 \\
\hline & & & \\
\hline
\end{tabular}

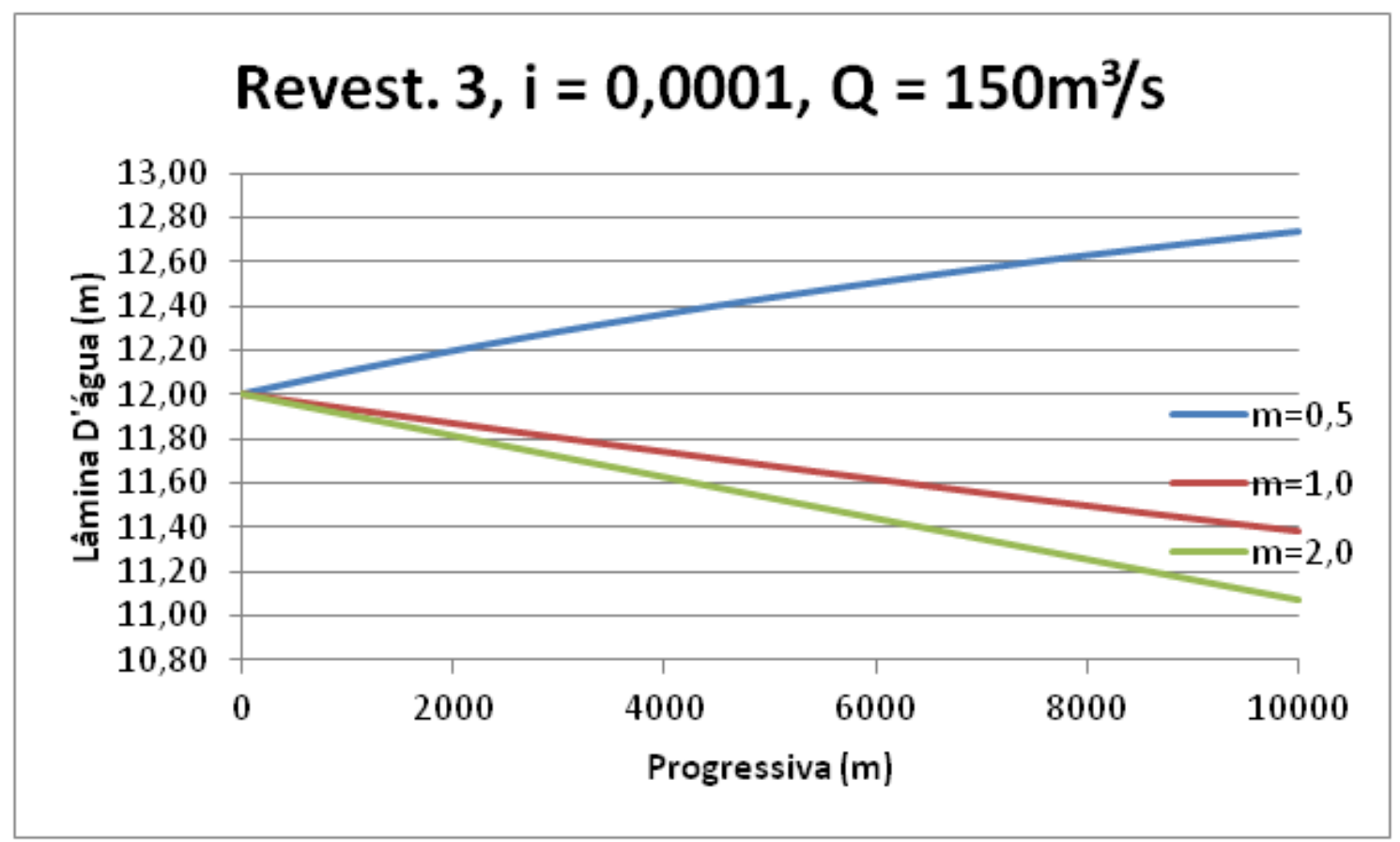




\begin{tabular}{|r|r|r|r|}
\hline \multirow{2}{*}{ Progr. } & \multicolumn{3}{|c|}{ Lâmina d'água $(\mathrm{m})$} \\
\cline { 2 - 4 } & $\mathrm{m}=0,5$ & $\mathrm{~m}=1,0$ & $\mathrm{~m}=2,0$ \\
\hline 0 & 12,00 & 12,00 & 12,00 \\
\hline 500 & 12,04 & 11,98 & 11,96 \\
\hline 1000 & 12,09 & 11,96 & 11,91 \\
\hline 1500 & 12,13 & 11,94 & 11,87 \\
\hline 2000 & 12,17 & 11,92 & 11,82 \\
\hline 2500 & 12,21 & 11,90 & 11,78 \\
\hline 3000 & 12,25 & 11,89 & 11,73 \\
\hline 3500 & 12,28 & 11,87 & 11,69 \\
\hline 4000 & 12,32 & 11,85 & 11,65 \\
\hline 4500 & 12,35 & 11,83 & 11,60 \\
\hline 5000 & 12,38 & 11,82 & 11,56 \\
\hline 5500 & 12,42 & 11,80 & 11,52 \\
\hline 6000 & 12,45 & 11,78 & 11,47 \\
\hline 6500 & 12,48 & 11,77 & 11,43 \\
\hline 7000 & 12,50 & 11,75 & 11,39 \\
\hline 7500 & 12,53 & 11,73 & 11,34 \\
\hline 8000 & 12,56 & 11,72 & 11,30 \\
\hline 8500 & 12,59 & 11,70 & 11,26 \\
\hline 9000 & 12,61 & 11,69 & 11,22 \\
\hline 9500 & 12,64 & 11,67 & 11,17 \\
\hline 10000 & 12,66 & 11,66 & 11,13 \\
\hline & & & \\
\hline
\end{tabular}

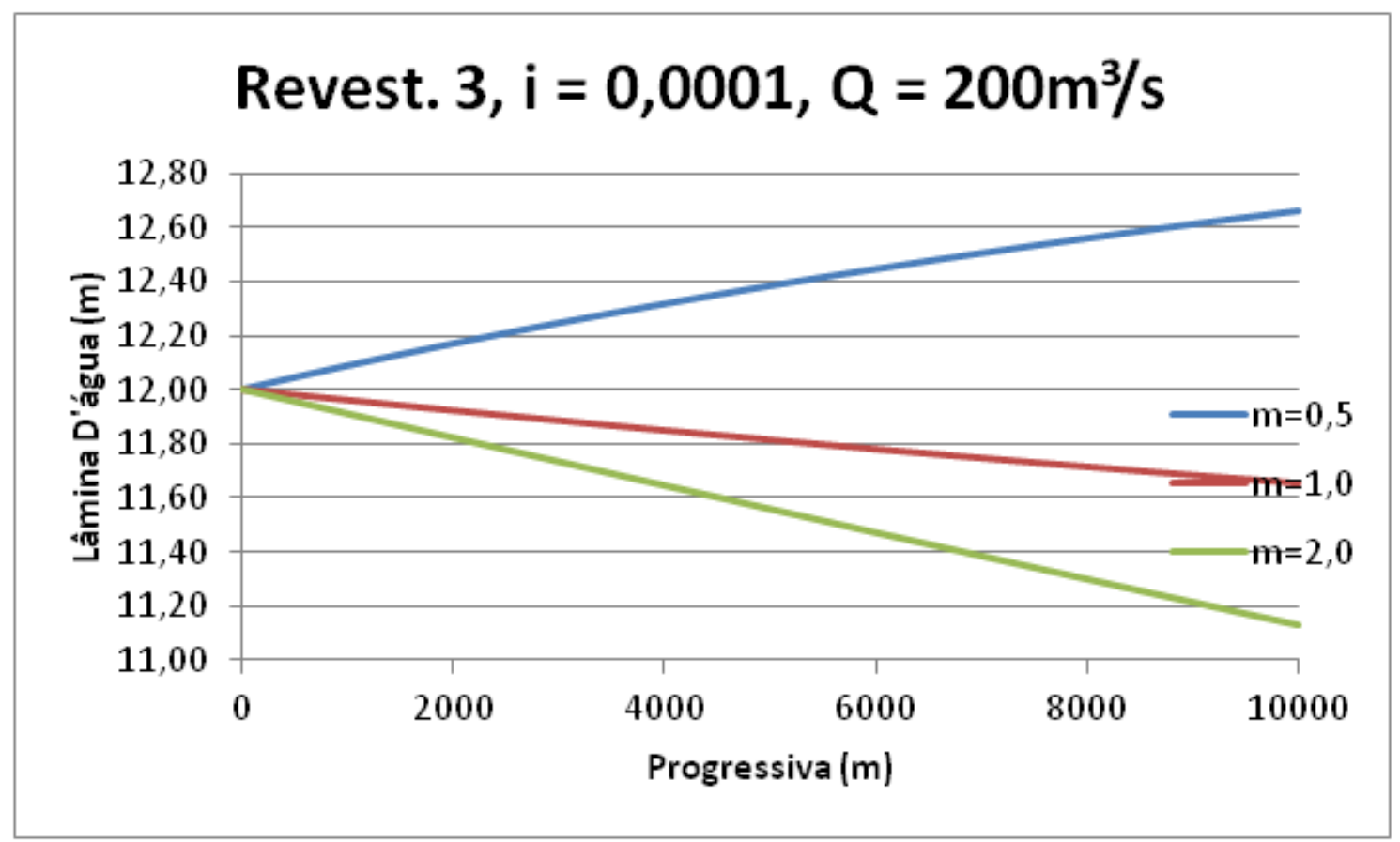




\begin{tabular}{|r|r|r|r|}
\hline \multirow{2}{*}{ Progr. } & \multicolumn{3}{|c|}{ Lâmina d'água $(\mathrm{m})$} \\
\cline { 2 - 4 } & $\mathrm{m}=0,5$ & $\mathrm{~m}=1,0$ & $\mathrm{~m}=2,0$ \\
\hline 0 & 12,00 & 12,00 & 12,00 \\
\hline 500 & 12,04 & 12,00 & 11,96 \\
\hline 1000 & 12,08 & 12,00 & 11,92 \\
\hline 1500 & 12,11 & 11,99 & 11,88 \\
\hline 2000 & 12,15 & 11,99 & 11,83 \\
\hline 2500 & 12,18 & 11,99 & 11,79 \\
\hline 3000 & 12,22 & 11,99 & 11,75 \\
\hline 3500 & 12,25 & 11,99 & 11,71 \\
\hline 4000 & 12,28 & 11,99 & 11,67 \\
\hline 4500 & 12,31 & 11,98 & 11,63 \\
\hline 5000 & 12,34 & 11,98 & 11,59 \\
\hline 5500 & 12,37 & 11,98 & 11,55 \\
\hline 6000 & 12,40 & 11,98 & 11,51 \\
\hline 6500 & 12,42 & 11,98 & 11,47 \\
\hline 7000 & 12,45 & 11,98 & 11,43 \\
\hline 7500 & 12,48 & 11,98 & 11,40 \\
\hline 8000 & 12,50 & 11,97 & 11,36 \\
\hline 8500 & 12,52 & 11,97 & 11,32 \\
\hline 9000 & 12,55 & 11,97 & 11,28 \\
\hline 9500 & 12,57 & 11,97 & 11,24 \\
\hline 10000 & 12,59 & 11,97 & 11,20 \\
\hline & & & \\
\hline
\end{tabular}

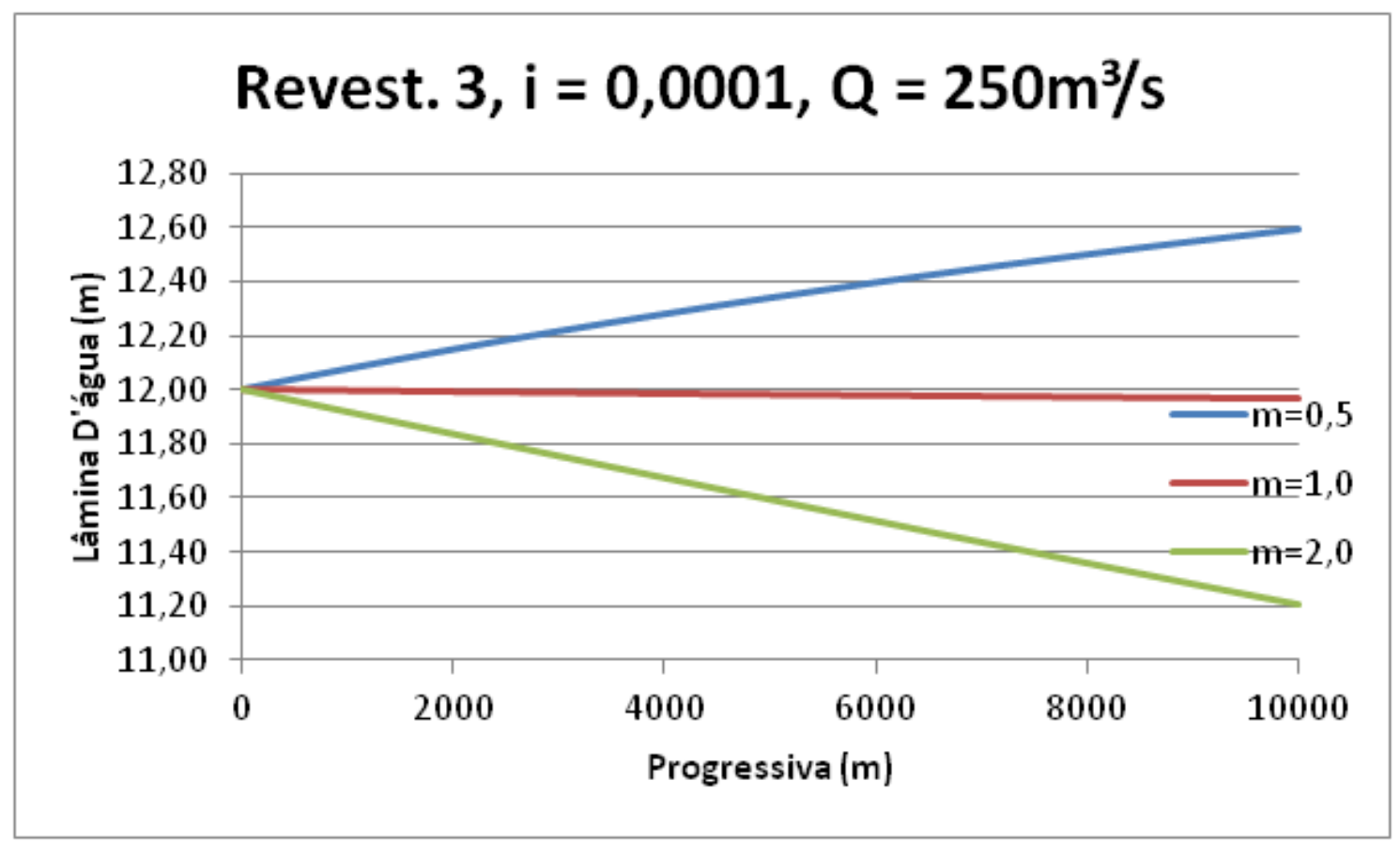




\begin{tabular}{|r|r|r|r|}
\hline \multirow{2}{*}{ Progr. } & \multicolumn{3}{|c|}{ Lâmina d'água $(\mathrm{m})$} \\
\cline { 2 - 4 } & $\mathrm{m}=0,5$ & $\mathrm{~m}=1,0$ & $\mathrm{~m}=2,0$ \\
\hline 0 & 12,00 & 12,00 & 12,00 \\
\hline 500 & 12,05 & 12,02 & 11,96 \\
\hline 1000 & 12,11 & 12,04 & 11,92 \\
\hline 1500 & 12,16 & 12,06 & 11,89 \\
\hline 2000 & 12,21 & 12,08 & 11,85 \\
\hline 2500 & 12,25 & 12,10 & 11,81 \\
\hline 3000 & 12,30 & 12,11 & 11,78 \\
\hline 3500 & 12,34 & 12,13 & 11,74 \\
\hline 4000 & 12,39 & 12,15 & 11,70 \\
\hline 4500 & 12,43 & 12,16 & 11,67 \\
\hline 5000 & 12,47 & 12,18 & 11,63 \\
\hline 5500 & 12,51 & 12,19 & 11,60 \\
\hline 6000 & 12,54 & 12,21 & 11,56 \\
\hline 6500 & 12,58 & 12,22 & 11,53 \\
\hline 7000 & 12,61 & 12,23 & 11,49 \\
\hline 7500 & 12,65 & 12,25 & 11,46 \\
\hline 8000 & 12,68 & 12,26 & 11,42 \\
\hline 8500 & 12,71 & 12,27 & 11,39 \\
\hline 9000 & 12,75 & 12,29 & 11,36 \\
\hline 9500 & 12,78 & 12,30 & 11,32 \\
\hline 10000 & 12,81 & 12,31 & 11,29 \\
\hline & & & \\
\hline
\end{tabular}

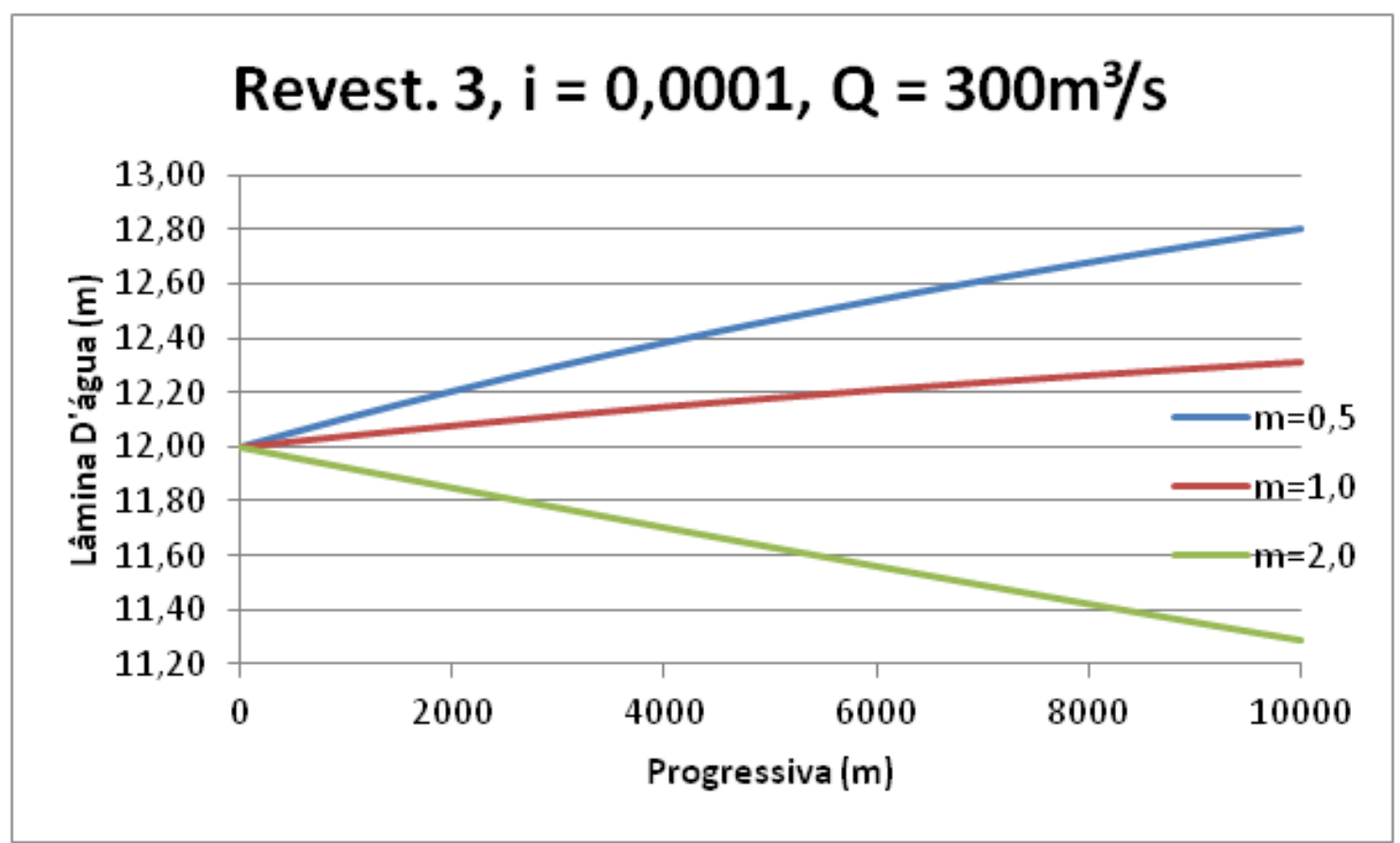




\begin{tabular}{|r|r|r|r|}
\hline \multirow{2}{*}{ Progr. } & \multicolumn{3}{|c|}{ Lâmina d'água $(\mathrm{m})$} \\
\cline { 2 - 4 } & $\mathrm{m}=0,5$ & $\mathrm{~m}=1,0$ & $\mathrm{~m}=2,0$ \\
\hline 0 & 12,00 & 12,00 & 12,00 \\
\hline 500 & 12,04 & 12,05 & 11,97 \\
\hline 1000 & 12,08 & 12,09 & 11,93 \\
\hline 1500 & 12,12 & 12,14 & 11,90 \\
\hline 2000 & 12,15 & 12,18 & 11,87 \\
\hline 2500 & 12,19 & 12,22 & 11,84 \\
\hline 3000 & 12,22 & 12,26 & 11,80 \\
\hline 3500 & 12,26 & 12,29 & 11,77 \\
\hline 4000 & 12,29 & 12,33 & 11,74 \\
\hline 4500 & 12,32 & 12,36 & 11,71 \\
\hline 5000 & 12,35 & 12,40 & 11,68 \\
\hline 5500 & 12,38 & 12,43 & 11,65 \\
\hline 6000 & 12,41 & 12,46 & 11,62 \\
\hline 6500 & 12,44 & 12,49 & 11,59 \\
\hline 7000 & 12,47 & 12,52 & 11,56 \\
\hline 7500 & 12,50 & 12,54 & 11,53 \\
\hline 8000 & 12,52 & 12,57 & 11,50 \\
\hline 8500 & 12,55 & 12,59 & 11,47 \\
\hline 9000 & 12,57 & 12,62 & 11,44 \\
\hline 9500 & 12,60 & 12,64 & 11,42 \\
\hline 10000 & 12,62 & 12,67 & 11,39 \\
\hline & & & \\
\hline
\end{tabular}

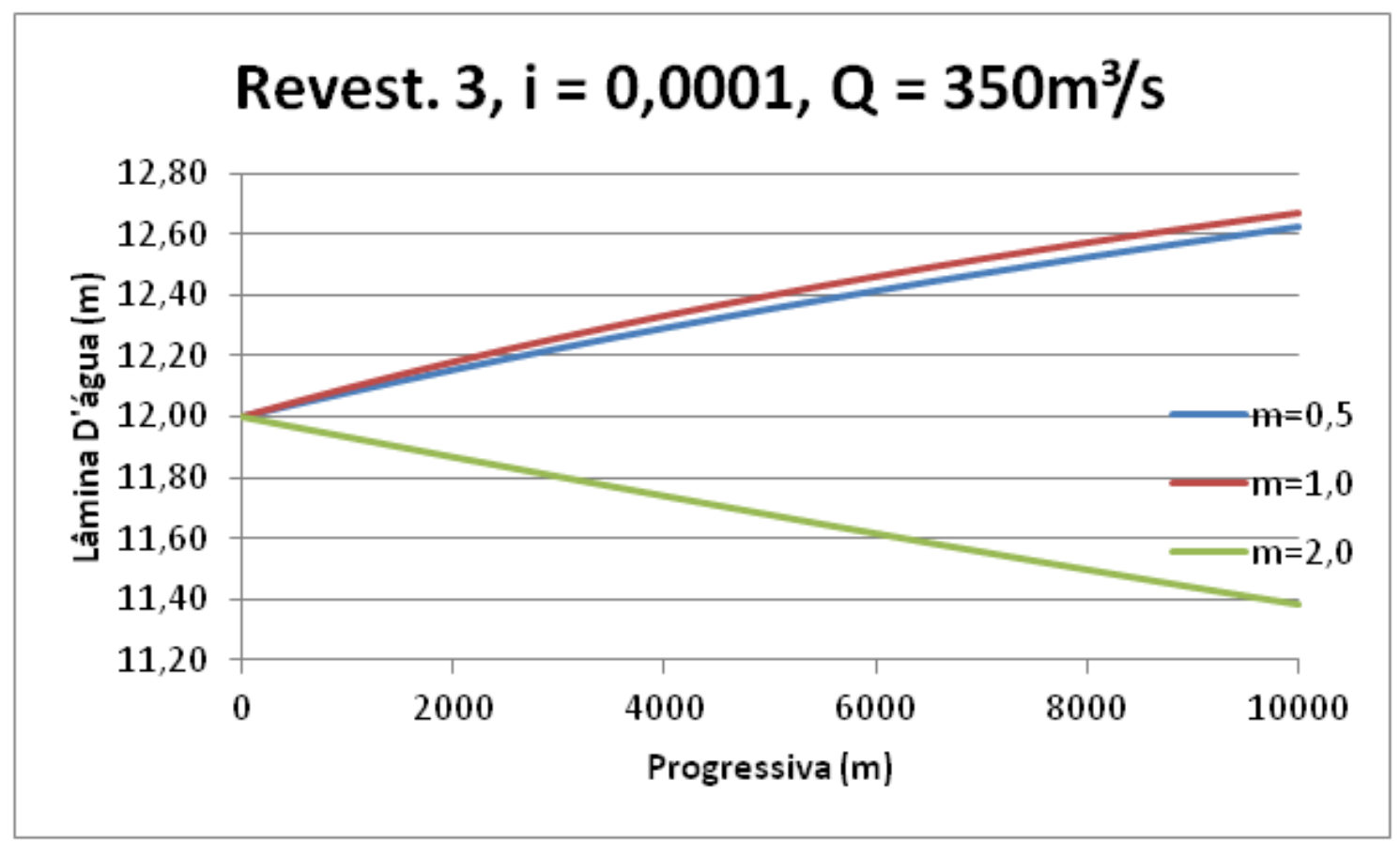




\begin{tabular}{|r|r|r|r|}
\hline \multirow{2}{*}{ Progr. } & \multicolumn{3}{|c|}{ Lâmina d'água $(\mathrm{m})$} \\
\cline { 2 - 4 } & $\mathrm{m}=0,5$ & $\mathrm{~m}=1,0$ & $\mathrm{~m}=2,0$ \\
\hline 0 & 12,00 & 12,00 & 12,00 \\
\hline 500 & 11,91 & 11,90 & 11,90 \\
\hline 1000 & 11,83 & 11,80 & 11,80 \\
\hline 1500 & 11,74 & 11,70 & 11,70 \\
\hline 2000 & 11,66 & 11,60 & 11,60 \\
\hline 2500 & 11,57 & 11,50 & 11,50 \\
\hline 3000 & 11,49 & 11,40 & 11,40 \\
\hline 3500 & 11,41 & 11,30 & 11,30 \\
\hline 4000 & 11,32 & 11,21 & 11,20 \\
\hline 4500 & 11,24 & 11,11 & 11,10 \\
\hline 5000 & 11,16 & 11,01 & 11,00 \\
\hline 5500 & 11,08 & 10,91 & 10,90 \\
\hline 6000 & 11,00 & 10,81 & 10,80 \\
\hline 6500 & 10,92 & 10,71 & 10,71 \\
\hline 7000 & 10,84 & 10,61 & 10,61 \\
\hline 7500 & 10,77 & 10,51 & 10,51 \\
\hline 8000 & 10,69 & 10,41 & 10,41 \\
\hline 8500 & 10,62 & 10,31 & 10,31 \\
\hline 9000 & 10,54 & 10,21 & 10,21 \\
\hline 9500 & 10,47 & 10,12 & 10,11 \\
\hline 10000 & 10,40 & 10,02 & 10,01 \\
\hline & & & \\
\hline
\end{tabular}

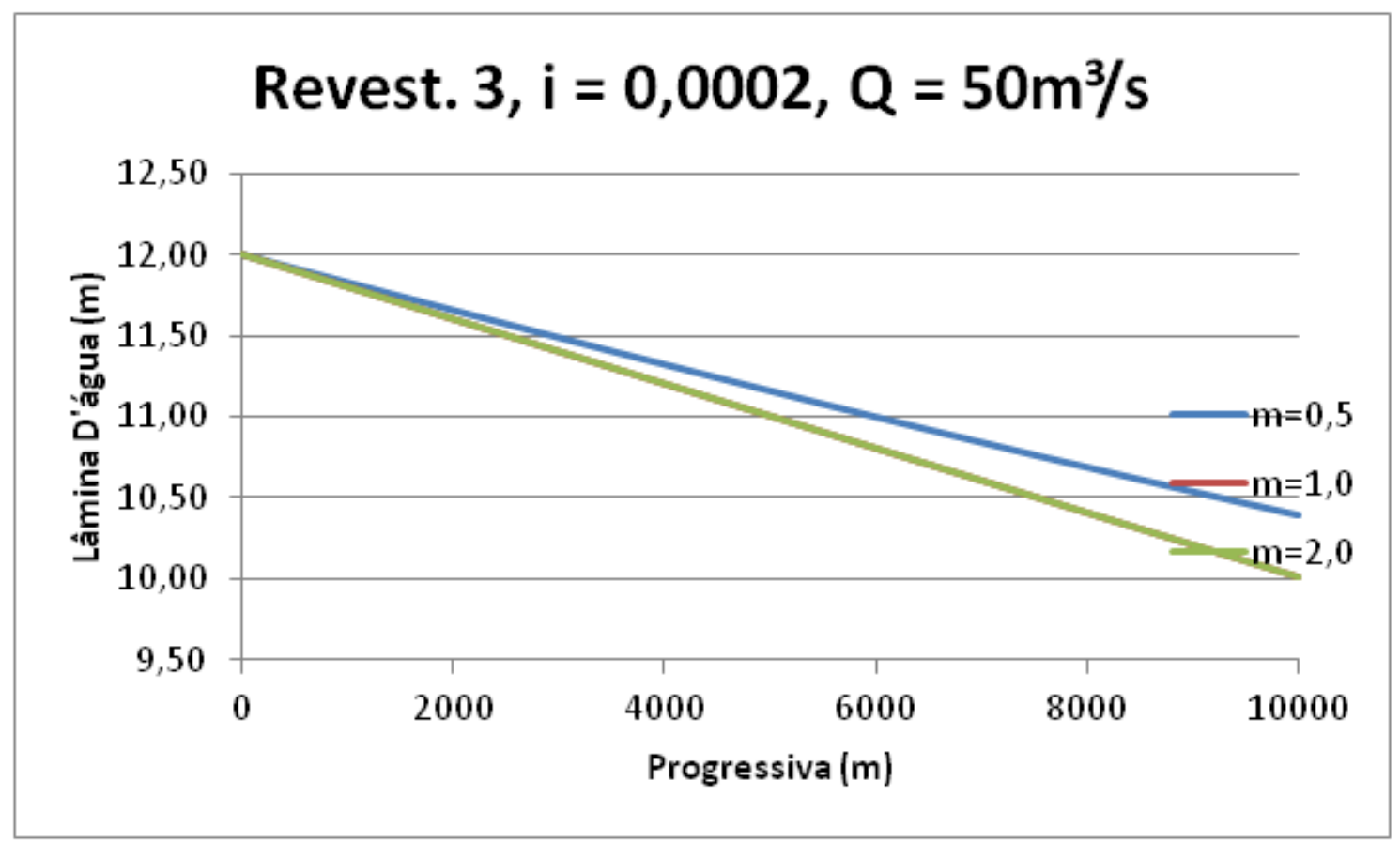




\begin{tabular}{|r|r|r|r|}
\hline \multirow{2}{*}{ Progr. } & \multicolumn{3}{|c|}{ Lâmina d'água $(\mathrm{m})$} \\
\cline { 2 - 4 } & $\mathrm{m}=0,5$ & $\mathrm{~m}=1,0$ & $\mathrm{~m}=2,0$ \\
\hline 0 & 12,00 & 12,00 & 12,00 \\
\hline 500 & 11,95 & 11,90 & 11,90 \\
\hline 1000 & 11,91 & 11,80 & 11,80 \\
\hline 1500 & 11,87 & 11,71 & 11,70 \\
\hline 2000 & 11,82 & 11,61 & 11,61 \\
\hline 2500 & 11,78 & 11,51 & 11,51 \\
\hline 3000 & 11,74 & 11,42 & 11,41 \\
\hline 3500 & 11,70 & 11,32 & 11,31 \\
\hline 4000 & 11,67 & 11,22 & 11,21 \\
\hline 4500 & 11,63 & 11,12 & 11,11 \\
\hline 5000 & 11,60 & 11,03 & 11,02 \\
\hline 5500 & 11,56 & 10,93 & 10,92 \\
\hline 6000 & 11,53 & 10,84 & 10,82 \\
\hline 6500 & 11,50 & 10,74 & 10,72 \\
\hline 7000 & 11,46 & 10,64 & 10,62 \\
\hline 7500 & 11,43 & 10,55 & 10,53 \\
\hline 8000 & 11,40 & 10,45 & 10,43 \\
\hline 8500 & 11,38 & 10,36 & 10,33 \\
\hline 9000 & 11,35 & 10,26 & 10,23 \\
\hline 9500 & 11,32 & 10,16 & 10,14 \\
\hline 10000 & 11,30 & 10,07 & 10,04 \\
\hline & & & \\
\hline
\end{tabular}

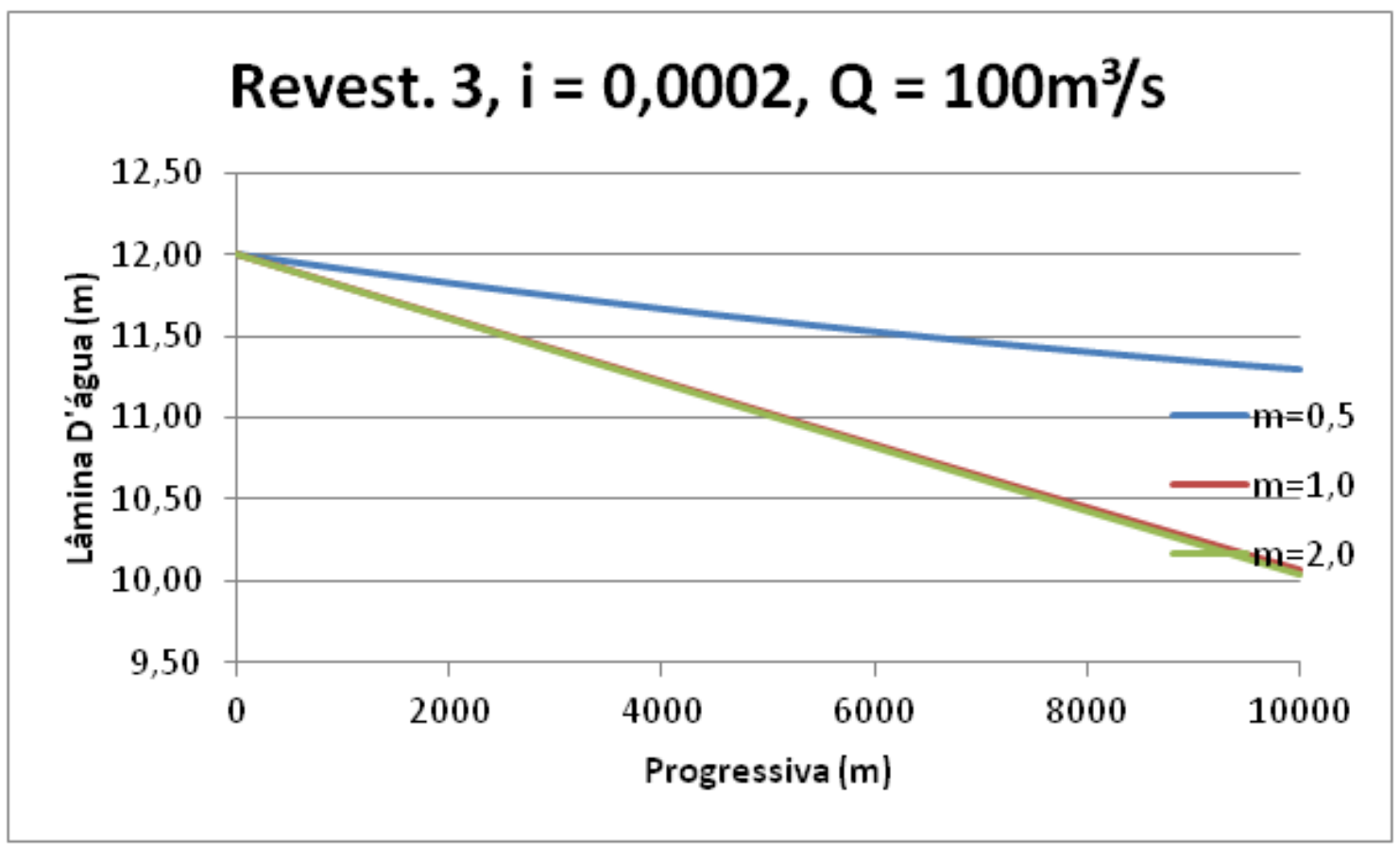




\begin{tabular}{|r|r|r|r|}
\hline \multirow{2}{*}{ Progr. } & \multicolumn{3}{|c|}{ Lâmina d'água $(\mathrm{m})$} \\
\cline { 2 - 4 } & $\mathrm{m}=0,5$ & $\mathrm{~m}=1,0$ & $\mathrm{~m}=2,0$ \\
\hline 0 & 12,00 & 12,00 & 12,00 \\
\hline 500 & 11,98 & 11,91 & 11,90 \\
\hline 1000 & 11,97 & 11,81 & 11,81 \\
\hline 1500 & 11,95 & 11,72 & 11,71 \\
\hline 2000 & 11,94 & 11,62 & 11,61 \\
\hline 2500 & 11,92 & 11,53 & 11,52 \\
\hline 3000 & 11,91 & 11,44 & 11,42 \\
\hline 3500 & 11,90 & 11,34 & 11,32 \\
\hline 4000 & 11,88 & 11,25 & 11,23 \\
\hline 4500 & 11,87 & 11,16 & 11,13 \\
\hline 5000 & 11,86 & 11,06 & 11,03 \\
\hline 5500 & 11,85 & 10,97 & 10,94 \\
\hline 6000 & 11,84 & 10,88 & 10,84 \\
\hline 6500 & 11,83 & 10,79 & 10,75 \\
\hline 7000 & 11,82 & 10,70 & 10,65 \\
\hline 7500 & 11,81 & 10,60 & 10,56 \\
\hline 8000 & 11,80 & 10,51 & 10,47 \\
\hline 8500 & 11,79 & 10,42 & 10,37 \\
\hline 9000 & 11,78 & 10,33 & 10,28 \\
\hline 9500 & 11,77 & 10,24 & 10,18 \\
\hline 10000 & 11,76 & 10,15 & 10,09 \\
\hline & & & \\
\hline
\end{tabular}

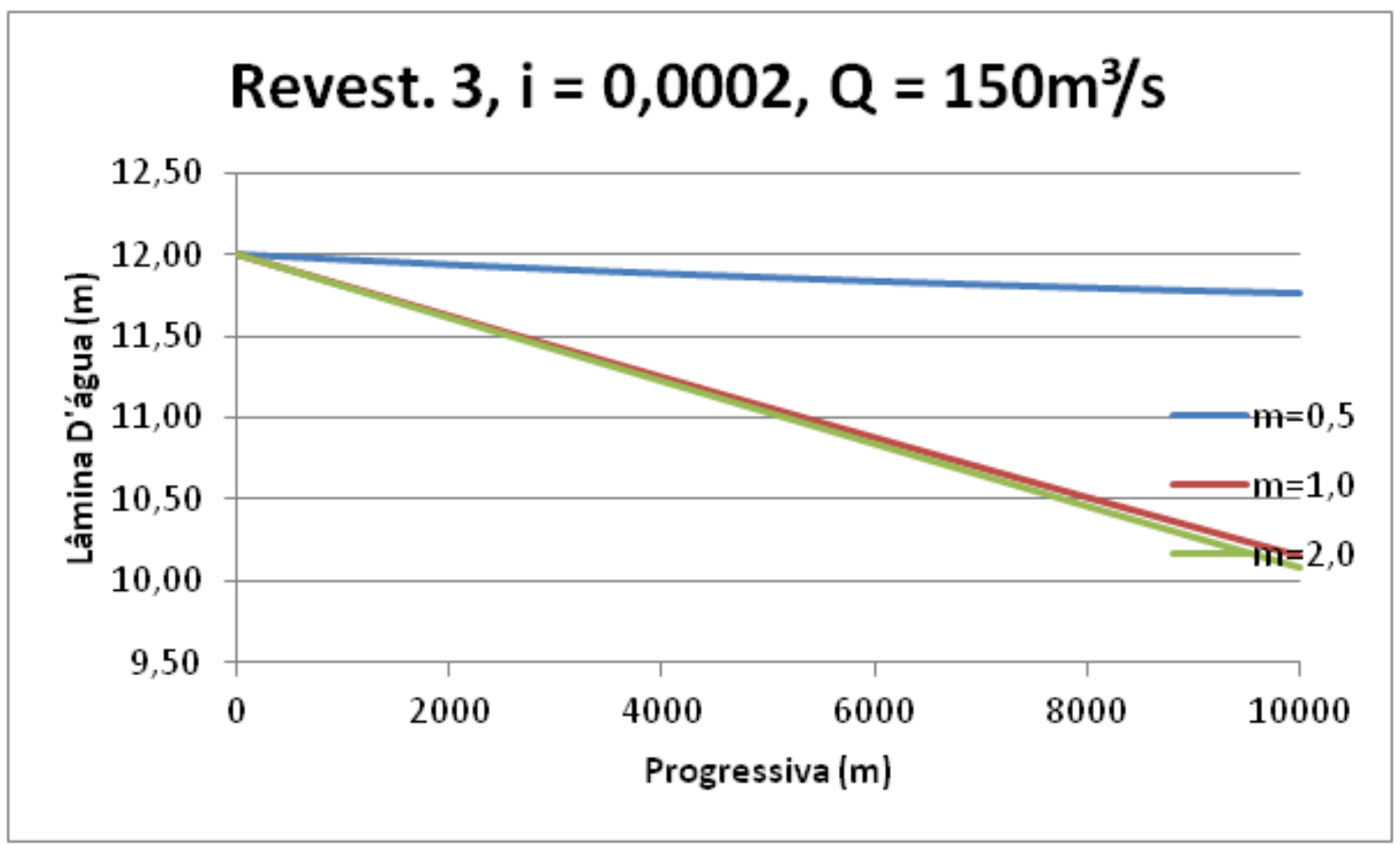




\begin{tabular}{|r|r|r|r|}
\hline \multirow{2}{*}{ Progr. } & \multicolumn{3}{|c|}{ Lâmina d'água $(\mathrm{m})$} \\
\cline { 2 - 4 } & $\mathrm{m}=0,5$ & $\mathrm{~m}=1,0$ & $\mathrm{~m}=2,0$ \\
\hline 0 & 12,00 & 12,00 & 12,00 \\
\hline 500 & 11,98 & 11,91 & 11,91 \\
\hline 1000 & 11,96 & 11,82 & 11,81 \\
\hline 1500 & 11,94 & 11,73 & 11,72 \\
\hline 2000 & 11,92 & 11,64 & 11,62 \\
\hline 2500 & 11,90 & 11,55 & 11,53 \\
\hline 3000 & 11,89 & 11,46 & 11,43 \\
\hline 3500 & 11,87 & 11,37 & 11,34 \\
\hline 4000 & 11,85 & 11,29 & 11,25 \\
\hline 4500 & 11,84 & 11,20 & 11,15 \\
\hline 5000 & 11,82 & 11,11 & 11,06 \\
\hline 5500 & 11,81 & 11,03 & 10,97 \\
\hline 6000 & 11,79 & 10,94 & 10,88 \\
\hline 6500 & 11,78 & 10,85 & 10,79 \\
\hline 7000 & 11,76 & 10,77 & 10,70 \\
\hline 7500 & 11,75 & 10,68 & 10,61 \\
\hline 8000 & 11,74 & 10,60 & 10,52 \\
\hline 8500 & 11,73 & 10,52 & 10,43 \\
\hline 9000 & 11,72 & 10,43 & 10,34 \\
\hline 9500 & 11,70 & 10,35 & 10,25 \\
\hline 10000 & 11,69 & 10,27 & 10,16 \\
\hline & & & \\
\hline
\end{tabular}

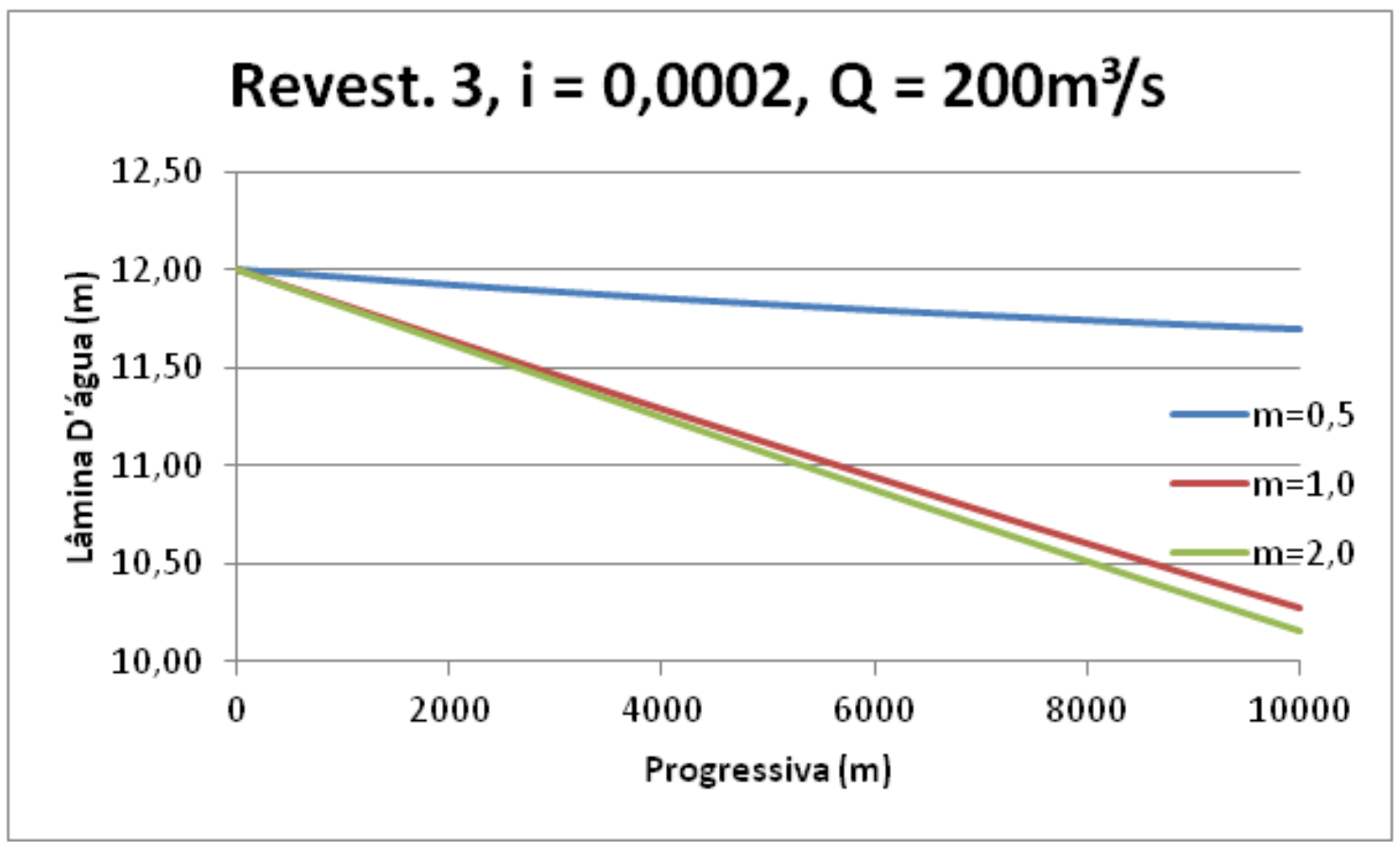




\begin{tabular}{|r|r|r|r|}
\hline \multirow{2}{*}{ Progr. } & \multicolumn{3}{|c|}{ Lâmina d'água $(\mathrm{m})$} \\
\cline { 2 - 4 } & $\mathrm{m}=0,5$ & $\mathrm{~m}=1,0$ & $\mathrm{~m}=2,0$ \\
\hline 0 & 12,00 & 12,00 & 12,00 \\
\hline 500 & 11,99 & 11,91 & 11,91 \\
\hline 1000 & 11,98 & 11,83 & 11,82 \\
\hline 1500 & 11,97 & 11,75 & 11,72 \\
\hline 2000 & 11,96 & 11,66 & 11,63 \\
\hline 2500 & 11,95 & 11,58 & 11,54 \\
\hline 3000 & 11,94 & 11,50 & 11,45 \\
\hline 3500 & 11,93 & 11,42 & 11,36 \\
\hline 4000 & 11,93 & 11,33 & 11,27 \\
\hline 4500 & 11,92 & 11,25 & 11,18 \\
\hline 5000 & 11,91 & 11,17 & 11,10 \\
\hline 5500 & 11,90 & 11,09 & 11,01 \\
\hline 6000 & 11,89 & 11,02 & 10,92 \\
\hline 6500 & 11,89 & 10,94 & 10,83 \\
\hline 7000 & 11,88 & 10,86 & 10,75 \\
\hline 7500 & 11,87 & 10,78 & 10,66 \\
\hline 8000 & 11,87 & 10,71 & 10,58 \\
\hline 8500 & 11,86 & 10,63 & 10,49 \\
\hline 9000 & 11,86 & 10,56 & 10,41 \\
\hline 9500 & 11,85 & 10,49 & 10,33 \\
\hline 10000 & 11,85 & 10,41 & 10,25 \\
\hline & & & \\
\hline
\end{tabular}

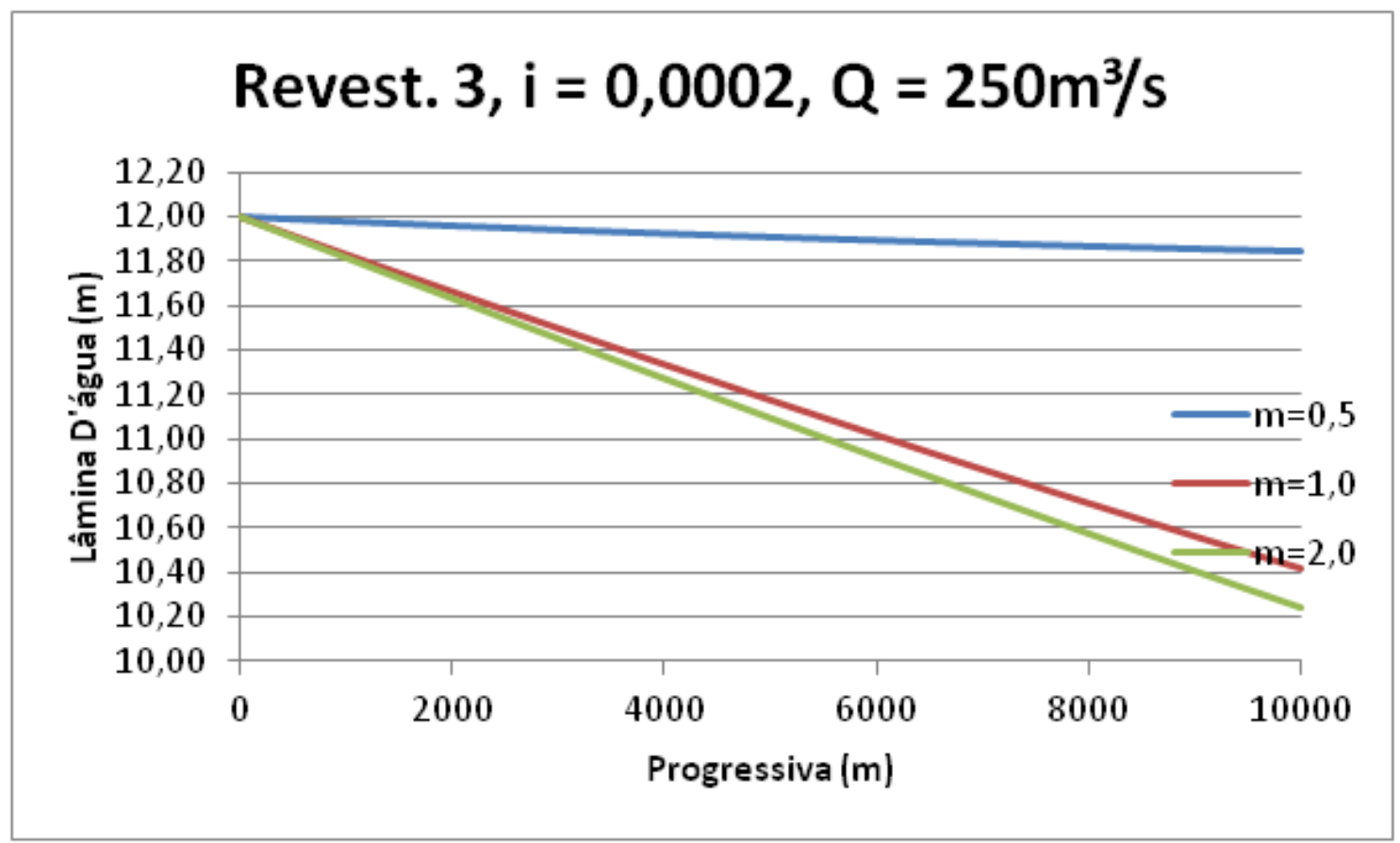




\begin{tabular}{|r|r|r|r|}
\hline \multirow{2}{*}{ Progr. } & \multicolumn{3}{|c|}{ Lâmina d'água $(\mathrm{m})$} \\
\cline { 2 - 4 } & $\mathrm{m}=0,5$ & $\mathrm{~m}=1,0$ & $\mathrm{~m}=2,0$ \\
\hline 0 & 12,00 & 12,00 & 12,00 \\
\hline 500 & 11,99 & 11,92 & 11,91 \\
\hline 1000 & 11,97 & 11,84 & 11,82 \\
\hline 1500 & 11,96 & 11,77 & 11,74 \\
\hline 2000 & 11,95 & 11,69 & 11,65 \\
\hline 2500 & 11,93 & 11,62 & 11,56 \\
\hline 3000 & 11,92 & 11,54 & 11,48 \\
\hline 3500 & 11,91 & 11,47 & 11,39 \\
\hline 4000 & 11,90 & 11,39 & 11,31 \\
\hline 4500 & 11,89 & 11,32 & 11,22 \\
\hline 5000 & 11,88 & 11,25 & 11,14 \\
\hline 5500 & 11,87 & 11,18 & 11,06 \\
\hline 6000 & 11,86 & 11,11 & 10,97 \\
\hline 6500 & 11,85 & 11,04 & 10,89 \\
\hline 7000 & 11,84 & 10,97 & 10,81 \\
\hline 7500 & 11,83 & 10,90 & 10,73 \\
\hline 8000 & 11,82 & 10,84 & 10,65 \\
\hline 8500 & 11,81 & 10,77 & 10,58 \\
\hline 9000 & 11,80 & 10,71 & 10,50 \\
\hline 9500 & 11,79 & 10,65 & 10,42 \\
\hline 10000 & 11,79 & 10,58 & 10,35 \\
\hline & & & \\
\hline
\end{tabular}

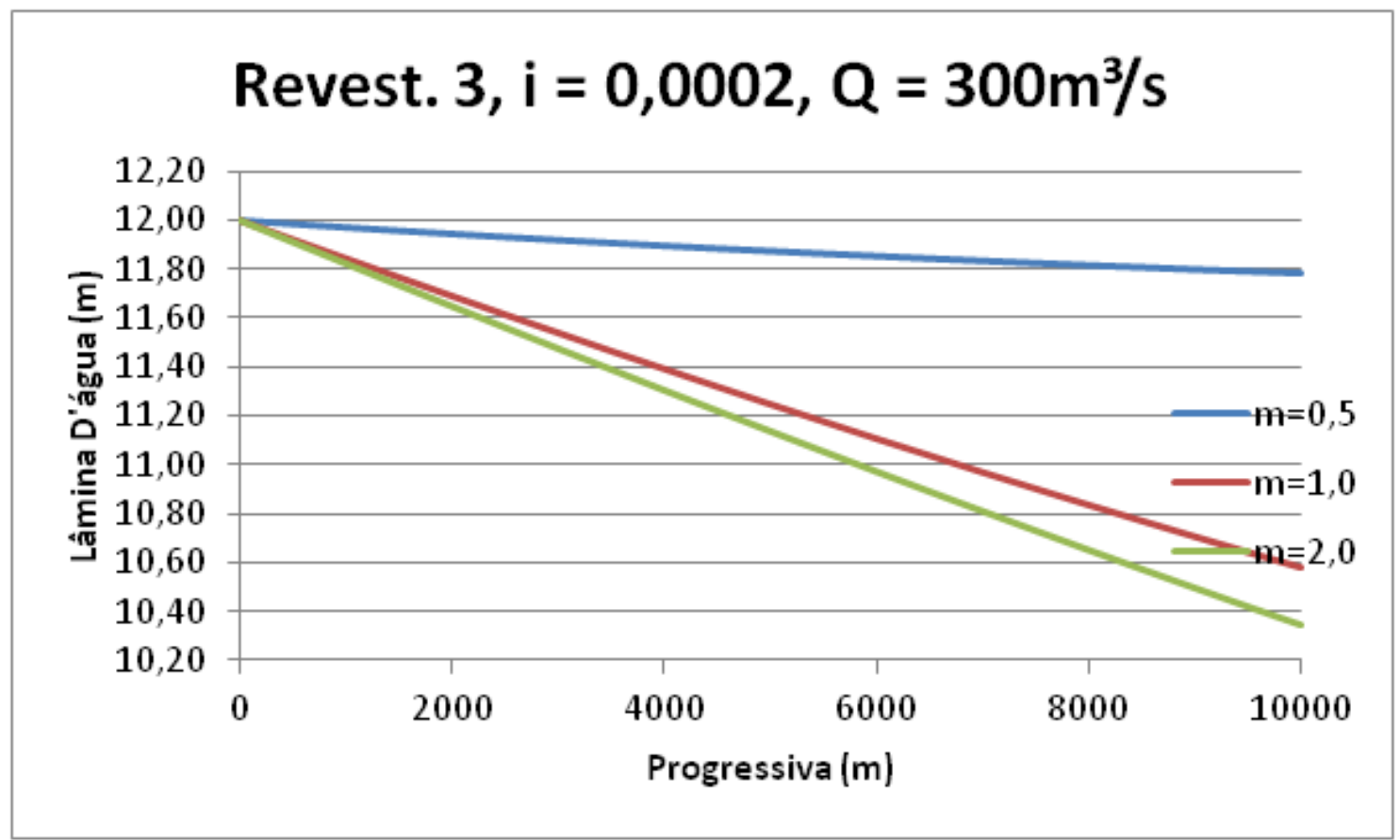




\begin{tabular}{|r|r|r|r|}
\hline \multirow{2}{*}{ Progr. } & \multicolumn{3}{|c|}{ Lâmina d'água $(\mathrm{m})$} \\
\cline { 2 - 4 } & $\mathrm{m}=0,5$ & $\mathrm{~m}=1,0$ & $\mathrm{~m}=2,0$ \\
\hline 0 & 12,00 & 12,00 & 12,00 \\
\hline 500 & 11,99 & 11,93 & 11,92 \\
\hline 1000 & 11,98 & 11,86 & 11,83 \\
\hline 1500 & 11,97 & 11,79 & 11,75 \\
\hline 2000 & 11,97 & 11,72 & 11,67 \\
\hline 2500 & 11,96 & 11,66 & 11,58 \\
\hline 3000 & 11,95 & 11,59 & 11,50 \\
\hline 3500 & 11,94 & 11,53 & 11,42 \\
\hline 4000 & 11,94 & 11,46 & 11,34 \\
\hline 4500 & 11,93 & 11,40 & 11,27 \\
\hline 5000 & 11,92 & 11,34 & 11,19 \\
\hline 5500 & 11,92 & 11,28 & 11,11 \\
\hline 6000 & 11,91 & 11,22 & 11,04 \\
\hline 6500 & 11,90 & 11,16 & 10,96 \\
\hline 7000 & 11,90 & 11,10 & 10,89 \\
\hline 7500 & 11,89 & 11,04 & 10,81 \\
\hline 8000 & 11,89 & 10,99 & 10,74 \\
\hline 8500 & 11,88 & 10,93 & 10,67 \\
\hline 9000 & 11,88 & 10,88 & 10,60 \\
\hline 9500 & 11,87 & 10,82 & 10,53 \\
\hline 10000 & 11,87 & 10,77 & 10,46 \\
\hline & & & \\
\hline
\end{tabular}

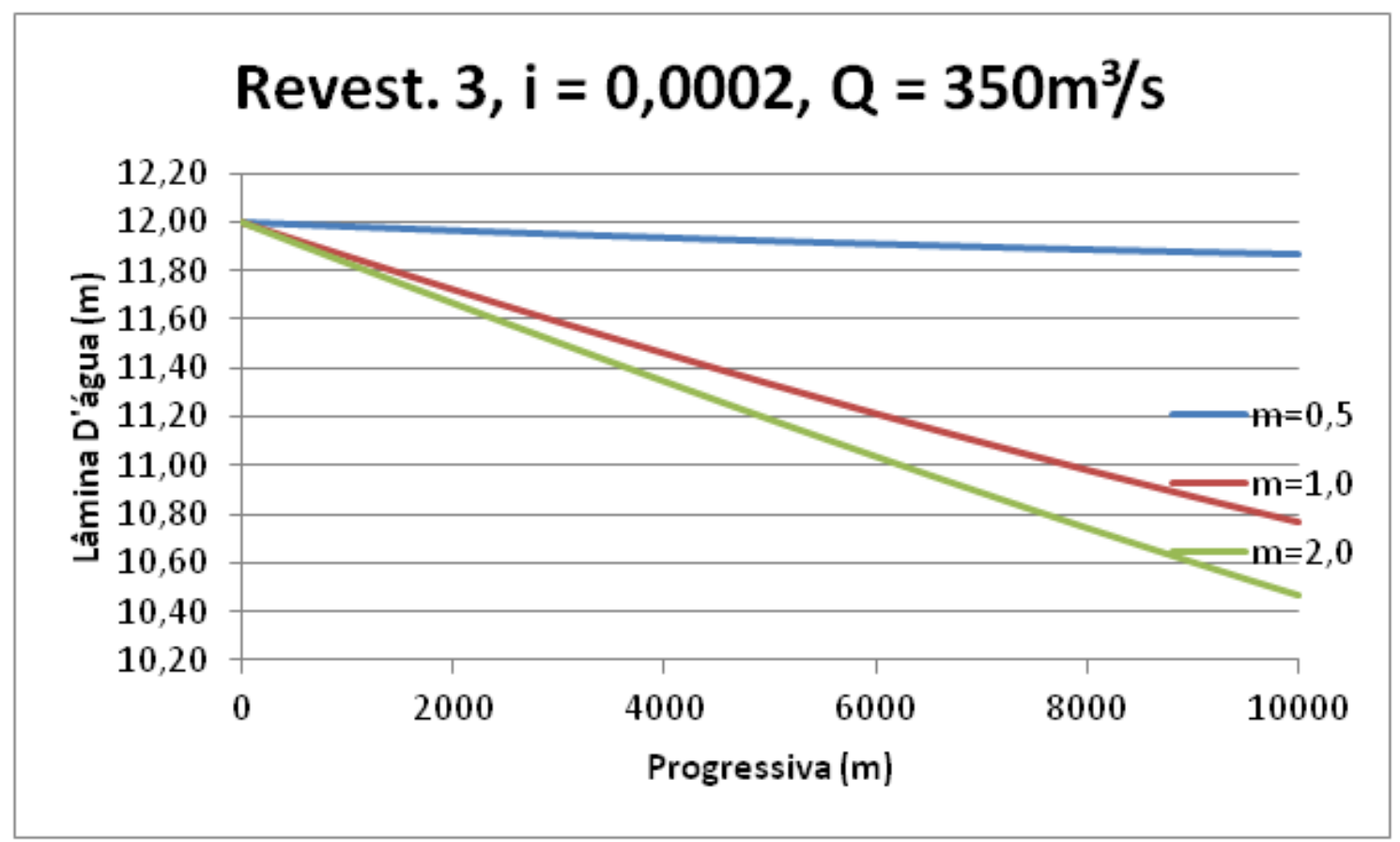




\begin{tabular}{|r|r|r|r|}
\hline \multirow{2}{*}{ Progr. } & \multicolumn{3}{|c|}{ Lâmina d'água $(\mathrm{m})$} \\
\cline { 2 - 4 } & $\mathrm{m}=0,5$ & $\mathrm{~m}=1,0$ & $\mathrm{~m}=2,0$ \\
\hline 0 & 12,00 & 12,00 & 12,00 \\
\hline 500 & 11,76 & 11,75 & 11,75 \\
\hline 1000 & 11,53 & 11,50 & 11,50 \\
\hline 1500 & 11,29 & 11,26 & 11,25 \\
\hline 2000 & 11,06 & 11,01 & 11,00 \\
\hline 2500 & 10,83 & 10,76 & 10,75 \\
\hline 3000 & 10,60 & 10,51 & 10,50 \\
\hline 3500 & 10,37 & 10,27 & 10,25 \\
\hline 4000 & 10,15 & 10,02 & 10,00 \\
\hline 4500 & 9,93 & 9,77 & 9,75 \\
\hline 5000 & 9,72 & 9,53 & 9,50 \\
\hline 5500 & 9,51 & 9,28 & 9,25 \\
\hline 6000 & 9,30 & 9,04 & 9,01 \\
\hline 6500 & 9,10 & 8,80 & 8,76 \\
\hline 7000 & 8,91 & 8,56 & 8,51 \\
\hline 7500 & 8,72 & 8,31 & 8,26 \\
\hline 8000 & 8,54 & 8,08 & 8,01 \\
\hline 8500 & 8,37 & 7,84 & 7,76 \\
\hline 9000 & 8,21 & 7,61 & 7,52 \\
\hline 9500 & 8,05 & 7,37 & 7,27 \\
\hline 10000 & 7,91 & 7,15 & 7,02 \\
\hline & & & \\
\hline
\end{tabular}

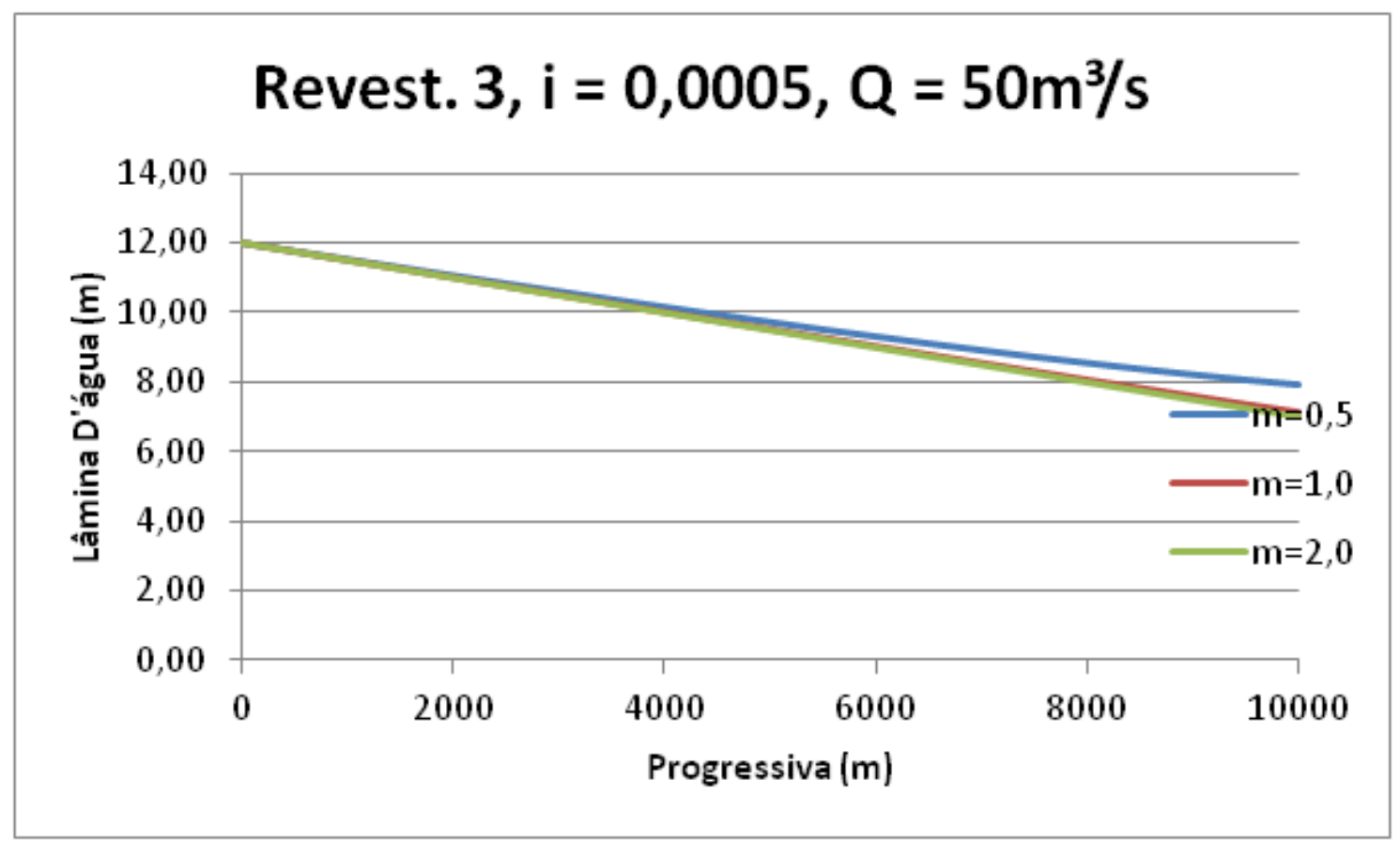




\begin{tabular}{|r|r|r|r|}
\hline \multirow{2}{*}{ Progr. } & \multicolumn{3}{|c|}{ Lâmina d'água $(\mathrm{m})$} \\
\cline { 2 - 4 } & $\mathrm{m}=0,5$ & $\mathrm{~m}=1,0$ & $\mathrm{~m}=2,0$ \\
\hline 0 & 12,00 & 12,00 & 12,00 \\
\hline 500 & 11,80 & 11,76 & 11,75 \\
\hline 1000 & 11,61 & 11,51 & 11,50 \\
\hline 1500 & 11,42 & 11,27 & 11,25 \\
\hline 2000 & 11,23 & 11,03 & 11,00 \\
\hline 2500 & 11,06 & 10,79 & 10,76 \\
\hline 3000 & 10,89 & 10,55 & 10,51 \\
\hline 3500 & 10,72 & 10,31 & 10,26 \\
\hline 4000 & 10,57 & 10,08 & 10,01 \\
\hline 4500 & 10,42 & 9,84 & 9,76 \\
\hline 5000 & 10,28 & 9,61 & 9,52 \\
\hline 5500 & 10,15 & 9,38 & 9,27 \\
\hline 6000 & 10,02 & 9,16 & 9,02 \\
\hline 6500 & 9,91 & 8,93 & 8,78 \\
\hline 7000 & 9,81 & 8,71 & 8,53 \\
\hline 7500 & 9,71 & 8,50 & 8,29 \\
\hline 8000 & 9,62 & 8,29 & 8,05 \\
\hline 8500 & 9,54 & 8,09 & 7,80 \\
\hline 9000 & 9,47 & 7,89 & 7,56 \\
\hline 9500 & 9,41 & 7,71 & 7,32 \\
\hline 10000 & 9,35 & 7,53 & 7,09 \\
\hline & & & \\
\hline
\end{tabular}

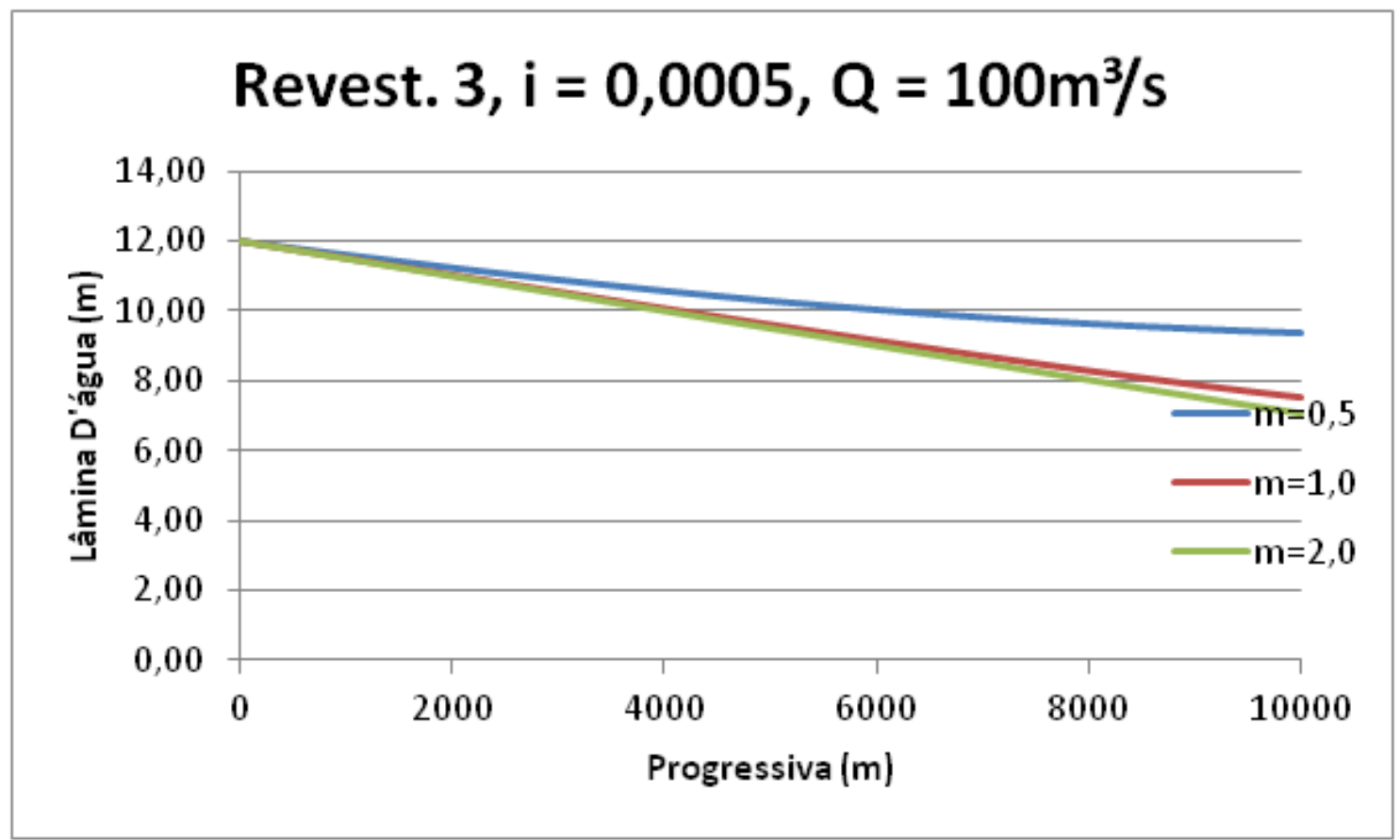




\begin{tabular}{|r|r|r|r|}
\hline \multirow{2}{*}{ Progr. } & \multicolumn{3}{|c|}{ Lâmina d'água $(\mathrm{m})$} \\
\cline { 2 - 4 } & $\mathrm{m}=0,5$ & $\mathrm{~m}=1,0$ & $\mathrm{~m}=2,0$ \\
\hline 0 & 12,00 & 12,00 & 12,00 \\
\hline 500 & 11,78 & 11,76 & 11,75 \\
\hline 1000 & 11,56 & 11,53 & 11,50 \\
\hline 1500 & 11,35 & 11,30 & 11,26 \\
\hline 2000 & 11,14 & 11,07 & 11,01 \\
\hline 2500 & 10,93 & 10,84 & 10,76 \\
\hline 3000 & 10,73 & 10,61 & 10,52 \\
\hline 3500 & 10,53 & 10,39 & 10,27 \\
\hline 4000 & 10,33 & 10,17 & 10,03 \\
\hline 4500 & 10,14 & 9,96 & 9,78 \\
\hline 5000 & 9,96 & 9,74 & 9,54 \\
\hline 5500 & 9,78 & 9,54 & 9,29 \\
\hline 6000 & 9,60 & 9,34 & 9,05 \\
\hline 6500 & 9,44 & 9,15 & 8,81 \\
\hline 7000 & 9,27 & 8,96 & 8,57 \\
\hline 7500 & 9,12 & 8,78 & 8,34 \\
\hline 8000 & 8,97 & 8,61 & 8,10 \\
\hline 8500 & 8,83 & 8,45 & 7,87 \\
\hline 9000 & 8,70 & 8,30 & 7,64 \\
\hline 9500 & 8,58 & 8,17 & 7,41 \\
\hline 10000 & 8,46 & 8,04 & 7,19 \\
\hline & & & \\
\hline
\end{tabular}

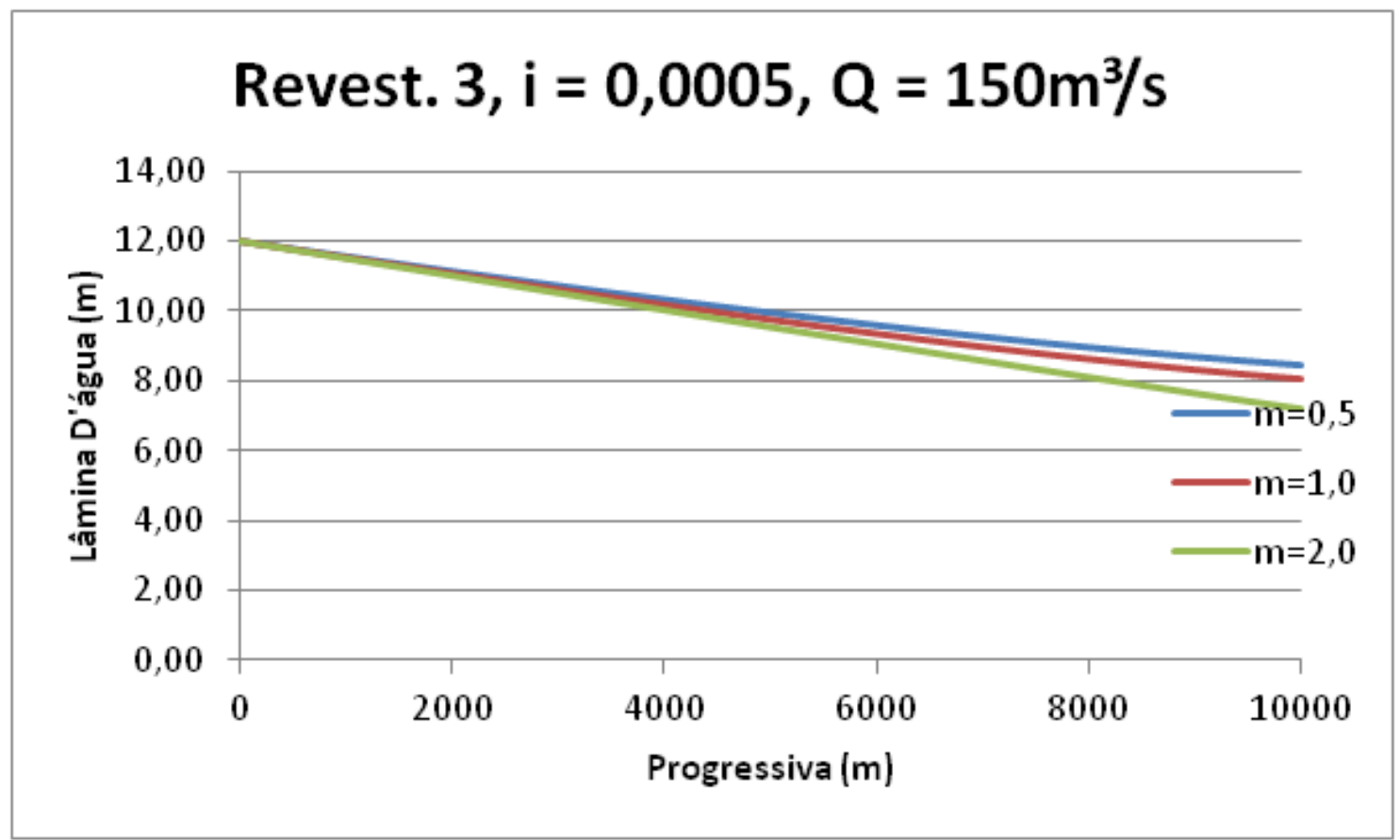




\begin{tabular}{|r|r|r|r|}
\hline \multirow{2}{*}{ Progr. } & \multicolumn{3}{|c|}{ Lâmina d'água $(\mathrm{m})$} \\
\cline { 2 - 4 } & $\mathrm{m}=0,5$ & $\mathrm{~m}=1,0$ & $\mathrm{~m}=2,0$ \\
\hline 0 & 12,00 & 12,00 & 12,00 \\
\hline 500 & 11,81 & 11,77 & 11,75 \\
\hline 1000 & 11,62 & 11,55 & 11,51 \\
\hline 1500 & 11,43 & 11,33 & 11,26 \\
\hline 2000 & 11,25 & 11,12 & 11,02 \\
\hline 2500 & 11,07 & 10,91 & 10,77 \\
\hline 3000 & 10,90 & 10,70 & 10,53 \\
\hline 3500 & 10,74 & 10,50 & 10,29 \\
\hline 4000 & 10,58 & 10,30 & 10,05 \\
\hline 4500 & 10,43 & 10,11 & 9,80 \\
\hline 5000 & 10,28 & 9,93 & 9,57 \\
\hline 5500 & 10,14 & 9,75 & 9,33 \\
\hline 6000 & 10,01 & 9,58 & 9,09 \\
\hline 6500 & 9,89 & 9,42 & 8,86 \\
\hline 7000 & 9,77 & 9,27 & 8,63 \\
\hline 7500 & 9,66 & 9,13 & 8,40 \\
\hline 8000 & 9,56 & 9,00 & 8,18 \\
\hline 8500 & 9,46 & 8,88 & 7,96 \\
\hline 9000 & 9,37 & 8,77 & 7,74 \\
\hline 9500 & 9,29 & 8,67 & 7,53 \\
\hline 10000 & 9,22 & 8,59 & 7,33 \\
\hline & & & \\
\hline
\end{tabular}

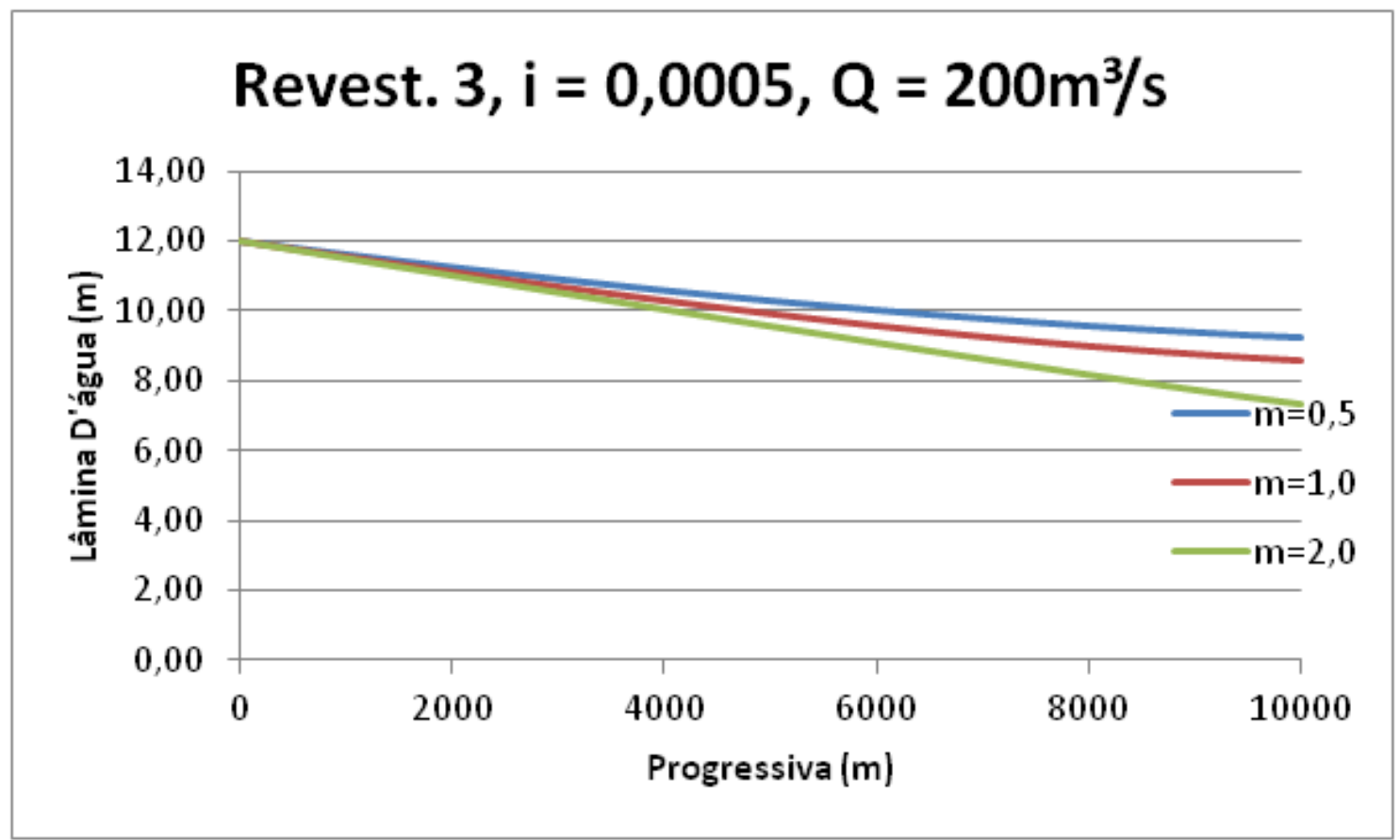




\begin{tabular}{|r|r|r|r|}
\hline \multirow{2}{*}{ Progr. } & \multicolumn{3}{|c|}{ Lâmina d'água $(\mathrm{m})$} \\
\cline { 2 - 4 } & $\mathrm{m}=0,5$ & $\mathrm{~m}=1,0$ & $\mathrm{~m}=2,0$ \\
\hline 0 & 12,00 & 12,00 & 12,00 \\
\hline 500 & 11,84 & 11,79 & 11,76 \\
\hline 1000 & 11,68 & 11,58 & 11,51 \\
\hline 1500 & 11,53 & 11,38 & 11,27 \\
\hline 2000 & 11,39 & 11,19 & 11,03 \\
\hline 2500 & 11,25 & 10,99 & 10,79 \\
\hline 3000 & 11,12 & 10,81 & 10,55 \\
\hline 3500 & 11,00 & 10,63 & 10,31 \\
\hline 4000 & 10,88 & 10,46 & 10,07 \\
\hline 4500 & 10,77 & 10,30 & 9,84 \\
\hline 5000 & 10,66 & 10,14 & 9,60 \\
\hline 5500 & 10,56 & 10,00 & 9,37 \\
\hline 6000 & 10,47 & 9,86 & 9,14 \\
\hline 6500 & 10,39 & 9,74 & 8,92 \\
\hline 7000 & 10,31 & 9,62 & 8,70 \\
\hline 7500 & 10,24 & 9,51 & 8,48 \\
\hline 8000 & 10,17 & 9,42 & 8,27 \\
\hline 8500 & 10,11 & 9,33 & 8,07 \\
\hline 9000 & 10,06 & 9,25 & 7,87 \\
\hline 9500 & 10,01 & 9,19 & 7,68 \\
\hline 10000 & 9,96 & 9,13 & 7,50 \\
\hline & & & \\
\hline
\end{tabular}

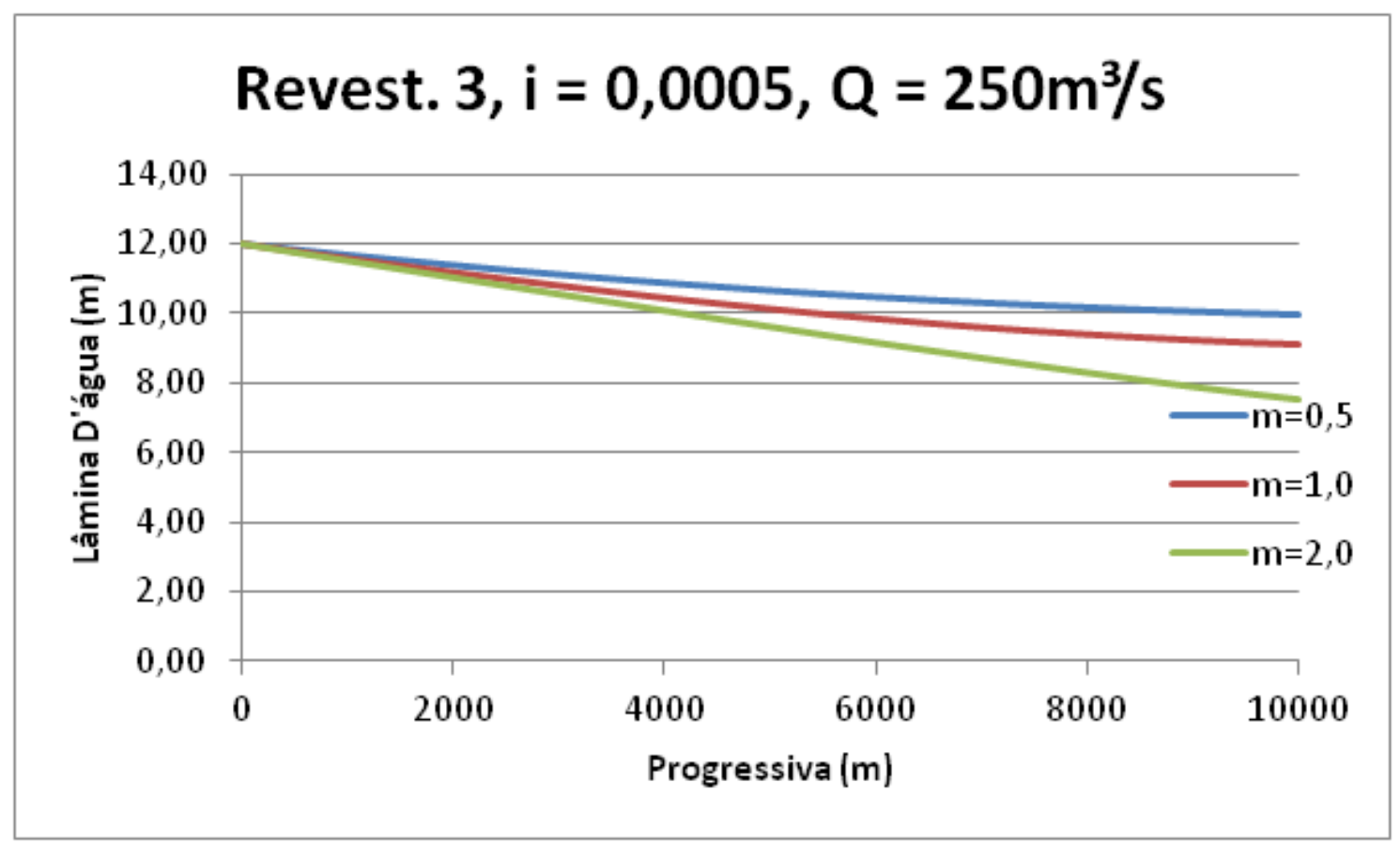




\begin{tabular}{|r|r|r|r|}
\hline \multirow{2}{*}{ Progr. } & \multicolumn{3}{|c|}{ Lâmina d'água $(\mathrm{m})$} \\
\cline { 2 - 4 } & $\mathrm{m}=0,5$ & $\mathrm{~m}=1,0$ & $\mathrm{~m}=2,0$ \\
\hline 0 & 12,00 & 12,00 & 12,00 \\
\hline 500 & 11,79 & 11,79 & 11,76 \\
\hline 1000 & 11,59 & 11,58 & 11,52 \\
\hline 1500 & 11,39 & 11,38 & 11,28 \\
\hline 2000 & 11,19 & 11,18 & 11,04 \\
\hline 2500 & 11,00 & 10,99 & 10,80 \\
\hline 3000 & 10,81 & 10,80 & 10,57 \\
\hline 3500 & 10,62 & 10,62 & 10,33 \\
\hline 4000 & 10,44 & 10,44 & 10,10 \\
\hline 4500 & 10,27 & 10,28 & 9,87 \\
\hline 5000 & 10,10 & 10,12 & 9,65 \\
\hline 5500 & 9,94 & 9,96 & 9,43 \\
\hline 6000 & 9,78 & 9,82 & 9,21 \\
\hline 6500 & 9,62 & 9,69 & 8,99 \\
\hline 7000 & 9,48 & 9,56 & 8,78 \\
\hline 7500 & 9,34 & 9,45 & 8,58 \\
\hline 8000 & 9,20 & 9,34 & 8,38 \\
\hline 8500 & 9,08 & 9,24 & 8,20 \\
\hline 9000 & 8,96 & 9,16 & 8,02 \\
\hline 9500 & 8,85 & 9,08 & 7,85 \\
\hline 10000 & 8,74 & 9,01 & 7,69 \\
\hline & & & \\
\hline
\end{tabular}

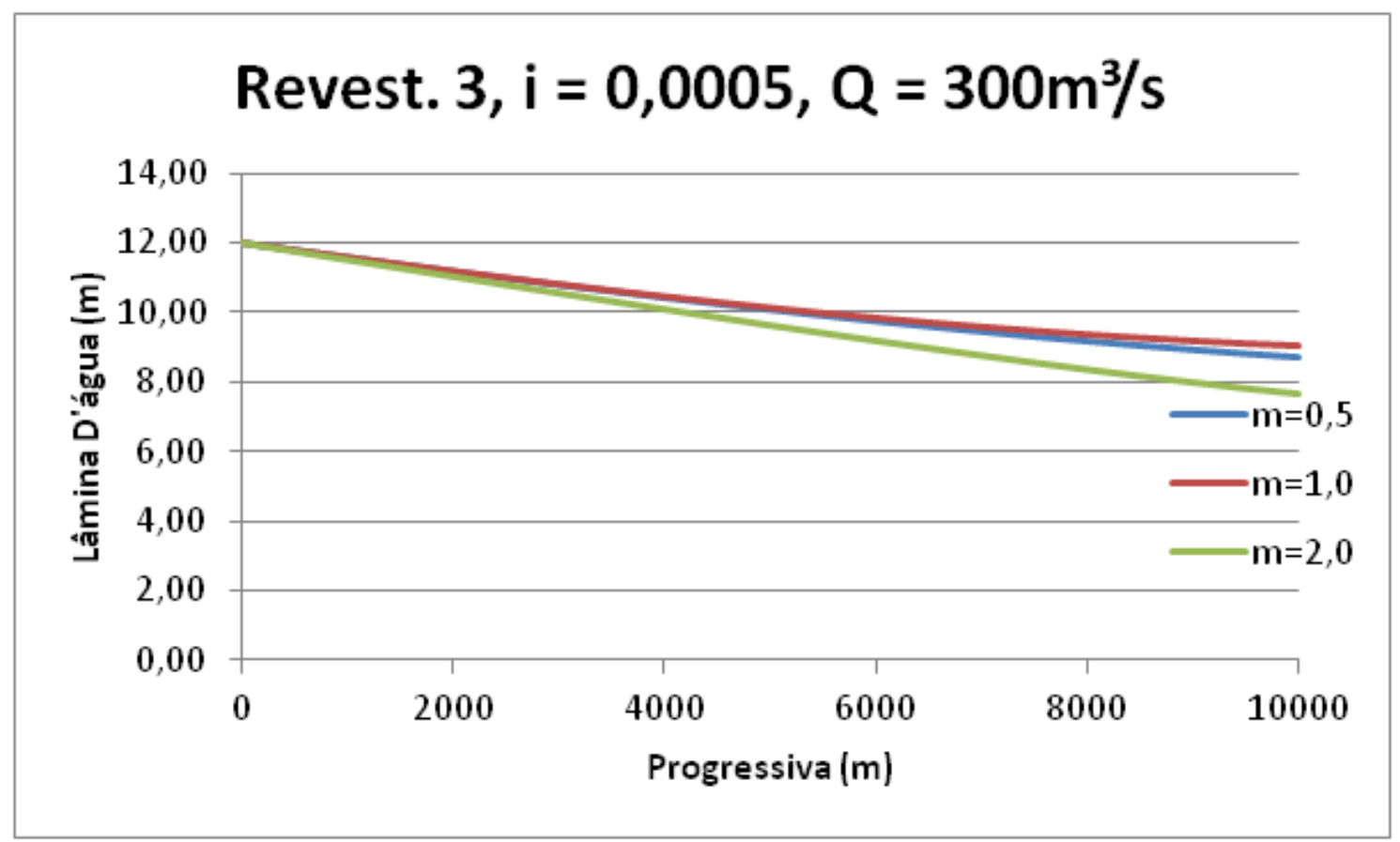




\begin{tabular}{|r|r|r|r|}
\hline \multirow{2}{*}{ Progr. } & \multicolumn{3}{|c|}{ Lâmina d'água $(\mathrm{m})$} \\
\cline { 2 - 4 } & $\mathrm{m}=0,5$ & $\mathrm{~m}=1,0$ & $\mathrm{~m}=2,0$ \\
\hline 0 & 12,00 & 12,00 & 12,00 \\
\hline 500 & 11,81 & 11,80 & 11,76 \\
\hline 1000 & 11,62 & 11,61 & 11,52 \\
\hline 1500 & 11,44 & 11,43 & 11,29 \\
\hline 2000 & 11,26 & 11,25 & 11,05 \\
\hline 2500 & 11,09 & 11,07 & 10,82 \\
\hline 3000 & 10,92 & 10,91 & 10,59 \\
\hline 3500 & 10,76 & 10,75 & 10,36 \\
\hline 4000 & 10,60 & 10,60 & 10,14 \\
\hline 4500 & 10,45 & 10,45 & 9,92 \\
\hline 5000 & 10,30 & 10,32 & 9,70 \\
\hline 5500 & 10,16 & 10,19 & 9,49 \\
\hline 6000 & 10,03 & 10,08 & 9,28 \\
\hline 6500 & 9,90 & 9,97 & 9,08 \\
\hline 7000 & 9,78 & 9,87 & 8,88 \\
\hline 7500 & 9,67 & 9,78 & 8,69 \\
\hline 8000 & 9,56 & 9,70 & 8,51 \\
\hline 8500 & 9,46 & 9,63 & 8,34 \\
\hline 9000 & 9,37 & 9,56 & 8,18 \\
\hline 9500 & 9,28 & 9,50 & 8,03 \\
\hline 10000 & 9,20 & 9,45 & 7,89 \\
\hline & & & \\
\hline
\end{tabular}

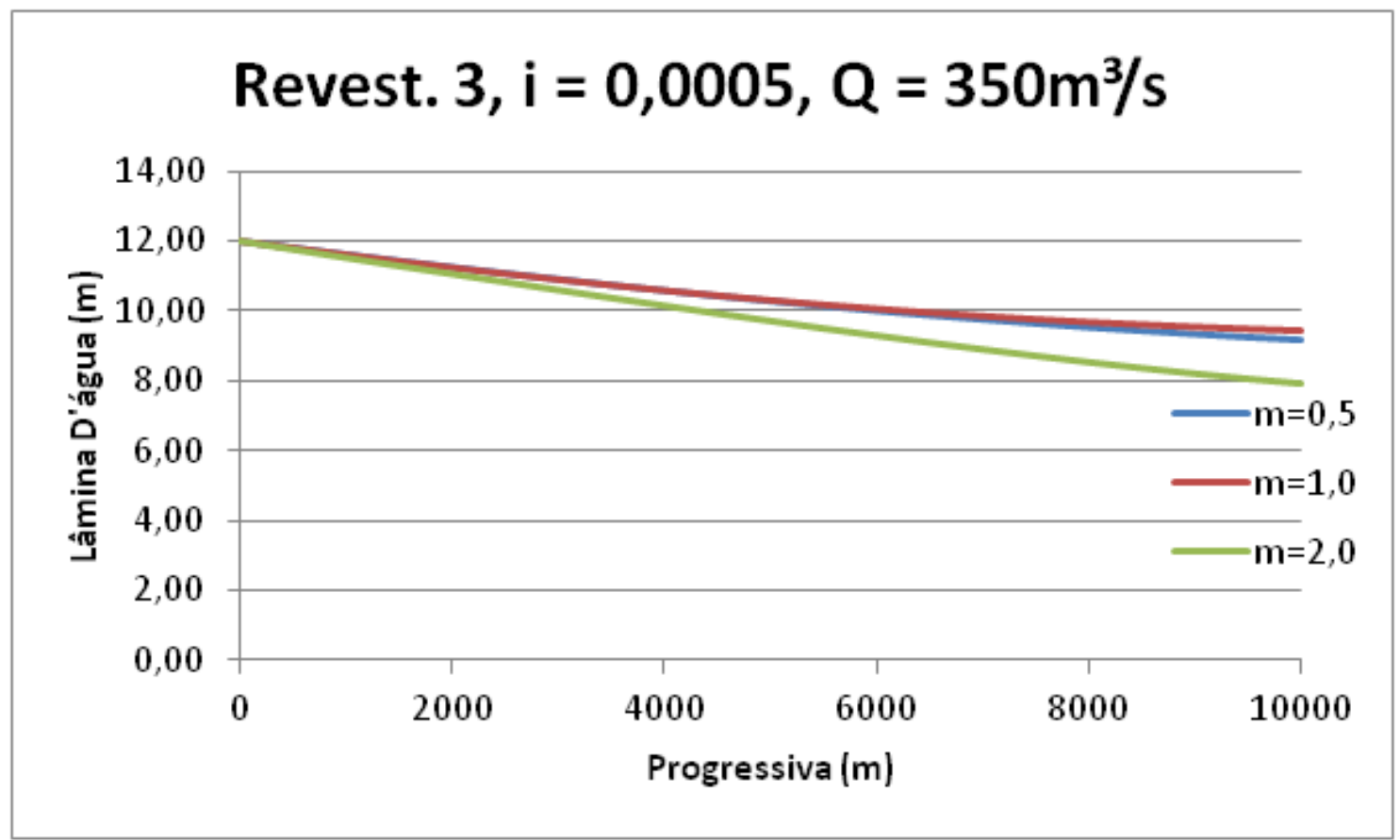




\begin{tabular}{|r|r|r|r|}
\hline \multirow{2}{*}{ Progr. } & \multicolumn{3}{|c|}{ Lâmina d'água $(\mathrm{m})$} \\
\cline { 2 - 4 } & $\mathrm{m}=0,5$ & $\mathrm{~m}=1,0$ & $\mathrm{~m}=2,0$ \\
\hline 0 & 12,00 & 12,00 & 12,00 \\
\hline 500 & 11,95 & 11,95 & 11,95 \\
\hline 1000 & 11,90 & 11,90 & 11,90 \\
\hline 1500 & 11,85 & 11,85 & 11,85 \\
\hline 2000 & 11,81 & 11,81 & 11,80 \\
\hline 2500 & 11,76 & 11,76 & 11,75 \\
\hline 3000 & 11,71 & 11,71 & 11,70 \\
\hline 3500 & 11,66 & 11,66 & 11,65 \\
\hline 4000 & 11,61 & 11,61 & 11,60 \\
\hline 4500 & 11,56 & 11,56 & 11,55 \\
\hline 5000 & 11,51 & 11,52 & 11,50 \\
\hline 5500 & 11,47 & 11,47 & 11,45 \\
\hline 6000 & 11,42 & 11,42 & 11,40 \\
\hline 6500 & 11,37 & 11,37 & 11,35 \\
\hline 7000 & 11,32 & 11,32 & 11,30 \\
\hline 7500 & 11,27 & 11,27 & 11,25 \\
\hline 8000 & 11,22 & 11,23 & 11,20 \\
\hline 8500 & 11,17 & 11,18 & 11,16 \\
\hline 9000 & 11,13 & 11,13 & 11,11 \\
\hline 9500 & 11,08 & 11,08 & 11,06 \\
\hline 10000 & 11,03 & 11,03 & 11,01 \\
\hline & & & \\
\hline
\end{tabular}

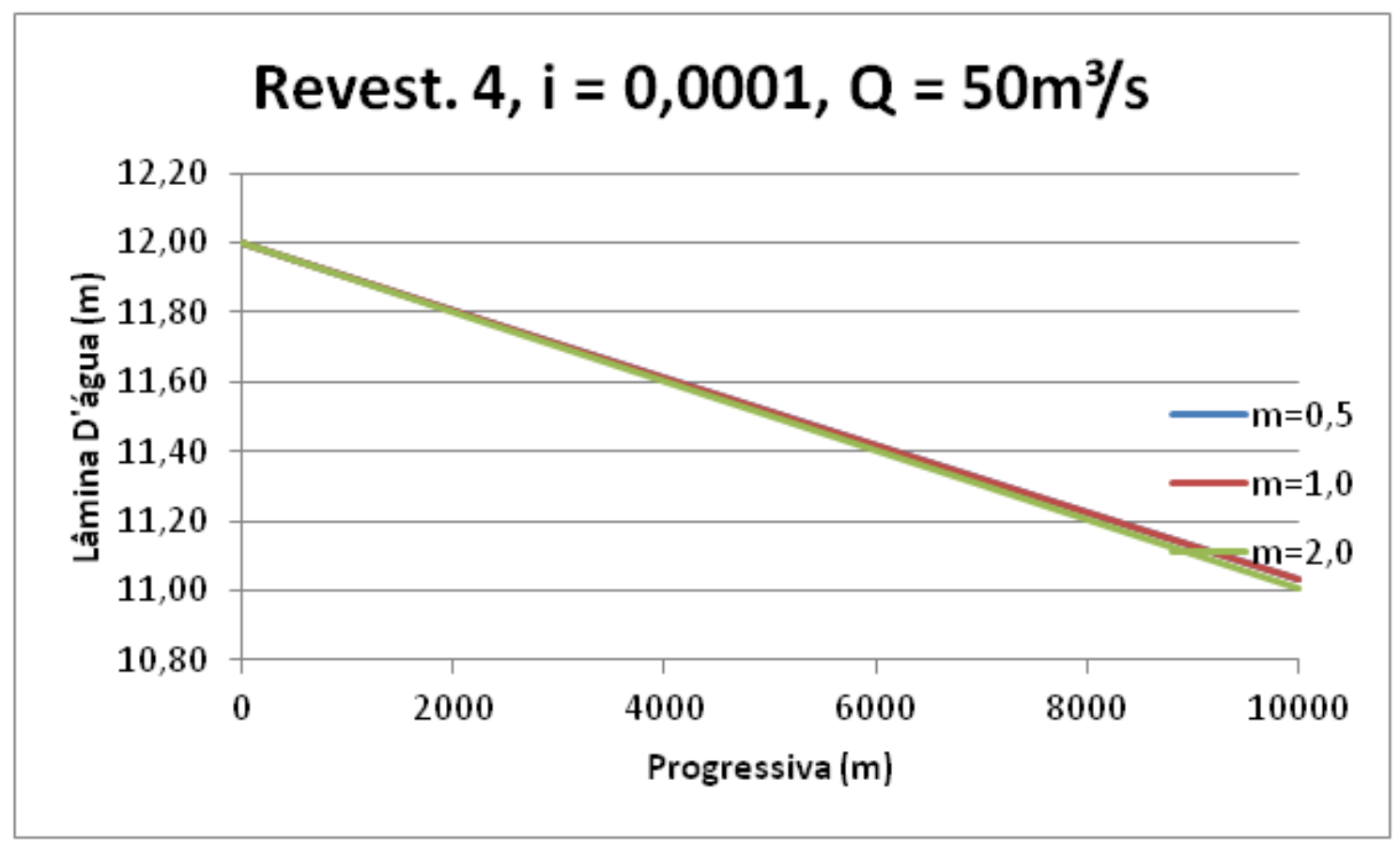




\begin{tabular}{|r|r|r|r|}
\hline \multirow{2}{*}{ Progr. } & \multicolumn{3}{|c|}{ Lâmina d'água $(\mathrm{m})$} \\
\cline { 2 - 4 } & $\mathrm{m}=0,5$ & $\mathrm{~m}=1,0$ & $\mathrm{~m}=2,0$ \\
\hline 0 & 12,00 & 12,00 & 12,00 \\
\hline 500 & 11,99 & 11,96 & 11,95 \\
\hline 1000 & 11,98 & 11,91 & 11,90 \\
\hline 1500 & 11,97 & 11,87 & 11,85 \\
\hline 2000 & 11,97 & 11,82 & 11,80 \\
\hline 2500 & 11,96 & 11,78 & 11,76 \\
\hline 3000 & 11,95 & 11,73 & 11,71 \\
\hline 3500 & 11,94 & 11,69 & 11,66 \\
\hline 4000 & 11,94 & 11,65 & 11,61 \\
\hline 4500 & 11,93 & 11,60 & 11,56 \\
\hline 5000 & 11,92 & 11,56 & 11,51 \\
\hline 5500 & 11,91 & 11,52 & 11,46 \\
\hline 6000 & 11,91 & 11,47 & 11,41 \\
\hline 6500 & 11,90 & 11,43 & 11,36 \\
\hline 7000 & 11,89 & 11,39 & 11,32 \\
\hline 7500 & 11,89 & 11,35 & 11,27 \\
\hline 8000 & 11,88 & 11,30 & 11,22 \\
\hline 8500 & 11,87 & 11,26 & 11,17 \\
\hline 9000 & 11,87 & 11,22 & 11,12 \\
\hline 9500 & 11,86 & 11,18 & 11,07 \\
\hline 10000 & 11,86 & 11,13 & 11,02 \\
\hline & & & \\
\hline
\end{tabular}

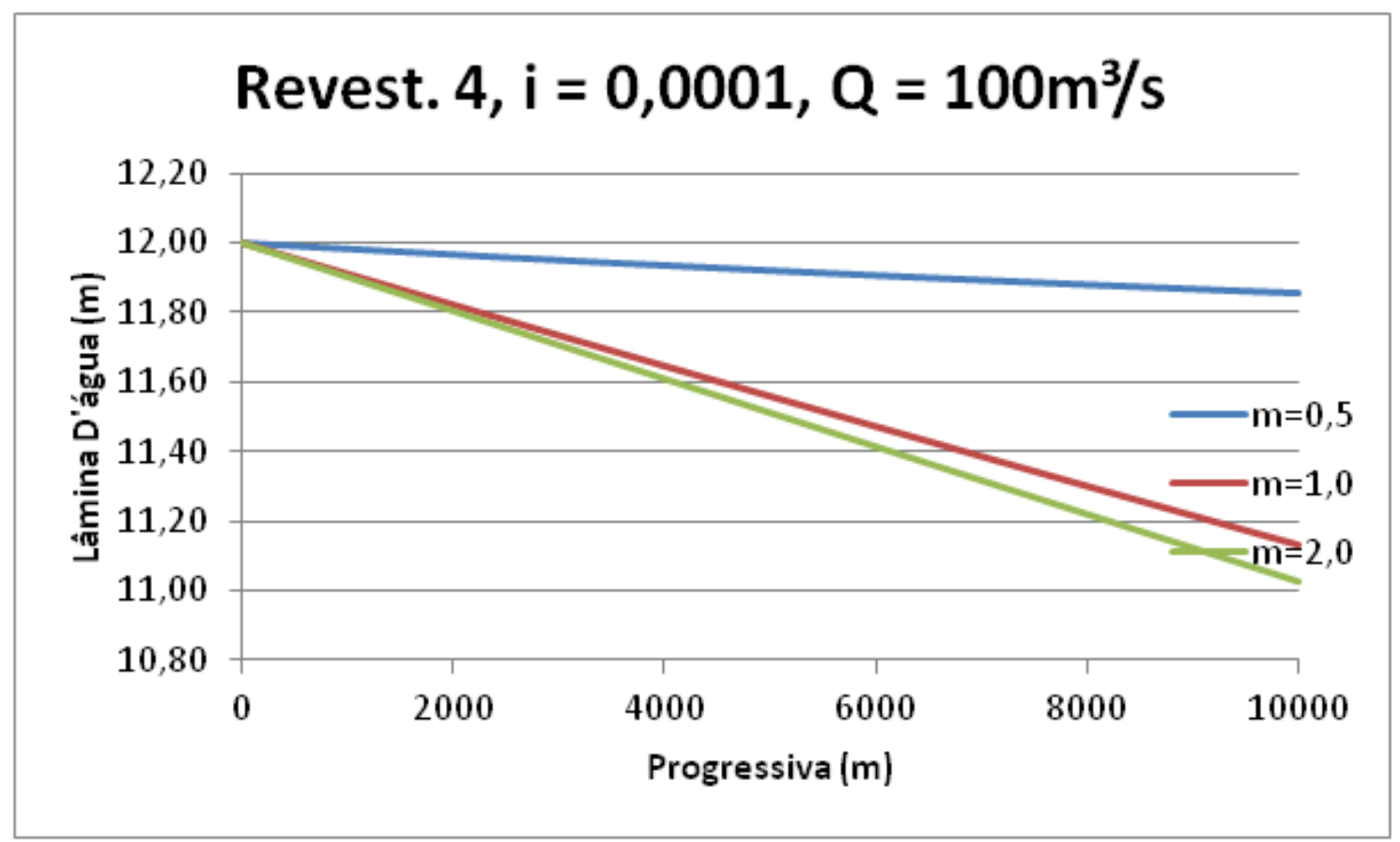




\begin{tabular}{|r|r|r|r|}
\hline \multirow{2}{*}{ Progr. } & \multicolumn{3}{|c|}{ Lâmina d'água $(\mathrm{m})$} \\
\cline { 2 - 4 } & $\mathrm{m}=0,5$ & $\mathrm{~m}=1,0$ & $\mathrm{~m}=2,0$ \\
\hline 0 & 12,00 & 12,00 & 12,00 \\
\hline 500 & 12,05 & 11,96 & 11,95 \\
\hline 1000 & 12,09 & 11,93 & 11,90 \\
\hline 1500 & 12,13 & 11,89 & 11,86 \\
\hline 2000 & 12,17 & 11,85 & 11,81 \\
\hline 2500 & 12,21 & 11,81 & 11,76 \\
\hline 3000 & 12,25 & 11,78 & 11,71 \\
\hline 3500 & 12,28 & 11,74 & 11,67 \\
\hline 4000 & 12,32 & 11,71 & 11,62 \\
\hline 4500 & 12,35 & 11,67 & 11,57 \\
\hline 5000 & 12,38 & 11,63 & 11,52 \\
\hline 5500 & 12,41 & 11,60 & 11,48 \\
\hline 6000 & 12,44 & 11,56 & 11,43 \\
\hline 6500 & 12,47 & 11,53 & 11,38 \\
\hline 7000 & 12,50 & 11,49 & 11,34 \\
\hline 7500 & 12,52 & 11,46 & 11,29 \\
\hline 8000 & 12,55 & 11,43 & 11,24 \\
\hline 8500 & 12,58 & 11,39 & 11,20 \\
\hline 9000 & 12,60 & 11,36 & 11,15 \\
\hline 9500 & 12,62 & 11,33 & 11,10 \\
\hline 10000 & 12,64 & 11,29 & 11,06 \\
\hline & & & \\
\hline
\end{tabular}

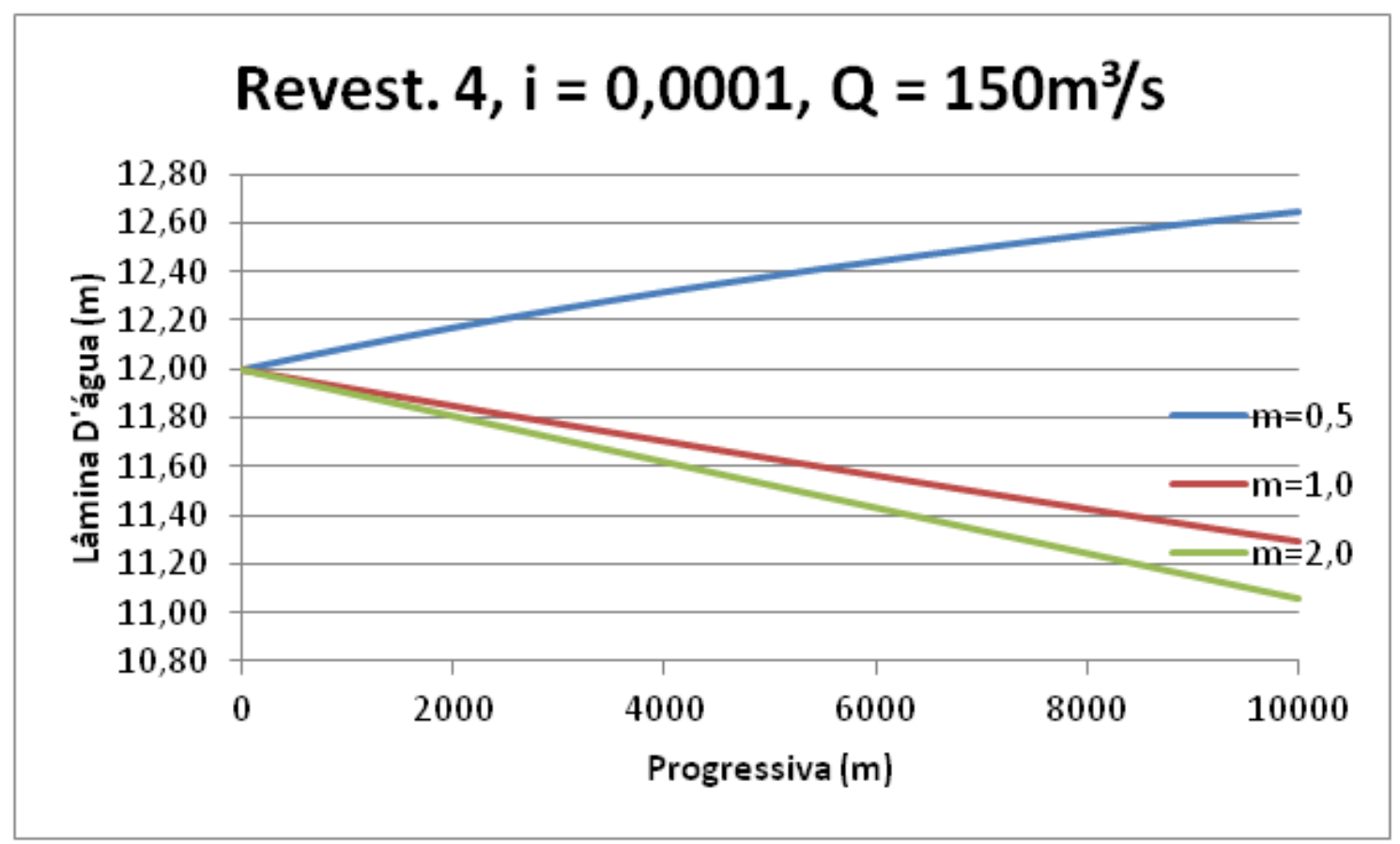




\begin{tabular}{|r|r|r|r|}
\hline \multirow{2}{*}{ Progr. } & \multicolumn{3}{|c|}{ Lâmina d'água $(\mathrm{m})$} \\
\cline { 2 - 4 } & $\mathrm{m}=0,5$ & $\mathrm{~m}=1,0$ & $\mathrm{~m}=2,0$ \\
\hline 0 & 12,00 & 12,00 & 12,00 \\
\hline 500 & 12,03 & 11,97 & 11,95 \\
\hline 1000 & 12,07 & 11,95 & 11,91 \\
\hline 1500 & 12,10 & 11,92 & 11,86 \\
\hline 2000 & 12,13 & 11,89 & 11,82 \\
\hline 2500 & 12,16 & 11,86 & 11,77 \\
\hline 3000 & 12,19 & 11,84 & 11,73 \\
\hline 3500 & 12,22 & 11,81 & 11,68 \\
\hline 4000 & 12,25 & 11,79 & 11,63 \\
\hline 4500 & 12,27 & 11,76 & 11,59 \\
\hline 5000 & 12,30 & 11,74 & 11,54 \\
\hline 5500 & 12,32 & 11,71 & 11,50 \\
\hline 6000 & 12,35 & 11,69 & 11,45 \\
\hline 6500 & 12,37 & 11,66 & 11,41 \\
\hline 7000 & 12,39 & 11,64 & 11,36 \\
\hline 7500 & 12,41 & 11,62 & 11,32 \\
\hline 8000 & 12,44 & 11,59 & 11,27 \\
\hline 8500 & 12,46 & 11,57 & 11,23 \\
\hline 9000 & 12,48 & 11,55 & 11,19 \\
\hline 9500 & 12,50 & 11,53 & 11,14 \\
\hline 10000 & 12,52 & 11,50 & 11,10 \\
\hline & & & \\
\hline
\end{tabular}

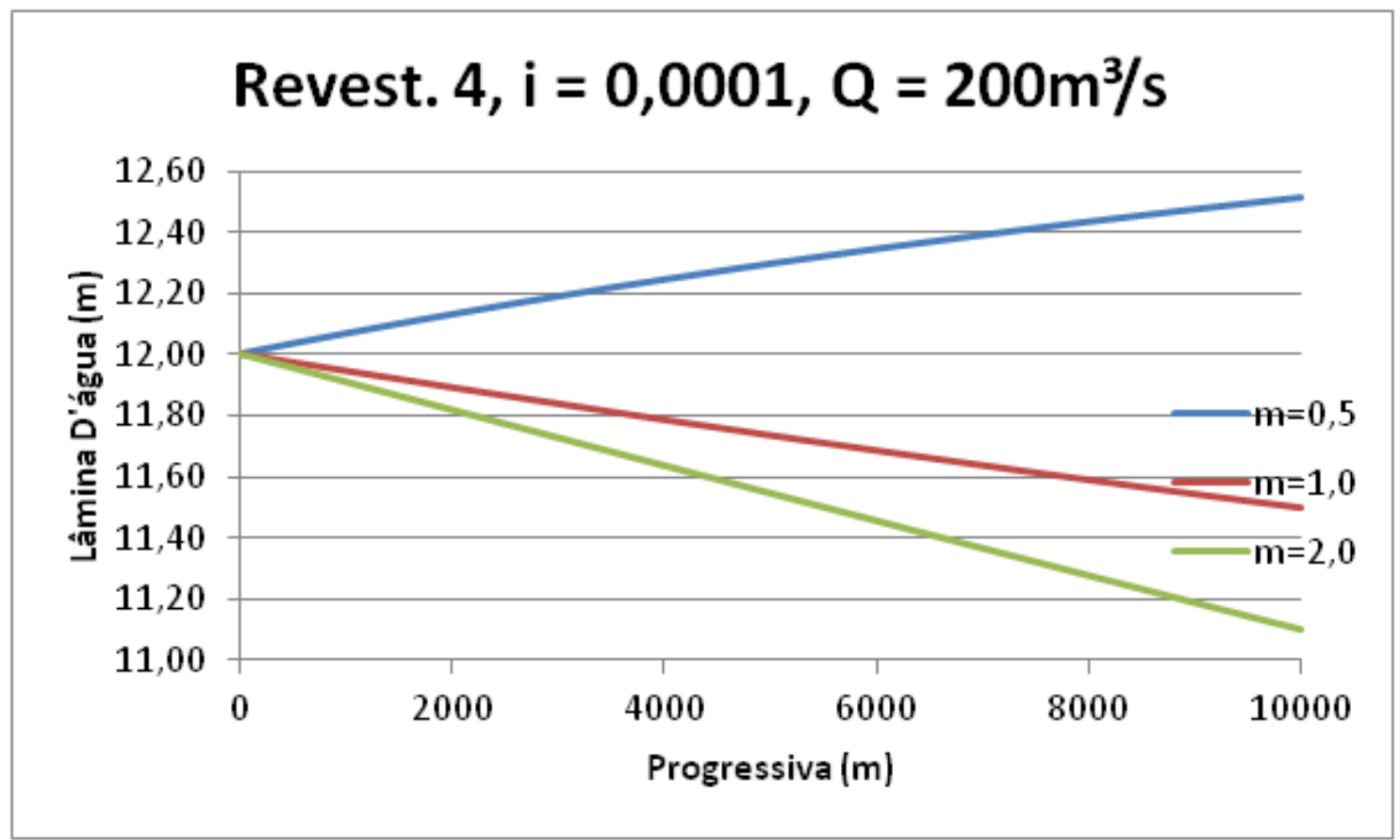




\begin{tabular}{|r|r|r|r|}
\hline \multirow{2}{*}{ Progr. } & \multicolumn{3}{|c|}{ Lâmina d'água $(\mathrm{m})$} \\
\cline { 2 - 4 } & $\mathrm{m}=0,5$ & $\mathrm{~m}=1,0$ & $\mathrm{~m}=2,0$ \\
\hline 0 & 12,00 & 12,00 & 12,00 \\
\hline 500 & 12,05 & 11,99 & 11,96 \\
\hline 1000 & 12,11 & 11,97 & 11,91 \\
\hline 1500 & 12,16 & 11,96 & 11,87 \\
\hline 2000 & 12,20 & 11,94 & 11,83 \\
\hline 2500 & 12,25 & 11,93 & 11,78 \\
\hline 3000 & 12,29 & 11,92 & 11,74 \\
\hline 3500 & 12,34 & 11,90 & 11,70 \\
\hline 4000 & 12,38 & 11,89 & 11,65 \\
\hline 4500 & 12,42 & 11,88 & 11,61 \\
\hline 5000 & 12,46 & 11,87 & 11,57 \\
\hline 5500 & 12,49 & 11,85 & 11,53 \\
\hline 6000 & 12,53 & 11,84 & 11,48 \\
\hline 6500 & 12,56 & 11,83 & 11,44 \\
\hline 7000 & 12,60 & 11,82 & 11,40 \\
\hline 7500 & 12,63 & 11,81 & 11,36 \\
\hline 8000 & 12,66 & 11,80 & 11,32 \\
\hline 8500 & 12,69 & 11,79 & 11,27 \\
\hline 9000 & 12,72 & 11,77 & 11,23 \\
\hline 9500 & 12,75 & 11,76 & 11,19 \\
\hline 10000 & 12,78 & 11,75 & 11,15 \\
\hline & & & \\
\hline
\end{tabular}

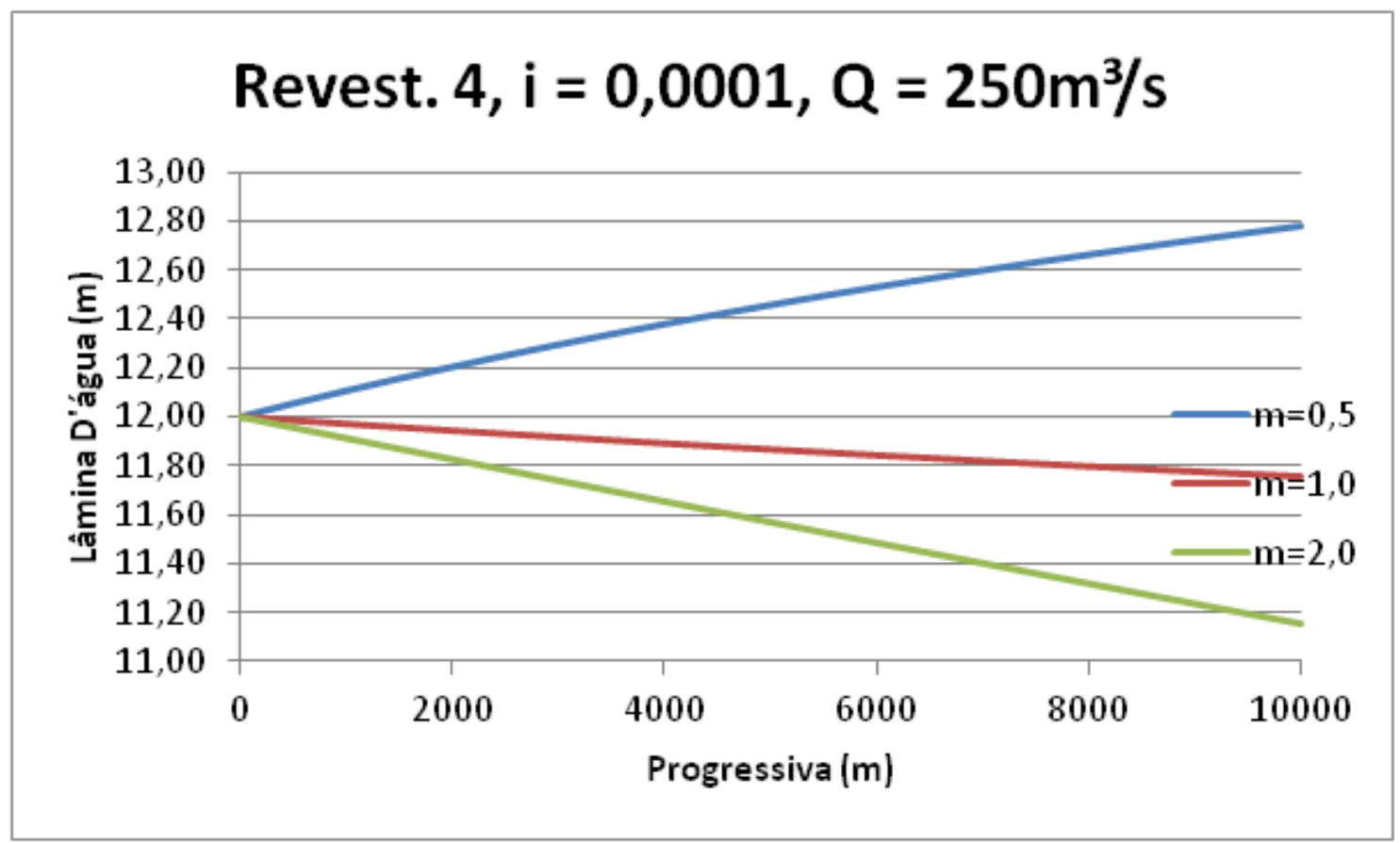




\begin{tabular}{|r|r|r|r|}
\hline \multirow{2}{*}{ Progr. } & \multicolumn{3}{|c|}{ Lâmina d'água $(\mathrm{m})$} \\
\cline { 2 - 4 } & $\mathrm{m}=0,5$ & $\mathrm{~m}=1,0$ & $\mathrm{~m}=2,0$ \\
\hline 0 & 12,00 & 12,00 & 12,00 \\
\hline 500 & 12,04 & 12,00 & 11,96 \\
\hline 1000 & 12,07 & 12,00 & 11,92 \\
\hline 1500 & 12,11 & 12,01 & 11,88 \\
\hline 2000 & 12,14 & 12,01 & 11,84 \\
\hline 2500 & 12,17 & 12,01 & 11,80 \\
\hline 3000 & 12,20 & 12,01 & 11,76 \\
\hline 3500 & 12,23 & 12,01 & 11,72 \\
\hline 4000 & 12,26 & 12,02 & 11,68 \\
\hline 4500 & 12,29 & 12,02 & 11,64 \\
\hline 5000 & 12,32 & 12,02 & 11,60 \\
\hline 5500 & 12,35 & 12,02 & 11,56 \\
\hline 6000 & 12,37 & 12,02 & 11,52 \\
\hline 6500 & 12,40 & 12,02 & 11,48 \\
\hline 7000 & 12,42 & 12,03 & 11,44 \\
\hline 7500 & 12,45 & 12,03 & 11,40 \\
\hline 8000 & 12,47 & 12,03 & 11,37 \\
\hline 8500 & 12,49 & 12,03 & 11,33 \\
\hline 9000 & 12,52 & 12,03 & 11,29 \\
\hline 9500 & 12,54 & 12,03 & 11,25 \\
\hline 10000 & 12,56 & 12,03 & 11,22 \\
\hline & & & \\
\hline
\end{tabular}

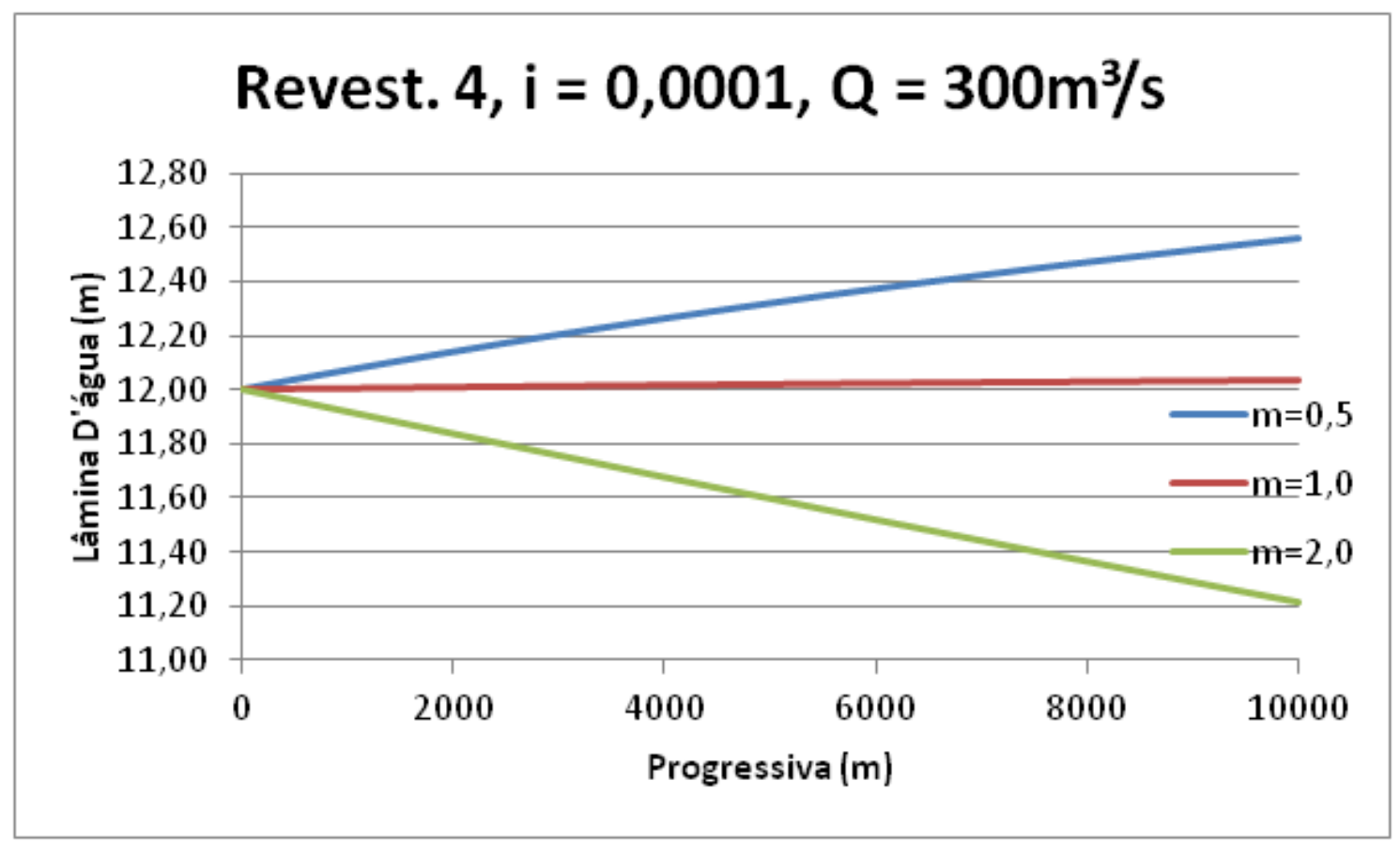




\begin{tabular}{|r|r|r|r|}
\hline \multirow{2}{*}{ Progr. } & \multicolumn{3}{|c|}{ Lâmina d'água $(\mathrm{m})$} \\
\cline { 2 - 4 } & $\mathrm{m}=0,5$ & $\mathrm{~m}=1,0$ & $\mathrm{~m}=2,0$ \\
\hline 0 & 12,00 & 12,00 & 12,00 \\
\hline 500 & 12,05 & 12,02 & 11,96 \\
\hline 1000 & 12,09 & 12,04 & 11,92 \\
\hline 1500 & 12,14 & 12,07 & 11,89 \\
\hline 2000 & 12,18 & 12,09 & 11,85 \\
\hline 2500 & 12,23 & 12,11 & 11,81 \\
\hline 3000 & 12,27 & 12,13 & 11,78 \\
\hline 3500 & 12,30 & 12,14 & 11,74 \\
\hline 4000 & 12,34 & 12,16 & 11,70 \\
\hline 4500 & 12,38 & 12,18 & 11,67 \\
\hline 5000 & 12,42 & 12,20 & 11,63 \\
\hline 5500 & 12,45 & 12,21 & 11,60 \\
\hline 6000 & 12,48 & 12,23 & 11,56 \\
\hline 6500 & 12,52 & 12,24 & 11,53 \\
\hline 7000 & 12,55 & 12,26 & 11,49 \\
\hline 7500 & 12,58 & 12,27 & 11,46 \\
\hline 8000 & 12,61 & 12,29 & 11,42 \\
\hline 8500 & 12,64 & 12,30 & 11,39 \\
\hline 9000 & 12,67 & 12,31 & 11,36 \\
\hline 9500 & 12,69 & 12,33 & 11,32 \\
\hline 10000 & 12,72 & 12,34 & 11,29 \\
\hline & & & \\
\hline
\end{tabular}

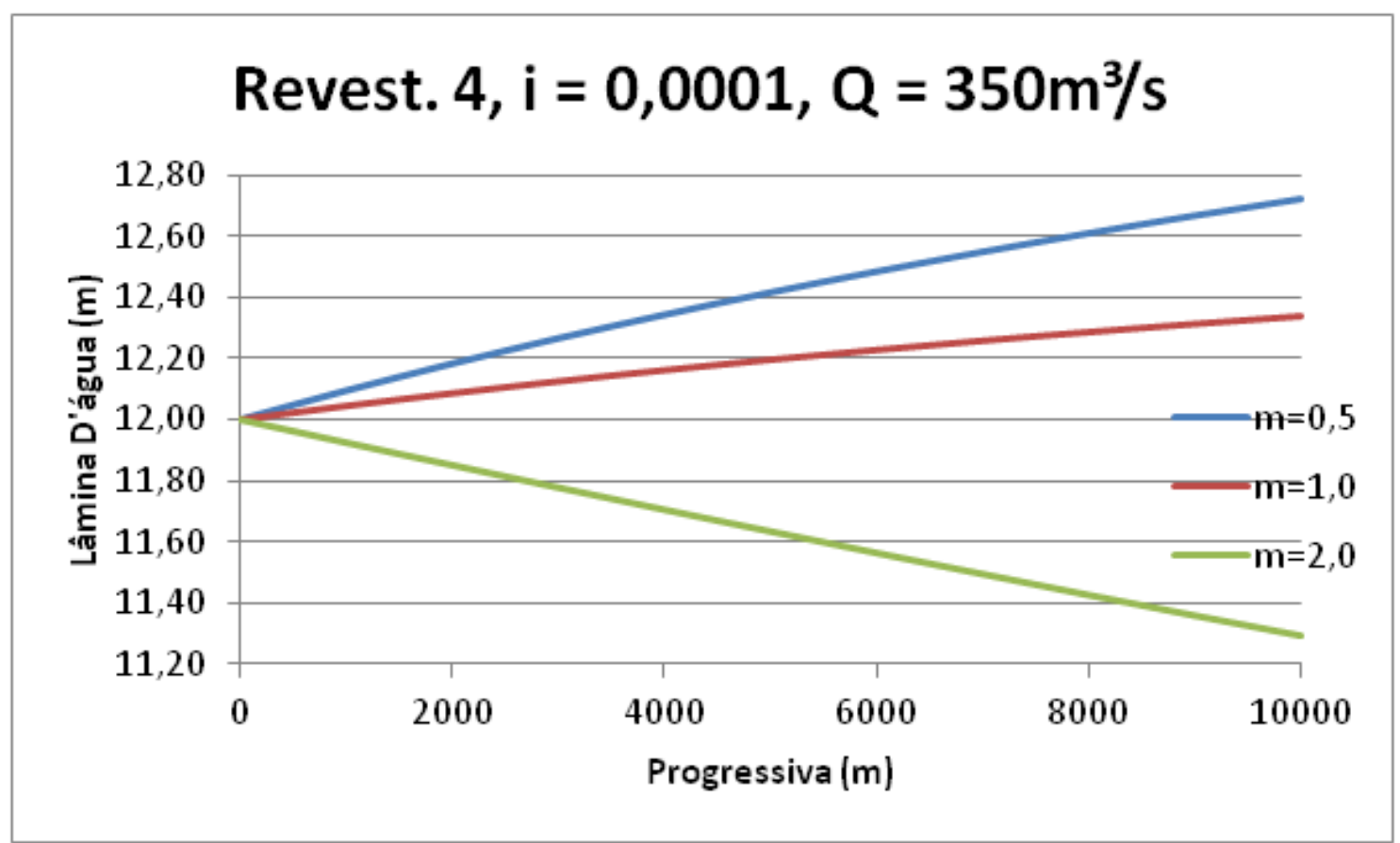




\begin{tabular}{|r|r|r|r|}
\hline \multirow{2}{*}{ Progr. } & \multicolumn{3}{|c|}{ Lâmina d'água $(\mathrm{m})$} \\
\cline { 2 - 4 } & $\mathrm{m}=0,5$ & $\mathrm{~m}=1,0$ & $\mathrm{~m}=2,0$ \\
\hline 0 & 12,00 & 12,00 & 12,00 \\
\hline 500 & 11,91 & 11,90 & 11,90 \\
\hline 1000 & 11,82 & 11,80 & 11,80 \\
\hline 1500 & 11,73 & 11,70 & 11,70 \\
\hline 2000 & 11,64 & 11,60 & 11,60 \\
\hline 2500 & 11,55 & 11,50 & 11,50 \\
\hline 3000 & 11,47 & 11,40 & 11,40 \\
\hline 3500 & 11,38 & 11,30 & 11,30 \\
\hline 4000 & 11,29 & 11,20 & 11,20 \\
\hline 4500 & 11,21 & 11,10 & 11,10 \\
\hline 5000 & 11,12 & 11,01 & 11,00 \\
\hline 5500 & 11,03 & 10,91 & 10,90 \\
\hline 6000 & 10,95 & 10,81 & 10,80 \\
\hline 6500 & 10,87 & 10,71 & 10,70 \\
\hline 7000 & 10,78 & 10,61 & 10,60 \\
\hline 7500 & 10,70 & 10,51 & 10,50 \\
\hline 8000 & 10,62 & 10,41 & 10,41 \\
\hline 8500 & 10,54 & 10,31 & 10,31 \\
\hline 9000 & 10,46 & 10,21 & 10,21 \\
\hline 9500 & 10,38 & 10,11 & 10,11 \\
\hline 10000 & 10,30 & 10,01 & 10,01 \\
\hline & & & \\
\hline
\end{tabular}

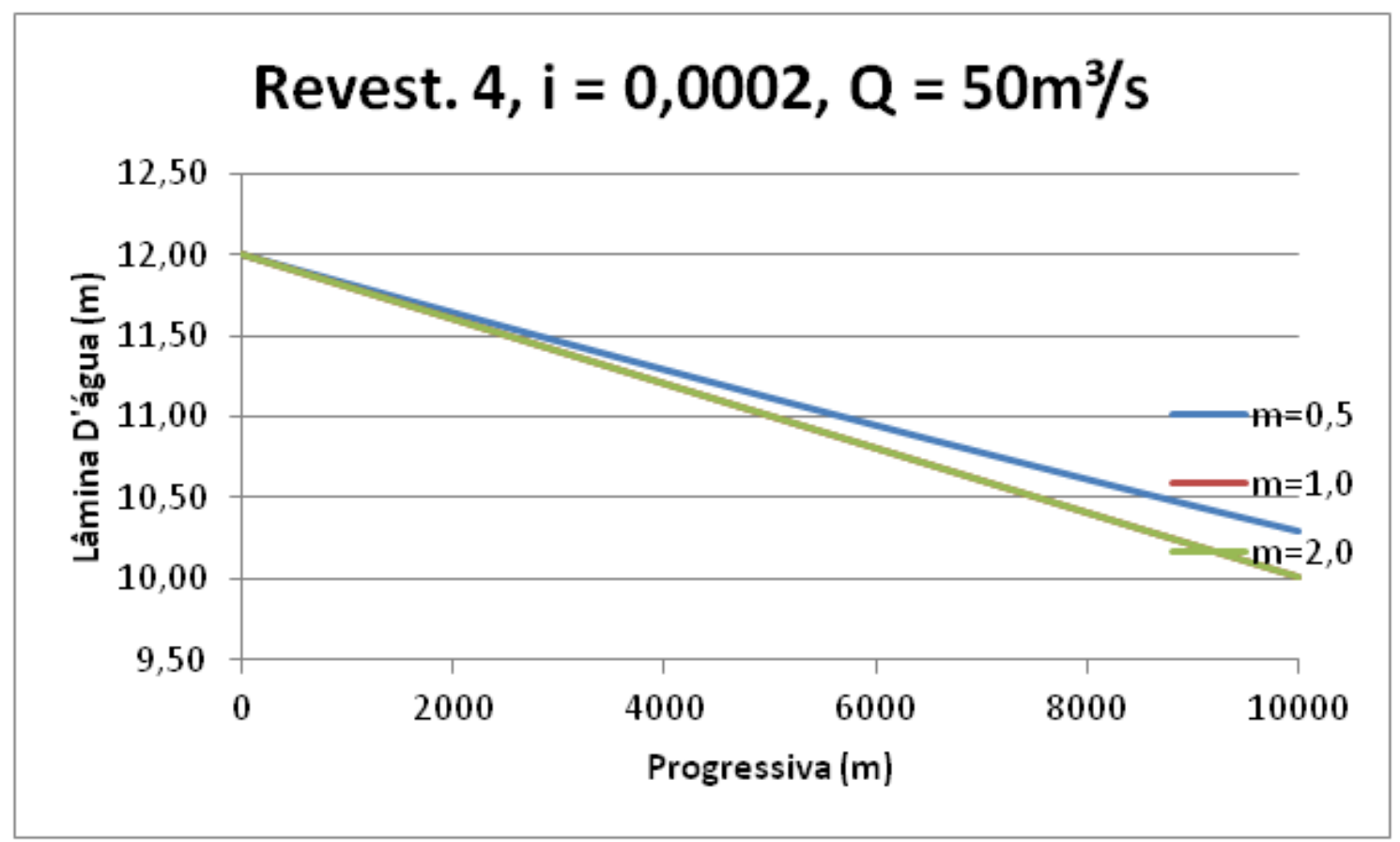




\begin{tabular}{|r|r|r|r|}
\hline \multirow{2}{*}{ Progr. } & \multicolumn{3}{|c|}{ Lâmina d'água $(\mathrm{m})$} \\
\cline { 2 - 4 } & $\mathrm{m}=0,5$ & $\mathrm{~m}=1,0$ & $\mathrm{~m}=2,0$ \\
\hline 0 & 12,00 & 12,00 & 12,00 \\
\hline 500 & 11,94 & 11,90 & 11,90 \\
\hline 1000 & 11,88 & 11,80 & 11,80 \\
\hline 1500 & 11,82 & 11,71 & 11,70 \\
\hline 2000 & 11,77 & 11,61 & 11,60 \\
\hline 2500 & 11,71 & 11,51 & 11,50 \\
\hline 3000 & 11,66 & 11,41 & 11,41 \\
\hline 3500 & 11,61 & 11,31 & 11,31 \\
\hline 4000 & 11,55 & 11,22 & 11,21 \\
\hline 4500 & 11,50 & 11,12 & 11,11 \\
\hline 5000 & 11,45 & 11,02 & 11,01 \\
\hline 5500 & 11,41 & 10,92 & 10,91 \\
\hline 6000 & 11,36 & 10,83 & 10,81 \\
\hline 6500 & 11,31 & 10,73 & 10,72 \\
\hline 7000 & 11,27 & 10,63 & 10,62 \\
\hline 7500 & 11,22 & 10,53 & 10,52 \\
\hline 8000 & 11,18 & 10,44 & 10,42 \\
\hline 8500 & 11,14 & 10,34 & 10,32 \\
\hline 9000 & 11,10 & 10,24 & 10,22 \\
\hline 9500 & 11,06 & 10,15 & 10,13 \\
\hline 10000 & 11,03 & 10,05 & 10,03 \\
\hline & & & \\
\hline
\end{tabular}

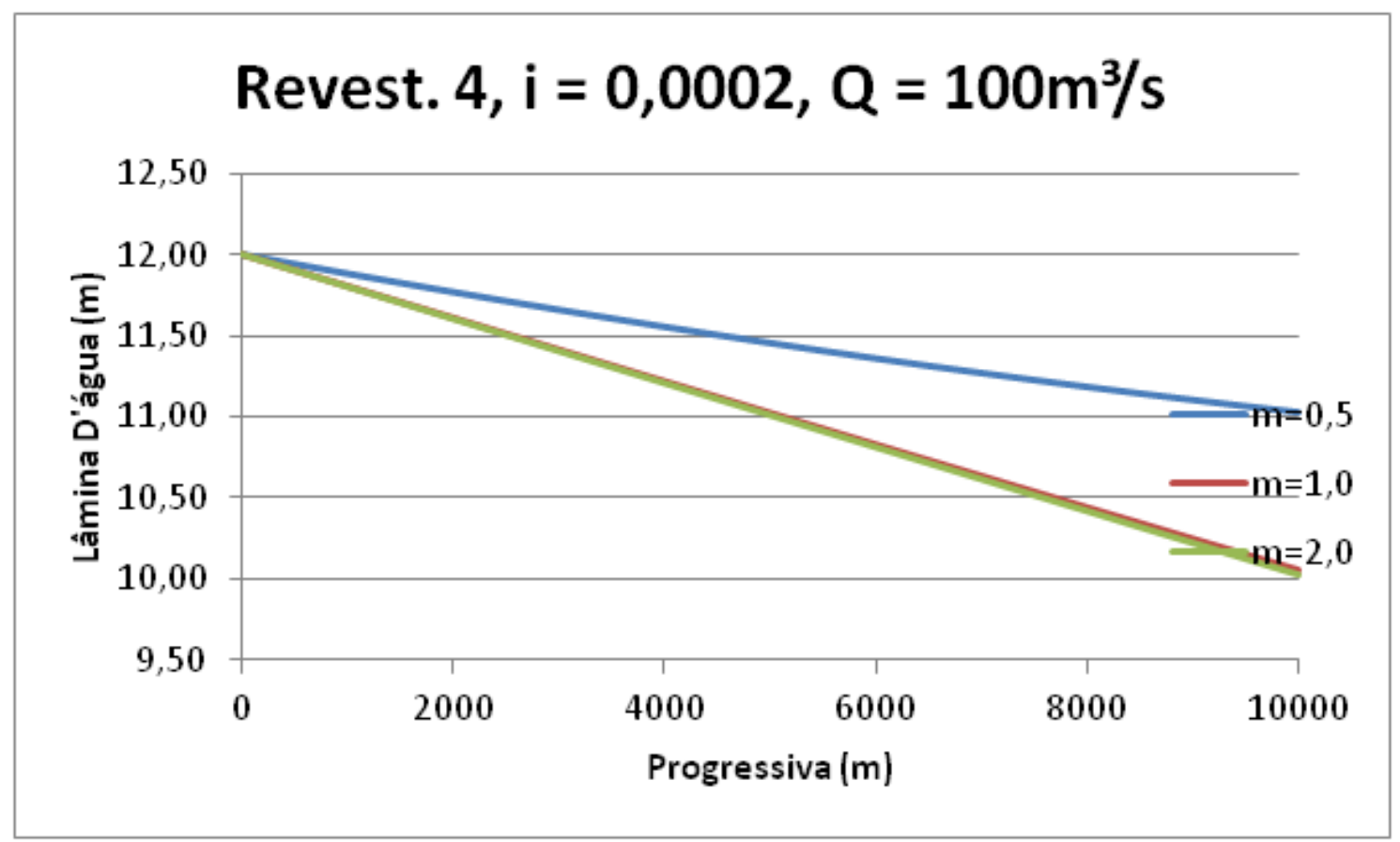




\begin{tabular}{|r|r|r|r|}
\hline \multirow{2}{*}{ Progr. } & \multicolumn{3}{|c|}{ Lâmina d'água $(\mathrm{m})$} \\
\cline { 2 - 4 } & $\mathrm{m}=0,5$ & $\mathrm{~m}=1,0$ & $\mathrm{~m}=2,0$ \\
\hline 0 & 12,00 & 12,00 & 12,00 \\
\hline 500 & 11,99 & 11,90 & 11,90 \\
\hline 1000 & 11,99 & 11,81 & 11,80 \\
\hline 1500 & 11,98 & 11,71 & 11,71 \\
\hline 2000 & 11,97 & 11,62 & 11,61 \\
\hline 2500 & 11,97 & 11,52 & 11,51 \\
\hline 3000 & 11,96 & 11,43 & 11,41 \\
\hline 3500 & 11,96 & 11,33 & 11,32 \\
\hline 4000 & 11,95 & 11,23 & 11,22 \\
\hline 4500 & 11,95 & 11,14 & 11,12 \\
\hline 5000 & 11,94 & 11,05 & 11,02 \\
\hline 5500 & 11,94 & 10,95 & 10,93 \\
\hline 6000 & 11,94 & 10,86 & 10,83 \\
\hline 6500 & 11,93 & 10,76 & 10,73 \\
\hline 7000 & 11,93 & 10,67 & 10,64 \\
\hline 7500 & 11,92 & 10,58 & 10,54 \\
\hline 8000 & 11,92 & 10,48 & 10,45 \\
\hline 8500 & 11,92 & 10,39 & 10,35 \\
\hline 9000 & 11,91 & 10,30 & 10,26 \\
\hline 9500 & 11,91 & 10,20 & 10,16 \\
\hline 10000 & 11,91 & 10,11 & 10,07 \\
\hline & & & \\
\hline
\end{tabular}

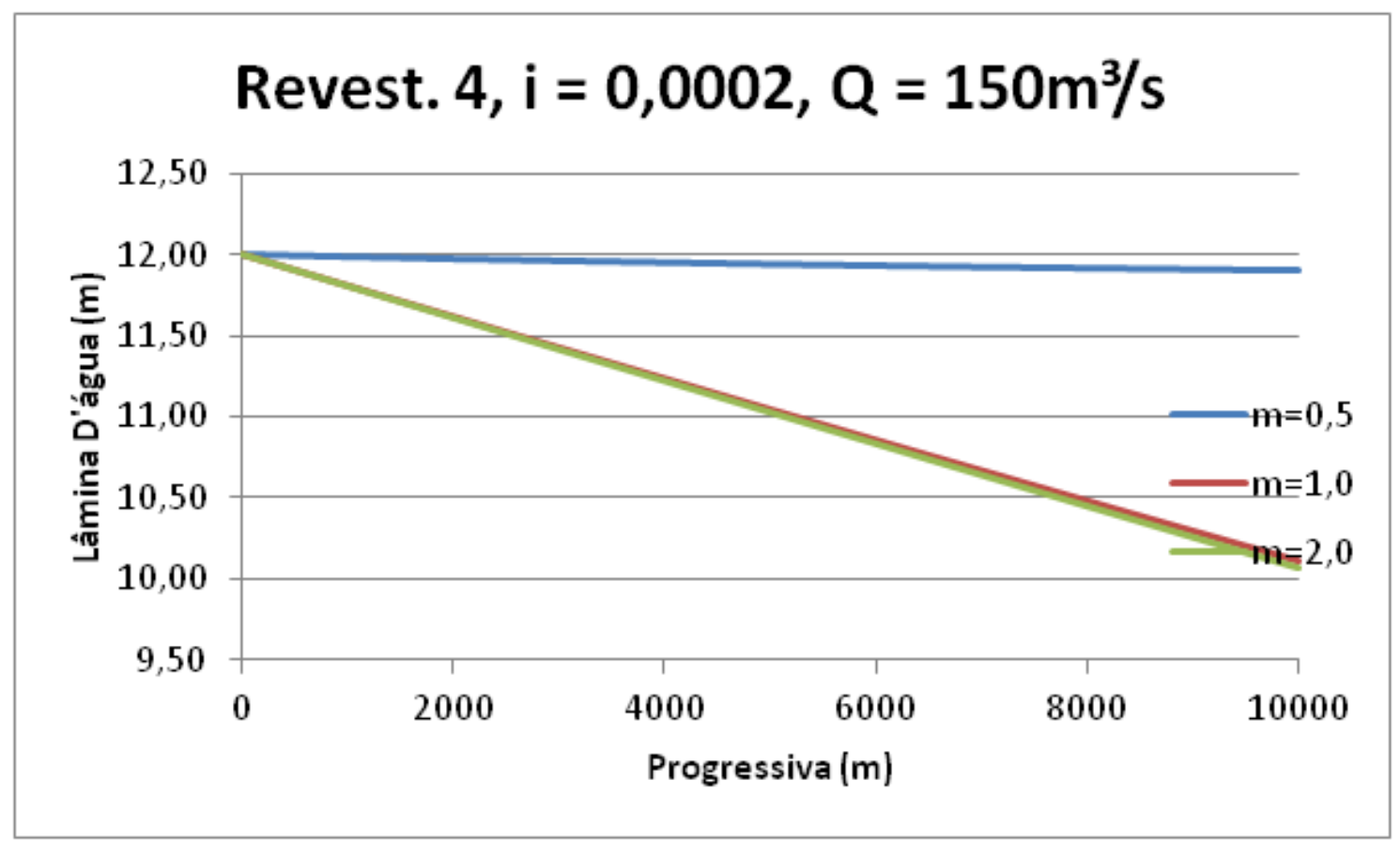




\begin{tabular}{|r|r|r|r|}
\hline \multirow{2}{*}{ Progr. } & \multicolumn{3}{|c|}{ Lâmina d'água $(\mathrm{m})$} \\
\cline { 2 - 4 } & $\mathrm{m}=0,5$ & $\mathrm{~m}=1,0$ & $\mathrm{~m}=2,0$ \\
\hline 0 & 12,00 & 12,00 & 12,00 \\
\hline 500 & 11,98 & 11,91 & 11,90 \\
\hline 1000 & 11,96 & 11,81 & 11,81 \\
\hline 1500 & 11,95 & 11,72 & 11,71 \\
\hline 2000 & 11,93 & 11,63 & 11,62 \\
\hline 2500 & 11,91 & 11,54 & 11,52 \\
\hline 3000 & 11,90 & 11,44 & 11,42 \\
\hline 3500 & 11,88 & 11,35 & 11,33 \\
\hline 4000 & 11,87 & 11,26 & 11,23 \\
\hline 4500 & 11,85 & 11,17 & 11,14 \\
\hline 5000 & 11,84 & 11,08 & 11,04 \\
\hline 5500 & 11,83 & 10,99 & 10,95 \\
\hline 6000 & 11,82 & 10,90 & 10,86 \\
\hline 6500 & 11,80 & 10,81 & 10,76 \\
\hline 7000 & 11,79 & 10,72 & 10,67 \\
\hline 7500 & 11,78 & 10,63 & 10,58 \\
\hline 8000 & 11,77 & 10,55 & 10,48 \\
\hline 8500 & 11,76 & 10,46 & 10,39 \\
\hline 9000 & 11,75 & 10,37 & 10,30 \\
\hline 9500 & 11,74 & 10,28 & 10,21 \\
\hline 10000 & 11,73 & 10,20 & 10,11 \\
\hline & & & \\
\hline
\end{tabular}

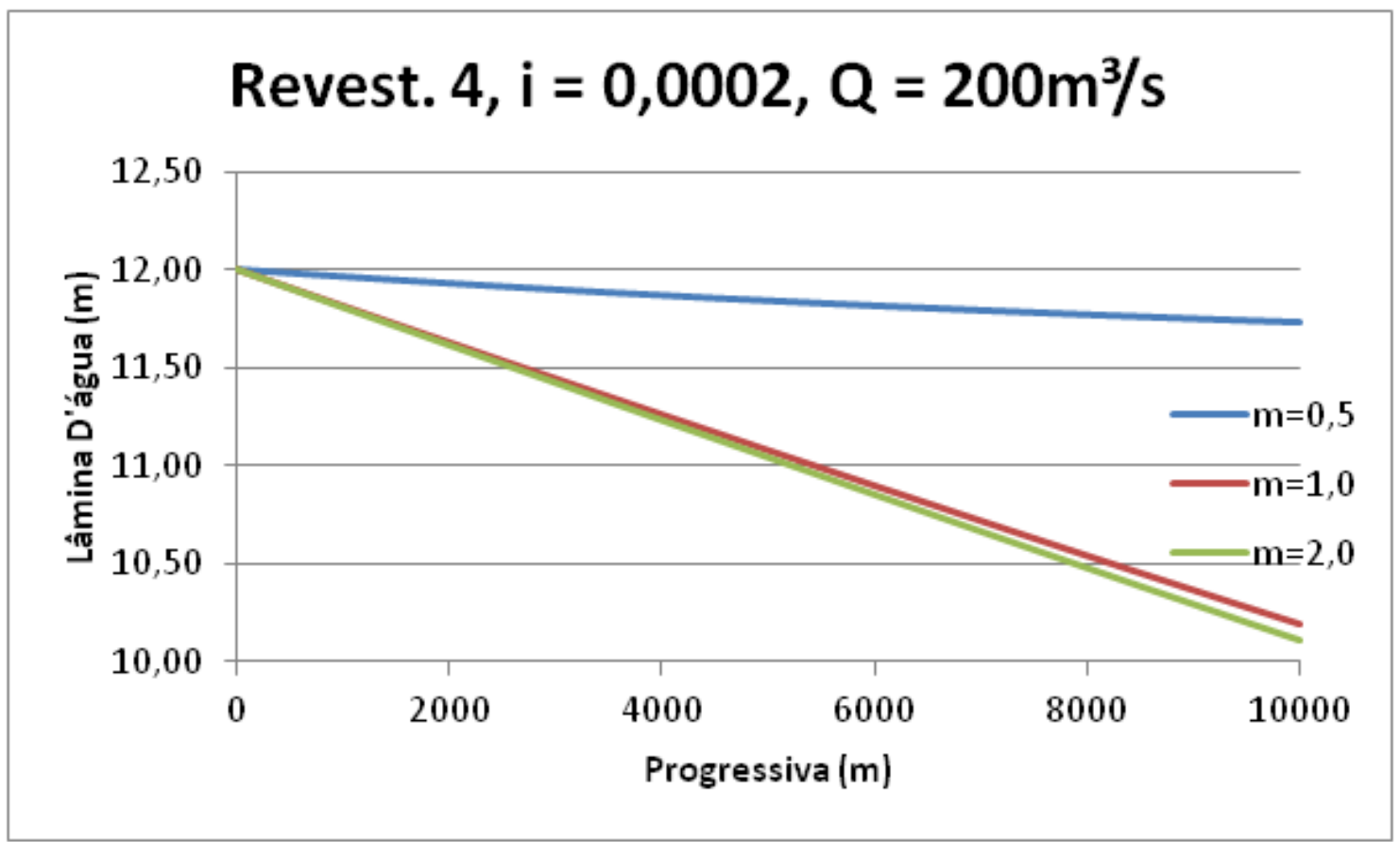




\begin{tabular}{|r|r|r|r|}
\hline \multirow{2}{*}{ Progr. } & \multicolumn{3}{|c|}{ Lâmina d'água $(\mathrm{m})$} \\
\cline { 2 - 4 } & $\mathrm{m}=0,5$ & $\mathrm{~m}=1,0$ & $\mathrm{~m}=2,0$ \\
\hline 0 & 12,00 & 12,00 & 12,00 \\
\hline 500 & 11,99 & 11,93 & 11,91 \\
\hline 1000 & 11,98 & 11,87 & 11,81 \\
\hline 1500 & 11,97 & 11,80 & 11,72 \\
\hline 2000 & 11,96 & 11,74 & 11,62 \\
\hline 2500 & 11,95 & 11,68 & 11,53 \\
\hline 3000 & 11,94 & 11,62 & 11,44 \\
\hline 3500 & 11,93 & 11,56 & 11,35 \\
\hline 4000 & 11,92 & 11,50 & 11,25 \\
\hline 4500 & 11,91 & 11,44 & 11,16 \\
\hline 5000 & 11,90 & 11,38 & 11,07 \\
\hline 5500 & 11,90 & 11,33 & 10,98 \\
\hline 6000 & 11,89 & 11,27 & 10,89 \\
\hline 6500 & 11,88 & 11,22 & 10,80 \\
\hline 7000 & 11,87 & 11,17 & 10,71 \\
\hline 7500 & 11,87 & 11,12 & 10,62 \\
\hline 8000 & 11,86 & 11,07 & 10,53 \\
\hline 8500 & 11,85 & 11,02 & 10,44 \\
\hline 9000 & 11,85 & 10,98 & 10,35 \\
\hline 9500 & 11,84 & 10,93 & 10,26 \\
\hline 10000 & 11,84 & 10,89 & 10,18 \\
\hline & & & \\
\hline
\end{tabular}

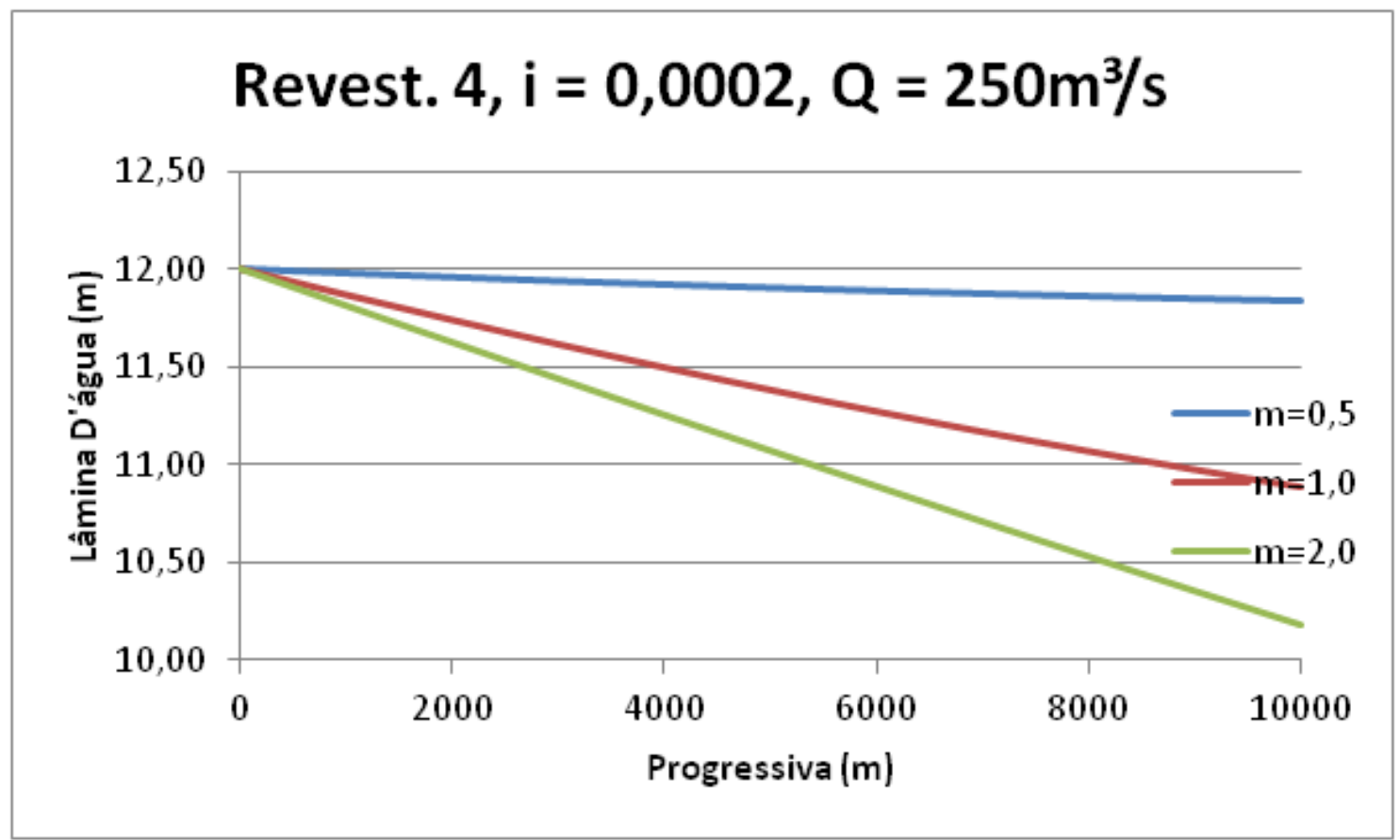




\begin{tabular}{|r|r|r|r|}
\hline \multirow{2}{*}{ Progr. } & \multicolumn{3}{|c|}{ Lâmina d'água $(\mathrm{m})$} \\
\cline { 2 - 4 } & $\mathrm{m}=0,5$ & $\mathrm{~m}=1,0$ & $\mathrm{~m}=2,0$ \\
\hline 0 & 12,00 & 12,00 & 12,00 \\
\hline 500 & 11,99 & 11,95 & 11,91 \\
\hline 1000 & 11,98 & 11,90 & 11,82 \\
\hline 1500 & 11,97 & 11,85 & 11,73 \\
\hline 2000 & 11,96 & 11,80 & 11,63 \\
\hline 2500 & 11,96 & 11,76 & 11,54 \\
\hline 3000 & 11,95 & 11,71 & 11,45 \\
\hline 3500 & 11,94 & 11,67 & 11,37 \\
\hline 4000 & 11,93 & 11,63 & 11,28 \\
\hline 4500 & 11,93 & 11,58 & 11,19 \\
\hline 5000 & 11,92 & 11,54 & 11,10 \\
\hline 5500 & 11,91 & 11,51 & 11,01 \\
\hline 6000 & 11,91 & 11,47 & 10,93 \\
\hline 6500 & 11,90 & 11,43 & 10,84 \\
\hline 7000 & 11,89 & 11,40 & 10,75 \\
\hline 7500 & 11,89 & 11,36 & 10,67 \\
\hline 8000 & 11,88 & 11,33 & 10,58 \\
\hline 8500 & 11,88 & 11,30 & 10,50 \\
\hline 9000 & 11,87 & 11,27 & 10,42 \\
\hline 9500 & 11,87 & 11,24 & 10,33 \\
\hline 10000 & 11,86 & 11,21 & 10,25 \\
\hline & & & \\
\hline
\end{tabular}

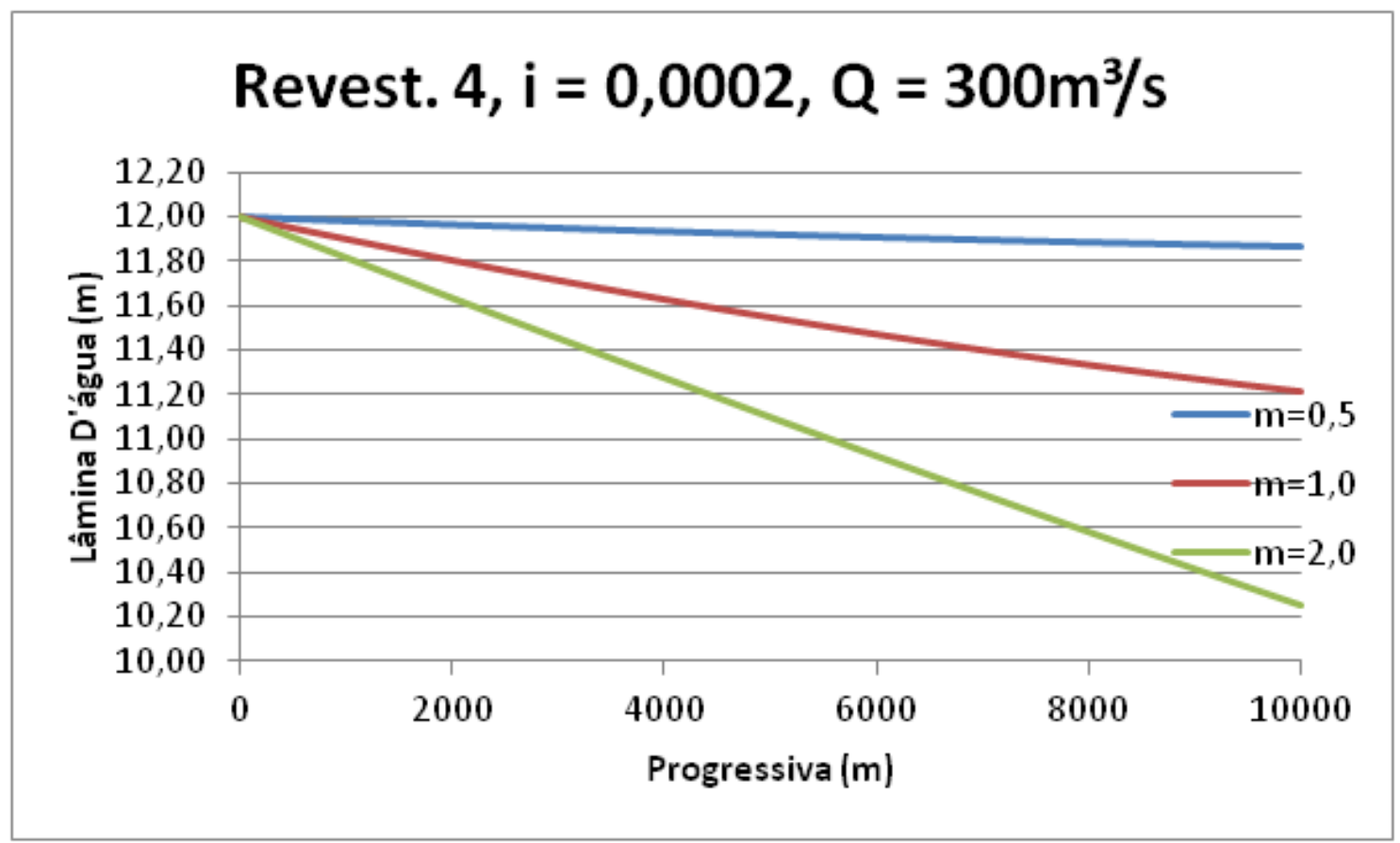




\begin{tabular}{|r|r|r|r|}
\hline \multirow{2}{*}{ Progr. } & \multicolumn{3}{|c|}{ Lâmina d'água $(\mathrm{m})$} \\
\cline { 2 - 4 } & $\mathrm{m}=0,5$ & $\mathrm{~m}=1,0$ & $\mathrm{~m}=2,0$ \\
\hline 0 & 12,00 & 12,00 & 12,00 \\
\hline 500 & 12,00 & 11,97 & 11,91 \\
\hline 1000 & 12,00 & 11,94 & 11,82 \\
\hline 1500 & 12,00 & 11,91 & 11,73 \\
\hline 2000 & 12,00 & 11,88 & 11,65 \\
\hline 2500 & 12,00 & 11,85 & 11,56 \\
\hline 3000 & 12,00 & 11,83 & 11,47 \\
\hline 3500 & 12,00 & 11,80 & 11,39 \\
\hline 4000 & 12,00 & 11,78 & 11,30 \\
\hline 4500 & 12,00 & 11,75 & 11,22 \\
\hline 5000 & 12,00 & 11,73 & 11,14 \\
\hline 5500 & 12,00 & 11,71 & 11,05 \\
\hline 6000 & 12,00 & 11,69 & 10,97 \\
\hline 6500 & 12,00 & 11,67 & 10,89 \\
\hline 7000 & 12,00 & 11,65 & 10,81 \\
\hline 7500 & 12,00 & 11,63 & 10,73 \\
\hline 8000 & 12,00 & 11,61 & 10,65 \\
\hline 8500 & 12,00 & 11,59 & 10,57 \\
\hline 9000 & 12,00 & 11,58 & 10,49 \\
\hline 9500 & 12,00 & 11,56 & 10,42 \\
\hline 10000 & 12,00 & 11,55 & 10,34 \\
\hline & & & \\
\hline
\end{tabular}

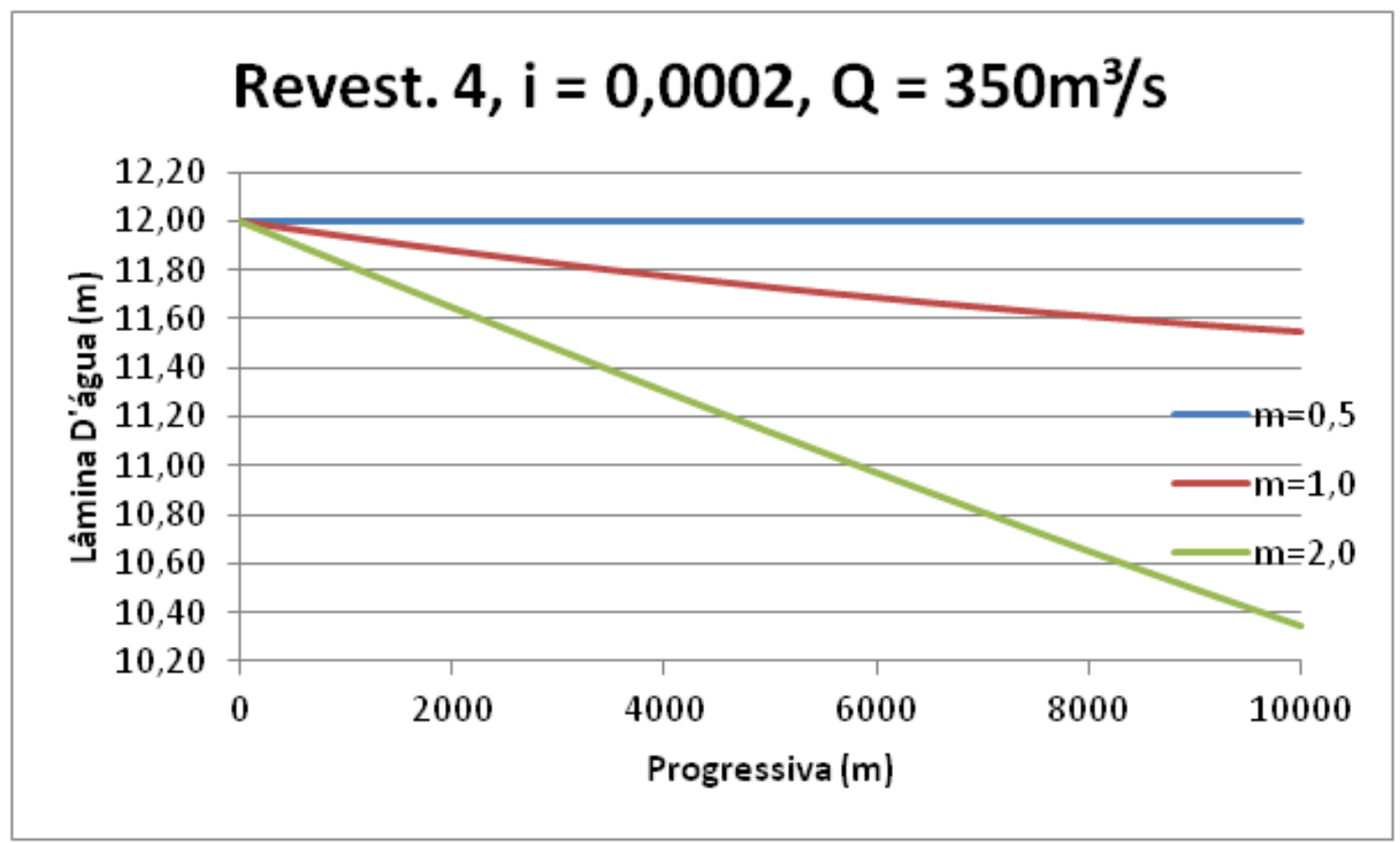




\begin{tabular}{|r|r|r|r|}
\hline \multirow{2}{*}{ Progr. } & \multicolumn{3}{|c|}{ Lâmina d'água $(\mathrm{m})$} \\
\cline { 2 - 4 } & $\mathrm{m}=0,5$ & $\mathrm{~m}=1,0$ & $\mathrm{~m}=2,0$ \\
\hline 0 & 12,00 & 12,00 & 12,00 \\
\hline 500 & 11,76 & 11,75 & 11,75 \\
\hline 1000 & 11,52 & 11,50 & 11,50 \\
\hline 1500 & 11,28 & 11,25 & 11,25 \\
\hline 2000 & 11,04 & 11,00 & 11,00 \\
\hline 2500 & 10,81 & 10,75 & 10,75 \\
\hline 3000 & 10,57 & 10,51 & 10,50 \\
\hline 3500 & 10,34 & 10,26 & 10,25 \\
\hline 4000 & 10,11 & 10,01 & 10,00 \\
\hline 4500 & 9,88 & 9,76 & 9,75 \\
\hline 5000 & 9,66 & 9,51 & 9,50 \\
\hline 5500 & 9,44 & 9,26 & 9,25 \\
\hline 6000 & 9,22 & 9,02 & 9,00 \\
\hline 6500 & 9,01 & 8,77 & 8,75 \\
\hline 7000 & 8,80 & 8,52 & 8,51 \\
\hline 7500 & 8,60 & 8,28 & 8,26 \\
\hline 8000 & 8,41 & 8,03 & 8,01 \\
\hline 8500 & 8,22 & 7,79 & 7,76 \\
\hline 9000 & 8,04 & 7,54 & 7,51 \\
\hline 9500 & 7,87 & 7,30 & 7,26 \\
\hline 10000 & 7,71 & 7,06 & 7,01 \\
\hline & & & \\
\hline
\end{tabular}

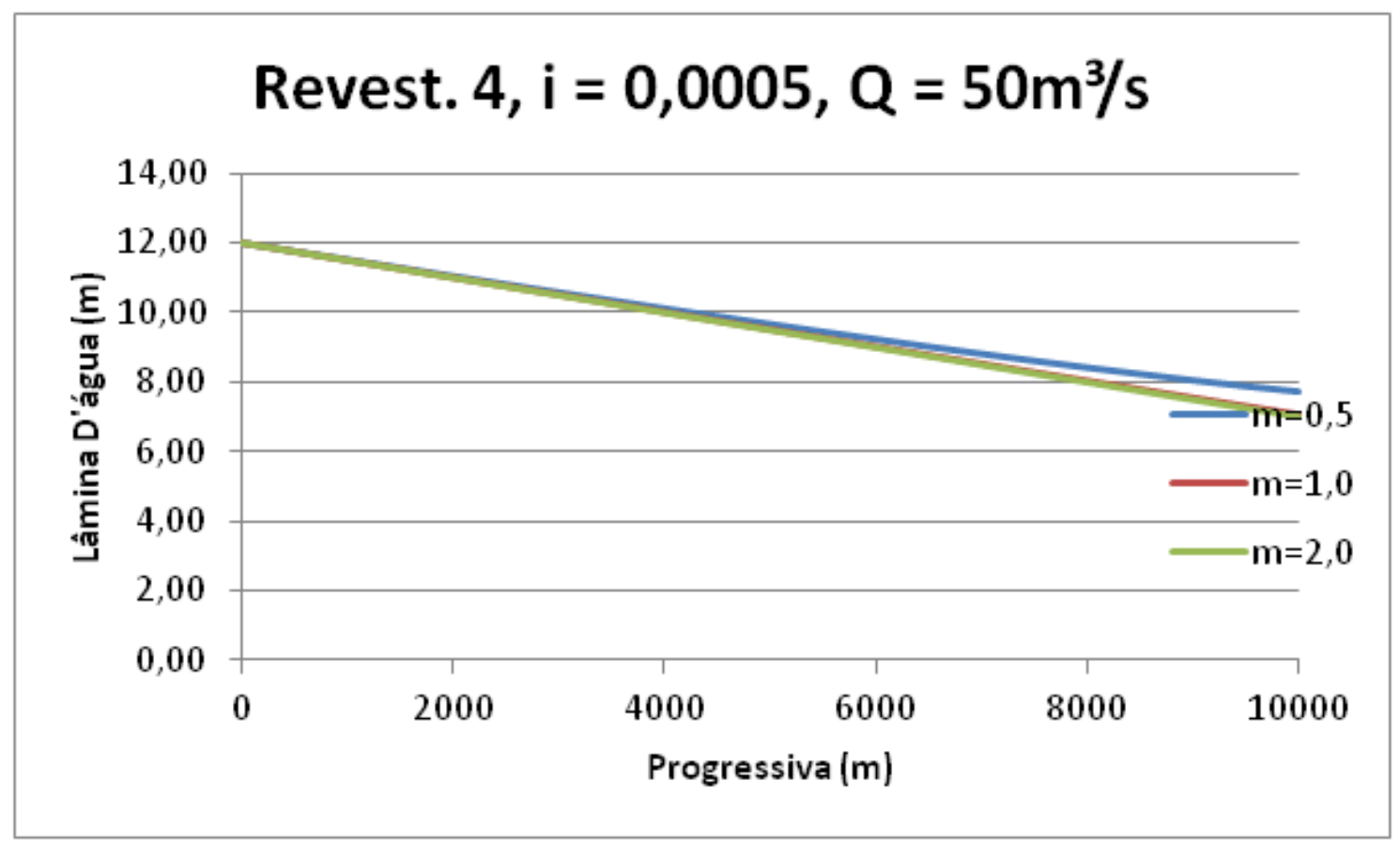




\begin{tabular}{|r|r|r|r|}
\hline \multirow{2}{*}{ Progr. } & \multicolumn{3}{|c|}{ Lâmina d'água $(\mathrm{m})$} \\
\cline { 2 - 4 } & $\mathrm{m}=0,5$ & $\mathrm{~m}=1,0$ & $\mathrm{~m}=2,0$ \\
\hline 0 & 12,00 & 12,00 & 12,00 \\
\hline 500 & 11,79 & 11,75 & 11,75 \\
\hline 1000 & 11,58 & 11,51 & 11,50 \\
\hline 1500 & 11,37 & 11,26 & 11,25 \\
\hline 2000 & 11,17 & 11,01 & 11,00 \\
\hline 2500 & 10,98 & 10,77 & 10,75 \\
\hline 3000 & 10,79 & 10,52 & 10,50 \\
\hline 3500 & 10,60 & 10,28 & 10,26 \\
\hline 4000 & 10,42 & 10,03 & 10,01 \\
\hline 4500 & 10,25 & 9,79 & 9,76 \\
\hline 5000 & 10,09 & 9,55 & 9,51 \\
\hline 5500 & 9,94 & 9,31 & 9,26 \\
\hline 6000 & 9,79 & 9,07 & 9,01 \\
\hline 6500 & 9,66 & 8,83 & 8,77 \\
\hline 7000 & 9,53 & 8,59 & 8,52 \\
\hline 7500 & 9,41 & 8,36 & 8,27 \\
\hline 8000 & 9,31 & 8,13 & 8,03 \\
\hline 8500 & 9,21 & 7,90 & 7,78 \\
\hline 9000 & 9,12 & 7,67 & 7,54 \\
\hline 9500 & 9,04 & 7,45 & 7,30 \\
\hline 10000 & 8,97 & 7,23 & 7,06 \\
\hline & & & \\
\hline
\end{tabular}

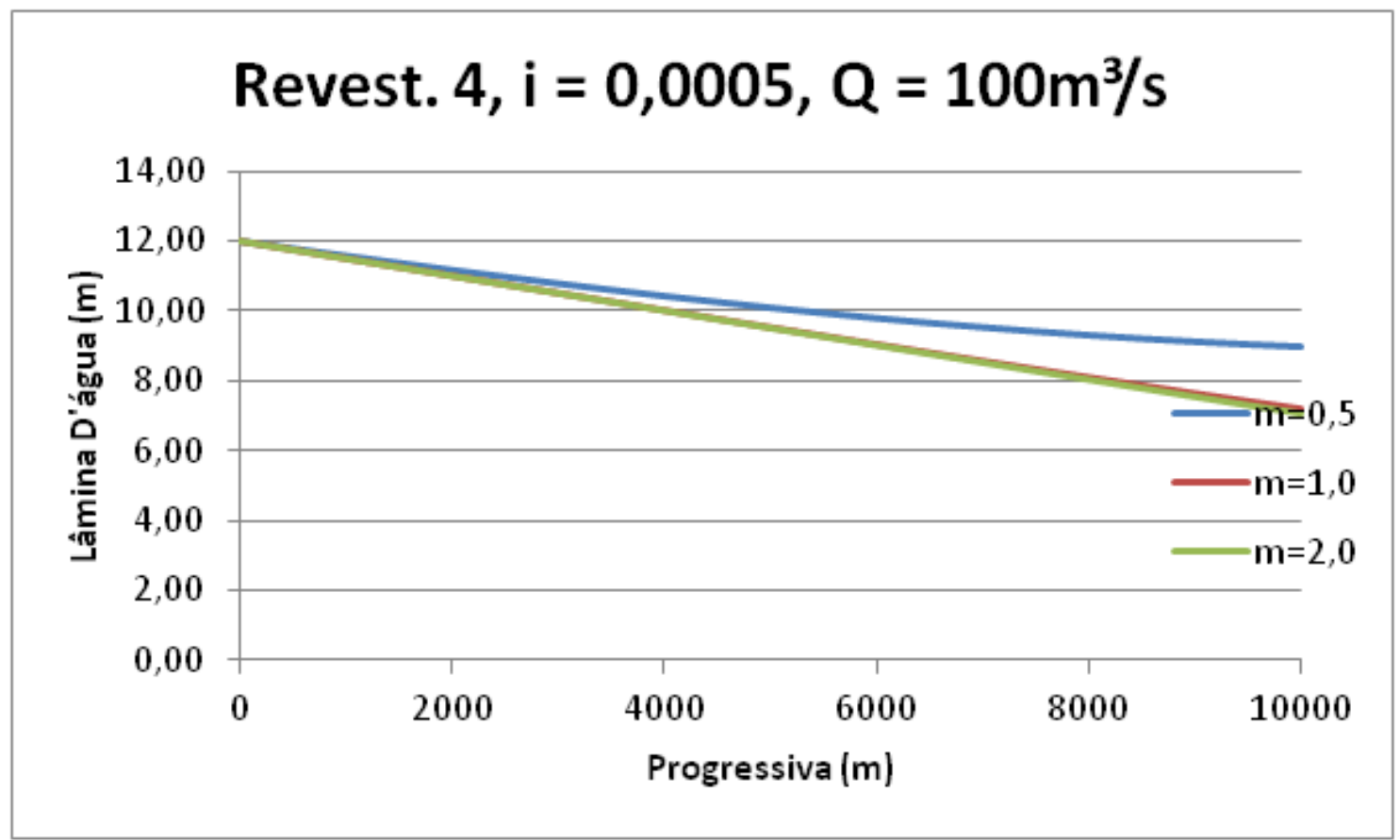




\begin{tabular}{|r|r|r|r|}
\hline \multirow{2}{*}{ Progr. } & \multicolumn{3}{|c|}{ Lâmina d'água $(\mathrm{m})$} \\
\cline { 2 - 4 } & $\mathrm{m}=0,5$ & $\mathrm{~m}=1,0$ & $\mathrm{~m}=2,0$ \\
\hline 0 & 12,00 & 12,00 & 12,00 \\
\hline 500 & 11,83 & 11,76 & 11,75 \\
\hline 1000 & 11,68 & 11,51 & 11,50 \\
\hline 1500 & 11,53 & 11,27 & 11,25 \\
\hline 2000 & 11,38 & 11,03 & 11,01 \\
\hline 2500 & 11,25 & 10,79 & 10,76 \\
\hline 3000 & 11,12 & 10,55 & 10,51 \\
\hline 3500 & 11,00 & 10,31 & 10,26 \\
\hline 4000 & 10,89 & 10,08 & 10,02 \\
\hline 4500 & 10,79 & 9,84 & 9,77 \\
\hline 5000 & 10,70 & 9,61 & 9,52 \\
\hline 5500 & 10,61 & 9,38 & 9,28 \\
\hline 6000 & 10,53 & 9,15 & 9,03 \\
\hline 6500 & 10,46 & 8,93 & 8,79 \\
\hline 7000 & 10,40 & 8,71 & 8,55 \\
\hline 7500 & 10,34 & 8,49 & 8,30 \\
\hline 8000 & 10,29 & 8,28 & 8,06 \\
\hline 8500 & 10,25 & 8,07 & 7,83 \\
\hline 9000 & 10,21 & 7,87 & 7,59 \\
\hline 9500 & 10,17 & 7,68 & 7,36 \\
\hline 10000 & 10,14 & 7,49 & 7,12 \\
\hline & & & \\
\hline
\end{tabular}

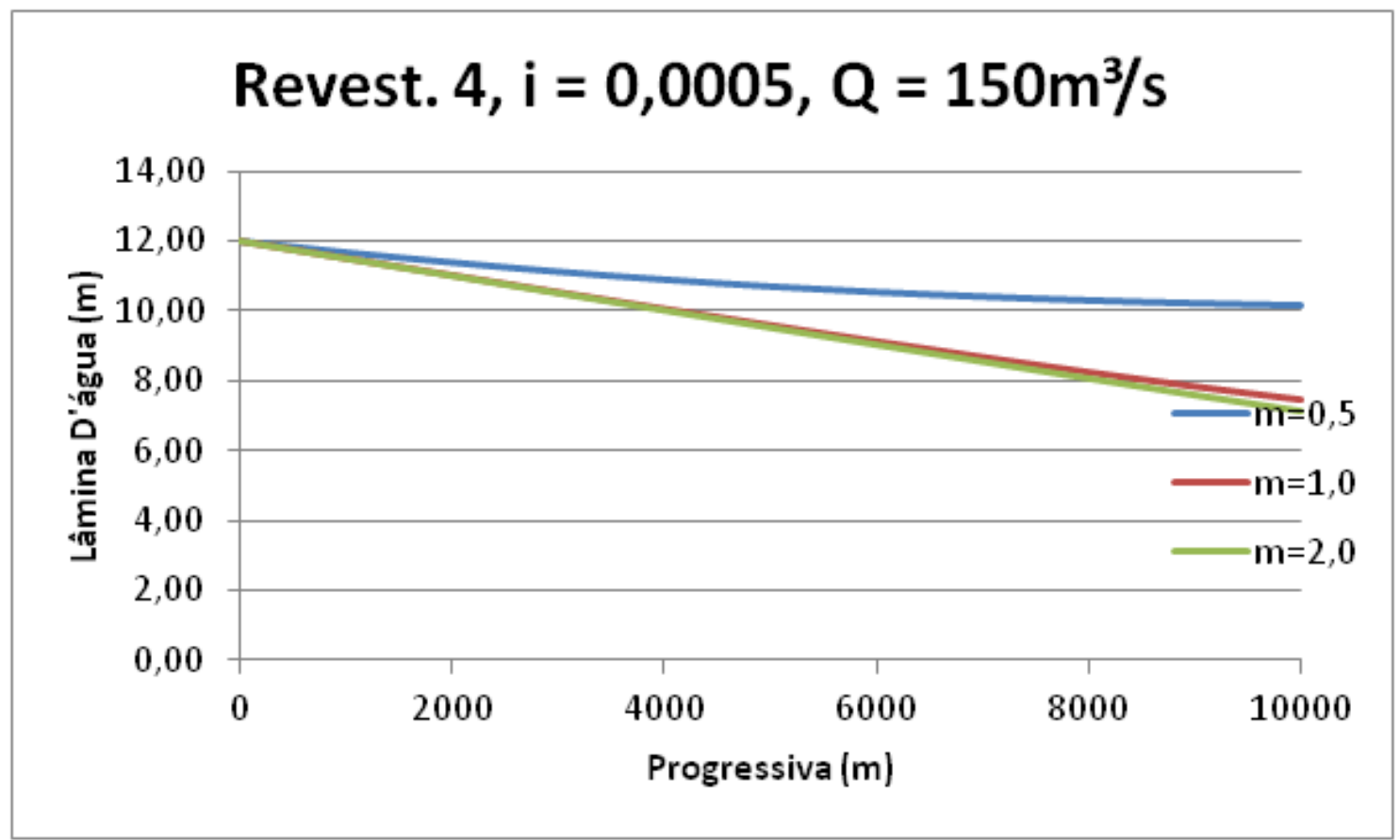




\begin{tabular}{|r|r|r|r|}
\hline \multirow{2}{*}{ Progr. } & \multicolumn{3}{|c|}{ Lâmina d'água $(\mathrm{m})$} \\
\cline { 2 - 4 } & $\mathrm{m}=0,5$ & $\mathrm{~m}=1,0$ & $\mathrm{~m}=2,0$ \\
\hline 0 & 12,00 & 12,00 & 12,00 \\
\hline 500 & 11,79 & 11,77 & 11,75 \\
\hline 1000 & 11,58 & 11,54 & 11,50 \\
\hline 1500 & 11,38 & 11,31 & 11,26 \\
\hline 2000 & 11,18 & 11,08 & 11,01 \\
\hline 2500 & 10,98 & 10,86 & 10,76 \\
\hline 3000 & 10,79 & 10,63 & 10,52 \\
\hline 3500 & 10,60 & 10,42 & 10,27 \\
\hline 4000 & 10,42 & 10,21 & 10,03 \\
\hline 4500 & 10,25 & 10,00 & 9,78 \\
\hline 5000 & 10,08 & 9,80 & 9,54 \\
\hline 5500 & 9,91 & 9,60 & 9,30 \\
\hline 6000 & 9,76 & 9,41 & 9,06 \\
\hline 6500 & 9,61 & 9,23 & 8,82 \\
\hline 7000 & 9,46 & 9,05 & 8,58 \\
\hline 7500 & 9,33 & 8,89 & 8,35 \\
\hline 8000 & 9,20 & 8,74 & 8,11 \\
\hline 8500 & 9,08 & 8,59 & 7,88 \\
\hline 9000 & 8,97 & 8,46 & 7,66 \\
\hline 9500 & 8,87 & 8,34 & 7,44 \\
\hline 10000 & 8,78 & 8,24 & 7,22 \\
\hline & & & \\
\hline
\end{tabular}

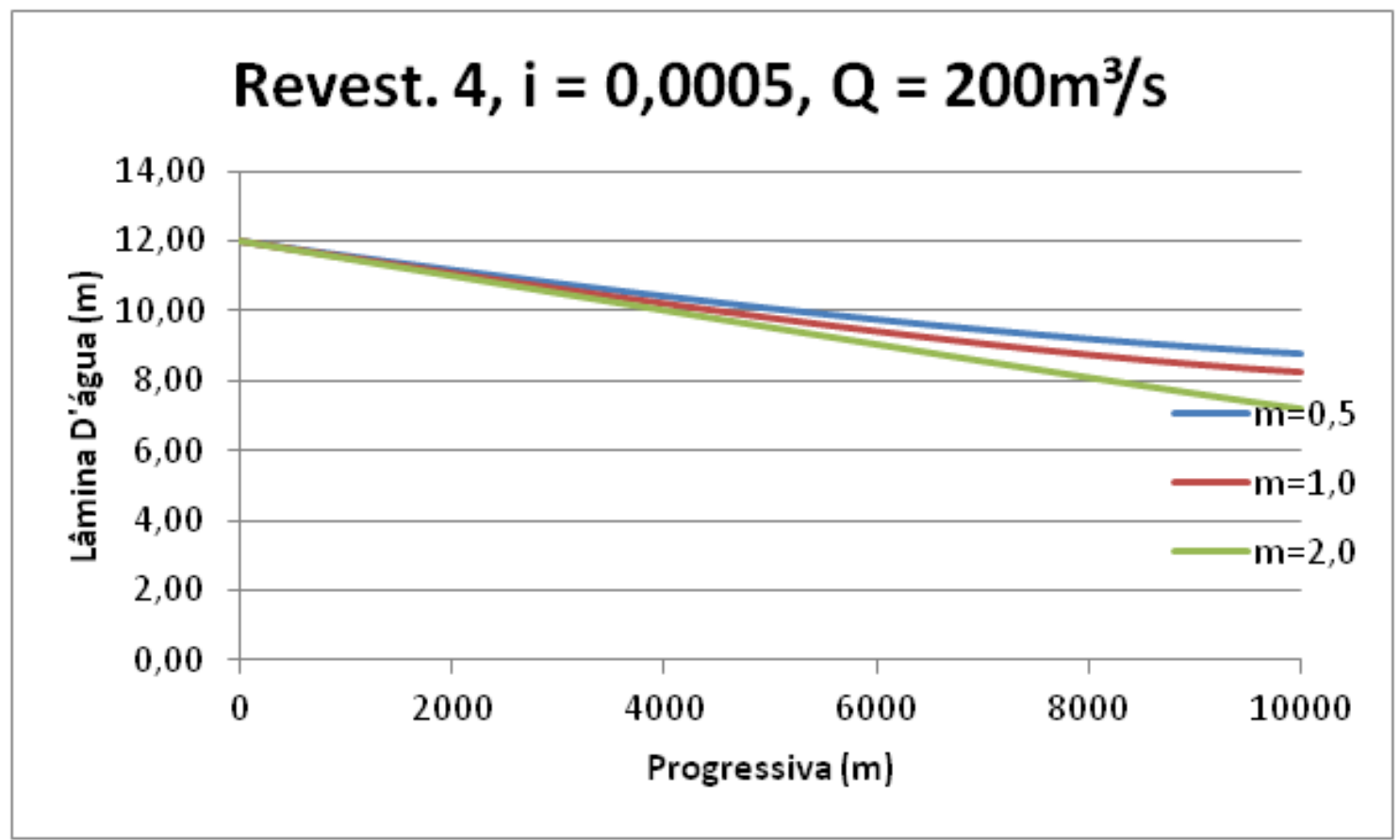




\begin{tabular}{|r|r|r|r|}
\hline \multirow{2}{*}{ Progr. } & \multicolumn{3}{|c|}{ Lâmina d'água $(\mathrm{m})$} \\
\cline { 2 - 4 } & $\mathrm{m}=0,5$ & $\mathrm{~m}=1,0$ & $\mathrm{~m}=2,0$ \\
\hline 0 & 12,00 & 12,00 & 12,00 \\
\hline 500 & 11,81 & 11,78 & 11,75 \\
\hline 1000 & 11,63 & 11,56 & 11,51 \\
\hline 1500 & 11,45 & 11,34 & 11,26 \\
\hline 2000 & 11,28 & 11,13 & 11,02 \\
\hline 2500 & 11,11 & 10,92 & 10,77 \\
\hline 3000 & 10,95 & 10,71 & 10,53 \\
\hline 3500 & 10,80 & 10,51 & 10,29 \\
\hline 4000 & 10,65 & 10,32 & 10,04 \\
\hline 4500 & 10,51 & 10,13 & 9,80 \\
\hline 5000 & 10,38 & 9,96 & 9,56 \\
\hline 5500 & 10,25 & 9,79 & 9,33 \\
\hline 6000 & 10,13 & 9,62 & 9,09 \\
\hline 6500 & 10,02 & 9,47 & 8,86 \\
\hline 7000 & 9,91 & 9,33 & 8,63 \\
\hline 7500 & 9,82 & 9,20 & 8,40 \\
\hline 8000 & 9,73 & 9,08 & 8,18 \\
\hline 8500 & 9,64 & 8,97 & 7,96 \\
\hline 9000 & 9,57 & 8,87 & 7,74 \\
\hline 9500 & 9,50 & 8,79 & 7,54 \\
\hline 10000 & 9,44 & 8,71 & 7,34 \\
\hline & & & \\
\hline
\end{tabular}

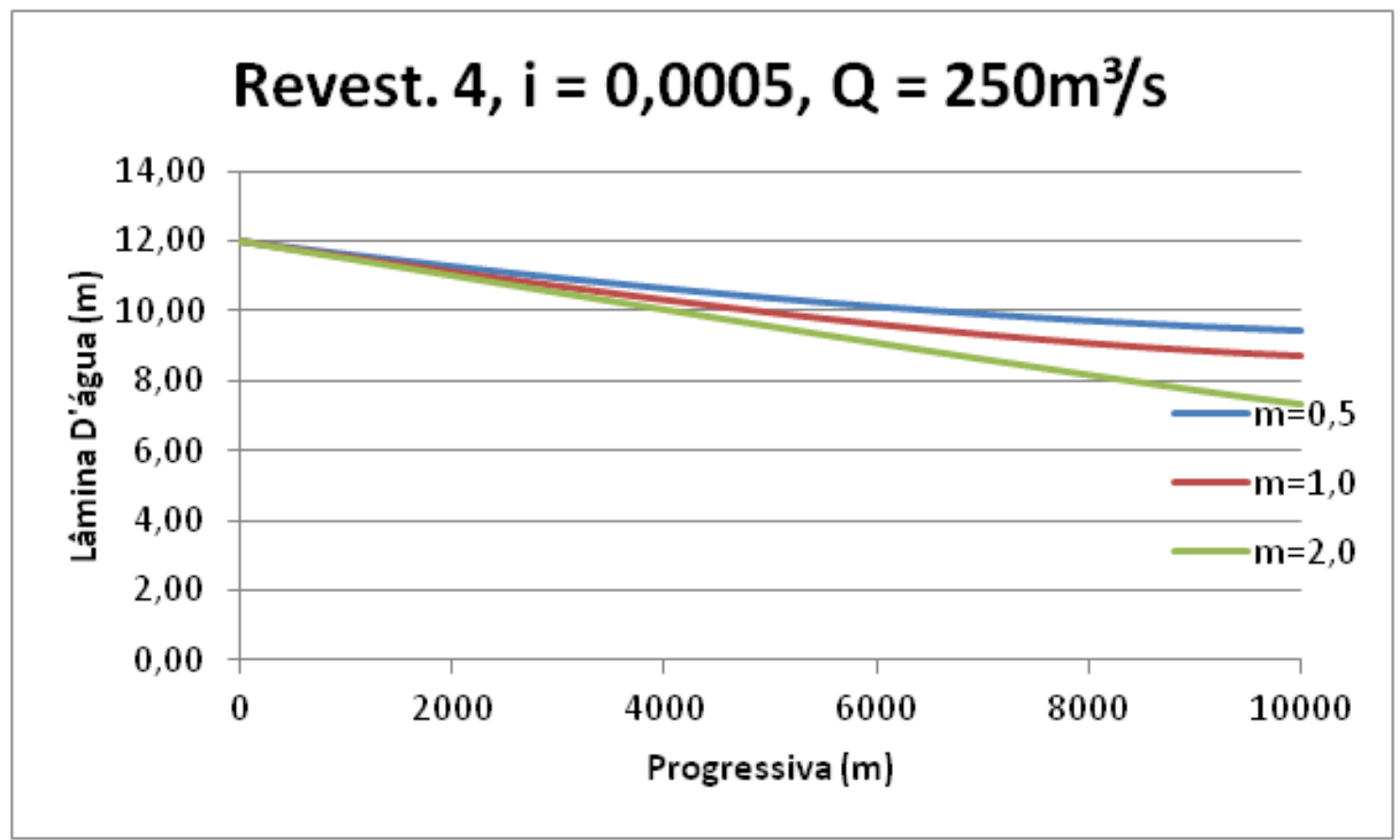




\begin{tabular}{|r|r|r|r|}
\hline \multirow{2}{*}{ Progr. } & \multicolumn{3}{|c|}{ Lâmina d'água $(\mathrm{m})$} \\
\cline { 2 - 4 } & $\mathrm{m}=0,5$ & $\mathrm{~m}=1,0$ & $\mathrm{~m}=2,0$ \\
\hline 0 & 12,00 & 12,00 & 12,00 \\
\hline 500 & 11,79 & 11,79 & 11,76 \\
\hline 1000 & 11,59 & 11,58 & 11,51 \\
\hline 1500 & 11,38 & 11,38 & 11,27 \\
\hline 2000 & 11,18 & 11,18 & 11,02 \\
\hline 2500 & 10,99 & 10,99 & 10,78 \\
\hline 3000 & 10,80 & 10,81 & 10,54 \\
\hline 3500 & 10,61 & 10,63 & 10,30 \\
\hline 4000 & 10,43 & 10,46 & 10,06 \\
\hline 4500 & 10,26 & 10,30 & 9,83 \\
\hline 5000 & 10,09 & 10,15 & 9,59 \\
\hline 5500 & 9,92 & 10,00 & 9,36 \\
\hline 6000 & 9,76 & 9,87 & 9,13 \\
\hline 6500 & 9,61 & 9,75 & 8,91 \\
\hline 7000 & 9,47 & 9,64 & 8,68 \\
\hline 7500 & 9,33 & 9,54 & 8,47 \\
\hline 8000 & 9,20 & 9,45 & 8,25 \\
\hline 8500 & 9,08 & 9,37 & 8,05 \\
\hline 9000 & 8,96 & 9,30 & 7,85 \\
\hline 9500 & 8,85 & 9,23 & 7,66 \\
\hline 10000 & 8,75 & 9,18 & 7,47 \\
\hline & & & \\
\hline
\end{tabular}

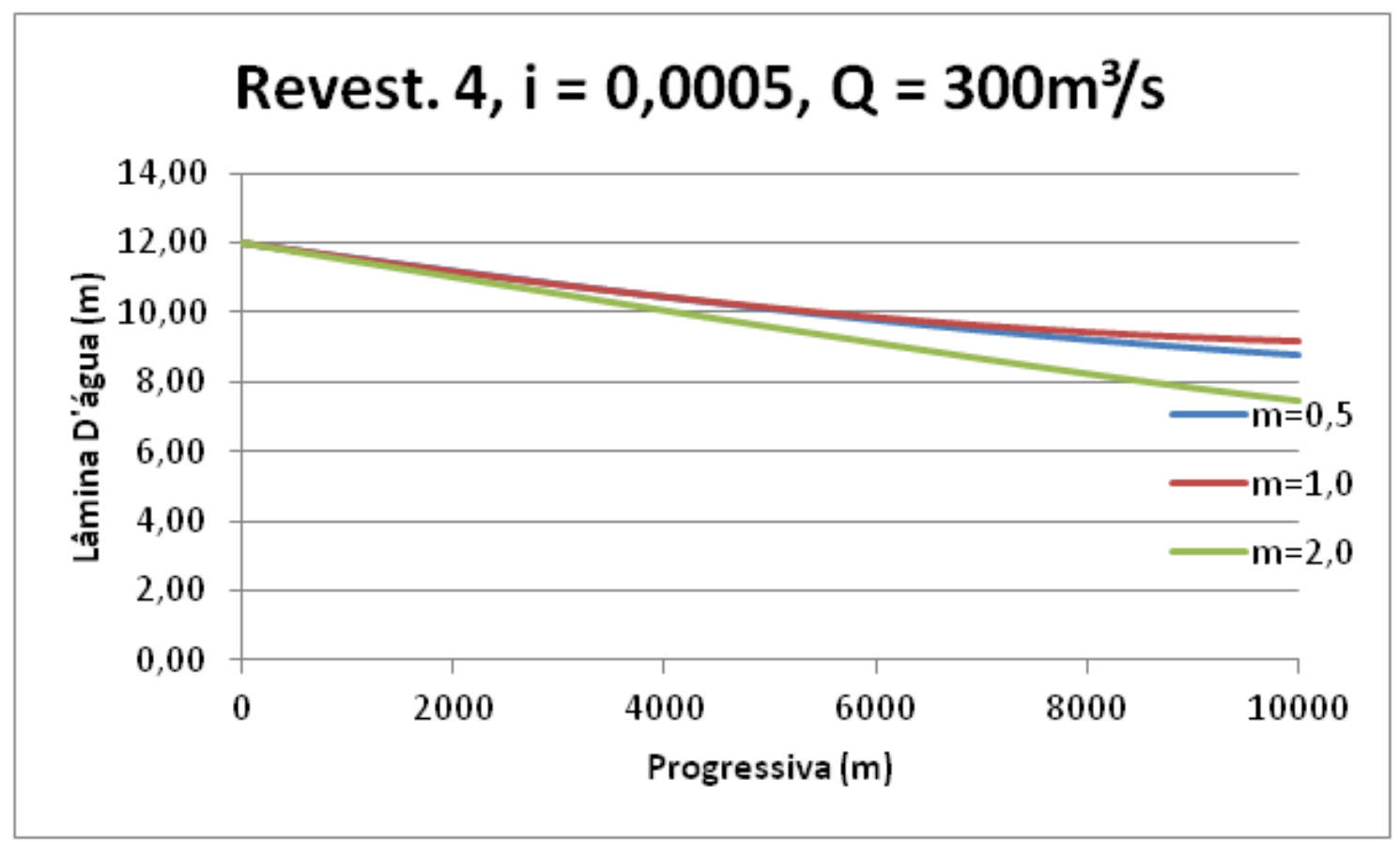




\begin{tabular}{|r|r|r|r|}
\hline \multirow{2}{*}{ Progr. } & \multicolumn{3}{|c|}{ Lâmina d'água $(\mathrm{m})$} \\
\cline { 2 - 4 } & $\mathrm{m}=0,5$ & $\mathrm{~m}=1,0$ & $\mathrm{~m}=2,0$ \\
\hline 0 & 12,00 & 12,00 & 12,00 \\
\hline 500 & 11,81 & 11,80 & 11,76 \\
\hline 1000 & 11,62 & 11,61 & 11,51 \\
\hline 1500 & 11,43 & 11,43 & 11,27 \\
\hline 2000 & 11,25 & 11,25 & 11,03 \\
\hline 2500 & 11,08 & 11,08 & 10,79 \\
\hline 3000 & 10,91 & 10,92 & 10,56 \\
\hline 3500 & 10,75 & 10,77 & 10,32 \\
\hline 4000 & 10,59 & 10,62 & 10,09 \\
\hline 4500 & 10,44 & 10,49 & 9,86 \\
\hline 5000 & 10,29 & 10,36 & 9,63 \\
\hline 5500 & 10,15 & 10,25 & 9,40 \\
\hline 6000 & 10,02 & 10,14 & 9,18 \\
\hline 6500 & 9,89 & 10,05 & 8,96 \\
\hline 7000 & 9,77 & 9,96 & 8,75 \\
\hline 7500 & 9,66 & 9,89 & 8,54 \\
\hline 8000 & 9,56 & 9,82 & 8,34 \\
\hline 8500 & 9,46 & 9,76 & 8,15 \\
\hline 9000 & 9,37 & 9,71 & 7,97 \\
\hline 9500 & 9,29 & 9,67 & 7,79 \\
\hline 10000 & 9,22 & 9,64 & 7,63 \\
\hline & & & \\
\hline
\end{tabular}

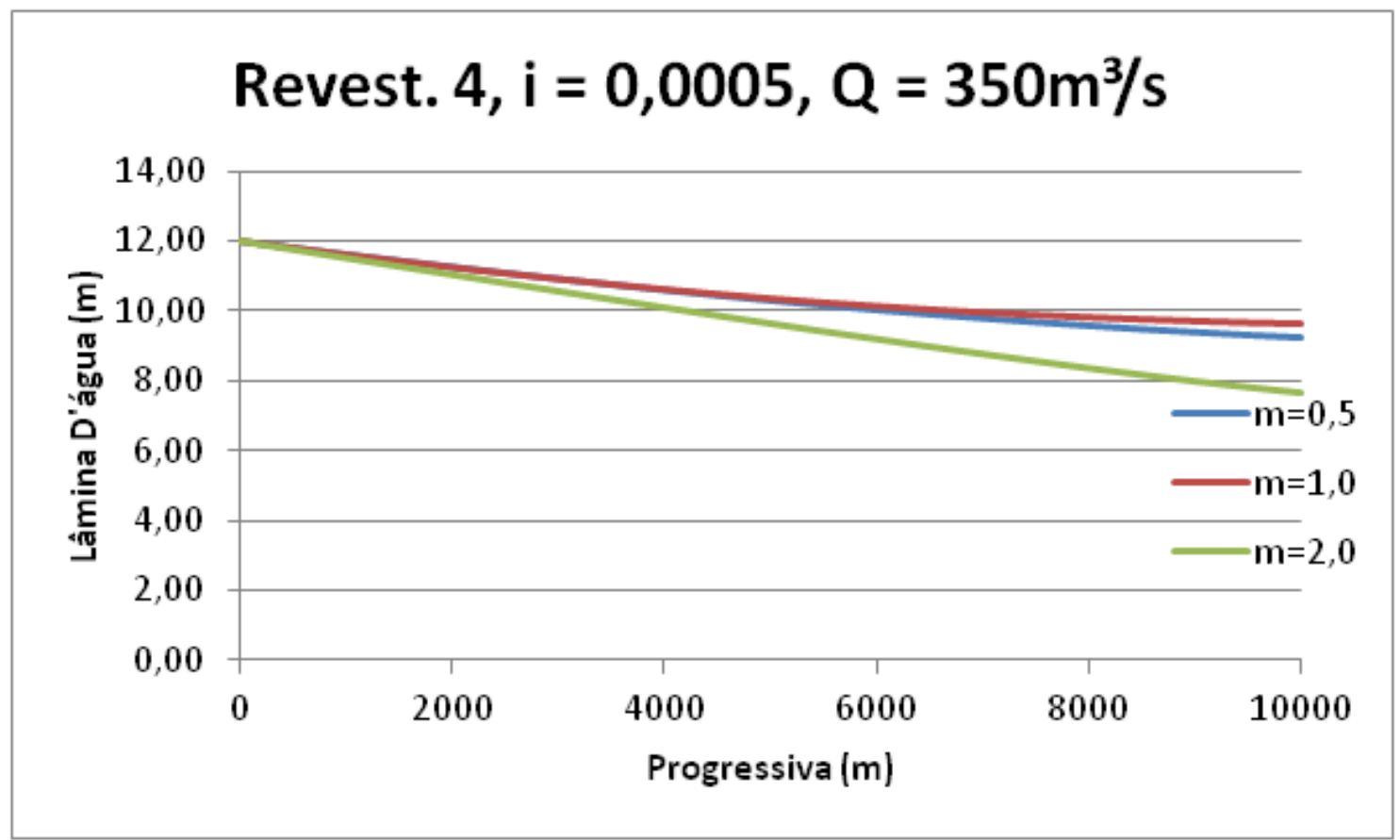




\begin{tabular}{|r|r|r|r|}
\hline \multirow{2}{*}{ Progr. } & \multicolumn{3}{|c|}{ Lâmina d'água $(\mathrm{m})$} \\
\cline { 2 - 4 } & $\mathrm{m}=0,5$ & $\mathrm{~m}=1,0$ & $\mathrm{~m}=2,0$ \\
\hline 0 & 12,00 & 12,00 & 12,00 \\
\hline 500 & 11,98 & 11,95 & 11,95 \\
\hline 1000 & 11,96 & 11,91 & 11,90 \\
\hline 1500 & 11,94 & 11,86 & 11,85 \\
\hline 2000 & 11,92 & 11,82 & 11,80 \\
\hline 2500 & 11,90 & 11,77 & 11,75 \\
\hline 3000 & 11,88 & 11,73 & 11,70 \\
\hline 3500 & 11,86 & 11,68 & 11,66 \\
\hline 4000 & 11,85 & 11,64 & 11,61 \\
\hline 4500 & 11,83 & 11,59 & 11,56 \\
\hline 5000 & 11,81 & 11,55 & 11,51 \\
\hline 5500 & 11,79 & 11,50 & 11,46 \\
\hline 6000 & 11,77 & 11,46 & 11,41 \\
\hline 6500 & 11,76 & 11,41 & 11,36 \\
\hline 7000 & 11,74 & 11,37 & 11,31 \\
\hline 7500 & 11,72 & 11,32 & 11,26 \\
\hline 8000 & 11,71 & 11,28 & 11,21 \\
\hline 8500 & 11,69 & 11,23 & 11,17 \\
\hline 9000 & 11,68 & 11,19 & 11,12 \\
\hline 9500 & 11,66 & 11,14 & 11,07 \\
\hline 10000 & 11,64 & 11,10 & 11,02 \\
\hline & & & \\
\hline
\end{tabular}

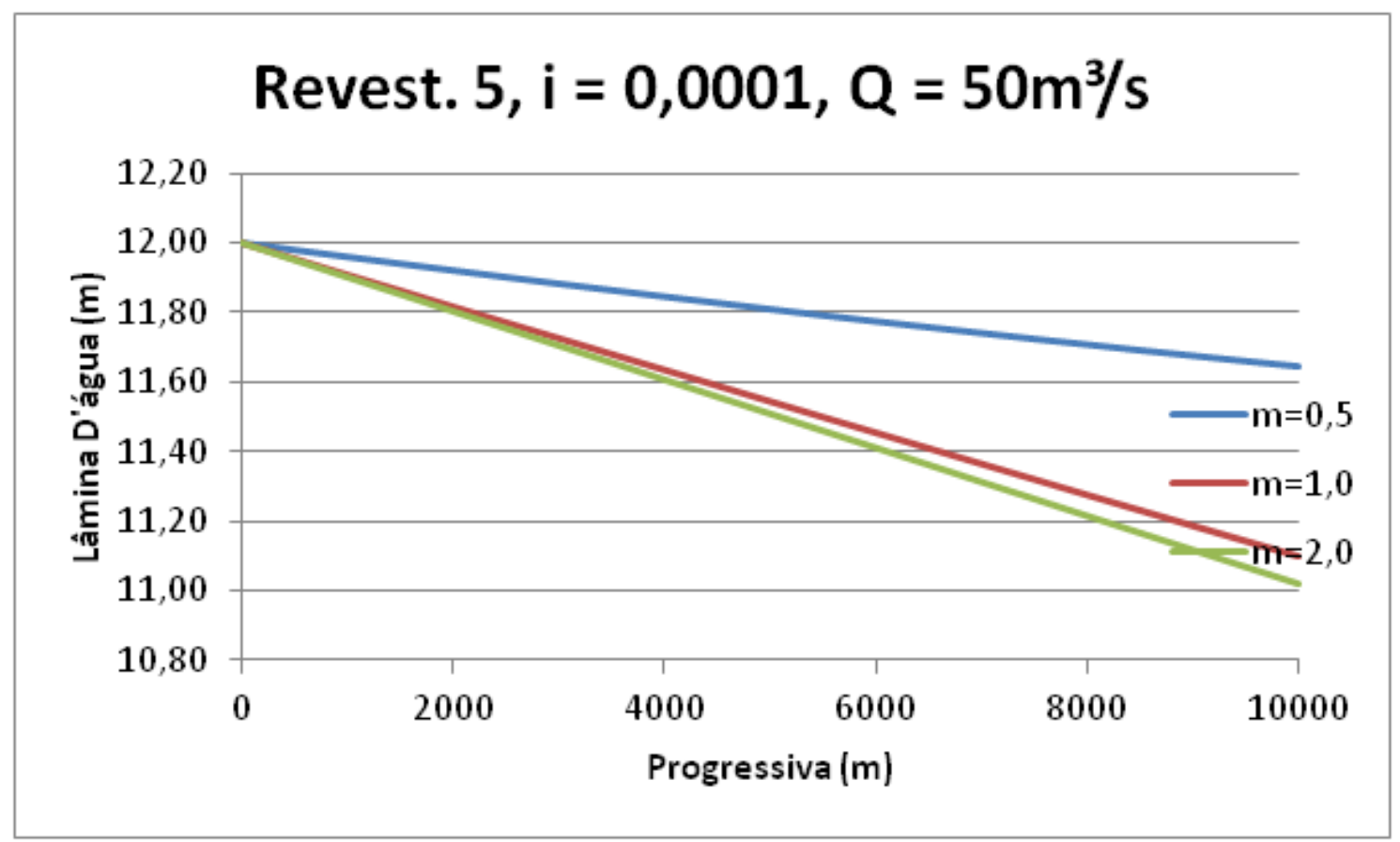




\begin{tabular}{|r|r|r|r|}
\hline \multirow{2}{*}{ Progr. } & \multicolumn{3}{|c|}{ Lâmina d'água $(\mathrm{m})$} \\
\cline { 2 - 4 } & $\mathrm{m}=0,5$ & $\mathrm{~m}=1,0$ & $\mathrm{~m}=2,0$ \\
\hline 0 & 12,00 & 12,00 & 12,00 \\
\hline 500 & 12,05 & 11,97 & 11,95 \\
\hline 1000 & 12,10 & 11,93 & 11,91 \\
\hline 1500 & 12,14 & 11,90 & 11,86 \\
\hline 2000 & 12,18 & 11,87 & 11,81 \\
\hline 2500 & 12,22 & 11,83 & 11,77 \\
\hline 3000 & 12,26 & 11,80 & 11,72 \\
\hline 3500 & 12,30 & 11,77 & 11,67 \\
\hline 4000 & 12,34 & 11,74 & 11,63 \\
\hline 4500 & 12,37 & 11,71 & 11,58 \\
\hline 5000 & 12,41 & 11,68 & 11,53 \\
\hline 5500 & 12,44 & 11,64 & 11,49 \\
\hline 6000 & 12,47 & 11,61 & 11,44 \\
\hline 6500 & 12,50 & 11,58 & 11,39 \\
\hline 7000 & 12,53 & 11,55 & 11,35 \\
\hline 7500 & 12,56 & 11,52 & 11,30 \\
\hline 8000 & 12,59 & 11,49 & 11,26 \\
\hline 8500 & 12,62 & 11,47 & 11,21 \\
\hline 9000 & 12,64 & 11,44 & 11,17 \\
\hline 9500 & 12,67 & 11,41 & 11,12 \\
\hline 10000 & 12,69 & 11,38 & 11,07 \\
\hline & & & \\
\hline
\end{tabular}

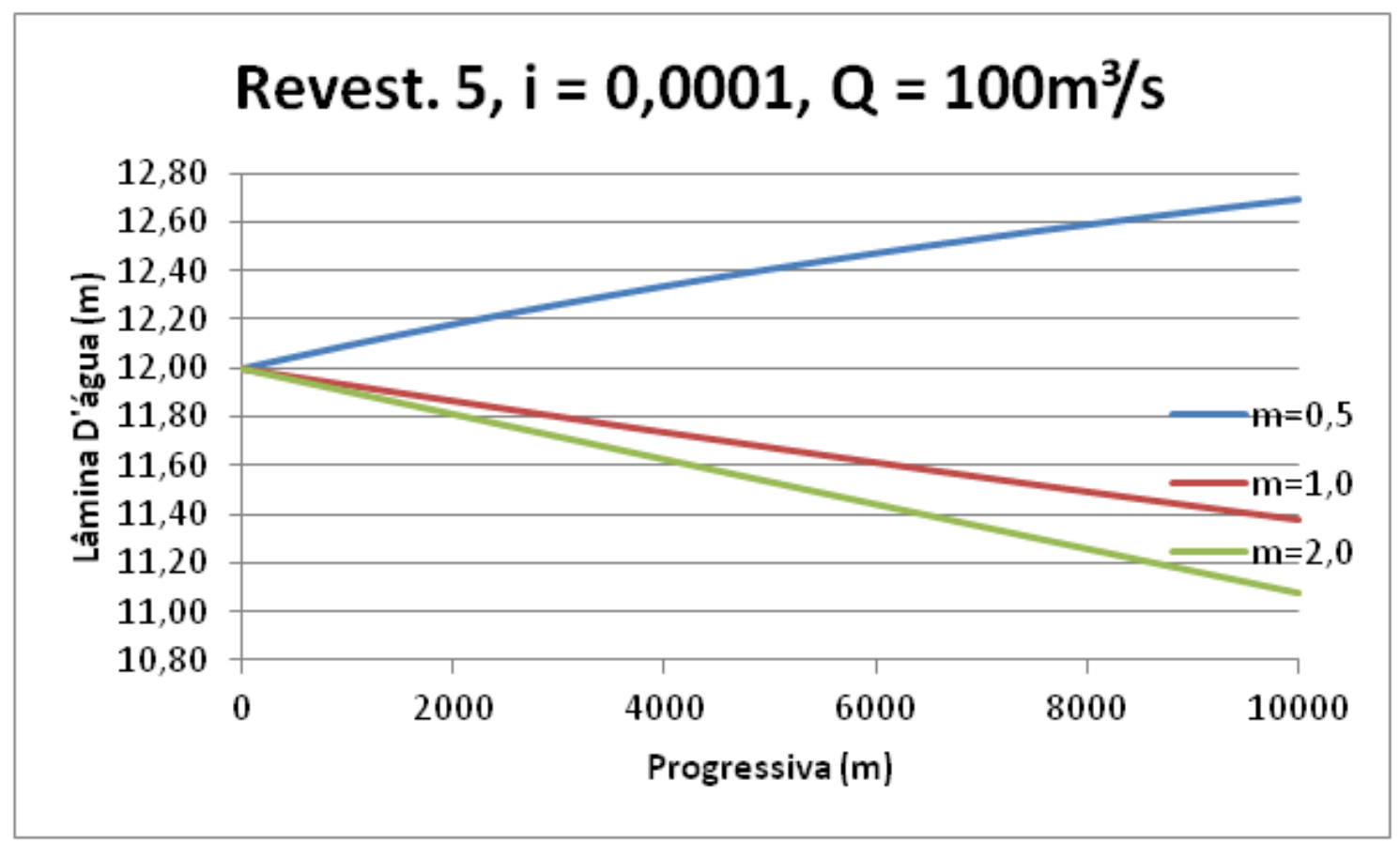




\begin{tabular}{|r|r|r|r|}
\hline \multirow{2}{*}{ Progr. } & \multicolumn{3}{|c|}{ Lâmina d'água $(\mathrm{m})$} \\
\cline { 2 - 4 } & $\mathrm{m}=0,5$ & $\mathrm{~m}=1,0$ & $\mathrm{~m}=2,0$ \\
\hline 0 & 12,00 & 12,00 & 12,00 \\
\hline 500 & 12,02 & 11,99 & 11,96 \\
\hline 1000 & 12,03 & 11,97 & 11,91 \\
\hline 1500 & 12,05 & 11,96 & 11,87 \\
\hline 2000 & 12,07 & 11,95 & 11,83 \\
\hline 2500 & 12,08 & 11,94 & 11,79 \\
\hline 3000 & 12,10 & 11,93 & 11,74 \\
\hline 3500 & 12,12 & 11,91 & 11,70 \\
\hline 4000 & 12,13 & 11,90 & 11,66 \\
\hline 4500 & 12,14 & 11,89 & 11,62 \\
\hline 5000 & 12,16 & 11,88 & 11,57 \\
\hline 5500 & 12,17 & 11,87 & 11,53 \\
\hline 6000 & 12,19 & 11,86 & 11,49 \\
\hline 6500 & 12,20 & 11,85 & 11,45 \\
\hline 7000 & 12,21 & 11,84 & 11,41 \\
\hline 7500 & 12,23 & 11,83 & 11,37 \\
\hline 8000 & 12,24 & 11,82 & 11,33 \\
\hline 8500 & 12,25 & 11,81 & 11,29 \\
\hline 9000 & 12,26 & 11,80 & 11,24 \\
\hline 9500 & 12,27 & 11,79 & 11,20 \\
\hline 10000 & 12,29 & 11,78 & 11,16 \\
\hline & & & \\
\hline
\end{tabular}

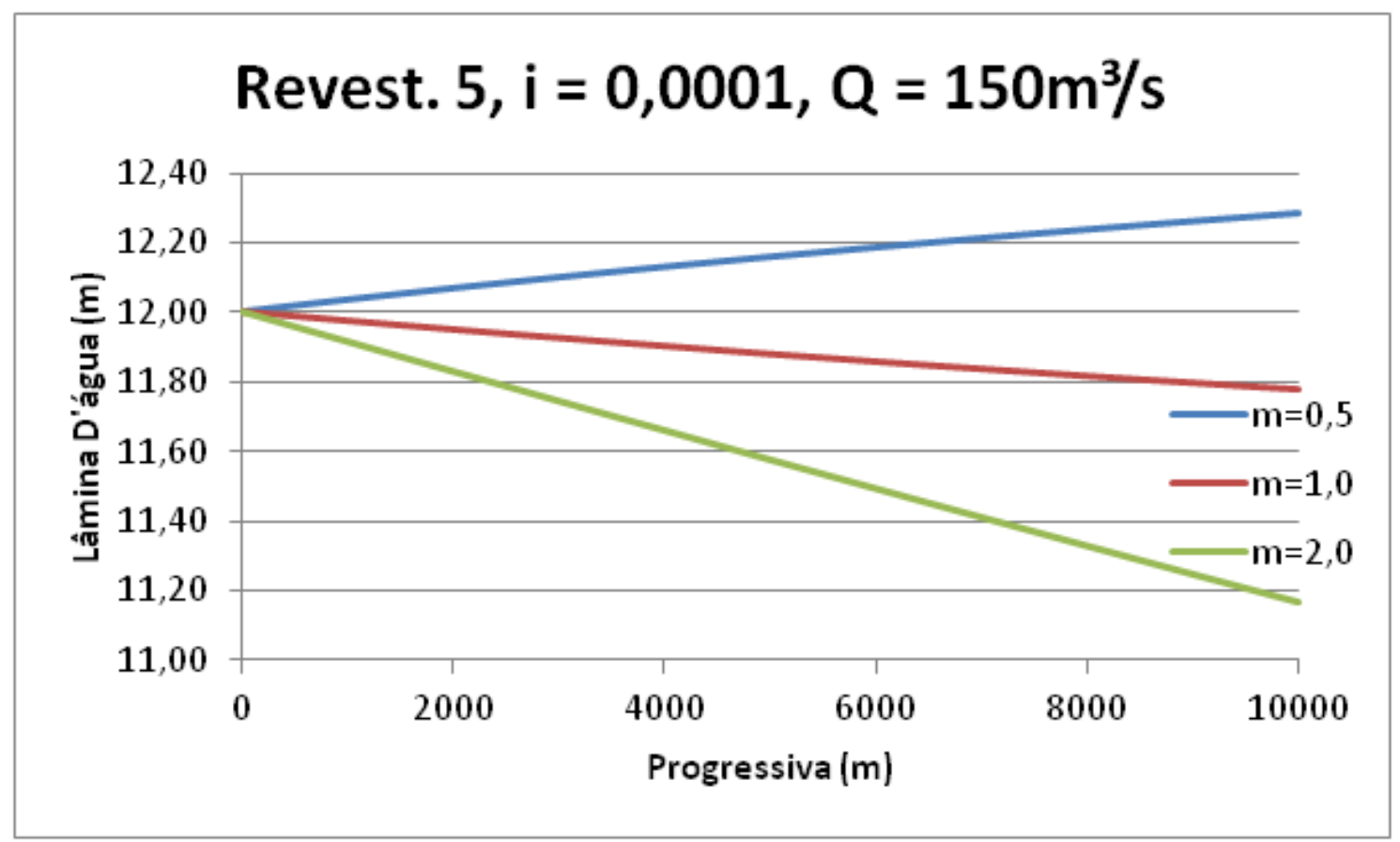




\begin{tabular}{|r|r|r|r|}
\hline \multirow{2}{*}{ Progr. } & \multicolumn{3}{|c|}{ Lâmina d'água $(\mathrm{m})$} \\
\cline { 2 - 4 } & $\mathrm{m}=0,5$ & $\mathrm{~m}=1,0$ & $\mathrm{~m}=2,0$ \\
\hline 0 & 12,00 & 12,00 & 12,00 \\
\hline 500 & 12,05 & 12,02 & 11,96 \\
\hline 1000 & 12,09 & 12,03 & 11,92 \\
\hline 1500 & 12,14 & 12,05 & 11,89 \\
\hline 2000 & 12,18 & 12,06 & 11,85 \\
\hline 2500 & 12,22 & 12,08 & 11,81 \\
\hline 3000 & 12,26 & 12,09 & 11,78 \\
\hline 3500 & 12,30 & 12,11 & 11,74 \\
\hline 4000 & 12,34 & 12,12 & 11,70 \\
\hline 4500 & 12,38 & 12,13 & 11,67 \\
\hline 5000 & 12,41 & 12,15 & 11,63 \\
\hline 5500 & 12,45 & 12,16 & 11,59 \\
\hline 6000 & 12,48 & 12,17 & 11,56 \\
\hline 6500 & 12,52 & 12,18 & 11,52 \\
\hline 7000 & 12,55 & 12,19 & 11,49 \\
\hline 7500 & 12,58 & 12,21 & 11,45 \\
\hline 8000 & 12,61 & 12,22 & 11,42 \\
\hline 8500 & 12,64 & 12,23 & 11,39 \\
\hline 9000 & 12,67 & 12,24 & 11,35 \\
\hline 9500 & 12,70 & 12,25 & 11,32 \\
\hline 10000 & 12,72 & 12,26 & 11,28 \\
\hline & & & \\
\hline
\end{tabular}

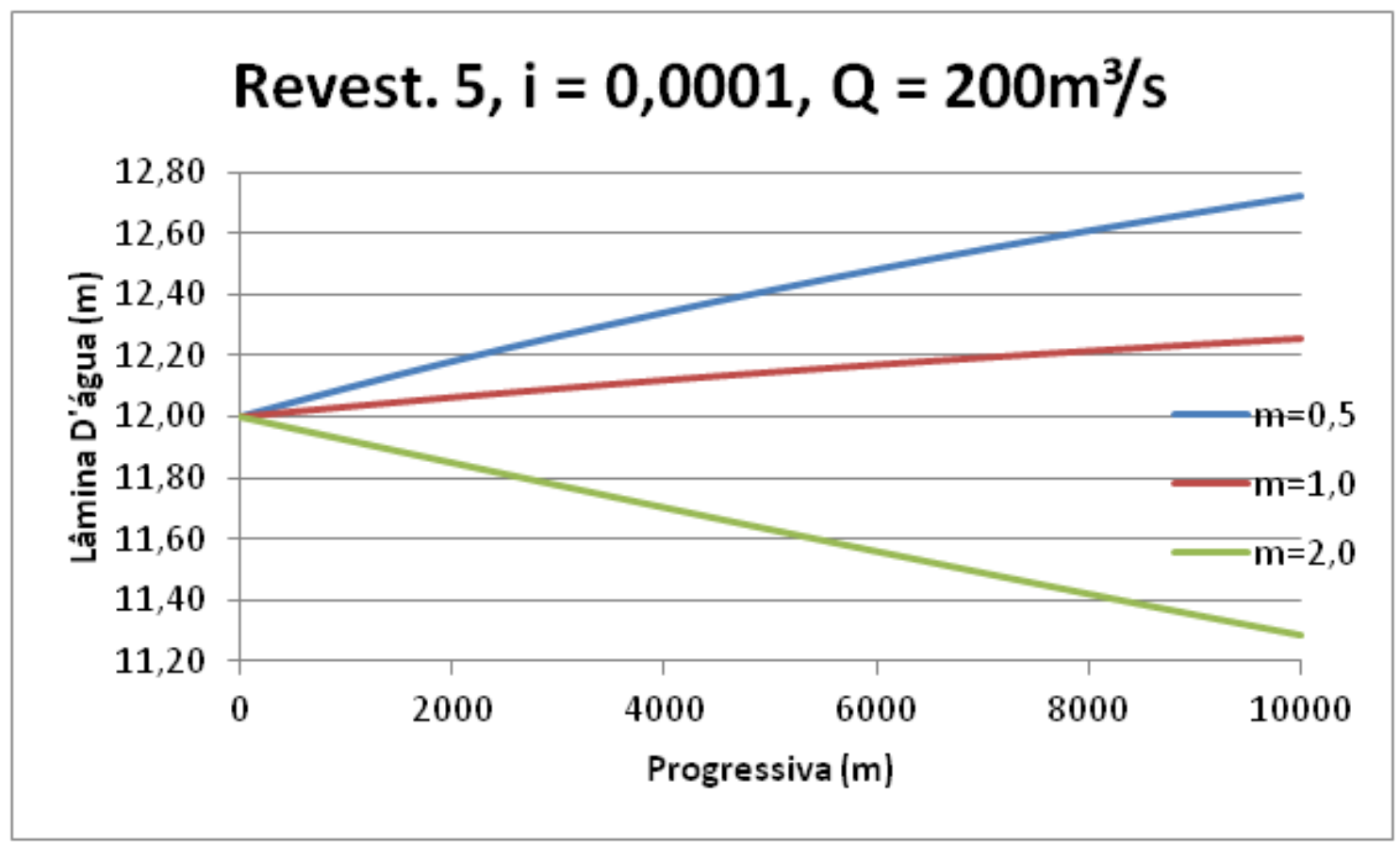




\begin{tabular}{|r|r|r|r|}
\hline \multirow{2}{*}{ Progr. } & \multicolumn{3}{|c|}{ Lâmina d'água $(\mathrm{m})$} \\
\cline { 2 - 4 } & $\mathrm{m}=0,5$ & $\mathrm{~m}=1,0$ & $\mathrm{~m}=2,0$ \\
\hline 0 & 12,00 & 12,00 & 12,00 \\
\hline 500 & 12,05 & 12,06 & 11,97 \\
\hline 1000 & 12,10 & 12,11 & 11,94 \\
\hline 1500 & 12,15 & 12,16 & 11,91 \\
\hline 2000 & 12,20 & 12,21 & 11,88 \\
\hline 2500 & 12,25 & 12,25 & 11,85 \\
\hline 3000 & 12,29 & 12,30 & 11,82 \\
\hline 3500 & 12,33 & 12,34 & 11,79 \\
\hline 4000 & 12,37 & 12,38 & 11,76 \\
\hline 4500 & 12,42 & 12,42 & 11,73 \\
\hline 5000 & 12,45 & 12,45 & 11,70 \\
\hline 5500 & 12,49 & 12,49 & 11,67 \\
\hline 6000 & 12,53 & 12,53 & 11,65 \\
\hline 6500 & 12,57 & 12,56 & 11,62 \\
\hline 7000 & 12,60 & 12,59 & 11,59 \\
\hline 7500 & 12,64 & 12,62 & 11,56 \\
\hline 8000 & 12,67 & 12,65 & 11,54 \\
\hline 8500 & 12,70 & 12,68 & 11,51 \\
\hline 9000 & 12,73 & 12,71 & 11,48 \\
\hline 9500 & 12,76 & 12,74 & 11,46 \\
\hline 10000 & 12,79 & 12,76 & 11,43 \\
\hline & & & \\
\hline
\end{tabular}

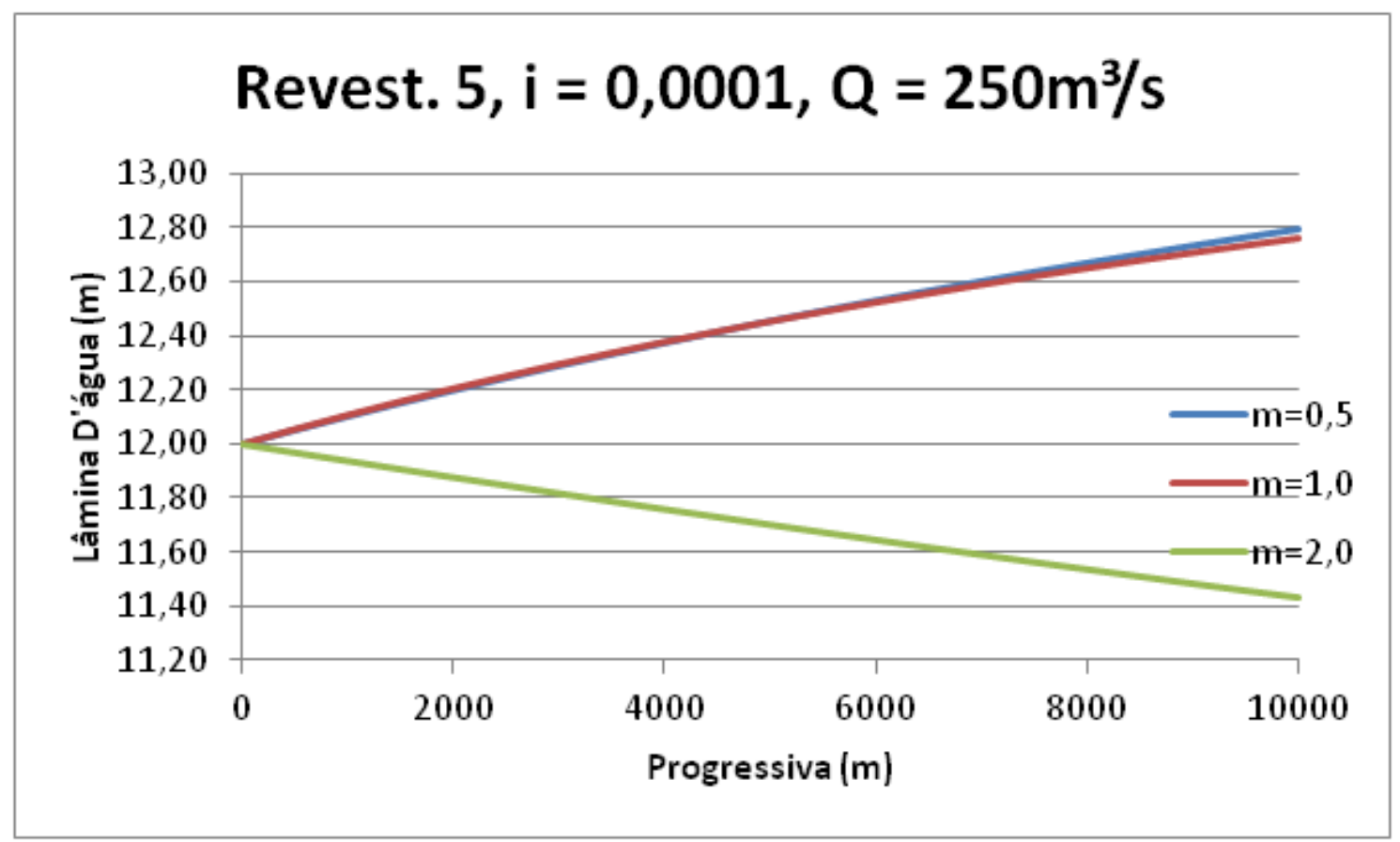




\begin{tabular}{|r|r|r|r|}
\hline \multirow{2}{*}{ Progr. } & \multicolumn{3}{|c|}{ Lâmina d'água $(\mathrm{m})$} \\
\cline { 2 - 4 } & $\mathrm{m}=0,5$ & $\mathrm{~m}=1,0$ & $\mathrm{~m}=2,0$ \\
\hline 0 & 12,00 & 12,00 & 12,00 \\
\hline 500 & 12,04 & 12,06 & 11,98 \\
\hline 1000 & 12,08 & 12,11 & 11,95 \\
\hline 1500 & 12,11 & 12,16 & 11,93 \\
\hline 2000 & 12,15 & 12,21 & 11,91 \\
\hline 2500 & 12,18 & 12,26 & 11,89 \\
\hline 3000 & 12,21 & 12,31 & 11,87 \\
\hline 3500 & 12,25 & 12,35 & 11,85 \\
\hline 4000 & 12,28 & 12,39 & 11,83 \\
\hline 4500 & 12,31 & 12,43 & 11,81 \\
\hline 5000 & 12,34 & 12,47 & 11,79 \\
\hline 5500 & 12,37 & 12,51 & 11,77 \\
\hline 6000 & 12,40 & 12,54 & 11,75 \\
\hline 6500 & 12,42 & 12,58 & 11,73 \\
\hline 7000 & 12,45 & 12,61 & 11,71 \\
\hline 7500 & 12,48 & 12,65 & 11,69 \\
\hline 8000 & 12,50 & 12,68 & 11,67 \\
\hline 8500 & 12,53 & 12,71 & 11,65 \\
\hline 9000 & 12,55 & 12,74 & 11,63 \\
\hline 9500 & 12,58 & 12,77 & 11,62 \\
\hline 10000 & 12,60 & 12,79 & 11,60 \\
\hline & & & \\
\hline
\end{tabular}

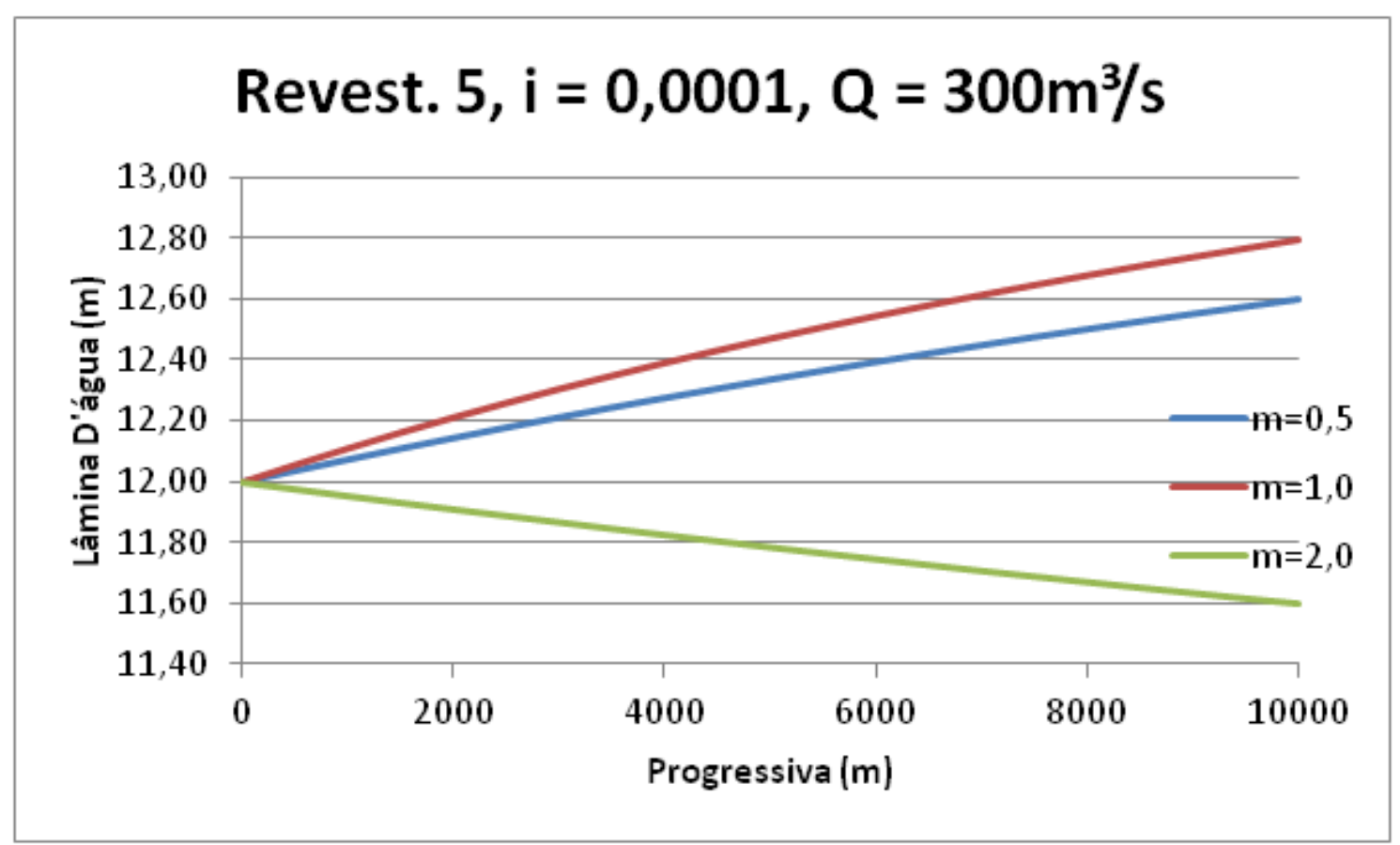




\begin{tabular}{|r|r|r|r|}
\hline \multirow{2}{*}{ Progr. } & \multicolumn{3}{|c|}{ Lâmina d'água $(\mathrm{m})$} \\
\cline { 2 - 4 } & $\mathrm{m}=0,5$ & $\mathrm{~m}=1,0$ & $\mathrm{~m}=2,0$ \\
\hline 0 & 12,00 & 12,00 & 12,00 \\
\hline 500 & 12,05 & 12,04 & 11,99 \\
\hline 1000 & 12,10 & 12,08 & 11,98 \\
\hline 1500 & 12,15 & 12,12 & 11,96 \\
\hline 2000 & 12,20 & 12,16 & 11,95 \\
\hline 2500 & 12,25 & 12,20 & 11,94 \\
\hline 3000 & 12,29 & 12,24 & 11,93 \\
\hline 3500 & 12,34 & 12,27 & 11,92 \\
\hline 4000 & 12,38 & 12,31 & 11,91 \\
\hline 4500 & 12,42 & 12,34 & 11,89 \\
\hline 5000 & 12,46 & 12,37 & 11,88 \\
\hline 5500 & 12,50 & 12,40 & 11,87 \\
\hline 6000 & 12,54 & 12,43 & 11,86 \\
\hline 6500 & 12,58 & 12,46 & 11,85 \\
\hline 7000 & 12,61 & 12,49 & 11,84 \\
\hline 7500 & 12,65 & 12,51 & 11,83 \\
\hline 8000 & 12,68 & 12,54 & 11,82 \\
\hline 8500 & 12,72 & 12,57 & 11,81 \\
\hline 9000 & 12,75 & 12,59 & 11,80 \\
\hline 9500 & 12,78 & 12,62 & 11,79 \\
\hline 10000 & 12,81 & 12,64 & 11,79 \\
\hline & & & \\
\hline
\end{tabular}

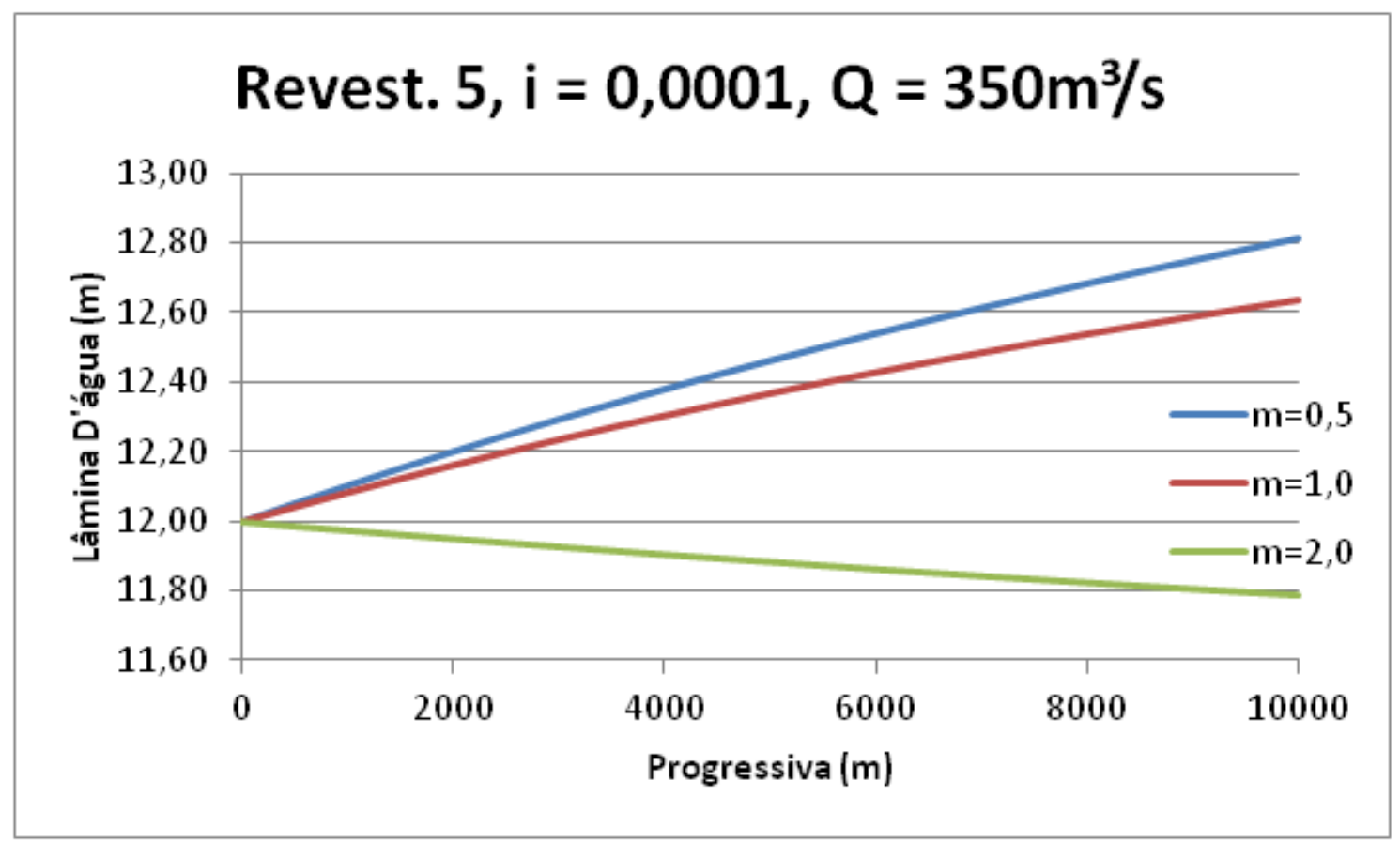




\begin{tabular}{|r|r|r|r|}
\hline \multirow{2}{*}{ Progr. } & \multicolumn{3}{|c|}{ Lâmina d'água $(\mathrm{m})$} \\
\cline { 2 - 4 } & $\mathrm{m}=0,5$ & $\mathrm{~m}=1,0$ & $\mathrm{~m}=2,0$ \\
\hline 0 & 12,00 & 12,00 & 12,00 \\
\hline 500 & 11,93 & 11,90 & 11,90 \\
\hline 1000 & 11,86 & 11,81 & 11,80 \\
\hline 1500 & 11,79 & 11,71 & 11,70 \\
\hline 2000 & 11,72 & 11,62 & 11,60 \\
\hline 2500 & 11,66 & 11,52 & 11,50 \\
\hline 3000 & 11,59 & 11,43 & 11,40 \\
\hline 3500 & 11,53 & 11,33 & 11,31 \\
\hline 4000 & 11,47 & 11,24 & 11,21 \\
\hline 4500 & 11,40 & 11,14 & 11,11 \\
\hline 5000 & 11,34 & 11,05 & 11,01 \\
\hline 5500 & 11,28 & 10,96 & 10,91 \\
\hline 6000 & 11,22 & 10,86 & 10,81 \\
\hline 6500 & 11,17 & 10,77 & 10,71 \\
\hline 7000 & 11,11 & 10,68 & 10,61 \\
\hline 7500 & 11,05 & 10,58 & 10,52 \\
\hline 8000 & 11,00 & 10,49 & 10,42 \\
\hline 8500 & 10,95 & 10,40 & 10,32 \\
\hline 9000 & 10,89 & 10,31 & 10,22 \\
\hline 9500 & 10,84 & 10,22 & 10,12 \\
\hline 10000 & 10,80 & 10,13 & 10,02 \\
\hline & & & \\
\hline
\end{tabular}

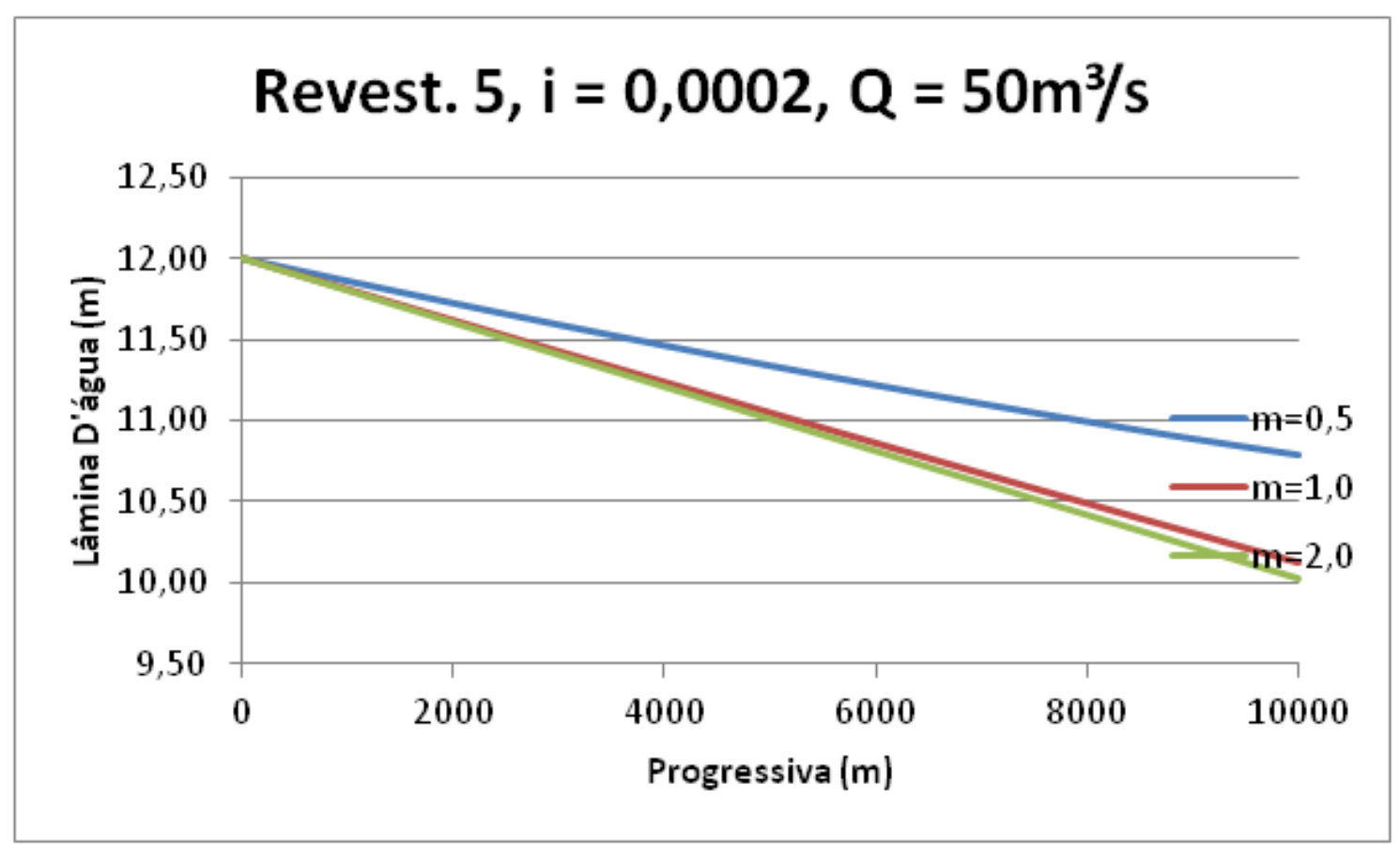




\begin{tabular}{|r|r|r|r|}
\hline \multirow{2}{*}{ Progr. } & \multicolumn{3}{|c|}{ Lâmina d'água $(\mathrm{m})$} \\
\cline { 2 - 4 } & $\mathrm{m}=0,5$ & $\mathrm{~m}=1,0$ & $\mathrm{~m}=2,0$ \\
\hline 0 & 12,00 & 12,00 & 12,00 \\
\hline 500 & 12,00 & 11,92 & 11,90 \\
\hline 1000 & 12,00 & 11,83 & 11,81 \\
\hline 1500 & 11,99 & 11,75 & 11,71 \\
\hline 2000 & 11,99 & 11,67 & 11,61 \\
\hline 2500 & 11,99 & 11,59 & 11,52 \\
\hline 3000 & 11,99 & 11,51 & 11,42 \\
\hline 3500 & 11,99 & 11,43 & 11,32 \\
\hline 4000 & 11,99 & 11,35 & 11,23 \\
\hline 4500 & 11,99 & 11,27 & 11,13 \\
\hline 5000 & 11,99 & 11,19 & 11,04 \\
\hline 5500 & 11,98 & 11,12 & 10,94 \\
\hline 6000 & 11,98 & 11,04 & 10,85 \\
\hline 6500 & 11,98 & 10,97 & 10,75 \\
\hline 7000 & 11,98 & 10,89 & 10,66 \\
\hline 7500 & 11,98 & 10,82 & 10,56 \\
\hline 8000 & 11,98 & 10,75 & 10,47 \\
\hline 8500 & 11,98 & 10,68 & 10,37 \\
\hline 9000 & 11,98 & 10,61 & 10,28 \\
\hline 9500 & 11,98 & 10,54 & 10,19 \\
\hline 10000 & 11,98 & 10,47 & 10,09 \\
\hline & & & \\
\hline
\end{tabular}

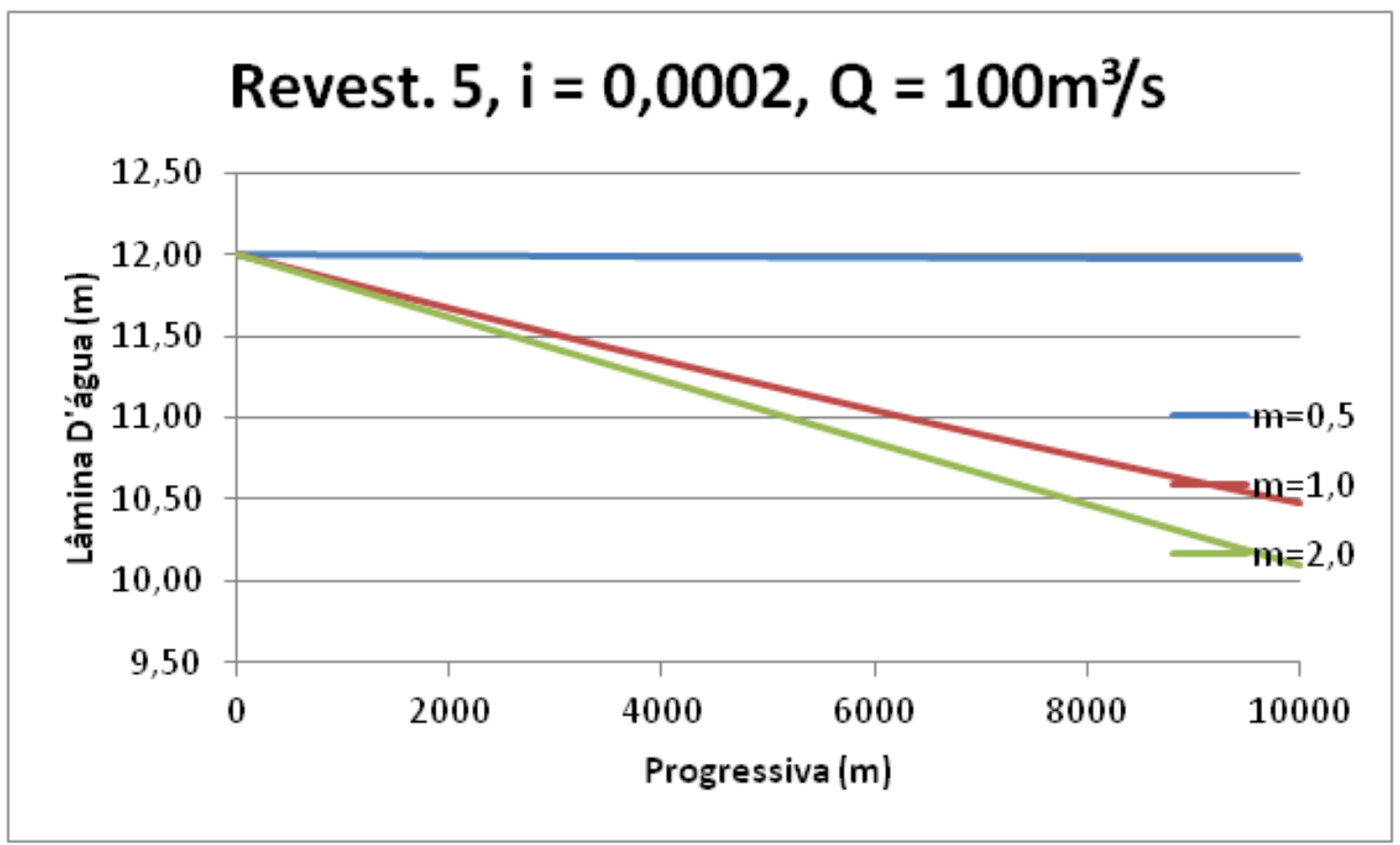




\begin{tabular}{|r|r|r|r|}
\hline \multirow{2}{*}{ Progr. } & \multicolumn{3}{|c|}{ Lâmina d'água $(\mathrm{m})$} \\
\cline { 2 - 4 } & $\mathrm{m}=0,5$ & $\mathrm{~m}=1,0$ & $\mathrm{~m}=2,0$ \\
\hline 0 & 12,00 & 12,00 & 12,00 \\
\hline 500 & 11,97 & 11,94 & 11,91 \\
\hline 1000 & 11,93 & 11,87 & 11,81 \\
\hline 1500 & 11,90 & 11,81 & 11,72 \\
\hline 2000 & 11,87 & 11,75 & 11,63 \\
\hline 2500 & 11,84 & 11,69 & 11,54 \\
\hline 3000 & 11,81 & 11,64 & 11,44 \\
\hline 3500 & 11,79 & 11,58 & 11,35 \\
\hline 4000 & 11,76 & 11,52 & 11,26 \\
\hline 4500 & 11,73 & 11,47 & 11,17 \\
\hline 5000 & 11,71 & 11,42 & 11,08 \\
\hline 5500 & 11,68 & 11,36 & 10,99 \\
\hline 6000 & 11,65 & 11,31 & 10,90 \\
\hline 6500 & 11,63 & 11,26 & 10,81 \\
\hline 7000 & 11,61 & 11,22 & 10,72 \\
\hline 7500 & 11,58 & 11,17 & 10,64 \\
\hline 8000 & 11,56 & 11,12 & 10,55 \\
\hline 8500 & 11,54 & 11,08 & 10,46 \\
\hline 9000 & 11,52 & 11,03 & 10,38 \\
\hline 9500 & 11,50 & 10,99 & 10,29 \\
\hline 10000 & 11,48 & 10,95 & 10,21 \\
\hline & & & \\
\hline
\end{tabular}

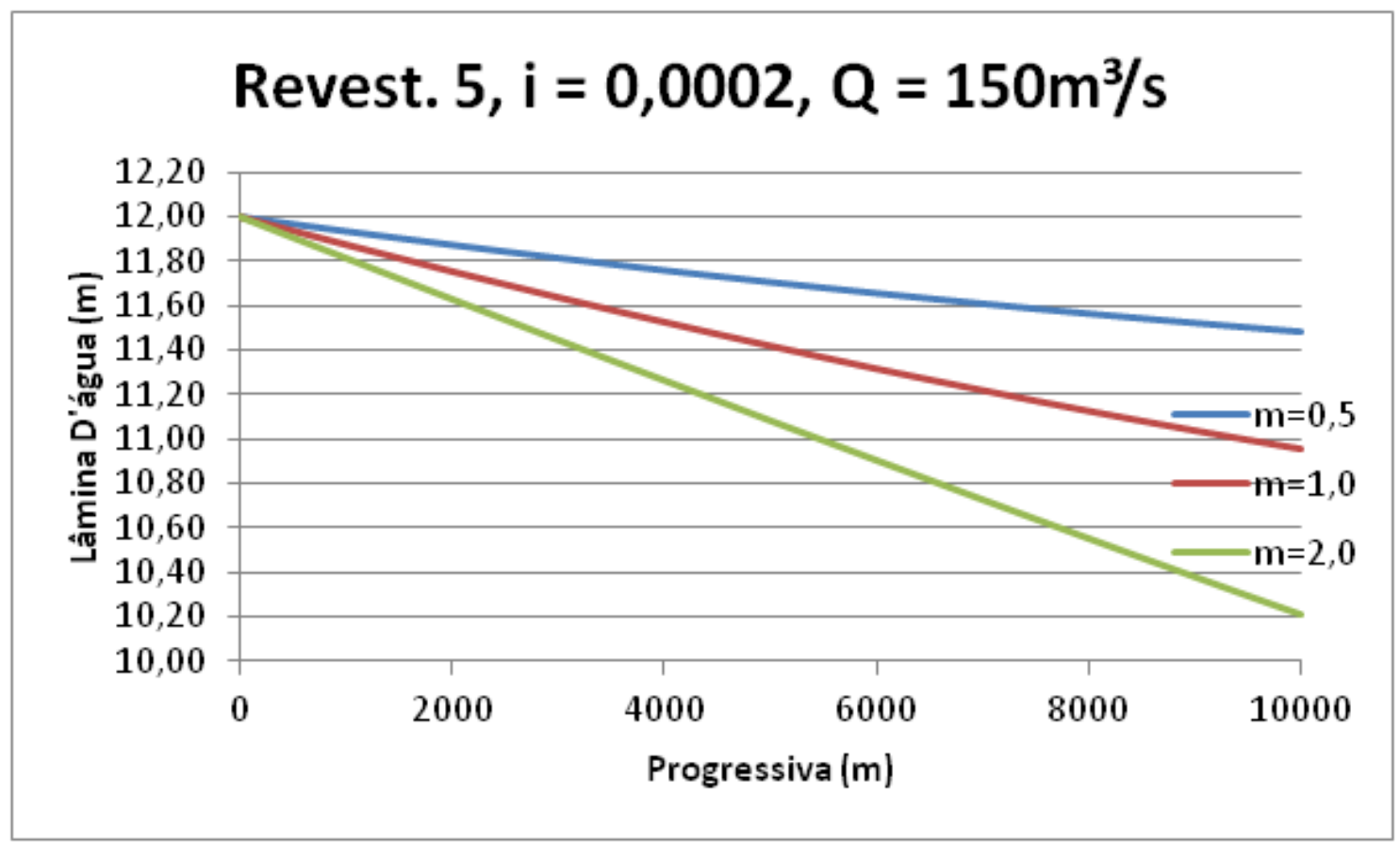




\begin{tabular}{|r|r|r|r|}
\hline \multirow{2}{*}{ Progr. } & \multicolumn{3}{|c|}{ Lâmina d'água $(\mathrm{m})$} \\
\cline { 2 - 4 } & $\mathrm{m}=0,5$ & $\mathrm{~m}=1,0$ & $\mathrm{~m}=2,0$ \\
\hline 0 & 12,00 & 12,00 & 12,00 \\
\hline 500 & 12,00 & 11,97 & 11,91 \\
\hline 1000 & 11,99 & 11,93 & 11,82 \\
\hline 1500 & 11,99 & 11,90 & 11,74 \\
\hline 2000 & 11,99 & 11,87 & 11,65 \\
\hline 2500 & 11,98 & 11,84 & 11,56 \\
\hline 3000 & 11,98 & 11,81 & 11,48 \\
\hline 3500 & 11,98 & 11,78 & 11,39 \\
\hline 4000 & 11,98 & 11,75 & 11,31 \\
\hline 4500 & 11,97 & 11,73 & 11,23 \\
\hline 5000 & 11,97 & 11,70 & 11,14 \\
\hline 5500 & 11,97 & 11,68 & 11,06 \\
\hline 6000 & 11,97 & 11,65 & 10,98 \\
\hline 6500 & 11,97 & 11,63 & 10,90 \\
\hline 7000 & 11,96 & 11,61 & 10,82 \\
\hline 7500 & 11,96 & 11,59 & 10,74 \\
\hline 8000 & 11,96 & 11,57 & 10,66 \\
\hline 8500 & 11,96 & 11,55 & 10,58 \\
\hline 9000 & 11,96 & 11,53 & 10,50 \\
\hline 9500 & 11,95 & 11,51 & 10,43 \\
\hline 10000 & 11,95 & 11,49 & 10,35 \\
\hline & & & \\
\hline
\end{tabular}

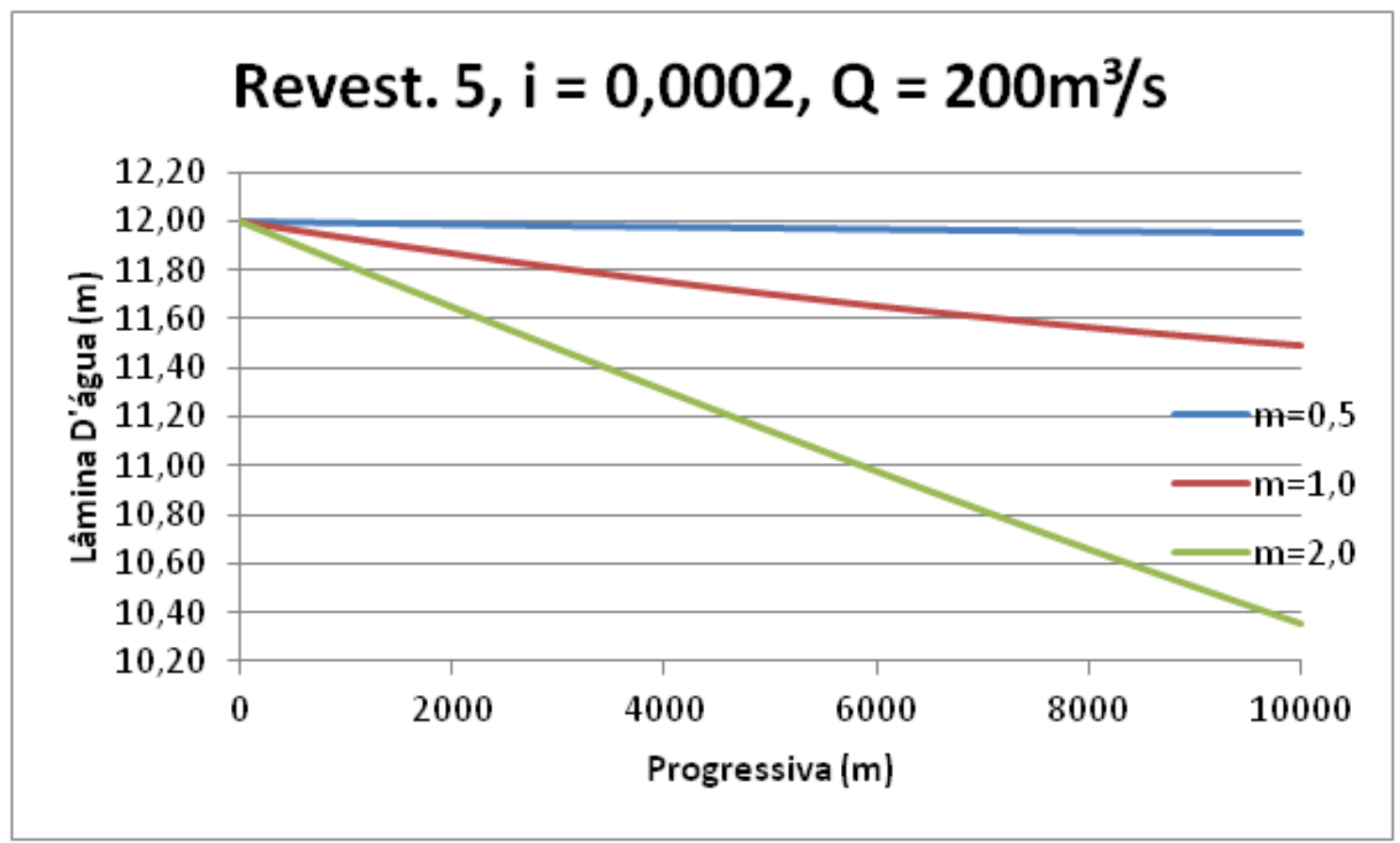




\begin{tabular}{|r|r|r|r|}
\hline \multirow{2}{*}{ Progr. } & \multicolumn{3}{|c|}{ Lâmina d'água $(\mathrm{m})$} \\
\cline { 2 - 4 } & $\mathrm{m}=0,5$ & $\mathrm{~m}=1,0$ & $\mathrm{~m}=2,0$ \\
\hline 0 & 12,00 & 12,00 & 12,00 \\
\hline 500 & 12,00 & 12,00 & 11,92 \\
\hline 1000 & 12,00 & 12,00 & 11,84 \\
\hline 1500 & 12,00 & 12,00 & 11,76 \\
\hline 2000 & 12,00 & 12,00 & 11,68 \\
\hline 2500 & 12,00 & 12,00 & 11,60 \\
\hline 3000 & 12,00 & 11,99 & 11,52 \\
\hline 3500 & 12,00 & 11,99 & 11,44 \\
\hline 4000 & 12,00 & 11,99 & 11,37 \\
\hline 4500 & 12,00 & 11,99 & 11,29 \\
\hline 5000 & 12,00 & 11,99 & 11,22 \\
\hline 5500 & 12,00 & 11,99 & 11,15 \\
\hline 6000 & 12,00 & 11,99 & 11,07 \\
\hline 6500 & 12,00 & 11,99 & 11,00 \\
\hline 7000 & 12,00 & 11,99 & 10,93 \\
\hline 7500 & 12,00 & 11,99 & 10,86 \\
\hline 8000 & 12,00 & 11,99 & 10,79 \\
\hline 8500 & 12,00 & 11,99 & 10,73 \\
\hline 9000 & 12,00 & 11,99 & 10,66 \\
\hline 9500 & 12,00 & 11,99 & 10,60 \\
\hline 10000 & 12,00 & 11,99 & 10,53 \\
\hline & & & \\
\hline
\end{tabular}

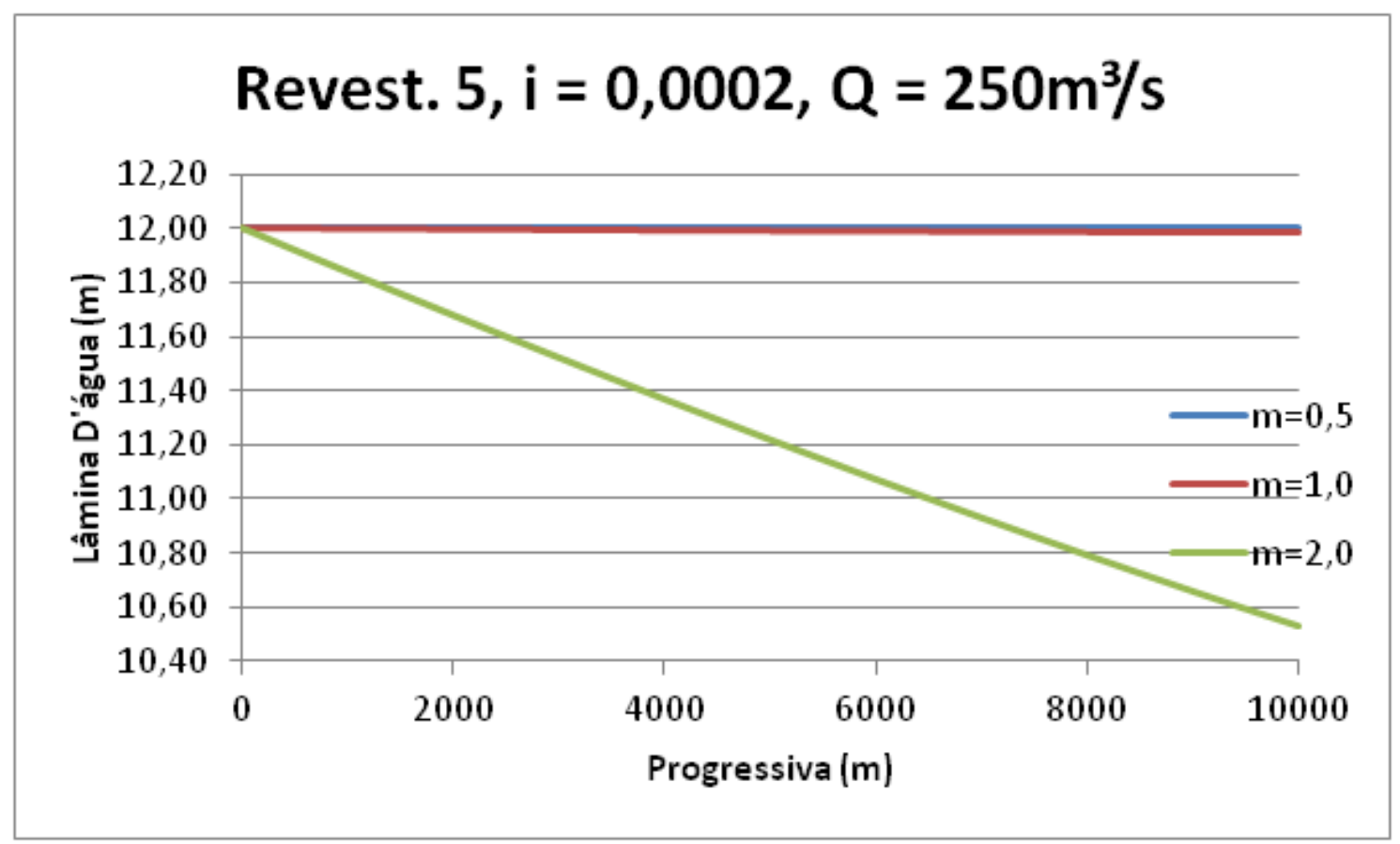




\begin{tabular}{|r|r|r|r|}
\hline \multirow{2}{*}{ Progr. } & \multicolumn{3}{|c|}{ Lâmina d'água $(\mathrm{m})$} \\
\cline { 2 - 4 } & $\mathrm{m}=0,5$ & $\mathrm{~m}=1,0$ & $\mathrm{~m}=2,0$ \\
\hline 0 & 12,00 & 12,00 & 12,00 \\
\hline 500 & 11,99 & 11,99 & 11,93 \\
\hline 1000 & 11,97 & 11,97 & 11,85 \\
\hline 1500 & 11,96 & 11,96 & 11,78 \\
\hline 2000 & 11,94 & 11,95 & 11,71 \\
\hline 2500 & 11,93 & 11,94 & 11,64 \\
\hline 3000 & 11,92 & 11,92 & 11,57 \\
\hline 3500 & 11,91 & 11,91 & 11,51 \\
\hline 4000 & 11,90 & 11,90 & 11,44 \\
\hline 4500 & 11,88 & 11,89 & 11,38 \\
\hline 5000 & 11,87 & 11,88 & 11,31 \\
\hline 5500 & 11,86 & 11,87 & 11,25 \\
\hline 6000 & 11,85 & 11,86 & 11,19 \\
\hline 6500 & 11,84 & 11,85 & 11,12 \\
\hline 7000 & 11,83 & 11,85 & 11,07 \\
\hline 7500 & 11,82 & 11,84 & 11,01 \\
\hline 8000 & 11,81 & 11,83 & 10,95 \\
\hline 8500 & 11,80 & 11,82 & 10,89 \\
\hline 9000 & 11,79 & 11,81 & 10,84 \\
\hline 9500 & 11,79 & 11,81 & 10,79 \\
\hline 10000 & 11,78 & 11,80 & 10,73 \\
\hline & & & \\
\hline
\end{tabular}

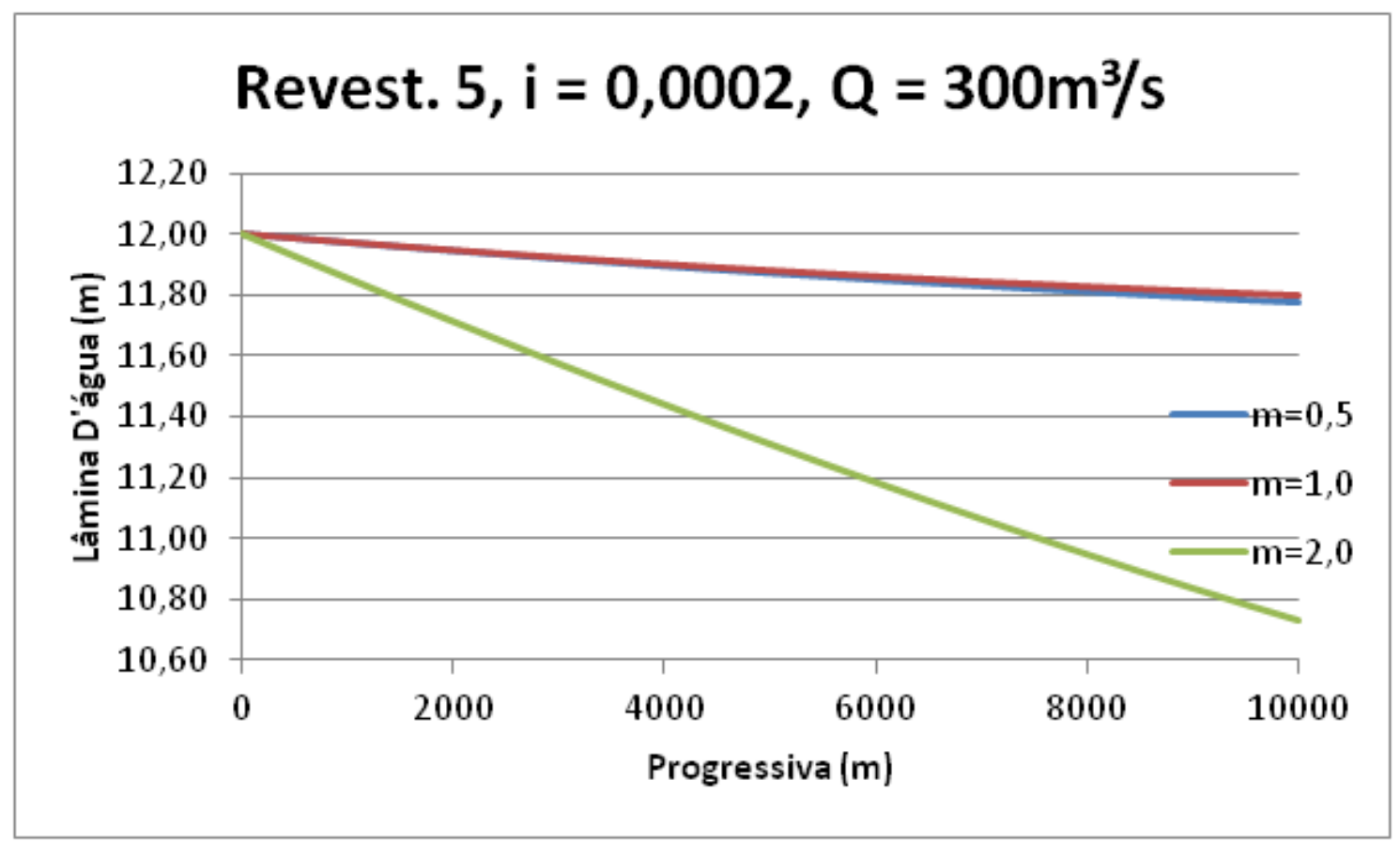




\begin{tabular}{|r|r|r|r|}
\hline \multirow{2}{*}{ Progr. } & \multicolumn{3}{|c|}{ Lâmina d'água $(\mathrm{m})$} \\
\cline { 2 - 4 } & $\mathrm{m}=0,5$ & $\mathrm{~m}=1,0$ & $\mathrm{~m}=2,0$ \\
\hline 0 & 12,00 & 12,00 & 12,00 \\
\hline 500 & 12,00 & 12,00 & 11,94 \\
\hline 1000 & 12,00 & 12,00 & 11,87 \\
\hline 1500 & 12,00 & 12,00 & 11,81 \\
\hline 2000 & 12,00 & 12,00 & 11,75 \\
\hline 2500 & 12,00 & 11,99 & 11,69 \\
\hline 3000 & 12,00 & 11,99 & 11,64 \\
\hline 3500 & 12,00 & 11,99 & 11,58 \\
\hline 4000 & 12,00 & 11,99 & 11,52 \\
\hline 4500 & 12,00 & 11,99 & 11,47 \\
\hline 5000 & 12,00 & 11,99 & 11,42 \\
\hline 5500 & 12,00 & 11,99 & 11,36 \\
\hline 6000 & 12,00 & 11,99 & 11,31 \\
\hline 6500 & 12,00 & 11,99 & 11,26 \\
\hline 7000 & 12,00 & 11,99 & 11,21 \\
\hline 7500 & 12,00 & 11,99 & 11,17 \\
\hline 8000 & 12,00 & 11,99 & 11,12 \\
\hline 8500 & 12,00 & 11,98 & 11,08 \\
\hline 9000 & 12,00 & 11,98 & 11,03 \\
\hline 9500 & 12,00 & 11,98 & 10,99 \\
\hline 10000 & 12,00 & 11,98 & 10,95 \\
\hline & & & \\
\hline
\end{tabular}

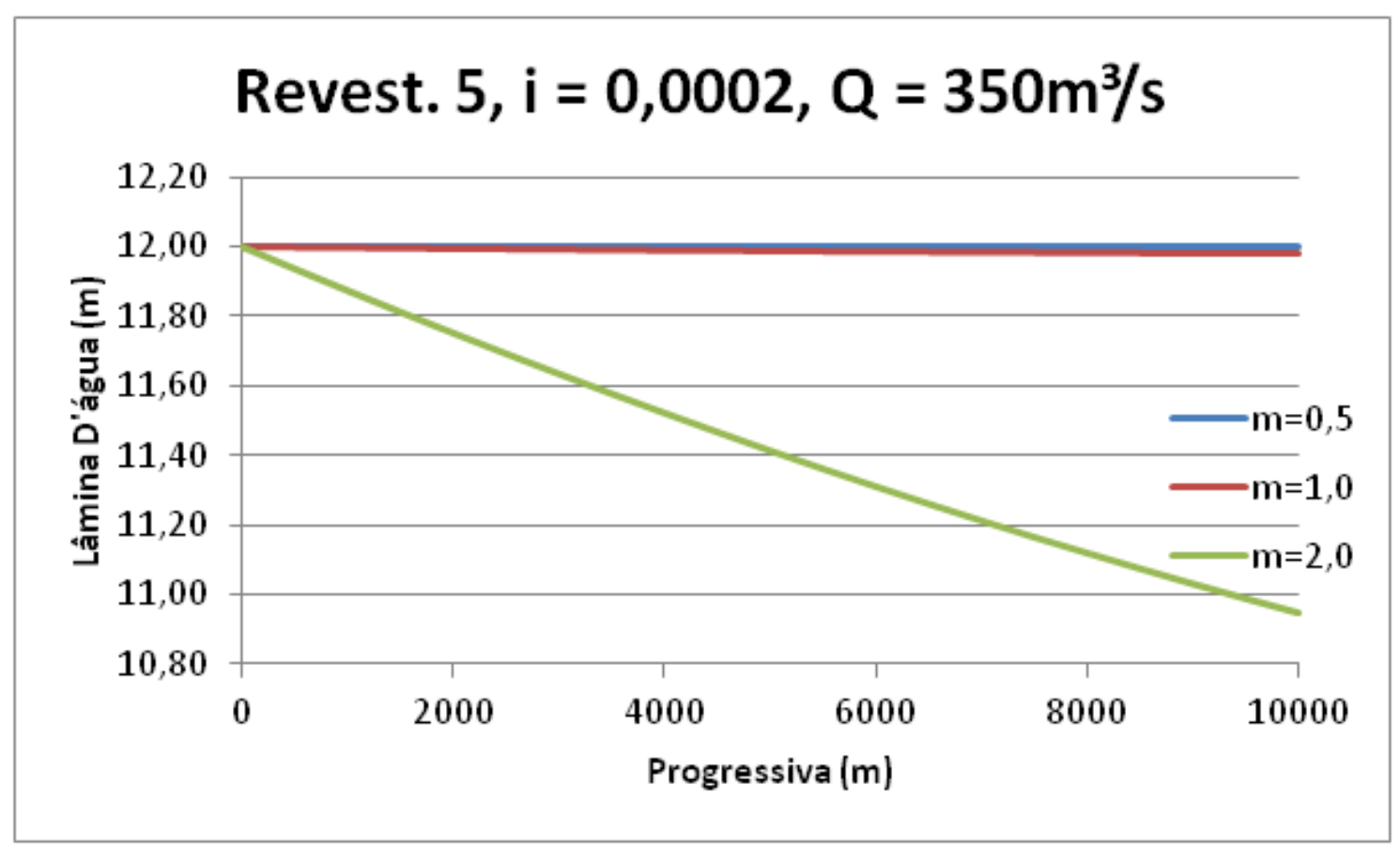




\begin{tabular}{|r|r|r|r|}
\hline \multirow{2}{*}{ Progr. } & \multicolumn{3}{|c|}{ Lâmina d'água $(\mathrm{m})$} \\
\cline { 2 - 4 } & $\mathrm{m}=0,5$ & $\mathrm{~m}=1,0$ & $\mathrm{~m}=2,0$ \\
\hline 0 & 12,00 & 12,00 & 12,00 \\
\hline 500 & 11,75 & 11,75 & 11,75 \\
\hline 1000 & 11,51 & 11,51 & 11,50 \\
\hline 1500 & 11,26 & 11,26 & 11,25 \\
\hline 2000 & 11,02 & 11,02 & 11,00 \\
\hline 2500 & 10,77 & 10,77 & 10,75 \\
\hline 3000 & 10,53 & 10,53 & 10,51 \\
\hline 3500 & 10,29 & 10,29 & 10,26 \\
\hline 4000 & 10,04 & 10,05 & 10,01 \\
\hline 4500 & 9,80 & 9,81 & 9,76 \\
\hline 5000 & 9,56 & 9,57 & 9,51 \\
\hline 5500 & 9,32 & 9,33 & 9,26 \\
\hline 6000 & 9,08 & 9,10 & 9,02 \\
\hline 6500 & 8,84 & 8,87 & 8,77 \\
\hline 7000 & 8,60 & 8,64 & 8,52 \\
\hline 7500 & 8,37 & 8,41 & 8,28 \\
\hline 8000 & 8,13 & 8,19 & 8,03 \\
\hline 8500 & 7,90 & 7,97 & 7,79 \\
\hline 9000 & 7,67 & 7,75 & 7,54 \\
\hline 9500 & 7,44 & 7,54 & 7,30 \\
\hline 10000 & 7,21 & 7,34 & 7,06 \\
\hline & & & \\
\hline
\end{tabular}

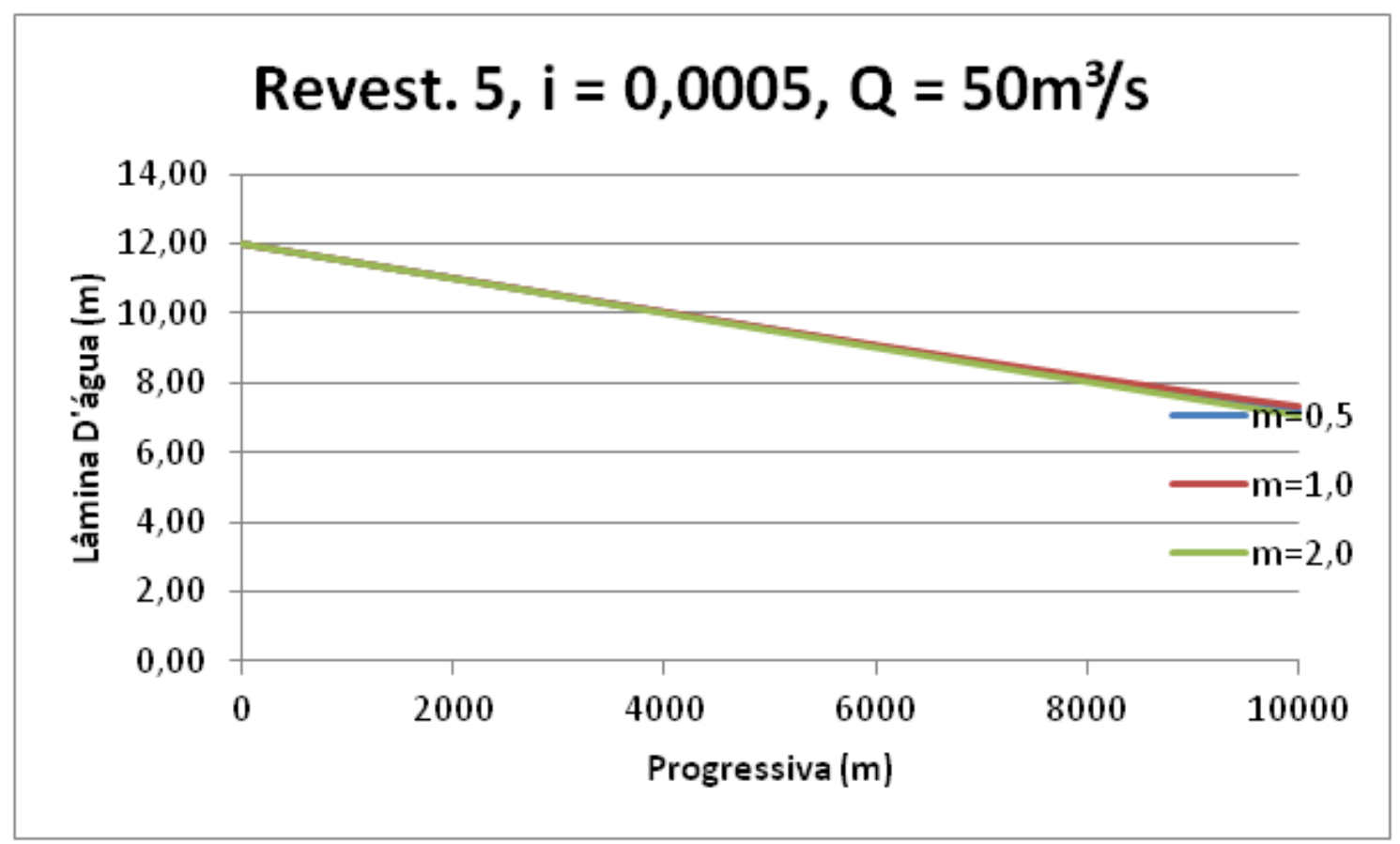




\begin{tabular}{|r|r|r|r|}
\hline \multirow{2}{*}{ Progr. } & \multicolumn{3}{|c|}{ Lâmina d'água $(\mathrm{m})$} \\
\cline { 2 - 4 } & $\mathrm{m}=0,5$ & $\mathrm{~m}=1,0$ & $\mathrm{~m}=2,0$ \\
\hline 0 & 12,00 & 12,00 & 12,00 \\
\hline 500 & 11,78 & 11,77 & 11,75 \\
\hline 1000 & 11,56 & 11,53 & 11,51 \\
\hline 1500 & 11,35 & 11,30 & 11,26 \\
\hline 2000 & 11,14 & 11,07 & 11,01 \\
\hline 2500 & 10,93 & 10,85 & 10,77 \\
\hline 3000 & 10,72 & 10,62 & 10,52 \\
\hline 3500 & 10,52 & 10,40 & 10,28 \\
\hline 4000 & 10,32 & 10,19 & 10,03 \\
\hline 4500 & 10,13 & 9,98 & 9,79 \\
\hline 5000 & 9,94 & 9,77 & 9,55 \\
\hline 5500 & 9,76 & 9,57 & 9,31 \\
\hline 6000 & 9,58 & 9,37 & 9,07 \\
\hline 6500 & 9,41 & 9,18 & 8,83 \\
\hline 7000 & 9,24 & 9,00 & 8,60 \\
\hline 7500 & 9,08 & 8,82 & 8,36 \\
\hline 8000 & 8,93 & 8,65 & 8,13 \\
\hline 8500 & 8,78 & 8,50 & 7,91 \\
\hline 9000 & 8,65 & 8,35 & 7,68 \\
\hline 9500 & 8,52 & 8,21 & 7,46 \\
\hline 10000 & 8,39 & 8,08 & 7,25 \\
\hline & & & \\
\hline
\end{tabular}

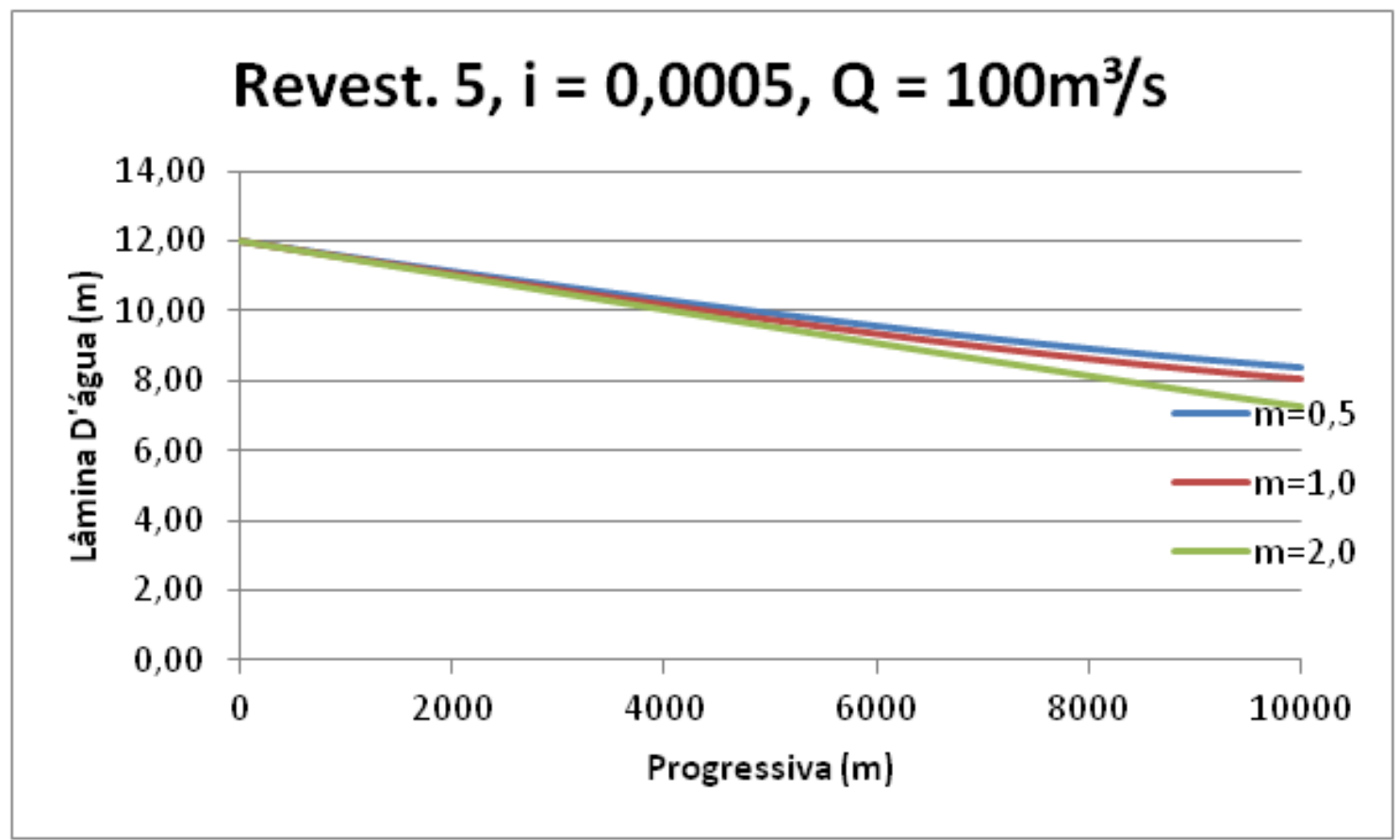




\begin{tabular}{|r|r|r|r|}
\hline \multirow{2}{*}{ Progr. } & \multicolumn{3}{|c|}{ Lâmina d'água $(\mathrm{m})$} \\
\cline { 2 - 4 } & $\mathrm{m}=0,5$ & $\mathrm{~m}=1,0$ & $\mathrm{~m}=2,0$ \\
\hline 0 & 12,00 & 12,00 & 12,00 \\
\hline 500 & 11,82 & 11,79 & 11,76 \\
\hline 1000 & 11,64 & 11,57 & 11,51 \\
\hline 1500 & 11,47 & 11,37 & 11,27 \\
\hline 2000 & 11,30 & 11,16 & 11,03 \\
\hline 2500 & 11,14 & 10,97 & 10,79 \\
\hline 3000 & 10,98 & 10,77 & 10,55 \\
\hline 3500 & 10,83 & 10,59 & 10,31 \\
\hline 4000 & 10,69 & 10,41 & 10,08 \\
\hline 4500 & 10,55 & 10,23 & 9,84 \\
\hline 5000 & 10,42 & 10,07 & 9,61 \\
\hline 5500 & 10,29 & 9,91 & 9,38 \\
\hline 6000 & 10,17 & 9,76 & 9,15 \\
\hline 6500 & 10,06 & 9,62 & 8,93 \\
\hline 7000 & 9,95 & 9,49 & 8,71 \\
\hline 7500 & 9,86 & 9,36 & 8,50 \\
\hline 8000 & 9,76 & 9,25 & 8,29 \\
\hline 8500 & 9,68 & 9,15 & 8,09 \\
\hline 9000 & 9,60 & 9,05 & 7,89 \\
\hline 9500 & 9,52 & 8,97 & 7,70 \\
\hline 10000 & 9,45 & 8,89 & 7,52 \\
\hline & & & \\
\hline
\end{tabular}

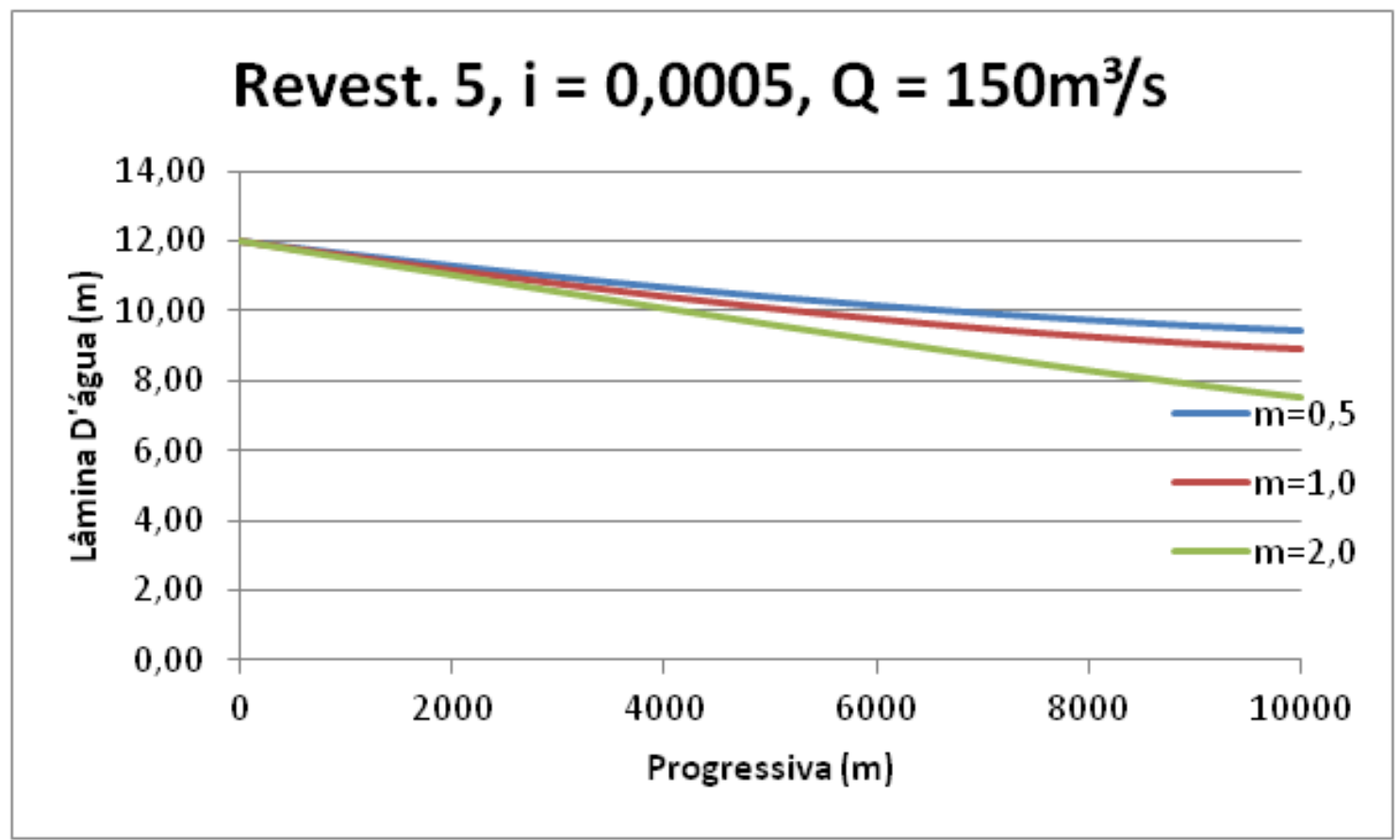




\begin{tabular}{|r|r|r|r|}
\hline \multirow{2}{*}{ Progr. } & \multicolumn{3}{|c|}{ Lâmina d'água $(\mathrm{m})$} \\
\cline { 2 - 4 } & $\mathrm{m}=0,5$ & $\mathrm{~m}=1,0$ & $\mathrm{~m}=2,0$ \\
\hline 0 & 12,00 & 12,00 & 12,00 \\
\hline 500 & 11,81 & 11,81 & 11,76 \\
\hline 1000 & 11,62 & 11,63 & 11,52 \\
\hline 1500 & 11,43 & 11,46 & 11,29 \\
\hline 2000 & 11,25 & 11,29 & 11,05 \\
\hline 2500 & 11,07 & 11,13 & 10,82 \\
\hline 3000 & 10,90 & 10,97 & 10,59 \\
\hline 3500 & 10,73 & 10,82 & 10,36 \\
\hline 4000 & 10,57 & 10,69 & 10,13 \\
\hline 4500 & 10,41 & 10,55 & 9,91 \\
\hline 5000 & 10,26 & 10,43 & 9,69 \\
\hline 5500 & 10,11 & 10,32 & 9,48 \\
\hline 6000 & 9,97 & 10,21 & 9,27 \\
\hline 6500 & 9,83 & 10,12 & 9,06 \\
\hline 7000 & 9,71 & 10,03 & 8,87 \\
\hline 7500 & 9,58 & 9,95 & 8,67 \\
\hline 8000 & 9,47 & 9,87 & 8,49 \\
\hline 8500 & 9,36 & 9,81 & 8,31 \\
\hline 9000 & 9,26 & 9,75 & 8,14 \\
\hline 9500 & 9,16 & 9,70 & 7,99 \\
\hline 10000 & 9,07 & 9,65 & 7,84 \\
\hline & & & \\
\hline
\end{tabular}

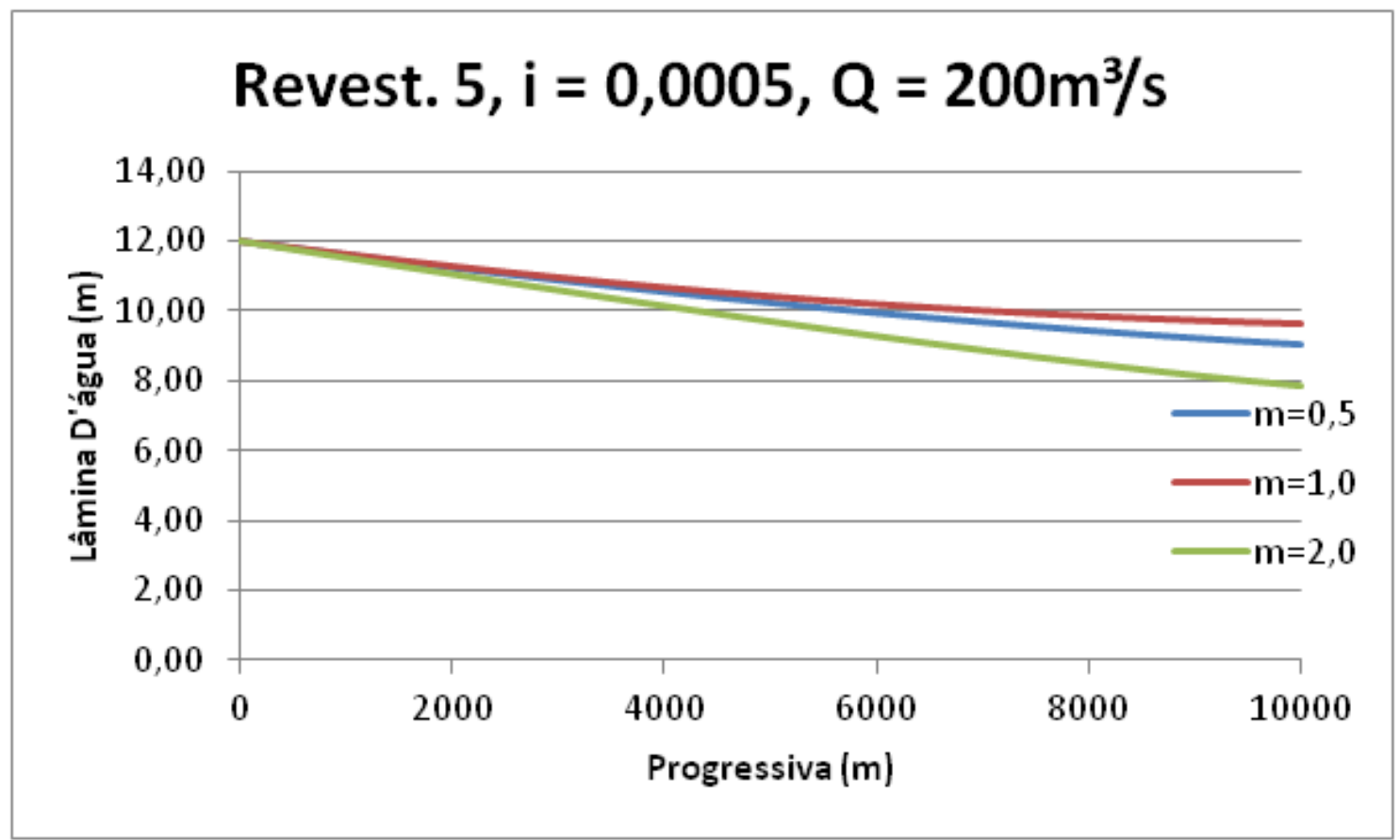




\begin{tabular}{|r|r|r|r|}
\hline \multirow{2}{*}{ Progr. } & \multicolumn{3}{|c|}{ Lâmina d'água $(\mathrm{m})$} \\
\cline { 2 - 4 } & $\mathrm{m}=0,5$ & $\mathrm{~m}=1,0$ & $\mathrm{~m}=2,0$ \\
\hline 0 & 12,00 & 12,00 & 12,00 \\
\hline 500 & 11,80 & 11,79 & 11,77 \\
\hline 1000 & 11,61 & 11,58 & 11,54 \\
\hline 1500 & 11,41 & 11,37 & 11,31 \\
\hline 2000 & 11,22 & 11,17 & 11,08 \\
\hline 2500 & 11,04 & 10,97 & 10,86 \\
\hline 3000 & 10,86 & 10,78 & 10,64 \\
\hline 3500 & 10,68 & 10,59 & 10,42 \\
\hline 4000 & 10,51 & 10,41 & 10,21 \\
\hline 4500 & 10,35 & 10,24 & 10,00 \\
\hline 5000 & 10,19 & 10,06 & 9,80 \\
\hline 5500 & 10,03 & 9,90 & 9,60 \\
\hline 6000 & 9,88 & 9,74 & 9,41 \\
\hline 6500 & 9,73 & 9,59 & 9,22 \\
\hline 7000 & 9,60 & 9,45 & 9,05 \\
\hline 7500 & 9,46 & 9,31 & 8,88 \\
\hline 8000 & 9,34 & 9,19 & 8,72 \\
\hline 8500 & 9,22 & 9,07 & 8,57 \\
\hline 9000 & 9,10 & 8,96 & 8,43 \\
\hline 9500 & 8,99 & 8,85 & 8,30 \\
\hline 10000 & 8,89 & 8,76 & 8,18 \\
\hline & & & \\
\hline
\end{tabular}

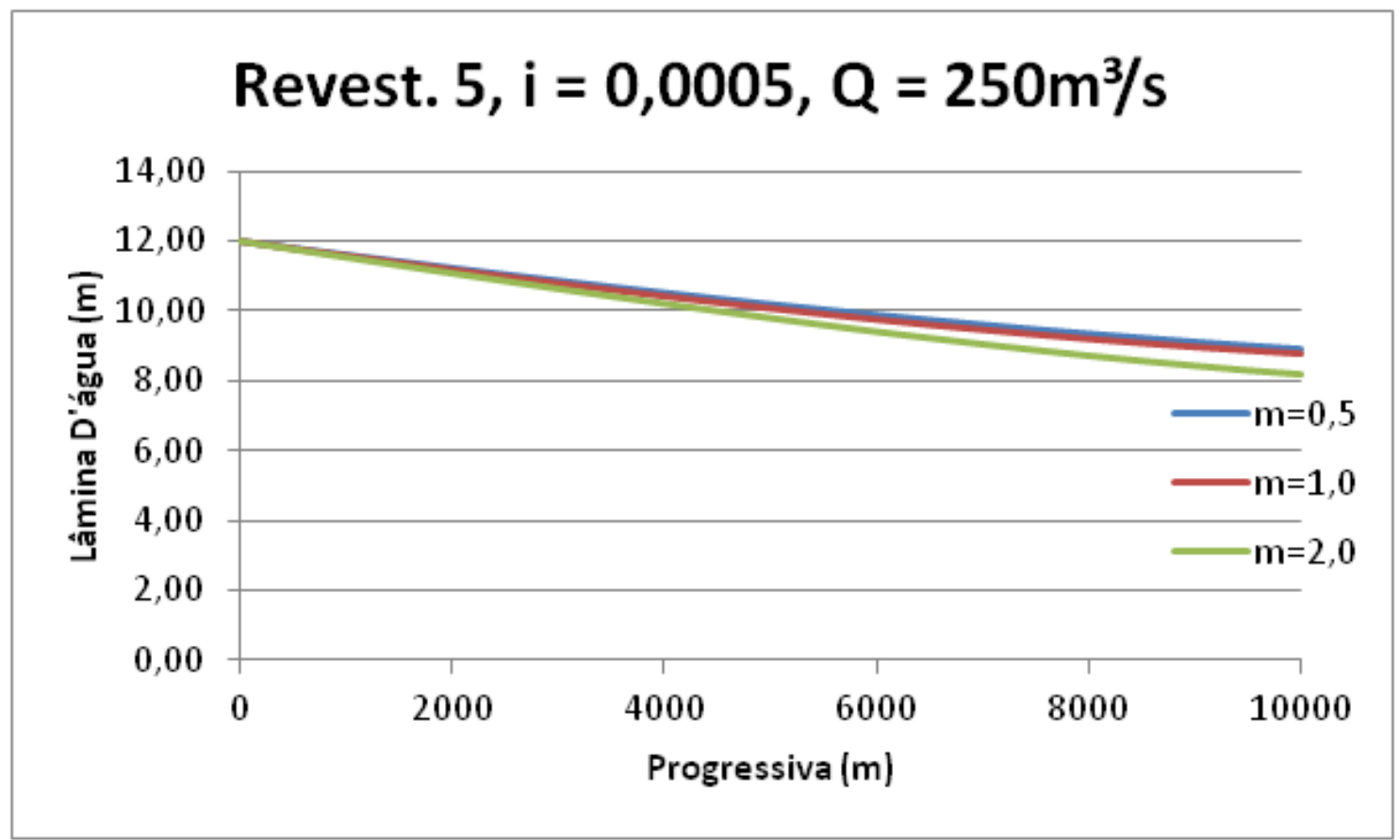




\begin{tabular}{|r|r|r|r|}
\hline \multirow{2}{*}{ Progr. } & \multicolumn{3}{|c|}{ Lâmina d'água $(\mathrm{m})$} \\
\cline { 2 - 4 } & $\mathrm{m}=0,5$ & $\mathrm{~m}=1,0$ & $\mathrm{~m}=2,0$ \\
\hline 0 & 12,00 & 12,00 & 12,00 \\
\hline 500 & 11,80 & 11,80 & 11,77 \\
\hline 1000 & 11,61 & 11,61 & 11,55 \\
\hline 1500 & 11,42 & 11,43 & 11,33 \\
\hline 2000 & 11,23 & 11,25 & 11,12 \\
\hline 2500 & 11,05 & 11,07 & 10,90 \\
\hline 3000 & 10,88 & 10,90 & 10,70 \\
\hline 3500 & 10,70 & 10,74 & 10,49 \\
\hline 4000 & 10,53 & 10,58 & 10,30 \\
\hline 4500 & 10,37 & 10,43 & 10,10 \\
\hline 5000 & 10,21 & 10,28 & 9,92 \\
\hline 5500 & 10,06 & 10,15 & 9,74 \\
\hline 6000 & 9,91 & 10,02 & 9,57 \\
\hline 6500 & 9,77 & 9,89 & 9,40 \\
\hline 7000 & 9,63 & 9,78 & 9,25 \\
\hline 7500 & 9,50 & 9,67 & 9,11 \\
\hline 8000 & 9,37 & 9,57 & 8,97 \\
\hline 8500 & 9,25 & 9,48 & 8,84 \\
\hline 9000 & 9,14 & 9,40 & 8,73 \\
\hline 9500 & 9,04 & 9,32 & 8,62 \\
\hline 10000 & 8,94 & 9,25 & 8,53 \\
\hline & & & \\
\hline
\end{tabular}

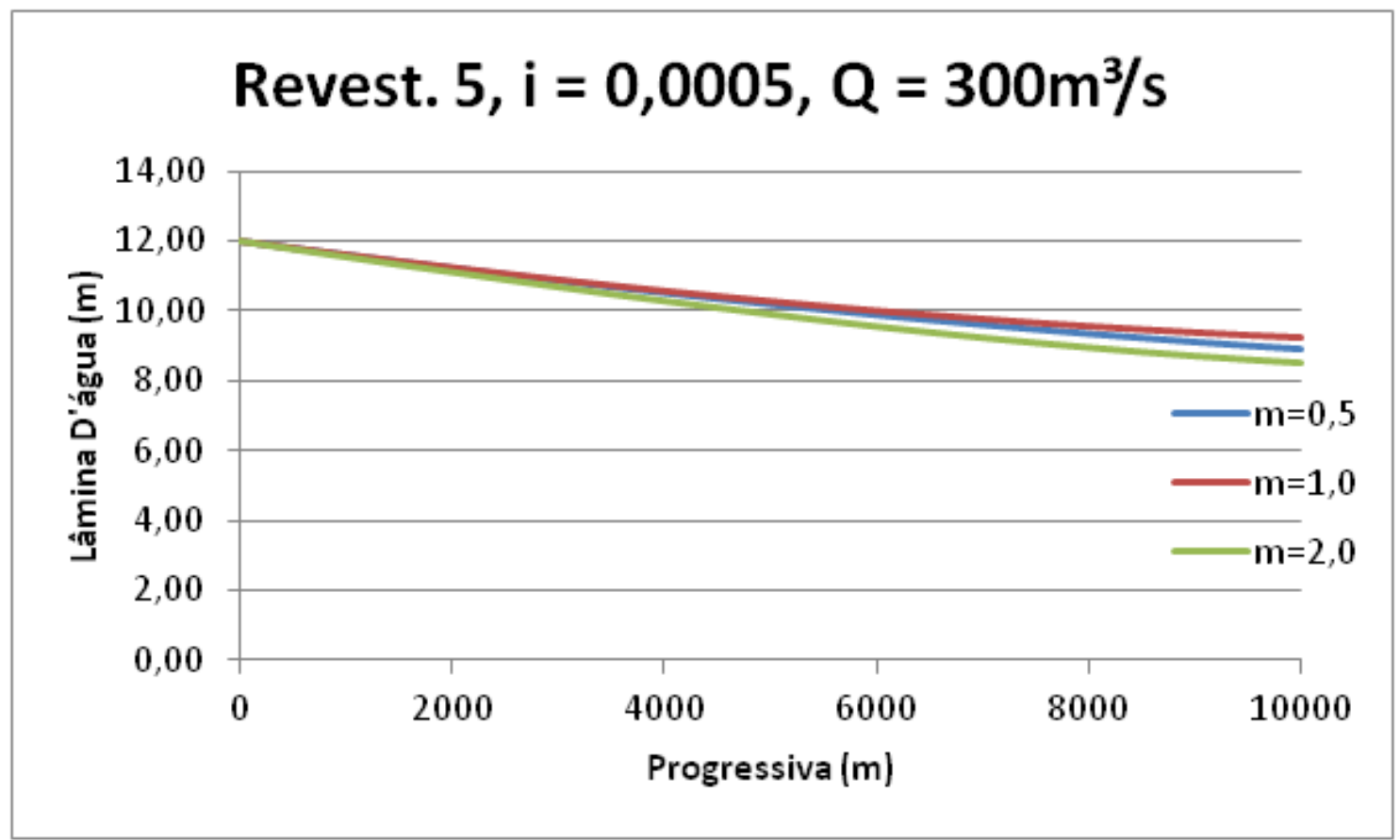




\begin{tabular}{|r|r|r|r|}
\hline \multirow{2}{*}{ Progr. } & \multicolumn{3}{|c|}{ Lâmina d'água $(\mathrm{m})$} \\
\cline { 2 - 4 } & $\mathrm{m}=0,5$ & $\mathrm{~m}=1,0$ & $\mathrm{~m}=2,0$ \\
\hline 0 & 12,00 & 12,00 & 12,00 \\
\hline 500 & 11,82 & 11,83 & 11,78 \\
\hline 1000 & 11,65 & 11,66 & 11,57 \\
\hline 1500 & 11,48 & 11,49 & 11,36 \\
\hline 2000 & 11,32 & 11,33 & 11,16 \\
\hline 2500 & 11,16 & 11,18 & 10,96 \\
\hline 3000 & 11,01 & 11,04 & 10,77 \\
\hline 3500 & 10,86 & 10,90 & 10,58 \\
\hline 4000 & 10,71 & 10,77 & 10,40 \\
\hline 4500 & 10,57 & 10,64 & 10,22 \\
\hline 5000 & 10,44 & 10,53 & 10,05 \\
\hline 5500 & 10,31 & 10,42 & 9,89 \\
\hline 6000 & 10,19 & 10,31 & 9,74 \\
\hline 6500 & 10,07 & 10,22 & 9,60 \\
\hline 7000 & 9,96 & 10,13 & 9,47 \\
\hline 7500 & 9,86 & 10,04 & 9,35 \\
\hline 8000 & 9,76 & 9,97 & 9,23 \\
\hline 8500 & 9,66 & 9,90 & 9,13 \\
\hline 9000 & 9,58 & 9,84 & 9,04 \\
\hline 9500 & 9,49 & 9,78 & 8,95 \\
\hline 10000 & 9,42 & 9,73 & 8,88 \\
\hline & & & \\
\hline
\end{tabular}

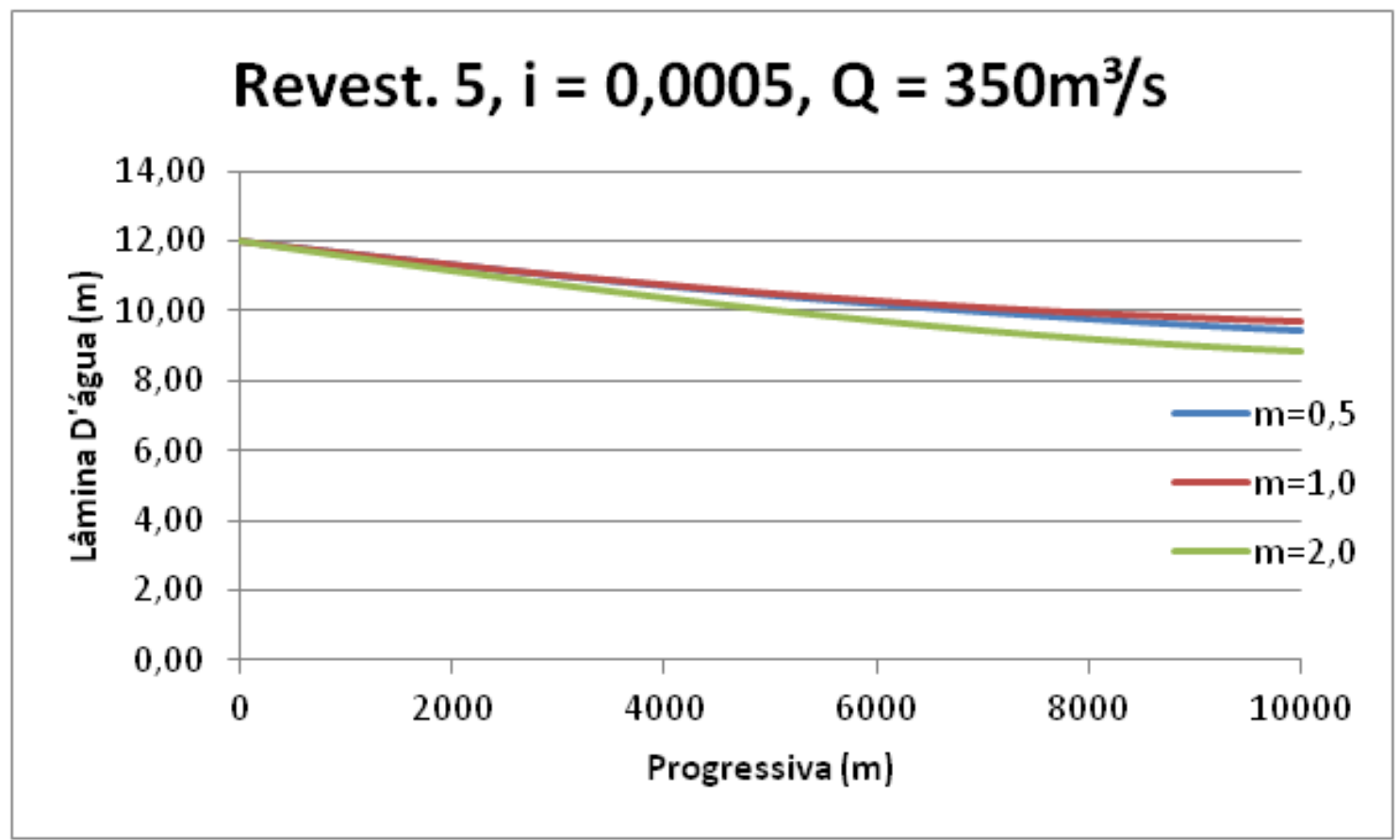


217

APÊNDICE A - MANUSCRITOS DE SOUZA, P. A. (S.D.)

1 :

(1)

Para $u=\phi(x, y)$, se $f(x, y)=0,0$ ponto extremo se determina por

$$
\begin{aligned}
& f(x, y)=0 \\
& \frac{\partial}{\partial x}[\phi(x, y)+\lambda f(x, y)]=0 \\
& \frac{\partial}{\partial y}[\varphi(x, y)+\lambda f(x, y)]=0
\end{aligned}
$$

$$
\begin{aligned}
& A R^{2 / 3}=\frac{\left[b y+m y^{2}\right]^{5 / 3}}{\left[b+2 y \sqrt{1+m^{2}}\right]^{2 / 3}}=\frac{A^{5 / 3}}{P^{2 / 3}}=\frac{Q K^{1 / 6}}{8 \sqrt{g} i} \\
& f(b, y)=A R^{2 / 3}-\frac{Q k^{1 / 6}}{8 \sqrt{g i}}=0=\frac{A^{5 / 3}}{P^{2 / 3}}-\frac{Q k^{1 / 6}}{8 \sqrt{g i}}
\end{aligned}
$$

$$
f(b, y)=\frac{\left[b y+m y^{2}\right]^{5 / 3}}{\left[b+2 y \sqrt{1+m^{2}}\right]^{2 / 3}}-\frac{Q k^{1 / 6}}{8 \sqrt{g i}}=0
$$

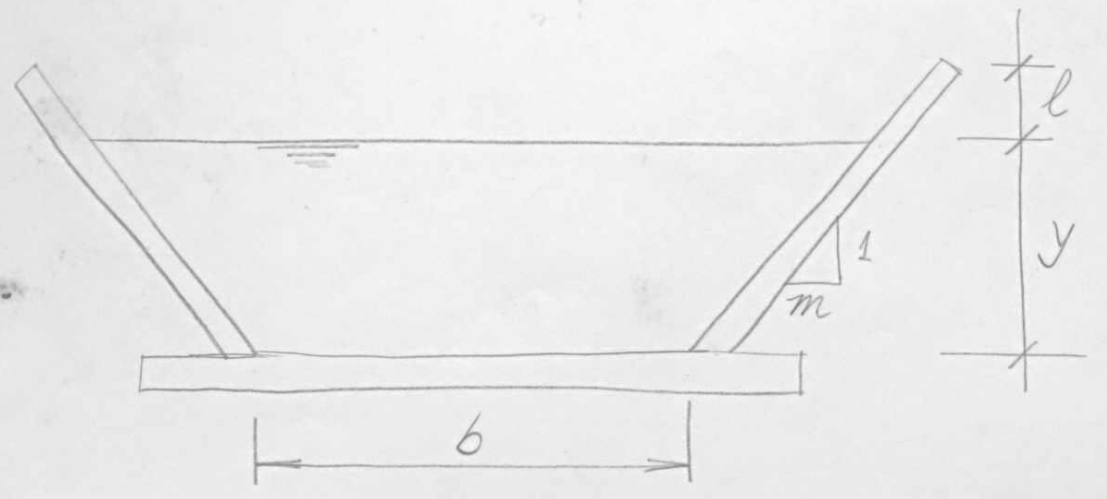


218

$$
\begin{aligned}
& \Gamma \text { custo total } \\
& C=C_{t}+C_{b}+C_{e}
\end{aligned}
$$

$\rightarrow$ custo de excavaciōo por unidade de comprimento.

- custo de revestimento da base por unidade de comprimento.

- custo de revestimento do talude por unidade de comprimento.

$$
\begin{aligned}
& c_{t}=2 \tau(y+l) \sqrt{1+m^{2}} \\
& c_{b}=b \cdot \beta+c \\
& c_{e}=\left[b(y+l)+m(y+l)^{2}\right] \varepsilon
\end{aligned}
$$

(2)

$I \rightarrow$ preco do revestimento do talude por unidade de área. $\beta \rightarrow$ preco do revestimento da base por
unidade de área.

$\varepsilon \rightarrow$ preço de escavaçã por unidade de volume.

$c \rightarrow$ precio do material do canto por unidade de comprimento 
219

(3)

$$
\begin{aligned}
& c=2 \tau(y+l) \sqrt{1+m^{2}}+b \beta+c+\left[b(y+l)+m(y+l)^{2}\right] \varepsilon \\
& c=c(b, y) \\
& \frac{\partial}{\partial b}[c(b, y)+\lambda f(b, y)]=0 \\
& \frac{\partial}{\partial y}[c(b, y)+\lambda f(b+y)]=0 \\
& =\frac{A^{5 / 3}}{P^{2 / 3}}-\frac{Q k^{1 / 6}}{8 \sqrt{g i}}=0=f(b, y) \\
& \left\{\begin{array}{l}
\frac{\partial}{\partial b}[c+\lambda f]=0 \\
\frac{\partial}{\partial y}[c+\lambda f]=0
\end{array}\right. \\
& \text { de (2) e (3) } \Rightarrow \\
& \left\{\begin{array}{l}
\frac{\partial c}{\partial b}+\lambda \frac{\partial f}{\partial b}=0 \\
\frac{\partial c}{\partial y}+\lambda \frac{\partial f}{\partial y}=0
\end{array}\right. \\
& \frac{\partial f / \partial b}{\partial f / \partial y}=\frac{\partial c / \partial b}{\partial c / \partial y}
\end{aligned}
$$


220

(4)

$$
\begin{aligned}
& \frac{\partial\left(A^{5 / 3} / P^{2 / 3}\right) / \partial b}{\partial\left(A^{5 / 3} / P^{2 / 3}\right) / \partial y}=\frac{\partial C / \partial b}{\partial C / \partial y} \\
& \frac{\frac{2}{3} A^{5 / 3} P^{1 / 3} \frac{\partial P}{\partial b}-\frac{5}{3} A^{2 / 3} P^{2 / 3} \frac{\partial A}{\partial b}}{\frac{2}{3} A^{5 / 3} P^{-1 / b} \frac{\partial P}{\partial y}-\frac{5}{3} A^{2 / 3} P^{2 / 3} \frac{\partial A}{\partial y}}=\frac{\frac{\partial C}{\partial b}}{\frac{\partial C}{\partial y}} \\
& \frac{\frac{2}{3} A \frac{\partial P}{\partial b}-\frac{5}{3} P \frac{\partial A}{\partial b}}{\frac{2}{3} A \frac{\partial P}{\partial y}-\frac{5}{3} P \frac{\partial A}{\partial y}}=\frac{\frac{\partial C}{\partial b}}{\frac{\partial C}{\partial y}} \\
& A=b y+m y^{2} \\
& \left\{\begin{array}{l}
\frac{\partial A}{\partial b}=y \\
\frac{\partial A}{\partial y}=b+2 m y
\end{array}\right. \\
& P=b+2 y \sqrt{1+m^{2}} \\
& \left\{\begin{array}{l}
\frac{\partial P}{\partial b}=1 \\
\frac{\partial P}{\partial y}=2 \sqrt{1+m^{2}}
\end{array}\right.
\end{aligned}
$$

$\left.A^{2 / 3} \cdot P^{-1 / 3}\right)$ 
(5)

$$
\begin{aligned}
& c=2 \tau(y+l) \sqrt{1+m^{2}}+b \beta+c+\left[b(y+l)+m(y+l)^{2}\right] \varepsilon \\
& \left\{\begin{array}{l}
\frac{\partial c}{\partial b}=\beta+(y+l) \varepsilon \\
\frac{\partial c}{\partial y}=2 \tau \sqrt{1+m^{2}}+b \varepsilon+2 m \varepsilon(y+l)
\end{array}\right. \\
& \frac{2\left(b y+m y^{2}\right)-5\left(b+2 y \sqrt{1+m^{2}}\right) y}{2\left(b y+m y^{2}\right) 2 \sqrt{1+m^{2}}-5\left(b+2 y \sqrt{1+m^{2}}\right)(b+2 m y)}=? \\
& \left.=\frac{\beta+(y+l) \varepsilon}{2 \tau \sqrt{1+m^{2}}+b \varepsilon+2 m \varepsilon(y+l)}\right] \\
& \left(\frac{y}{b}\right)^{2}\left[20\left(1+m^{2}\right)-4 m \sqrt{1+m^{2}}\left(1+4 \frac{\beta}{\tau}\right)\right]+ \\
& +\left(\frac{y}{b}\right)\left[6 \sqrt{1+m^{2}}\left(1-\frac{\beta}{\tau}\right)-10 m \frac{\beta}{\tau}\right]+\left[-\frac{5 \beta}{\tau}\right]=0 \\
& \left.k_{1}\left(\frac{y}{b}\right)^{2}+k_{2}\left(\frac{y}{b}\right)+k_{3}=0\right] \\
& \cdot k_{1}=\left[20\left(1+m^{2}\right)-\left(1+\frac{4 \beta}{\tau}\right) 4 m \sqrt{1+m^{2}}\right] \\
& \cdot k_{2}=\left[6 \sqrt{1+m^{2}}\left(1-\frac{\beta}{\tau}\right)-10 m\left(\frac{\beta}{\tau}\right)\right]
\end{aligned}
$$


222

(6)

$$
\cdot k_{3}=-\frac{5 \beta}{\tau}
$$

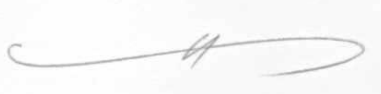

$$
\begin{aligned}
& \frac{\left[\frac{y}{b}+m\left(\frac{y}{b}\right)^{2}\right]^{5 / 3} b^{10 / 3}}{\left[1+2\left(\frac{y}{b}\right) \sqrt{1+m^{2}}\right]^{2 / 3} b^{2 / 3}}=\frac{Q k^{1 / 6}}{8 \sqrt{g i}} \\
& b=\left(\frac{Q k^{1 / 6}}{8 \sqrt{g i}}\right)^{3 / 8} \frac{\left[1+2\left(\frac{y}{b}\right) \sqrt{1+m^{2}}\right]^{1 / 4}}{\left[\left(\frac{y}{b}\right)+m\left(\frac{y}{b}\right)^{2}\right]^{5 / 8}}
\end{aligned}
$$

1. Entrada $\{Q, k, i, m, \beta, \tau, g, \varepsilon\}$

2. Cáleulo de $k_{1}, k_{2}, k_{3}$

3. Cálculo de $\left(\frac{y}{b}\right)$, Eq. ( )

4. Cálculo de b, Eq. ()

5. Cálculo de $y<b *\left(\frac{y}{b}\right)$

6. Faida $\{y, b\}$ 